\title{
Design and development of a microwave-enhanced diesel soot oxidation system
}

\author{
Bret Allen Rankin \\ West Virginia University
}

Follow this and additional works at: https://researchrepository.wvu.edu/etd

\footnotetext{
Recommended Citation

Rankin, Bret Allen, "Design and development of a microwave-enhanced diesel soot oxidation system" (1999). Graduate Theses, Dissertations, and Problem Reports. 1181.

https://researchrepository.wvu.edu/etd/1181

This Thesis is protected by copyright and/or related rights. It has been brought to you by the The Research Repository @ WVU with permission from the rights-holder(s). You are free to use this Thesis in any way that is permitted by the copyright and related rights legislation that applies to your use. For other uses you must obtain permission from the rights-holder(s) directly, unless additional rights are indicated by a Creative Commons license in the record and/ or on the work itself. This Thesis has been accepted for inclusion in WVU Graduate Theses, Dissertations, and Problem Reports collection by an authorized administrator of The Research Repository @ WVU. For more information, please contact researchrepository@mail.wvu.edu.
} 


\title{
Design and Development of a Microwave Enhanced Diesel Soot Oxidation System
}

\author{
Bret A. Rankin \\ Thesis submitted to the \\ College of Engineering and Mineral Resources \\ at West Virginia University \\ in partial fulfillment of the requirements \\ for the degree of \\ Masters of Science \\ in \\ Mechanical Engineering \\ Mridul Gautam, Ph.D., Chair \\ Kenneth Means, Ph.D. \\ Gary Morris, Ph.D. \\ Department of Mechanical and Aerospace Engineering
}

Morgantown, West Virginia 1999

Keywords: Regeneration, Soot, Particulate Matter, Exhaust Aftertreatment, PM filter, Diesel PM 


\section{Abstract \\ DESIGN AND DEVELOPMENT OF A MICROWAVE ENHANCED DIESEL SOOT OXIDATION SYSTEM}

By Bret A. Rankin

The research presented in this report is focused on the design and development of a microwave regeneration system to remove diesel soot from ceramic wall-flow filters. The focus of the experimental testing was to control the combustion of the soot within the filter during regeneration to promote sustained soot combustion, while at the same time, limiting the heat release rate to prevent filter damage.

As lowering emissions regulations continue to press the limits of conventional emissions control technologies, the need for exhaust aftertreatment system development will become increasingly important. Diesel particulate matter (PM) emissions have created considerable concern because PM is a suspected carcinogen. Up to this point, improved engine and fuel system design and control schemes have made the use of diesel particulate aftertreatment systems unnecessary for most applications in the United States, but the continued decreasing trend of emissions regulations may necessitate the use of PM filters for many applications.

In most particulate filtration systems, the trapped diesel soot forms a layer on the filtration surface or within the filter, acting as an additional filtration surface. This increases the filtration efficiency, but also increases the pressure drop across the filter for a given flow rate. It is therefore, necessary to remove the entrapped particulate from the filter in order to maintain the exhaust backpressure within an engine's design constraints. One of the more promising methods of removing the entrapped soot is through 
regeneration. During regeneration, the temperature of a portion of the soot within the filter is increased beyond the ignition temperature of the soot (typically $600{ }^{\circ} \mathrm{C}$ to $650{ }^{\circ} \mathrm{C}$ $-1112{ }^{\circ} \mathrm{F}$ to $1202{ }^{\circ} \mathrm{F}$ ). The exothermic reaction which ensues generates the energy needed to sustain the regeneration event throughout the filter.

Many methods have been developed to generate a controlled, reliable regeneration event within PM filters, none of which have been proven to be completely successful. These methods include exhaust throttling, fuel catalysis, filter catalysis, electrical heating, and burner systems. One very unique regeneration method incorporates the use of microwave energy to selectively heat the particulate matter within diesel PM filters. In the research presented in this work, a microwave regeneration system was designed, fabricated, developed, and tested. Due to the lack of basic regeneration performance data from the previously published microwave regeneration studies, this research program focused on the control of four of the most important regeneration parameters: initial collected soot mass, preheating time, combustion airflow, and combustion air temperature.

The results demonstrated that the microwave regeneration system was very effective in selectively heating the diesel particulate matter within the filter. The amount of soot removed from the filter during regeneration was seen to increase with increasing initial soot masses and preheating times, and was observed to decrease with increasing airflow rates. The combustion air temperature did not have a significant impact on the amount of soot removed from the filter during regeneration. 


\section{Dedication}

I would like to dedicate this work to my Father and Mother, Herb and Twila Rankin. Almost every piece of equipment that was designed and fabricated during the first two years of this study passed through their garage at some point in time. Their donation of time, equipment, advice, and energy was indispensable. Their dedication and help during the initial stages of this project was critical in its development. As they have done for all the years that I have known them, they carried a load that was not their own. So for these reasons and countless others, Mom and Dad, this work is for you. 


\section{Acknowledgments}

I would first and foremost like to thank my Lord and Savior Jesus Christ for giving me the strength and the ability to perform this research. He guided me through even the most difficult problems encountered during my undergraduate and graduate studies, and for that I am truly grateful.

I would like to thank my wife, Sharae, for being so supportive and understanding during my graduate studies. She was always willing to listen to all the latest and greatest problems that surfaced, and she allowed me the freedom to work during the midnight hours whenever necessary (which seemed like a majority of the time). Without her, I would have lost what little remains of my sanity.

I definitely have to thank my partner in crime, Sriram, the Pentagonal Flangemaster himself. He was there every step of the way, during good times and bad. At times it seemed as if there was no light at the end of the tunnel, but together we were able to keep the project moving in the right direction.

I would like to thank Dr. Gautam for giving me the opportunity to work on this project. He did a tremendous job of providing funding for this project when it seemed like there was none available. I would also like to thank him for correcting this thesis on short notice, as well as taking care of the paperwork for my graduation at the last minute.

I would like to express my gratitude to Leo Marbun for giving a helping hand during the experimental stage of the project, and for running all my errands at WVU when I could not be there personally. If he had processed all my graduation forms for me at the last possible moment, I could not have graduated on time. Thanks again, Leo. I 
also need to thank Linda Cox for giving me a thorough explanation of the graduation requirements.

I would like to thank Dan Carder, Ryan Barnett, and Wesley Riddle for helping with the testing during the last two hectic months of testing. I would like to thank Cliff Judy for all his help in the shop. He conveyed a wealth of practical information to me over the years, and he always allowed me to use his equipment when necessary. I would like to express my gratitude to Marylin ("Mom") Host and Gene Kopasko for their help with all my purchasing problems and blunders, and for having such great senses of humor. Marylin and Gene, if there are still receipts missing for any of my purchases, they are in the mail. I would also like to thank Richard Atkison for providing help with the automated valve control and wiring.

Finally, I would like to express my appreciation to Dr. Al Hoffmanner and Eric Tekrul of Walker, Inc. for providing the stuffing cone and initial trap assembly. 
Table of Contents

$\underline{\text { Page }}$

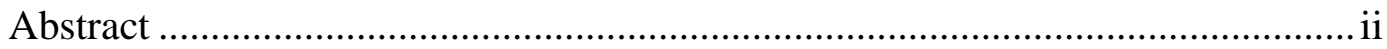

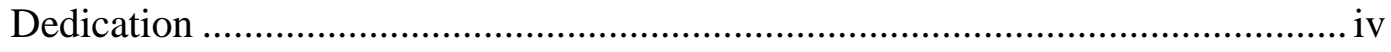

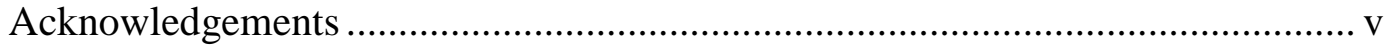

Table of Contents .................................................................................... vii

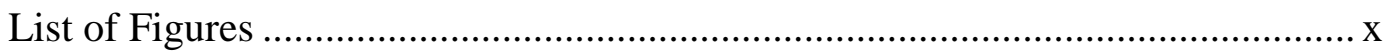

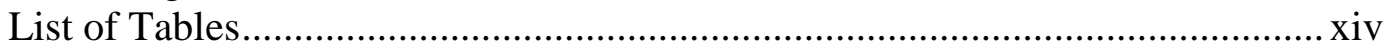

Chapter

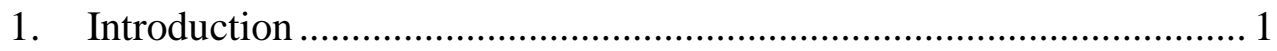

2. Literature Review ..................................................................... 14

2.1 Filtration Media.............................................................. 14

2.2 Regeneration Systems ................................................... 16

2.2.1 Throttling........................................................ 16

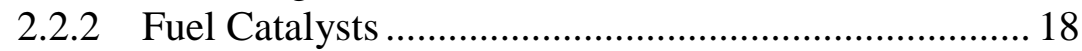

2.2.3 Catalyzed Filters..................................................... 19

2.2.4 Electrical Heating Systems.................................... 21

2.2.5 Burner Systems ................................................. 24

2.2.6 Microwave Regeneration Systems ........................... 29

2.2.6.1 Microwave Background ............................ 30

2.2.6.2 Microwave Regeneration Studies ................ 35

2.2.6.3 Microwave Safety................................... 45

3. Design, Development, and Fabrication ...................................... 50

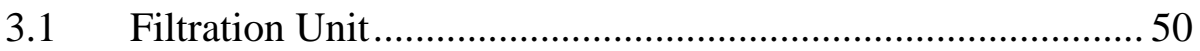

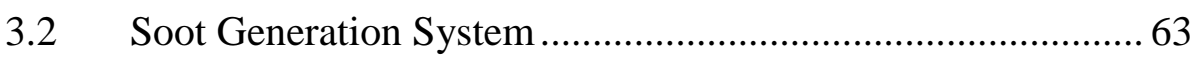

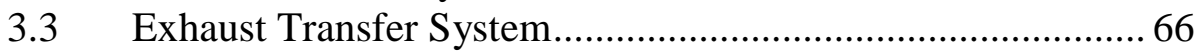

3.3.1 Exhaust Flow Measurement ..................................... 67

3.3.2 Orifice Meter Calibration ........................................ 78

3.3.3 Exhaust Diffusers .................................................. 90

3.3.4 Exhaust Surge Tank ............................................... 92

3.3.5 In-cell Microwave Attenuation Assembly ................ 102

3.3.6 Exhaust Multiple-inlet Sliding Gate Valve ................ 107

3.3.7 Exhaust Bypass Flow Control System ..................... 108 
3.4 Regeneration System............................................................ 129

3.4.1 Microwave Generation/Transmission Assembly ...... 129

3.4.1.1 Magnetron............................................... 129

3.4.1.2 Waveguides ................................................ 131

3.4.1.3 Waveguide Power Transmission

Test Chamber ............................................... 141

3.4.1.4 Waveguide Gate Valve ................................ 144

3.4.1.5 Waveguide Water Jacket ............................. 145

3.4.2 Combustion Air Supply System ................................. 159

3.4.3 Out-of-cell Regeneration Assembly .......................... 173

3.5 Soot Conditioning System...................................................... 181

3.6 Exhaust Backpressure Control Assembly ………………….... 188

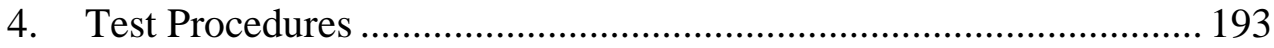

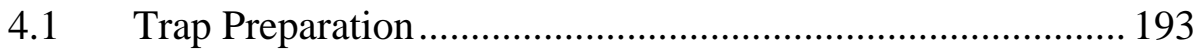

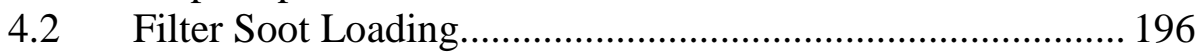

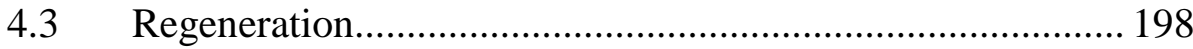

4.4 Filter Post-regeneration Conditioning .................................... 202

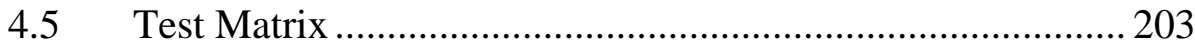

5. Microwave Regeneration Results and Discussion ............................. 207

5.1 Effect of Initial Soot Mass …………………………….......... 207

5.2 Effect of Preheating Time ……………………………......... 225

5.3 Effect of Airflow Rate ........................................................... 237

5.4 Effect of Combustion Air Temperature …………………...... 248

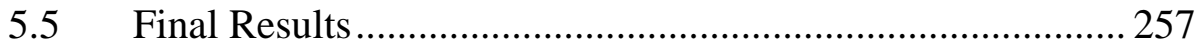

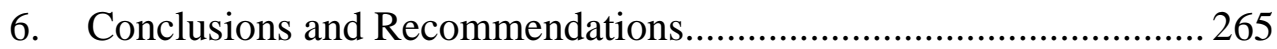

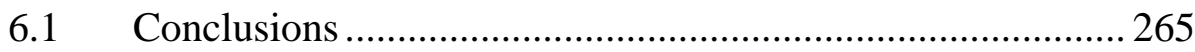

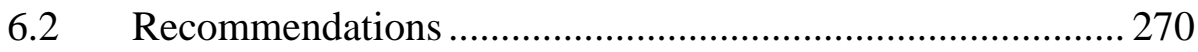

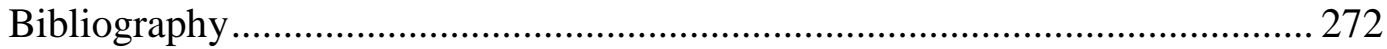

Appendix A: Exhaust System and Flow Control Components.................... 277

Appendix B: Laminar Flow Element Calibration Data ............................... 282

Appendix C: $\quad$ Exhaust Orifice Meter Calibration Program ……………….... 285

Appendix D: Exhaust Orifice Meter Calibration Data.................................2295

Appendix E: $\quad$ High-flow Calibration Air Filter ........................................... 299

Appendix F: $\quad$ Exhaust Bypass Flow Control Program .................................. 301

Appendix G: $\quad$ Microwave Generation/Transmission Components ............... 316

Appendix H: Combustion Air Supply Cart............................................... 320

Appendix I: $\quad$ Combustion Air Orifice Meter Calibration Data...................... 323 
Appendix J: $\quad$ Filter Conditioning Assembly ......................................... 325

Appendix K: $\quad$ Out-of-cell Regeneration Assembly .................................... 328

Appendix L: $\quad$ Regeneration Data Acquisition Program............................. 331

Appendix M: $\quad$ Engine Backpressure Limiting Switch ................................. 340

Appendix N: $\quad$ Filter Preparation Assembly ............................................. 342

Appendix O: $\quad$ Soot Loading Period Data .................................................. 345 


\section{List of Figures}

$\underline{\text { Figure }}$

$\underline{\text { Page }}$

3.1.1 Wall-flow Monolith Cross-section.............................................. 53

3.1.2 Soot Filtration Assembly Cross-section..................................... 57

3.1.3 Filtration Assembly Outlet .................................................... 57

3.1.4 Filtration Assembly Side View ................................................. 58

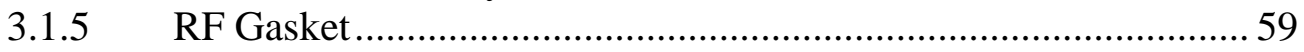

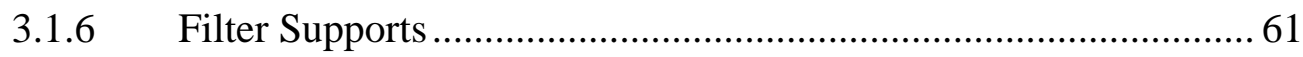

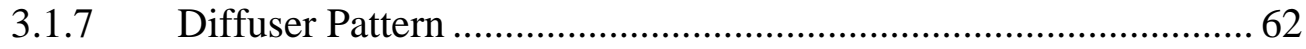

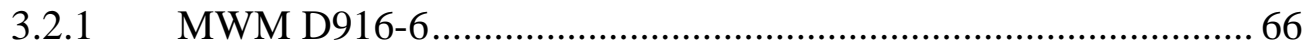

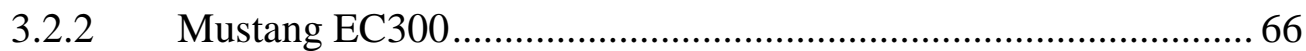

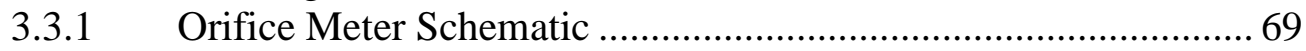

3.3.2 Engine Intake Air and Exhaust Flow Diagram .......................... 79

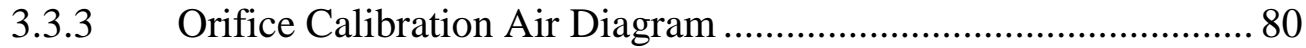

3.3.4 Surge Tank Cross-section.......................................................... 96

3.3.5 Microwave Water Trap and Water Supply Assembly ............... 105

3.3.6 Automated Exhaust Valve System ........................................... 110

3.3.7 Strain Gauge Placement on the Butterfly Valve Input Shaft ...... 113

3.3.8 Stress Analysis of a Shaft in Torsion ........................................ 115

3.3.9 Stepper Motor Control Electrical Diagram .............................. 118

3.4.1 Waveguide Schematic and Theoretical Boundary Conditions.... 133

3.4.2 Electric and Magnetic Field Distributions

in a Waveguide for $\mathrm{TE}_{10}$ Mode Propagation ............................. 134

3.4.3 Microwave Power Transmission Test Assembly ....................... 141

3.4.4 Temperature Profiles of Inner Air and Aluminum
Waveguide for Forced Convection Only .............................. 153

3.4.5 Temperature Profiles of Inner Air and Aluminum
Water Jacketed Waveguide .................................................... 158

3.4.6 Air Supply Cart Flow Schematic ............................................ 162

3.4.7 Out-of-cell Water Trap .............................................................. 174

3.4.8 Out-of-cell Regeneration Testing Apparatus ............................. 176

3.4.9 Filter Conditioning Chamber .................................................. 184

3.4.10 Engine Backpressure Limit Control Assembly .......................... 191

5.1.1 Test \#1 Trap Surface Temperature Profiles ............................... 208

5.1.2 Surface Thermocouple Positions on the Trap Housing.............. 209

5.1.3 Test \#1 Combustion Airflow Rate ............................................... 210

5.1.4 Test \#1 Combustion Air Temperature.......................................... 210

5.1.5 Test \#1 Trap Differential Pressure ............................................ 210

5.1.6 Test \#1 Low CO Analyzer ADC Output...................................... 211

5.1.7 Test \#1 High CO Analyzer ADC Output ..................................... 211

5.1.8 Test \#1 CO $\mathrm{CO}_{2}$ Analyzer ADC Output ......................................... 211

5.1.9 Test \#2 Trap Surface Temperature Profiles ............................... 214

5.1.10 Test \#2 Combustion Airflow Rate .............................................. 215

5.1.11 Test \#2 Combustion Air Temperature......................................... 215 
5.1.12 Test \#2 Trap Differential Pressure ............................................. 215

5.1.13 Test \#2 Low CO Analyzer ADC Output .................................... 216

5.1.14 Test \#2 High CO Analyzer ADC Output .................................... 216

5.1.15 Test \#2 $\mathrm{CO}_{2}$ Analyzer ADC Output......................................... 216

5.1.16 Test \#3 Trap Surface Temperature Profiles ............................... 218

5.1.17 Test \#3 Combustion Airflow Rate .............................................. 218

5.1.18 Test \#3 Combustion Air Temperature........................................ 219

5.1.19 Test \#3 Trap Differential Pressure .............................................. 219

5.1.20 Test \#3 Low CO Analyzer ADC Output .................................... 219

5.1.21 Test \#3 High CO Analyzer ADC Output ................................... 220

5.1.22 Test \#3 $\mathrm{CO}_{2}$ Analyzer ADC Output............................................ 220

5.1.23 Test \#4 Trap Surface Temperature Profiles ................................ 221

5.1.24 Test \#4 Combustion Airflow Rate ............................................. 222

5.1.25 Test \#4 Combustion Air Temperature........................................ 222

5.1.26 Test \#4 Trap Differential Pressure ............................................ 222

5.1.27 Test \#4 Low CO Analyzer ADC Output ..................................... 223

5.1.28 Test \#4 High CO Analyzer ADC Output .................................... 223

5.1.29 Test \#4 $\mathrm{CO}_{2}$ Analyzer ADC Output........................................ 223

5.1.30 Damaged Filter .................................................................. 225

5.2.1 Test \#5 Combustion Airflow Rate ........................................... 226

5.2.2 Test \#5 Combustion Air Temperature........................................ 226

5.2.3 Test \#6 Trap Surface Temperature Profiles ............................... 227

5.2.4 Test \#6 Combustion Airflow Rate ........................................... 228

5.2.5 Test \#6 Combustion Air Temperature......................................... 228

5.2.6 Test \#7 Trap Surface Temperature Profiles ............................... 229

5.2.7 Test \#7 Combustion Airflow Rate ............................................... 230

5.2.8 Test \#7 Combustion Air Temperature......................................... 230

5.2.9 Test \#7 Trap Differential Pressure ............................................. 230

5.2.10 Test \#7 Low CO Analyzer ADC Output ................................... 231

5.2.11 Test \#7 High CO Analyzer ADC Output .................................... 231

5.2.12 Test \#7 $\mathrm{CO}_{2}$ Analyzer ADC Output........................................... 2231

5.2.13 Test \#8 Trap Surface Temperature Profiles .............................. 232

5.2.14 Test \#9 Trap Surface Temperature Profiles .............................. 233

5.2.15 Test \#9 Combustion Airflow Rate ............................................ 234

5.2.16 Test \#9 Combustion Air Temperature........................................ 235

5.2.17 Test \#9 Trap Differential Pressure .............................................. 235

5.2.18 Test \#9 Low CO Analyzer ADC Output .................................... 235

5.2.19 Test \#9 High CO Analyzer ADC Output ................................... 236

5.2.20 Test \#9 $\mathrm{CO}_{2}$ Analyzer ADC Output ......................................... 236

5.3.1 Test \#10 Trap Surface Temperature Profiles .............................. 238

5.3.2 Test \#10 Combustion Airflow Rate ............................................. 239

5.3.3 Test \#10 Combustion Air Temperature...................................... 239

5.3.4 Test \#10 Trap Differential Pressure ............................................. 240

5.3.5 Test \#10 Low CO Analyzer ADC Output................................... 240 
$\underline{\text { Figure }}$

5.3.6 Test \#10 High CO Analyzer ADC Output ................................ 240

5.3.7 Test \#10 $\mathrm{CO}_{2}$ Analyzer ADC Output ......................................... 241

5.3.8 Test \#11 Trap Surface Temperature Profiles ............................. 242

5.3.9 Test \#11 Combustion Airflow Rate ........................................... 243

5.3.10 Test \#11 Combustion Air Temperature..................................... 243

5.3.11 Test \#11 Trap Differential Pressure ............................................ 243

5.3.12 Test \#11 Low CO Analyzer ADC Output.................................. 244

5.3.13 Test \#11 High CO Analyzer ADC Output ................................ 244

5.3.14 Test \#11 CO $\mathrm{CO}_{2}$ Analyzer ADC Output ......................................... 244

5.3.15 Test \#12 Trap Surface Temperature Profiles ............................. 246

5.3.16 Test \#12 Low CO Analyzer ADC Output.................................. 246

5.3.17 Test \#12 $\mathrm{CO}_{2}$ Analyzer ADC Output ......................................... 247

5.4.1 Test \#13 Trap Surface Temperature Profile ................................ 248

5.4.2 Test \#13 Combustion Airflow Rate ........................................... 249

5.4.3 Test \#13 Combustion Air Temperature...................................... 249

5.4.4 Test \#14 Trap Surface Temperature Profiles ............................. 250

5.4.5 Test \#14 Combustion Airflow Rate ........................................... 251

5.4.6 Test \#14 Combustion Air Temperature..................................... 251

5.4.7 Test \#14 Trap Differential Pressure ............................................ 20. 251

5.4.8 Test \#14 Low CO Analyzer ADC Output.................................. 252

5.4.9 Test \#14 $\mathrm{CO}_{2}$ Analyzer ADC Output ........................................ 252

5.4.10 Test \#15 Trap Surface Temperature Profiles ............................ 253

5.4.11 Test \#15 Combustion Airflow Rate ........................................... 254

5.4.12 Test \#15 Combustion Air Temperature...................................... 255

5.4.13 Test \#15 Trap Differential Pressure ............................................ 255

5.4.14 Test \#15 Low CO Analyzer ADC Output................................. 255

5.4.15 Test \#15 High CO Analyzer ADC Output ................................ 256

5.4.16 Test \#15 $\mathrm{CO}_{2}$ Analyzer ADC Output ...................................... 256

5.5.1 Filter Outlet Regeneration Pattern........................................... 257

5.5.2 Internal Regeneration Pattern (side view) ................................. 259

5.5.3 Internal Regeneration Pattern (top view) ................................. 259

5.5.4 Effect of Initial Soot Mass on Regeneration Efficiency ............. 263

5.5.5 Effect of Preheating Time on Regeneration Efficiency ............. 263

$\begin{array}{ll}\text { 5.5.6 } & \text { Effect of Combustion Airflow Rate on } \\ \text { Regeneration Efficiency ....................................................... } 264\end{array}$

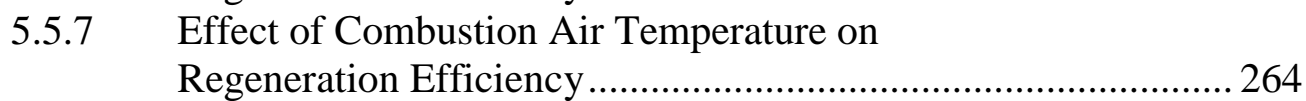

A.1 Exhaust Line Components ................................................... 278

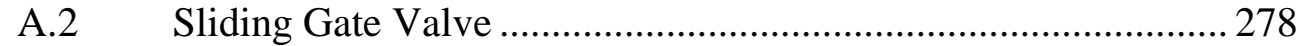

A.3 Sliding Gate Valve Cross-section .............................................. 279

A.4 Automated Butterfly Valve .................................................. 279

A.5 Microwave Water Trap ........................................................ 280

A.6 Adjustable Height Water Tower ................................................. 280

A.7 Stepper Motor Assembly ........................................................... 281 
A.8 Power Supply for Stepper Motor Assembly ……….................. 281

B.1 25 acfm Laminar Flow Element Calibration Curve .................... 283

B.2 $400 \mathrm{acfm}$ Laminar Flow Element Calibration Curve ...................284

D.1 Orifice Meter 1 Calibration Data ............................................. 297

D.2 Orifice Meter 1 Calibration Repeatability Data .......................... 297

D.3 Orifice Meter 2 Calibration Data ……………........................... 298

D.4 Orifice Meter 2 Calibration Repeatability Data ........................... 298

E.1 High-flow Filter Cross-section.................................................... 300

E.2 High-flow Filter Housing ........................................................... 300

G.1 WR284 Waveguide Assembly ................................................... 317

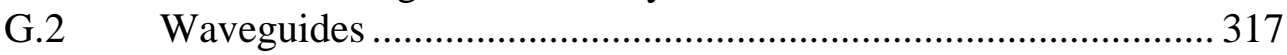

G.3 Microwave Power Transmission Test Chamber .......................... 318

G.4 Voltage Doubler Circuit and Magnetron Schematic ..................... 318

G.5 Waveguide Gate Valve (inlet side) ..............................................319

G.6 Waveguide Gage Valve (outlet side) .........................................319

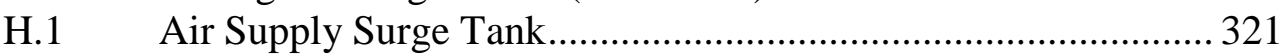

H.2 Air Supply Oil System .............................................................. 321

H.3 Air Supply Components (cart side view) ..................................... 322

H.3 Air Supply Components (cart read view) ..................................... 322

I.1 Combustion Air Orifice Meter Calibration Curve ...................... 324

J.1 Filter Conditioning Chamber (external view) .............................. 326

J.2 Filter Conditioning Chamber (internal view) ..............................3 326

J.3 Filter Conditioning Chamber Filter Support Assembly ................ 327

K.1 Out-of-cell Water Trap................................................................. 329

K.2 Out-of-cell Regeneration Assembly (overall view) ...................... 329

K.3 Out-of-cell Magnetron Control Unit and Data

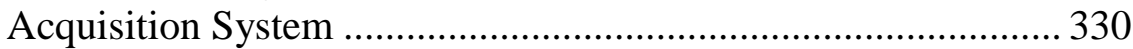

K.4 Out-of-cell Regeneration System Faraday Cage Components.... 330

M.1 Engine Protection Control Box .................................................. 341

N.1 Filter Insertion Equipment ....................................................... 343

N.2 Arbor Press (side view) ................................................................ 344

N.3 Small Oven Used to Dry Filters ................................................... 344

O.1 Engine Exhaust Backpressure Profile During Soot Loading (test \#2) ................................................................. 346

O.2 Valve Position during Soot Loading (degrees from fully-open - test \#2) ............................................... 346

O.3 Mass Flow Rate Ratio during Soot Loading (bypass flow rate/total flow rate x 100 - test \#2) 


\section{List of Tables}

$\underline{\text { Table }}$

$\underline{\text { Page }}$

1.1 Federal Heavy-duty Truck Engine Emission

Standards (g/bhp-hr)............................................................ 1

1.2 Federal Heavy-duty Urban Bus Engine Emission

Standards (g/bhp-hr).............................................................. 2

1.2 Federal Heavy-duty Urban Bus Engine Smoke

Standards (\% Opacity) ............................................................ 2

3.1 MWM D916-6 Emissions Profile (1500 rpm, 50\% Load)........... 64

3.2 Commercial Waveguide Specifications .................................... 139

4.1 Microwave Regeneration Test Matrix........................................ 205

5.1 Effect of Initial Soot Mass on Regeneration Efficiency ............. 261

5.2 Effect of Preheating Time on Regeneration Efficiency .............. 261

5.3 Effect of Combustion Airflow on Regeneration Efficiency........ 262

5.4 Effect of Combustion Air Temperature on

Regeneration Efficiency ...................................................... 262

D.1 Exhaust Orifice Meter Calibration Data.................................... 296

I.1 Combustion Air Orifice Meter Calibration Data....................... 324 


\section{Chapter 1 \\ Introduction}

Increasingly stringent emissions standards for diesel engines have required design changes in combustion chamber geometries, enhanced bowl-in-piston designs, increased injection pressures, electronic injection control strategies, injection rate shaping, timing retardation/advancement, exhaust gas recirculation (EGR), and other means of incylinder emissions reduction. Tables 1.1 to 1.3 provide the past, present, and proposed future, federal, on-highway emissions regulations for heavy-duty diesel engines ${ }^{\ddagger}$.

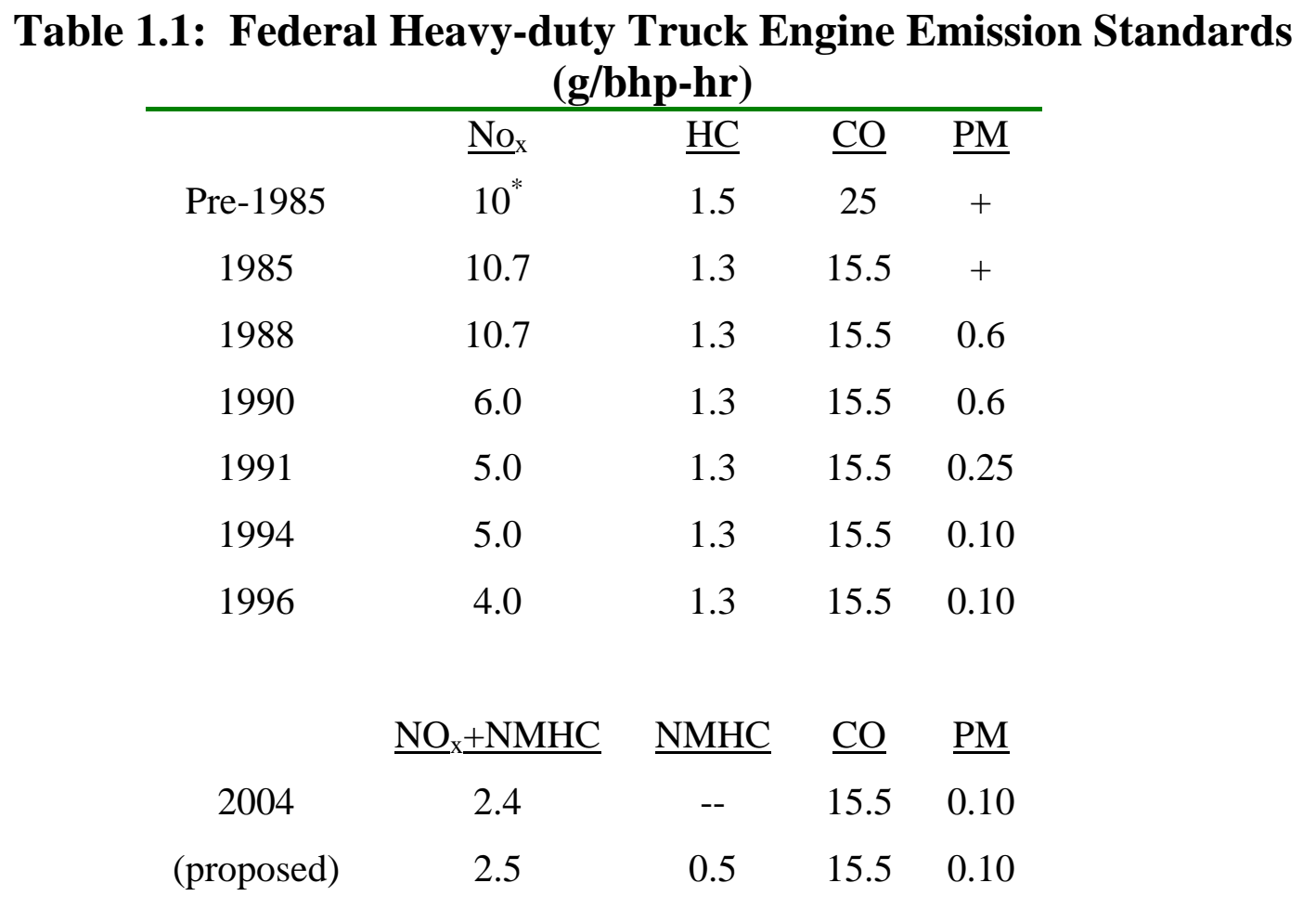

* The sum of $\mathrm{HC}$ and $\mathrm{NO}_{\mathrm{x}}$ must not exceed 10

+ Particulates (PM) were not regulated prior to 1988

NMHC refer to non-methane hydrocarbons

\footnotetext{
$\ddagger$ Table values were taken from a Detroit Diesel Emissions Standards pamphlet (revised in Nov. 1996)
} 
Table 1.2: Federal Heavy-duty Urban Bus Engine Emission Standards (g/bhp-hr)

\begin{tabular}{ccccc}
\hline & ${\underline{\mathrm{No}_{\mathrm{x}}}}_{10}$ & $\underline{\mathrm{HC}}$ & $\underline{\mathrm{CO}}$ & $\underline{\mathrm{PM}}$ \\
1991 & 5.0 & 1.3 & 15.5 & 0.25 \\
1993 & 5.0 & 1.3 & 15.5 & 0.10 \\
1994 & 5.0 & 1.3 & 15.5 & 0.07 \\
1996 & 5.0 & 1.3 & 15.5 & $0.05^{\#}$ \\
1998 & 4.0 & 1.3 & 15.5 & $0.05^{\#}$ \\
& & & & \\
2004 & $\underline{\mathrm{NO}_{x}+\mathrm{NMHC}}$ & $\underline{\mathrm{NMHC}}$ & $\underline{\mathrm{CO}}$ & $\underline{\mathrm{PM}}$ \\
(proposed) & 2.4 & -- & 15.5 & $0.05^{\#}$ \\
\hline \# The in-use PM standard for urban buses is $0.07 \mathrm{~g} / \mathrm{bhp}-\mathrm{hr}$
\end{tabular}

\section{Table 1.3: Federal Heavy-duty Urban Bus Engine Smoke Standards (\% Opacity)

\begin{tabular}{cc}
\hline & Opacity \\
Acceleration & $20 \%$ \\
Peak & $50 \%$ \\
Lug & $15 \%$ \\
\hline
\end{tabular}

Due to the interrelations between emission component formation, tighter restrictions on one pollutant may lead to difficulties in complying with the standards for other regulated pollutants. For example, EGR is frequently used to lower $\mathrm{NO}_{\mathrm{x}}$ emissions by recirculating a portion of the exhaust gas into the intake manifold. $\mathrm{NO}_{\mathrm{x}}$ emissions are formed in the high-temperature region of the combustion zone while particulate emissions are formed due to the incomplete combustion of the fuel, primarily during the diffusion-controlled combustion phase. Incomplete fuel combustion is an inherent characteristic of diesel 
engines due to preignition and subsequent fuel injection, and due to the nonhomogeneous nature of diesel sprays (in terms of local air-to-fuel ratios). Lower peak in-cylinder temperatures lead to lower $\mathrm{NO}_{\mathrm{x}}$ emissions, but the reduced temperatures promote incomplete combustion and, hence, increased particulate emissions. EGR decreases the in-cylinder peak temperatures, so increased exhaust gas recirculation flow rates lead to lower $\mathrm{NO}_{\mathrm{x}}$ emissions levels, but there also exists a corresponding increase in PM emissions. For this reason, lower emissions standards for $\mathrm{NO}_{\mathrm{x}}$ emissions may call for increasing levels of EGR, but this may lead to difficulties in maintaining the current PM emissions standards. Thus, as the aforementioned means of emissions control reach their respective limitations, cylinder-out emissions reduction techniques will become necessary. Exhaust particulate traps and oxidation catalysts appear to be two of the more promising techniques of exhaust aftertreatment systems, but the increases in cost and maintenance associated with these aftertreatment devices have precluded their extensive use on diesel engines to-date.

Catalytic converters are typically used to decrease gaseous emissions levels. Catalytic oxidation can also reduce the mass emission rate of particulate matter by reducing the levels of the soluble organic fraction (SOF). However, depending upon the fuel type, catalyst formulation, and engine operating condition, a reduction in the carbonaceous PM levels may be associated with an increase in sulfate emission levels. The sulfates condense onto the carbon particles and result in an increase in the mass of particulates emitted into the atmosphere. These increases in particulate emissions via sulfate production may easily outweigh the modest particulate reductions caused by SOF emissions reduction. 
Particulate matter (PM) is defined, from a regulatory perspective as any material collected from a diluted exhaust sample on a filter media at a temperature at or below 125 ${ }^{\circ} \mathrm{F}\left(52{ }^{\circ} \mathrm{C}\right)^{\S}$. It consists of a carbonaceous core (elemental carbon), unburned or partially burned fuel and lube oil, sulfates, and wear metal. The size of diesel PM typically ranges from $0.01 \mu \mathrm{m}$ to $0.8 \mu \mathrm{m}$ in terms of aerodynamic diameter. When diesel exhaust is released to the atmosphere, it is quickly cooled to ambient conditions. Under these circumstances vapor phase hydrocarbons adsorb onto the particles, adding to the overall particulate mass. In order to simulate this phenomenon, PM is typically measured using a dilution tunnel in which engine exhaust is mixed with ambient air. A sample is drawn from the dilution tunnel and is passed through a filter. Particulate matter in this case is defined as any solid or liquid matter that is trapped on the filter. A typical particulate sample is composed of solid material (carbon), volatile material, sulfates, and wear metal. The volatile material is composed of polyaromatic hydrocarbons, unburned hydrocarbons, and a soluble organic fraction. The amount of volatile material that is present in a PM sample is dependent on condensation/evaporation and adsorption/desorption. Adsorption/desorption refers to the adherence of hydrocarbon compounds to the surface of the particles in the exhaust, and it is dependent on the physical and chemical characteristics of the particles as well as the saturation ratio (the ratio of the vapor pressure of a species to the total pressure). Condensation/evaporation is dependent on the thermodynamic condition of the mixed sample, so a maximum filter face temperature of $125^{\circ} \mathrm{F}\left(52^{\circ} \mathrm{F}\right)$ is required for sampling purposes (Ferguson, 1993).

\footnotetext{
$\S$ All units in this work are given based on the units which are frequently given in published literature for the specific subject matter under consideration.
} 
Humans are likely to be exposed to diesel exhaust both in ambient air and occupational settings, and potential adverse health effects associated with diesel exhaust exposure include cancer and other pulmonary and cardiovascular diseases. In order to evaluate the human risk associated with diesel exhaust exposure, the Health Effects Institute (1995) evaluated background papers which had undergone peer reviews of qualified experts. The report presents conclusions drawn from the available data, and also identifies gaps in the knowledge base. They found that diesel exhaust raised health concerns for several reasons. The gaseous phase of diesel exhaust contains many irritants and toxins; and oxides of nitrogen, which are ozone precursors, compose a substantial portion of diesel exhaust. Ninety percent of the particles in diesel exhaust are below 1 micron in diameter which allows them to penetrate deep into the human lung when inhaled (i.e. most diesel particles are respirable). Hundreds of chemicals are adsorbed onto the surface of these particles, and many of these are known or suspected mutagens or carcinogens. The deep penetration of these particles into the lung brings them into close contact with the respiratory epithelium, which would allow them to interact with the DNA. Researchers have still not determined whether the mutagens and carcinogens adsorbed on the PM particles are bioavailable (i.e. whether enough of the carcinogenic compounds could be desorbed from the particles to cause cancer). Some researchers have proposed that some carcinogens indirectly affect genes through processes such as cytotoxicity and cell proliferation. The latter mechanism is important in diesel exhaust risk assessment because it implies that there may be an exposure threshold to some carcinogens, that is the carcinogen will cause cancer only if exposures exceed the threshold concentration for a given amount of time. These findings indicate that safe 
levels of diesel exhaust emissions must be determined and maintained (Health Effects Institute, 1995).

Human health hazards associated with diesel exhaust exposure are difficult to assess due to the lack of human epidemiological data, confounding factors in the existing human bioassays, and ambiguity in extrapolating animal bioassays to human risk assessment. There are no unique biological tracers for diesel soot absorbed by the human body, so it is difficult to assess the health hazards associated with diesel soot exposure because diesel soot is only one of many particulate air pollutants. Combustion of fossil fuels and tobacco produce many of the same emissions as diesel fuel combustion, and both man-made and naturally occurring respirable particles are present in the atmosphere. Also, the composition of diesel exhaust has changed over the years due to improvements in engine design and fuel formulation, so current health effects could differ greatly from those in the past (Health Effects Institute, 1995).

A review by the Health Effects Institute (1995) of thirty epidemiological studies of workers exposed to diesel emissions led to the following conclusion that there exists a weak link between exposure to diesel exhaust and lung cancer. It was reported that workers with long-term exposure to diesel exhaust had a 1.2 to 1.5 -fold increase in the risk of developing lung cancer than workers who were considered unexposed. This conclusion is in question due to the presence of potential confounding factors such as smoking, ambient non-diesel particles, environmental tobacco smoke, and asbestos exposure. It is very difficult to account for these factors in an environment which is not controlled. Also, none of the studies determined the levels of emissions during the period 
of exposure, so risk was assessed based on work history alone (Health Effects Institute, 1995).

Data concerning exposure to diesel emissions is limited. In some occupations, diesel particulate matter comprises a large portion of the particulate matter air pollutants. Estimates of workplace exposures ranged from 1 to $100 \mu \mathrm{g} / \mathrm{m}^{3}$ in occupations such as trucking or transportation to 100 to $1,700 \mu \mathrm{g} / \mathrm{m}^{3}$ for underground mining. Information regarding ambient PM exposures is even sparser. Studies in Los Angeles estimated that exhaust particulate matter ambient levels ranged from 1 to $3 \mu \mathrm{g} / \mathrm{m}^{3}$ in areas with low levels of air pollution. Levels up to $10 \mu \mathrm{g} / \mathrm{m}^{3}$ were observed in areas of high air pollution during winter, the season of highest exposures (Health Effects Institute, 1995).

Due to the lack of information and uncertainties in human diesel exhaust exposure studies, animal bioassays are typically used as the basis for diesel exhaust risk assessment. The Health Effects Institute examined research from hamster, mice, and rat bioassays. They concluded that diesel exhaust does cause cancer in laboratory rats. Nearly lifetime exposures to high levels of diesel PM $\left(2,000\right.$ to $\left.10,000 \mu \mathrm{g} / \mathrm{m}^{3}\right)$ for 35 hours or more per week led to increases in the incidence of lung tumors in rats. The lungs were found to be the organ most sensitive to diesel soot exposure, and filtered exhaust (exhaust with no PM) was not found to cause cancer in rats. The same exposure levels of unfiltered diesel exhaust did not induce lung tumors in hamsters or mice, so species-specific factors were suspected to play a part in the induction of lung cancer caused by exposure to diesel PM. It was uncertain as to whether rat, hamster, or mouse bioassays were the most appropriate for human extrapolation; so rat bioassays were chosen to ensure safe emissions standards. The Health Effects Institute (1995) reviewed 
the results from two independent laboratories which indicated that adsorbed chemicals on the PM did not play a major role in the development of lung cancer in rats. In these studies one set of rats was exposed to diesel exhaust and another set was exposed to carbon black. No significant differences in lung cancer development were observed, but the affect of adsorbed chemicals may have been masked by the high concentration of particulate exposure. An understanding of the mechanism behind lung tumor development in rats due to diesel PM exposure is incomplete. The data seemed to indicate that diesel PM exposure caused cancer in rats through indirect or "nongenotoxic" mechanisms and not through direct interaction with DNA as would be caused by mutagenic chemicals adsorbed on the PM. This implied that even particles which are considered benign, if inhaled for a prolonged period of time, could impair the lung clearance mechanisms and damage the surrounding tissue. There appeared to be a particulate exposure threshold in rats for impaired lung clearance, but this threshold was dependent on the dose rate (continuous or intermittent exposure), the length of exposure, and the particulate concentration. Below this threshold, diesel exhaust particulate matter did not cause inflammation or cell proliferation, so no lung tumors developed. The threshold for rats was on the order of $200 \mathrm{mg} / \mathrm{m}^{3}$-hr (Health Effects Institute, 1995).

Extrapolating rat threshold data to humans is difficult because it must be assumed that the same mechanism which causes cancer in rats due to diesel particulate matter exposure is the same as in humans. It must also be assumed that this same mechanism occurs at low doses. One mathematical extrapolation model predicted that intermittent PM levels of 500 to $1,000 \mu \mathrm{g} / \mathrm{m}^{3}$ would be necessary to depress lung clearance 
mechanisms in humans. This level is much higher than those present in most work sites (Health Effects Institute, 1995).

Due to the uncertain and potentially hazardous effects of diesel PM exposure, PM emissions standards may continue to lower, necessitating a means of PM removal from the exhaust of diesel engines. Exhaust filters may be used to decrease particulate emissions by entrapping the diesel soot on or within the filter. The particulate entrapment blocks the vacant spaces within the filter which restricts the flow through the filter causing an increase in exhaust backpressure. Excessive levels of exhaust backpressure can cause engine overheating, decreased engine performance, increased emissions levels, increased fuel consumption, and may cause the exhaust valve to "float" which decreases the amount of air delivered to the cylinder on the intake stroke, and in extreme cases can cause piston/valve interference. The limitation on the acceptable level of exhaust backpressure for a given engine requires that the soot be removed from the filter in some manner. Vehicle space constraints as well as cost constraints limit the overall size of the filter which may be used which, in turn, typically prohibits the use of a disposable filter or manual filter cleansing. Space constraints necessitate the use of a compact filter which requires frequent soot removal and/or disposal. One of the most promising methods of soot removal from exhaust filters is the oxidation of the trapped soot. This method of soot removal is frequently termed regeneration.

Several filtration media and regeneration techniques have been employed in previous studies in an attempt to find a viable exhaust filtration system. These systems usually include a filtration medium, an external energy input, and a controller. The most common filtration media are the metal mesh filter, ceramic fiber filter, the ceramic foam 
filter, and the ceramic monolith (wall-flow filter). Some of the most promising regeneration techniques are intake or exhaust throttling, fuel catalysts, catalyzed traps, electrical heating systems, burner systems, and microwave systems. Of all of these systems, the microwave regeneration system provides the greatest flexibility at a relatively low cost. Chapter 2 provides a description of each of the aforementioned regeneration techniques along with a summary past research. The apparent advantages and disadvantages of each system are included.

Due to its potential and the lack of basic system and performance information, a microwave enhanced oxidation system was analyzed. The objectives of this work were to design and fabricate a microwave soot oxidation system, develop an evaluation scheme, and analyze the performance of the system as a whole. The criterion for this evaluation was regeneration efficiency, which was defined as the ratio of the amount of soot oxidized during regeneration to the amount of soot present within the filter prior to regeneration. The basic system included a standard microwave oven magnetron, a customized WR 284 waveguide; a waveguide gate valve; a stainless steel trap housing; Interam ${ }^{\mathrm{TM}}$ matting, a 5.66" $(14.4 \mathrm{~cm})$ diameter and 6" $(15.2 \mathrm{~cm})$ long, cordierite wallflow filter (200 cells/in); and a water trap. The $1 \mathrm{~kW}$ magnetron was used to generate microwaves at a frequency of $2.45 \mathrm{GHz}$, and the waveguide was used to direct the microwaves to the filter inlet face. The custom-designed waveguide gate valve was used to isolate the magnetron and waveguide from the exhaust gas and regeneration air when the magnetron was not activated. The stainless steel trap housing was used to direct the exhaust flow and the microwaves to the filter element, so it served both as an exhaust line and as a waveguide. The Interam ${ }^{\mathrm{TM}}$ matting was used to seal the circumference of the 
filter element, so no exhaust gas or regeneration air could escape without passing through the filter. The filter element was used to filter the exhaust gas by trapping the soot within the inlet filter channels. The water trap was used to absorb any radiation which was unattenuated by the contents of the filter housing.

An MWM D916-6 indirect injection (IDI), naturally aspirated diesel engine was used to load the filter element. The engine exhaust flow rate and emissions rates were much higher than those allowable for the single filter element, so an exhaust splitting system was designed and developed. Custom-built orifice meters were used to measure the total exhaust and bypass flow rates. A ratio of these values was compared to a target value (the experimentally-determined flow rate ratio necessary to allow acceptable exhaust backpressures, constant exhaust flow through the filter for repeatable soot loads, and filter loading times which were as short as practically possible), and an automated butterfly valve was actuated in $0.9^{\circ}$ increments as necessary. In this manner, the soot could be loaded in a repeatable manner, without excessive exhaust backpressures. Chapter 3 provides a detailed description of the design and fabrication of the entire microwave enhanced soot oxidation system.

The general test procedure consisted of weighing a conditioned filter element. The filter was conditioned in a soot conditioning chamber which was designed and fabricated at WVU. The conditioning chamber allowed the filter to be weighed in an environment of constant temperature $\left(66{ }^{\circ} \mathrm{F},+/-4{ }^{\circ} \mathrm{F} ; 19{ }^{\circ} \mathrm{C},+/-2.2{ }^{\circ} \mathrm{C}\right)$ and humidity $(<10 \% \mathrm{RH})$. The conditioned filter element was loaded by operating the engine exhaust splitting system in bypass mode. Since the particulate matter mass emissions rate of the engine was determined, and the flow rate of exhaust through the filter was measured, the 
amount of soot deposited within the filter at any given time could be estimated. When the amount of collected soot reached the pre-determined target value, the filter was removed from the exhaust line, conditioned, and weighed once again. Once the filter weight had stabilized, the filter was placed within the microwave regeneration system. The soot was preheated by activating the magnetron for a predetermined amount of time. After this period the magnetron was deactivated; the waveguide gate valve was closed; and metered, heated air was provided to the filter by a custom-built air cart. During this convective combustion period, the soot combustion which began at the front of the filter during the preheating phase, propagated towards the outlet of the filter. Air was provided to the filter until the trap temperature decreased substantially and the $\mathrm{CO} / \mathrm{CO}_{2}$ emissions reached ambient levels. At this point, the trap was conditioned once again, the weight was recorded, and the filter was backflushed with dry, filtered, high-pressure shop air to remove as much of the remaining soot as possible. The clean filter was conditioned once more, and the entire process was repeated. A detailed description of the test procedures used in the preliminary testing of the microwave enhanced oxidation system is provided in Chapter 4.

The main parameters of interest in the evaluation of the microwave regeneration system were the preheating time, combustion airflow rate, combustion air temperature, and initial soot loading. In order to determine the effects that each of the parameters had on the regeneration efficiency a test matrix was developed. In this testing scheme, three of the parameters were held constant while the fourth was varied. The preheating time was varied from 10 minutes to 17.5 minutes; the airflow rate ranged from $5 \mathrm{scfm}$ to 20 $\operatorname{scfm}\left(0.14 \mathrm{~m}^{3} / \mathrm{min}\right.$ to $\left.0.57 \mathrm{~m}^{3} / \mathrm{min}\right)$, the air temperature ranged from $80{ }^{\circ} \mathrm{F}$ to $635{ }^{\circ} \mathrm{F}$ 
$\left(27^{\circ} \mathrm{C}\right.$ to $\left.335^{\circ} \mathrm{C}\right)$, and the initial soot loading was maintained between $9.6 \mathrm{~g}$ and $29.6 \mathrm{~g}$. Regeneration efficiencies were determined for all test conditions. Within the ranges listed above the regeneration efficiency (based on a gravimetric analysis) varied from $30 \%$ to $72.9 \%$ with no filter damage. A discussion of the results of the regeneration testing is given in Chapter 5, while conclusions and recommendations are provided in Chapter 6. 


\section{CHAPTER 2 \\ Literature Review}

This chapter presents a summary of some of the past research regarding the regeneration of diesel soot from filtration media. The systems of interest include intake and exhaust throttling, fuel-borne catalysts, catalyzed filters, electrical heaters, burner systems, and microwave systems. The filtration media which are typically used with these systems are described, and the advantages and disadvantages of each regeneration system and filtration medium are included. A brief background of microwaves is given, as well as a discussion of the safety issues involved with exposure to microwaves.

\subsection{Filtration Media}

The filtration media for a regeneration system must be capable of collecting most of the particulate matter in the exhaust stream, capable of withstanding high temperatures, have a high filtration surface-to-volume ratio, be inexpensive, durable, and must impose a low pressure loss even when loaded (MacDonald et al., 1988). Ludecke and Dimick (1983) listed the ceramic fiber filter, ceramic foam filter, metal mesh, and wall-flow monolith as the filters that were considered to have the properties necessary for particulate entrapment and incineration. The ceramic fiber and wall-flow monolith are surface collection materials that build a layer of soot on the filtration surfaces. The layer of collected soot then enhances the filtration of soot. The wall-flow monolith is composed of a honeycomb structure with alternately plugged channels. The exhaust gas

passes into an inlet channel and is then forced to flow through the ceramic walls and into the outlet channels. The metal mesh and ceramic foam filters allow penetration of the 
soot into the filter. The particulates are deposited on the intertwining strands of the filter. The surface collection filters (especially wall-flow filters) typically have higher collection efficiencies, but the exhaust backpressure builds up rapidly requiring regeneration at frequent intervals. The ceramic foam and metal mesh filters were considered difficult to regenerate without overheating due to the high concentration of soot near the front of the filter. Another observed difficulty was that transient engine cycles tended to dislodge particles from the trap (Ludecke and Dimick, 1983). Clogging can be a problem with surface collection filters, and backpressure levels can become high enough to stall an engine (Kiyota et al. 1986). Many researchers have chosen the wall-flow monolith for the filtration medium due to its high filtration area-to-volume ratio, high collection efficiency, and packed-bed filtration characteristic which requires only one end of the filter to be heated to soot ignition temperatures before a sustained burning occurs (Barris and Rocklitz, 1989). Some researchers have preferred ceramic foam filters to wall-flow filters because ceramic foam filters can be manufactured in a variety of shapes and feature a "deep bed" type of filtration collection which allows the external energy source for regeneration to be focused in the area of greatest soot deposition. Also, wall-flow filters are not as tolerant of thermal stresses in the radial direction, so uniform heating of the filter inlet face is essential to avoid filter damage. Ceramic foam filters are isotropic, so they can withstand larger temperature gradients than wall-flow filters (Walton et al., 1990).

It is apparent that choosing an appropriate filtration medium is a tradeoff between desirable and undesirable characteristics that depend upon geometric constraints, the collection efficiency that is necessary for a given engine to meet emissions requirements, 
and the type of regeneration technique. The following paragraphs describe some of the regeneration studies which have been performed by various researchers. All of the aforementioned filtration media have been tested and evaluated in conjunction with a variety of regeneration systems in the following studies.

\subsection{Regeneration Systems}

\subsubsection{Throttling}

Throttling techniques require the placement of a throttling valve either in the intake or in the exhaust system of an engine. For intake throttling, the airflow restriction decreases the amount of air in the cylinder, but the same quantity of fuel is injected. This causes an increase in the exhaust temperatures which can regenerate exhaust filters if the exhaust temperatures exceed the soot ignition temperature, which is on the order of 600 ${ }^{\circ} \mathrm{C}$ to $650{ }^{\circ} \mathrm{C}\left(1112{ }^{\circ} \mathrm{F}\right.$ to $\left.1202{ }^{\circ} \mathrm{F}\right)$ for uncatalyzed traps and fuels. Intake air throttling with timing retardation was used by Kiyota et al. (1986) as a backup regeneration scheme for a catalyzed trap regeneration system. Intake air throttling was necessary if the engine was operated at low-load conditions for extended periods of time. Test results demonstrated that the exhaust temperatures were sufficient for regeneration even at moderate engine load conditions (Kiyota et al., 1986). An intake air throttling system was also developed and tested by Ludecke and Dimick (1983) who had employed a flowthrough, catalyzed, metal mesh trap, and a ceramic foam trap. Significant engine loading was required for regeneration if the filter was not catalyzed. Pattas et al. (1986) developed an exhaust throttling regeneration system that employed an uncatalyzed ceramic monolith [5.66" $(14.4 \mathrm{~cm})$ diameter and 6" $(15.2 \mathrm{~cm})$ length with 100 cells/in $\left.{ }^{2}\right]$ 
for urban buses. A throttling plate was placed in the exhaust line downstream of the filter, and was manually activated by the vehicle operator when filter regeneration was necessary. Only two positions were used for throttle operation - "open" and "closed." Holes were drilled in the throttling plate, so when the throttle was closed for regeneration, the exhaust was forced to flow through the holes, increasing the exhaust backpressure and temperature. Some laboratory tests were performed to determine system operability. The maximum exhaust temperature that could be achieved with exhaust throttling was 1330 ${ }^{\circ} \mathrm{F}\left(720^{\circ} \mathrm{C}\right)$ [the maximum allowable backpressure was set at $100 ” \mathrm{H}_{2} \mathrm{O}(25 \mathrm{kPa})$ ], and significant engine loading was necessary to achieve exhaust temperatures exceeding 650 ${ }^{0} \mathrm{C}\left(1200{ }^{\circ} \mathrm{F}\right)$. Some of the filters were damaged during regeneration due to excessive thermal stresses. The operator had to ensure that the trap peak temperature did not exceed $650{ }^{\circ} \mathrm{C}\left(1200{ }^{\circ} \mathrm{F}\right)$ by controlling the rack position during the acceleration period which was necessary for regeneration. Due to the high variability associated with the manually controlled regeneration, an automated regeneration system was proposed (Pattas et al., 1986).

The obvious advantages of a throttling regeneration system are its simplicity and low cost. The disadvantages are decreased engine performance, fuel economy penalty, and high engine exhaust backpressure during regeneration, as well as the high engine load requirement for soot ignition (regeneration cannot occur at all engine conditions), especially for uncatalyzed traps or fuel. Another disadvantage is that with most throttling systems, there is no control over the exhaust flow during regeneration. This makes it difficult to maintain acceptable peak temperature levels within the filter. 


\subsubsection{Fuel Catalysts}

As mentioned previously, the ignition temperature of uncatalyzed soot is approximately $650{ }^{\circ} \mathrm{C}\left(1200{ }^{\circ} \mathrm{F}\right)$. This is not within the range of typical exhaust temperatures for normal driving conditions. Hence, for soot ignition to occur either the exhaust temperature must be increased (high engine loading or throttling), or an external energy source must be used (electrical heater or burner), or the soot ignition temperature must be lowered (catalyzed trap or fuel catalyst). One of the methods of decreasing the ignition temperature of the soot collected within a filter is through the use of a fuel-borne catalyst. Ludecke and Dimick (1983) performed laboratory tests with manganese fuel additives in which the ignition temperature of the soot was decreased by $80{ }^{\circ} \mathrm{C}\left(144{ }^{\circ} \mathrm{F}\right)$. Copper and lead additives decreased the ignition temperature by $150{ }^{\circ} \mathrm{C}\left(270{ }^{\circ} \mathrm{F}\right)$, but the fuel additives left a large amount of incombustible material in the filter after regeneration. They concluded that the autoignition of catalyzed soot was not a dependable regeneration scheme (Ludecke and Dimick, 1983). Wade et al. (1983) also investigated the use of fuel catalysts for regeneration. The catalysts tested were lead, copper, copper/lead, manganese, copper/manganese, and calcium. Lead and copper were found to lower the ignition temperature of the soot to the greatest degree, and a copper/lead additive produced the best results $\left[190{ }^{\circ} \mathrm{C}\left(374^{\circ} \mathrm{F}\right)\right.$ soot ignition temperature]. A 10,000 mile durability test was performed and frequent regenerations were observed because the 190 ${ }^{\circ} \mathrm{C}\left(374{ }^{\circ} \mathrm{F}\right)$ ignition temperature was frequently present during normal engine operating conditions. These fuel-borne catalyst based passive regeneration systems resulted in decreased initial soot loadings in the filter than a burner system (that was tested 
previously). Hence, lower peak temperatures were encountered within the filter during regeneration. Analysis of the sample filters used for particulate emissions measurement showed that practically all the lead and copper were filtered by the trap. Noncombustible residue was found in the trap, after the durability test, to such a large degree that many of the channels at the outlet end of the filter were completely blocked. Deposits in the fuel injectors were also a problem (Wade et al., 1983).

The advantages of the use of a fuel catalyst for regeneration are low initial cost and maintenance as well as simplicity (no external energy source is required). Catalyst deterioration is not an issue because it is replenished with the fuel. The major disadvantages are the long-term cost, a modest fuel economy penalty (MacDonald et al., 1988), increased engine wear, and in-combustible soot build-up within the filter. Another disadvantage is that the engine cannot be regenerated at all operating conditions. Additionally, use of copper based fuel-borne catalysts has been linked to dioxin formation. Recent concern regarding emissions of nanoparticles from PM trap-equipped vehicles is particularly targeted towards fuel-borne catalyst regeneration systems.

\subsubsection{Catalyzed Filters}

Another method of auto-regeneration through lowered soot ignition temperature is catalyzed traps. In this method, a catalyst impregnated on the filtration surfaces lowers the ignition temperature of the soot it comes into contact with. The aforementioned intake throttling system of Ludecke and Dimick (1983) incorporated the use of a flowthrough, catalyzed, metal mesh trap. Initially, low-load regenerations could be performed [only $310^{\circ} \mathrm{C}\left(590{ }^{\circ} \mathrm{F}\right)$ exhaust temperatures were required], but the catalyst deteriorated 
rather rapidly, and higher engine loads were eventually required for regeneration. Sulfate emissions were substantially increased due to the presence of a catalyst in the exhaust. During regeneration, the sulfate emissions increased even further. A catalyzed ceramic foam trap was also used in conjunction with the intake throttling system. It was discovered that the filter had a relatively low collection efficiency (46\%) and a high degree of particulate blow-off during heavy engine loading. Also, relatively high engine loads were required for regeneration (Ludecke and Dimick, 1983). Kiyota et al. (1986) developed a catalyst for the ceramic foam filter used in their regeneration testing. The trap was developed for self-regeneration at moderate to high engine load conditions. Intake air throttling with timing retardation was used as a backup regeneration mechanism if the filter became overloaded due to extended low-load driving conditions. Filter overloading is undesirable because it causes uncontrolled regeneration to occur due to the exothermic nature of diesel soot combustion. Catalyst development was necessary in order to find a catalyst which did not promote sulfate formation and yet, enhanced soot oxidation at lower temperatures. A catalyst was developed which did not promote sulfate formation and which lowered the soot ignition temperature to $350{ }^{\circ} \mathrm{C}\left(660{ }^{\circ} \mathrm{F}\right)$. This catalyst showed no signs of deterioration even after 50,000 miles of operation. No results were presented on to the amount of ash that was left in the filter after the durability testing (Kiyota et al., 1986). Arai et al. (1987) performed regeneration testing with a wire mesh trap, a ceramic foam trap, and a wall-flow trap. All the traps were catalyzed, and the soot ignition temperature was lowered to $400{ }^{\circ} \mathrm{C}$ to $450{ }^{\circ} \mathrm{C}\left(750{ }^{\circ} \mathrm{F}\right.$ to $\left.840{ }^{\circ} \mathrm{F}\right)$. Catalyst deterioration, sulfate formation, and trap plugging were all found to be 
problems, and relatively high engine load factors were still necessary for regeneration (Arai et al, 1987).

From these studies it may be concluded that catalyst durability, increased sulfate production, ash formation within the filter, and selective engine operating conditions for regeneration are the disadvantages of this type of regeneration scheme. Also, the trap cannot be regenerated at all conditions, and, as with fuel catalysts, there is typically no control over the oxygen flow rate during regeneration. Due to the limited contact area of the catalyst and the soot, the soot ignition temperatures for catalyst coated traps are typically higher than those associated with fuel catalysts. The advantages of this type of system are its simplicity and low cost.

\subsubsection{Electrical Heating Systems}

Electrical heating techniques employ a heating element near the inlet and/or outlet face of the filter element. The heating element is activated when filter regeneration is necessary. Arai et al. (1987) analyzed an electrical heating regeneration system on a turbocharged, heavy-duty diesel engine. The system was comprised of a $1.5 \mathrm{~kW}$ electrical heating element and a soot filtering element. The filtration element was a catalyzed ceramic monolith, and a bypass line with muffler was incorporated to aid in regeneration control. The bypass valve was closed during the preheating period of the regeneration process and was opened and held at a specified angle once soot ignition occurred. It was found that the heating element had to be in contact with filter face in order to achieve the temperatures necessary for regeneration. There were problems achieving soot combustion within the outer edges of the filter. Hence, a gas flow 
distributor was installed to force the air into the periphery of the trap, but this caused the filter temperatures in the core of the filter to become excessive and trap damage ensued. Only $10 \mathrm{~g}$ to $12 \mathrm{~g}$ of soot could be collected in the $5.6 "(14.4 \mathrm{~cm})$ diameter, 6" $(15.2 \mathrm{~cm})$ long wall-flow filter or filter damage occurred during regeneration, even with increased airflow rates. Since smaller initial soot loadings resulted in incomplete regeneration, a narrow range soot loading prior to regeneration was required for controlled and complete regeneration.

Barris and Rocklitz (1989) performed an electrical heating regeneration study utilizing modeling techniques to predict flow characteristics, temperature distributions, and thermal stresses within the filter element. An electrically heated bypass regeneration system was developed using a cordierite wall-flow monolith as the filtration medium. Thermal stresses within the filter were minimized by limiting the amount of oxygen present during regeneration. A perforated inlet to the trap was used to disperse the particulate through the trap in a more uniform manner. A theoretical filtration model was used to estimate the filtration medium performance and pressure loss. A computational fluid dynamics (CFD) program was also used to determine the flow characteristics through the filter with various inlet geometries and flow conditions. Uniform flow during filter loading was found to be necessary to create uniform soot deposition within the filter which decreased thermal stresses within the filter during regeneration. Uniform flow characteristics during regeneration were even more critical, because nonuniform flow characteristics caused localized hot zones within the filter due to lack of convective heat transfer, and it also caused nonuniform temperature profiles at the filter inlet face due to electrical heating element perturbations. A CFD model was also used to estimate 
temperature profiles within the filter due to radiative and convective heat transfer rates caused by the heating element and the airflow. An interesting observation regarding the modeling results was that due to the high temperatures which were present during regeneration, natural convection forces exceeded the forced convection forces. This implied that the trap orientation would affect the temperature distribution within the trap, and regeneration models must account for this phenomenon. The temperature distribution data provided by the fluid dynamics models was used as input data for a finite element model which was used to determine the stresses within the filter. The stress data allowed experimental regeneration techniques to be developed and filter failure was subsequently minimized. The data was also used to design a suitable heating element which provided uniform heating of the filter inlet face. Unfortunately, other than a few internal trap temperature readings, no experimental results were presented (Barris and Rocklitz, 1989).

One of the major advantages of an electrical heating regeneration system is that regeneration can occur at any engine operating condition. Bypass lines can also be installed to allow control of the exhaust or airflow which allows better control of the combustion rate. Disadvantages of the system include high cost and high electrical load requirements for the vehicle's alternator, and a control unit is required. The heating element is installed in a corrosive atmosphere, thus threatening the life of the element. Also, if the design requires that the heating element be in contact with the filter face, increased exhaust backpressures would be expected. Uniform flow characteristics are required to achieve uniform temperature distributions at the filter inlet face due to 
convective heat loss perturbations of the heating element. Uniform flow characteristics are difficult to achieve at all engine operating conditions and for all exhaust systems.

\subsubsection{Burner Systems}

A significantly large amount of development work has been done on burner systems for regeneration. Most of these systems use diesel burners to increase the temperature of the air or exhaust passing through the filter to exceed soot ignition temperatures. Ludecke and Dimick (1983) found that a large amount of energy was required if the entire exhaust passed through the filter during regeneration, but only a fraction of the energy was required if only a small percentage of the total exhaust flowed through the filter (Ludecke and Dimick, 1983). Thus, to conserve energy and to allow better combustion control, bypass systems are frequently used in conjunction with burner systems. These systems include either a muffler in the bypass line, in which case the exhaust is unfiltered during regeneration, or a second trap so that the exhaust is always filtered.

Wade et al. (1983) published the results of a burner regeneration study that employed wall-flow filters. They found that the burner exhaust had to be well mixed with the oxygen supply (diesel exhaust in this case) in order to provide uniform filter inlet temperature distributions during regeneration. Hence, a mixing cone was placed at the outlet of the gas burner. A mixed stream of $650{ }^{\circ} \mathrm{C}\left(1200{ }^{\circ} \mathrm{F}\right)$ was targeted in order to ensure that the particulate matter trapped in the periphery of the filter was regenerated. The burner efficiency was defined as the ratio of the actual temperature rise of the filter face relative to the exhaust temperature to the theoretical temperature rise of the gas and 
exhaust streams mixing with no heat transfer losses to the environment. Burner efficiencies ranged from $55 \%$ at low engine speeds (high rates of heat transfer to the environment) to $98 \%$ at high engine speeds. Rapid and reliable ignition of the burner was found to be one of the most difficult requirements to meet for burner regeneration systems. Rapid ignition aided in reliable regeneration and reduced emissions generated by the burner system. A glow plug was used initially to ignite the burner gas, but it could not create ignition under moderate- to high-load conditions. Hence, a spark ignition system was employed instead. Spark plug fouling was still found to be a problem. One major disadvantage of a burner system was the emissions produced by the burner combustion. The burner emissions were reduced by changing the solenoid valve in the fuel supply line to a ball valve, placing the ball valve as near to the burner as possible, and initiating swirl in the combustion zone. The difference in backpressure prior to and after regeneration was compared to the difference in backpressure of the loaded trap and an unloaded filter. The ratio of these differences was used to define the regeneration efficiency. The results indicated that over a $90 \%$ regeneration efficiency could be achieved if the filter inlet face temperature was maintained above $732{ }^{\circ} \mathrm{C}\left(1350{ }^{\circ} \mathrm{F}\right)$ for 2 minutes with a peak trap temperature of about $1093{ }^{\circ} \mathrm{C}\left(2000{ }^{\circ} \mathrm{F}\right)$. High regeneration efficiencies such as this required careful control of the exhaust flow rate during regeneration, initial soot loading, and trap inlet temperature in order to prevent filter damage. Low exhaust flow rates during regeneration had to be avoided or filter damage would ensue. Due to the number and complexity of the parameters involved in a burner regeneration system, a feedback burner control system was deemed necessary. 
The complexity of the interactions of the parameters involved with a burner control system was also apparent in the research performed by Arai et al. (1987). Bench tests were performed using 5.66" $(14.4 \mathrm{~cm})$ diameter and 6" $(15.2 \mathrm{~cm})$ length ceramic monoliths. The initial soot loading and the trap inlet temperature were studied to determine the ranges in which trap damage did not occur. They found that the initial soot loading had to be kept less than $40 \mathrm{~g}$ to avoid trap damage. The gas temperature could be maintained at $600{ }^{\circ} \mathrm{C}\left(1110{ }^{\circ} \mathrm{F}\right)$ without trap damage, but total regeneration did not occur under these conditions. At $700{ }^{\circ} \mathrm{C}\left(1290{ }^{\circ} \mathrm{F}\right)$, the particulate was regenerated, but the rear, central portion of the trap had melted. A test sequence was then initiated in which the gas was inducted at $600{ }^{\circ} \mathrm{C}\left(1110^{\circ} \mathrm{F}\right)$ initially to regenerate the central portion of the filter, and then gas was introduced at $800{ }^{\circ} \mathrm{C}\left(1470{ }^{\circ} \mathrm{F}\right)$ to regenerate the periphery of the filter. This procedure allowed trap regeneration (on the order of $80 \%$ regeneration efficiency based on backpressure data) without trap failure.

A burner development study performed by General Motors was published in 1988. The burner was placed at the filter outlet and was positioned along the axis of the filter to provide more uniform heating of the filter element. A large diameter burner and a filter housing with a double wall to minimize heat losses were also chosen to aid this effect, and the filter housing had double walls to minimize heat losses. The final system imposed only an $80^{\circ} \mathrm{C}\left(144^{\circ} \mathrm{F}\right)$ difference across the filter face. A regeneration model was used to estimate the optimum combustion airflow rate, burner air/fuel ratio, and initial particulate loading. This model predicted peak trap temperatures of $1127{ }^{\circ} \mathrm{C}(2061$ ${ }^{\circ} \mathrm{F}$ ) under typical regeneration conditions. General Motors researchers observed that if peak trap temperatures were maintained below $1000{ }^{\circ} \mathrm{C}\left(1830{ }^{\circ} \mathrm{F}\right)$ then trap damage could 
be avoided. Due to lower the peak trap temperatures, it was necessary to attain relatively low soot loadings, relatively high airflow rates to enhance heat transfer, and a uniformly distributed heat source. It was recognized that increasing the heat transfer rates could cause increases in the thermal stresses within the filter, so in order to estimate the magnitude of these stresses, a stress analysis of the filter was performed. The results of this analysis indicated that $+/-35^{\circ} \mathrm{C} / \mathrm{cm}\left(+/-160{ }^{\circ} \mathrm{F} /\right.$ in $)$ was the maximum temperature gradient allowable that would not cause damage to the filter during repeated regeneration cycles. The stress analysis and the regeneration model were used to develop an experimental test schedule to test the durability of the filter under a given set of regeneration conditions. Experimental results indicated that using the first burner control scheme, the particulate combustion did not produce peak temperatures that would exceed the design constraints, but the design stresses were exceeded during burner start-up and shut-down. The burner schedule was modified to limit the stresses to within the design limitations of the filter. With this enhanced control scheme, acceptable peak temperatures of only $782^{\circ} \mathrm{C}\left(1440{ }^{\circ} \mathrm{F}\right)$ were observed, and over 300 regenerations were performed on one trap without filter failure (MacDonald et al., 1988).

Another burner study was performed by Ha et al. (1989) using catalyzed wallflow ceramic filters in a burner system. During the development stage, the initial soot loading and burner and fan activation were optimized to maintain the radial thermal gradients below $125{ }^{\circ} \mathrm{C} /$ in $\left(225^{\circ} \mathrm{F} /\right.$ in $)$ and the longitudinal gradients below $250{ }^{\circ} \mathrm{C} /$ in ( $450^{\circ} \mathrm{F} / \mathrm{in}$ ). During the implementation of the system, the traps were regenerated based on a time sequence (not based on any direct estimation of the particulate loading). The control system operated such that one trap was loaded while the other was regenerated. 
The traps were loaded for only 30 minutes and then regenerated. A durability test for 100 hours was performed with no trap failures (Ha et al., 1989).

A burner control system was developed by Meinrad et al. (1989) for the regeneration of ceramic monoliths on city buses. Both muffler bypass systems and dual trap systems were tested. Laboratory tests were performed using the burner control system. After a given amount of soot was trapped within the filter the burner was ignited, and an auxiliary air source was activated. After the soot began to oxidize, the burner was deactivated, but air was still channeled through the filter. Narrow ranges of airflow and initial soot loadings were required to maintain trap temperatures below $1100{ }^{\circ} \mathrm{C}(2012$ $\left.{ }^{\circ} \mathrm{F}\right)$. Similar to the findings of previous researchers, it was found that a minimum amount of soot loading was necessary for regeneration to proceed to completion, and there also existed a maximum amount of soot that could be collected before filter damage would occur during regeneration due to excessive peak filter temperatures. Because soot load estimation was deemed to be critical, an accurate estimate of the soot loading was necessary. To obtain this estimate, a venturi was placed in the exhaust line after the filter to measure the exhaust flow rate. The exhaust backpressure before the filter was also measured, and with these two measurements, the soot loading was estimated independently of the engine operating conditions. Durability tests were performed to determine system practicality and performance. A total of 2500 regenerations were performed on two filters. The filter weight was observed to increase as the number of successive regenerations increased due to noncombustible material build-up within the filter. Also, the collection efficiency of the filter decreased during the testing indicating trap damage (Meinrad et al., 1989). 
These studies indicate that the advantages of a burner system include the ability to regenerate at all engine operating conditions and a readily available energy supply. System disadvantages include system complexity (including the need of an ignition source, control unit, fuel pump, high-pressure air supply, and air pump), high cost, increased fuel consumption, and increased emissions during burner operation. Reliable burner ignition is very difficult to attain. If the burner fails to ignite, not only will emissions be increased, but also the filter could be sprayed with fuel which could cause filter failure during a subsequent regeneration sequence (Wade et al., 1983). Another major problem appears to be fouling of the nozzle due to carbon deposits. This problem was cited by numerous researchers (Ludecke and Dimick, 1983; Wade et al., 1983; Arai et al., 1987; MacDonald et al., 1988).

\subsubsection{Microwave Regeneration Systems}

Analysis of the aforementioned regeneration systems demonstrates that none of these systems performed suitably, that is, they failed to yield complete regeneration, long filter life, high collection efficiency, low emissions, low cost, low engine power loss and fuel penalty, regeneration capability at all engine operating conditions, and repeatable regenerations. One type of regeneration scheme which has shown great potential is the microwave regeneration system. Relatively little research has been performed to date using this type of system, and very little basic information is available concerning system configuration and performance. A brief summary of microwave energy as well as a summary of published literature on microwave regeneration systems is given below. 


\subsubsection{Microwave Background}

Microwaves are a form of electromagnetic energy that have frequencies in the range from $500 \mathrm{MHz}$ to $100 \mathrm{GHz}$ and which travel at the speed of light (approximately 186,000 miles per second). Microwaves are typically used for communications (such as radar, satellite communications, and cell phones) and heating (conventional and industrial applications). The frequencies used for heating are near $900 \mathrm{MHz}$ or $2450 \mathrm{MHz}$ in order to avoid interference with communications. Other electromagnetic energy forms include radio waves, infrared radiation, visible light, ultraviolet rays, X-rays, and gamma rays (Meredith, 1998). Gallawa (1997) compared microwaves (and all electromagnetic waves for that matter) to the disturbance caused by a pebble thrown into a quiescent pond. The disturbance causes the water to move up and down in the form of ripples on the pond's surface. The ripples grow in ever-widening circles away from the center of origin. The ripples are examples of transverse waves, which are waves whose direction of propagation is at right angles to the wave disturbance motion. The water serves as the medium through which the waves propagate. In this sense, the ripples are a better example of sound waves which use molecules to transmit disturbances in air or water. On the other hand, electromagnetic waves have no need of a medium such as air or water because electromagnetic waves are, in themselves, stored energy in motion composed of electric and magnetic fields. Current flowing through a wire generates electric and magnetic fields around the wire due to the flow of electrons through the wire. Electric and magnetic fields are force at a distance concepts (similar to gravitational force) created by charges (such as electrons) and charge motion. If the current through the wire were to oscillate very rapidly, the electromagnetic field would be launched into space at 
the speed of light in the form of electromagnetic waves. The alternating electric and magnetic fields which comprise electromagnetic waves such as microwaves travel at right angles to each other and to the direction of motion. Waves are believed to be comprised of tiny packets of energy termed photons which contain both energy and momentum (Gallawa, 1997). The energy of a photon carried in an electromagnetic wave is defined by the Einstein-Plank relation:

$$
E=h f=\frac{h c}{\lambda}
$$

where,

$$
\begin{aligned}
& \mathrm{h}=\text { Plank's Constant }=6.62 * 10^{-27} \text { erg-s } \\
& \mathrm{f}=\text { frequency }(\mathrm{Hz}) \\
& \mathrm{c}=\text { speed of light }=3.0 * 10^{8} \mathrm{~m} / \mathrm{s} \\
& \lambda=\text { wavelength }(\mathrm{m})
\end{aligned}
$$

From this relation it can be deduced that electromagnetic waves which have high frequencies or short wavelengths have more energy than electromagnetic waves with low frequencies or short wavelengths. The intensity of electromagnetic radiation is based on the number of photons it carries per unit of time. Photons of different energy levels will cause different effects when they are absorbed. Bright sunlight can cause sunburn if the skin is exposed to it for a given length of time, but exposure to an infrared heat lamp for the same amount of time would not cause sunburn. Similarly, electromagnetic radiation of different wavelengths will cause different effects on molecules. Molecules are composed of atoms which are in turn composed of protons, neutrons, and electrons which undergo complex and unique motions. If radiation at a given wavelength should match the resonant frequency of one of these motions (vibrational or rotational motion), there is a high probability of absorption of the radiation (Jahnke, 1993). The wavelength of the 
radiation, therefore, plays a large part in determining how the waves will interact with objects that they encounter. X-rays have very short wavelengths and can penetrate many objects that would absorb light rays which have longer wavelengths. Microwaves have wavelengths which are of the order of a few centimeters and match the resonant frequency of water fairly well. Therefore, microwaves are readily absorbed by water molecules in foods or liquids (Tipler, 1991). Electromagnetic waves with short wavelengths (high energy levels) such as gamma rays can have detrimental effects to living cell tissue. Radiation which can damage living cell tissue is termed ionizing radiation. This type of radiation is powerful and penetrating due to its high energy level and short wavelengths, and it can actually change the molecular structure of the cells. Xrays, gamma rays, and cosmic rays are considered ionizing radiation. Microwaves are considered non-ionizing radiation because they have much lower frequencies and energy levels than ionizing radiation which makes them much less of a health threat (Gallawa, 1997).

The concept of electromagnetic absorption was outlined in the preceding paragraph, but the direct application of microwaves to diesel soot regeneration has yet to be discussed. The power absorbed by a material in an electromagnetic field is dependent on the dielectric and magnetic loss factors of the material as well as the electric and magnetic field strengths and the frequency of the electromagnetic waves. This power absorption is caused by the rotation and vibration of molecules that compose the material. The more susceptible the molecules are to move under the influence of electromagnetic waves (i.e. the higher the values of the dielectric and magnetic loss factors), the more power will be absorbed. Friction between the moving molecules causes the temperature 
of the substance to increase. Magnetic materials can be heated by both electric and magnetic fields, but diesel soot is not magnetic and hence can only be heated via the electric field of the RF energy (Walton et al., 1990). The dielectric properties of a material are described by the complex permittivity:

$$
\varepsilon=\varepsilon^{\prime}-j \varepsilon^{\prime \prime}
$$

The real part is the dielectric constant which is a direct indication of the amount of energy that can be stored in a substance in the form of electric field. The imaginary part is the dielectric loss factor which indicates the amount of energy that can be dissipated by a material in the form of heat. The power absorbed by a material is directly proportional to the complex permittivity, the frequency of the irradiation (f), and the electric field strength $(\mathrm{E})$.

$$
P=55.63 f E^{2} \varepsilon^{\prime} \tan \delta
$$

$\operatorname{Tan} \delta$ is the loss tangent of the material

$$
\tan \delta=\varepsilon^{\prime \prime} / \varepsilon^{\prime}
$$

Therefore, for a given microwave frequency and electric field strength, the complex permittivity can be used to determine the amount of microwave power absorption of a material (Ma et al., 1997).

Ma et al. (1997), stated that one of the major drawbacks of thermal regeneration is that both the filter and the soot must be heated up to soot ignition temperatures. This reduces filter life, consumes energy unnecessarily, and increases the total regeneration time. Microwave regeneration, on the other hand, has a selective heating nature. Suresh Babu et al. (1995), performed cavity perturbation techniques to measure the real and imaginary parts of the dielectric constants for both soot and ceramic trap material at 8.7 
GHz. They found that the dielectric loss factor for diesel soot (7.4) was five orders of magnitude larger than that of the ceramic trap material $\left(6.0^{*} 10^{-5}\right)$. These results show that diesel soot, like water, has a high dielectric loss factor; so microwaves are readily absorbed by the soot. Ceramic filters have a low dielectric loss factor, so they are relatively transparent to microwaves. This indicates that microwaves can be used to heat diesel soot trapped in a ceramic filter directly, and the filter element will be heated indirectly via conduction, convection, and radiation.

Microwave regeneration systems have many advantages over conventional heating systems. Control over the electric and magnetic fields within the filter offer a great deal more flexibility in soot combustion control. Many standard microwave oven components can be used in the regeneration system, so the cost of microwave energy based systems is relatively inexpensive. The soot is heated directly, so time and energy are not wasted unnecessarily in heating of the filtration element. Disadvantages include difficulty in uniform heating of the filter, necessity of a customized alternator (or another type of power supply) and a control unit, increased safety concerns, and complexity in predicting microwave behavior within the filter. The final point stems from the fact that electromagnetic energy can be reflected and refracted as well as absorbed. Diesel soot has a high dielectric loss factor, so it will absorb most of the microwave energy that is transmitted to it. Ceramic materials (such as cordierite) have low dielectric loss factors, so RF energy will pass through them with little attenuation, reflection, or refraction. Conductors reflect microwave energy, so microwaves transmitted to metal walls will be reflected. All of these substances are present in a diesel filtration unit, so the geometry of the metal filter housing, the soot loading, and the intensity and spatial distribution of the 
microwave energy transmitted to the filter face will determine the electric and magnetic field distributions within the filter (Walton et al., 1990).

\subsubsection{Microwave Regeneration Studies}

One of the first microwave regeneration studies was performed by Garner and Dent at Loughborough University of Technology in 1989. Due to its high filtration efficiency (70\% to $90 \%)$ and suitable regeneration characteristics, a ceramic monolith (wall-flow filter) was chosen as the filtration element over the fibrous mesh and ceramic foam types of filtration elements. The first generation system included a diffuser; a filter housing which held the monolith, and a nozzle. The exhaust entered at the diffuser inlet, and the microwaves entered on an off-axis inlet to the diffuser. An exhaust bypass line and valve were incorporated into the filter housing. During filter loading the bypass line was closed which forced the particulate laden exhaust through the filter. When regeneration was desired, the bypass line was opened which allowed most of the exhaust to bypass the filter before the magnetron was activated. As regeneration proceeded, the flow restriction across the trap decreased due to the decreasing soot mass. If the bypass valve was not adjusted during regeneration, the decrease in flow restriction would create an increase in the exhaust flow through the filter which would provide more oxygen for combustion as well as remove energy from the filter at a higher rate. A regeneration test of this assembly resulted in a 39\% regeneration efficiency (based on a gravimetric method) with $37.1 \mathrm{~g}$ of soot trapped initially, a 400s preheating time, and an exhaust flow rate of $43.4 \mathrm{acfm}\left(1.2 \mathrm{~m}^{3} / \mathrm{min}\right)$ (approximately $14 \%$ oxygen by volume) at approximately $300{ }^{\circ} \mathrm{F}\left(149{ }^{\circ} \mathrm{C}\right)$. Bench tests were also performed on the first generation system. These 
tests were very similar to the engine tests; instead of using the engine exhaust as the source of oxygen for soot oxidation, a warm air pump capable of providing air at 39.3 $\operatorname{acfm}\left(1.1 \mathrm{~m}^{3} / \mathrm{min}\right)$ at $185{ }^{\circ} \mathrm{F}\left(85^{\circ} \mathrm{C}\right)$ was used. The bench test resulted in an $83 \%$ regeneration efficiency with $44.8 \mathrm{~g}$ of initial soot loading, a 400s preheating time, and an airflow rate of $39.3 \mathrm{acfm}\left(1.1 \mathrm{~m}^{3} / \mathrm{min}\right)$ at $185^{\circ} \mathrm{F}\left(85^{\circ} \mathrm{C}\right)$. A thermal scanning camera was used to monitor the temperature of the outlet face of the filter during the bench tests. The results demonstrated that much of the outlet filter face did not reach the temperatures necessary for regeneration.

In order provide more even heating of the filter element, a second-generation system was developed. This system differed from the first-generation system in that the waveguide outlet was positioned along the diffuser centerline and the exhaust inlet was placed on the side of the diffuser. A bench test of the second-generation system with operating conditions similar to the first bench test resulted in a $60 \%$ regeneration efficiency (23\% lower than the first-generation bench test), and an on-line test with 500s preheating time resulted in a regeneration efficiency of $43 \%$ (4\% higher than the firstgeneration test). The data from the thermal scanning camera showed more uniform heating of the filter outlet face with the second-generation system, although the test results did not indicate a higher degree of soot combustion (Garner and Dent, 1989).

In 1990, Garner and Dent published results of their continued efforts in microwave regeneration. In this study, a microwave regeneration system was fitted to a minibus. They discovered that control of the exhaust flow rate during regeneration was difficult. Hence, they proposed that an ambient air source should be used to provide the oxygen during the convective combustion phase of the regeneration process. As a result 
of this finding, a third-generation microwave regeneration system was developed. In this system, a bypass line outside of the trap housing was used instead of a bypass line in the trap housing. An air pump was also used to provide airflow during the regeneration process. During regeneration, the exhaust was forced to flow through the bypass line, and the air pump was activated after a predetermined preheating time. A series of ten bench tests with the third-generation system was performed. The test results indicated that a high initial soot loading resulted in trap melting, but if the initial soot loading were too low, the oxidation of soot would not go to completion (i.e. low regeneration efficiency). They also found that although a short preheating time was desirable in order to save energy, the preheating time had to be sufficiently long in order to ensure complete regeneration. They also discovered that the total regeneration time (both the preheating period and the convective combustion period) was strongly dependent on only the initial soot loading at high masses. They claimed that lower flow rates were required at high soot loadings in order to prevent damage to the filters. They recommended an initial soot loading of $15 \mathrm{~g}$ to $25 \mathrm{~g}$, a preheating time of 10 minutes, and an airflow period of 10 minutes (i.e. a 20 minute total regeneration time). They did not indicate an optimal airflow rate or the expected regeneration efficiency.

At the same time, results from a novel microwave regeneration study performed by Walton, Hayward, and Wren (1990) were published. In this study the filter cavity and the filter material were designed to make efficient use of the electric and magnetic fields which are present during the preheating phase of microwave regeneration. A waveguide was positioned along the centerline of the diffuser that was attached to the filter housing. An adjustable center conductor in the diffuser and a movable reflector plate at the trap 
outlet were used to optimize the geometry of the cavity. The optimized cavity design allowed the electric and magnetic field peaks to be positioned at chosen locations within the cavity. The exhaust and air entered and exited radially through perforated plates. A ferrite compound was used to replace the inlet plugs of a ceramic monolith. This compound acted as a dual-mode susceptor (the compound was capable of being heated by both changing electric and magnetic fields). Through computer modeling the cavity was optimized so that the magnetic field was uniformly distributed over the ferrite end plugs. This allowed uniform heating of the filter inlet face, which reduced the thermal stresses on the filter. RF energy of $600 \mathrm{~W}$ at $2.45 \mathrm{GHz}$ was used to preheat the loaded filter $(20 \mathrm{~g}$ initial soot loading). For the ceramic wall-flow filters, a 4-minute preheating time was used with no airflow. After the preheating time, $5 \mathrm{scfm}\left(0.14 \mathrm{~m}^{3} / \mathrm{min}\right)$ of air was provided while the magnetron was still activated. After 1 minute, the airflow rate was increased to $25 \mathrm{scfm}\left(0.71 \mathrm{~m}^{3} / \mathrm{min}\right)$, and the magnetron was deactivated. Except for a ring of channels on the outside of the filter, regeneration was complete.

Experiments were also performed with ceramic foam filters. Their initial objective was to design a microwave regeneration system that did not require a modified ceramic foam filter. Ceramic foam filters can be manufactured in a variety of shapes (as opposed to wall-flow filters), and this flexibility aided in an optimal cavity design. The geometry that was used in this case was a tubular filtration element with the exhaust flowing from the inlet of the tube to the outlet. Ceramic foam filters feature a "deep bed" type of soot loading (most of the soot is trapped near the inlet face and decreases exponentially with increasing depth), so the authors envisioned that a dual-mode susceptor could be placed on the side of the filter element on which most of the soot was 
trapped (the results of this study were not presented). The cavity was designed such that the electric field peaks were positioned where the majority of the soot was trapped. RF energy of $600 \mathrm{~W}$ at $2.45 \mathrm{GHz}$ was again used to preheat the loaded filter (30g initial soot loading) for 5 to 6 minutes. After the preheating period, $5 \mathrm{scfm}$ of combustion air was provided and the temperature was monitored using non-RF-intrusive temperature probes. When the temperature began to rise after the air had been allowed to flow into the filter, the flow rate was increased to $25 \mathrm{scfm}\left(0.71 \mathrm{~m}^{3} / \mathrm{min}\right)$. After the internal temperature began to drop, the magnetron was deactivated. Other than a ring of soot around the outlet of the filter element, regeneration was complete. It was concluded that the interconnected pore structure of the ceramic foam filters allowed the combustion to proceed isotropically which allowed complete combustion and the resulting lower thermal stresses within the filter at lower temperatures unlike the degree of combustion reported for wall-flow monoliths $\left[640{ }^{\circ} \mathrm{C}\right.$ to $740{ }^{\circ} \mathrm{C}\left(1185^{\circ} \mathrm{F}\right.$ to $\left.1365^{\circ} \mathrm{F}\right)$ for ceramic foam filters to $900{ }^{\circ} \mathrm{C}$ to $1000{ }^{\circ} \mathrm{C}\left(1650{ }^{\circ} \mathrm{F}\right.$ to $\left.1830{ }^{\circ} \mathrm{F}\right)$ for wall-flow filters]. Also, the isotropic expansion characteristics of ceramic foam filters allowed better resistance to melting and cracking than wall-flow filters (Walton et al., 1990).

Chunrun et al. (1994) published their work which included a 2-dimensional, transient, mathematical model of the regeneration process. Two types of ceramic foam and one type of wall-flow filter were used in the experimental portion of the study. The only differentiation cited between the two types of ceramic foam used was the characteristics of the vacant spaces within the filters. The first type of foam had a smaller average pore diameter with a higher pore density and porosity than the second type of ceramic foam. The wall-flow filter had a much smaller pore diameter than the ceramic 
foam filters, and had a lower porosity value as well. The microwave test system included microwave power meters, a frequency indicator, and variable attenuators. This system allowed the microwave characteristics of both loaded and unloaded filter elements to be measured. The results showed that the attenuation factor for the loaded filters was much higher than that of the unloaded filters. This verified the selective heating of the diesel soot by microwaves, which has been shown by other investigators as well (Suresh Babu et al., 1995 and Suresh Babu et al., 1996). The power of the RF energy used during the heating period was varied between 0 and $1.5 \mathrm{~kW}$ at $2.45 \mathrm{GHz}$. Neither the amount of initial soot loading nor the length of the heating period was given. No air was forced through the filter during the heating process, so oxygen was only allowed to diffuse into the filter. After regeneration the first type of ceramic foam, which had a large attenuation factor, was melted, but the second type of ceramic foam did not appear to be damaged after regeneration. The wall-flow filter was also damaged after regeneration. No regeneration efficiency results were given based on the experimental results, but some indications of expected regeneration efficiencies were given based on the model results. The model was developed in order to give an indication of the temperature distributions inside the filters during regeneration. Under the assumption that soot would oxidize if heated above $600{ }^{\circ} \mathrm{C}\left(1110^{\circ} \mathrm{F}\right)$ and using estimations of the maximum allowable filter temperatures, they found that $580 \mathrm{~W}$ to $600 \mathrm{~W}$ could be safely used during regeneration. This was a compromise between the area of the filter that reached regeneration temperatures with no portions of the filter exceeding the temperature limitations. The results indicated that $79 \%$ of the cross-section for the type 1 ceramic foam would reach regeneration temperatures as opposed to $66 \%$ for the type 2 ceramic foam. 
A similar study was published by Zhi et al. (1995). No experimental work was presented, but a 2-dimensional, transient model was used to provide guidelines for microwave regeneration of ceramic foam filters. No forced airflow was allowed during regeneration. The model results were based on the following assumptions:

thermophysical properties of the filter were constant, the soot was made entirely of carbon, the soot loading and the electromagnetic fields were assumed to be axisymmetric, conduction was assumed to be the only mode of heat transfer, and the gas temperature was the same as the filter element temperature. The regeneration efficiency, the peak temperatures within the filter element, and the regeneration duration were the main parameters of interest. The results demonstrated that as the attenuation constant of the loaded filter increased (i.e. higher initial soot loading or different types of filter materials), both the regeneration efficiency and the peak filter temperature increased, but the regeneration time decreased. Also, as the filter length was increased, the regeneration efficiency and the peak filter temperature increased. The authors indicate that there is a limitation on the amount of soot that may be collected due to the high temperatures encountered during the exothermic oxidation of soot. High thermal stresses would result in the melting or cracking of the filter element, so in order to increase the regeneration efficiency and avoid filter damage, an optimal amount of soot was needed in conjunction with an increase in the oxygen flow rate to promote faster regeneration especially in the internal regions of the filter where the oxygen supply was most limited. It was noted that the total regeneration duration was not greatly affected by increases in initial soot loading. Increases in the microwave power transmitted to the filter caused increases in regeneration efficiencies and peak filter temperatures with decreases in the total 
regeneration time. It should be noted that there was a limitation to the amount of power that could be provided due to high thermal stresses inside the filter. The results also showed that a uniform electromagnetic field on the filter face had the highest regeneration efficiency, but this is very difficult to achieve in practice (Zhi et al., 1995).

The results of another microwave regeneration study were published by Ma et al. (1997). In this study, a direct comparison of microwave and electrical regeneration was made. A measurement system using a transmission line method was developed to measure the complex permittivity of diesel soot, catalysts, and catalyst support materials. The measurement system consisted of a variable $5 \mathrm{~kW}$ magnetron (frequency of 2.45 $\mathrm{GHz}$ ), a waveguide, power meters, a triple-stub tuner, a pyrometer, a quartz reactor, and a water load to absorb any irradiation not absorbed in the reactor. A pyrometer was used to measure the reaction temperatures, and in an attempt to reduce temperature measurement errors, the emissive coefficient of the pyrometer was adjusted to match the temperature readings of a thermocouple, which was inserted into the reaction bed after the microwave heating period. Soot samples were placed into the quartz reactor $[1 \mathrm{~cm}(0.39$ " diameter and $30 \mathrm{~cm}(11.8$ ") long], and a feed gas of $10 \%$ oxygen in nitrogen was used for the combustion air. The outlet gases were monitored for $\mathrm{CO}$ and $\mathrm{CO}_{2}$ concentrations. The electrical regeneration system was similar to the microwave regeneration system except that the microwave heating assembly was replaced with an electrical heating assembly (no details of the electrical heating assembly were given).

The objective of their study (Ma. et al., 1997) was to determine a suitable combination of soot, catalyst, and catalyst support material. The ideal combination would involve a large degree of microwave absorption by the soot; a moderate degree of 
microwave absorption by the catalyst to allow some heat conversion to promote soot oxidation while lowering the ignition temperature of the soot; and a microwave transparent, thermally insulating support material. The complex permittivities of diesel soot, carbon black, and various catalysts and support materials were measured in order to determine the optimal combination.

The dielectric property measurements indicated that the complex permittivity of diesel soot was much higher than that of the support materials or the catalysts. Carbon black had a higher complex permittivity than the soot samples because the soot was found to contain more oxygen, ash, iron, aluminum, silicon, calcium, and phosphorus but less elemental carbon. It was deduced that the carbon content is a major factor in the value of the complex permittivity. Soot combustion experiments indicated that cordierite, $\mathrm{TiO}_{2}$, and zirconia were all suitable washcoat materials for catalyst preparation in terms of their microwave regeneration characteristics. Of the three, $\mathrm{TiO}_{2}$ was chosen as the optimal washcoat material because it promoted soot oxidation at low levels of microwave input power. With $\mathrm{TiO}_{2}$ as the carrier, several catalysts were tested to determine which was the most suitable for microwave regeneration. Ma et al. (1997) found iron-based catalysts to be the most energy efficient during microwave regeneration, that is, they required the lowest levels of microwave input power to regenerate a given amount of soot (Ma et al., 1997).

Non-catalytic combustion produced higher levels of carbon monoxide than catalytically enhanced combustion, so catalysts were presumed to be responsible for the oxidation of CO. Palladium catalysts were found to produce the most complete 
combustion (in terms of reduced CO levels). This was found to be true for both conventional and microwave regeneration (Ma et al., 1997).

Ma et al. (1997) found that soot that was burned in the presence of a catalyst had a higher heat release rate than soot oxidized without a catalyst. It was deduced that the catalytic oxidation of the soot enhanced the microwave absorption properties. The peak temperature of the soot oxidized in the presence of a catalyst was higher than that of soot oxidized without a catalyst, but the elevated temperatures present during catalytically enhanced microwave regeneration remained lower than the peak temperatures which occurred during electrical regeneration.

Much lower soot ignition temperatures were present during microwave regeneration than with electrical regeneration for both catalytic and non-catalytic cases. Differences of over $200{ }^{\circ} \mathrm{C}\left(390{ }^{\circ} \mathrm{C}\right)$ were observed when iron and copper catalysts were present. This suggested a microwave enhancement effect when the soot was combusted in the presence of a catalyst. Copper was the most active catalyst in electrical regeneration, while iron was found to be the most active catalyst in microwave regeneration. Electrical regeneration provided more complete combustion (lower CO emissions) than microwave regeneration under the test conditions studied due to the more rapid reaction rates associated with microwave regeneration, but these effects were minimized when palladium was used as the catalyst (Ma et al., 1997).

Another microwave regeneration study was recently published by Zhi and He (1999). Ceramic foam filters made of both silicone carbide and cordierite were incorporated into a microwave regeneration system. The exhaust was forced to flow through a bypass line during regeneration, and an external air supply was used to allow 
better combustion control. A quartz window was placed between the filter and the magnetron. The quartz glass allowed the microwaves to be transmitted to the filter, but exhaust gases were prevented from coming into contact with the magnetron. Sixteen successive regenerations were performed with regeneration efficiencies on the order of $80 \%$. The regeneration efficiency was based on backpressure measurements as in the study performed by Wade et al. (1983). There appeared to be no backpressure increase between subsequent regenerations, and the conclusion was that no particulate buildup was present within the filter. The back surface and the periphery of the filter remained unregenerated. Regeneration durations of 10 to 15 minutes were found to be optimal for this system. Durations less than this resulted in incomplete regeneration, and durations longer than this resulted in overheating of the filter element. Particulate loading did not appear to have a significant effect on regeneration, but the supply of oxygen to the filter was found to be critical for complete regeneration. They performed tests with no airflow during regeneration and compared the resulting regeneration efficiencies to those with airflow under the same conditions. Much higher regeneration efficiencies occurred when air was supplied to the filter during regeneration, but no indication was given as to the amount of airflow that was supplied.

\subsubsection{Microwave Safety}

The use of microwaves for regeneration generates some safety related issues. As was stated previously, microwaves do not contain enough energy to be considered ionizing radiation, but microwaves can readily penetrate the human skin. In most cases, the human body can remove external heat input via increased blood flow, but beyond a 
certain threshold, irreversible damage can occur (thermal damage). There has also been concern over the potentially hazardous effects of long-term exposure to microwaves (non-thermal damage).

In 1966, the United States had developed an exposure safety standard of 10 $\mathrm{mW} / \mathrm{cm}^{2}$ at a distance of $5 \mathrm{~cm}$ (2") for whole-body exposure for an unlimited time (Osepchuck, 1978). This limit represents a power density on the same order of magnitude as the heat flux from the human body in a sitting position. This implies that the human body could easily dissipate external energy inputs at this level (Metaxas and Meredith, 1983). Other studies performed to determine a safe radiation threshold found that below $100 \mathrm{~mW} / \mathrm{cm}^{2}$, no permanent health effects were observed. The eye was found to be the most sensitive organ with a threshold of approximately $150 \mathrm{~mW} / \mathrm{cm}^{2}$. Above this limit, cataracts began to form after $1 \frac{1}{1} 2$ hours of continuous exposure. The male genitals were also found to be sensitive to microwaves. Based on these results, the 10 $\mathrm{mW} / \mathrm{cm}^{2}$ standard was believed to include a significant safety factor in terms of exposure limits (Gardid, 1984). In the 1968 Senate hearings with industry groups it was generally accepted that a limit for microwave leakage should be related to this exposure limit. The conservative choice of $10 \mathrm{~mW} / \mathrm{cm}^{2}$ at $5 \mathrm{~cm}$ (2") from the oven was chosen, but, unfortunately, there was some confusion over the terms exposure and emission, and the standard was accepted as an emission standard instead of an exposure standard. Obviously, an emission standard is much more conservative than an exposure standard because exposure limits also consider the amount of time that one is exposed to the radiation whereas emissions standards do not (Osepchuk, 1978). The current microwave emissions standard for consumer and commercial equipment is $1 \mathrm{~mW} / \mathrm{cm}^{2}$ at $5 \mathrm{~cm}$ before 
purchase and $5 \mathrm{~mW} / \mathrm{cm}^{2}$ at $5 \mathrm{~cm}$ (2”) after purchase (Stuchly, 1977). This is an extremely conservative standard because electromagnetic radiation power transmission from a point source follows the inverse square law. Also, the sun provides $100 \mathrm{~mW} / \mathrm{cm}^{2}$ of infrared radiation on a clear summer day which is 20 times greater than the current emissions standards for microwaves (Gardid, 1984).

Some studies have proposed a link between electromagnetic field (EMF) exposure and various adverse health effects such as cancer, cataracts, and a reduction in personal efficiency (Gallawa, 1998). Jauchem $(1991,1993,1995)$ has published many papers regarding the health effects associated with EMF exposure. He found the results of these studies to be contradictory and inconsistent. One study which was cited reported degeneration of the brain as well as deterioration of the kidneys and myocardium of small animals that were exposed to microwaves. Jauchem (1993) pointed out that these changes were associated with gross thermal effects (high power density levels), as opposed to non-thermal effects of EMF exposure which are more of a concern. Other studies which were cited hypothesized a connection between electric or magnetic field (EMF) exposure and breast cancer in men. These indicated that EMF exposure led to decreased melatonin production in animals, and decreased melatonin production could be associated with breast cancer. Jauchem (1993) believed this correlation was tenuous because rodents may be far more sensitive to EMF exposure than humans, so they may not be a useful model for human exposure. Also, studies of decreased melatonin production used levels of electromagnetic energy which were much higher than those present in the environment, and no clear exposure/response relationship was found. Also, the results of these studies could not be replicated in further studies. Other researchers 
have pointed out that decreased melatonin levels may be caused by the change in metabolism caused by the cancer, so the cancer may actually cause the decreased melatonin levels. The environmental protection agency (EPA) had indicated that there is a link between EMF and cancer, but Jaucham (1993) stated that they had incorrectly cited research that was not attempting to study the effects of EMF on the subjects. In many cases the EPA made these claims when the research they were citing pointed to other causes instead. Based on a review of the studies published concerning the effects of EMF exposure on human health, Jaucham (1993) had found no proven hazards associated with low levels of EMF exposure.

Due to concerns over long-term exposure to microwave radiation emitted from satellites, Osepchuk (1996) published a paper addressing these concerns. He stated that many misconceptions exist regarding the health effects of EMF exposure. Thousands of papers have been published regarding the health effects of microwave exposure, and, in most cases, serious effects only occurred when exposure to microwave energy well above any existing exposure limits in the world were encountered. Some studies using animals have been published showing some ill effects of long-term exposure to microwaves, but in these cases the animals were exposed to unchanging electromagnetic fields for years. This was unrealistic, because no one would be exposed to these levels of radiation continuously. The animal's accelerated life span also may have biased the results. Osepchuk's (1996) overall conclusion was that microwave exposures can generally be considered benign unless intense, penetrating fields are far above the safe-exposure limits are encountered. 
It can be concluded from the aforementioned analyses that as long as the microwave emissions standards are not exceeded, there should be no adverse health effects associated with a microwave regeneration system as a result of microwave exposure under normal operating conditions. Osepchuck (1978) stated that a properly designed microwave oven has less than $1 \%$ power leakage from the unit with the door as the largest source of leakage. Microwave regeneration systems should have no need of doors, so the leakage should be negligible.

Other safety issues regarding microwave regeneration systems involve the activation of the magnetron when the system is in service or if system integrity is compromised and high voltages. Interlocks will be necessary to ensure system deactivation during service, and impact switches may be necessary in order to deactivate the magnetron in case of an accident compromising the integrity of the system (Garner and Dent, 1989). Standard electrical precautions will also have to be taken regarding the high-voltages associated with the secondary circuit of the power supply unit. 


\section{Chapter 3 \\ Design, Development, and Fabrication}

The microwave enhanced oxidation system can be divided into five basic subsystems: devices used for trap preparation before loading, the soot generation system, the exhaust transfer system, the regeneration assembly, and the soot conditioning system. The latter four of these systems and their components will be discussed in this chapter. The filtration unit, consisting of the filtration element, the filter housing, and Interam ${ }^{\mathrm{TM}}$ matting, is a part of all the subsystems and is described in Section 3.1.

\subsection{Filtration Unit}

The heart of any diesel soot oxidation system is the filtration unit. The filtration unit will be defined as the filtration element, the filter housing (including the diffuser and reducer), and the Interam ${ }^{\mathrm{TM}}$ matting. The filtration element is used to remove particulate matter from the exhaust. The filter housing is used to support the filter element, and the Interam ${ }^{\mathrm{TM}}$ matting is used as a seal between the filter element and the filter housing. The purpose of this system is to remove as much of the particulate matter from the exhaust as possible and to allow effective regeneration of the entrapped soot. The purpose has many facets which must be considered in order to design an effective microwave filtration unit. The filtration element type, size, and shape must be considered as well as the housing material and shape. The Interam ${ }^{\mathrm{TM}}$ matting must also be carefully selected.

Chapter 2 provides the background information necessary to choose the appropriate filter type and shape. The ceramic monolith (wall-flow filter) and the ceramic foam filtration elements have shown the greatest potential for microwave 
regeneration. The ceramic monolith tends to provide greater filtration efficiency as well as a packed bed type of soot loading which is amenable to sustained soot combustion. The ceramic foam filter can be manufactured in a variety of shapes and provides a deep bed type of soot loading. The isotropic nature of the ceramic foam makes it capable of handling higher thermal stresses than the ceramic monolith. Due to its high filtration efficiency and organized soot loading characteristics, the ceramic monolith was chosen as the filtration element for this study. Cordierite was chosen as the medium due to its availability, low cost, and low attenuation factor (that is, low dielectric loss factor). The low attenuation factor allowed the microwaves to selectively heat the soot, so the filter was heated only by secondary means (conduction, convection, and radiation). This implied that the microwaves would be used efficiently, but it also indicated that nonuniform soot loadings could adversely affect the regeneration results because only the soot was used to absorb the microwaves. Due to the fundamental nature of this study, the effects of nonuniformities in soot loading were left for future research. An uncatalyzed trap was used because both fuel and filter catalysts lead to the buildup of incombustible material within the filter (see Chapter 2).

The choice of a wall-flow filter basically dictated that the filter shape would be a right cylinder due to filter manufacturing constraints. This limitation was acceptable because the circular frontal area of the filter element allows more uniform flow characteristics throughout the entire filter to be generated, and this led to more uniform soot loading. Due to the complex and transient nature of the electromagnetic fields within the filtration unit during the preheating period (during magnetron activation), it is unknown at this point as to whether a cylindrical cavity is the most efficient for 
microwave regeneration. Cavity design and optimization were beyond the scope of this study. Future modeling studies are required to determine the most effective filter shape and size.

The final decisions regarding the filter element involved an appropriate choice of cell density, porosity, and overall filter size. In order to maintain the exhaust backpressure as low as possible without sacrificing a large degree of durability, a cell density of 100 cells $/ \mathrm{in}^{2}\left(15.5\right.$ cells $\left./ \mathrm{cm}^{2}\right)$ was chosen with a porosity of 0.5 (defined as the ratio of vacant volume to total volume of the filter material). These specifications allowed a relatively low exhaust backpressure (with an unloaded filter) with a relatively high filtration efficiency. An assessment of the durability of this type of filter was achieved after sufficient testing was performed. The overall filter size was chosen to be $5.66 "(14.4 \mathrm{~cm})$ in diameter and 6" $(15.2 \mathrm{~cm})$ in length. This filter element was undersized for the test engine, but the low cost of the filters, low power requirements for regeneration, exhaust piping space constraints, reduced filter loading times, and filtration unit cost were factors which aided in the choice of this filter size. The regeneration efficiency (defined as the ratio of combusted to the initial soot mass) was determined using a gravimetric method. A large filter and housing would have made the use of this method difficult. Also, most regeneration systems require a bypass line, so alternating exhaust flow and subsequent regeneration in two small filters may be necessary to provide filtered exhaust at all times. Based on the above specifications, a Corning EX-80 filter was chosen as the filtration element. An estimation of the total filtration area of a wall-flow filter with these specifications can be estimated as follows. It must first be 
realized that the inlet cells and outlet cells alternate, so not every cell is involved in filtration. A cross-sectional schematic of a wall-flow filter is given in Figure 3.1.1:

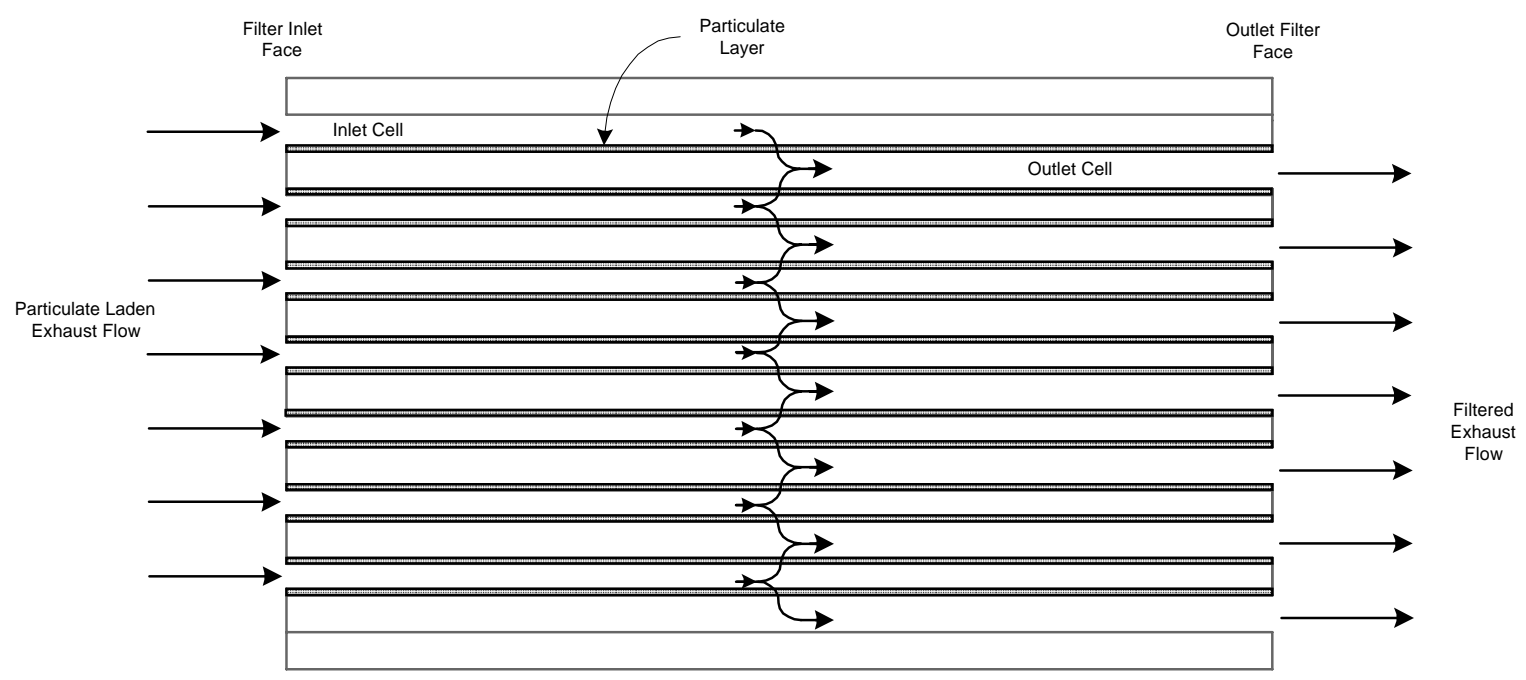

Figure 3.1.1: Wall-flow Monolith Cross-section

Although not all of the cells are used for filtration, all of the walls within the filter are involved in filtration. The number of walls in a filter can be determined by considering an $n x 1$ matrix, where $\mathrm{n}$ is the number of cells (rows in this case). It is apparent that with this single column of cells, the number of walls is $(3 n+1)$. If additional columns are added to form an $n x n$ matrix, walls are shared. In this case, the number of walls is $n(3 n+1)-n(n-1)$. The first term represents the number of walls of each column considered independently, while the second term represents the number of shared walls. This equation can be reduced to the following form:

$$
\# \text { walls }=2\left(n^{2}+n\right) \quad(\text { for an } n x n \text { matrix }) \quad 3.1 .1
$$

The total number of cells for a 5.66" $(14.4 \mathrm{~cm})$ diameter filter with 100 cells/in ${ }^{2}(15.5$ cells $/ \mathrm{cm}^{2}$ ) can be calculated using the following formula: 
$\#$ cells $=\frac{\pi}{4}(d)^{2}\left(\#\right.$ cells $\left./ \mathrm{in}^{2}\right)$

where,

$\mathrm{d}=$ diameter of the filter section with active cells

The cells around the circumference of a wall-flow filter are blocked to prevent flow through the outer walls of the filter. This decreases the active diameter of the filter (that is, the portion of the filter involved in filtration). For a 5.66" $(14.4 \mathrm{~cm})$ diameter filter, the active diameter is approximately 5.46" $(13.9 \mathrm{~cm})$. Using this value, the total number of cells for the filtration element is 2341 cells. If the filter is approximated to be an $n x n$ matrix, then $n=\sqrt{2341} \approx 48$ cells. The total number of filtration walls can be calculated using a form of Equation 3.1.1:

$$
\text { \# filtration walls }=2\left(n^{2}+n\right)-4 n
$$

The last term is an estimate of the number of inactive walls around the circumference of the filter. It is an estimate because the number of walls on the circumference of the actual filter will be greater than the last term in Equation 3.1.3 due to the circular frontal area of the filter element. Using this equation, the number of active filtration walls is estimated to be 4512. The total filtration area can be calculated using the following equation:

$$
\text { Filtration area }=(\# \text { walls })(\text { wall height })(\text { cell length })
$$

In this case the total cell height is $0.1 "(0.25 \mathrm{~cm})$, and the wall thickness is approximately $0.017 "(0.043 \mathrm{~cm})$ with a cell length of $6 "(15.2 \mathrm{~cm})$. With these values, the total filtration area can be calculated as,

$$
\text { Filtration area }=(4512)\left(0.1^{\prime \prime}-0.017^{\prime \prime}\right)\left(6^{\prime \prime}\right)=2247 \mathrm{in}^{2}=1.45 \mathrm{~m}^{2}
$$

The shape of the filtration housing was dictated by the shape of the filtration element (that is, a right cylinder). The housing was made of 409 stainless steel with 
$0.054 "(0.137 \mathrm{~cm})$ thickness, and was fabricated and donated by Walker, Inc. Stainless steel was chosen for its corrosion resistance. It also conducts electricity sufficiently well to reflect any microwave energy that was transmitted to the housing walls. The total length of the filtration housing without the diffuser and reducer was 8 " $(20.3 \mathrm{~cm})$, with a diameter of 6" $(15.2 \mathrm{~cm})$. The 6" $(15.2 \mathrm{~cm})$ diameter allowed 1/4" $(0.64 \mathrm{~cm})$ Interam $^{\mathrm{TM}}$ matting to be placed around the filter element to prevent leakage of exhaust flow around the filter element. The Interam ${ }^{\mathrm{TM}}$ matting was manufactured by $3-\mathrm{M}$, and was designed for high-temperature automotive applications. The attenuation factor of the Interam ${ }^{\mathrm{TM}}$ matting was unknown, so tests were performed to ensure that the Interam ${ }^{\mathrm{TM}}$ matting did not absorb a large degree of microwave energy. In these tests the Interam ${ }^{\mathrm{TM}}$ matting was placed around the circumference of the filter between the filter housing and the filtration element, and microwaves were transmitted through an unloaded filter element placed within the filter housing. A water trap was positioned at the outlet end of the filter housing (see Figure 3.4.7) to absorb any unattenuated microwave energy. The test assembly is explained in greater detail in Section 3.4. The results demonstrated that the temperature of the filter housing did not increase significantly while the temperature of the water placed after the filter rose substantially. This indicated that the Interam ${ }^{\mathrm{TM}}$ matting and filter element assembly had a low attenuation factor; hence, very little microwave energy was expected to be absorbed by the matting or the element during the regeneration tests.

The diffuser and the reducer portion of the filter housing were designed essentially to promote uniform flow characteristics. A relatively small diffuser half angle also allowed the microwaves to refract to a sufficient degree to reach the filter cells near 
the edge of the filter element. This promoted more uniform heating of the filter face, but testing was required to determine if this alone would create sufficiently uniform heating to prevent filter failure at high regeneration efficiencies. The diffuser inlet diameter was 4" $(10.2 \mathrm{~cm})$, and the outlet diameter was 6" $(15.2 \mathrm{~cm})$. The length of the diffuser was $7.5 "(19 \mathrm{~cm})$ (half angle $\left.=7 \cdot 6^{\circ}\right)$. The inlet diameter was chosen to allow a WR 284 or a WR 340 rectangular waveguide to be attached to the diffuser without corner interference. Section 3.4.1.2 describes some basic waveguide theory and the reasoning behind the choice of these waveguides. The outlet diameter was chosen to mate with the filter housing. The 5" $(12.7 \mathrm{~cm})$ long reducer had an inlet diameter of 6" $(15.2 \mathrm{~cm})$ with an outlet diameter of $5 "(12.7 \mathrm{~cm})$. The outlet diameter was chosen to allow a large outlet pipe to be used, if necessary, to reduce backpressure. Testing demonstrated that only a 3" $(7.6 \mathrm{~cm})$ diameter transfer pipe was needed after the filtration assembly, so another reducer was used to decrease the transfer pipe size from 5" to $3 "(12.7 \mathrm{~cm}$ to $7.6 \mathrm{~cm})$. A schematic of the entire filtration assembly is provided in Figure 3.1.2., and photographs are provided in Figures 3.1.3 and 3.1.4. 


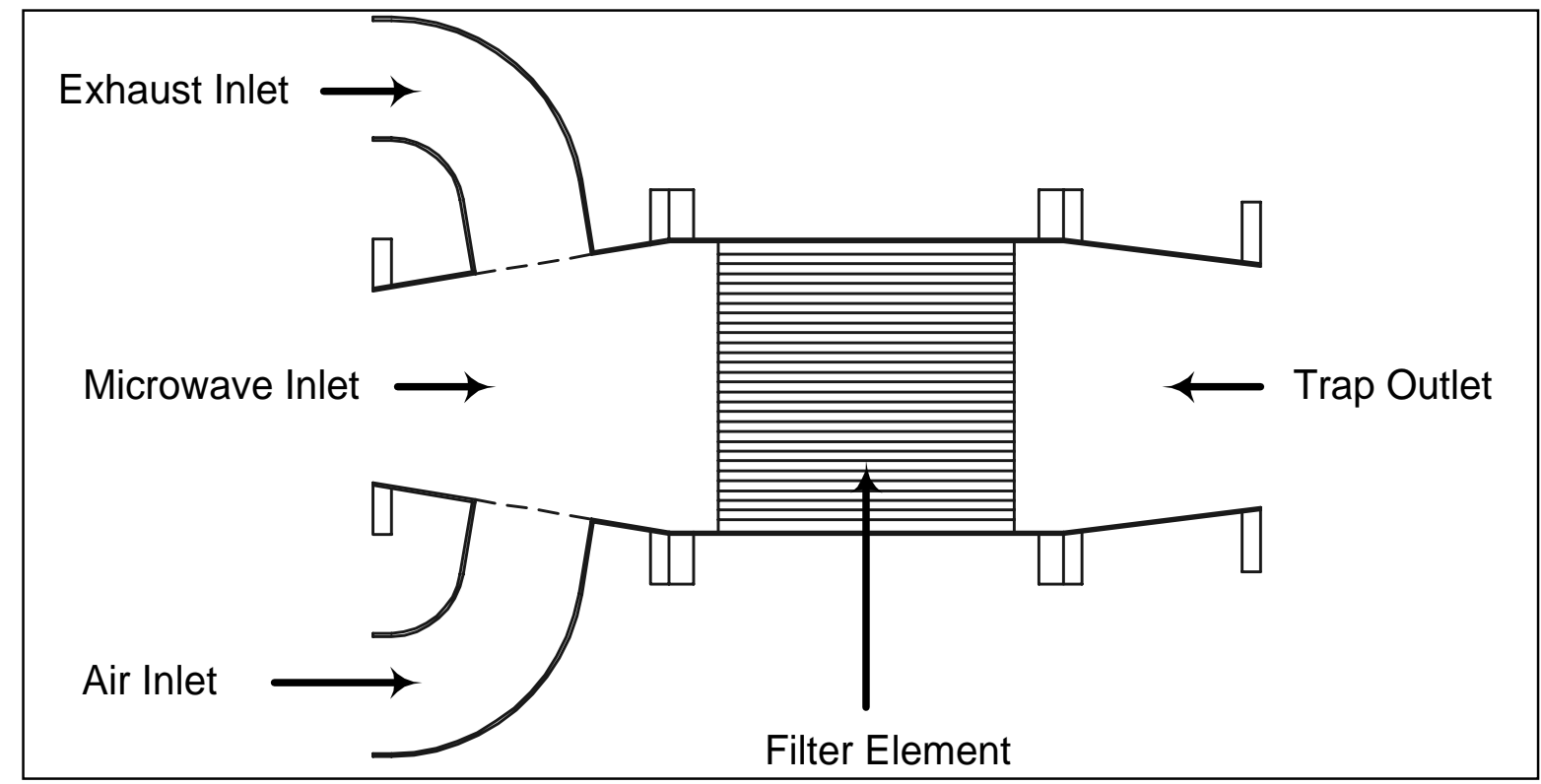

Figure 3.1.2: Soot Filtration Assembly Cross-section

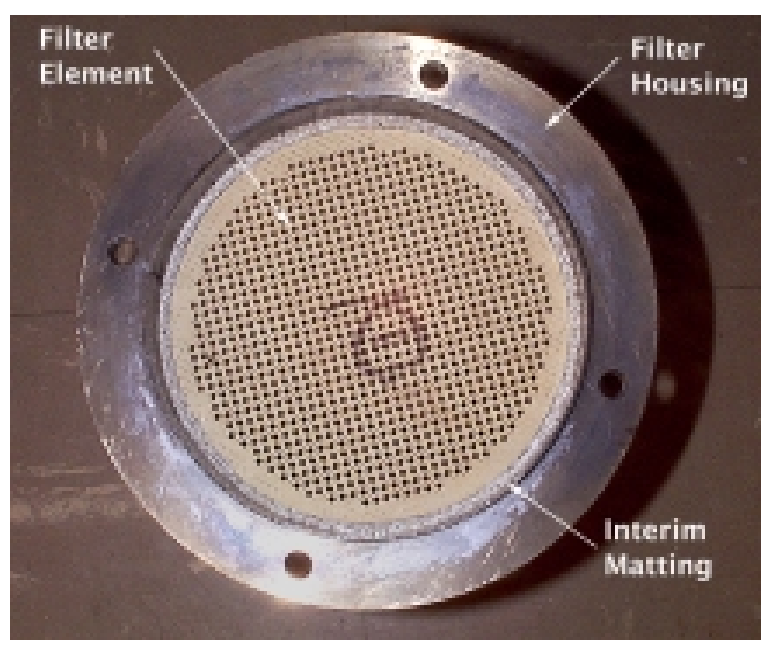

Figure 3.1.3 : Filtration Assembly Outlet 


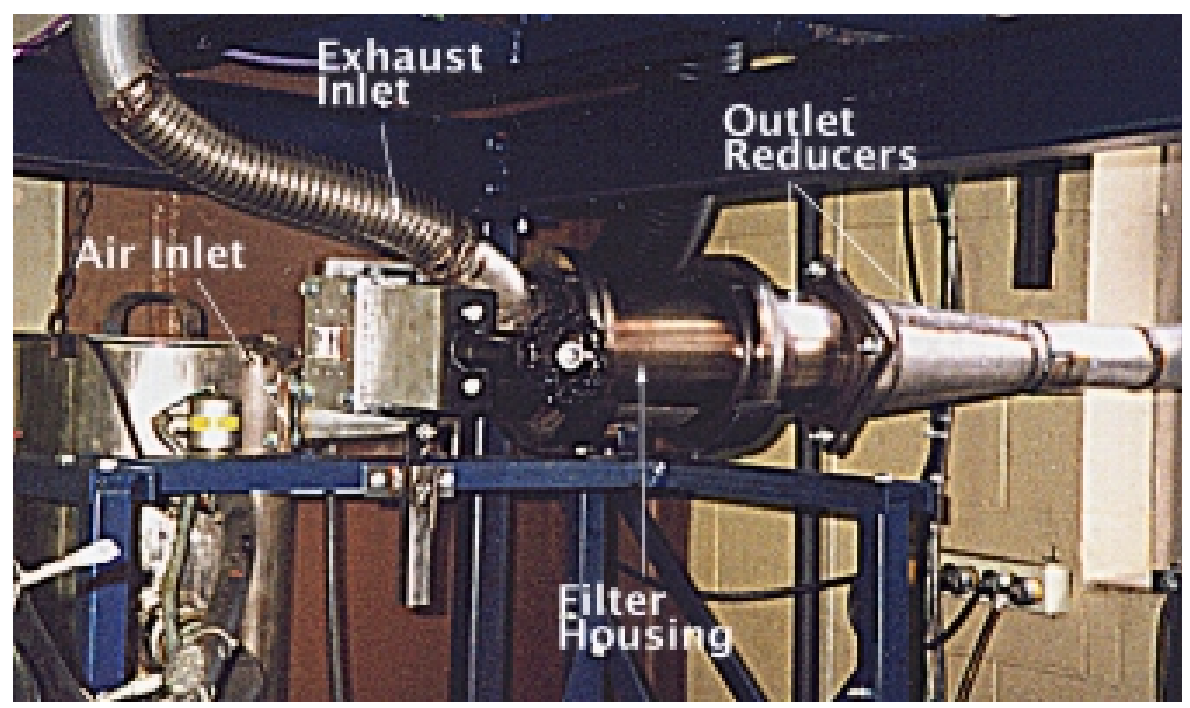

Figure 3.1.4: Filtration Assembly Side View

The relative placement of the waveguide, exhaust inlet, and air inlet were based on the work done by Garner and Dent $(1989,1990)$. The waveguide and filter element centerlines were matched in order to promote more uniform heating of the filter element. The air entered the filtration assembly on the side of the diffuser through an RF gasket. The diffuser was used to allow the exhaust to diffuse into all the inlet channels, and it was also used to allow the microwave energy exiting the waveguide to refract to a sufficient degree to uniformly heat a large portion of the filter face. Figure 3.1.5 is a picture of an RF gasket which was welded onto the air inlet of the diffuser used in the out-of-cell (offline) testing. For the off-line testing, the filter assembly was removed from the engine's exhaust system and was regenerated in a more controlled environment. This regeneration assembly is described in detail in Section 3.4. 


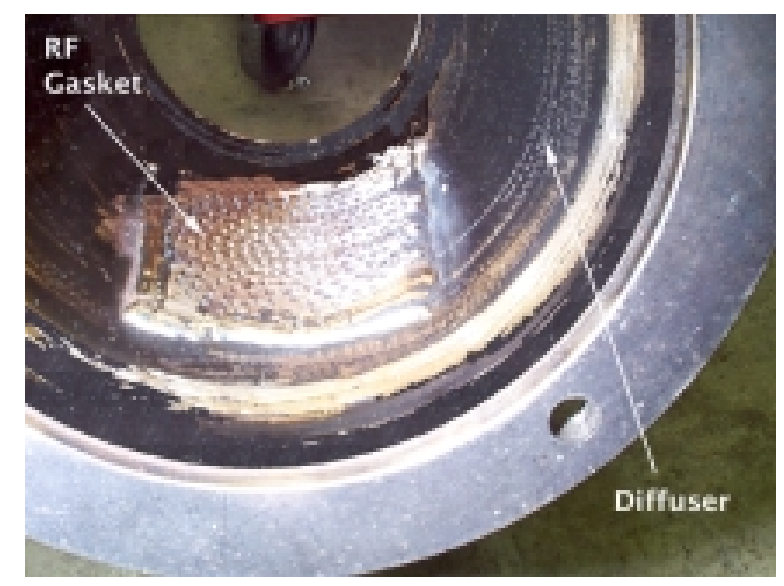

Figure 3.1.5: RF Gasket

The RF gaskets utilized one of the unique aspects of microwaves: microwaves cannot pass through holes which are much smaller than their wavelength. When microwaves are transmitted to a surface which has small holes, currents are generated around the circumference of the hole. The currents generated by the microwaves in the metal travel about one wavelength during one microwave period. Therefore, as long as the current has enough time to traverse around the hole before it is forced to change direction by the fluctuating electromagnetic field, the RF gasket acts essentially as a solid metal sheet and no microwave energy will be transmitted a significant distance beyond the hole (Bloomfield, howthingswork.viginia.edu.microwave_ovens.html). While air and exhaust readily passed through the holes, no microwaves could be transmitted through the air or exhaust lines. It should be noted that the consequent backpressure penalty was insignificant.

Graphite gaskets were used to seal all the flanged joints of the filtration assembly. Graphite was chosen as the gasket material for several reasons. Foremost was that it was capable of conducting electricity to a sufficient degree to prevent the escape of 
microwaves from the joints. Graphite is also easy to cut, so gaskets of various geometries were easily formed. Also, graphite compresses well and is capable of withstanding extremely high temperatures, so the joints were leak-proof for microwaves, air, and exhaust.

Preliminary testing demonstrated that the force exerted by the elevated exhaust pressure on the filter face was sufficient to overcome the holding force of the Interam ${ }^{\mathrm{TM}}$ matting and the force exerted by the pressure on the filter outlet face. This resulted in the filter being pushed towards the reducer of the filtration assembly during loading. The peak backpressure was estimated at approximately $65 " \mathrm{H}_{2} \mathrm{O}(2.35 \mathrm{psi}=16.2 \mathrm{kPa})$. The total diameter of the filter element with Interam ${ }^{\mathrm{TM}}$ matting was $6 "(15.2 \mathrm{~cm})$, so the force on the filter face (including the Interam ${ }^{\mathrm{TM}}$ matting) was estimated as follows:

$$
\begin{aligned}
& F=p A=p\left(\frac{\pi}{4} d^{2}\right) \\
& \text { where, } \\
& \mathrm{F}=\text { estimated force } \\
& \mathrm{A}=\text { effective area } \\
& \mathrm{p}=\text { static pressure } \\
& \mathrm{d}=\text { effective diameter } \\
& F=2.35 p s i\left[\frac{\pi}{4}\left(6^{\prime \prime}\right)^{2}\right]=66.4 l b f
\end{aligned}
$$

The pressure on the backside of the filter was assumed to be atmospheric because the filter was very restrictive relative to the exhaust line after the filter. This is a significant force, so some means of filter support had to be provided. Figure 3.1.6 shows the filter supports that were welded into the filter housing. 


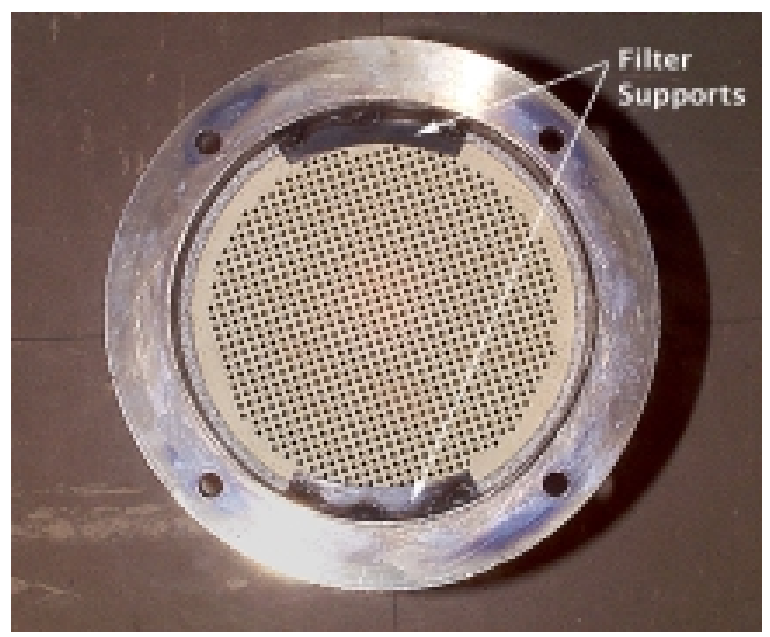

Figure 3.1.6: Filter Supports

The supports were metal tabs of sufficient thickness to enable them to reflect any microwaves which were transmitted to them without overheating, which causes arcing to occur. The height of the filter supports allowed them to provide support to the filter element and Interam ${ }^{\mathrm{TM}}$ matting without interfering with any of the active channels. A second steel filter housing with diffuser and expander was fabricated to allow the filter housing to be removed from the assembly within the engine test cell and placed in the Faraday cage for regeneration. This allowed the diffusers to remain undisturbed in each test area when the filter housing had to be removed. Adjustable filter supports were incorporated into this housing to allow the filter position to be varied longitudinally within the housing. The effects of filter position on regeneration efficiency were concurrently presented by Popuri (1999). Steel was chosen as the filter housing material for ease of fabrication. The reducer outlet diameter was changed from 5" to 4" $(12.7 \mathrm{~cm}$ to $10.2 \mathrm{~cm}$ ) to mate with the water trap inlet, and the wall thickness was increased form 0.054 " to $0.060 "$ " $(0.137 \mathrm{~cm}$ to $0.152 \mathrm{~cm})$, but other than these changes, the overall 
dimensions were the same as that of the stainless steel filter housing. Figure 3.1.7 shows a general pattern for a diffuser and/or reducer.

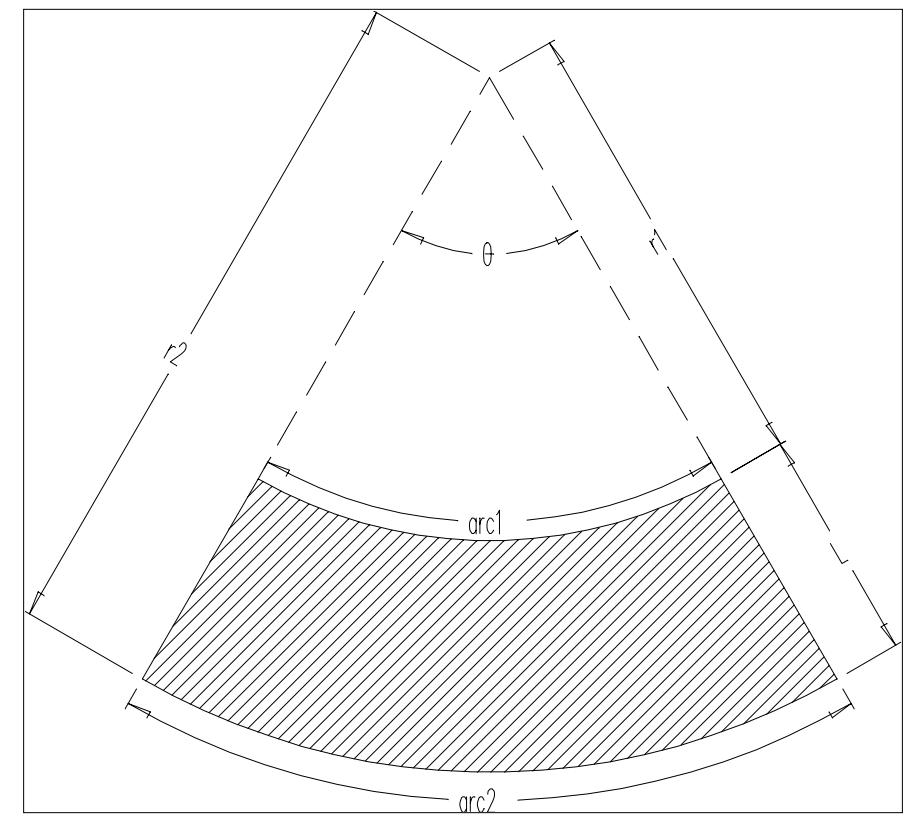

Figure 3.1.7 : Diffuser Pattern

The dimensions for the patterns of both the diffuser and reducer were determined using the following relations:

$$
\begin{aligned}
& \operatorname{arc} 1=\pi \mathrm{d}_{1}=[\theta(\mathrm{rad})] \mathrm{r}_{1} \\
& \operatorname{arc} 2=\pi \mathrm{d}_{2}=[\theta(\mathrm{rad})] \mathrm{r}_{2} \\
& \mathrm{r}_{2}=\mathrm{r}_{1}+\mathrm{L} \\
& L=\sqrt{\left(\frac{d_{2}-d_{1}}{2}\right)^{2}+l^{2}}
\end{aligned}
$$

where,

$\mathrm{d}_{1}=$ diffuser inlet diameter

$\mathrm{d}_{2}=$ diffuser outlet diameter

$1=$ longitudinal diffuser length

* all other symbols are indicated in Figure 3.1.7

By substitution, 


$$
\begin{aligned}
& {[\theta(\operatorname{rad})]\left(\mathrm{r}_{1}+\mathrm{L}\right)=\operatorname{arc} 2} \\
& r_{1}=\left(\frac{\operatorname{arc} 2}{\theta}\right)-L
\end{aligned}
$$

By solving Equation 3.1.6 for $\mathrm{r}_{1}$ and substituting into Equation 3.1.11,

$$
\begin{aligned}
& \operatorname{arc} 1=\left[\left(\frac{\operatorname{arc} 2}{\theta}\right)-L\right] \theta(\operatorname{rad}) \\
& \theta(\operatorname{rad})=\left(\frac{\operatorname{arc} 2-\operatorname{arc} 1}{L}\right)=\frac{\pi\left(d_{2}-d_{1}\right)}{L}
\end{aligned}
$$

In this case, $d_{2}$ and $d_{1}$ are known, so $r_{1}, r_{2}$, and $\theta(r a d)$ can be calculated, and a pattern can be formed either manually or in a drawing package such as Cadkey or Autocad. Once the sheet metal was cut out in the form of the pattern, the metal was rolled to form the diffuser (or reducer), and the desired flanges were fabricated and welded on the inlet and outlet.

\subsection{Soot Generation System}

An MWM D916-6 naturally aspirated, indirect injection, in-line six cylinder diesel engine was used to generate the soot and exhaust flow necessary to load the filter. The engine displacement was $379 \mathrm{in}^{3}$ (6.2 L, 4.13" bore and 4.72" stroke), and the compression ratio was $22: 1$. The derated peak torque was $211 \mathrm{ft}-\mathrm{lbs}$ at $1500 \mathrm{rpm}$, and the rated power was $82 \mathrm{hp}$ at $2100 \mathrm{rpm}$. The in-line fuel pump and fuel injectors were calibrated to the necessary fuelling rates by Blue Ridge Diesel prior to testing. All of the soot loading for the regeneration tests presented in this paper was performed at $1500 \mathrm{rpm}$ and 50\% load (106 ft-lbs of torque). The engine emissions rates at this engine operating 
condition are presented in Table 3.1. The data is based on the average of three tests using low-sulfur fuel ${ }^{\dagger}$.

Table 3.1: MWM D916-6 Emissions Profile (1500 rpm, 50\% Load)

\begin{tabular}{cc}
\hline Emission Type & Emissions Rate $(\mathrm{g} / \mathrm{hr})$ \\
\hline $\mathrm{PM}$ & 14.468 \\
$\mathrm{HC}$ & 2.800 \\
$\mathrm{CO}$ & 29.00 \\
$\mathrm{CO}_{2}$ & 18219.52 \\
$\mathrm{NO}_{\mathrm{x}}$ & 185.600 \\
\hline
\end{tabular}

These emissions measurements were made using a full-flow dilution tunnel. PM measurements were determined using a gravimetric method. A heated flame ionization detector was used to measure hydrocarbon emissions (HC), nondispersive infrared analyzers were used to measure carbon monoxide $(\mathrm{CO})$ and carbon dioxide $\left(\mathrm{CO}_{2}\right)$ emissions, and a chemiluminescent analyzer was used to measure $\mathrm{NO}_{\mathrm{x}}$ emissions. The main parameter of interest in this case was the PM emissions rate because this value was used to determine a preliminary estimate of filter loading times, which were based on an estimate of the required exhaust split percentage to maintain acceptable total exhaust backpressure levels at minimum filter loading times (discussed in Section 3.3). As was mentioned previously, the filter was not of sufficient volume to filter the entire exhaust flow, so an automated butterfly valve in the main exhaust line was used to control the exhaust flow rate through the filter. The exhaust split percentage was defined as the

\footnotetext{
${ }^{\dagger}$ Table values were taken from a West Virginia Diesel Equipment Commission report (Gautam, 1998)
} 
percentage of total exhaust flow which was forced through the filter. The exhaust flow control system is described in detail in Section 3.3.7. It was recognized that the preliminary predicted filter loading time estimates would be shorter than those actually required because the filtration took place in the exhaust line at elevated temperatures. Under these conditions, the vapor phase organics which are adsorbed on PM particles at lower temperatures (such as those in the dilution tunnel) passed through the filter, reducing the amount of collected particulate mass within the wall-flow filter.

An air-cooled eddy-current dynamometer (Mustang EC300) was used to provide engine load. An eddy current dynamometer provides engine load by using energized DC coils to induce eddy currents in iron discs, which are directly connected to the engine driveshaft. The discs are forced to rotate in the magnetic field generated by the coils, and the eddy currents which are generated provide a resistance torque in the opposite direction of disc rotation. The amount of current passed through the coils as well as the angular speed of the disc determines the amount of braking torque generated. The power which is absorbed is dissipated in the form of heat (Gautam, 1995).

A Dyn-Loc IV dynamometer controller and Dyne-Systems Co. DTC-1 throttle controller were used to regulate engine speed and load. The controller was operated in RPM mode which allowed a target engine speed to be set (+/-2 rpm). In this control mode, no load was applied to the engine until the target engine speed was attained. The throttle controller was used to set the rack position of the engine. For testing undertaken in this research, the throttle controller was operated manually, although the system was capable of automation. Prior to testing, the throttle position was incrementally increased until the target engine speed was reached. The throttle position was then increased 
further to generate the desired engine load. During testing, the throttle position had to be periodically adjusted to compensate for increasing exhaust backpressure caused by increased filter loading. Pictures of the engine and dynamometer are provided in Figures 3.2.1 and 3.2.2.

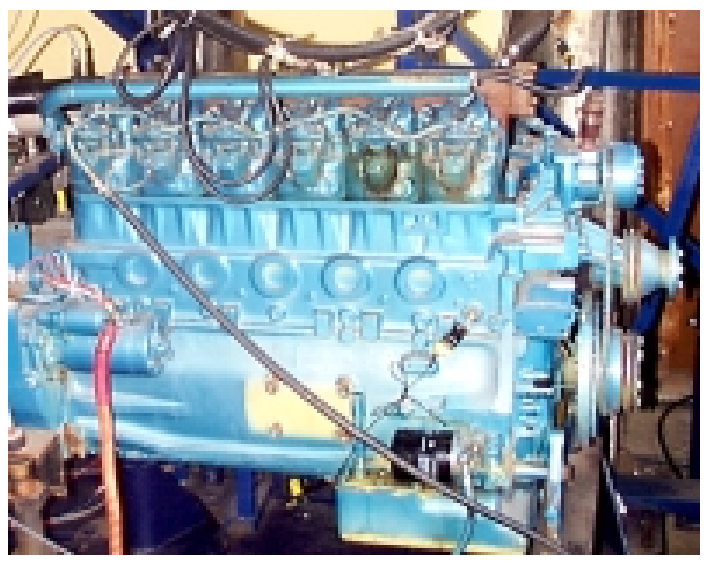

Figure 3.2.1 : MWM D916-6

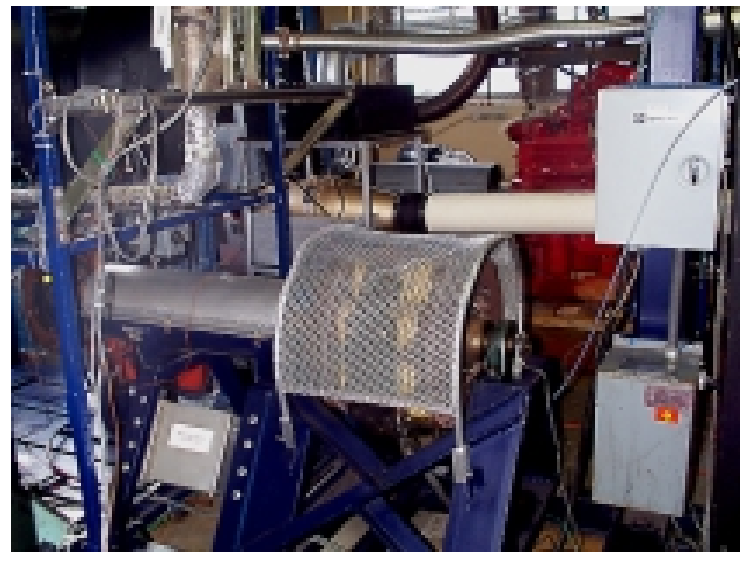

Figure 3.2.2: Mustang EC300

\subsection{Exhaust Transfer System}

As was mentioned previously, the filter size was much smaller than was necessary to filter the entire exhaust flow from the engine. For this reason, an elaborate exhaust transfer system was required to force a predetermined percentage of the total exhaust flow rate through the filter.

Uniform loading characteristics within the filter were required to allow meaningful comparisons to be made between regeneration tests, because variations in soot load profiles within the filter from test to test would create differences in the attenuation factors within the filter. If the soot loading variations were not minimized, another variable affecting the regeneration efficiency would exist, and a direct comparison of the parameters of interest would be invalid. The parameters of interest for 
this research were the initial soot loading mass, preheating time, combustion airflow rate, and combustion airflow temperature. In order to maintain uniform soot loading characteristics within the filter, the flow rate of the exhaust through the filter had to be maintained at a near constant value, and the engine had to be operated at constant speed and load. The dynamometer and throttle controllers capable of maintaining constant engine operating conditions, but an automated exhaust splitting scheme had to be developed in order to maintain the required flow rates during filter loading. Automation was necessary because increasing entrapped soot mass within the filter created decreasing flow rates through the filter bypass line for a given total exhaust flow rate. It can be inferred from this that some means was necessary to continuously balance the flow rates between the filter bypass line and the primary exhaust transfer line.

\subsubsection{Exhaust Flow Measurement}

A measurement of the exhaust flow rate within the transfer tubes was necessary to determine the exhaust split ratio. The flow rate balance could not be based on static pressure within the transfer tubes alone because the pressure drop within the filter continuously changed at a given exhaust flow rate which created continuously varying static pressures. The corrosive environment, the high temperatures, and the presence of particulate matter limited the choice of an exhaust flow rate meter substantially. Four means of exhaust flow rate measurement were considered: venturies, square-edged orifice meters, flow nozzles, and Kurz mass flow meters. Venturies allow volume flow rate to be measured based on pressure drop across smooth converging contraction which contracts to a narrow throat that is followed by a diverging section. This means of flow 
measurement creates little permanent pressure loss (Figliola, 1991). Small values of permanent pressure loss were desirable due to the total exhaust backpressure limitations of the engine. Flow nozzles are similar to venturies in that pressure drop is measured across a gradual contraction which contracts to a narrow throat. The lack of a diverging section causes the permanent pressure loss to be higher than that associated with a venturi of similar size and flow characteristics, but the cost of a flow nozzle is less than that of a venturi. An orifice meter consists of an orifice plate, which is inserted into a pipe. The plate is typically positioned such that the orifice diameter and pipe diameter are concentric, although in some special cases the orifice is positioned near the bottom of the pipe to allow solid matter to pass through the orifice. The differential pressure across the plate is correlated to the volume flow rate through the orifice. The lack of converging and diverging sections results in an increased value of the permanent pressure loss relative to venturies and flow nozzles, but the low cost of orifice meters makes them an attractive alternative to venturies or flow nozzles. Kurz insertion mass flow elements use constant temperature anemometry in which the rate heat loss from a probe (or the heating power input necessary to maintain constant probe temperature in this case) is directly correlated to flow velocity. One temperature probe and one mass velocity sensor are inserted together into an exhaust line to determine the mass flow rate of the exhaust. This type of measurement device would typically provide the highest resolution of the flow measurement devices considered, but it is also more sensitive to flow nonuniformities and variations. Probe fouling was a concern as well. This type of system was the most expensive of those considered. Due to expense limitations, the orifice meter was chosen as the means of measuring the exhaust flow rates in the exhaust transfer tubes. To save 
additional expense, the orifice meters were fabricated and calibrated at West Virginia University. A general schematic of an orifice meter is provided in Figure 3.3.1.

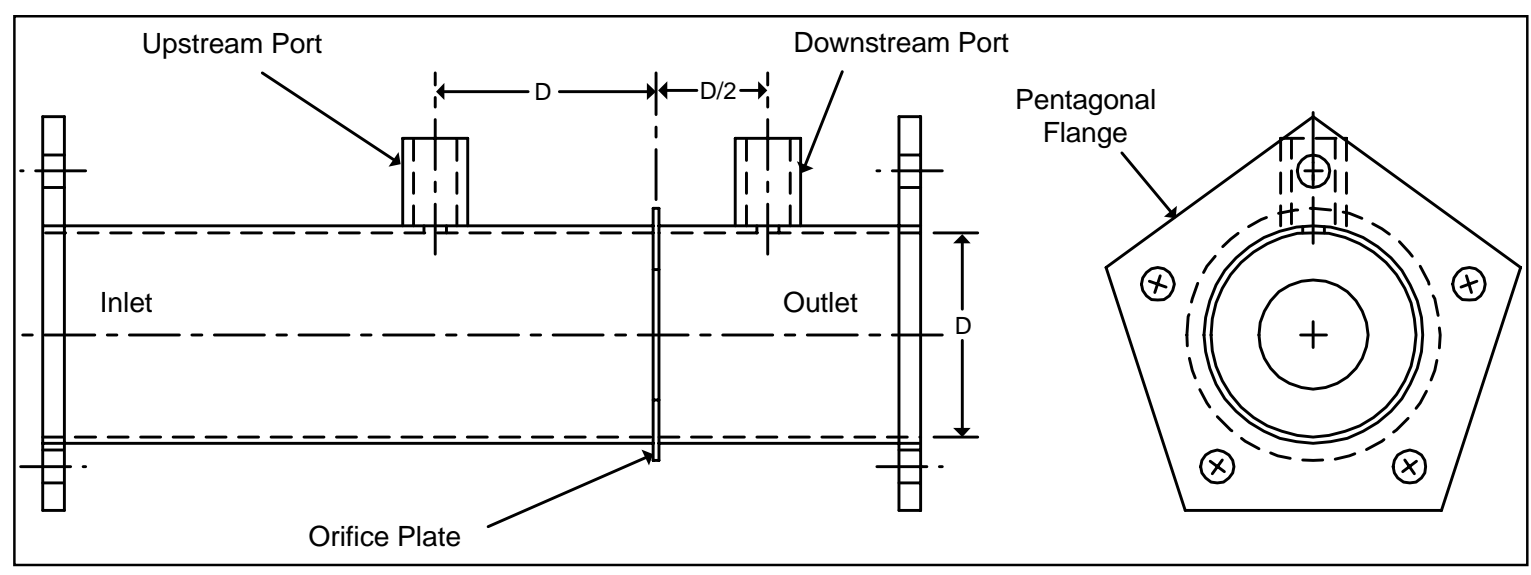

Figure 3.3.1: Orifice Meter Schematic

Steel, 2.5" $(6.4 \mathrm{~cm})$ diameter exhaust tubing [2.345" $(5.956 \mathrm{~cm})$ inside diameter] was used for the orifice meter fabrication. The diameter ratio, $\beta$, which is the ratio of the orifice diameter to the tube's inner diameter, was chosen to be 0.831 (orifice diameter $=$ $1.95 "=4.95 \mathrm{~cm})$. This tubing and orifice size created sufficient flow velocities at the orifice to provide differential pressures which were capable of being detected by standard differential pressure transducers (Validyne P305D) at all engine test conditions without generating excessive permanent pressure loss. Pentagonal five bolt flanges with graphite gaskets were used to provide more uniform holding force than four bolt flanges. The flanged joints allowed the orifice meter to be connected into the exhaust line without any significant flow disturbance.

An estimation of the differential pressure across the orifice meters at the engine operating condition which was proposed for testing was performed in order to determine 
the range of the pressure transducer. Some form of Equation 3.3.1 is typically used to determine the volumetric flow rate through an orifice meter (Figliola, 1991).

$$
\begin{aligned}
& Q_{a}=C E A Y \sqrt{\frac{2 \Delta p}{\rho_{1}}}=K A Y \sqrt{\frac{2 \Delta p}{\rho_{1}}} \\
& \text { where, } \\
& \mathrm{Q}_{\mathrm{a}}=\text { actual volumetric flow rate } \\
& \mathrm{C}=\text { discharge coefficient } \\
& \mathrm{E}=\text { velocity approach factor } \\
& \mathrm{A}=\text { cross sectional area of orifice } \\
& \mathrm{Y}=\text { compressible adiabatic expansion factor } \\
& \mathrm{K}=\text { flow coefficient }=\mathrm{CE} \\
& \Delta \mathrm{p}=\text { differential pressure across the orifice } \\
& \rho_{1}=\text { density of the air/exhaust upstream of the orifice } \\
& * \text { The subscript } 1 \text { indicates conditions upstream of the orifice }
\end{aligned}
$$

This equation is valid for steady, one-dimensional flow, with no heat transfer from the orifice meter. It is also valid for both compressible and incompressible flows. If temperature of the orifice meter at the test conditions is significantly different from the calibration conditions, the expansion and/or contraction of the orifice and the orifice pipe can cause errors in the flow measurement. For these cases, an additional coefficient known as the thermal expansion factor, $\mathrm{F}_{\mathrm{a}}$, can be added to Equation 3.3.1 (Fluid Meters:

Their Theory and Application, 1971):

$$
Q_{a}=K F_{a} A Y \sqrt{\frac{2 \Delta p}{\rho_{1}}}
$$

The thermal expansion factor can be calculated using the following formula given in Measurement of Fluid Flow in Pipes Using Orifice, Nozzle, and Venturi (1971):

$$
\left.F_{a}=1+\frac{2}{1-\beta^{4}}\left[\alpha_{P E}-\beta^{4} \alpha_{p}\right\rceil T-T_{c a l}\right]
$$

where,

$$
\begin{aligned}
& \alpha_{\mathrm{PE}}=\text { thermal expansion factor of the orifice plate material } \\
& \alpha_{\mathrm{p}}=\text { thermal expansion factor of the orifice pipe }
\end{aligned}
$$




$$
\begin{aligned}
& \mathrm{T}=\text { temperature of the orifice at the test conditions } \\
& \mathrm{T}_{\text {cal }}=\text { temperature of the orifice at the calibration conditions }
\end{aligned}
$$

For the orifice meters used in this testing, both the orifice plate and pipe were made of carbon steel. The thermal expansion factor for this material is listed in Mechanical Engineering Design (1989) as $6.0 \times 10^{-6}{ }^{0} \mathrm{~F}^{-1}$. The expected temperature at each orifice meter during testing was on the order of $500{ }^{\circ} \mathrm{F}\left(260{ }^{\circ} \mathrm{C}\right)$, and the temperature during calibration was near $105{ }^{\circ} \mathrm{F}\left(41{ }^{\circ} \mathrm{C}\right)$ on average (the actual temperature of the orifice meter material was assumed to be identical to these values at each condition).

Substituting these values and the orifice meter diameter ratio of 0.83 into Equation 3.3.3, the thermal expansion factor was found to be 1.0047, which represents an error of $0.47 \%$ in the flow measurement. Because the exhaust lines were well insulated, the same degree of error was expected in the flow measurements of both orifice meters. For this testing, it was the ratio of the orifice flow rates which was used to control the flow through the exhaust filter, so both orifice meters would be biased in the same direction, canceling some of the relative error. Due to this fact and the relatively small errors associated with the thermal expansion factor, it was assumed to be unity in the calculation of the exhaust flow rate through the orifice meters.

The adiabatic expansion factor, $\mathrm{Y}$, which ranges from 0 to 1 , is typically only significant if the pressure ratio $\left(\Delta \mathrm{p} / \mathrm{p}_{1}\right)$ is greater than or equal to 0.1 (Figliola, 1991). This parameter is used to account for compressibility effects if the fluid is forced to flow through the orifice at high differential pressures. Experiments demonstrated that the gauge pressure upstream of the orifice did not exceed $24 " \mathrm{H}_{2} \mathrm{O}(0.866 \mathrm{psig})$ under the engine operating condition used during filter loading, and the barometric pressure was 
typically near $14.2 \mathrm{psi}(97.9 \mathrm{kPa})$. Using these values, the pressure ratio was calculated as follows:

$$
\begin{aligned}
& \text { pressure ratio }=\frac{0.866 p s i}{0.866 p s i+14.2 p s i}=0.057<0.1 \\
& \text { so, } \\
& Y \cong 1
\end{aligned}
$$

An estimate of the volumetric efficiency of the engine at the operating condition used during filter loading was used to calculate the total exhaust flow rate. The volumetric efficiency can be defined as follows for diesel engines (Ferguson, 1986):

$$
e_{v}=\frac{2 m_{a}}{\rho_{i} V_{d} R_{s}}
$$

where,

$\mathrm{e}_{\mathrm{v}}=$ volumetric efficiency

$m_{a}=$ intake air mass flow rate

$\rho_{\mathrm{i}}=$ air density in the intake manifold

$\mathrm{V}_{\mathrm{d}}=$ engine displacement

$\mathrm{R}_{\mathrm{s}}=$ engine rotational speed $(\mathrm{rpm})$

The volumetric efficiency was assumed to be 0.9 , and the intake manifold air density was estimated to be $1.1 \mathrm{~kg} / \mathrm{m}^{3}$. The engine displacement was $379 \mathrm{in}^{3}(6.2 \mathrm{~L})$, and the test engine speed was $1500 \mathrm{rpm}$. Using these values, and solving Equation 3.3.4 for the intake air mass flow rate, the mass flow rate was found to be $4.61 \mathrm{~kg} / \mathrm{m}^{3}(0.0768 \mathrm{~kg} / \mathrm{s})$. The exhaust flow rate was approximated to be equal to the intake airflow rate (that is, the contribution of the fuel mass flow rate was neglected).

Based on temperature and pressure measurements at the proposed orifice meter locations during engine testing prior to the insertion of orifice meters, the temperature upstream of the first orifice meter was predicted to stabilize approximately $500{ }^{\circ} \mathrm{F}(533$ $\mathrm{K})$, while the absolute pressure was estimated at $15.1 \mathrm{psi}(104.2 \mathrm{kPa})$ [based on 24 " $\mathrm{H}_{2} \mathrm{O}$ 
(5.97 kPa) gauge pressure and $14.2 \mathrm{psi}(97.9 \mathrm{kPa})$ barometric pressure]. The ideal gas

law was used to calculate the density of the exhaust flowing through the orifice meter:

$$
\begin{aligned}
& \rho_{\text {exh }}=\frac{p}{\left(\bar{R} / M W_{\text {exh }}\right) T} \\
& \text { where, } \\
& \quad \rho_{\text {exh }}=\text { exhaust density } \\
& \\
& \quad R=\text { Universal gas constant }=8.314 \mathrm{KJ} / \mathrm{kmol}-\mathrm{K}=1.986 \mathrm{Btu} / \mathrm{lbmol}-^{\circ} \mathrm{R} \\
& \\
& \mathrm{MW} \text { exh }=\text { molecular weight of exhaust } \\
& \mathrm{p}=\text { absolute pressure } \\
& \mathrm{T}=\text { absolute temperature }
\end{aligned}
$$

The molecular weight of the exhaust was assumed to be closely approximated by that of air $(28.97 \mathrm{~kg} / \mathrm{kmol})$. Using the aforementioned values for pressure, temperature, and molecular weight, the density was found to be $0.681 \mathrm{~kg} / \mathrm{m}^{3}$. The validity of the ideal gas model was evaluated by calculating the compressibility factor of the exhaust under the test conditions.

$$
\begin{aligned}
& Z=\frac{p v_{e x h}}{\left(\bar{R} / M W_{e x h}\right) T} \\
& \text { where, } \\
& \quad \mathrm{v}_{\text {exh }}=\text { specific volume of the exhaust } \\
& \mathrm{Z}=\text { compressibility factor }
\end{aligned}
$$

If the compressibility factor under the test conditions is unity, the ideal gas relationship is valid for the exhaust gas flow. An independent value for the specific volume was not known for the exhaust, so the compressibility factor could not be calculated directly. In many thermodynamic texts, plots of the compressibility factor versus reduced pressure are given. Typically, families of curves at various reduced temperatures are given in these plots. Such a graph is provided in Fundamentals of Engineering Thermodynamics, $2^{\text {nd }}$ ed. by Moran et al. (1992). The authors state that it can be inferred from the graph 
that if the reduced pressure is below approximately 0.05 or if the reduced temperature is above 15 , the compressibility factor is approximately unity. These approximations are true for various gases including air, nitrogen, methane, ethane, and water (Moran et al., 1992). The reduced pressure and temperature were defined as follows:

$$
\begin{aligned}
p_{R}=\frac{p}{p_{c}} & \\
T_{R}=\frac{T}{T_{c}} & \\
\text { where, } & \\
\mathrm{p}_{\mathrm{R}} & =\text { reduced pressure } \\
\mathrm{p}_{\mathrm{c}} & =\text { critical pressure } \\
\mathrm{T}_{\mathrm{r}} & =\text { reduced temperature } \\
\mathrm{T}_{\mathrm{c}} & =\text { critical temperature }
\end{aligned}
$$

The critical pressure and temperature of the exhaust was assumed to be the same as that for air: $3770 \mathrm{kPa}(546.8 \mathrm{psi})$ and $133 \mathrm{~K}\left(-220{ }^{\circ} \mathrm{F}\right)$ respectively (Moran et al., 1992). Using these values for the critical temperature and pressure and the values for the pressure and temperature during testing, the reduced pressure was found to be 0.028 , and the reduced temperature was calculated as 4.0. The reduced pressure was below the minimum required value, so the ideal gas relationship was valid.

The viscosity of the exhaust was assumed to be near the viscosity of air at 1 atm $(101.3 \mathrm{kPa})$ and $500{ }^{\circ} \mathrm{F}\left(260{ }^{\circ} \mathrm{C}\right)$, which is $5.81 \times 10^{-7} \mathrm{lbf}-\mathrm{s} / \mathrm{ft}^{2}\left(2.78 \times 10^{-5} \mathrm{~N}-\mathrm{s} / \mathrm{m}^{2}\right)($ Munson et al., 1990). The interior area of the exhaust pipe was calculated to be $0.00279 \mathrm{~m}^{2}$ $\left(4.324 \mathrm{in}^{2}\right)$ (based on an interior diameter of $\left.0.0596 \mathrm{~m}=2.345 \mathrm{in}\right)$. The actual volumetric flow rate through the orifice meter was calculated using the following relation for onedimensional flows with constant, uniform thermodynamic properties:

$$
Q_{a}=\frac{\dot{m}}{\rho}
$$


Using the calculated values for the exhaust mass flow rate and density, the actual flow rate was determined to be $0.113 \mathrm{~m}^{3} / \mathrm{s}$ (239 acfm). The flow was assumed to be one dimensional, so the average velocity of the exhaust prior to the orifice was calculated using the following relation:

$$
V=\frac{Q_{a}}{A}
$$

where,

$\mathrm{V}=$ exhaust average velocity

$\mathrm{Q}_{\mathrm{a}}=$ actual volumetric flow rate

$\mathrm{A}=$ exhaust tubing cross sectional area

The exhaust velocity was found to be $40.4 \mathrm{~m} / \mathrm{s}$.

Values for the density, viscosity, velocity, and tubing diameter were used to calculate the Reynolds number of the exhaust flow.

$$
\operatorname{Re}=\frac{\rho_{e x h} V d_{1}}{\mu_{e x h}}=\frac{\rho_{e x h} Q_{a}}{(\pi / 4) d_{1} \mu_{e x h}}=\frac{\dot{m}}{(\pi / 4) d_{1} \mu_{e x h}}
$$

where,

$$
\begin{aligned}
& \mathrm{Re}=\text { Reynolds number } \\
& \mathrm{d}_{1}=\text { tubing inner diameter } \\
& \mu_{\text {exh }}=\text { viscosity of the exhaust flow }
\end{aligned}
$$

Under the specified conditions, the Reynolds number was calculated to be $5.9 \times 10^{4}$. The Reynolds number was used to determine the flow coefficient, K, used in Equation 3.3.1. An empirical expression for $\mathrm{K}$ as a function of the diameter ratio $(\beta)$, the tubing inner diameter $\left(\mathrm{d}_{1}\right)$, and the Reynolds number $(\mathrm{Re})$ is provided in Theory and Design for Mechanical Measurements (Figliola, 1991). 


$$
K=\frac{1}{\left(1-\beta^{4}\right)^{1 / 2}}\left[\begin{array}{l}
0.5959+0.0312 \beta^{2.1}-0.184 \beta^{8}+ \\
0.09\left(\frac{1}{d_{1}}\right) \beta^{4}\left(\frac{1}{1-\beta^{4}}\right) \\
-0.0337\left(\frac{1}{d_{1}}\right) \beta^{3}+91.71 \beta^{2.5}\left(\frac{1}{\mathrm{Re}^{.75}}\right)
\end{array}\right]
$$

This expression requires that the units for the pipe diameter must be in inches. Using this expression, the flow coefficient was found to be 0.851 . The expression was extrapolated beyond the given $\beta$ range, and the equation was based on data taken from orifice meters with flange taps (although this should not affect the $\mathrm{K}$ value significantly); but only approximate estimates were deemed necessary for differential pressure prediction. The predicted differential pressure drop was calculated by solving Equation 3.3.1 for $\Delta \mathrm{p}$ and using the calculate values for the density, actual volumetric flow rate, flow area, and flow coefficient. Under the specified conditions, the differential pressure was predicted to be $6.51 " \mathrm{H}_{2} \mathrm{O}(1.62 \mathrm{kPa})$. It was realized that many assumptions were made in this prediction. Orifice tubing eccentricity, pressure tap placement, and flow disturbances in the exhaust lines were also expected to cause the actual differential pressure values to deviate from the theoretical values, but the differential pressure estimate allowed a suitable pressure transducer diaphragm to be selected. Diaphragms with larger ranges were used to allow the differential pressure at rated conditions to be measured with no risk of over-pressurization of the transducer.

The permanent pressure loss associated with the orifice meters under these conditions was estimated by using a plot of permanent pressure loss versus diameter ratio (Figliola, 1991). With this plot, it can be seen that the permanent pressure loss for a square-edged orifice with a diameter ratio of 0.83 is approximately $31 \%$ of the 
differential pressure. This resulted in a predicted permanent pressure loss of 2.0 " $\mathrm{H}_{2} \mathrm{O}$ $(0.50 \mathrm{kPa})$ for the conditions specified above. The benefit of having an orifice meter with a large diameter ratio is readily apparent due to the small permanent pressure loss.

The orifice meter static pressure taps were positioned according to recommended standard tap placements for orifice meters (Figliola, 1991). The purpose of choosing a particular tap placement was to allow stable differential pressure measurements which are sensitive to small changes in flow. The relative tap placement is critical if tabulated values for the volumetric flow rates are to be used based on differential pressure measurements across the orifice, but the orifice meters which were used in the exhaust line were calibrated on-site (that is, they were calibrated while in the exhaust line), so the position of the pressure taps relative to the orifice plate was not critical. Care was taken to provide as much straight pipe length prior to the orifice meters as possible. In his text, Theory and Design for Mechanical Measurements, Figliola (1991) provides some estimates for the required straight pipe lengths before and after orifice meters in various pipe geometries such as valves and elbows. It is apparent that the upstream straight pipe length is always larger than the downstream pipe length. For this reason, the orifice meters were fabricated such that the orifice plate was nearer to the outlet end. The listed pipe length values were given to provide engineers with guidelines regarding the necessary straight pipe lengths which are needed if tabulated flow rate values are to be used. It is recommended that if sufficient straight pipe length cannot be provided, the orifice meter should be calibrated on-site (Figliola, 1991). The physical constraints of the test cell prevented sufficient straight pipe length to be placed before one of the orifice meters, so on-site calibration was necessary. 


\subsubsection{Orifice Meter Calibration}

The majority of the exhaust transfer system remained intact during the orifice meter calibration. A schematic of the exhaust transfer system used during testing is provided in Figure 3.3.2. Photographs and cross-sectional views of some of the exhaust system components are provided in Appendix A. Descriptions of the individual components will be presented in subsequent sections. For calibration, the engine exhaust transfer line to the exhaust surge tank was disconnected, and an air transfer tube was connected to the surge tank inlet. The valves in the bypass line were closed during calibration, ensuring that the entire quantity of metered air passed through both orifice meters. The orifice meters were calibrated using a low-pressure air supply capable of flow rates over $400 \mathrm{scfm}\left(11.3 \mathrm{~m}^{3} / \mathrm{min}\right)$ at $15 \mathrm{psig}(103.4 \mathrm{kPa})$. The air transfer system which was used for orifice meter calibration is shown in Figure 3.3.3. 


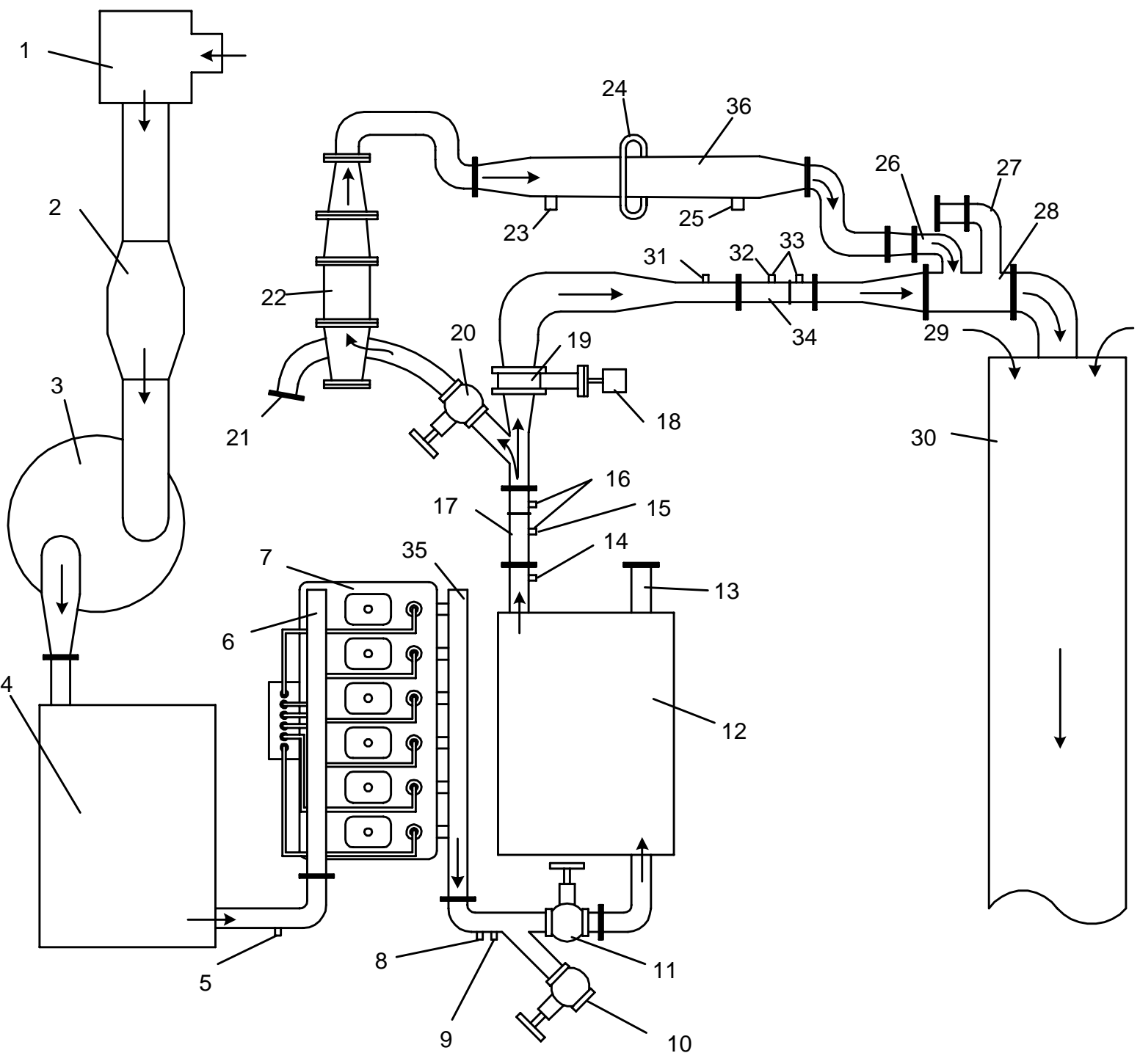

1 - Air Filter

2 - Laminar Flow Element

3 - Primary Intake Surge Tank

4 - Secondary Intake Surge Tank

5 - Intake Depression Port

6 - Intake Manifold

7 - MWM D916-6

8 - Exhaust Backpressure Port

9 - Temperature Port

10 - Bypass Gate Valve (closed)

11 - Main Line Gate Valve (open)

\author{
12 - Exhaust Surge \\ Tank \\ 13 - Second Surge \\ Tank Outlet (not used) \\ 14 - Temperature Port \\ 15 - Upstream Pressure \\ Port \\ 16 - Differential Pressure \\ Port \\ 17 - Orifice Meter 1 \\ 18 - Stepper Motor \\ 19 - Automated Butterfly \\ Valve \\ 20 - Bypass Gate Valve \\ 21 - Air Inlet \\ 22 - Filter Housing \\ 23 - Water Inlet
}

24 - Water Level Watch Glass

25 - Water Outlet

26 - First Valve Inlet

27 - Second Valve Inlet (closed)

28 - Sliding Gate Valve

29 - Dilution Air

30 - Dilution Tunnel

31 - Temperature Port

32 - Upstream Pressure Port

33 - Differential Pressure

Ports

34 - Orifice Meter 2

35 - Exhaust Manifold

36 - Microwave Water Trap

Figure 3.3.2: Engine Intake Air and Exhaust Flow Diagram 


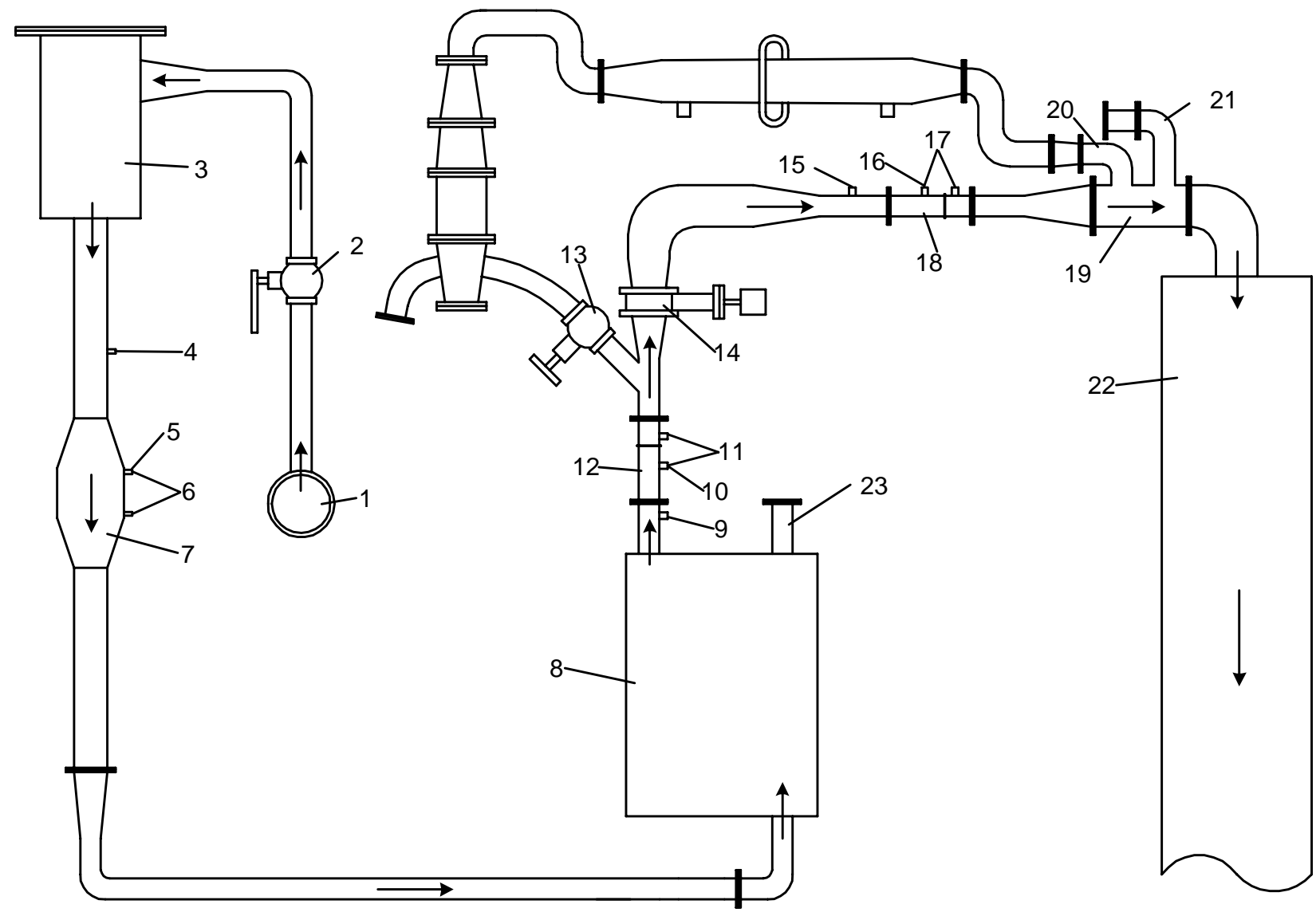

1 - Low Pressure Air Supply

2 - Ball Valve

3 - High Flow Air Filter

4 - Temperature Port

5 - Upstream Pressure Port

6 - Differential Pressure Ports

7 - 400 scfm Laminar

Flow Element
8 - Exhaust Surge

Tank

9 - Temperature Port

10 - Upstream Pressure

Port

11 - Differential Pressure Ports

12 - Orifice Meter 1

13 - Bypass Gate Valve (closed)

14 - Automated Butterfly Valve (open)
15 - Temperature Port 16 - Upstream Pressure Port

17 - Differential Pressure Ports

18 - Orifice Meter 2

19 - Sliding Gate Valve

20 - First Valve Inlet

21 - Second Valve Inlet

22 - Dilution Tunnel

23 - Surge Tank Second Outlet (closed)

Figure 3.3.3: Orifice Calibration Air Diagram 
A laminar flow element (Meriam model 50MC2) was used to measure the mass flow rate of air passing through the exhaust orifice meters during calibration. Laminar flow elements function similarly to other volume flow meters such as venturies and orifice meters in that the differential pressure across a flow obstruction is correlated to volume flow rate. In this case, the obstruction is a honeycomb structure. The differential pressure across the structure is measured, and a calibration curve provided by the manufacturer is used to determine the volume flow rate of the fluid passing through the element. The manufacturer provided coefficients for a second order polynomial curve fit of the actual volume flow rate versus differential pressure data. Calibration curves for both $400 \operatorname{acfm}\left(11.3 \mathrm{~m}^{3} / \mathrm{min}\right)$ and $25 \mathrm{acfm}\left(0.71 \mathrm{~m}^{3} / \mathrm{min}\right)$ (nominal ratings at conditions near standard temperature and pressure) are provided in Appendix B (the calibration curves were provided from Meriam for each LFE). The absolute pressure and temperature upstream of the honeycomb structure were also measured in order determine the pressure, temperature, and viscosity correction factors. The pressure and temperature correction factors for standardized flow rate calculation were based on the ideal gas law:

$$
\begin{aligned}
& Q_{s}=\left(\frac{p_{1}}{p_{s}}\right)\left(\frac{T_{s}}{T_{1}}\right) Q_{1} \\
& \text { where, } \\
& \mathrm{Q}_{\mathrm{s}}=\text { volume flow rate at standard conditions } \\
& \mathrm{T}_{\mathrm{s}}=\text { standard absolute temperature }\left(70^{\circ} \mathrm{F}=529.67{ }^{\circ} \mathrm{R}=294 \mathrm{~K}\right) \\
& \mathrm{p}_{\mathrm{s}}=\text { standard absolute pressure }(1 \mathrm{~atm}=101.3 \mathrm{kPa}) \\
& \mathrm{p}_{1}=\text { absolute upstream pressure } \\
& \mathrm{T}_{1}=\text { absolute upstream temperature } \\
& \mathrm{Q}_{1}=\text { actual volume flow rate from calibration curve }
\end{aligned}
$$


The first term on the right hand side of the equation is the pressure correction factor, while the second term is the temperature correction factor. Due to the small channels within the laminar flow element, a viscosity correction factor was also required ${ }^{* *}$ :

$$
\mu_{\text {cor }}=\frac{181.87}{\mu g}
$$

where,

$$
\mu g=\frac{14.58\left(\frac{459.67+T\left({ }^{o} F\right)}{1.8}\right)^{3 / 2}}{110.4\left(\frac{459.67+T\left({ }^{o} F\right)}{1.8}\right)}
$$

The viscosity correction factor in this form required the absolute temperature units to be in ${ }^{\circ} \mathrm{R}$. With this factor, the standardized flow rate through the laminar flow element was calculated as follows:

$$
Q_{s, L F E}=\left(\frac{P_{1}}{P_{s}}\right)\left(\frac{T_{s}}{T_{1}}\right) \mu_{c o r} Q_{1}
$$

where,

$$
\mathrm{Q}_{\mathrm{s}, \mathrm{LFE}}=\text { standardized flow rate through the laminar flow element }
$$

The mass flow rate of the air passing through the calibration system was calculated by solving Equation 3.3.9 for the mass flow rate, substituting the standardized flow rate value from Equation 3.3.15 for the volume flow rate, and using the ideal gas law to calculate the density of air at standard conditions (Equation 3.3.5).

The mass flow rate through the laminar flow element (LFE) was equal to the mass flow rate through the orifice meters during calibration (conservation of mass). The actual

\footnotetext{
** Viscosity correction factor from NBS 564
} 
flow rate through the orifice meters could be calculated using the known mass flow rate and the upstream temperature and pressure of each orifice meter.

$$
Q_{a}=\frac{\dot{m}_{\text {orf }}\left(R_{\text {air }} T\right)}{p}
$$

where,

$\mathrm{Q}_{\mathrm{a}}=$ orifice meter actual flow rate

$m_{\text {orf }}=$ orifice meter mass flow rate $=$ LFE mass flow rate

$\mathrm{R}_{\mathrm{air}}=$ Universal gas constant for air $=0.287 \mathrm{~kJ} /(\mathrm{kg}-\mathrm{K})$

$=0.0685 \mathrm{Btu} / \mathrm{lbm}-{ }^{\circ} \mathrm{R}$

$\mathrm{T}=$ orifice meter upstream absolute temperature

$\mathrm{P}=$ orifice meter upstream absolute pressure

The calculations shown above were incorporated into a Basic calibration program.

A copy of the program is provided in Appendix C. The program used the laminar flow element differential pressure and absolute upstream temperature and pressure to calculate the mass flow rate of air through the system. The mass flow rate of air through the system was then used to calculate the actual flow rate of air through each orifice meter based on the upstream temperature and pressure of each orifice meter. The laminar flow element differential and absolute pressures were measured using pressure transducers, and the upstream temperature was measured using a resistance temperature detector (RTD). The orifice meter absolute and differential pressures were also measured using pressure transducers, while the upstream temperatures were measured using K-type thermocouples. The signals from the sensing elements were passed through signal conditioners and into a data acquisition board which contained analog to digital (A/D) converters. The resulting digital signals were accessed using the calibration program and converted into engineering units. Prior to the orifice meter calibration, all the pressure transducers were calibrated using a hand pump. A reference gauge was mounted on the 
hand pump, and the pump outlet line was connected to the transducer positive pressure port. By closing a bleed valve on the pump, pump actuation would generate a positive pressure in the transducer. The pressure was adjusted via the bleed valve until the appropriate pressure was attained. The output signal from the transducer was adjusted until the reference gauge reading was achieved. The output of the differential pressure transducers at 0 differential pressure was adjusted to give a reading of zero (in terms of ADC code). The maximum pressure of each transducer was then generated using the hand pump, and the output signal was adjusted to give the maximum ADC code allowable (2047 or 4095, depending on the ADC code range of the signal conditioning rack). The differential pressure was then set back to zero, and the procedure was repeated until the transducer did not require any additional signal adjustment. The signal conditioners produced linear output signals from the pressure transducers, so only two data points were needed for calibration. The absolute pressure transducers were factory calibrated, so only the reading at atmospheric pressure was adjusted to read the barometric pressure. The thermocouple signal conditioners were calibrated by generating known voltages in the thermocouple circuits. The signal conditioner output was adjusted according to the voltage-input value. Again, only two calibration points were required due to the linear nature of the output signal. The thermocouples themselves were factory calibrated, and new thermocouples were installed prior to testing.

Due to the presence of particles and water droplets in the low-pressure air supply, a high-flow air filter was required in the air transfer pipe prior to the laminar flow element used for orifice meter calibration. An inexpensive high-flow filter element was readily available, but the excessive cost of the corresponding filter housing did not justify 
the purchase of the combined system. A stainless steel filter housing was used to force the air through the circumference of the filter element. A photograph and a crosssectional diagram of the filter are provided in Appendix E. The housing included a drain for accumulated liquid and a pressure gauge to monitor the state of the filter.

The orifice meter calibration procedure consisted of adjusting the airflow ball valve (see Figure 3.3.3) until the desired minimum flow rate for calibration was attained. The software displayed values for the temperatures, pressures, and airflow rates (both actual and standardized) for both the orifice meters and the laminar flow element in order to provide a means of determining when flow stabilization had occurred. Once the flow had stabilized, another section of the program was activated which calculated the average of the readings for ten seconds at approximately $10 \mathrm{~Hz}$. The final averaged values for the actual volumetric flow rate and the corresponding differential pressure of each orifice meter were recorded. The program was then reset to its initial display mode, and the ball valve was then adjusted to increase the flow rate by approximately $20 \mathrm{scfm}(0.57$ $\mathrm{m}^{3} / \mathrm{min}$ ), and the process was repeated until the orifice meter actual flow rates were near $400 \mathrm{scfm}\left(11.3 \mathrm{~m}^{3} / \mathrm{min}\right)$. The range of flow rates used to generate the calibration curve bracketed all the flow rates present in the orifice meters during testing.

Plots of the actual volumetric flow rate versus differential pressure for each orifice meter were generated based on the calibration data. Two calibration curves for both orifice meters from calibrations performed on different days are presented in Appendix D. The curves very nearly overlap, demonstrating the repeatable nature of the calibration process. 
The next step in the calibration procedure was to determine the values for the flow coefficient of each orifice meter based on the plot of actual flow rate versus differential pressure. During calibration, the temperature and upstream absolute pressure at each orifice meter did not vary significantly. This implied that the density during calibration was relatively constant. The upstream absolute pressure was near 14.75 psi (101.7 kPa), and the temperature was near $100{ }^{\circ} \mathrm{F}(311 \mathrm{~K})$ for both orifice meters during the entire calibration process. Using the ideal gas law, the density of the air under these conditions was found to be $0.00221 \mathrm{slug} / \mathrm{ft}^{3}\left(1.14 \mathrm{~kg} / \mathrm{m}^{3}\right)$. The orifice diameters of both orifice meters were equal $(1.95 \mathrm{in}=4.95 \mathrm{~cm})$, so both orifice meters had equivalent orifice cross sectional areas of $0.0207 \mathrm{ft}^{2}\left(0.00192 \mathrm{~m}^{2}\right)$. These values were substituted into Equation 3.3.1 in the following manner:

$$
\begin{aligned}
& Q_{a}(a c f m)=K(1)\left[.0207\left(f t^{2}\right)\right] \sqrt{\frac{2\left[.0361\left(p s i / " H_{2} O\right)\right]\left[144\left(i n^{2} / f t^{2}\right)\right]\left[\Delta p\left(" H_{2} O\right)\right]}{.00221\left(s l u g / f t^{3}\right)}}\left(\frac{60 s}{1 \mathrm{~min}}\right) \\
& Q_{a}(a c f m)=85.2(K) \sqrt{\Delta p\left(" \mathrm{H}_{2} O\right)} \\
& K=\frac{Q_{a}(a c f m)}{85.2 \sqrt{\Delta p\left(" \mathrm{H}_{2} \mathrm{O}\right)}}
\end{aligned}
$$

Sigmaplot was used for curve fitting the equation for the flow coefficient given above. Hence, the value for the flow coefficient which best fit the calibration data was found. The values for the flow coefficients of each orifice meter were found to be,

$\mathrm{K}_{1}=0.822=$ flow coefficient for the first orifice meter $\mathrm{K}_{2}=0.866=$ flow coefficient for the second orifice meter

The relatively large values for the flow coefficients were caused by the large diameter ratio of the orifice meters. Plots and charts of the calibration data with the generated curve fits are given in Appendix D. Using these values for the flow coefficients, the actual volume flow rate through the orifice meter during testing was determined using 
Equation 3.3.1. The upstream temperature and pressure were used to calculate the density of the exhaust flow, and values for the flow coefficient $(\mathrm{K})$, compressibility factor (Y), and orifice area (A), which were all considered to be constant, were substituted into this equation. The differential pressure across the orifice was measured, so the actual volume flow rate could be determined.

The final step in the calibration procedure was to determine the validity of the assumption that the flow coefficients were constant. The flow coefficient is a function of the Reynolds number, the diameter ratio, and the inner tubing diameter (ASME, 1935). The diameter ratio and the inner diameter of the exhaust tubing were constant. Therefore, the flow coefficient could only be a function of the Reynolds number, but for large values of Reynolds number, the flow coefficient is essentially constant. The Reynolds number for each orifice meter flow during calibration conditions and test conditions had to be compared in order to determine if significant errors would occur if the flow coefficients were assumed to be constant.

The Reynolds number for flow through the first orifice meter during typical test conditions was previously calculated to be $5.9 \times 10^{4}$, and the predicted flow coefficient was determined to be 0.851 . The Reynolds number of the orifice meter flow for the calibration conditions $(\mathrm{T}=311 \mathrm{~K} ; \mathrm{p}=101.7 \mathrm{kPa})$ at the same actual flow rate $(0.113$ $\mathrm{m}^{3} / \mathrm{s}$ ) was calculated as follows (see Equations 3.3.5 and 3.3.11):

$$
\begin{aligned}
& \rho=\frac{p}{R T}=\frac{101.7 \mathrm{kPa}}{(0.286 \mathrm{~kJ} / \mathrm{kmol}-\mathrm{K}) 311 \mathrm{~K}}=1.14 \mathrm{~kg} / \mathrm{m}^{3} \\
& \operatorname{Re}=\frac{\rho Q_{a}}{(\pi / 4) d \mu}=\frac{\left(1.14 \mathrm{~kg} / \mathrm{m}^{3}\right)\left(0.113 \mathrm{~m}^{3} / \mathrm{s}\right)}{(\pi / 4)(0.0596 \mathrm{~m})\left(1.87 \times 10^{-5} \mathrm{~N}-\mathrm{s} / \mathrm{m}^{2}\right)}=1.5 \times 10^{5}
\end{aligned}
$$


Using Equation 3.3.1, the flow coefficient was found to be 0.841 , which would represent only a $1.2 \%$ difference in the actual flow rate calculation between the calibration conditions and test conditions.

The exhaust flow rate through the second orifice meter during testing was approximately $55 \%$ of the flow rate through the first orifice meter because $45 \%$ of the exhaust was forced to flow through the filter bypass line. Using the calculated value for the mass flow rate of exhaust during test conditions, this represents a mass flow rate of $0.0422 \mathrm{~kg} / \mathrm{s}(0.00289 \mathrm{slug} / \mathrm{s})$. The density and viscosity of the exhaust were essentially the same as that of the flow through the first orifice meter $\left[0.681 \mathrm{~kg} / \mathrm{m}^{3}\left(0.00132 \mathrm{slug} / \mathrm{ft}^{3}\right)\right.$ and $2.78 \times 10^{-5} \mathrm{~N}-\mathrm{s} / \mathrm{m}^{2}\left(5.81 \times 10^{-7} \mathrm{lbf}-\mathrm{s} / \mathrm{ft}^{2}\right)$ respectively], so the actual volumetric flow rate was $0.0620 \mathrm{~m}^{3} / \mathrm{s}(131 \mathrm{acfm})$. The Reynolds number was calculated using Equation 3.3.11:

$$
\operatorname{Re}=\frac{\dot{m}}{(\pi / 4) d \mu}=\frac{0.0422 \mathrm{~kg} / \mathrm{s}}{(\pi / 4)(.0596 \mathrm{~m})\left(2.78 \times 10^{-5}\right)}=3.2 \times 10^{4}
$$

The corresponding flow coefficient is approximately 0.863 . The density and viscosity of the air flowing through the second orifice meter during calibration was essentially the same as that of the first orifice meter $\left[1.14 \mathrm{~kg} / \mathrm{m}^{3}\left(0.00221 \mathrm{slug} / \mathrm{ft}^{3}\right)\right.$ and $1.87 \times 10^{-5} \mathrm{~N}-\mathrm{s} / \mathrm{m}^{2}$ $\left(3.91 \times 10^{-7} \mathrm{lbf}-\mathrm{s} / \mathrm{ft}^{2}\right)$ respectively]. The Reynolds number based on the same actual flow rate of the flow during testing was calculated as follows:

$$
\operatorname{Re}=\frac{\rho Q_{a}}{(\pi / 4) d \mu}=\frac{\left(1.14 \mathrm{~kg} / \mathrm{m}^{3}\right)\left(0.0620 \mathrm{~m}^{3} / \mathrm{s}\right)}{(\pi / 4)(.0596 \mathrm{~m})\left(1.87 \times 10^{-5} \mathrm{~N}-\mathrm{s} / \mathrm{m}^{2}\right)}=8.1 \times 10^{4}
$$

The corresponding flow coefficient is approximately 0.847 which represents a difference of $1.9 \%$ between the calibration and test conditions. The strong agreement in flow 
coefficients between the calibration conditions and the test conditions validated the assumption that the flow coefficients were constant.

There are several other items worth mentioning concerning orifice meter calibration. The effects of humidity and the presence of particulate in the exhaust on the orifice meter flow measurement were assumed to be negligible. The effects of particulate deposition within the orifice meter were minimized by calibrating the orifice meter after one year of service. Prior to calibration, the orifice meters were removed from the exhaust system and inspected. A thin layer of soot was found to have deposited on the orifice meter interior surfaces, but no orifice plate deformation or other damage was found. It should also be noted that small diameter thermocouples (1/16") were used for temperature measurement. These thermocouples were placed multiple tube diameters upstream of the orifice meters. The exhaust pipes were well insulated, so the effects of transfer between the point of temperature measurement and the upstream pressure tap were minimal. The final point concerns the assumption that the molecular weight of the exhaust was the same as that of air. The molecular weight of the exhaust will vary depending on engine operating conditions and the conditions of the intake air. In order to predict the molecular weight of the exhaust for a given operating condition, either raw or dilute emissions data would have to be used to estimate the composition of the exhaust near each orifice meter. The effort required to predict this molecular weight variation was not considered to be necessary to calculate the small deviations of the molecular weight of the exhaust from that of air. 


\subsubsection{Exhaust Diffusers}

Numerous devices were required in addition to the orifice meters in the exhaust transfer system to allow accurate exhaust flow measurement and transfer. Five-inch diameter exhaust line was used when possible to decrease the total exhaust backpressure. The tubing used for the orifice meters was $2.5 "(6.4 \mathrm{~cm})$ in diameter, so diffusers and nozzles were needed to provide smooth transitions between tubes of different diameters. The nozzle and diffuser geometries were based on work published by the General Motors Corporation (Wendland et al., 1995). This work involved the design and analysis of diffusers used for catalytic converters used on passenger vehicles. It was discovered that typical diffusers used in conjunction with catalytic converters promoted jet flow of the exhaust. The diffuser half angles were sufficiently steep to create flow instability, and the instability caused the flow to separate from the diffuser walls, creating jet flow. The jet flow caused the pressure drop across the catalytic converters to be higher than necessary, unnecessarily increasing the engine load which decreased fuel economy. It was found that diffusers with smaller half angles followed by an abrupt expansion significantly decreased the pressure drop across the converters. A small diffuser half angle allowed the flow to follow the diffuser walls without stall. Reducers with smaller half angles were also tested, but they were not found to substantially reduce the pressure loss. A flow stability chart of diffuser half angle versus the ratio of diffuser length to inlet diameter was provided for two-dimensional diffusers. Stability charts were not provided for conical diffusers, but similar flow behavior patterns were expected. The length of the diffuser was related to the half angle in the following manner (Wendland et al., 1995): 


$$
\tan \phi=\frac{\left(\frac{D_{2}-D_{1}}{2}\right)}{L}
$$

where,

$$
\begin{aligned}
& \phi=\text { diffuser half angle (angle between centerline and wall) } \\
& D_{1}=\text { diffuser inlet diameter } \\
& D_{2}=\text { diffuser outlet diameter } \\
& L=N=\text { diffuser length }
\end{aligned}
$$

The relation between the diameter ratio and the line of first stall was given in the following form (Wendland et al.,1995):

$$
\frac{D_{2}}{D_{1}}=1+\frac{14 \pi}{90}\left(\frac{L}{D_{1}}\right)\left[\frac{L}{D_{1} \Re}\right]^{-0.544}
$$

where,

$$
\mathfrak{R}=\text { risk factor }
$$

The risk factor is an indication of flow stability. Risk factors greater than 1 indicate flows that are unstable. A risk factor of zero indicates a very stable flow. A risk factor of one indicates that the flow is on the verge of becoming unstable. Solving Equation 3.3.18 for the length of the diffuser, the following equation was attained:

$$
L=\left(D_{1}\right)\left(\frac{90}{14 \pi \Re^{0.544}}\left(\frac{D_{2}}{D_{1}}-1\right)\right)^{2.19}
$$

Most of the diffusers in the exhaust line had inlet diameters of 2.345" and outlet diameters of $4.875 "(12.383 \mathrm{~cm})$. If a flow stability factor of 1 is used, the length of the diffuser based on Equation 3.3.19 is calculated as 13.3" (33.8 cm). Unfortunately, space constraints precluded the use of such a long diffuser. The maximum length which could be used in most cases was 10 " $(25.4 \mathrm{~cm})$. The risk factor associated with a diffuser of 10 " $(25.4 \mathrm{~cm})$ length, 2.345 " $(5.965 \mathrm{~cm})$ inlet diameter, and 4.875" $(12.383 \mathrm{~cm})$ outlet diameter $\left(\phi=7.5^{\circ}\right)$ was calculated using the following form of Equation 3.3.18: 


$$
\Re=\left[\left(\frac{D_{2}}{D_{1}}-1\right)\left(\frac{90 D_{1}}{14 L \pi}\right)\right]^{1.84}\left(\frac{L}{D_{1}}\right)
$$

For a diffuser with the aforementioned geometric constraints, the risk factor was calculated to be 1.27 . This indicates that the flow would have some separation from the walls of the diffuser, creating some stall, but the line of appreciable stall was not exceeded (as was given in Wendland et al., 1995), so little permanent pressure loss was expected. The significance of the diffuser half angle on pressure loss is also confirmed in a plot of loss coefficient versus total diffuser angle for a typical diffuser is provided in Fundamentals of Fluid Mechanics (Munson et al., 1990). It is apparent that above diffuser half angles of approximately $8^{\circ}$, the loss coefficient becomes significantly larger than the loss coefficient of a diffuser with $0^{\circ}$ half angle (that is, a straight pipe).

\subsubsection{Exhaust Surge Tank}

The orifice meters in the exhaust line were calibrated using steady airflow. Unfortunately, pulsations were present in the exhaust flow generated by the engine. Pulsations in the exhaust flow would cause errors in flow measurement because orifice meters are nonlinear flow measurement devices. This indicates that the average flow rate of exhaust through the orifice meters would not be well represented by the flow measurement if pulsations were present in the exhaust flow. In order to ensure accurate flow measurement, an exhaust surge tank was used to attenuate pulsations in both pressure and flow. Taylor (1985) recommends that the volume of an exhaust surge tank should be 50 times the volume of one cylinder for multi-cylinder engines. For the engine used for this application, the exhaust surge tank volume was calculated as follows: 


$$
\begin{aligned}
V_{s t} & =50\left(V_{1 c y l}\right)=50\left(\frac{379 \mathrm{in}^{3}}{6 c y l}\right)=3158 \mathrm{in}^{3}=13.7 \mathrm{gal} \\
& =51.9 \mathrm{~L}
\end{aligned}
$$

where,

$$
\begin{aligned}
& \mathrm{V}_{\text {st }}=\text { surge tank volume } \\
& \mathrm{V}_{1 \mathrm{cyl}}=\text { volume of one engine cylinder }
\end{aligned}
$$

Another method of determining an appropriate surge tank volume for a given engine application was published by Roussopoulos (1990). In this publication, the Helmholtz resonator equation was used to size intake air surge tanks. He found that the operating frequency of the engine had to be nearly three times greater than the resonant frequency of the surge tank in order to minimize the airflow pulsations. If it is assumed that the Helmholtz resonator equation is valid for pulsating exhaust flow through a surge tank with sinusoidal velocity pulsations (with amplitudes on the order of the mean exhaust velocity) at the surge tank inlet and a flow resistance length, L, at the surge tank outlet; the following equation, as given by Roussopoulos (1990) for intake surge tanks, may be used to determine the minimum required surge tank volume:

$$
V_{s t}=\frac{c^{2} A_{2}}{\omega^{2} L}
$$

where,

$$
\begin{aligned}
& c=\text { speed of sound in the exhaust } \\
& A_{2}=\text { cross sectional area of the surge tank outlet } \\
& \omega=\text { surge tank resonance frequency } \\
& L=\text { length between the surge tank outlet and the upstream orifice meter } \\
& \text { pressure tap }
\end{aligned}
$$

For an ideal gas, the speed of sound may be calculated as follows:

$$
c=\sqrt{k R T}
$$

where,

$$
\mathrm{k}=\text { specific heat ratio of the gas }
$$


For engine operation at $1500 \mathrm{rpm}$ and $50 \%$ load, the exhaust temperature at the surge tank outlet was on the order of $500{ }^{\circ} \mathrm{F}\left(260{ }^{\circ} \mathrm{C}\right)$. Assuming that the exhaust properties are the same as those of air $(\mathrm{k}=1.4, \mathrm{R}=0.287 \mathrm{~kJ} / \mathrm{kg}-\mathrm{K})$, the speed of sound in the exhaust under these conditions was $463 \mathrm{~m} / \mathrm{s}(1519 \mathrm{ft} / \mathrm{s})$. The frequency of the pulsations for the four-stroke, single exhaust valve per cylinder engine was calculated using the following equation:

$$
f=\frac{(R P M)(\# c y l)}{120}
$$

where,

$\mathrm{f}=$ exhaust pulsation frequency $(\mathrm{Hz})$

$\mathrm{RPM}=$ engine angular speed $(\mathrm{rpm})$

$\#$ cyl = number of engine cylinders

Using Equation 3.3.24 for 6-cylinder engine operation at $1500 \mathrm{rpm}$, the exhaust pulsation frequency was found to be $75 \mathrm{~Hz}$. According to Roussopoulos (1990), the surge tank resonance frequency was required to be $1 / 3$ of this value $(25 \mathrm{~Hz})$. The distance between the surge tank outlet and the first orifice meter upstream pressure tap was approximately 12 " $(0.305 \mathrm{~m})$, and the outlet pipe diameter was $2.345 "\left(\right.$ cross-sectional area $\left.=.00279 \mathrm{~m}^{2}\right)$. Substituting these values in Equation 3.3.22, the minimum required surge tank volume for the engine operating conditions used for this research was calculated as,

$$
V_{s t}=\frac{(463 \mathrm{~m} / \mathrm{s})^{2}\left(.00279 \mathrm{~m}^{2}\right)}{(2 \pi \times 25 \mathrm{~Hz})^{2}(0.305 \mathrm{~m})}=0.0790 \mathrm{~m}^{3}=21.0 \mathrm{gal}=79.5 \mathrm{~L}
$$

At idle (approximately $700 \mathrm{rpm})$, the exhaust temperature was near $275^{\circ} \mathrm{F}(135$

$\left.{ }^{\circ} \mathrm{C}\right)$. Using Equation 3.3.23, the speed of sound in the exhaust under these conditions was $405 \mathrm{~m} / \mathrm{s}(1329 \mathrm{ft} / \mathrm{s})$. The frequency of the pulsations at idle was calculated to be $35 \mathrm{~Hz}$ (Equation 3.3.24), so the required resonant frequency of the surge tank was $11.7 \mathrm{~Hz}$. Using Equation 3.3.22, the required surge tank volume was calculated to be $0.278 \mathrm{~m}^{3}$ or 
73 gal. It is apparent that, according to the model proposed by Roussopoulos, an extremely large surge tank would be required if test conditions at idle were necessary (Roussopoulos, 1990). It must be noted that many simplifying assumptions were used by Roussopoulos in his derivation of the Helmholtz resonator equation for intake surge tanks, so care must be used if this method alone is to be used for surge tank sizing.

Roussopoulos (1990) also stated that if the surge tank or transfer pipe dimensions approach the half wavelength of the acoustic waves at the operating frequency, then the surge tank system would actually amplify the pulsations instead of attenuating them. The half wavelength was calculated using the following equation (Roussopoulos, 1990):

$$
\frac{1}{2} \lambda=\lambda_{1 / 2}=\frac{c}{2 f}
$$

where,

$\lambda_{1 / 2}=$ half wavelength at the operating frequency, $\mathrm{f}$

$\mathrm{c}=$ speed of sound (Equation 3.3.23)

$\mathrm{f}=$ operating frequency (Equation 3.3.24)

At $1500 \mathrm{rpm}$ and $50 \%$ load, the half wavelength was calculated to be,

$$
\lambda_{1 / 2}=\frac{463 \mathrm{~m} / \mathrm{s}}{2(75 \mathrm{~Hz})}=3.1 \mathrm{~m}=10.2 \mathrm{ft}
$$

This length is much longer than any dimension of the surge tank volume or of the transfer pipe between the surge tank and the first orifice meter. The length of the transfer pipe between the surge tank and the second orifice meter did exceed the half wavelength calculated above, but the exhaust butterfly valve which was present in this transfer line [approximately $0.711 \mathrm{~m}(2.33 \mathrm{ft})$ from the surge tank outlet] and the wall-flow filter in the bypass line were believed to provide sufficient flow restriction to dampen any higher order resonance's which may have normally occurred without the presence of the butterfly valve and filter. 
Based on the minimum surge tank volumes predicted by Taylor (1985) and Roussopoulos (1990), a surge tank target volume of 30 gallons (114 L) was thought to be necessary to ensure accurate flow rate measurement. Figure 3.3.4 is a cross-sectional schematic of the exhaust surge tank used for testing.

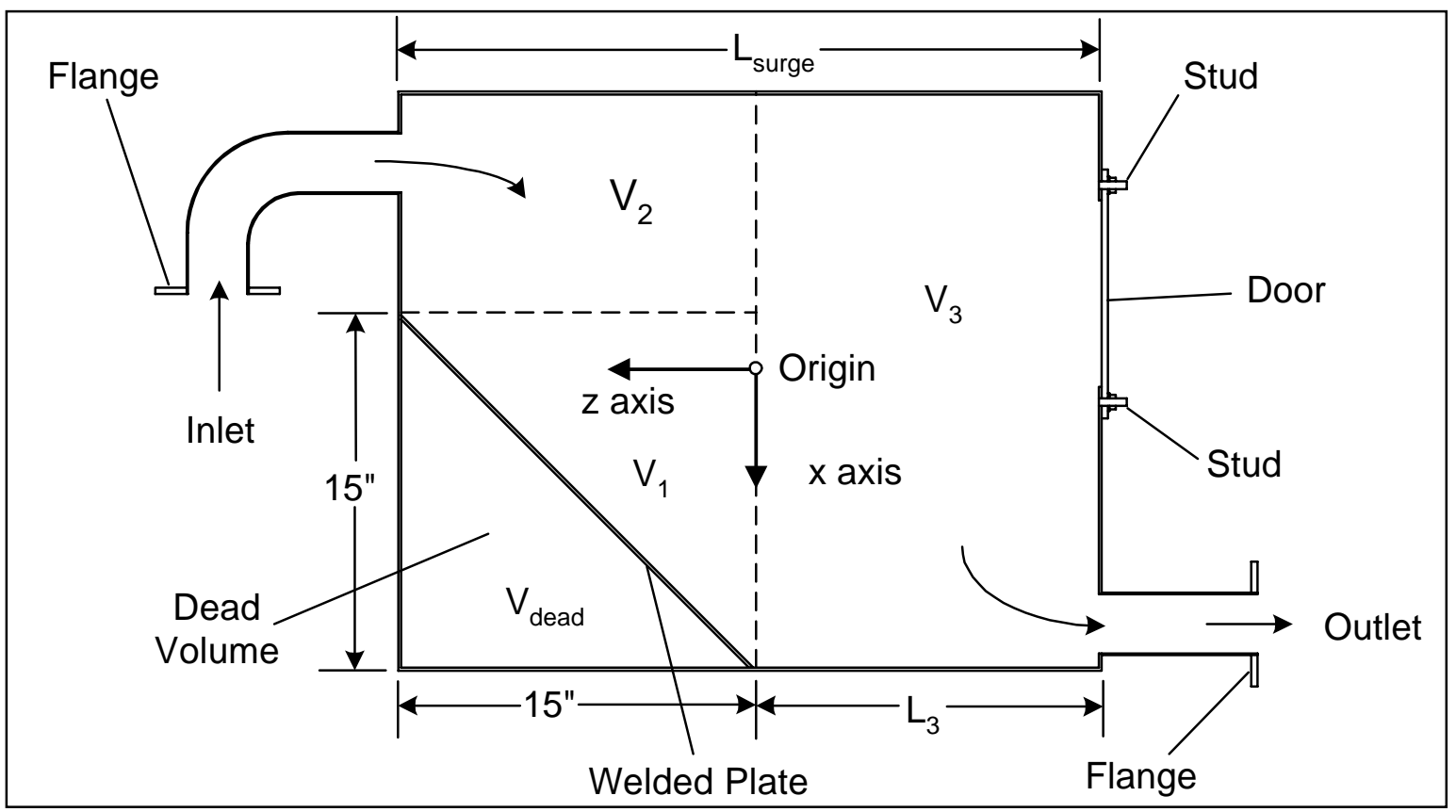

Figure 3.3.4: Surge Tank Cross-section

The surge tank diameter was fixed at $22.5 "(57.2 \mathrm{~cm})$. The inlet and outlet inner diameters were both $2.345 "(5.956 \mathrm{~cm})$. A door was placed above the outlet in order to allow access for cleaning. A flat steel plate was welded into the surge tank on approximately a $45^{\circ}$ angle with respect to the surge tank centerline to inhibit soot buildup along the bottom corner. The plate was also used to decrease the permanent pressure loss caused by the surge tank by preventing the formation of eddies near the bottom corner. With the steel plate length and position as well as the surge tank diameter fixed, the necessary surge tank length that would result in a total damping volume of 30 gallons 
$\left(6896\right.$ in $\left.^{3}=114 \mathrm{~L}\right)$ had to be determined. The Cartesian coordinate axes used in the surge tank volume calculation are shown in Figure 3.3.4. The total surge tank volume was broken into four sections as depicted in the illustration. In order to calculate the volume, $\mathrm{V}_{1}$, the equation of the plane generated by the steel plate had to be determined. The general equation of a plane can be represented as follows (Riddle, 1984):

$$
A\left(x-x_{1}\right)+B\left(y-y_{1}\right)+C\left(z-z_{1}\right)=0 \quad 3.3 .26
$$

where,

$[\mathrm{A}, \mathrm{B}, \mathrm{C}]=$ direction numbers of a vector perpendicular to the plane $(\mathrm{x}, \mathrm{y}, \mathrm{z})=$ an infinite number of points on the plane $\left(\mathrm{x}_{1}, \mathrm{y}_{1}, \mathrm{z}_{1}\right)=\mathrm{a}$ single point on the plane

From Figure 3.3.4 it can be deduced that the vector perpendicular to the plane generated by the plate intersected both the $\mathrm{x}$ and $\mathrm{z}$ axes at $45^{\circ}$ angles. Because $\sin \left(45^{\circ}\right)=\cos \left(45^{\circ}\right)$, one vector which is perpendicular to the plane is $(1,0,1)$, so the direction numbers for the plane are $[1,0,1]$. The radius of the surge tank was fixed at $11.25 "(28.58 \mathrm{~cm})$, so it is apparent from Figure 3.3.4 that one point which is contained in the plane is $(11.25,0,0)$ (note that the $\mathrm{z}$ axis is on the surge tank centerline). Substituting the direction numbers and the point contained in the plane into Equation 3.3.26, the equation of the plane was determined:

$$
\begin{aligned}
& 1(x-11.25)+1(z-0)=0 \\
& z=11.25-x
\end{aligned}
$$

If the surge tank cylinder is projected onto the $x y$ plane, the equation of the circle which results is,

$$
\begin{aligned}
& x^{2}+y^{2}=11.25^{2} \\
& y=\sqrt{11.25^{2}-x^{2}}
\end{aligned}
$$


Volume 1 is bounded by $\mathrm{z}=0, \mathrm{z}=11.25-\mathrm{x}$, and $y=\sqrt{11.25^{2}-x^{2}}$. Using these boundary conditions, $\mathrm{V}_{1}$ can be determined by evaluating the following triple integral (note that the volume is symmetric about the $x z$ plane):

$$
\begin{aligned}
V_{1} & =2 \int_{-3.75}^{11.25} \int_{0}^{\sqrt{11.25^{2}-x^{2}}} \int_{0}^{(11.25-x)} d z d y d x \\
& =2 \int_{-3.75}^{11.25} \int_{0}^{\sqrt{11.25^{2}-x^{2}}}[(11.25-x)-0] d y d x \\
& =2 \int_{-3.75}^{11.25}\left(11.25^{2}-x^{2}\right)^{1 / 2}(11.25-x) d x
\end{aligned}
$$

Expanding the integral,

$$
\begin{aligned}
V_{1}= & 2 \int_{-3.75}^{11.25} 11.25\left(11.25^{2}-x^{2}\right)^{1 / 2} d x+ \\
& -2 \int_{-3.75}^{11.25} x\left(11.25^{2}-x^{2}\right)^{1 / 2} d x
\end{aligned}
$$

Each integral in Equation 3.3.30 will be evaluated separately, so let,

$$
\begin{aligned}
& \text { Integral \#1 }=22.5 \int_{-3.75}^{11.25}\left(11.25^{2}-x^{2}\right)^{1 / 2} d x \\
& \text { Integral \#2 }=2 \int_{-3.75}^{11.25} x\left(11.25^{2}-x^{2}\right)^{1 / 2} d x
\end{aligned}
$$

Evaluating Integral \#1 using trigonometric substitution:

$$
\begin{aligned}
\text { Let } x= & 11.25 \sin \theta \\
& x^{2}=11.25^{2}(\sin \theta) \\
& d x=11.25(\cos \theta) d \theta \\
& \text { when } x=11.25, \theta=\pi / 2 \\
& \text { when } x=-3.75, \theta=-0.3398
\end{aligned}
$$

Substituting these values into Equation 3.3.31,

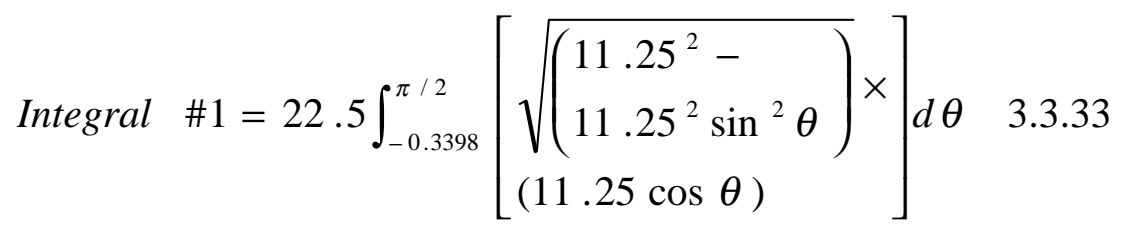

But, 


$$
\begin{aligned}
\sqrt{11.25^{2}-11.25^{2} \sin ^{2} \theta}=\sqrt{11.25^{2}\left(1-\sin ^{2} \theta\right)} \\
=\sqrt{11.25^{2} \cos ^{2} \theta}=11.25 \cos \theta
\end{aligned}
$$

Substituting Equation 3.3.34 into Equation 3.3.33,

$$
\begin{aligned}
& \text { Integral \#1 }=22.5 \int_{-0.3398}^{\pi / 2}\left(11.25^{2} \cos ^{2} \theta\right) d \theta= \\
& =22.5 \int_{-0.3398}^{\pi / 2} \frac{11.25^{2}}{2}(1+\cos 2 \theta) d \theta \\
& \text { Integral } \# 1=\left.22.5\left(\frac{11.25^{2}}{2}\right)\left[\theta+\frac{1}{2} \sin 2 \theta\right]\right|_{-0.3398} ^{\pi / 2}= \\
& =22.5\left(\frac{11.25^{2}}{2}\right)\left[\frac{\pi}{2}-(-0.3398-0.3142)\right] \\
& \text { Integral } \# 1=22.5\left(\frac{11.25^{2}}{2}\right)[140.8] \\
& \text { Integral } \# 1=3168
\end{aligned}
$$

The second integral was evaluated as follows:

$$
\text { Integral \#2 }=2 \int_{-3.75}^{11.25} x\left(11.25^{2}-x^{2}\right)^{1 / 2} d x
$$

Using U substitution

$$
\begin{aligned}
& \text { Let } \mathrm{U}=11.25^{2}-\mathrm{x}^{2} \\
& \mathrm{dU}=-2 \mathrm{x} d \mathrm{x} \\
& -1 / 2 \mathrm{dU}=\mathrm{x} \mathrm{dx} \\
& \text { when } \mathrm{x}=11.25, \mathrm{U}=0 \\
& \text { when } \mathrm{x}=-3.75, \mathrm{U}=112.5
\end{aligned}
$$

Substituting these values and into Equation 3.3.38, the following equation is produced:

$$
\begin{aligned}
& \text { Integral } \# 2=2 \int_{112.5}^{0}-\frac{1}{2} U^{1 / 2} d U \\
& =-\left.\frac{2}{3} U^{3 / 2}\right|_{112.5} ^{0}=-\left.\frac{2}{3}\left(11.25^{2}-x^{2}\right)^{3 / 2}\right|_{-3.75} ^{11.25}
\end{aligned}
$$




$$
\begin{aligned}
\text { Integral \#2 } & =-\frac{2}{3}\left[0-\left(11.25^{2}-(-3.75)^{2}\right)^{3 / 2}\right] \\
& =\frac{2}{3}(1193)=795
\end{aligned}
$$

The volume, $\mathrm{V}_{1}$, may now be calculated by subtracting the two integrals as follows:

$$
\begin{aligned}
& V_{1}=\text { Integral } \# 1-\text { Integral } \# 2=3168-795 \\
& V_{1}=2373 \mathrm{in}^{3}=38.9 \mathrm{~L}
\end{aligned}
$$

Volume $\mathrm{V}_{2}$ shown in Figure 3.3.4 is bounded by the planes $\mathrm{x}=-3.75, \mathrm{z}=0$, and $\mathrm{z}$ $=15$ as well as by the projected circle, $y=\sqrt{11.25^{2}-x^{2}} \cdot \mathrm{V}_{2}$ was determined by evaluating the following triple integral (note again that the volume is symmetric about the $x z$ plane):

$$
\begin{aligned}
V_{2} & =2 \int_{-11.25}^{-3.75} \int_{0}^{\sqrt{11.25^{2}-x^{2}}} \int_{0}^{15} d z d y d x \\
V_{2} & =2 \int_{-11.25}^{-3.75} 15 \sqrt{11.25^{2}-x^{2}} d x \\
& =30 \int_{-11.25}^{-3.75} \sqrt{11.25^{2}-x^{2}} d x
\end{aligned}
$$

This integral has been evaluated previously (see Equation 3.3.30), with the only difference being the coefficient. The final form is given in Equation 3.3.36. Using this form, the following equation is obtained:

$$
\begin{aligned}
V_{2} & =\left.30\left(\frac{11.25^{2}}{2}\right)\left[\theta+\frac{1}{2} \sin 2 \theta\right]\right|_{-\pi / 2} ^{-0.3398}= \\
& =30\left(\frac{11.25^{2}}{2}\right)\left[(-0.3398-0.3142)-\left(-\frac{\pi}{2}\right)\right] \\
V_{2} & =30(58.02)=1740 \mathrm{in}^{3}=28.5 \mathrm{~L}
\end{aligned}
$$

Volumes $\mathrm{V}_{1}$ and $\mathrm{V}_{2}$ can be combined to yield the volume of the surge tank above the plate, $\mathrm{V}_{\text {comb }}$ : 


$$
V_{\text {comb }}=V_{1}+V_{2}=2373+1740=4113 \text { in }^{3}=17.8 \mathrm{gal}=67.4 \mathrm{~L}
$$

This combined volume value can be checked by calculating the dead volume, $\mathrm{V}_{\text {dead }}$, beneath the plate and subtracting this volume from the volume of a $22.5 "(57.2 \mathrm{~cm})$ cylinder with 15 " length $(38.1 \mathrm{~cm})$. The dead volume is bounded by the planes $\mathrm{z}=15$ and $\mathrm{z}=11.25-\mathrm{x}$ as well as the projected circle $y=\sqrt{11.25^{2}-x^{2}}$. This volume was calculated by solving the following integrals:

$$
\begin{aligned}
V_{\text {dead }}= & 2 \int_{-3.75}^{11.25} \int_{0}^{\sqrt{11.25^{2}-x^{2}}} \int_{(11.25-x)}^{15} d z d y d x= \\
= & 2 \int_{-3.75}^{11.25} \int_{0}^{\sqrt{11.25^{2}-x^{2}}} 15-(11.25-x) d y d x \\
= & 2 \int_{-3.75}^{11.25}(3.75+x)\left(11.25^{2}-x^{2}\right) d x \\
V_{\text {dead }}= & 7.5 \int_{-3.75}^{11.25}\left(11.25^{2}-x^{2}\right)^{1 / 2} d x+ \\
& 2 \int_{-3.75}^{11.25} x\left(11.25^{2}-x^{2}\right)^{1 / 2} d x
\end{aligned}
$$

Both of the integrals on the right hand side of Equation 3.3.45 have been evaluated previously (see Equations 3.3.31 and 3.3.32). If the evaluated integrals (Equations 3.3.37 and 3.3.40, respectively) are substituted into Equation 3.3.45 the following result is obtained:

$$
V_{\text {void }}=7.5[140.8]+[795]=1851 \mathrm{in}^{3}=30.3 \mathrm{~L}
$$

The volume of a cylinder, $\mathrm{V}_{\text {cyl }}, 15 "(38.1 \mathrm{~cm})$ long with $22.5 "(57.2 \mathrm{~cm})$ diameter can be calculated as follows:

$$
V_{c y l}=\frac{\pi}{4}\left(22.5^{\prime \prime}\right)^{2} 15^{\prime \prime}=5964 \mathrm{in}^{3}=91.7 \mathrm{~L}
$$

The volume of the surge tank above the plate, $\mathrm{V}_{\mathrm{comb}}$, can be determined by subtracting the dead volume from the cylinder volume: 


$$
\begin{aligned}
V_{c o m b} & =V_{c y l}-V_{\text {dead }}=5964-1851=4113 \mathrm{in}^{3} \\
& =67.4 \mathrm{~L}
\end{aligned}
$$

This agrees with the result that was previously obtained.

The overall length of the surge tank can be determined by calculating the necessary length, $\mathrm{L}_{3}$, of volume, $\mathrm{V}_{3}$, shown in Figure 3.3.4 to create a surge tank with a total volume of 30 gallons $\left(6930 \mathrm{in}^{3}=113.6 \mathrm{~L}\right)$. This length, $\mathrm{L}_{\text {surge, }}$ was determined as follows:

$$
V_{\text {surge }}=\frac{\pi}{4} d_{\text {surge }}^{2} L_{3}+V_{\text {comb }}
$$

where,

$$
\begin{aligned}
& \mathrm{V}_{\text {surge }}=\text { total surge tank volume }=6930 \mathrm{in}^{3}=113.6 \mathrm{~L} \\
& \mathrm{D}_{\text {surge }}=\text { surge tank diameter }=22.5^{\prime \prime}=57.2 \mathrm{~cm}
\end{aligned}
$$

Using these values, the length, $\mathrm{L}_{3}$, was calculated to be 7.08 " $(18.0 \mathrm{~cm})$. The total surge tank length, $\mathrm{L}_{\text {surge, }}$ was calculated as,

$$
L_{\text {surge }}=15^{\prime \prime}+L_{3}=22.08 " \cong 22 "=55.9 \mathrm{~cm}
$$

\subsubsection{In-cell Microwave Attenuation Assembly}

The preliminary test matrix for this research included a large amount of regeneration testing which was to be performed with the trap connected to the engine exhaust system as shown in Figure 3.3.2. Tests which were to be performed using this regeneration system were termed "in-cell tests," referring to regeneration performed within the confines of the test cell. Using this system, the magnetron was to be activated after the soot loading period, heating the soot near the front of the filter above the ignition temperature. The oxygen required for the convective combustion portion of the regeneration event was to be provided via the engine exhaust. One of the challenges 
associated with this system was to develop a method of attenuating the microwaves which pass through the filter during the preheating portion of the regeneration process. A perforated plate could have been positioned at the outlet end of the filter, but this would have increased the total exhaust backpressure and would have reflected some of the microwaves in the direction of the magnetron antenna, decreasing the magnetron lifetime. Due to its large dielectric loss factor and specific heat values, water is an ideal candidate for microwave absorption and subsequent energy storage. The challenge was to introduce water into the bypass line only during the regeneration portion of the testing, in a manner which would not increase the exhaust backpressure substantially and which would not damage any of the exhaust system components. The water trap, shown in Figure 3.3.2, was the device used to hold the water during in-cell regeneration. Water filled only the lower portion of the trap, so the exhaust passed freely over the surface of the water while the microwaves transmitted to the water trap were absorbed. Space constraints limited the length of the water trap considerably, so water evaporation during extended preheating times with simultaneous exhaust flow introduced at high temperatures and flow rates was a concern. In order to overcome this difficulty, it was decided that a constant flow of water flow through the trap had to be provided in order to allow a large degree of test parameter flexibility (that is, longer preheating times, sequential preheating and convective combustion periods, higher exhaust flow rates, higher-temperature exhaust, etc.). The water flow had to be provided in such a way that trap overflow was not a possibility and the water level had to remain constant within the trap. The water source and level limiting system also had to inexpensive, reliable, and rapidly fabricated. Figure 3.3 .5 is a schematic of the water source and level limiting 
system which was designed and fabricated in accordance with the aforementioned specifications. Photographs of the water level limiting system and water trap are presented in Appendix A. 


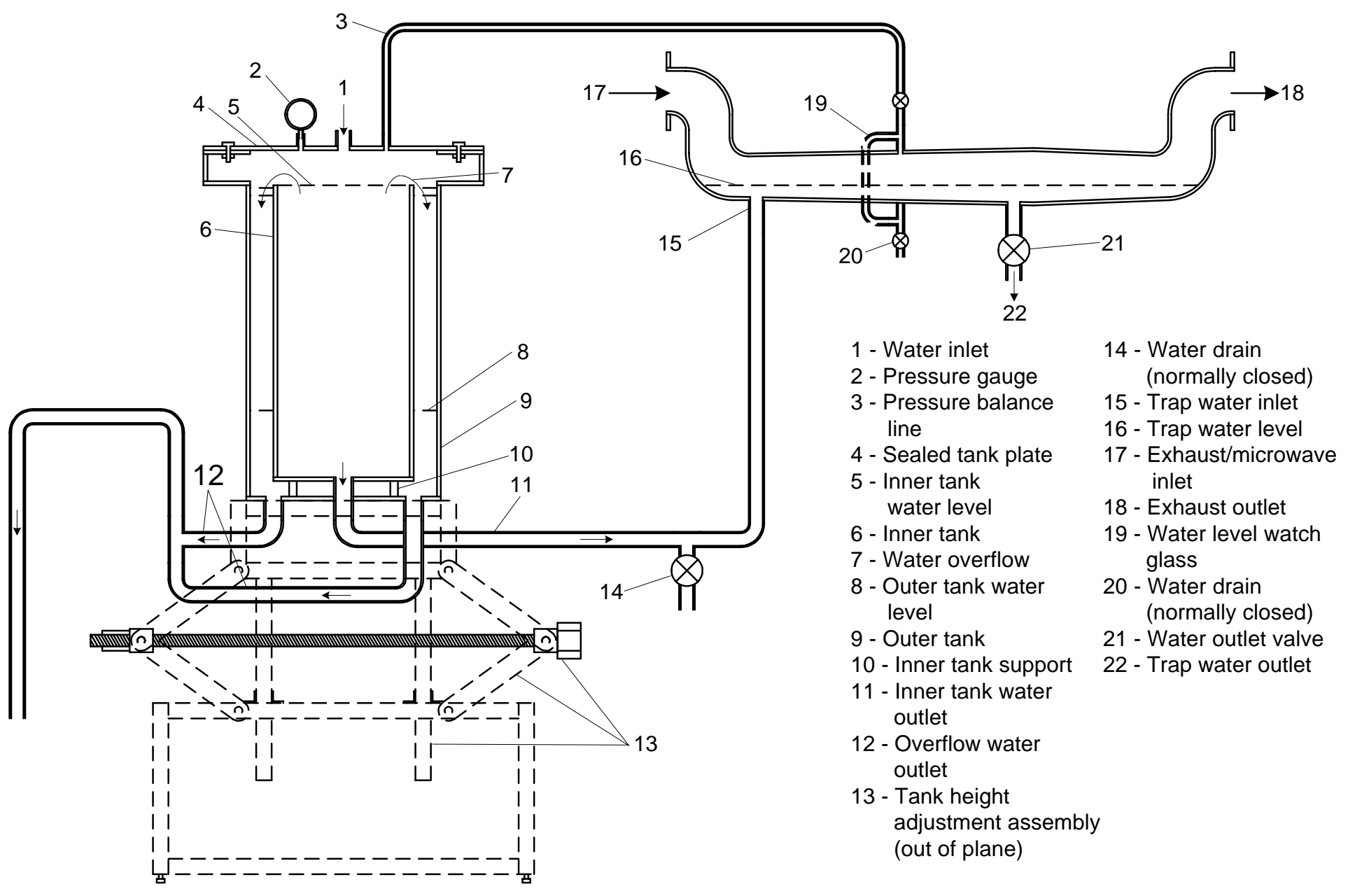

Figure 3.3.5: Microwave Water Trap and Water Supply Assembly 
The desired water level within the water trap was achieved by providing a constant flow of water into the inner water tank. The source water flow rate was sufficient to keep the inner tank overflowing with water at all times. The overflow water was drained from the tank via gravity through multiple water drains in the bottom of the outer tank. The water drain hoses were positioned such that some overflow water was present in the outer tank at all times. This allowed the tank to be slightly pressurized via the pressure balance line. The pressure balance line was used to equalize the pressures in the water tank and the water trap in order to maintain the water level at the set value under all exhaust flow conditions. Source water for the water trap was provided via a transfer line connected to a water outlet in the bottom of the inner tank. Large diameter tubing was used for the transfer line, so the permanent pressure loss through the line at the low flow rates which were used was negligible. Water flow through the trap was regulated by adjusting the position of a gate valve placed in the water outlet of the trap. A watch glass was used to monitor the water level. The water level was adjusted by initiating the source water flow to the inner tank and adjusting the height of the water tank until the desired water level was attained. Once the water level was set under static conditions, no further water tank height adjustment was needed when exhaust or air flowed through the trap due to the pressure balance between the water trap and the water tank.

A microwave leak detector was used to determine the effectiveness of the water trap during magnetron activation by measuring microwave radiation which would be transmitted, if at all, past the water trap. Experiments showed that no measurable microwave radiation was transmitted past the trap, so the trap was deemed capable of providing safe levels of microwave irradiation in the test cell during magnetron 
activation. The water trap was drained during filter loading. Therefore, it served simply as an exhaust transfer tube during most of the test sequence.

Due to the lack of data concerning the effects microwave regeneration parameters such as preheating time, airflow rate, airflow temperature, and initial soot load, a test matrix of a more fundamental nature was proposed for the research presented in this thesis. For this reason, the water trap and water leveling system were not required for the research presented here. The water trap was to be used in subsequent microwave regeneration research efforts (Popuri, 1999). However, Popuri (1999) conducted his tests at low exhaust flow rates, and therefore, water flow through the trap was not required. For this reason, the water leveling system has not been used in any documented microwave regeneration tests to-date. However, due to its novelty, it has been presented here for academic purposes.

\subsubsection{Exhaust Multiple-inlet Sliding Gate Valve}

Also shown in Figure 3.3.2 is the relative placement of a sliding gate valve. This valve was designed and fabricated at West Virginia University as an inexpensive means of preventing substantial backflow through the exhaust bypass line when the filter housing was not in position during engine operation. Examples of instances when the gate valve was used were troubleshooting and basic system performance checks. The valve was also used as a means of reintroducing the bypass exhaust into the main exhaust flow with minimal permanent pressure loss. A photograph and cross-sectional diagram of the valve are shown in Appendix A. The valve contained inlets from two exhaust bypass lines, although only one of the inlets was used in this research. The second inlet 
was provided for other research projects which were simultaneously being performed using the same engine and exhaust system. The valve gate could be positioned so that both bypass inlets were closed, or such that either of the two inlets were open (although not simultaneously).

\subsubsection{Exhaust Bypass Flow Control System}

The necessity of an exhaust splitting scheme for this particular engine and filtration application was discussed previously, but the details of the design and development of the automated exhaust splitting system are presented in this section. A high temperature, stainless steel, 4 " $(10.2 \mathrm{~cm})$ internal diameter butterfly valve manufactured by Krom-Schroder was the mechanism used to increase the restriction of the exhaust flow through the main exhaust line which forced more exhaust flow through the bypass line, and hence, the filter (see Figure 3.3.2). A stepper motor was chosen as the device used to actuate the valve due to its high holding torque and high resolution in terms of angular displacement relative to other motors such as servo motors. In order to specify an appropriate stepper motor, it was necessary to determine the torque requirement of the system. The torque requirement included the torque required to accelerate the valve assembly to the next incremental position of the stepper motor, and the torque required to hold the valve in position at all exhaust flow conditions. The torque required to accelerate the valve assembly, $\mathrm{T}_{\mathrm{a}}$, was calculated as follows (Oriental Motor General Catalog, 1997):

$$
T_{a}=\left(\frac{J_{0}+J_{L}}{g}\right)\left(\frac{\pi \theta_{s}}{180^{o}}\right) \frac{f_{2}-f_{1}}{t_{1}}
$$

where,

$$
\mathbf{J}_{0}=\text { polar moment of inertia of stepper motor rotor }
$$




$$
\begin{aligned}
& \mathrm{J}_{\mathrm{L}}=\text { polar moment of inertia of valve assembly } \\
& \mathrm{g}=\text { gravitational constant }=9.81 \mathrm{~m} / \mathrm{s}^{2} \\
& \theta_{\mathrm{s}}=\text { step increment } \\
& \mathrm{f}_{2}=\text { operating pulse frequency } \\
& \mathrm{f}_{1}=\text { starting pulse frequency } \\
& \mathrm{t}_{1}=\text { acceleration/deceleration period }
\end{aligned}
$$

It was decided that the stepper motor should be capable of rotating the valve from fullyopen to fully-closed in $2.5 \mathrm{~s}$ or less. The total range of motion encompassed $87.3^{\circ}$. The valve was constrained from rotating the full $90^{\circ}$ in order to allow some area for flow through the valve in the event of stepper motor malfunction. The 2-phase stepper motor under consideration was capable of a rotational resolution of $1.8^{\mathrm{o}}$ in full-step mode (2 phase excitation) and $0.9^{\circ}$ in half-step mode (1-2 phase excitation). If half-step mode was used to provide higher resolution $\left(\theta_{\mathrm{s}}=0.9^{\circ}\right)$, the total number of steps which had to occur in the $2.5 \mathrm{~s}$ time limit was $87.3^{\circ} /\left(0.9^{\circ} /\right.$ step $)=97$ steps. The necessary operating frequency, $\mathrm{f}_{2}$, and the period for one step, $\mathrm{T}_{1 \text { step }}$, were calculated as follows:

$$
\begin{aligned}
& f_{2}=\frac{\# \text { steps }}{\text { total time }}=\frac{97 \text { steps }}{2.5 \mathrm{~s}}=38.8 \mathrm{~Hz} \\
& T_{1_{\text {step }}}=\frac{1}{f_{2}}=0.0258 \mathrm{~s}
\end{aligned}
$$

An appropriate estimate of the acceleration/deceleration time is $25 \%$ of the event time (Oriental Motor General Catalog, 1997). In this case the event time is 0.0258s, so the time required for acceleration/deceleration was estimated as $t_{1}=(25 \%)(0.0258 \mathrm{~s})=$ $0.00644 \mathrm{~s}$.

For the type of operation required for this application, the starting frequency, $\mathrm{f}_{1}$, was zero because the exhaust butterfly valve was incrementally activated. The flow readings from the orifice meters were used to calculate the exhaust split ratio (ratio of exhaust flow rate through the bypass line to the exhaust flow rate through the main 
exhaust line). This value was compared to the target exhaust split ratio, and if the actual value was outside of the allowable range, the stepper motor/valve assembly was incrementally activated until the target value was reached. In each instance the stepper motor/butterfly valve assembly was stationary prior to activation, so the starting frequency was zero.

The polar inertia of the valve assembly was calculated by considering the geometries and densities of the various components. A schematic of the automated valve system is given in Figure 3.3.6:

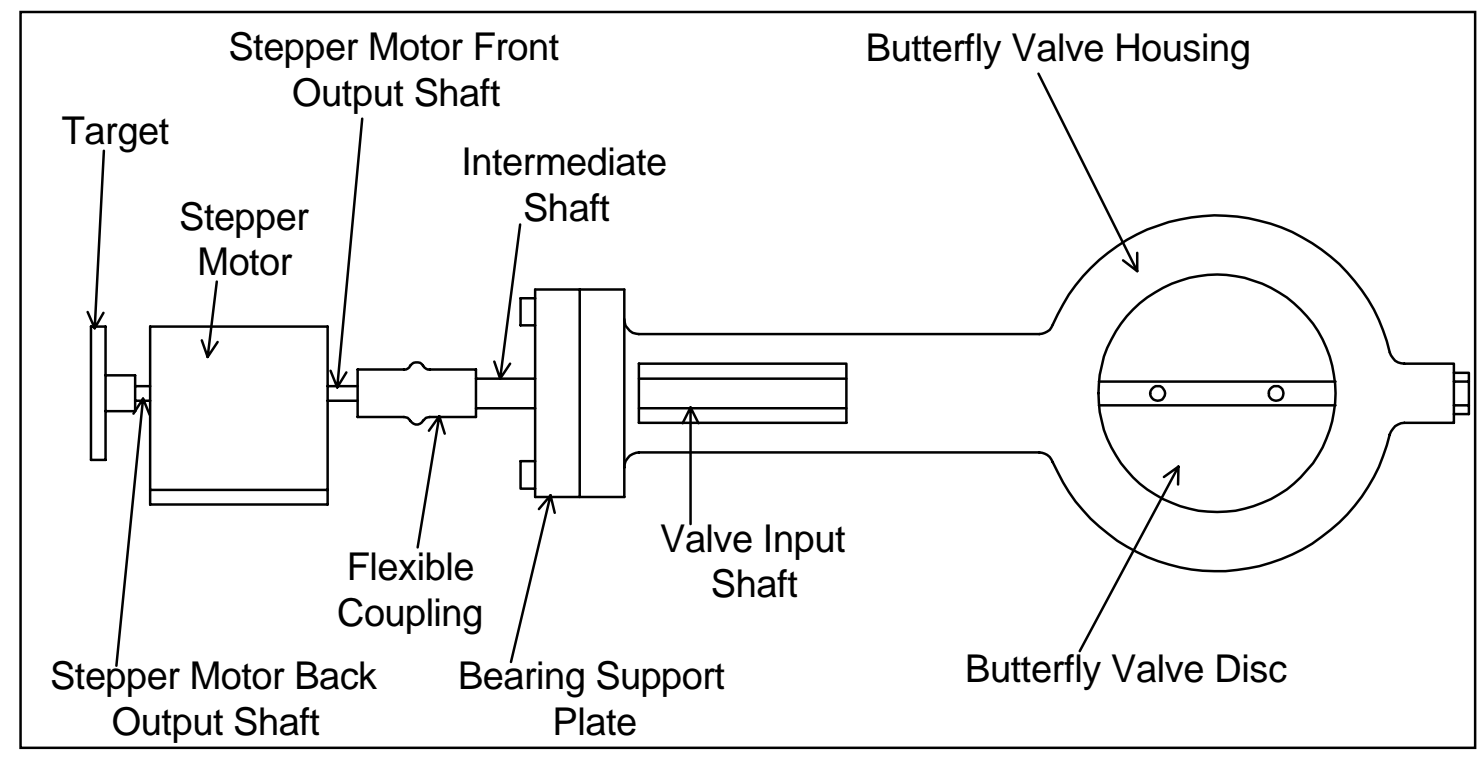

Figure 3.3.6: Automated Exhaust Valve System

The components of interest were the stainless steel butterfly valve disc (plate) and shaft, and a steel intermediate shaft. The butterfly valve shaft was bolted to the butterfly valve plate in order to provide a means of rotating the valve plate. A bearing-mounted intermediate shaft was used to connect a flexible coupling, which was attached to the 
output shaft of the stepper motor, to the valve shaft. A flexible coupling was used to negate any misalignment between the stepper motor and the intermediate shaft. The flexible coupling was made of rubber, so the polar moment of inertia associated with this component was neglected. The combined polar moment of inertia of the rest of the assembly was calculated as follows (Oriental Motor General Catalog, 1997):

$$
\begin{aligned}
J_{L}= & J_{v l v}+J_{v l v s h f t}+J_{\text {int shft }} \\
J_{L}= & \frac{1}{4}\left[\rho_{s s}\left(\frac{\pi}{4} D_{v v l v}^{2}\right) t_{v l v}\right]\left(\frac{D_{v l v}^{2}}{4}+\frac{t_{v l v}^{2}}{3}\right)+ \\
& \frac{\pi}{32} \rho_{s s}\left(L_{v l v s h t t}\right) D_{v l v ~ s h f t}^{4}+\frac{\pi}{32} \rho_{s} L_{\text {int shft }} D_{\text {int shft }}^{4}
\end{aligned}
$$

where,

$\mathbf{J}_{\mathrm{vlv}}=$ polar moment of inertia of the valve plate

$\mathrm{J}_{\mathrm{vlv} \text { shft }}=$ polar moment of inertia of the valve shaft

$\mathrm{J}_{\text {int shft }}=$ polar moment of inertia of the intermediate shaft

$\rho_{\mathrm{ss}}{ }^{\dagger}=$ density of stainless steel $=7920 \mathrm{~kg} / \mathrm{m}^{3}=4.58 \mathrm{oz} / \mathrm{in}^{3}$

$\rho_{\mathrm{s}}=$ density of steel $=7860 \mathrm{~kg} / \mathrm{m}^{3}=4.55 \mathrm{oz} / \mathrm{in}^{3}$

$D_{\text {vlv }}=$ valve plate diameter $=4 "=10.2 \mathrm{~cm}$

$\mathrm{t}_{\mathrm{vlv}}=$ valve plate thickness $=0.25 "=0.64 \mathrm{~cm}$

$\mathrm{L}_{\mathrm{vlv} \text { shft }}=$ length of valve shaft $=6 "=15.2 \mathrm{~cm}$

$\mathrm{D}_{\text {vlv shft }}=$ valve shaft diameter $=0.5 "=1.3 \mathrm{~cm}$

$\mathrm{L}_{\text {int shft }}=$ length of intermediate shaft $=2 "=5.1 \mathrm{~cm}$

$\mathrm{D}_{\text {int shft }}=$ diameter of intermediate shaft $=0.5 "=1.3 \mathrm{~cm}$

Substituting the given values into Equation 3.3.52, the polar moment of inertia of

the valve assembly was calculated as $14.6 \mathrm{oz}-\mathrm{in}^{2}$. The final term necessary to solve Equation 3.3.50 is the polar moment of inertia of the stepper motor rotor. The stepper motor under consideration was model number CSK266BT manufactured by Oriental Motor Corporation. The polar moment of inertia of the rotor was listed as $1.64 \mathrm{oz}-\mathrm{in}^{2}$. Substituting the appropriate values into Equation 3.3.50, the torque required to accelerate the butterfly valve assembly from a stationary position within the mandatory time frame was calculated as $T_{a}=3.98$ oz-in . 
A second torsional value which had to be generated by the stepper motor was the torque placed on the valve shaft by the exhaust flow passing through the valve. In order to determine this value, a temporary $1 "(2.54 \mathrm{~cm})$ diameter intermediate shaft was connected to the valve shaft. The valve was composed of steel, and it was supported by ball bearings mounted in pillow blocks which were bolted to the valve support frame after the intermediate shaft was vertically aligned with the valve shaft using aluminum spacers. Four strain gauges were attached to the end of the shaft opposite of the valve in the following configuration ${ }^{\dagger \dagger}$ :

\footnotetext{
${ }^{\dagger}$ Density values taken from Mechanics of Materials by F.P. Beer and E.R. Johnston, Jr., 1981

${ }^{\dagger \dagger}$ Diagrams based on information from Mechanical Measurements, $5^{\text {th }}$ ed. by T.G. Beckwith et al., 1993
} 


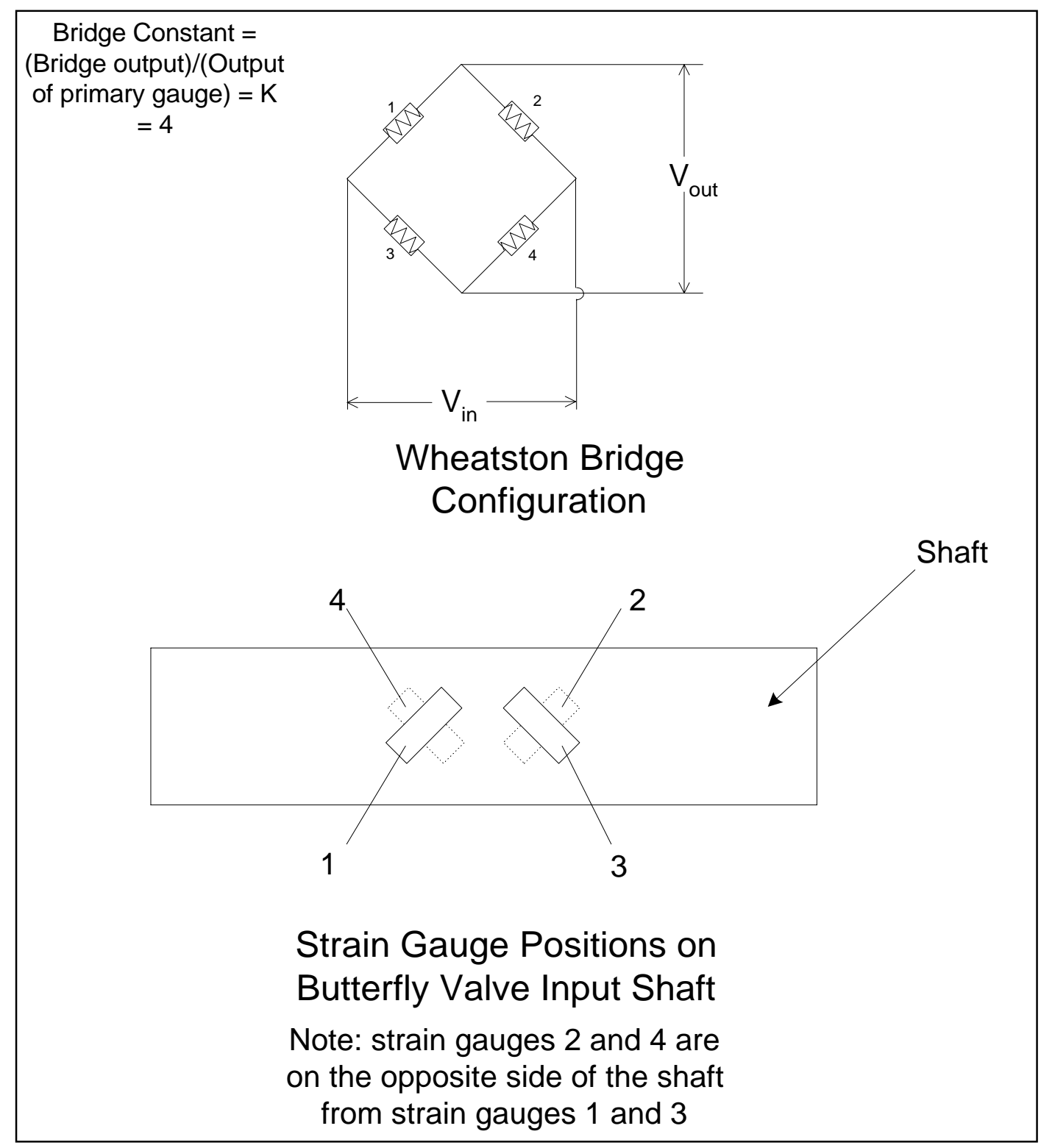

Figure 3.3.7: Strain Gauge Placement on the Butterfly Valve Input Shaft (Beckwith et al., 1993)

Voltage input was provided at the connection point between strain gauges 1 and 3 and at the junction between gauges 2 and 4 . The output voltage was measured at the junction between strain gauges 1 and 2 and at the junction between 3 and 4 . The output voltage was related to the resistance change of each strain gauge caused by the strain associated with the imposed torque on the shaft in the following manner (Beckwith et al., 1993): 


$$
V_{\text {out }}=\frac{V_{\text {in }}}{4}\left(\frac{\Delta R_{1}}{R_{1}}-\frac{\Delta R_{2}}{R_{2}}-\frac{\Delta R_{3}}{R_{3}}+\frac{\Delta R_{4}}{R_{4}}\right)
$$

where,

$\mathrm{V}_{\text {out }}=$ Wheatstone bridge output voltage

$\mathrm{V}_{\text {in }}=$ Wheatstone bridge input voltage

$\Delta \mathrm{R}=$ resistance change of a given strain gauge

$\mathrm{R}=$ unloaded resistance of a given strain gauge

The gauge factor, which is typically specified by the strain gauge manufacturer, is used to relate the bridge output voltage to the imposed shaft strain. The gauge factor is defined

as:

$$
F=\frac{1}{\varepsilon} \frac{\Delta R}{R}
$$

where,

$$
\begin{aligned}
& \mathrm{F}=\text { gauge factor (typically has a value near } 2.0 \text { ) } \\
& \varepsilon=\text { strain }
\end{aligned}
$$

For this application, all four strain gauges were identical. In this case, if Equation 3.3.54 is solved for $\Delta \mathrm{R} / \mathrm{R}$ and substituted into Equation 3.3.53, the following relation between the bridge output voltage and the generated strain is obtained:

$$
V_{\text {out }}=\frac{V_{\text {in }}}{4} F\left(\varepsilon_{1}-\varepsilon_{2}-\varepsilon_{3}+\varepsilon_{4}\right)
$$

Because torsion alone was imposed on the shaft, the following relation for the maximum shear stress generated along the entire shaft was valid (assuming that the ball bearings did not impose any counter torques):

$$
\tau=\frac{T c}{J}
$$

where,

$\tau=$ maximum shear stress on shaft surface

$\mathrm{c}=$ shaft radius 


$$
\mathrm{J}=\text { polar moment of inertia of the shaft about the centerline }
$$

Mohr's circle for circular shafts with torsional loading is given as follows $\stackrel{\ddagger}{\ddagger}$ :

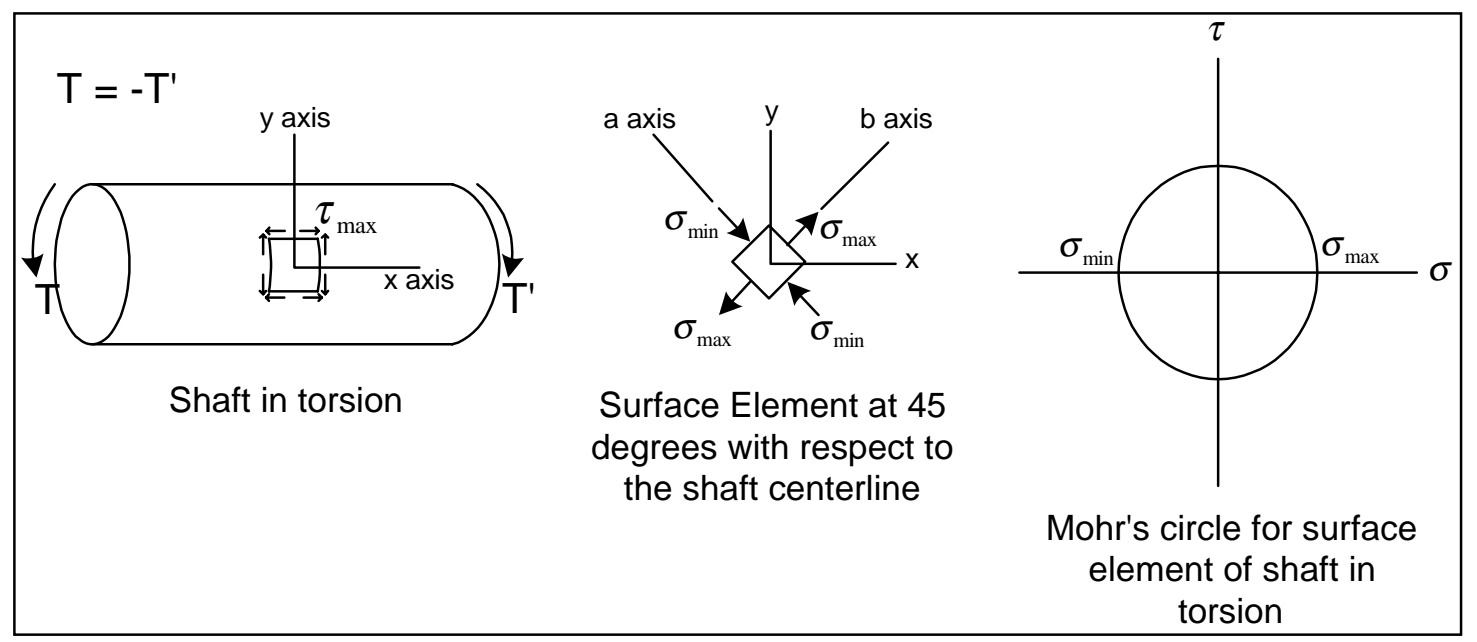

Figure 3.3.8: Stress Analysis of a Shaft in Torsion (Beer and Johnston, 1981)

It is apparent from the Mohr's circle for this loading that the maximum and minimum values for the longitudinal stress are equivalent to the maximum value of the shearing stress:

$$
\begin{aligned}
& \left|\sigma_{\text {max }}\right|=\left|\sigma_{\text {min }}\right|=|\tau| \\
& \sigma_{\text {max }}=-\sigma_{\text {min }}=\sigma
\end{aligned}
$$

It is also apparent that the strain gauges are located such that they are along the axes of maximum longitudinal stress, which is at a $45^{\circ}$ angle to the shaft centerline (see Figure 3.3.7). It can be seen from Figure 3.3.8, that the surface element shown in the diagram is biaxially stressed. The relationship between the longitudinal stress and the corresponding longitudinal strain for this state of stress is given by:

\footnotetext{
$\$$ Diagram based on information provided in Mechanics of Materials by F.P. Beer and E.R. Johnston, Jr., 1981
} 


$$
\begin{aligned}
& \varepsilon_{a}=\frac{1}{E}\left(\sigma_{\max }-v \sigma_{\text {min }}\right) \\
& \varepsilon_{a}=-\varepsilon_{b}=\varepsilon \\
& \varepsilon=\frac{\sigma}{E}(1+v)
\end{aligned}
$$

where,

$$
\begin{aligned}
& \varepsilon_{\mathrm{a}}=\text { strain generated by the longitudinal stress along the axis } a \\
& v=\text { Poisson's ratio for shaft material (steel) } \\
& \mathrm{E}=\text { modulus of elasticity of the shaft material (steel) }
\end{aligned}
$$

The strain along the axis $b$ in Figure 3.3 .8 would cause a change in resistance of the corresponding strain gauge. In this case it would cause the strain gauge to extend.

Another strain gauge was located along axis $a$. In this instance, the strain gauge would be compressed (negative strain). This would result in a change in resistance which was equal in value but opposite in sign to that of the strain gauge mounted along the axis $b$. The strain gauges mounted on the opposite side of the shaft also had equal values but opposite signs. It is apparent from Equation 3.3.53 that the opposing signs actually added to the voltage output, which increased the output signal strength. Equations 3.3.56 and 3.3.58 can be combined to yield:

$$
\left|\tau_{\max , \min }\right|=\left|\sigma_{\max , \min }\right|=\frac{\varepsilon E}{(1+v)}=\frac{T c}{J}
$$

Solving for the applied torque,

$$
T=\frac{J \varepsilon E}{c(1+v)}
$$

where,

$$
\begin{aligned}
& J=\frac{1}{32} \pi d_{\text {shft }, 2}^{4}=0.0982 \mathrm{in}^{4}=4.087 \mathrm{~cm}^{4} \\
& \mathrm{~d}_{\text {shft }, 2}=\text { shaft diameter }=1 "=2.54 \mathrm{~cm} \\
& \mathrm{E}=1 \times 10^{6} \mathrm{psi}=6.9 \times 10^{9} \\
& \mathrm{c}=0.5 "=1.3 \mathrm{~cm}
\end{aligned}
$$




$$
v_{\text {steel }}=0.261^{\S \S}
$$

Once the temporary shaft was in position with the strain gauges attached, the strain gauge leads were connected to a strain indicator box. The engine was operated at various (24.9 $\mathrm{kPa}$ ) conditions and the valve was rotated until the engine backpressure reached 100" $\mathrm{H}_{2} \mathrm{O}$. This backpressure was well beyond any backpressure which would be required during testing. The maximum holding torque was found to occur at rated speed and $100 \%$ load. The strain associated with this loading was measured as $4 \mu$ strains. Substituting the appropriate values into Equation 3.3.60, the torque required to hold the valve in position during the most severe shaft loading conditions was 0.623 in- $\mathrm{lb}=9.97$ oz-in. This torque value was superimposed upon the acceleration torque to give a stepper motor minimum required torque of $13.95 \mathrm{oz}-\mathrm{in}$. The bearings and seals used in conjunction with the valve shaft assembly generated very little friction, so the frictional torques were compensated by incorporating a safety factor into the analysis. A safety factor of 5 was chosen to ensure that the stepper motor could readily actuate the valve under all exhaust flow conditions, so the stepper motor required torque was 69.75 oz-in. The required torque was well below the stepper motor output torque capabilities in the required operating frequency range (graphs of maximum motor torque versus operating frequency were provided in the stepper motor manufacturer's catalog), so the stepper motor was more than adequate in terms of torque generation.

The final stepper motor specification involved the ratio of the polar moment of inertia of the valve assembly to the polar moment of inertia of the stepper motor rotor. If excessive inertia ratios are encountered, the motor may overshoot or undershoot the desired position. In this case the inertia ratio was calculated to be 8.9 which was less

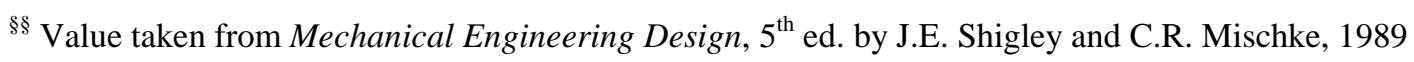


than the maximum inertia ratio specified by the manufacturer, so the stepper motor was deemed adequate for this application.

The stepper motor driver used to actuate the stepper motor was purchased with the motor. A schematic of the stepper motor control system is provided in Figure 3.3.9:

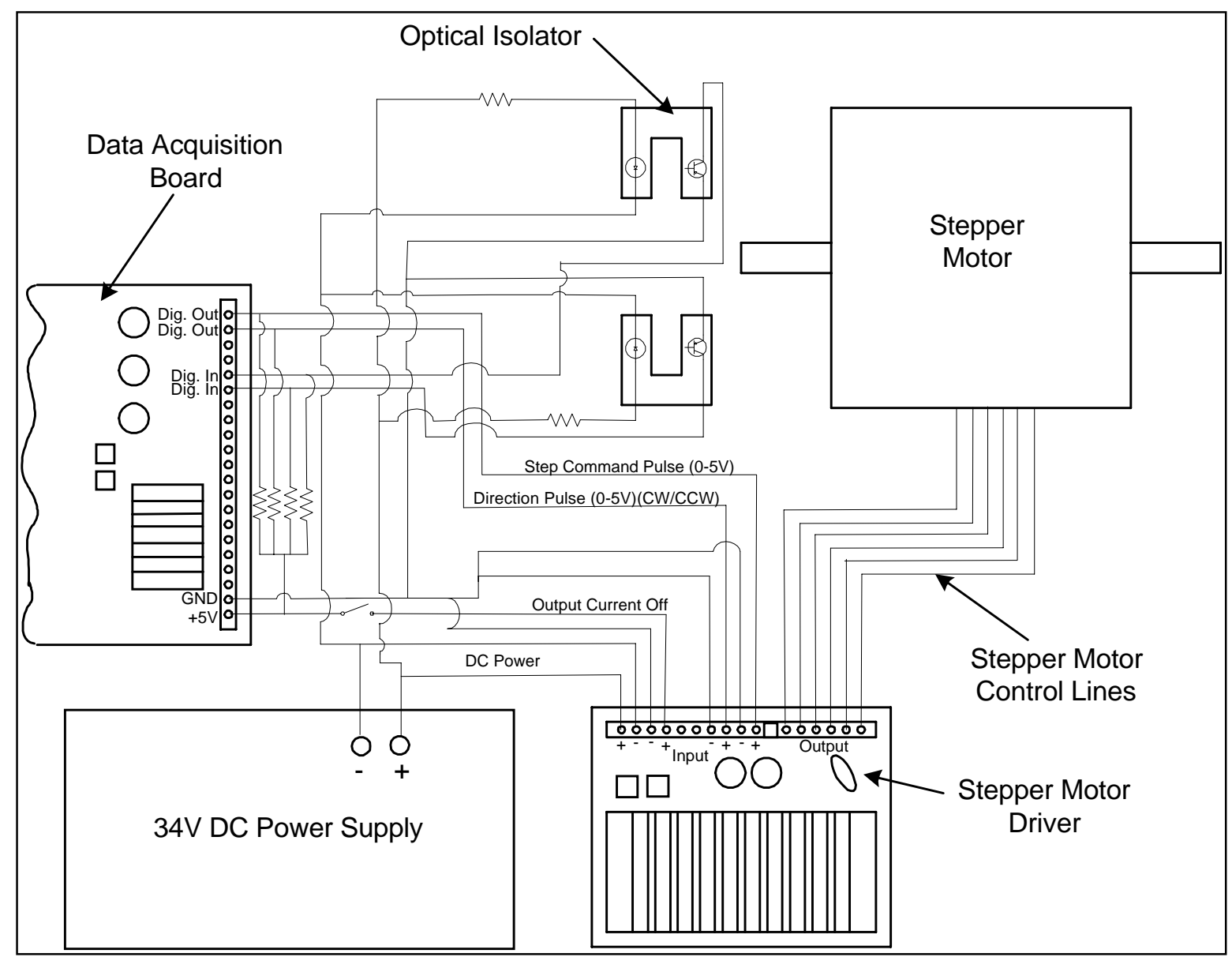

Figure 3.3.9: Stepper Motor Control Electrical Diagram

The stepper motor driver required three basic inputs: 36VDC power input (+/-10V), a direction pulse (0 to 5VDC), and a step command pulse (0 to 5VDC). The DC power input was used to power both the stepper motor driver and the stepper motor. The power supply was also used to operate the light emitting diodes (LED's) contained in the optical 
isolators, which will be discussed subsequently. A photograph of the power supply and power supply housing is contained in Appendix A. The step command pulse was used to actuate the stepper motor by one step for each five-volt input pulse. The direction pulse was used to dictate the direction of rotation of the stepper motor. A direction input pulse of five volts in conjunction with a five-volt step command input pulse resulted in clockwise rotation of the stepper motor. A direction input of zero volts in conjunction with a five-volt step command pulse resulted in counterclockwise rotation. Shielded twisted pair electrical lines were used to transmit the control signals in order to eliminate interference. The control signals were generated by the digital output terminals of an RTI 815 data acquisition board that was resident in the laboratory computer dedicated to this study. The digital output terminals were capable of absorbing much more current than they were capable of generating, so the board's constant five-volt supply terminal was used to provide the current required by the stepper motor driver. Resistors $(10 \mathrm{k} \Omega)$ were placed in the lines between the five-volt supply and each digital output terminal in order to limit the current supplied to the digital terminals. This arrangement provided a fivevolt output to the stepper motor controller when the digital output terminal operated at five volts. In this case, no current passed through the current-limiting resistor because both sides of the resistor had a voltage potential of five volts. In order to generate a pulse in the control signals, the digital output signals were set to zero volts. In this case, all the current provided by the constant five-volt supply terminal was grounded by the digital output terminals, so the motor driver pulsed input terminal had a potential of zero volts. The $10 \mathrm{k} \Omega$ resistors were used to limit the current absorbed by the digital output terminals. 
The operating condition of the digital output terminals was controlled by a Qbasic program which was written to control the exhaust split ratio during filter loading. A copy of this program is contained in Appendix F. This program acquired the pressure and temperature signals of the exhaust orifice meters and calculated the exhaust split ratio. The deviation of the exhaust split ratio from the target exhaust split ratio was calculated, and the desired number of steps for corrective action was determined from a look-up table within the program. After the stepper motor was activated, an iterative process was followed. The deviation of the exhaust split ratio from the target value was calculated again, and valve position adjustment was made if the deviation was outside the acceptable range.

Prior to each step, the digital input signals from two optical isolators (ECG3100) were analyzed in order to determine if the valve was in either of the limiting positions (fully-open or fully-closed). Optical isolators consist of an LED and a transistor on opposite sides of the device with an air gap between them. The light from the LED is focused on the transistor. If light from the LED reaches the transistor, the transistor essentially acts as a short circuit. If no light from the LED reaches the transistor, the transistor acts as on open circuit. This operation was used to control the input to the digital input terminals on the data acquisition board in order determine if the valve was in either of the limiting positions. The stepper motor contained two output shafts which were on opposing sides of the motor. One shaft was connected to the exhaust butterfly valve. A thin aluminum target was mounted on the opposing output shaft. This target was constrained to rotate between the LED's and transistors of both optical isolators, blocking the light transmitted from the LED. This resulted in the open condition of the 
transistor circuit. A small notch was machined in the target circumference, so if the stepper motor/valve assembly rotated to a position where the notch reached the optical isolator, light from the LED reached the transistor and the transistor circuit was grounded. The optical isolators were mounted approximately $87^{\circ}$ apart on an aluminum support which could be rotated about the centerline of the output shaft of the stepper motor. This allowed the fully-closed and fully-open position indications, given by the optical isolators, to be set initially based on the actual fully-open position of the butterfly valve. A photograph of the optical isolator support is provided in Appendix A. As shown in Figure 3.3.9, the 5-volt terminal of the data acquisition board was again used to create a 5-volt input to the digital input terminals connected to the optical isolator transistor circuit. Resistors $(10 \mathrm{k} \Omega)$ were again used to limit the current which was grounded by the digital input terminals when the transistor circuit was open. When the transistor circuit was grounded (that is, when light from the LED reached the transistor), essentially all the current provided by the five-volt supply passed through the transistor (short circuit condition) and into the grounding terminal of the board. This resulted in a digital input terminal voltage near zero volts when the target notch reached the optical isolator. This allowed the limiting positions of the stepper motor/valve assembly to be monitored in order to prevent overloading of the stepper motor. The power supply for the stepper motor and controller was also used to power the LED's contained in the optical isolators. The optical isolator manufacturer recommended a voltage of $1.5 \mathrm{~V}$ across the LED at $15 \mathrm{~mA}$. The supply voltage was $34 \mathrm{~V}$, so resistors were placed in the LED circuit to reduce the supply voltage and current to the manufacturer's recommendations. In this case the appropriate resistance for each LED circuit was calculated as follows: 


$$
R=\frac{34 V-1.5 V}{0.015 A}=2167 \Omega
$$

A combination of series and parallel standard resistors were used to create an equivalent resistance near the specified value.

A fourth stepper motor driver input, the output current-off input, was added for convenience. If a five-volt signal was applied to this terminal, the current was cut off to the stepper motor, which allowed the stepper motor to be rotated manually if necessary. This feature aided in troubleshooting and software development, because if the stepper motor driver was deactivated during an event such as a control malfunction, then three minutes were required before reactivation. The output current-off feature allowed the stepper motor driver to remain activated while the home position was reset.

The final design parameter considered for the exhaust splitting system was the cooling requirements for the stepper motor and driver. The stepper motor and driver were very sensitive to extreme temperatures, and for this reason they were placed in enclosures to decrease the heat transfer rates from the exhaust components. Fans mounted on the housings were used to increase the rate of convective heat transfer from the units. Air filters were incorporated in housings to minimize dust accumulation on the electrical components. Heat transfer via conduction through the butterfly valve shaft was also a concern. The flexible coupling used to connect the stepper motor to the intermediate shaft had a maximum temperature limitation of $160{ }^{\circ} \mathrm{F}\left(71{ }^{\circ} \mathrm{C}\right)$. The bearing used to support the intermediate shaft was also sensitive to extreme temperatures. To protect these components a design constraint of $160{ }^{\circ} \mathrm{F}\left(71{ }^{\circ} \mathrm{C}\right)$ maximum temperature was imposed on the tip of the butterfly valve shaft. In order to determine if external cooling was necessary, the butterfly valve shaft was modeled as a fin. The temperature 
profile of a constant cross-section, homogeneous, fin of constant properties with an insulated tip boundary condition ( $\mathrm{dT} / \mathrm{dx}=0$ at $\mathrm{x}=\mathrm{L})$ is given by Mills (1992):

$$
\begin{aligned}
& \frac{T-T_{e}}{T_{b}-T_{e}}=\frac{\cosh (\beta(L-x))}{\cosh (\beta L)} \\
& \text { where, } \\
& \mathrm{T}=\text { temperature at any x position on the fin } \\
& \mathrm{T}_{\mathrm{e}}=\text { temperature of the environment } \\
& \mathrm{T}_{\mathrm{b}}=\text { temperature at the base of the fin } \\
& \mathrm{L}=\text { length of the fin } \\
& \beta=\left(\mathrm{h}_{\mathrm{c}} \mathrm{P} / \mathrm{A}_{\mathrm{c}} \mathrm{k}\right) \\
& \mathrm{P}=\text { shaft perimeter }=\pi \mathrm{D}_{\text {sh }} \\
& \mathrm{A}_{\mathrm{c}}=\text { shaft cross sectional area }=\pi \mathrm{D}_{\text {sh }}{ }^{2} \\
& \mathrm{~h}_{\mathrm{c}}=\text { convective heat transfer coefficient } \\
& \mathrm{k}=\text { thermal conductivity of the fin }
\end{aligned}
$$

The insulated tip condition is a valid approximation because the area of the tip of the shaft is much less than the shaft perimeter surface area. It was assumed that the temperature was constant at every axial point along the shaft (radial temperature gradients $=0$ ), and the radiative heat transfer effects were neglected. To determine if any cooling mechanism was necessary, the initial convective heat transfer coefficient was based on natural convection. The natural convection heat transfer coefficient is a function of the Raleigh number, Ra, which is defined to be the product of the Grasshof number, Gr, and the Prandtl number, Pr. The Grasshof number is a dimensionless constant which is a ratio of buoyant forces to viscous forces. The Prandtl number is a ratio of momentum and thermal diffusivities (Mills, 1992). The Raleigh number for a convective heat transfer from a horizontal shaft may be written (Mills, 1992),

$$
\begin{aligned}
& R a_{D}=\frac{\beta_{\text {nat }} \Delta T g D_{s h}^{3}}{v^{2}} \operatorname{Pr} \\
& \text { where, } \\
& \quad \begin{array}{l}
\beta_{\text {nat }}=1 / \mathrm{T}_{\mathrm{av}} \\
\mathrm{T}_{\mathrm{av}}=\text { mean film temperature } \\
\mathrm{g}=\text { gravitational constant }=9.81 \mathrm{~m} / \mathrm{s}^{2}
\end{array}
\end{aligned}
$$




$$
\begin{aligned}
& v=\text { kinematic viscosity of the fluid } \\
& \operatorname{Pr}=c_{p} \mu / k
\end{aligned}
$$

The butterfly valve was subjected frequently to exhaust temperatures as high as $950{ }^{\circ} \mathrm{F}(783 \mathrm{~K})$ when the engine was operated at rated conditions for extended periods of time. Based on this value, the base temperature $\left(T_{b}\right)$ of the portion of the shaft extending from the valve was assumed to be $850{ }^{\circ} \mathrm{F}(728 \mathrm{~K})$. The ambient temperature, $\mathrm{T}_{\mathrm{e}}$, inside the cell was approximately $90{ }^{\circ} \mathrm{F}(305 \mathrm{~K})$ when the engine was operated at rated speed, $100 \%$ load for extended periods of time. The mean film temperature is frequently approximated as the mean value of the estimated average shaft temperature, $T_{\mathrm{av}}$, shft, and the ambient temperature. The estimated shaft temperature was found iteratively by choosing an initial average shaft temperature and modifying it accordingly after the average shaft value was calculated using the subsequent analysis. Initially the average shaft temperature was assumed to be $575^{\circ} \mathrm{F}(575 \mathrm{~K})$, then the mean film temperature was estimated as follows:

$$
\begin{aligned}
T_{a v} & =\frac{\left(T_{a v, s h t}+T_{e}\right)}{2}=\frac{\left(575^{\circ} \mathrm{F}+90^{\circ} \mathrm{F}\right)}{2} \\
& =380^{\circ} \mathrm{F}=466 \mathrm{~K}
\end{aligned}
$$

$\Delta \mathrm{T}$ was calculated as follows:

$$
\begin{aligned}
\Delta T & =\left(T_{a v, s h f t}-T_{e}\right)=(466 K-305 K) \\
& =161 K=290{ }^{\circ} \mathrm{F}
\end{aligned}
$$

The kinematic viscosity and thermal conductivity of air at the mean film temperature were taken as $33.29 \times 10^{-6} \mathrm{~m}^{2} / \mathrm{s}$ and $0.0369 \mathrm{~W} / \mathrm{m}-\mathrm{K}$, respectively (Mills, 1992). The Prandtl number is given as 0.69 , and the thermal conductivity of 304 stainless steel at the average shaft temperature is given as $20.4 \mathrm{~W} / \mathrm{m}-\mathrm{K}$. The shaft diameter was $0.0127 \mathrm{~m}$ which corresponds to a perimeter of 0.0399 , and a constant cross-sectional area 
of $0.000127 \mathrm{~m}^{2}\left(0.00137 \mathrm{ft}^{2}\right) . \beta_{\text {nat }}$ was calculated as 0.00263 (inverse of the mean film temperature). By substituting these values into Equation 3.3.62, the Raleigh number was found to be 5298. For Raleigh numbers within the range $1 \times 10^{-6}$ and $1 \times 10^{9}$, the Nusselt number for convective heat transfer from a horizontal cylinder is given as (Mills, 1992),

$$
\overline{N u_{D}}=0.36+\frac{0.518\left(R a_{D}\right)^{1 / 4}}{\left[0+(0.559 / \operatorname{Pr})^{9 / 16}\right]^{1 / 9}}
$$

Substituting the given Raleigh and Prandtl numbers yields a Nusselt number of 3.69. The average convective heat transfer coefficient was calculated using the following equation (Mills, 1992),

$$
\begin{aligned}
\overline{h_{c}} & =\left(\frac{k_{\text {air }}}{D_{s h}}\right) \overline{N u_{D}}=\left(\frac{0.0369 \mathrm{~W} / \mathrm{mK}}{0.0127 \mathrm{~m}}\right) 3.69 \\
& =10.7 \mathrm{~W} / \mathrm{m}^{2} \mathrm{~K}
\end{aligned}
$$

This value as well as the values for the shaft perimeter, cross-sectional area, and thermal conductivity were substituted into the formula for $\beta$ which was used in Equation 3.3.61. In this case $\beta$ was found to be 12.85 . This value was then substituted into Equation 3.3.61 along with the temperature at the base of the shaft and the temperature of the ambient air. The temperature of the end of the shaft was then calculated by setting $\mathrm{x}=\mathrm{L}$ and solving Equation 3.3.61 for T. Using these values, the temperature at the end of the shaft was found to be $474{ }^{\circ} \mathrm{F}(518 \mathrm{~K})$. Using this value, the average shaft temperature was calculated to be $662{ }^{\circ} \mathrm{F}\left(\left(850{ }^{\circ} \mathrm{F}+90{ }^{\circ} \mathrm{F}\right) / 2\right)(623 \mathrm{~K})$. This value was close to the initial estimated value of $670{ }^{\circ} \mathrm{F}(627 \mathrm{~K})$, so no iterations were necessary. The calculated shaft end temperature was much higher than the required value of $160{ }^{\circ} \mathrm{F}(344 \mathrm{~K})$, so some means of external cooling was required. 
It was decided that a high-flow box fan could be used to draw air in from outside the test cell and forced over the valve shaft. A flexible duct could then be used to direct the air onto the shaft [the outlet of the 4" $(10.2 \mathrm{~cm})$ duct which was used after the analysis was performed is shown in the photograph labeled, "Automated Butterfly Valve" contained in Appendix A]. The fan under consideration was 5" $(12.7 \mathrm{~cm})$ in diameter and was capable of providing $145 \mathrm{acfm}\left(4.1 \mathrm{~m}^{3} / \mathrm{min}\right)$ of airflow with minimal pressure restriction and room temperature. With a 4" $(10.2 \mathrm{~cm})$ outlet, the velocity of the flow over the valve was estimated as follows:

$$
\begin{aligned}
V=\frac{Q_{a}}{A} & =\frac{145 \mathrm{acfm}}{\frac{\pi}{4}(.333 \mathrm{ft})^{2}} \\
& =1665 \mathrm{ft} / \mathrm{min}=8.46 \mathrm{~m} / \mathrm{s}
\end{aligned}
$$

Equation 3.3.61 was still applicable for the shaft temperature prediction. The only difference between this case (forced convection) and the previous case (natural convection) was the convective heat transfer coefficient. The ambient temperature was estimated to be $80{ }^{\circ} \mathrm{F}(300 \mathrm{~K})$, and the average shaft temperature was initially estimated to be $475^{\circ} \mathrm{F}(519 \mathrm{~K})$, and at this temperature, the thermal conductivity of stainless steel was listed as $18.4 \mathrm{~W} / \mathrm{mK}$ (Mills, 1992). The properties of the air flowing around the shaft were determined at the mean film temperature as was done in the natural convection case. The mean film temperature was calculated as $277^{\circ} \mathrm{F}(410 \mathrm{~K})$. At this temperature, the properties of air were given as follows (Mills, 1992):

$$
\begin{aligned}
& \rho_{\text {air }}=0.865 \mathrm{~kg} / \mathrm{m}^{3} \\
& \mu_{\text {air }}=22.9 * 10^{-6} \mathrm{~m}^{2} / \mathrm{s} \\
& \mathrm{k}_{\text {air }}=0.0326 \mathrm{~W} / \mathrm{mK} \\
& \operatorname{Pr}=0.69
\end{aligned}
$$

The Reynolds number of the airflow over the shaft was calculated as, 


$$
\begin{aligned}
\operatorname{Re}_{D} & =\frac{\rho_{\text {air }} V D}{\mu_{\text {air }}} \\
& =\frac{\left(0.865 \mathrm{~kg} / \mathrm{m}^{3}\right)(8.46 \mathrm{~m} / \mathrm{s})(0.1027 \mathrm{~m})}{22.9 \times 10^{-6} \mathrm{~m}^{2} / \mathrm{s}} \\
& =4.06 \times 10^{3}
\end{aligned}
$$

For external flows with Reynolds numbers less than $1 \times 10^{4}$, the average Nusselt number can be written as (Mills, 1992),

$$
\overline{N u_{D}}=0.3+\frac{(0.62)\left(\operatorname{Re}_{D}\right)^{1 / 2} \operatorname{Pr}^{1 / 3}}{\left[1+(0.4 / \operatorname{Pr})^{2 / 3}\right]^{1 / 4}}
$$

Substituting $\operatorname{Re}_{\mathrm{D}}$ and Pr into Equation 3.3.69, the average Nusselt number was calculated to be 30.9. The convective heat transfer coefficient was calculated using the following relation (Mills, 1992):

$$
\begin{aligned}
\overline{h_{c}} & =\left(\frac{k_{a i r}}{D_{s h}}\right) \overline{N u_{D}}=\left(\frac{0.0326 \mathrm{~W} / \mathrm{mK}}{0.0127 \mathrm{~m}}\right) 30.9 \\
& =79.3 \mathrm{~W} / \mathrm{m}^{2} \mathrm{~K}
\end{aligned}
$$

Solving Equation 3.3.61 for $\mathrm{T}$ and substituting in the appropriate values for $\mathrm{x}=\mathrm{L}$, the shaft end temperature was found to be $117^{\circ} \mathrm{F}(320 \mathrm{~K})$. Using this value and the shaft base temperature $\left(850{ }^{\circ} \mathrm{F}=728 \mathrm{~K}\right)$, the average shaft temperature was calculated as 483 ${ }^{\circ} \mathrm{F}$ which was near the estimated value of $475{ }^{\circ} \mathrm{F}(519 \mathrm{~K})$, so no further iterations were necessary. The predicted shaft end temperature was well below the design temperature limitation of $160{ }^{\circ} \mathrm{F}(344 \mathrm{~K})$, so the fan and the necessary ductwork were incorporated into the exhaust splitting control system.

Once the fan and air transfer ducts were put in place, a surface thermocouple was attached to the intermediate shaft. The engine was operated at rated speed, $100 \%$ load and the temperature was monitored with and without the fan operating. It was found that 
the fan was indeed necessary to maintain the shaft temperatures below the design constraints.

Once all the components of the exhaust splitting system were in place and the control software was developed, a target exhaust split percentage was determined by operating the system with the engine operating at the target speed and load (1500 rpm, $106 \mathrm{ft}-\mathrm{lbs})$. The filter housing with no trap installed was placed in position to seal the bypass line, and the exhaust splitting system was run at various split ratios. The exhaust backpressure was monitored during this process. In order to minimize the soot loading times, the maximum exhaust split percentage which would not result in excessive exhaust backpressure levels had to be determined. Based on the exhaust backpressure data, it was estimated that with the filter in place, a split ratio of 45 to $55 \%$ would provide acceptable filter loading times and acceptable exhaust backpressure values. The system was then tested with the filter in place. The engine was again operated at $1500 \mathrm{rpm}$, and $106 \mathrm{ft}-\mathrm{lbs}$ of torque. The initial exhaust split percentage was 55\%. A target filter loading of $24 \mathrm{~g}$ was required (see chapter 4 for more details on this choice of initial soot loading), so with soot emissions rate of $14.5 \mathrm{~g} / \mathrm{hr}$, the estimated filter loading time was calculated to be 3 hrs $(24 \mathrm{~g} /(14.5 \mathrm{~g} / \mathrm{hr} \times 0.55)$. After approximately 2.5 hours, the exhaust backpressure level exceeded the limiting value of 80 " $\mathrm{H}_{2} \mathrm{O}(19.9 \mathrm{kPa})$. The program had a control loop which decreased the target exhaust split percentage by $5 \%$ when the exhaust backpressure exceeded $80 " \mathrm{H}_{2} \mathrm{O}(19.9 \mathrm{kPa}$ ), so the target split percentage was decreased to $50 \%$ and the loading process continued. The exhaust backpressure limiting value was subsequently exceeded, so the exhaust split target value was decreased to $45 \%$ before the target soot loading was achieved. It was realized that the PM mass emission rate was 
higher than the mass emissions rate present in the exhaust because the specified emissions rate was based on diluted exhaust emissions. In the exhaust lines, condensation of various species onto the soot particles increases the mass of the soot particles. Filtration of the exhaust entraps the soot before the absorption/adsorption process is complete, so the mass of soot filtered out of the raw exhaust in the exhaust transfer line will be inherently less than the mass of soot which would be filtered out of the same exhaust if it were diluted and cooled prior to the filter. Also, the engine emissions rates were based on data prior to injector and pump calibration, so the emissions levels were expected to deviate slightly from those given in Table 3.1. For this reason, the filter loading times were expected to be longer than those predicted based on the engine emissions data. Numerous experimental results demonstrated that the soot emissions rate in the undiluted exhaust at the filter was near $11.2 \mathrm{~g} / \mathrm{hr}$. It was decided that the target exhaust split percentage should be $45 \%$ to ensure repeatable filter loadings with acceptable exhaust backpressure levels during the filter loading process. This resulted in filter loading times of 5 hours or more to achieve an entrapped soot mass of 24 g.

\subsection{Regeneration System}

\subsubsection{Microwave Generation/Transmission Assembly}

\subsubsection{Magnetron}

The magnetron is the device that is used to generate microwave energy. It does so by converting negative DC voltage to electromagnetic energy in microwave ovens. Within the microwave, a transformer is used to increase the voltage which is typically 
provided by a conventional household outlet (120VAC). This voltage is then rectified and increased further via a voltage doubler circuit which is contained in the microwave oven housing. A schematic of the voltage doubler circuit, based on the information given by J.C. Gallawa (www.gallawa.com/microtech/magnetron.html), is provided in Appendix G. The voltage doubler circuit consists of a high-voltage capacitor and diode. When the voltage from the secondary coil of the transformer is positive with respect to ground, the capacitor is charged through the diode. When the voltage becomes negative on the second half of the voltage cycle, the capacitor begins to discharge. Current cannot flow through the diode in the direction needed to discharge the capacitor, so the current is forced to flow into the magnetron. Additional voltage is provided by the transformer (the capacitor and transformer at this stage act essentially as voltage sources in series), so a pulsed voltage on the order of $-5600 \mathrm{VDC}$ at $60 \mathrm{~Hz}$ is applied to the magnetron. This voltage is theoretical. The actual voltages present are typically near -4000 VDC. A low voltage secondary winding is used to provide low-voltage, alternating current to the magnetron filament (Gallawa, www.gallawa.com/microtech/magnetron.html).

The filament serves as the cathode of the magnetron. The low-voltage ( 3 to 4VAC) supplied from the transformer is used to heat the filament, which emits electrons. A hollow cylinder around the filament serves as the anode of the magnetron. Fins protrude inward from this iron cylinder, and they are positioned to form resonant chambers. The high-voltage generated by the transformer and the voltage doubler circuit is used to provide a large voltage potential from the filament to the chamber walls. If these were the only components of the magnetron, the electrons would flow from the filament to the anode walls in a straight line. If this were the case, no microwaves would 
be generated. To prevent this type of electron flow from occurring, strong permanent magnets are placed around the walls of the anode. This generates a strong magnetic field within the anode chambers, so instead of the following a straight path from the cathode to anode, the electrons follow a curved path. The motion of many electrons results in a whirling cloud of electrons which emanate from the cathode and proceed toward the anode. Normally, the electrons would be attracted to each fin which protrudes toward the cathode equally. To prevent this from happening, alternating walls of the chambers are connected together using strap rings. This results in the electron cloud forming in the shape of a pinwheel. A temporary positive charge is induced in fins closest to the tips of the electron clouds. This induces a negative charge in the adjacent fins. The tips of the electron cloud are repelled from the positive fins and attracted to the negative fins, so the motion proceeds, and an alternating flow of electrons in the chambers is induced. An antenna attached to one of the walls of the resonant cavities is used to transmit the RF energy from the resonant cavity to the waveguide. The power supplied to the magnetron must include the power transmitted via the antenna and any power losses due to heat dissipation (Gallawa, www.gallawa.com/microtech/magnetron.html).

\subsubsection{Waveguides}

Waveguides are used to transmit electromagnetic energy waves above approximately $3.0 \mathrm{GHz}$. The losses which occur in conductors and dielectrics used to support the conductors become excessive when the electromagnetic waves which are to be transmitted exceed this limit, so metallic tubes called waveguides are used as the medium for transmission. Waveguides are typically rectangular in cross-section, 
although other cross-sectional shapes can be used. The electromagnetic waves which propagate through the waveguide induce currents in the walls of the waveguide which result in power loss. To reduce these losses, the walls of the waveguide are made of a conducting material, which reduces the resistance within the walls, and hence, reduces the transmission power losses (Roddy, 1986).

For analytical purposes, the walls of the waveguide were considered to be perfect conductors. This resulted in two boundary conditions: the tangential component of the electric field was zero at the walls of the waveguide and the normal component of the magnetic field was zero at the walls (Roddy, 1986). These conditions are illustrated in Figure 3.4.1 ${ }^{* * *}$. One possible mode of propagation through a waveguide with the aforementioned boundary conditions for the magnetic field to form loops within the waveguide as shown in Figure 3.4.2 (Roddy, 1986) ${ }^{\text {市 }}$ :

\footnotetext{
${ }^{* * *}$ Schematic based on information provided in Microwave Technology by D. Roddy, 1986.

${ }^{\dagger+\dagger}$ Diagram based on information provided in Microwave Technology by D. Roddy, 1986
} 


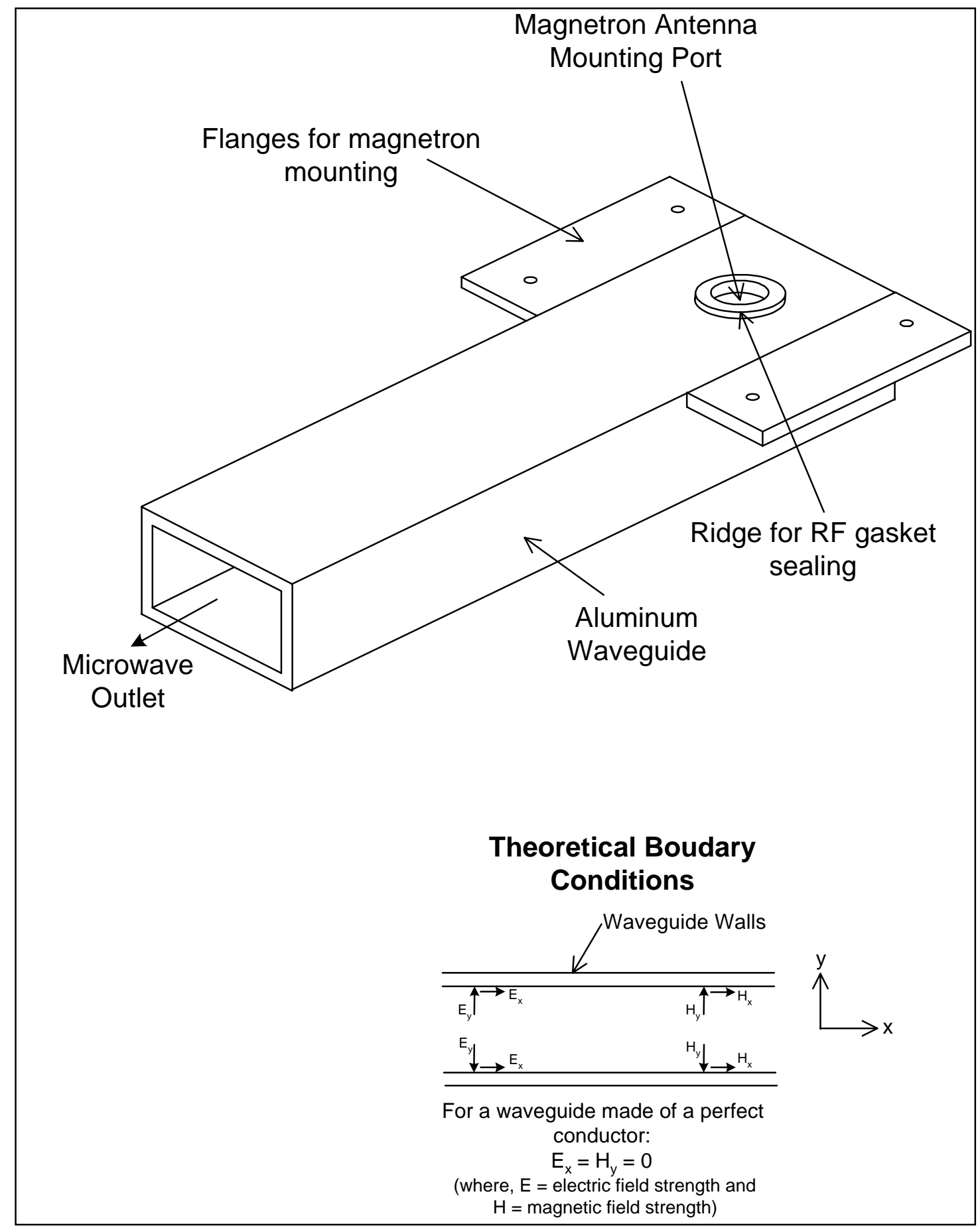

Figure 3.4.1: Waveguide Schematic and Theoretical Boundary Conditions (Roddy, 1986) 


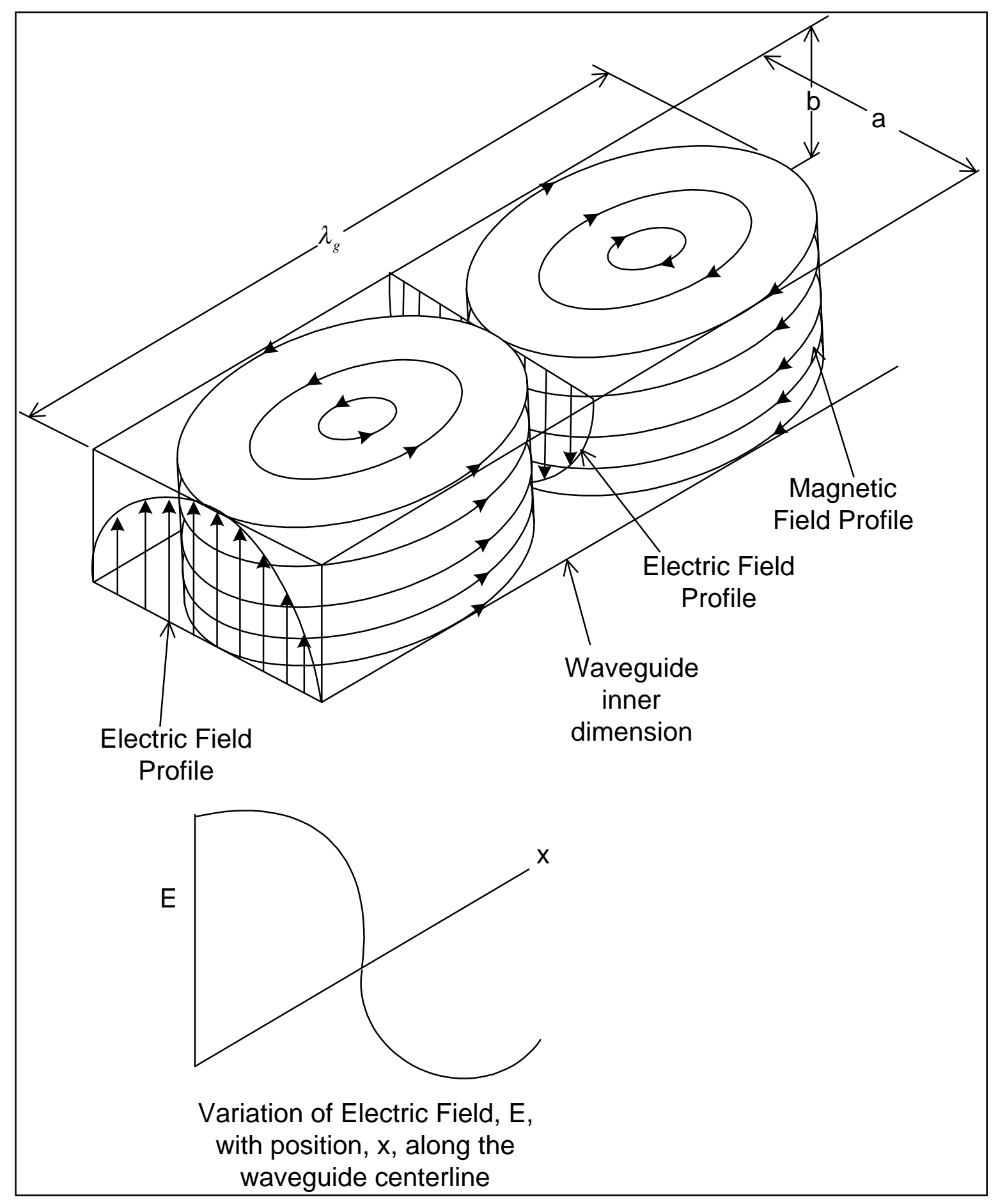

Figure 3.4.2: Electric and Magnetic Field Distributions in a Waveguide for $\mathrm{TE}_{10}$ Mode Propagation (Roddy, 1986) 
It should be noted that the electric field is always perpendicular to the magnetic field, and it varies along the direction of propagation as shown at the bottom of Figure 3.4.2. The type of wave propagation shown in Figure 3.4.2 is known as $\mathrm{TE}_{10}$ (transverse electric) mode. The subscripts denote the number of half-cycle variations in the magnetic field in the $a$ and $b$ dimensions respectively. A full cycle variation in the magnetic field would contain both a both a clockwise and counterclockwise magnetic field distribution as shown in the illustration (as viewed from the top or bottom of the waveguide). For this type of propagation, there is one half-cycle variation in the $a$ dimension (denoted by the first subscript), and no half-cycle variations in the $b$ dimension (denoted by the second subscript). $\mathrm{TE}_{10}$ mode is typically the dominant mode in electromagnetic wave propagation in waveguides because it supports the lowest frequency mode of propagation (Roddy, 1986).

Roddy (1986) also demonstrated how a TE mode of propagation could be formed from two intersecting transverse electromagnetic waves (TEM waves). If the TEM waves are constrained to reflect along the larger dimension (dimension $a$ as shown in Figure 3.4.2) of a waveguide made of a perfect conductor, a $\mathrm{TE}_{10}$ wave is formed as shown in Figure 3.4.2. The TEM waves move at the speed of light, $\mathrm{c}$, at a given wavelength, $\lambda$, and frequency, $\mathrm{f}$. These three variables are related according to the following relation:

$$
c=\lambda f
$$

The $\mathrm{TE}_{10}$ wave which is formed has the same frequency as the TEM waves, but its phase velocity, $\mathrm{V}_{\mathrm{p}}$, differs from the velocity of the TEM waves (Roddy, 1986). The velocity of a point of constant phase defines the phase velocity, and this phase velocity is always 
greater than the velocity of light (Ghandi, 1981). Ghandi (1981) compared the phase velocity within the waveguide to the velocity of a ripple on the bank of a river pond. The ripple may move at a very rapid rate through the interaction of fluid molecules with one another. The actual velocity of the fluid may be very small, but the ripple could be moving at a very rapid rate because the individual fluid elements experience the ripple peak at different times.

The wavelength of the $\mathrm{TE}_{10}$ wave, $\lambda_{\mathrm{g}}$, which is also known as the guide wavelength, is the distance required to encapsulate two sequential magnetic field loop alternates as shown in Figure B. The relationship between these parameters is defined according to the following equation (Roddy, 1986):

$$
\mathrm{V}_{\mathrm{p}}=\lambda_{\mathrm{g}} \mathrm{f}
$$

Based on the preceding relations and the geometric relationships formed by TEM waves reflecting between the walls of the largest dimension of a waveguide made of a perfect conductor, the following relation between the wavelength of the TEM waves, and the guide wavelength can be derived (Roddy, 1986):

$$
\frac{1}{\lambda_{g}^{2}}=\frac{1}{\lambda^{2}}-\frac{1}{(2 a)^{2}}=\frac{1}{\lambda^{2}}-\frac{1}{\lambda_{c}^{2}}
$$

If the wavelength of the TEM waves is equal to two times the width of the waveguide, $a$, the guide wavelength is equal to zero. This indicates that a TEM wave with a wavelength of $2 a$ would reflect back and forth along the waveguide width without propagating down the length of the waveguide. With this being the case, the longest TEM wavelength which can be introduced into the waveguide is $2 a$, so $2 a$ is effectively the cutoff wavelength of the waveguide, $\lambda_{c}$. TEM waves with wavelengths less than this can create 
TE waves within the waveguide which will be transmitted down its length (Roddy, 1986).

The cutoff wavelength corresponds to a cutoff frequency. Frequencies above the cutoff frequency, which have wavelengths smaller than the cutoff wavelength, can be transmitted through the waveguide. A general form of the cutoff frequency is given as follows (Ghandi, 1981):

$$
\begin{aligned}
& f_{c}=c \sqrt{\left(\frac{m}{2 a}\right)^{2}+\left(\frac{n}{2 b}\right)^{2}} \\
& \text { where, } \\
& \mathrm{f}_{\mathrm{c}}=\text { cutoff frequency } \\
& \mathrm{c}=\text { speed of light } \\
& \mathrm{a}=\text { larger waveguide cross-sectional dimension } \\
& \mathrm{b}=\text { smaller waveguide cross-sectional dimension } \\
& \mathrm{m}=\text { first subscript in wave propagation designation }\left(\mathrm{TE}_{\mathrm{mn}}\right) \\
& \mathrm{n}=\text { second subscript in wave propagation designation }\left(\mathrm{TE}_{\mathrm{mn}}\right)
\end{aligned}
$$

The TEM waves are reflected back and forth along the walls of the waveguide, so the velocity at which the energy waves propagate down the waveguide, which is known as the group velocity $\left(\mathrm{V}_{\mathrm{g}}\right)$, is less than the velocity of the TEM waves, c. This velocity was expressed as a function of the TEM wave velocity, $c$, and wavelength, $\lambda$, as well as the guide wavelength, $\lambda_{\mathrm{g}}$, as follows (Roddy, 1986):

$$
V_{g}=c \frac{\lambda}{\lambda_{g}}
$$

Waveguides are typically designed to promote only one mode of propagation. Multiple modes of propagation cause interference between the modes because the modes have different phase velocities. For rectangular waveguides, the $\mathrm{TE}_{10}$ mode is frequently chosen as the mode for propagation because it has the lowest cutoff frequency. The next higher order modes are $\mathrm{TE}_{20}$ and $\mathrm{TE}_{01}$. Investigation of Equation 3.4.4 indicates that for 
these higher modes, the cutoff frequencies are greater than the $\mathrm{TE}_{10}$ mode. Because any frequencies higher than the cutoff frequency for a given mode can be transmitted through a waveguide, this relation can be used to ensure the propagation of only the $\mathrm{TE}_{10}$ mode by choosing the waveguide dimensions such that the signal frequency is above the lower cutoff frequency of the $\mathrm{TE}_{10}$ mode and below the cutoff frequencies of the $\mathrm{TE}_{20}$ and $\mathrm{TE}_{01}$ modes. Equation 3.4.4 also indicates that if $\mathrm{b}=\mathrm{a} / 2$ the cutoff frequency for both the $\mathrm{TE}_{20}$ and the $\mathrm{TE}_{01}$ modes would be identical. In order to provide distinct cutoff frequencies for both modes, in many waveguides, the $b$ dimension is made smaller than a/2. This increases the cutoff frequency of the $\mathrm{TE}_{01}$ mode above that of the $\mathrm{TE}_{20}$ mode, so, as long as the $b$ dimension is less than one half of the $a$ dimension, only the choice of the $a$ dimension will affect the upper limit of the cutoff frequency range (Ghandi, 1981).

Ghandi (1981) stated that for practical purposes, the $a$ dimension of the waveguide is typically chosen such that the signal frequency is $15 \%$ to $20 \%$ higher than the lower cutoff frequency (c/2a) and $90 \%$ to $95 \%$ of the upper cutoff frequency (c/a). This frequency range was expressed mathematically as follows (Ghandi, 1981):

$$
(1.15 \text { to } 1.2) \frac{c}{2 a} \leq f \leq(0.9 \text { to } 0.95) \frac{c}{a}
$$

Based on the above criteria, there are several standard rectangular waveguide configurations which promote $\mathrm{TE}_{10}$ mode propagation of microwaves generated at 2.45 GHz. These include the WR284, the WR340, and the WR284. The only difference between these waveguides is their inner dimensions as shown in Table $3.2^{\text {tot }}$

Table values taken from Microwave Engineering and Applications by Ghandi, 1981. 


\section{Table 3.2: Commercial Waveguide Specifications}

\begin{tabular}{ccc}
\hline $\begin{array}{c}\text { Waveguide } \\
\text { Designation }\end{array}$ & $\begin{array}{c}a \text { Dimension } \\
\text { (inches) }\end{array}$ & $\begin{array}{c}b \text { Dimension } \\
\text { (inches) }\end{array}$ \\
\hline WR284 & 2.84 & 1.34 \\
WR340 & 3.40 & 1.70 \\
WR430 & 4.3 & 2.15 \\
\hline
\end{tabular}

Of the three waveguides listed in Table 3.2, the WR284 and WR340 waveguides were fabricated at West Virginia University in order to determine which of the two was most efficient for microwave power transmission at $2.45 \mathrm{GHz}$. A third waveguide was also fabricated based on the dimensions of the waveguides used in commercial microwave ovens for household use $\left(\mathrm{a}=3.134 "=7.960 \mathrm{~cm}, \mathrm{~b}=1.355^{\prime \prime}=3.442 \mathrm{~cm}\right)$. Each waveguide was $16 "(40.6 \mathrm{~cm})$ in length. Photographs of the waveguides are contained in Appendix G, and a general schematic was provided in Figure 3.4.1. The waveguides were machined from 6061-T3 aluminum. Aluminum was chosen because it is a very good conductor of both electricity and heat. It is also amenable to machining and welding. Two halves of each waveguide were machined separately. The halves were then aligned and welded together (see Appendix G). As can be seen from the photographs, mounting flanges for the magnetron were welded onto the sides of the waveguides near the enclosed end, and another mounting flange was welded onto the open end of the waveguide, so the entire assembly could be bolted to the filter housing. The antennae from the magnetron protruded into the waveguide at the center of the longer cross-sectional dimension, $a$. The antennae was positioned $1 / 4$ of a free space wavelength away from the back wall (see Figure 3.4.1). This was done to reflect the waves which were transmitted from the antennae towards the back wall. The reflection 
caused a $180^{\circ}$ phase shift in the wave. The reflected wave then had to travel an additional $1 / 4$ wavelength back to the antennae. By this time, the reflected wave was in phase with a new wave traveling in the forward direction (towards the open end of the waveguide). In this way, power was not dissipated unnecessarily. Ghandi (1981) had recommended using $1 / 4$ of the group wavelength instead of the free space wavelength (the free space wavelength assumes a simple, sinusoidal wave). The differences in the antenna positions were less than $1 / 2 "(1.3 \mathrm{~cm})$, and the antenna position in conventional oven waveguides tend towards the free space wavelength, so $1 / 4$ of the free space wavelength was chosen. Little interference was expected for $\mathrm{TE}_{10}$ mode propagation using either wavelength as the criteria for the antenna position.

The theoretical power loss per unit length of a rectangular waveguide made of a perfect conductor for $\mathrm{TE}_{10}$ mode propagation can be written as follows (Ghandi, 1981):

$$
\begin{aligned}
\frac{P_{l}}{L_{\text {wave }}} & =\frac{1}{2} H_{10}^{2}(a) \frac{f^{2}}{f_{10}^{2}}\left[1+\frac{2 b}{a} \frac{f_{10}^{2}}{f^{2}}\right] \\
& =\frac{1}{2} H_{10}^{2} \frac{4 a^{2} f^{2}}{c^{2}}\left[1+\frac{8 b a f_{10}^{2}}{c^{2}}\right]
\end{aligned}
$$

where,

$$
\begin{aligned}
& \mathrm{P}_{1}=\text { power loss } \\
& \mathrm{L}_{\text {wave }}=\text { waveguide length }=16 "=40.6 \mathrm{~cm} \\
& \mathrm{H}_{10}=\text { magnetic field strength }\left(\mathrm{TE}_{10} \text { mode }\right) \\
& \mathrm{a}=\text { longer waveguide cross-sectional dimension } \\
& \mathrm{b}=\text { smaller waveguide cross-sectional } \\
& \mathrm{c}=\text { speed of light in dry air }\left(3 \times 10^{8} \mathrm{~m} / \mathrm{s}\right) \\
& \mathrm{f}=\text { transmission frequency }=2.45 \mathrm{GHz} \\
& \mathrm{f}_{10}=\text { cutoff frequency for } \mathrm{TE}_{10} \text { mode }=\mathrm{c} / 2 \mathrm{a}
\end{aligned}
$$

If the magnitude of the magnetic field could be estimated, the theoretical power loss per unit length through the waveguide could be determined. The theoretical power loss through the three types of waveguides used in the WVU microwave regeneration study was performed by Popuri (1999). 


\subsubsection{Waveguide Power Transmission Test Chamber}

Variations in the actual waveguide dimensions and properties from the theoretical values were expected to cause larger power losses than those calculated using waveguide power transmission theory. In order to account for these variations, a power transmission test assembly was used to determine which waveguide was the most efficient at microwave power transmission at $2.45 \mathrm{GHz}$ using a $1 \mathrm{~kW}$ magnetron. A cross-sectional diagram of the assembly is provided in Figure 3.4.3

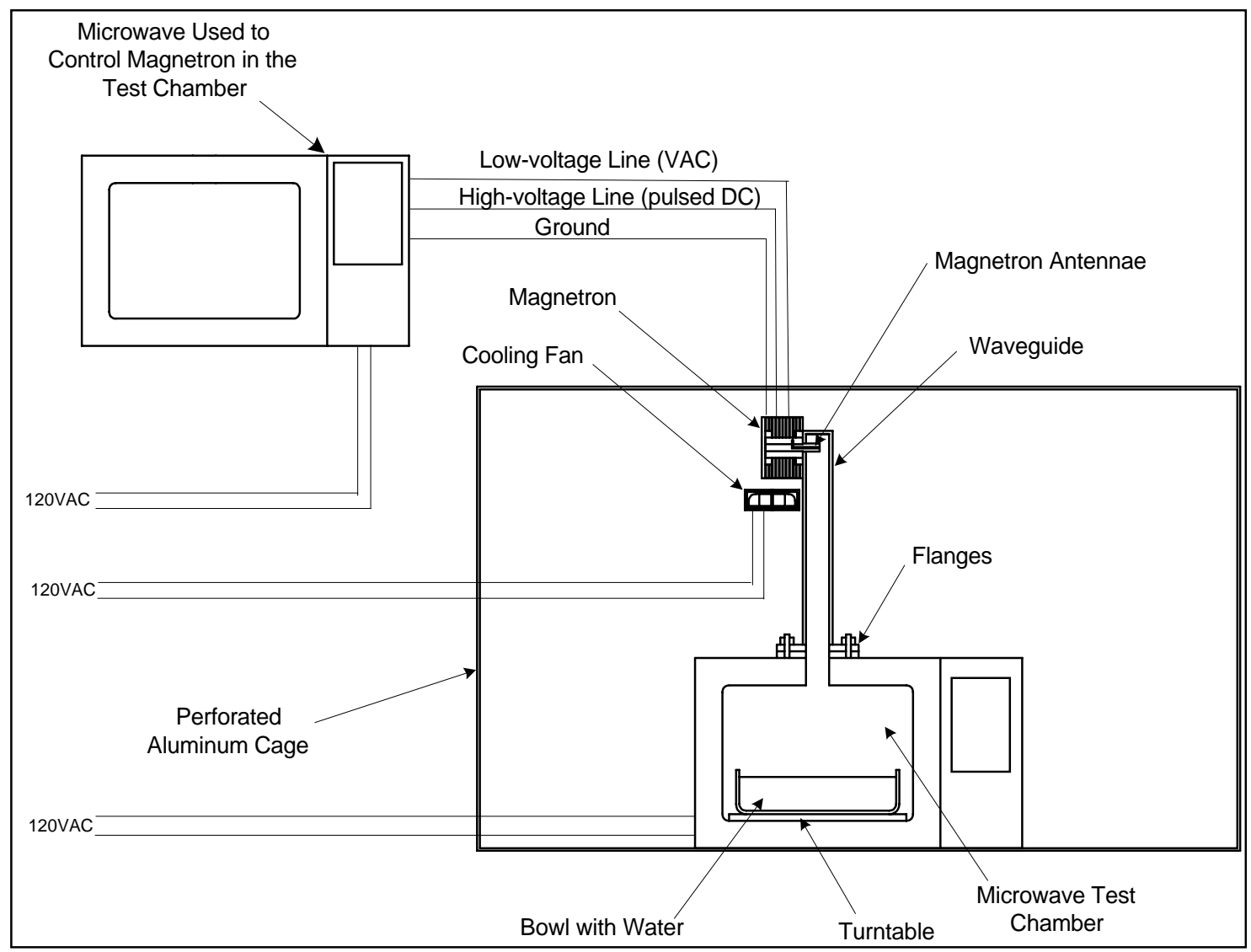

Figure 3.4.3: Microwave Power Transmission Test Assembly 
Each waveguide was attached to a microwave oven test cavity. The microwave cavity was simply a conventional microwave oven for household use. The conventional waveguide was removed from the oven and an adapting flange was welded to what had previously been the conventional waveguide outlet, and the test waveguides were bolted to this flange. The magnetron and transformer were also removed from the oven, but the interior light and turntable were left intact and operational. A large bowl of water was placed inside the oven, and the magnetron which was attached to the test waveguide was activated using a second microwave oven (Sharp model R-5H16). The magnetron which had originally been in this oven was removed. The power supply and controls of this oven were used to control the test $1 \mathrm{~kW}$ magnetron (Sharp model \# 2M248J(L)), which was attached to the test waveguide. After the temperature and mass of the water was recorded prior to the test, the magnetron was activated for a predetermined length of time. Prior to the activation of the magnetron, a perforated, aluminum cage was placed over the test chamber/waveguide assembly. This was done in case any leaks existed in the system. Because the diameter of the holes in the cage was much smaller than the wavelength of the microwaves, no microwaves could escape out of the cage. The perforated sheets allowed the microwave test chamber to be monitored for arcs and turntable operation. After the magnetron was deactivated, the water was stirred vigorously and the temperature was recorded. The mass of water remaining was also recorded for all tests in which the period of magnetron activation was above five minutes (for tests in which the magnetron activation time exceeded five minutes, the amount of water which vaporized was significantly higher). The power absorbed by the water was calculated using the following equation: 


$$
P_{a b s}=\frac{\left[m_{f}\left(c_{p}\right)\left(T_{f}-T_{i}\right)+m_{e v}\left(h_{f g}\right)\right]}{\Delta t}
$$

where,

$$
\begin{aligned}
& \mathrm{P}_{\mathrm{abs}}=\text { power absorbed by the water } \\
& \mathrm{m}_{\mathrm{f}}=\text { final mass of water in the bowl } \\
& \mathrm{m}_{\mathrm{ev}}=\text { mass of water evaporated } \\
& \mathrm{c}_{\mathrm{p}}=\text { specific heat of water } \\
& \mathrm{T}_{\mathrm{f}}=\text { final water temperature } \\
& \mathrm{T}_{\mathrm{i}}=\text { initial water temperature } \\
& \Delta \mathrm{t}=\text { magnetron activation duration } \\
& \mathrm{h}_{\mathrm{fg}}=\text { enthalpy of vaporization for water }
\end{aligned}
$$

For most of the tests, the magnetron activation time was below five minutes, so the second term was neglected (that is, the mass of evaporated water was negligible). A detailed explanation of the test procedure for waveguide power transmission as well as a listing of the results is presented elsewhere (Popuri, 1999). The test results demonstrated that the WR284 waveguide was the most efficient in terms of transmitting microwave energy at $2.45 \mathrm{GHz}$. For the 16 " $(40.6 \mathrm{~cm})$ long waveguide which was used, the WR284 waveguide was capable of transmitting $900 \mathrm{~W}$ to the water contained in the test chamber. For this reason, the WR284 waveguide was used in all the microwave regeneration tests presented in this thesis.

Due to the small penetration depth of microwaves into metals, the outer dimensions of the waveguides are not significant in terms of microwave power transmission (Ghandi, 1981). The outer dimensions do become significant when other engineering aspects are considered such as heat transfer rates, mechanical stresses, and manufacturing considerations. 


\subsubsection{Waveguide Gate Valve}

Magnetrons are sensitive to temperature extremes. In a conventional microwave oven, a thermal fuse is mounted near the magnetron. Therefore, if the cooling capacity is insufficient, current to the magnetron is interrupted to prevent magnetron damage. For the magnetron used in this research, a thermal fuse was mounted on the magnetron mounting flanges (see Figure 3.4.1) in order to prevent magnetron damage in the event of a cooling fan failure or excessive waveguide temperatures. The magnetron has various charged components. Diesel soot particles are also charged (both positive and negative charges) at various engine loads and speeds (Kittelson et al. 1986), so if the soot particles are carried into the vicinity of the magnetron antenna (such as in the event of an exhaust leak around the magnetron antenna), the potential for magnetron fouling exists. Also, radiation from regenerating filters posed potential heating problems for the waveguide and magnetron. In order to prevent these problems, some means of isolating the waveguide from the microwave trap had to be incorporated into the overall design. Other investigators have used quartz glass to isolate the waveguide assembly (Zhi Ning, 1999). Quartz has a low dielectric loss factor, so microwaves will pass through the quartz window with little attenuation. The inherent problem with this assembly is fouling of the quartz. Buildup on the glass over time would cause attenuation of the microwaves which would decrease the power supplied to the filter during the preheating phase. In order to circumvent this type of problem, a microwave gate valve was designed and fabricated at WVU. The main body of the valve was made of aluminum, while the valve gate and shaft were composed of steel. The inner dimensions of the valve inlet matched the WR284 waveguide inner dimensions. The inner dimensions of the valve outlet were 
much larger than the waveguide inner dimensions. In this way, little interference was caused by the presence of the valve in the microwave transmission path. The valve gate was designed such that when it was in the closed position, the front face of the gate pressed against the wall of the gate housing. Although this would not provide an air-tight seal if large pressures were encountered, the waveguide assembly itself was airtight (the waveguide was welded together and the magnetron was sealed to the waveguide using a RTV compound), so the waveguide/valve combination provided sufficient restriction to prevent any air or exhaust flow from entering the waveguide at the pressures which were expected to be present in the trap. In the case of an in-cell test, the valve was closed during the soot loading period and was opened only during the preheating portion of the regeneration event. The valve was closed immediately after the preheating period to minimize radiation effects (peak trap regeneration temperatures occurred during the convective combustion portion of the regeneration event which succeeded the preheating phase). In the case of out-of-cell testing, the waveguide and waveguide gate valve were not connected to the trap housing during the filter loading period, so the gate valve was opened during the preheating period and was closed at the end of the preheating cycle. In this manner the magnetron was protected against soot deposition and radiation. Photographs of the waveguide gate valve are provided in Appendix G.

\subsubsection{Waveguide Water Jacket}

Although the waveguide gate valve and the glossy inner and outer surfaces of the waveguide minimized the effects of radiation to the magnetron, magnetron could have experienced excessively high temperatures via conduction through the waveguide. As 
was mentioned previously, the waveguide was made of aluminum because aluminum is a good conductor of electricity. This allowed the waveguide boundary conditions to approach the ideal boundary conditions for $\mathrm{TE}_{10}$ mode propagation (see Figure 3.4.1). Materials that are good conductors of electricity also tend to conduct heat well (that is, these materials have large thermal conductivities). The extreme temperatures within the trap could cause high heat transfer rates through the waveguide, because in order to cause minimal transmission attenuation, it must be constructed of a material which is a good conductor of electricity. This could potentially cause magnetron deactivation (via the triggering of the thermal fuse) or damage. Therefore, measures to maintain the waveguide end temperatures below $140{ }^{\circ} \mathrm{F}\left(60{ }^{\circ} \mathrm{C}\right)$ (the thermal fuse cutoff temperature) had to be taken.

One proposed method of controlling the waveguide temperatures near the magnetron involved using a fan and ductwork to create a forced convection boundary condition on the external surfaces of the waveguide. This would allow energy to be carried away in the air stream, thus decreasing the waveguide temperature as distance from the microwave trap increased. In order to determine if this waveguide temperature control scheme would be sufficient, the waveguide was modeled as a dual-fin. The air inside the waveguide was considered to be one fin, and the aluminum was modeled as a second fin which surrounded the air "fin." Because the waveguide gate valve was closed during regeneration and because the waveguide surfaces were glossy, radiation effects were neglected. The two governing equations in this case were,

$$
\begin{array}{r}
k_{\text {alum }} A_{\text {alum }} \frac{d^{2} T_{\text {alum }}}{d x^{2}}-h_{e} P_{\text {out }}\left(T_{\text {alum }}-T_{e}\right)+ \\
h_{\text {in }} P_{\text {in }}\left(T_{\text {air }}-T_{\text {alum }}\right)=0
\end{array}
$$




$$
k_{\text {air }} A_{\text {air }} \frac{d^{2} T_{\text {air }}}{d x^{2}}-h_{\text {in }} P_{\text {in }}\left(T_{\text {air }}-T_{\text {alum }}\right)=0
$$

where,

$\mathrm{k}_{\mathrm{alum}}=$ thermal conductivity of the aluminum

$\mathrm{k}_{\text {air }}=$ thermal conductivity of the air inside the waveguide

$\mathrm{A}_{\text {alum }}=$ cross sectional area of the aluminum

$\mathrm{A}_{\text {air }}=$ cross sectional area of the waveguide inner dimensions

$\mathrm{P}_{\text {out }}=$ outer perimeter of waveguide

$\mathrm{P}_{\mathrm{in}}=$ inner perimeter of waveguide

$\mathrm{h}_{\text {in }}=$ convective heat transfer coefficient between the air inside the waveguide and the aluminum

$\mathrm{h}_{\mathrm{e}}=$ convective heat transfer coefficient between the air outside the waveguide and the aluminum

$\mathrm{x}=$ centerline distance from the base of the waveguide (at the waveguide gate valve) to any point on the waveguide

$\mathrm{T}_{\mathrm{e}}=$ ambient temperature

$\mathrm{T}_{\mathrm{alum}}=$ temperature of the aluminum at any position, $\mathrm{x}$

$\mathrm{T}_{\mathrm{air}}=$ temperature of the air inside the waveguide at any position, $\mathrm{x}$

It was assumed that temperature of the aluminum and air were uniform along the given cross section at any position, $\mathrm{x}$ (no temperature gradients in the $\mathrm{y}$ direction). Properties of aluminum, the air inside the waveguide, and the air outside the waveguide were assumed to be constant. The values of the air properties were based on an estimation of the mean film temperature ( estimated average temperature between the air and the aluminum). Using the notation, $\mathrm{T}^{\prime \prime}=\mathrm{d}^{2} \mathrm{~T} / \mathrm{dx}^{2}$, and $\mathrm{T}^{\prime,},{ }^{\prime}=\mathrm{d}^{4} \mathrm{~T} / \mathrm{dx}^{4}$, Equations 3.4 .9 and 3.4.10 may be written as follows:

$$
\begin{aligned}
& k_{\text {alum }} A_{\text {alum }} T_{\text {alum }}^{\prime \prime}-\left(h_{e} P_{\text {out }}-h_{\text {in }} P_{\text {in }}\right) T_{\text {alum }}+ \\
& h_{\text {in }} P_{\text {in }} T_{\text {air }}+h_{e} P_{\text {out }} T_{e}=0 \\
& T_{\text {alum }}=-\left(\frac{k_{\text {air }} A_{\text {air }}}{h_{\text {in }} P_{\text {in }}}\right) T_{\text {air }}+T_{\text {air }}
\end{aligned}
$$

Taking the second derivative of Equation 3.4.12 with respect to $\mathrm{x}$,

$$
T_{\text {alum }}^{\prime \prime}=-\left(\frac{k_{\text {air }} A_{\text {air }}}{h_{\text {in }} P_{\text {in }}}\right) T_{\text {air }}^{\text {"'! }}+T_{\text {air }}^{\prime \prime}
$$


Substituting Equation 3.4.13 into Equation 3.4.11, the following equation is obtained:

$$
T_{a i r}^{\prime \prime \prime}-\left(\frac{X}{W}\right) T_{a i r}^{\prime \prime}+\left(\frac{Y}{W}\right) T_{a i r}=\left(\frac{Z}{W}\right)
$$

where,

$$
\begin{aligned}
& \mathrm{W}=\left(\mathrm{k}_{\text {alum }} \mathrm{A}_{\text {alum }} \mathrm{k}_{\text {air }} \mathrm{A}_{\text {air }}\right) /\left(\mathrm{h}_{\text {in }} \mathrm{P}_{\text {in }}\right)=\text { constant } \\
& \mathrm{X}=\mathrm{k}_{\text {alum }} \mathrm{A}_{\text {alum }}+\left(\left(\mathrm{h}_{\mathrm{e}} \mathrm{P}_{\mathrm{e}}+\mathrm{h}_{\mathrm{in}} \mathrm{P}_{\text {in }}\right) \mathrm{k}_{\text {air }} \mathrm{A}_{\text {air }}\right) /\left(\mathrm{h}_{\text {in }} \mathrm{P}_{\text {in }}\right)=\text { constant } \\
& \mathrm{Y}=\mathrm{h}_{\mathrm{e}} \mathrm{P}_{\text {out }}=\text { constant } \\
& \mathrm{Z}=\mathrm{h}_{\mathrm{e}} \mathrm{P}_{\text {out }} \mathrm{T}_{\mathrm{e}}=\text { constant }
\end{aligned}
$$

The air and aluminum properties were evaluated by assuming that the fan and necessary ductwork around the waveguide could provide an airflow velocity of $15 \mathrm{~m} / \mathrm{s}(49.2 \mathrm{ft} / \mathrm{s})$ over the entire waveguide length $\left(\mathrm{L}_{\text {wave }}=16 "=0.4064 \mathrm{~m}\right)$. The mass flow rate of the air and the diameter of the ductwork were assumed to be large enough to maintain a constant ambient air temperature of $70^{\circ} \mathrm{F}\left(\mathrm{T}_{\mathrm{e}}=294 \mathrm{~K}\right)$ over the entire length of the waveguide (this is obviously a "best-case" scenario - the temperature of the cooling air would, in reality, increase slightly over the waveguide length, thus, decreasing the heat transfer rate from the waveguide to the air). The average temperature of aluminum was estimated to be 890 ${ }^{\circ} \mathrm{F}(750 \mathrm{~K})$, so the estimated mean film temperature of the air outside the waveguide was $530{ }^{\circ} \mathrm{F}(550 \mathrm{~K})$. Evaluating the properties of air at $530{ }^{\circ} \mathrm{F}(550 \mathrm{~K})$ and the properties of aluminum at $890{ }^{\circ} \mathrm{F}(750 \mathrm{~K})$, the following values were obtained ${ }^{\S \S}$ :

$$
\begin{aligned}
& \mathrm{k}_{\text {air }}=.0418 \mathrm{~W} / \mathrm{mK} \\
& \mathrm{V}_{\text {air }}=\text { kinematic viscosity }=43.9 \times 10^{-6} \mathrm{~m}^{2} / \mathrm{s} \\
& \mathrm{Pr}=0.69 \\
& \mathrm{k}_{\text {alum }}=221 \mathrm{~W} / \mathrm{mK}
\end{aligned}
$$

The average Reynolds number for this external flow was then evaluated as,

$$
\operatorname{Re}=\frac{V L_{\text {wave }}}{v_{\text {air }}}=1.4 \times 10^{5}
$$

\footnotetext{
$\S \S$ Unless otherwise noted, all aluminum and air property values in this section are taken from Heat Transfer, by A.F. Mills, 1992.
} 
The average Nusselt number was approximated as (Mills, 1992),

$$
\overline{N u}_{L}=0.664 \operatorname{Re}_{t r}^{1 / 2} \operatorname{Pr}^{1 / 3}+0.036 \operatorname{Re}_{L}^{.8} \operatorname{Pr}^{.43}\left(1-\left(\frac{\operatorname{Re}_{t r}}{\operatorname{Re}_{L}}\right)^{.8}\right)
$$

where,

$$
\mathrm{Re}_{\mathrm{tr}}=\text { transition Reynolds number }=1 \times 10^{5}
$$

$\mathrm{Re}_{\mathrm{L}}$ was slightly outside the suggested Reynolds number range for Equation 3.4.15, but for modeling purposes, it was deemed adequate. Substituting the appropriate values into Equation 3.4.15, the average Nusselt number was found to be 278. Using this value, the external convective heat transfer coefficient was evaluated as follows (Mills, 1992):

$$
h_{e}=\frac{k_{\text {air }, e x}}{L_{\text {wave }}} \overline{N u}_{L}=28.6 \mathrm{~W} / \mathrm{m}^{2} \mathrm{~K}
$$

The waveguide was mounted horizontally, and the waveguide wall temperature around the perimeter at any centerline location, $\mathrm{x}$, was assumed to be uniform, so natural convection was not expected to enhance the heat transfer rates from the air inside the waveguide to the aluminum. The average internal convective heat transfer coefficient was estimated as follows:

$$
h_{\text {in }}=\frac{k_{\text {in }}}{b}=\frac{0.0531 \mathrm{~W} / \mathrm{mK}}{0.034036 \mathrm{~m}}=1.56 \mathrm{~W} / \mathrm{m}^{2} \mathrm{~K}
$$

where,

$$
\begin{aligned}
& \left.\mathrm{k}_{\text {in }}=\text { thermal conductivity of air (evaluated at } 750 \mathrm{~K}\right) \\
& \mathrm{b}=\text { smaller inner waveguide dimension }=1.34 "=3.4 \mathrm{~cm}
\end{aligned}
$$

The geometric values (such as $\mathrm{P}_{\text {in }}, \mathrm{P}_{\text {out }}, \mathrm{A}_{\text {air }}, \mathrm{A}_{\text {alum}}$ ) were based on the inner dimensions of the WR284 waveguide (2.84"x1.34" or $7.21 \mathrm{~cm} \mathrm{x} 3.40 \mathrm{~cm})$ with $1 / 4$ " $(0.64 \mathrm{~cm})$ wall thickness:

$$
\begin{aligned}
& \mathrm{P}_{\text {in }}=0.2123 \mathrm{~m}=0.697 \mathrm{ft} \\
& \mathrm{P}_{\text {out }}=0.2631 \mathrm{~m}=0.8632 \mathrm{ft}
\end{aligned}
$$




$$
\begin{aligned}
& \mathrm{A}_{\text {air }}=0.002455 \mathrm{~m}^{2}=0.02643 \mathrm{ft}^{2} \\
& \mathrm{~A}_{\text {alum }}=0.001510 \mathrm{~m}^{2}=0.01625 \mathrm{ft}^{2}
\end{aligned}
$$

Using all the aforementioned values, the constants W, X, Y, Z listed in Equation 3.4.14 could be evaluated.

Equation 3.4.14 is a fourth order, nonhomogeneous, differential equation. The general equation was solved by solving for a solution to the homogeneous equation ( $\left.\mathrm{T}_{\text {air,homog }}\right)$, then finding one solution to the nonhomogeneous equation $\left(\mathrm{T}_{\text {air,nonhomog }}\right)$, and adding the two solutions together $\left(\mathrm{T}_{\mathrm{air}}=\mathrm{T}_{\mathrm{air}, \text { homog }}=\mathrm{T}_{\text {air,nonhomog }}\right)$. The homogeneous equation was evaluated by assuming the following solution form:

$$
T_{\text {air }, \text { hom } o g}=A_{0} e^{r x}
$$

where,

$$
\begin{aligned}
& \mathrm{A}_{\mathrm{o}}=\text { an arbitrary constant } \\
& \mathrm{r}=\mathrm{a} \text { constant }
\end{aligned}
$$

Substituting this solution form into Equation 3.4.14 as well as the values for W, X, and Y; the following equation is obtained:

$$
r^{4}-3251.803 r^{2}+72823.707=0
$$

Using Matlab to solve this equation, four values of $r$ were found:

$$
\begin{aligned}
& r_{1}=56.8265 \\
& r_{2}=-56.8265=-r_{1} \\
& r_{3}=4.74882 \\
& r_{4}=-7.74882=-r_{3}
\end{aligned}
$$

This yielded a homogeneous solution:

$$
T_{\text {air }, \text { hom } o g}=A e^{r_{1} x}+B e^{-r_{1} x}+C e^{r_{2} x}+D e^{-r_{2} x}
$$

where, 


\section{$\mathrm{A}, \mathrm{B}, \mathrm{C}$, and D are constants}

A solution to the nonhomogeneous equation was found by assuming the $\mathrm{T}_{\text {air }}$ was a constant. In this case, Equation 3.4.14 yielded the following solution:

$$
T_{\text {air }, \text { hom } o g}=\left(\frac{Z}{W}\right)=T_{e}
$$

Combing the homogeneous and nonhomogeneous solutions gave the general solution to for the air temperature as a function of distance from the waveguide base, $\mathrm{x}$ :

$$
T_{\text {air }}=A e^{r_{1} x}+B e^{-r_{1} x}+C e^{r_{2} x}+D e^{-r_{2} x}+T_{e}
$$

This is an equation with four unknowns, so four equations were needed to evaluate the constants. Four boundary conditions which were imposed on the systems are given as follows:

$$
\begin{aligned}
& \left.T_{\text {air }}\right|_{x=0}=\left.T_{\text {alum }}\right|_{x=0}=1280^{\circ} \mathrm{F}=967 \mathrm{~K} \\
& \left.T_{\text {air }}^{\prime}\right|_{x=L_{\text {wave }}}=\left.T_{\text {alum }}^{\prime}\right|_{x=L_{\text {wave }}}=0
\end{aligned}
$$

The first set of boundary conditions assumes that the base of the waveguide was at a constant temperature $1280{ }^{\circ} \mathrm{F}(966 \mathrm{~K})$. For out-of-cell tests and for most in-cell tests, this temperature would not be approached. This temperature was based on the assumption that some in-cell tests would be performed in which the preheating phase would ensue after a filter loading period at rated conditions. At rated conditions the exhaust temperatures in the exhaust manifold frequently exceeded $1000{ }^{\circ} \mathrm{F}(811 \mathrm{~K})$. The exhaust lines were well insulated, so the trap housing temperatures could easily exceed $800{ }^{\circ} \mathrm{F}$ (700 K). These initial temperatures coupled with the heat transfer, from soot combustion during regeneration, to the waveguide gate valve were used to estimate an appropriate waveguide base temperature for design purposes. The last two boundary conditions were 
“insulated tip" boundary conditions. These were deemed appropriate because the heat transfer area of the end of the waveguide (and inner air "fin") was assumed to be negligible compared to the heat transfer area of the perimeter of the waveguide (and inner air "fin"). Using these boundary conditions to evaluate Equations 3.4.22 and 3.4.12, the 4 equations needed to determine the values for constants $\mathrm{A}, \mathrm{B}, \mathrm{C}$, and D were generated:

$$
\begin{aligned}
& 673=A+B+C+D \\
& 0=-A r_{1} e^{-r_{1} L_{\text {wave }}}+B r_{1} e^{r_{1} L_{\text {wave }}}-C r_{2} e^{-r_{2} L_{\text {wave }}}+D r_{2} e^{r_{2} L_{\text {wave }}} \\
& 673=-\left(\frac{k_{a i r} A_{a i r}}{h_{i n} P_{i n}}\right)\left(A r_{1}^{2}+B r_{1}^{2}+C r_{2}^{2}+D r_{2}^{2}\right)+ \\
& (A+B+C+D) \\
& \text { but, } A+B+C+D=673 \text {, so } \\
& 0=A r_{1}^{2}+B r_{1}^{2}+C r_{2}^{2}+D r_{2}^{2} \\
& 0=-\left(\frac{k_{\text {air }} A_{\text {air }}}{h_{\text {in }} P_{\text {in }}}\right)\left(\begin{array}{l}
-A r_{1}^{3} e^{-r_{1} L_{\text {wave }}}+B r_{1}^{3} e^{r_{1} L_{\text {wave }}}+ \\
-C r_{2}^{3} e^{-r_{2} L_{\text {wave }}}+D r_{2}^{3} e^{r_{2} L_{\text {wave }}}
\end{array}\right)+ \\
& \left(-A r_{1} e^{-r_{1} L_{\text {wave }}}+B r_{1} e^{r_{1} L_{\text {wave }}}-C r_{2} e^{-r_{2} L_{\text {wave }}}+D r_{2} e^{r_{2} L_{\text {wave }}}\right)
\end{aligned}
$$

Matlab was used to solve these simultaneous equations to find A, B, C, and D. The results are given as follows:

$$
\begin{aligned}
& A=-4.73291 \\
& B=-4.1275 \times 10^{-20} \\
& C=663.747 \\
& D=13.986
\end{aligned}
$$

These values were then substituted into Equations 3.4.22 and 3.4.12 to solve for the temperature of the air inside the waveguide and the temperature of the aluminum at any $\mathrm{x}$ position. Using these equations, the temperature of the inner air at the end of the waveguide under these conditions was predicted to be $416.4{ }^{\circ} \mathrm{F}(486.7 \mathrm{~K})$ and the temperature of the aluminum was predicted to be $415.6^{\circ} \mathrm{F}(486.3 \mathrm{~K})$. These temperatures 
were far higher than the design limit of $140{ }^{\circ} \mathrm{F}(333 \mathrm{~K})$, so another method of waveguide temperature control was necessary. The average temperature of the aluminum and air only deviated slightly from the estimated average values, so no further iterations in aluminum or air property values were necessary. The temperature profiles of the air and aluminum as predicted by the model are given in the Figure 3.4.4:

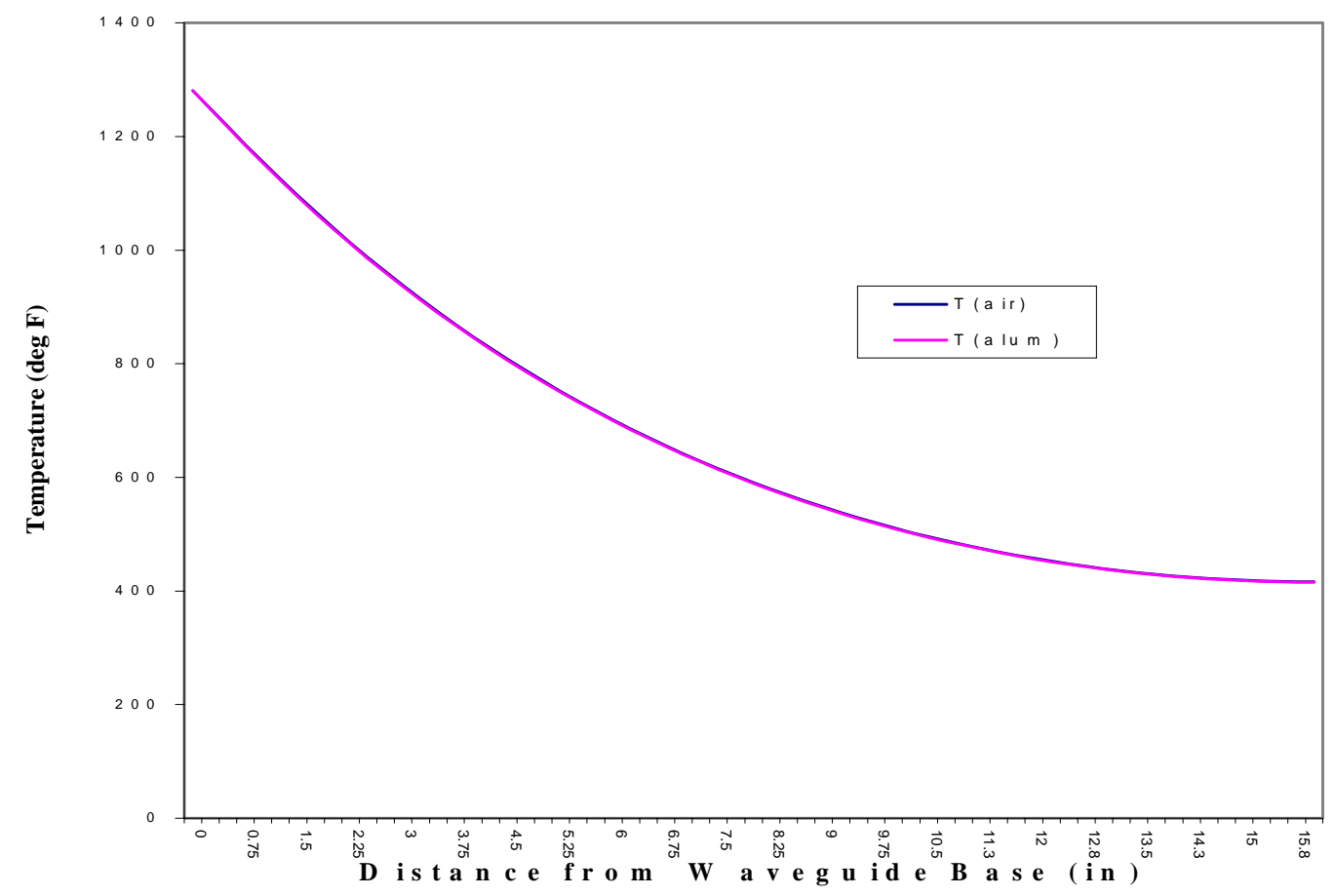

Figure 3.4.4: Temperature Profiles of Inner Air and Aluminum Waveguide for Forced Convection Only

The reason that the inner air and aluminum waveguide temperatures follow each other so closely was that the thermal conductivity of the air was two orders of magnitude lower than the inner convective heat transfer coefficient. This effect was also magnified because the cross-sectional area of the inner air had a much smaller value than the inner perimeter. This made the ratio of $\left(\mathrm{k}_{\text {air }} \mathrm{A}_{\text {air }}\right) /\left(\mathrm{h}_{\mathrm{in}} \mathrm{P}_{\text {in }}\right)$ in Equation 3.4.12 an extremely small value, so the difference between the temperature of the inner air and the aluminum 
waveguide was minimal. From a practical standpoint, the thermal resistance between the air and the aluminum was much smaller than the thermal resistance encountered through the air "fin." Hence, a great deal of heat transfer occurred between the air and the aluminum instead of the heat being conducted through the air "fin."

Due to the high specific heat and high density of water, it is an excellent cooling medium. For this reason the second cooling alternative was a water jacket surrounding a significant portion of the waveguide. This method was slightly more expensive and much more time consuming to fabricate than forced convection case, so a similar analysis was performed as in the case of forced convection to ensure that the waveguide temperatures would be below the design constraint value.

For modeling purposes, it was assumed that the first eight inches of the waveguide (relative to the microwave trap) were surrounded by a water jacket with a cross sectional area of $0.00287 \mathrm{~m}^{2}\left(0.0309 \mathrm{ft}^{2}\right)$ (this corresponded to the walls of the water jacket spaced approximately $3 / 8$ " from the walls of the waveguide). The heat transfer characteristics of the final eight inches of the waveguide were based on a forced convection of air over the waveguide walls. The waveguide was again modeled as a dual fin: the air "fin" surrounded by an aluminum fin, but in this case there were two distinct waveguide sections which resulted in four governing equations which were of the same form as Equations 3.4.9 and 3.4.10:

$$
\begin{gathered}
k_{\text {alum } 1} A_{\text {alum } 1} \frac{d^{2} T_{\text {alum } 1}}{d x^{2}}-h_{e 1} P_{\text {out }}\left(T_{\text {alum } 1}-T_{e 1}\right)+ \\
h_{\text {in } 1} P_{\text {in } 1}\left(T_{\text {air } 1}-T_{\text {alum } 1}\right)=0 \\
k_{\text {air } 1} A_{\text {air } 1} \frac{d^{2} T_{\text {air } 1}}{d x^{2}}-h_{\text {in } 1} P_{\text {in } 1}\left(T_{\text {air } 1}-T_{\text {alum } 1}\right)=0
\end{gathered}
$$




$$
\begin{gathered}
k_{\text {alum } 2} A_{\text {alum } 2} \frac{d^{2} T_{\text {alum } 2}}{d x^{2}}-h_{e 2} P_{\text {out } 2}\left(T_{\text {alum } 2}-T_{e 2}\right)+ \\
h_{\text {in } 2} P_{\text {in } 2}\left(T_{\text {air } 2}-T_{\text {alum } 2}\right)=0 \\
k_{\text {air }} A_{\text {air }} \frac{d^{2} T_{\text {air }}}{d x^{2}}-h_{\text {in }} P_{\text {in }}\left(T_{\text {air }}-T_{\text {alum }}\right)=0
\end{gathered}
$$

where,

subscript 1 refers to the water jacketed waveguide section subscript 2 refers to waveguide section exposed to air

For the water jacketed portion of the waveguide, it was assumed that the distance between the waveguide walls and the water jacket walls was large enough to estimate the heat transfer characteristics based on flow over a flat plate. The heat transfer characteristics could have also been evaluated as flow through a pipe by calculating an equivalent hydraulic diameter. Neither case models the flow exactly, but in case of pipe flow, the flow would have been turbulent, thus increasing the convective heat transfer coefficient relative to the flat plate model. In order to provide a "worst-case" validation, the flat plate model was chosen.

It was assumed that the water temperature was constant at $80^{\circ} \mathrm{F}(300 \mathrm{~K})$ at a mass flow rate of $0.2 \mathrm{~kg} / \mathrm{s}(0.0137 \mathrm{slug} / \mathrm{s})$. Evaluating the properties of water at these conditions, the Reynolds number of the water flow through the waveguide based on flow over a flat plate was found to be $1.64 \times 10^{4}$. The corresponding Nusselt number was calculated as 153.6, and the resulting convective heat transfer coefficient was found to be $462 \mathrm{~W} /\left(\mathrm{m}^{2} \mathrm{~K}\right)$ (based on relations given in Mills, 1992). The convective heat transfer coefficient for the stagnant air inside the waveguide was calculated based on an estimated average air temperature of $620^{\circ} \mathrm{F}(600 \mathrm{~K})$. Evaluating the properties of air based on this 
temperature resulted in a predicted inner-waveguide heat transfer coefficient of 1.313 $\mathrm{W} /\left(\mathrm{m}^{2} \mathrm{~K}\right)$ for the water-jacketed portion.

For the end of the waveguide exposed to air, it was assumed that the air passed over the length of the exposed waveguide at an average of $7 \mathrm{~m} / \mathrm{s}(23 \mathrm{ft} / \mathrm{s})$. The ambient air temperature was taken as $70{ }^{\circ} \mathrm{F}(294 \mathrm{~K})$. The heat transfer characteristics were again calculated based on correlations for flow over a flat plate. Properties of air were calculated based on an estimated air skin temperature of $80{ }^{\circ} \mathrm{F}(300 \mathrm{~K})$. Based on these assumptions, the Reynolds number was found to be $9.083 \times 10^{4}$ (laminar flow) with a corresponding Nusselt number of 176.8 (based on relations given in Mills, 1992). The outer convective heat transfer coefficient was then calculated to be $23.24 \mathrm{~W} /\left(\mathrm{m}^{2} \mathrm{~K}\right)$, and the inner heat transfer coefficient was estimated as $0.815 \mathrm{~W} /\left(\mathrm{m}^{2} \mathrm{~K}\right)($ the inner air properties were also evaluated at $300 \mathrm{~K})$.

The four governing equations were evaluated in the same fashion as in the previous model. The resulting solution to the simultaneous differential equations was in the form of four equations, for the temperature of air and aluminum of each discrete section of the waveguide as function of $\mathrm{x}$ position. The equations are given as follows:

$$
\begin{aligned}
& T_{\text {air } 1}= A e^{-r_{1} x}+B e^{r_{1} x}+C e^{-r_{2} x}+D e^{r_{2} x}+288 K \\
& T_{\text {alum } 1}=-\left(\frac{k_{\text {air } 1} A_{\text {air }}}{h_{\text {in } 1} P_{\text {in }}}\right)\left[\begin{array}{l}
A r_{1}^{2} e^{-r_{1} x}+B r_{1}^{2} e^{r_{1} x}+ \\
C r_{2}^{2} e^{-r_{2} x}+D r_{2}^{2} e^{r_{2} x}
\end{array}\right]+ \\
&\left(A e^{-r_{1} x}+B e^{r_{1} x}+C e^{-r_{2} x}+D e^{r_{2} x}+288 K\right) \\
& T_{\text {air } 2}=E e^{-r_{3} x}+F e^{r_{3} x}+G e^{-r_{4} x}+H e^{r_{4} x}+294 K \\
& T_{\text {alum } 2}=-\left(\frac{k_{\text {air } 2} A_{\text {air }}}{h_{\text {in } 2} P_{\text {in }}}\right)\left[\begin{array}{l}
E r_{3}^{2} e^{-r_{3} x}+F r_{3}^{2} e^{r_{3} x}+ \\
G r_{4}^{2} x+H r_{4}^{2} e^{r_{4} x}
\end{array}\right]+ \\
&\left(E e^{-r_{3} x}+F e^{r_{3} x}+G e^{-r_{4} x}+H e^{r_{4} x}+294 K\right)
\end{aligned}
$$


The eight unknown coefficients $(\mathrm{A}, \mathrm{B}, \mathrm{C}, \mathrm{D}, \mathrm{E}, \mathrm{F}, \mathrm{G})$ required four more boundary conditions than were needed in the first model. The heat transfer at the base of the waveguide was again estimated to be $1280{ }^{\circ} \mathrm{F}(967 \mathrm{~K})$. The free end of the waveguide was again modeled using the insulated tip boundary conditions. This resulted in four boundary conditions which were equivalent to those used in the previous model (see Equations 3.4.23 and 3.4.24). The four extra boundary conditions were found by splining together the temperature profiles of each air segment and also the temperature profiles of each aluminum segment at the junction of the water jacketed and free end portions. The first derivatives of the temperature profiles with respect to $x$ position (again taken as the waveguide centerline distance from the base of the waveguide) were also equated at this junction, so a total of four additional boundary conditions were generated. These four boundary conditions are given as follows:

$$
\begin{aligned}
& \left.T_{\text {air } 1}\right|_{x=L_{\text {wave }} / 2}=\left.T_{\text {air } 2}\right|_{x=L_{\text {wave }} / 2} \\
& T_{\text {alum }\left.1\right|_{x=L_{\text {wave }} / 2}}=\left.T_{\text {alum } 2}\right|_{x=L_{\text {wave }} / 2} \\
& \left.T_{\text {air } 1}^{\prime}\right|_{x=L_{\text {wave }} / 2}=\left.T_{\text {air } 2}^{\prime}\right|_{x=L_{\text {wave }} / 2} \\
& \left.T_{\text {alum } 1}^{\prime}\right|_{x=L_{\text {wave }} / 2}=\left.T_{\text {alum } 2}^{\prime}\right|_{x=L_{\text {wave }} / 2}
\end{aligned}
$$

These boundary conditions were used to evaluate the constants in Equations 3.4.33 to 3.4.36. Matlab was used to calculate the values of the constants in the resulting $8 \times 8$ matrix. Once the constants were known, the temperature profiles of the aluminum and the air inside the waveguide could be analyzed. The resulting temperature profiles are shown in Figure 3.4.5: 


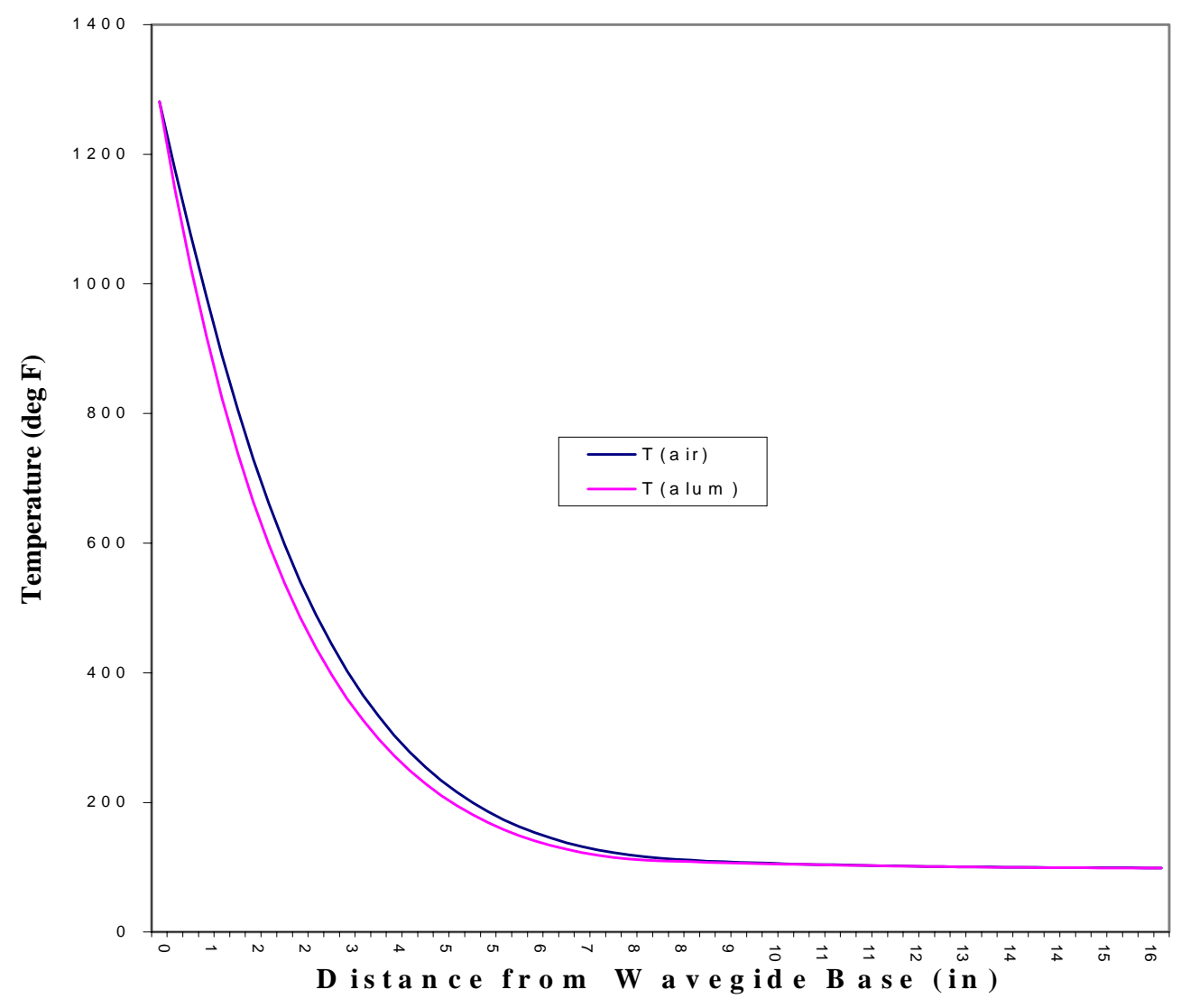

Figure 3.4.5: Temperature Profiles of Inner Air and Aluminum Water Jacketed Waveguide

It is apparent from Figure 3.4.5 that the water jacket was predicted to be very effective at reducing the temperatures of both the inner air and the aluminum. The predicted temperature at the end of the waveguide was below $100{ }^{\circ} \mathrm{F}(311 \mathrm{~K})$. This was well below the design temperature of $140{ }^{\circ} \mathrm{F}(333 \mathrm{~K})$, so a water jacket was considered to be a necessity for continued magnetron operation under all test conditions. A water jacket was welded onto the WR284 waveguide. Photographs of the water jacket and waveguide are shown in Appendix A. 


\subsubsection{Combustion Air Supply System}

One of the four main parameters of interest in the microwave regeneration testing presented in this research was the combustion airflow rate during the convective combustion portion of the regeneration event. This airflow was provided through an inlet port in the trap housing (see Figure 3.1.2). In order to determine airflow rate range to be used for testing purposes during the convective combustion portion of the regeneration process, it was desirable to model the combustion of the soot. The combustion of soot within a ceramic monolith is a very complex process. The microwaves are used during the preheating phase to increase the temperature of the soot entrapped near the end of the filter nearest to the waveguide outlet above the soot oxidation temperature. Oxygen is then provided via an air or exhaust source to sustain this combustion process. As long as the localized temperature of the soot within the reaction zone remains above the soot oxidation temperature, the reaction will proceed along the length of the layer of soot entrapped within a given filter channel. Heat is transferred from the soot by all three heat transfer mechanisms (conduction, convection, and radiation) both axially and radially. Also, the microwaves may not heat the soot uniformly across the filter face, so the combustion process is complicated even further. The combustion process can be limited by the oxygen transfer rate or the chemical reaction rate. The chemical reaction rate can be characterized by the Arrhenius expression (Garner and Dent, 1988):

$$
\begin{aligned}
& K=A e^{\left(\frac{-E}{R T}\right)} \\
& \text { where, } \\
& \mathrm{K}=\text { chemical reaction rate } \\
& \mathrm{A}=\text { frequency factor } \\
& \mathrm{E}=\text { activation energy } \\
& \mathrm{R}=\text { Universal gas constant }
\end{aligned}
$$




$$
\mathrm{T}=\text { absolute temperature }
$$

Unfortunately, there exists an extremely wide range of published values for the frequency factor and the activation energy, which results in a wide range of predicted chemical reaction rates. At high temperatures, the chemical reaction rate is large for the oxidation of soot, so the oxygen transfer rate is typically the limiting value. At low temperatures the chemical reaction rate is small, compared to the oxygen transfer rate to the soot, so the chemical reaction rate is the limiting value (Garner and Dent, 1988). From a practical standpoint, a sufficient amount of air must be provided to sustain the soot oxidation process during the convective combustion portion of the regeneration event. An additional amount of air must also be provided in order to remove excess energy from the filter to prevent filter damage. This further complicates the reaction process because a portion of the supplied air is involved in the soot oxidation process, and the remaining portion of the air is used to transfer energy from the filter.

The conclusion which was drawn from all the aforementioned complicating factors was that the convective combustion process is extremely difficult to model accurately even using computational techniques, so the range of combustion airflow rate that was of interest was based on the range of airflow rates used in previous studies. The range of airflow rates used in previous regeneration studies was on the order of $5 \mathrm{scfm}$ to $40 \mathrm{scfm}\left(0.14 \mathrm{~m}^{3} / \mathrm{min}\right.$ to $\left.1.1 \mathrm{~m}^{3} / \mathrm{min}\right)$ for small-scale wall-flow monoliths (Garner and Dent, 1989; Garner and Dent, 1990; Walton et al., 1990). It was decided that the air supply system had to be capable of bracketing this range, so a target range of $1 \mathrm{scfm}$ to $60 \mathrm{scfm}\left(0.028 \mathrm{~m}^{3} / \mathrm{min}\right.$ to $\left.1.7 \mathrm{~m}^{3} / \mathrm{min}\right)$ was chosen. The air supply system had to be capable of accurately measuring and metering air within this range of airflow. The entire 
airflow system was expected to include a surge tank, an orifice meter or laminar flow element, various lengths of 2.5" $(6.4 \mathrm{~cm})$ diameter flex line and $2.5 "(6.4 \mathrm{~cm})$ diameter solid steel tubing, air heaters, the trap assembly, and a water trap. Based on an estimation of the predicted pressure drops across these components at the maximum expected airflow rate, a design pressure of 4 psi $(27.6 \mathrm{kPa})$ (prior to the surge tank) was chosen as the maximum expected pressure required by air supply at an airflow rate of $60 \mathrm{scfm}(1.7$ $\mathrm{m}^{3} / \mathrm{min}$ ). Another design constraint of the air supply system was that it had to be capable of providing a steady flow of air (that is, the air supply system had to be capable of providing a constant airflow rate during a test).

The Engineering Research Center at WVU had both high- and low-pressure air supplies. The high-pressure air supply was regulated near $100 \mathrm{psi}(690 \mathrm{kPa})$ for low flow rates, but it was not capable of providing the $60 \mathrm{scfm}\left(1.7 \mathrm{~m}^{3} / \mathrm{min}\right)$ upper flow target value. Steady flow control at low flow rates was also a problem. The low-pressure air supply was capable of flow rates of over $400 \mathrm{scfm}\left(11.3 \mathrm{~m}^{3} / \mathrm{min}\right)$ at pressures below 15 psi $(103.4 \mathrm{kPa})$, but due to safety concerns during the initial phases of this project, it was uncertain as to whether these facilities would be available for the regeneration portion of the testing. This uncertainty imposed another design constraint on the air supply system: mobility.

Several quotations from pump manufacturers were obtained for air supply systems which met all the design constraints. Unfortunately, these systems were exorbitantly expensive. Hence none of the manufactured systems was a viable alternative. In order to meet all the design constraints with the available funds, a portable 
air supply system was designed and built at WVU. A flow schematic of the system is provided in Figure 3.4.6.

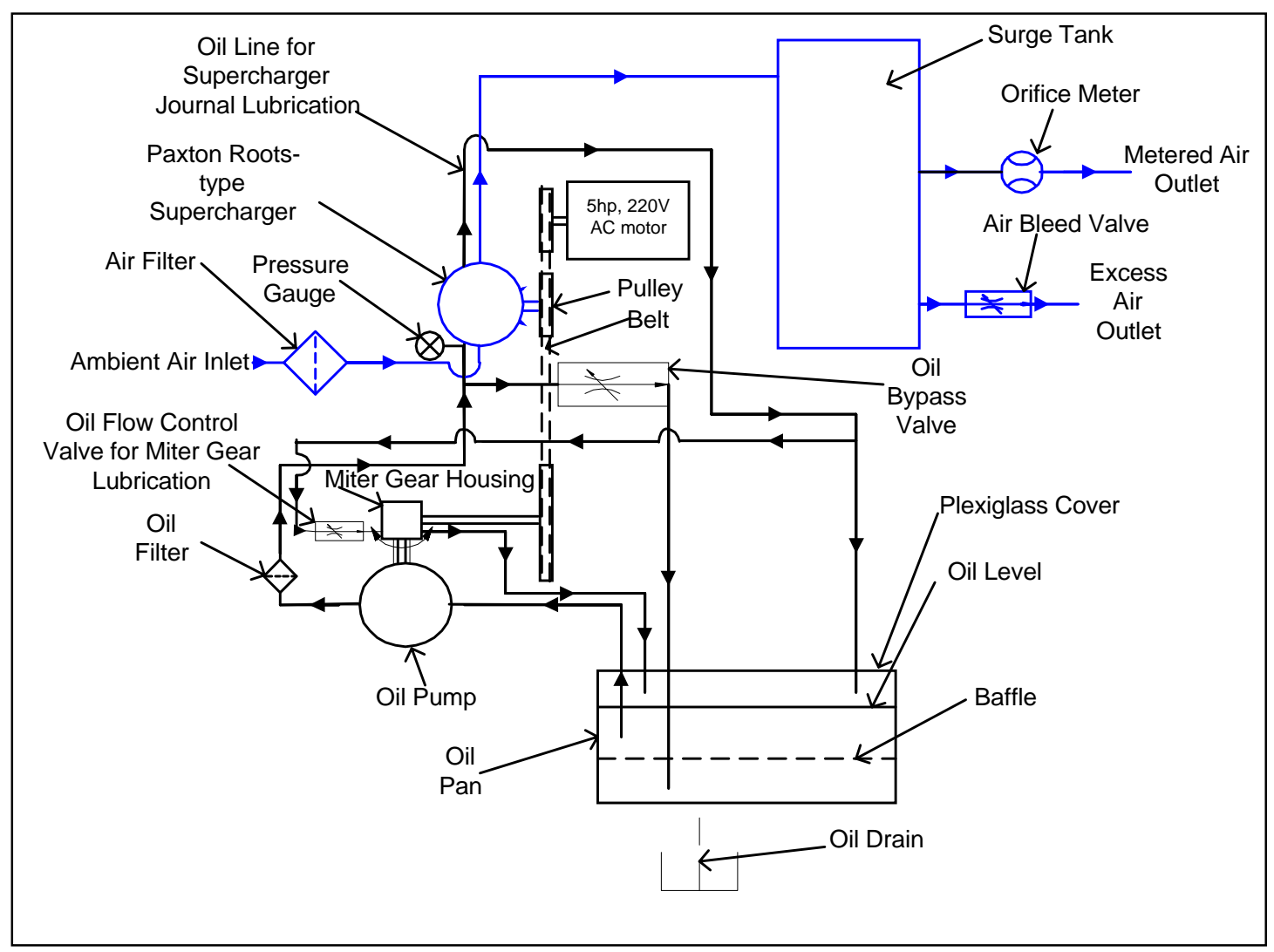

Figure 3.4.6: Air Supply Cart Flow Schematic

Photographs of this system are provided in Appendix H. The heart of the system was a small, Roots-type, Paxton supercharger which was originally found disassembled with some of the components missing. All of the seals were replaced including the shaft end seal which prevented oil from flowing out of the supercharger between the input shaft and the shaft housing. The shaft end seal had apparently been a nonstandard size. Another option was that it may have sealed on the support neck of a specialized pulley with an O-ring used to seal the joint between the pulley and the input shaft. In either 
case, neither the pulley nor the seal were found with the original components, and neither was available from the manufacturer. The seal was replaced by using a standard seal and an aluminum spacer which was machined and pressed into the end of the input shaft housing. The lobe Teflon end seals were replaced, and a custom oil distribution plate was fabricated and mounted to the bottom of the supercharger in order to provide a means of distributing lubricating oil through the ports located on the bottom of the supercharger and to the rotor journals. An air filter adapter plate was also fabricated in order to mount a small automotive air filter to the air inlet of the supercharger. The air supply system components were mounted on a custom designed cart (as shown in Appendix H), so the system was entirely mobile.

A standard GM oil pump was used to provide lubricating oil to the supercharger. A GM oil pump was chosen because it required a paddle type input shaft. This type of shaft was much easier to fabricate than a hexagonal shaft which would have been required if a standard Ford oil pump was used. The oil pump was mounted to a custombuilt frame. The frame was also used to support a stainless steel oil sump, as well as the input shafts for the oil pump. Miter gears were used to position the oil pump drive pulley in the same plane as the supercharger and motor pulleys. The miter gears were contained in a sealed housing which allowed the gears to be lubricated during operation. A large quantity of oil was not required for miter gear lubrication, so a small ball valve was placed in the oil feed line to the miter gear housing (see Figure 3.4.6). The valve was nearly closed at all times, allowing only a small quantity of oil to reach the gears. The oil drained by gravity out of the housing and into the oil pan. A larger valve was placed in the oil bypass line. This valve was used to set the oil pressure in the supercharger feed 
line at $37 \mathrm{psi}(255 \mathrm{kPa})$ when the oil temperature stabilized. Although the oil pump drive pulley was made as large as possible to reduce the oil pump speed relative to the motor, the bypass oil flow was still relatively large. Therefore, the return oil flow was routed beneath a baffle in the oil pan. This forced the oil to flow through the baffle to reach the oil pickup tube, which prevented excessive oil swirl in the pan. A plexiglass cover was also placed over the oil pan to prevent dirt and dust buildup in the oil.

In order to size the motor for the air supply cart, the power required to drive both the supercharger and the oil pump at the maximum required flow $\left[60 \mathrm{scfm}\left(1.7 \mathrm{~m}^{3} / \mathrm{min}\right)\right.$ at 4 psi (27.6 kPa) gauge pressure] was calculated as follows. The power required to drive the supercharger under these conditions was represented using the following relation:

$$
\dot{W}_{\text {in, ideal }}=\dot{m}\left(h_{2}-h_{1}\right)
$$

where,

$$
\begin{aligned}
& \dot{W}=\text { input power to the unit } \\
& \dot{m}=\text { mass flow rate } \\
& \mathrm{h}_{2}=\text { specific enthalpy at the system outlet } \\
& \mathrm{h}_{1}=\text { specific enthalpy at the system inlet }
\end{aligned}
$$

This relation assumes that the kinetic and potential energy effects are negligible compared to the change in enthalpy, and that the air compression process is adiabatic. The inlet absolute pressure and temperature were assumed to be $14.7 \mathrm{psia}(101.4 \mathrm{kPa})$ and $70{ }^{\circ} \mathrm{F}(294 \mathrm{~K})$, respectively, and the outlet design pressure was set at 4 psig (or 18.7 psia $=128.9 \mathrm{kPa}$ ). The temperature of the air at the outlet was solved by using the following isentropic relation for ideal gases:

$$
\frac{p_{2}}{p_{1}}=\left(\frac{\rho_{2}}{\rho_{1}}\right)^{1.4}
$$


where,

$\mathrm{p}_{2}=$ absolute pressure at the supercharger outlet

$\mathrm{p}_{1}=$ absolute pressure at the supercharger inlet

$\rho_{1}=$ density at the supercharger inlet $=1.2 \mathrm{~kg} / \mathrm{m}^{3}$

$\rho_{2}=$ density at the supercharger outlet

$\mathrm{k}=$ specific heat ratio $=1.4$ for air

Solving for the density at the supercharger outlet and substituting the appropriate values into Equation 3.4.43, the density at the outlet was found to be $1.43 \mathrm{~kg} / \mathrm{m}^{3}\left(2.23 \times 10^{-6}\right.$ slug/ $\mathrm{ft}^{3}$. The ideal gas law was then used to calculate the temperature of the air at the outlet, which was calculated to be $105^{\circ} \mathrm{F}(314 \mathrm{~K})$. For ideal gases, the specific enthalpy is dependent only on the absolute temperature. The tabulated values of the specific enthalpy of air at the inlet and outlet conditions were found to be $314 \mathrm{~kJ} / \mathrm{kg}$ and $294 \mathrm{~kJ} / \mathrm{kg}$ respectively $^{* * * *}$. The maximum design volumetric airflow rate of $60 \mathrm{scfm}\left(1.7 \mathrm{~m}^{3} / \mathrm{min}\right)$ corresponds to a mass flow rate of $0.0340 \mathrm{~kg} / \mathrm{s}(0.00233 \mathrm{slug} / \mathrm{s})$. Substituting these values into Equation 3.4.42, the ideal input power required to operate the supercharger under these conditions was $680 \mathrm{~W}$ ( $0.912 \mathrm{hp})$. The actual power required to drive the supercharger under these conditions was estimated by assuming that the supercharger had a total efficiency (including both isentropic and mechanical efficiencies) of 75\%. Using this value, the actual power required to rotate the supercharger with a $60 \mathrm{scfm}(1.7$ $\left.\mathrm{m}^{3} / \mathrm{min}\right)$ flow rate with a pressure drop of $4 \mathrm{psi}(27.6 \mathrm{kPa})$ across the unit was estimated to be $907 \mathrm{~W}(1.22 \mathrm{hp})$.

The power required to operate the oil pump was calculated using Equation 3.4.42 and by assuming the oil to be incompressible. For an incompressible liquid, the change in specific enthalpy can be calculated using the following equation:

\footnotetext{
${ }^{* * * * *}$ Values taken from Fundamental of Engineering Thermodynamics, $2^{\text {nd }}$ ed. by M. Moran and H. Shapiro
} 


$$
h_{2, \text { oil }}-h_{1, \text { oil }}=\frac{1}{\rho_{\text {oil }}}\left(p_{2, \text { oil }}-p_{1, \text { oil }}\right)
$$

where,

$$
\begin{aligned}
& \mathrm{h}_{2, \text { oil }}=\text { specific enthalpy of oil at oil pump outlet } \\
& \mathrm{h}_{1, \text { oil }}=\text { specific enthalpy of oil at oil pump inlet } \\
& \rho_{\text {oil }}=\text { oil density } \\
& \mathrm{p}_{2, \text { oil }}=\text { absolute pressure at oil pump outlet } \\
& \mathrm{p}_{1, \text { oil }}=\text { absolute pressure at oil pump inlet }
\end{aligned}
$$

Substituting Equation 3.4.45 into Equation 3.4.42, the following equation for the input power required by the oil pump was obtained:

$$
\dot{W}_{\text {in,ideal }}=\dot{V}_{\text {oil }}\left(p_{2, \text { oil }}-p_{1, \text { oil }}\right)
$$

where,

$$
\dot{V}_{\text {oil }}=\text { oil volumetric flow rate }=\frac{m_{\text {oil }}}{\rho_{\text {oil }}}
$$

This equation does not consider the pumping work required to force the oil into and out of the oil pump passages. It also assumes that the potential and kinetic energy terms are negligible. The supercharger to oil pump drive ratio was $0.25: 1$. The supercharger was typically driven at $3000 \mathrm{rpm}$, so the oil pump was driven at an angular speed of $750 \mathrm{rpm}$. The oil pressure was predicted to be near $43 \mathrm{psig}$ ( $296 \mathrm{kPa}$ ) at the pump outlet, and at these conditions, the oil flow rate was estimated to be $4.5 \mathrm{gpm}\left(0.000284 \mathrm{~m}^{3} / \mathrm{s}\right)(\mathrm{Tim}$ Cross, Melling, Inc). The control volume considered included the pickup tube, so the inlet oil pressure was near atmospheric. Substituting these values into Equation 3.4.45, the ideal power required to pump the oil under these conditions was $84.2 \mathrm{~W}(0.113 \mathrm{hp})$. Due to pumping losses and inefficiencies, this value was expected to be much lower than the actual power required to pump the oil, but the pump input power was still expected to be less than $1 \mathrm{hp}$. 
Based on the predicted required power values of the supercharger and oil pump, a $220 \mathrm{~V}, 5 \mathrm{hp}$, constant-speed motor was chosen as the drive mechanism for both the supercharger and the oil pump. This motor provided sufficient power to accelerate the oil pump and supercharger during start-up, and provided extra power in the event that the air supply cart should be needed for higher flow rate applications. A fuse panel was mounted to the back of the cart to prevent excessive current from being supplied to the motor. An A-belt was used to transfer power from the motor to the supercharger and oil pump. An idler pulley was incorporated into the design to prevent excessive belt vibration.

The supercharger driven pulley was replaced by a standard 3" $(7.6 \mathrm{~cm})$ V-belt pulley, and this change required the input drive shaft to be replaced as well (the original shaft was too short). The original drive shaft was splined to an adaptor which bolted to one of the helical gears which were attached to the lobe shafts. Instead of splining the replacement shaft, the splined adaptor was replaced with a keyed adaptor. The supercharger drive shaft and adapter were machined out of 1018 steel. The ultimate and yield strengths of this type of steel were much lower than the original materials, so a stress analysis was performed. Under the maximum flow and pressure condition, the power required to operate the supercharger was found to be $907 \mathrm{~W}$ (1.2 hp). The torque imposed on the driveshaft (and the coupling) was calculated using the following relation:

$$
T_{\text {shaft }}=\frac{\dot{W}}{2 \pi R_{\text {shaft }}}
$$

where,

$$
\begin{aligned}
& \mathrm{T}_{\text {shaft }}=\text { torque imposed on the driveshaft } \\
& \dot{W}=\text { input power to the supercharger }=907 \mathrm{~W}=1.2 \mathrm{hp} \\
& \mathrm{R}_{\text {shaft }}=\text { shaft rotational speed }=3000 \mathrm{rpm}
\end{aligned}
$$


Substituting the appropriate values of power and angular speed into Equation 3.4.46, the torque imposed on the driveshaft at the condition requiring the maximum amount of power was calculated to be 25.6 in-lbf $(2.89 \mathrm{~N}-\mathrm{m})$. The end of the supercharger drive shaft on which the pulley was mounted was supported by a bearing. The bearing was mounted in the far end of the cylindrical support housing, which allowed the pulley to be mounted in close proximity to the bearing which minimized the bending moments on the driveshaft. For this reason, the bending moments imposed on the driveshaft were assumed to be negligible. The shearing stresses generated in the shaft due to torsional loading were found to be an order of magnitude larger than the shearing stresses created by transverse loading, so only torsional loads were considered in the stress analysis.

The first rotation yield of the driveshaft and its components were analyzed by considering the areas of maximum stress. These areas were found to be near the shaft fillets, the keyways, and the keys. There were three fillets in the drive shaft. The fillet which created the greatest stress concentration was near the pulley. The equation used to quantify the stress at this section of the shaft is given as follows (Beer and Johnston, 1981):

$$
\begin{gathered}
\tau_{\text {fillet }}=K_{\text {shear }} \frac{T_{\text {shaft }}}{\frac{1}{2} \pi c^{3}} \\
\text { where, } \\
\\
\tau_{\text {fillet }}=\text { shearing stress in the shaft } \\
\mathrm{K}_{\text {shear }}=\text { stress concentration factor } \\
\mathrm{c}=\text { shaft radius }
\end{gathered}
$$

At this section of the shaft, the diameter changed from $0.75 "$ to 0.788 " $(1.91 \mathrm{~cm}$ to 2.00 $\mathrm{cm})$, and the fillet radius was approximately $0.0625 "(0.159 \mathrm{~cm})$. The corresponding stress concentration factor was 1.15 (Beer and Johnston,1981). Substituting these values 
into Equation 3.4.47, the shearing stress at the fillet was found to be $0.355 \mathrm{kpsi}\left(2.45 \times 10^{6}\right.$ $\left.\mathrm{N} / \mathrm{m}^{2}\right)$. Keyways were present in both ends of the shaft. Both were $1.375 "(3.493 \mathrm{~cm})$ long and 3/16" $(0.4763 \mathrm{~cm})$ in width. The stress concentration factor associated with these keyways was taken to be $2.62^{\dagger+\dagger \dagger}$. The maximum shearing stress in the shaft in the keyed section of the shaft with the smallest diameter $(3 / 4 "=1.91 \mathrm{~cm})$ was calculated using Equation 3.4.47 and was found to be $0.810 \mathrm{kpsi}\left(5.58 \times 10^{6} \mathrm{~N} / \mathrm{m}^{2}\right)$.

The keyed sections of the shaft also had a bearing load imposed on them from the torque applied by the pulley. This load was equally imposed on the key and the walls of the keyed areas of the shaft, and the stress associated with this load was calculated using the following relation:

$$
\begin{aligned}
& \sigma_{\text {bearing }}=\frac{F_{\text {bearing }}}{A_{\text {bearing }}} \\
& \text { where, } \\
& \sigma_{\text {bearing }}=\text { bearing stress } \\
& \mathrm{F}=\text { load } \\
& \mathrm{A}_{\text {bearing }}=\text { cross-sectional area over which the load is applied } \\
& =1 / 2 \text { key height } * \text { key length }=3 / 32 " \times 13 / 8 "
\end{aligned}
$$

In this case the bearing load was related to the applied torque:

$$
T_{\text {shaft }}=\vec{r} \times \vec{F}
$$

where,

$$
\begin{aligned}
& \vec{r}=\text { position vector from shaft centerline to the point of load application } \\
& \vec{F}=\text { force vector }
\end{aligned}
$$

In this case the position vector was perpendicular to the force vector, so,

$$
T_{\text {shaft }}=r F
$$

where,

$$
r=\text { shaft radius at the keyed section }
$$

\footnotetext{
${ }^{+1+\dagger}$ Stress concentration value taken from Mechanical Engineering Design, $5^{\text {th }}$ ed. by J. Shigley and C. Mischke, 1989
} 
Note that in this case the force applied to the keys and keyed walls was approximated as the force present at the outer edge of the shaft diameter. The torque applied to the shaft and the shaft radius were known (the larger of the two shaft radii at the keyed sections was used in this case $-0.752 "=1.91 \mathrm{~cm}$ ). Therefore, Equation 3.4 .50 was solved for the bearing load which was substituted into Equation 3.4.48. The bearing stress imposed on both the shaft keyed walls and the keys was found to be $0.528 \mathrm{kpsi}\left(3.64 \times 10^{6} \mathrm{~N} / \mathrm{m}^{2}\right)$.

The torque applied from the pulley to the keys generated a shearing stress within the keys as well as a bearing load. The shearing stress within the key at the larger of the two keyed shaft diameters was calculated using the following equation:

$$
\tau_{\text {key }}=\frac{F}{A_{\text {key }}}
$$

where,

$$
\begin{aligned}
& \tau_{\text {key }}=\text { shearing stress within the key } \\
& \begin{aligned}
\mathrm{F}=\text { load } \\
\mathrm{A}_{\text {key }}=\text { cross sectional area of the key } \\
=\text { key width * key length }=3 / 16 " \times 13 / 8 \text { " }
\end{aligned}
\end{aligned}
$$

The applied load was the same as that of Equation 3.4.50, so the key shearing stress was found to be $0.264 \mathrm{kpsi}\left(1.82 \times 10^{6} \mathrm{~N} / \mathrm{m}^{2}\right)$.

The yield strength and ultimate strength of hot-rolled 1018 steel were found to be

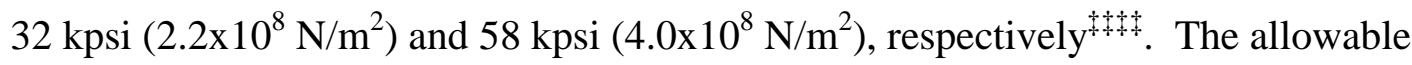
normal stress (bearing stress in this case) in the shaft had to be below the tensile strength of the steel, while the allowable shearing stress had to be below one half of the yield strength of the steel (Shigley and Mischke, 1989).

The Goodman fatigue theory was used to evaluate driveshaft fatigue. For a shaft loaded only in torsion, the following relation is applicable (Shigley and Mischke, 1989):

${ }^{*}$ Steel strength values taken from Mechanical Engineering Design, $5^{\text {th }}$ ed. by J. Shigley and C. Mischke 


$$
\frac{1}{n}=\frac{32 K_{\text {shaft }}}{\pi d_{\text {shaft }}^{3}}\left(\frac{T_{m}}{S_{u t}}\right)
$$

where,

$$
\begin{aligned}
& \mathrm{n}=\text { safety factor } \\
& \mathrm{d}_{\text {shaft }}=\text { shaft diameter } \\
& \mathrm{K}_{\text {shaft }}=\text { stress concentration factor } \\
& \mathrm{T}_{\mathrm{m}}=\text { mean applied torque } \\
& \mathrm{S}_{\mathrm{ut}}=\text { ultimate strength of the shaft material }
\end{aligned}
$$

The mean torque was taken as one half the value of the torque applied to the shaft during the maximum flow and pressure condition $(12.8 \mathrm{in}-\mathrm{lbf}=1.45 \mathrm{~N}-\mathrm{m})$. The point of maximum stress was used for the fatigue evaluation (that is, the keyed area of the shaft at the smaller of the two keyed diameters). As was stated in the first rotation yield analysis, the shaft diameter at this point was $0.75 "(1.91 \mathrm{~cm})$, and the stress concentration factor was 2.62. Substituting the appropriate values into Equation 3.4.52, the safety factor was found to be 71.6, which indicated that the shaft design was adequate for the operating conditions required during testing.

All of the stress values were well below the allowable values, so $1018 \mathrm{HR}$ steel was used as the shaft material (the steel used in the keys had strength values much higher those of 1018 HR steel). Similar first rotation yield and fatigue analyses were performed for the oil pump driveshafts and the supercharger driveshaft adapter. The dimensions of these components were not as restricted as the dimensions of the driveshaft, so the shaft and adapter analyses were not as critical as the driveshaft analysis.

Air from the supercharger was routed into a surge tank which was used to decrease the pulsations in the airflow. The surge tank was sized in the same manner as the engine exhaust surge tank (see Section 3.3), only in this case the two pulsations were generated per revolution instead of 3 pulses per revolution (6-cylinder, 4 stroke engine). The supercharger was typically operated at a angular speed of approximately $3000 \mathrm{rpm}$. 
At this speed, the supercharger was capable of flows through the surge tank over 125 $\operatorname{scfm}\left(3.54 \mathrm{~m}^{3} / \mathrm{min}\right)$. When necessary, the supercharger speed was varied by changing the pulley diameter ratio between the motor and the supercharger. Operational speed changes were not typically necessary, because the supercharger was capable of providing flow rates well in excess of the desired maximum design target airflow rate. The excess air was vented through a bleed air valve in the surge tank. A stainless steel ball valve was used to control the flow rate of the bleed air. This provided course control of the metered air flowing through the orifice meter in the second surge tank outlet (see Figure 3.4.6). Several orifice meters were fabricated to provide various flow ranges. The orifice meter which was used in this testing was calibrated from approximately $5 \mathrm{scfm}$ and 22 $\operatorname{scfm}\left(0.142 \mathrm{~m}^{3} / \mathrm{min}\right)$. It was calibrated in the same fashion as the orifice meters used in the engine exhaust lines (see Section 3.3). However, in this case, a 25 acfm $(0.708$ $\mathrm{m}^{3} / \mathrm{min}$ ) laminar flow element was positioned four feet downstream of the orifice meter during calibration. Validyne pressure transducers (model P304D) were used to monitor the differential pressure across the orifice meter as well as the upstream pressure. A Jtype thermocouple was used to monitor the upstream air temperature. The calibration plot for this orifice meter is provided in Appendix I. In this case, the properties of the air during testing were nearly identical to the air properties during calibration, so Reynolds number effects between the calibration conditions and the test conditions on the flow coefficient were negligible. It is apparent from the first and last points in the calibration curve that the orifice meter was operated in a range where small changes in flow coefficient occurred with changing Reynolds number (changed due to changes in flow rate). This effect was also predicted in the plot of flow coefficient versus Reynolds 
number for flat plate orifice meters given by Figliola et al. (1991). Additional orifice meters were fabricated for larger flow rates. In testing subsequent to this research, a laminar flow element was used to measure the combustion airflow rate for flow rates below $5 \mathrm{scfm}\left(0.14 \mathrm{~m}^{3} / \mathrm{min}\right)$. For the research presented in this work, measured airflow rates remained above $5 \mathrm{scfm}\left(0.14 \mathrm{~m}^{3} / \mathrm{min}\right)$. Large temperature changes were not present, so the orifice meter expansion factor was assumed to be 1 . Also, the orifice meter differential pressures were relatively low, so the compressibility factor was assumed to be 1.

\subsubsection{Out-of-cell Regeneration Assembly}

As was mentioned previously, all of the regeneration testing presented in this work was performed outside the engine test cell, although in-cell regeneration tests were performed using the same equipment (Popuri, 1999). For any of the regeneration tests, the main components which were required were the magnetron/waveguide assembly, the waveguide gate valve, the magnetron controls, the filter assembly, an oxygen supply, and a microwave absorption device positioned after the trap to absorb any microwaves which passed through the filter unattenuated. A schematic of the water trap which was used for the in-cell testing was shown in Figure 3.3.5, and photographs are contained in Appendix A. Space constraints prevented the incorporation of this water trap into the out-of-cell regeneration assembly, so a new water trap was designed and fabricated. A schematic of this device is presented in Figure 3.4.7, and photographs are contained in Appendix K. 


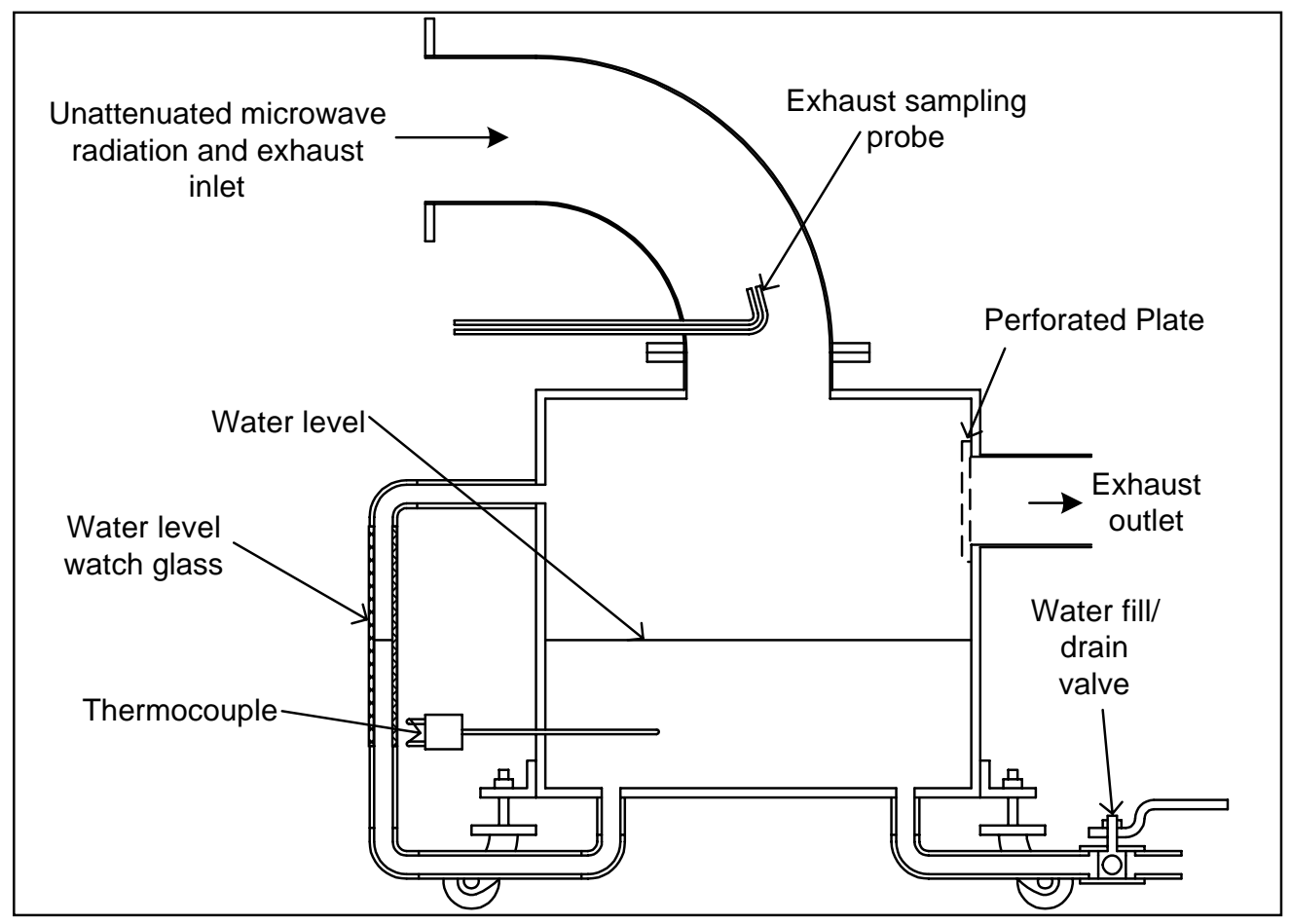

Figure 3.4.7: Out-of-cell Water Trap

Microwaves and/or products of combustion entered the water trap through a flanged elbow attached to the top of the tank and were directed towards a volume of water in the base of the tank. The microwaves entering the tank were absorbed by the water while the exhaust exited the tank through a perforated plate which was welded over the exhaust outlet tube. Because the tank was sealed, the water level was monitored through a watch glass. The watch glass and transfer tubes to the watch glass had diameters which were much smaller than the wavelength of the microwaves, so no microwaves were transmitted through the glass tube. Water was added or drained from the tank through a separate valve and pipe assembly. A sampling probe was positioned inside of the intake elbow to provide a means of sampling the products of combustion during regeneration. The sampling scheme will be discussed subsequently. A thermocouple was inserted into 
the water bath in order to monitor the temperature of the water before and after the period of magnetron activation (that is, the preheating period). The temperature difference of the water bath before and after the preheating period gave an indication as to the degree of microwave attenuation in the filter. If a large amount of soot remained in the filter during the entire preheating period, the temperature of the water did not increase significantly. If a large degree of soot was combusted during the preheating period, some of the microwaves were able to pass through the filter unattenuated, and the water temperature increased significantly. During the preheating period, the microwaves penetrated into the water to a sufficient depth to generate stray currents within the thermocouple, so no temperature readings could be taken until after the magnetron was deactivated.

A schematic that includes all the out-of-cell regeneration components is given in Figure 3.4.8: 


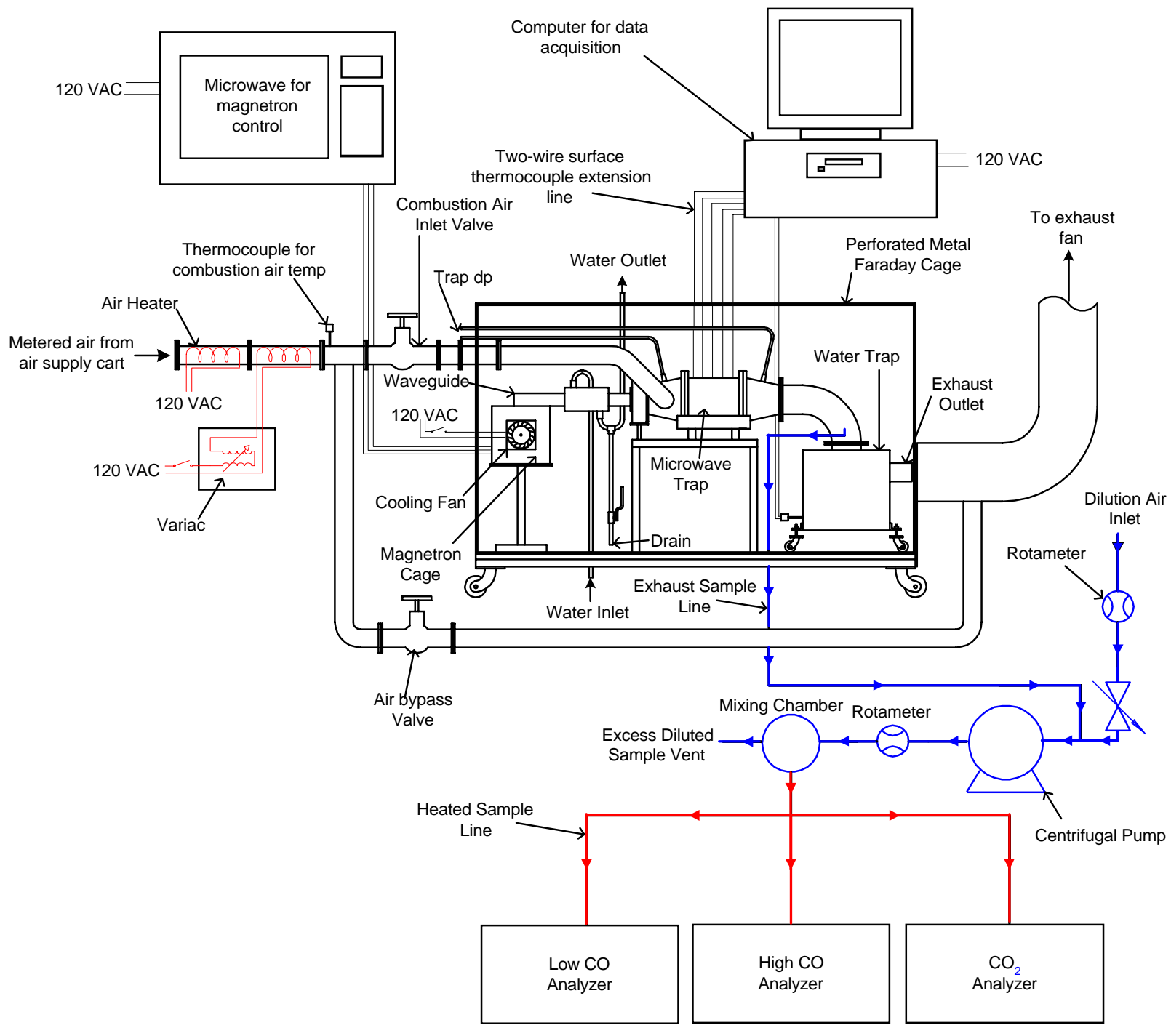

Figure 3.4.8: Out-of-cell Regeneration Testing Apparatus 
As indicated by the diagram, the air supply cart was used to generate the airflow for the convective combustion portion of the regeneration event. Metered air from the supercharger cart was directed through 2, 1000W air heaters that were in series. The air heaters were used to control the temperature of the combustion air supplied to the filter. A target air temperature value of $500{ }^{\circ} \mathrm{F}(533 \mathrm{~K})$ at $10 \mathrm{scfm}(0.00472 \mathrm{~kg} / \mathrm{s}=0.000323$ slug/s) was set as a design goal of the air heating system. Assuming that $80 \%$ of the nominal electrical energy was supplied to the air during the heating process, and neglecting kinetic and potential energy effects, the following form of the energy equation was used to determine the maximum air temperature that could be achieved with the two heaters:

$$
\dot{Q}_{\text {air }}=\dot{m}_{\text {air }}\left(h\left(T_{\text {out }}\right)-h\left(T_{\text {in }}\right)\right)
$$

where,

$$
\begin{aligned}
& \dot{Q}_{\text {air }}=\text { heat transfer rate }=2.00 \mathrm{~kW} \times 0.80=1.60 \mathrm{~kW} \\
& \dot{m}_{\text {air }}=\text { mass flow rate of air }=0.00472 \mathrm{~kg} / \mathrm{s}=0.000232 \mathrm{slug} / \mathrm{s} \\
& \mathrm{h}(\mathrm{T})=\text { enthalpy of the air as a function of temperature only }
\end{aligned}
$$

Assuming an inlet air temperature of $90{ }^{\circ} \mathrm{F}(305 \mathrm{~K})$ and using the corresponding enthalpy value (Moran and Shapiro, 1992), the enthalpy of the air exiting the air heaters was found to be $644 \mathrm{~kJ} / \mathrm{kg}$. This enthalpy value was found to correspond to a temperature of $715^{\circ} \mathrm{F}$ $(653 \mathrm{~K})$, so the air heaters were capable of meeting the design constraint.

Both air heaters required $120 \mathrm{VAC}$ electrical power input. The first air heater was only used when the second air heater alone could not increase the air temperature to the test target value. In cases where only one air heater was needed, the first air heater was not activated, and the second air heater was controlled by a variac. The variac allowed the power supplied to the air heater to be adjusted until the target air temperature at a 
given airflow rate was reached. In instances where both air heaters were needed, the first air heater was operated at maximum power, and the power input to the second air heater was adjusted until the target temperature was achieved.

Upon exiting the air heaters, the combustion air was either directed via high temperature gate valves into a bypass line or into the filter housing. Air was diverted into the bypass line so that the airflow rate and temperature could be set prior to regeneration. In this way, the trap inlet air temperature was essentially constant during regeneration. Air flowing through the bypass line eventually entered the large exhaust duct at the end of the Faraday cage. Airflow through this duct was vented to the atmosphere through a large exhaust blower. The high airflow rate through the exhaust duct was also used to vent the products of combustion from the water trap into the atmosphere during regeneration.

The magnetron and waveguide were used to generate and direct microwaves into the filter assembly during the preheating portion of regeneration. A 120VAC cooling fan and the waveguide water jacket were used to maintain the magnetron temperature at acceptable levels during regeneration. A drain hose was used to empty the water jacket at the end of each test to prevent scale buildup within the water jacket. The waveguide gate valve was positioned between the filter housing and the waveguide to protect the magnetron and waveguide during combustion. The controls of a Sharp microwave oven including the keypad, high and low voltage transformers, capacitor and rectifier were used to control the magnetron activation. The microwave was left essentially intact except for the magnetron and thermal switch removal. The power supply and ground lines were routed out of the back of the unit, through a notched trap door in the top of the 
Faraday cage and to the magnetron which was enclosed in a second, smaller Faraday cage (which was used to prevent microwave leakage during in-cell testing). The highvoltage and ground lines were placed in flexible plastic conduit and were routed away from all instrumentation and power supply lines to prevent interference.

Five fast-response, K-type, surface thermocouples with a self-adhesive backing (manufactured by Omega) were placed in a row on the surface of the filter housing along the trap centerline. The thermocouples were equally spaced and were used to give an indication of the propagation of the flame front through the filter. The signals from these thermocouples were recorded by a data acquisition system which consisted of a Dell computer, and Omega temperature board and software, thermocouple extensions wire, and a junction box. Temperatures were recorded from 1 to 5 seconds depending on the length of the test.

During the convective combustion portion of regeneration the combustion air was routed through the filter assembly. Pressure ports before and after the filter were used to monitor the differential pressure across the trap. Excess air and products of combustion (and unabsorbed microwaves if the magnetron remained activated during convective combustion) exited the filter assembly and entered into the water trap through a $90^{\circ}$ elbow. A sample of the exhaust was drawn through a sampling probe in this elbow. This sample was used to determine the onset of combustion, the rate of combustion, and the degree of complete combustion. A centrifugal vacuum pump was used to draw the sample through the probe as well as dilution air. The dilution air was drawn into the pump through a rotameter which was used to measure the quantity of dilution air. A restrictor valve was used to adjust the ratio of sample mass flow rate to dilution mass 
flow rate. The sample flow rate was calculated by measuring the outlet flow of the pump via a second rotameter. This provided a measure of the total flow through the pump, so the sample flow rate was calculated by subtracting the dilution airflow rate from the exhaust flow rate (assuming identical molecular weights). The diluted sample exited the rotameter and entered a mixing chamber which allowed residence time for mixing. The emissions analyzer sampling assembly was designed to draw an exhaust sample from a dilution tunnel. For this reason, the mixing chamber had a vent which released some of the diluted sample to the atmosphere. The pump flow rate was much greater than the flow required by the analyzers, so no extra dilution air was drawn into the mixing chamber. The sample flow drawn from the mixing chamber by the analyzers was transported through heated lines maintained at $375^{\circ} \mathrm{F}\left(191{ }^{\circ} \mathrm{C}\right)$ to prevent condensation. The Rosemount low CO (0 to 1000 ppm and 0-5000 ppm ranges), high CO (0 to $2 \%$ and 0 to $10 \%$ ranges), and $\mathrm{CO}_{2}$ ( 0 to $5 \%$ and 0 to $20 \%$ ranges) analyzers were used as an indicators of the onset of and the relative magnitude of the soot combustion within the filter assembly.

A data acquisition program was written in BASIC to display and record values of combustion airflow rate and temperature, test time, trap differential pressure CO digital output signal (from an analog to digital converter), and a $\mathrm{CO}_{2}$ digital output signal. This data acquisition program was completely independent of the data acquisition system used to display and monitor the trap surface temperature and the water trap temperature. Several versions of the program were used because some hardware changes were made during the test matrix execution. Some of these changes included the included the incorporation of both the low $\mathrm{CO}$ and high $\mathrm{CO}$ analyzer signals, as well as a change in 
flow metering devices for low flow measurements (LFE replaced the orifice meter). One version of this program is included in Appendix L.

\subsection{Soot Conditioning System}

The regeneration efficiency was one of the main results of interest in determining the effectiveness of a given combination of parameters (combustion airflow rate and temperature, initial soot loading, and preheating time) in terms of soot regeneration in the ceramic monolith. In many regeneration studies, the initial soot loading and/or the regeneration efficiency were determined indirectly by measuring the differential pressure across the filter at a given airflow or exhaust flow rate (Wade et al., 1983). This type of estimation can lead to a great deal of uncertainty in the values of the initial soot loading and regeneration efficiency. Therefore, adopting a more direct approach, the initial soot loading and the mass of soot remaining in the trap after regeneration were determined gravimetrically. Using this technique, the regeneration efficiency was defined as follows:

$$
\begin{aligned}
& \eta_{\text {reg }}=\frac{m_{i}-m_{f}}{m_{i}-m_{p}} \\
& \text { where, } \\
& \qquad \begin{array}{l}
\mathrm{m}_{\mathrm{i}}=\text { mass of filtration assembly after soot loading } \\
\mathrm{m}_{\mathrm{f}}=\text { mass of filtration assembly after regeneration } \\
\mathrm{m}_{\mathrm{p}}=\text { mass of filtration assembly prior to soot loading }
\end{array}
\end{aligned}
$$

Note that the numerator represents the amount of soot combusted during regeneration, and the denominator represents the mass of soot trapped within the filter prior to regeneration.

Because it was extremely difficult to remove the filter from the housing without disturbing the soot, the mass of soot in the filter was determined by weighing the filter while it was still encased in the trap housing. An Acculab VA-8000 scale with a 
readability of $0.2 \mathrm{~g}$ was used to weigh the combination of soot, filter housing, Interam ${ }^{\mathrm{TM}}$ matting, and ceramic monolith. To determine whether or not it was valid to allow the filter to remain in the housing during the weighing process, the weight of a new filter was documented. This filter was then placed into the filter housing, the assembly was baked at $575{ }^{\circ} \mathrm{F}$ to $600{ }^{\circ} \mathrm{F}\left(302{ }^{\circ} \mathrm{C}\right.$ to $\left.316^{\circ} \mathrm{C}\right)$ for conditioning the Interam ${ }^{\mathrm{TM}}$ matting, and the weight of the assembly was recorded. The filter was then loaded and regenerated. The assembly was weighed again, and mass of the remaining soot was calculated by subtracting the initial assembly weight from the final assembly weight. The filter was then carefully removed from the housing, and the filter containing residual soot was weighed. The weight of the bare filter was subtracted from this value to determine the weight of the residual soot. The residual soot mass determined using each of these two weighing methods agreed to within $0.2 \mathrm{~g}$ (which was also the readability rating of the scale). This process was also repeated for a filter which was used for multiple regeneration events. Both weighing methods were again found to be in very close agreement.

The effects of thermal buoyancy and water adsorption to the diesel soot were potential sources of error in the gravimetric regeneration efficiency calculation. The effects of each of these variables on filter weight were investigated by Walton et al. (1992). The sulfur present during the combustion of fuel in a diesel engine leads to the formation of sulfates in the exhaust. These sulfates can condense onto the soot particles as they traverse through the exhaust lines increasing their size and weight. Sulfates are capable of adsorbing water present in the atmosphere, which would increase the apparent weight of the soot. This implies that varying ambient humidity levels can lead to 
variations in the apparent initial soot loading. Due to the high temperatures encountered in the exhaust flow and during the regeneration event, the filter temperature can vary significantly. If the filter is weighed as it cools, its weight will appear to increase. This was a result of the thermal buoyancy of the filter element (Walton et al., 1992).

In order to negate the effects of sulfate/water adsorption and thermal buoyancy a filter conditioning chamber was designed and fabricated. The goal of this chamber was to condition the filter in a low-humidity, constant-temperature environment. It was desirable to generate humidity levels below $10 \%$ relative humidity. This would ensure that the effects of water adsorption on the sulfates would be negligible, and the measured loaded filter assembly weight would only represent an increase due to soot entrapment. The absence of water on the entrapped soot also removed one variable in terms of the overall dielectric loss factor of a loaded filter, which aided in the comparison of regeneration efficiencies at different regeneration conditions. A schematic of the filter conditioning chamber is shown in Figure 3.4.9. Photographs of the chamber are given in Appendix J. 


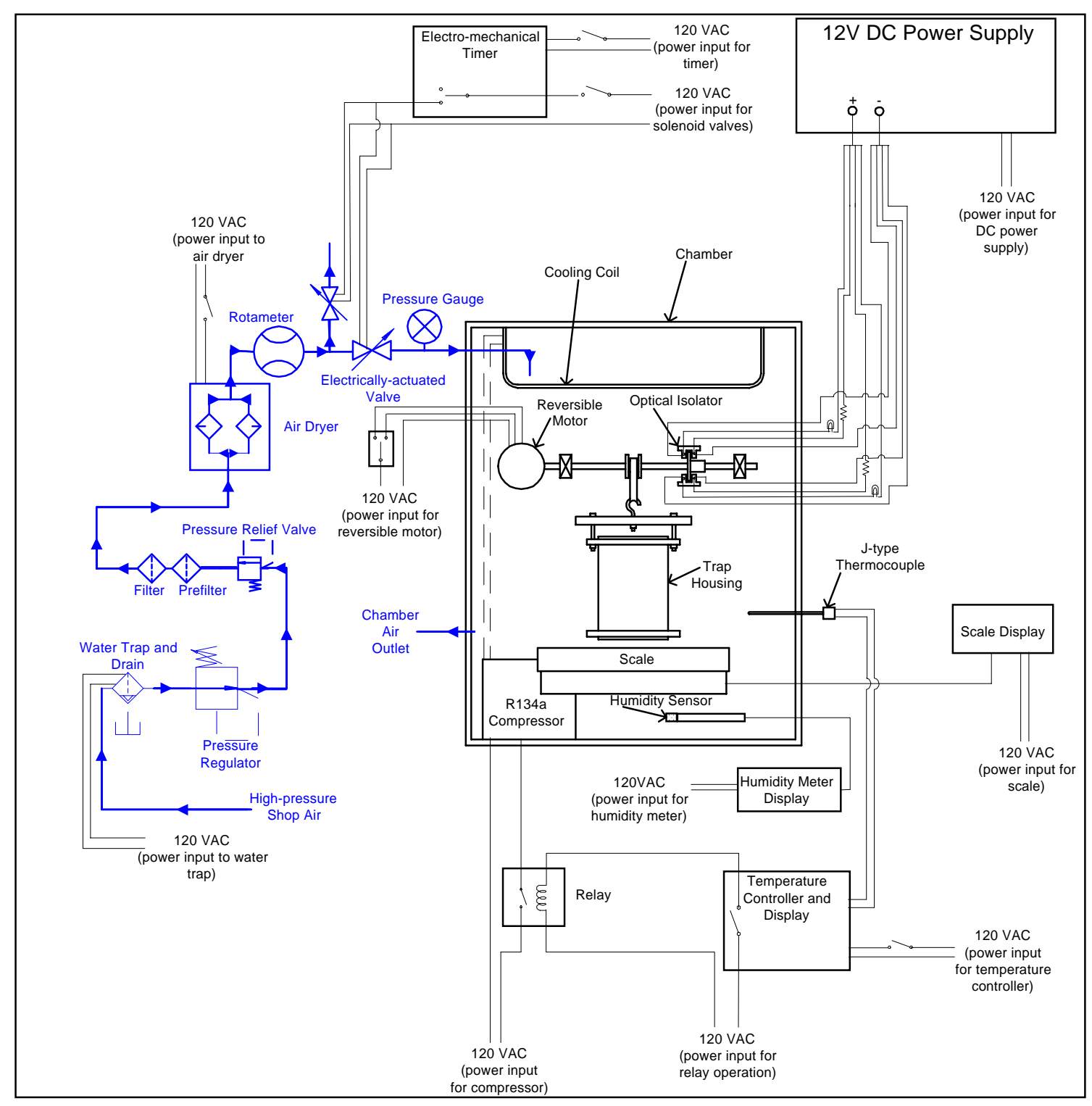

Figure 3.4.9: Filter Conditioning Chamber 
The chamber itself was a small GE refrigerator $\left[3.7 \mathrm{ft}^{3}\left(0.105 \mathrm{~m}^{3}\right)\right.$ internal volume], which was modified to provide sufficient support for the filter assembly, scale, and reversible motor support frame. The glass shelves were replaced with $1 / 8$ " steel plate, and the door shelves were cut off with a dye grinder and sealed with silicone sealant to allow clearance between the door and the support frame. The standard refrigerator gas-filled thermal sensor and switch were replaced with a J-type thermocouple and Omega temperature PID controller. In this case, the control operation was on/off, so the PID control option was not used. The temperature within the chamber was maintained at $65{ }^{\circ} \mathrm{F}\left(+/-4{ }^{\circ} \mathrm{F}\right)\left[18.3{ }^{\circ} \mathrm{C}\left(+/-7.2{ }^{\circ} \mathrm{C}\right)\right]$. The temperature controller was used to control the operation of the R134a compressor. The current capacity of the control switch within the temperature controller was not sufficient to sustain the required peak current to the compressor, so a relay was used as to isolate the controller from the compressor.

Because conditioning times were expected to be on the order of hours, it was desirable to have a method of adding and removing the filter assembly to and from the scale during conditioning without opening the chamber door. To create this option, a reversible motor and driveshaft assembly was mounted to a frame that surrounded the scale and filter assembly. A nylon strap was attached to a small aluminum pulley which was affixed to the driveshaft. The other end of the strap was attached to a hook which supported a square aluminum beam. Two $1 / 4$ " bolts which protruded down from the ends of this beam aligned with two of the holes in the filter housing flange. The bolts were of sufficient length to protrude through the beam and the flange with one inch of space between the filter housing and the beam. Nuts were placed on the ends of the bolts to 
attach the housing to the beam. The reversible motor was then activated via a three-pole switch until the filter assembly was suspended one inch above the scale. Because no means was available to view the filter position without opening the chamber door, an optical isolator and an external LED were used to provide and indication of this position. Due to space constraints, the reversible motor had to be mounted at a $90^{\circ}$ angle to the driveshaft. Miter gears were used to connect the motor output shaft to the driveshaft. A target with a notch in its outer circumference was mounted to the driveshaft. The target was oriented such that when the filter housing was in the suspended position, the notch was positioned in front of the first optical isolator. This allowed light to reach the transistor in the optical isolator which allowed current to flow through an external red LED which provided an indication to the reversible motor operator that the desired filter assembly position had been achieved. When the filter assembly was to be weighed, the reversible motor was activated such that the filter assembly was lowered onto the scale. The assembly was lowered until the filter housing came into full contact with the scale, and the aluminum beam which was used to support the scale was suspended above the scale. In this position, the bolts used to attach the filter to the beam, were suspended within the holes in the filter housing flange, so no external weight was applied to the filter housing by the filter suspension assembly. If the reversible motor was activated too long, the beam would have come into contact with the filter housing, giving an erroneous filter assembly weight reading. To prevent this situation from occurring, a second optical isolator was mounted to the support frame. This isolator was oriented such that when the filter was in the lowered position with the beam suspended above it, the notch in the optical isolator target was in front of this second optical isolator. This allowed light to be 
transmitted to the transistor in the isolator, which allowed current to flow through an external green LED. This provided a signal to the motor operator that the filter weighing position had been reached. The scale display was mounted externally to the chamber, so the filter weight could be recorded without opening the chamber door.

To provide dry air to the chamber, an MDH3 air dryer by Twin Tower Engineering was incorporated into the chamber design. The air dryer required an input of clean compressed air at $50 \mathrm{psig}(345 \mathrm{kPa})$. High-pressure shop air which was filtered and regulated to 50 psig was used as the input air source. The 0.01 micron air filter was preceded by a 5 micron coalescing filter. A water trap and drain was placed upstream of the pressure regulator to remove excess water from the air supply. This trap contained a timer which drained any trapped water every hour. The dryer contained two towers which contained molecular sieves to separate the water from the air. At any given time, one tower was active while the other was purged of the entrapped water. Once every minute, the airflow was switched so that the tower which had been purged became active, and the tower which had been drying the air was purged. The dry air which exited the air dryer was metered as it passed through a rotameter. The airflow was regulated to 0.3 scfm $\left(0.0085 \mathrm{~m}^{3} / \mathrm{min}\right)$ to keep the air dryer from becoming overloaded. If the highpressure air source was a small pump, the temperature of the compressed air supplied to the chamber could have been relatively high. Continued high-temperature airflow into the chamber would have exceeded the cooling capacity of the refrigerator, and the temperature of the air within the chamber would have been variable. To prevent overloading of the cooling coil, two electrically-actuated valves were placed in the air line between the rotameter and the chamber. These valves were actuated by the input 
from an electro-mechanical timer. One valve was normally-open and the other was normally-closed, so when current was allowed to pass through the output circuit in the timer, one valve opened and the other closed. In this manner, air from the dryer was allowed to vent to the atmosphere for a predetermined length of time, then the air from the dryer was routed into the chamber for another predetermined length of time. The air supply to the dryer during this testing was shop air which had a larger reservoir and pump, so the temperature of the supply air was relatively low. This allowed a continuous flow of dry air into the chamber, except during the filter weighing process. In this case, power to the valves was discontinued. The valve which vented to the atmosphere was normally-open, and the valve connected to the chamber was normally closed, so air from the dryer was vented to the atmosphere during the weighing process.

In order to monitor the humidity of the air within the filter conditioning chamber, the sensor from a handheld hygrometer/thermometer (Omega RH 201) was mounted near the bottom of the chamber. The display for this unit was mounted external to the chamber, so the humidity could be monitored without opening the chamber door. The air dryer was found to maintain the humidity in the chamber between $5 \%$ to $7 \%$ relative humidity once equilibrium was achieved.

\subsection{Exhaust Backpressure Control Assembly}

Research involving aftertreatment systems must be performed with care in order to avoid damage to the engine. Specifically in the case of microwave regeneration, some means of microwave absorption must be implemented to prevent the transmission of microwaves through the exhaust lines beyond the filter. For this study, water traps and 
stainless steel gate valves were used to prevent this undesirable transmission of microwaves beyond the regeneration assembly. In the general case of diesel exhaust filtration, care must be taken not to create excessive exhaust temperatures and pressures in engine head or exhaust manifold. Because a variety of programs could be used to control the engine, it was considered desirable to have an exhaust backpressure limiting control which was hardwired to the engine fuel on/off solenoid (that is, the control operated independently of the computer programs). To achieve this end, a pressure switch unit from Omega was used to monitor the exhaust backpressure. The pressure switch unit actually contained two switches: one which was normally-open and one which was normally-closed. The switch set point was adjusted such that if the exhaust backpressure exceeded 110 " $\mathrm{H}_{2} \mathrm{O}(27.3 \mathrm{kPa})$, the normally-open switch would become closed and the normally-closed switch would become open. Unfortunately, the switches were non-latching, so the rack on/off control solenoid could not be controlled directly using the pressure switch. This was the case because if the exhaust backpressure limit was exceeded, the normally-closed switch in the pressure switch housing would open, cutting off the current to the engine rack on/off control solenoid, thus terminating the flow of fuel to the engine. As the fuel supply was being stopped, the engine speed would decrease, decreasing the exhaust flow, and thereby decreasing the exhaust pressure. Once the exhaust pressure decreased below the set limit of the pressure switch, current to the control solenoid would once again be supplied. For the particular engine used in this testing, this was not a major issue because the rack on/off control solenoid contained two solenoids: a primary coil to move the fuel control valve into the open position, and a smaller coil to hold the valve in the open position. The normally-closed pressure switch 
could have been wired into the circuit of the secondary coil, so that even if the current was supplied to the coil, insufficient force would be generated to open the fuel valve. The starter switch alone would be used to control the primary coil.

It can be inferred that the pressure switch could have been used to deactivate the engine if the exhaust backpressure limit was exceeded, but this system could not have been used for all engines, and it could not have provided a means of indicating that the backpressure limit had been exceeded (such as with an indicator lamp). In order to provide a system which deactivated the engine as well as activated an indicator lamp when excessive backpressures occurred, the system shown in Figure 3.4.10 was fabricated. A photograph of the unit is shown in Appendix M. 


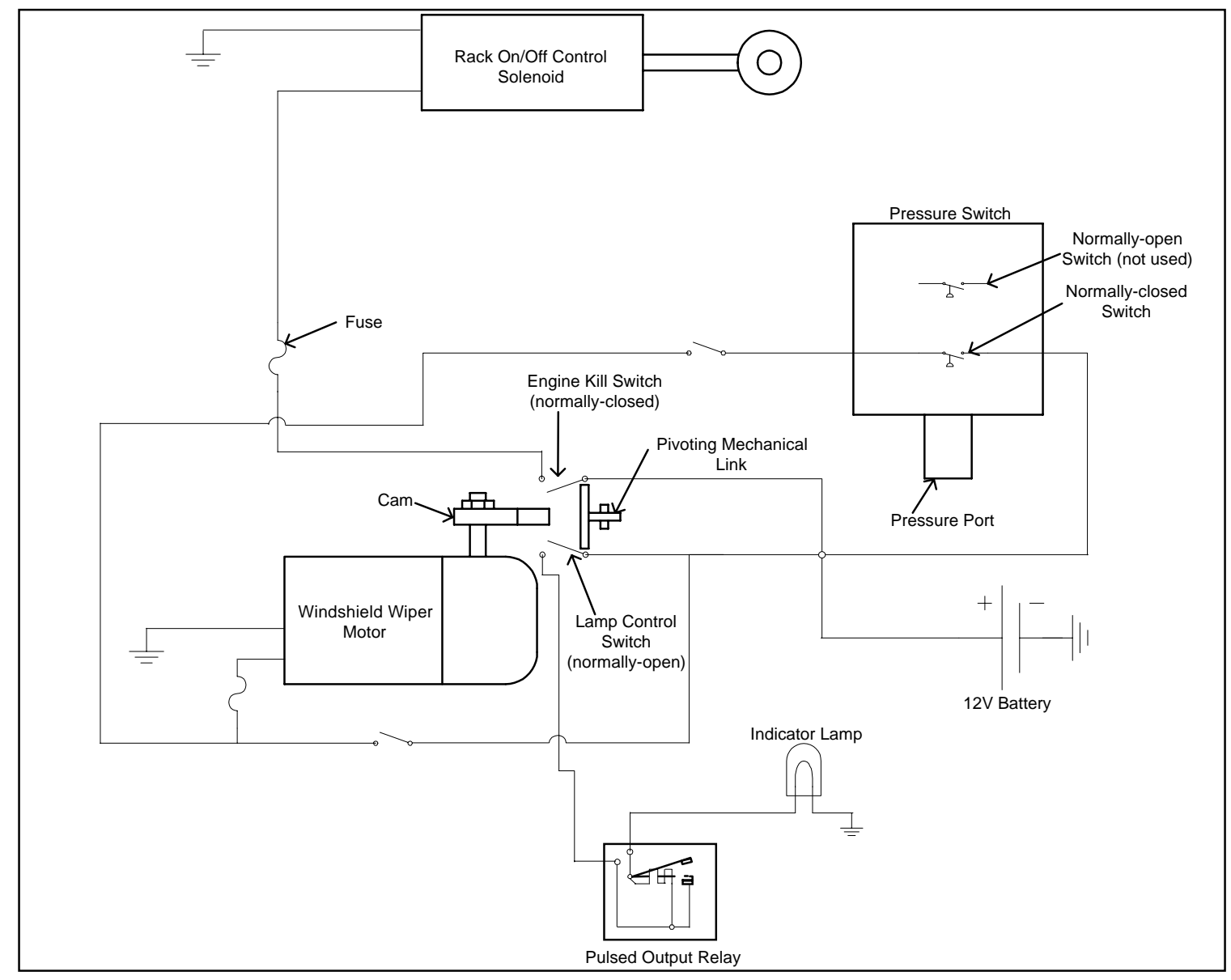

Figure 3.4.10: Engine Backpressure Limit Control Assembly ${ }^{\S \S \S ~}$

Other control schemes could have been used to provide adequate control, but this unit had the added benefit that it was made almost entirely from used components, so the cost was minimal. For this system, when the exhaust backpressure limit of the pressure switch was exceeded, current was supplied to a windshield wiper motor. A cam mounted on the wiper motor output shaft triggered the rotation of a pivoting mechanical link. The motion of the link was used to trip two toggle switches: one which was normally-open, and one which was normally-closed. The normally-open switch was used to control an 
indicator lamp which was used to signal that the exhaust backpressure was excessive. A pulsed output relay was also incorporated into the lamp circuit, so the lamp flashed when activated. The normally-closed switch was used to control the current flow to the rack on/off solenoid. For this system, once the switches had been triggered, they remained in their respective positions, so the indicator lamp remained activated and the rack solenoid remained deactivated. In some cases when the exhaust backpressure limit was exceeded and the wiper motor was activated, the cam remained in contact with the pivoting link. In order to reset the system, the wiper motor output shaft had to be manually rotated. To provide a manual means of activating the wiper motor, a second control line with a toggle switch was added to the system. Power to the system was provided by the same 12 VDC battery used to power the engine's electrical components.

\footnotetext{
$\S \S \S \S$ The schematic for the pulsed output relay was based on information provided in Ford V8 Mustang Automotive Repair Manual by J.H. Haynes, 1979.
} 


\section{Chapter 4 \\ Test Procedures}

In this chapter, the procedures used for filter assembly preparation, filter soot loading, and regeneration are discussed. These procedures were used for the majority of the regeneration tests performed both in this study and a concurrent study (Popuri, 1999). In some instances hardware was incorporated into the testing assembly after some of the initial tests had been performed. In other cases, additional hardware and procedures were required for specific test requirements such as the measurement of temperature profiles within the filter (Popuri, 1999). Only the general procedures which were required for the majority of the testing, presented in this report, will be considered.

\subsection{Trap Preparation}

The initial steps, prior to beginning the tests, required preparation of the filter assembly. The Corning EX-80 filter, which was to be used for testing, was weighed using the Acculab scale that was placed in the filter conditioning chamber (see Section 3.5). This weight was recorded and was used to validate the method of weighing the entire trap assembly to determine the soot mass within the filter. The validation process was discussed in Section 3.5. After the weighing process, Interam ${ }^{\mathrm{TM}}$ matting was placed around the circumference of the filter and this combination was pressed into the filter housing using a customized arbor press, stuffing cone, and force distribution plate. Photographs of the arbor press, stuffing cone, and force distribution plate are contained in Appendix N. To press the filter into the housing, the filter with an Interam ${ }^{\mathrm{TM}}$ mat was placed into the large end of the stuffing cone. The stuffing cone was tapered so that the 
filter with Interam ${ }^{\mathrm{TM}}$ mat could easily be positioned in the cone. The small end of the cone had the same inner diameter as the filter housing inner diameter. The stuffing cone also contained a groove around its smaller inner diameter so that the lip of the housing could be used as a guide to align the stuffing cone with the housing. The stuffing cone was placed on top of the filter housing, and the assembly was placed in the arbor press which was used to press the filter and interim mat through the stuffing cone and into the housing. A force distribution plate was placed beneath the rack of the arbor press, so that the force provided by the arbor press was distributed across the filter face. A rubber gasket was placed between the distribution plate and the filter to ensure no filter damage occurred during the filter transfer to the housing. The filter with Interam ${ }^{\mathrm{TM}}$ mat was pressed into the housing until the filter came into contact with the metal support tabs at the lower end of the housing (see Figure 3.1.6). At this point, the rack was lifted, and the housing with filter was removed from the press. The filter assembly (including the housing, filter, and Interam ${ }^{\mathrm{TM}}$ matting) was weighed and the weight was recorded. This weight was not used in the calculation of the regeneration efficiency. It was used only to determine the change in Interam ${ }^{\mathrm{TM}}$ matting weight after the filter assembly was baked. An arbor press with the height and throat depth necessary to press the filter from the stuffing cone to the filter housing was very expensive. Hence, a shorter, 2-ton Jet arbor press with sufficient throat depth was purchased. It was recognized that force required to press the filter into the housing was much less than the load rating of the press, so modifications could be made to the press without a concern for the stresses exceeding the mechanical limits of the modified press. The base of the press was removed and an extension made of a truncated I-beam was used to extend the height of 
the press. Because the metal of the original press was poor quality cast iron, it could not be welded directly to the extension. Instead, steel plates were bolted to the sides of the press, and the plates were then welded to the extension. The other end of the extension was welded to a 1" thick steel base plate. The modified press was then bolted to a steel frame. The original rack with metric pitch was replaced with an extended rack of standard pitch, which required the original gear assembly to be replaced as well.

The next step in the filter assembly preparation was to bake the filter assembly in a conventional electric oven at $575{ }^{\circ} \mathrm{F}$ to $600{ }^{\circ} \mathrm{F}\left(302{ }^{\circ} \mathrm{C}\right.$ to $\left.316{ }^{\circ} \mathrm{C}\right)$. This exercise served to purposes: (i) it allowed any and all volatiles in the matting to vaporize, thereby removing bias error from the gravimetric regeneration efficiency calculation, and (ii) it allowed the matting to expand within the housing, sealing the gap between the filter element and the housing. The filter was baked for approximately 1.5 hours. After this process, the filter assembly was removed from the oven and placed in a pre-conditioning chamber. The preconditioning chamber was simply a small refrigerator which contained a steel shelf and a large canister of dessicant. The filter was left in this chamber until the temperature of the assembly decreased sufficiently, so that it could be placed in the conditioning chamber (see Figure 3.4.9). The filter was kept in the chamber [at $65{ }^{\circ} \mathrm{F}(18$ $\left.{ }^{\circ} \mathrm{C}\right)$ and $<10 \%$ relative humidity] until the weight of the assembly had stabilized. When the weight of the filter had stabilized, it was recorded. This weight was used to calculate the trapped soot mass on the filter (see Equation 3.5.1). 


\subsection{Filter Soot Loading}

Once the filter assembly had been prepared and conditioned and the initial weight recorded, the assembly was ready for loading. Prior to engine operation, the orifice meter and exhaust pressure transducers were calibrated to ensure accurate pressure measurements.

The filename in the path used for data acquisition in the exhaust split control program was also modified and the filename was recorded for referencing purposes. The file generated by the program documented readings such as exhaust backpressure, valve position (based on the number and direction pulse signals to the stepper motor), the exhaust split ratio, and the elapsed test time. The readings were recorded every thirty seconds in order to provide sufficient data resolution without unnecessarily large file sizes.

The filter assembly was then positioned between the diffuser and nozzle in the exhaust bypass line and was bolted in position. Graphite gaskets were placed between the flanges to create an airtight seal. The gate valve in the exhaust bypass line and the sliding plate gate valve were both closed initially to prevent exhaust flow through the filter during the engine warm-up period (see Figure 3.3.3). This ensured repeatable soot loading between tests. Prior to engine operation, all cooling fans were activated (such as the dyno cooling fan, the stepper motor and driver cooling fans, the power supply cooling fan, etc.), and a BASIC program used to monitor test cell parameters such as engine backpressure, coolant temperatures, oil temperature, and dilution airflow rate was initiated. 
After the dilution tunnel blower (constant volume sampling system - CVS) was activated to remove the engine exhaust from the building, the engine was run through a "warm-up" routine, which was used to prevent damage to the engine and to ensure that the collected soot had similar properties for all the tests (soot was not collected until the engine had reached equilibrium at the desired test condition). The engine was started and operated at idle until the oil temperature reached $110{ }^{\circ} \mathrm{F}\left(43{ }^{\circ} \mathrm{C}\right)$ (temperature values are approximate). The engine was then operated at intermediate speed and 50\% load until the engine oil temperature reached $130{ }^{\circ} \mathrm{F}\left(54^{\circ} \mathrm{C}\right)$ at which time the load was increased to $100 \%$. Once the oil temperature reached $160{ }^{\circ} \mathrm{F}\left(71{ }^{\circ} \mathrm{C}\right)$, the engine speed was increased to $2100 \mathrm{rpm}$ (100\% load). When the oil temperature reached approximately $190{ }^{\circ} \mathrm{F}(88$ ${ }^{\circ} \mathrm{C}$ ), the engine speed and load were set at the values used for filter soot loading (1500 $\mathrm{rpm}, 106 \mathrm{ft}-\mathrm{lb})$. Once the engine oil temperature reached approximately $205^{\circ} \mathrm{F}\left(96^{\circ} \mathrm{C}\right)$, the bypass line gate valve and sliding plate gate valve were opened and the exhaust split control program was activated. During the filter soot loading period, the exhaust pressure slowly rose due to the increase in exhaust restriction created by the butterfly valve that was used to maintain a constant flow through the filter. The soot build-up within the filter created more flow restriction through the filter, so the exhaust butterfly valve had to be incrementally closed to maintain the flow. The increase in exhaust backpressure required additional power from the engine to overcome the restriction in the exhaust lines. Therefore, the rack setting had to be incrementally adjusted during the filter loading period to maintain a constant brake torque output of $106 \mathrm{ft}-\mathrm{lbf}(144 \mathrm{~N}-\mathrm{m})$. The program used to control the exhaust butterfly valve predicted the soot load on the filter based on the particulate mass emissions rate of the engine (see Section 3.3.7). When the 
predetermined target soot loading was reached, the engine was operated at idle and the gate valve in the bypass line was closed as well as the sliding plate gate valve. The filter assembly was carefully removed from the exhaust line, and placed in the preconditioning chamber. When the temperature of the filter assembly was sufficiently low, the assembly was placed in the conditioning chamber and weighed. This weight was not used in the regeneration efficiency calculation, but was used to ensure that the target entrapped soot mass was achieved. After the filter assembly weight had stabilized, the weight was recorded, and the entrapped soot mass was calculated (see Equation 3.5.1).

\subsection{Regeneration}

After the collected soot mass had been determined, the filter assembly was placed in the Faraday cage (see Figure 3.4.8). The inlet end of the filter housing was bolted to the diffuser in the Faraday cage, while the outlet end was connected to the water trap (see Figure 3.4.7). Graphite gaskets were once again used to seal the flanged joints. Five Ktype surface thermocouples with self-adhesive backing (manufactured by Omega) used to track the flame front within the filter were attached to the filter housing. The thermocouple leads were then attached to the thermocouple leads from a junction box. The outlet leads from the junction box were connected to the temperature data acquisition board. The thermocouple in the water trap was also connected to one of the leads from the junction box. Once the trap was in place, the thermocouples were in position, and the leads connected to the junction box, an exhaust sample transfer tube was connected between the sampling probe and a bulk head connector in the Faraday cage. The two removable perforated sheets of the Faraday cage were then bolted in position. The 
temperature data acquisition program was initiated in control mode so that the temperature readings from the thermocouples could be checked to ensure that they were reading properly. Any thermocouple which was not indicating the ambient temperature was replaced. The waveguide gate valve which was attached to the diffuser inlet was opened, and the gate valve in the air line to the filter assembly was closed. The gate valve in the combustion air bypass line was opened, and the exhaust fans and all cooling fans were activated. A water supply line was attached to the waveguide water jacket inlet line, and the water supply valve was opened and adjusted to achieve a sufficient flow of water through the water jacket. The zero and span settings of the low $\mathrm{CO}$, high $\mathrm{CO}$, and the $\mathrm{CO}_{2}$ analyzers were adjusted, the analyzer particulate filters were changed if necessary, and the analyzer sample pumps were activated. The heating elements in the heated exhaust sample lines were also activated, and the temperatures were allowed to stabilize. The orifice meter and trap pressure transducers were calibrated, and the orifice meter and air supply line thermocouple readings were checked at ambient conditions to ensure they were reading properly.

The filenames for data storage in the data acquisition programs were changed and documented for referencing purposes. The filename change ensured that past data files would not be written over with the new data entry. The data acquisition program used to document the orifice meter flow rate, air supply temperature, etc. was initiated in display mode, and the air supply cart was activated (see Figure 3.4.6).

The bypass gate valve was adjusted so that the predetermined target airflow rate was achieved. In some instances the air-bleed valve on the air supply cart was adjusted as well, to achieve the desired flow rate. Power was supplied to the air heater(s) and the 
variac was adjusted so that the desired combustion air temperature was achieved. At this point, all the combustion air supplied by the cart bypassed the filter assembly and was exhausted out of the building via the exhaust blower. In this manner the combustion airflow at the target temperature could be supplied to the filter assembly immediately without having to wait for the air heater(s) to slowly bring the combustion air temperature from ambient levels to the desired value. The exhaust sampling pump was activated, and the dilution air restrictor valve was adjusted and the rotameter readings were monitored until the desired exhaust sample dilution ratio was achieved.

At this point the system was prepared for the regeneration event. To begin the preheating phase of the regeneration, the data acquisition programs were set to data acquisition mode. Immediately thereafter, the magnetron was activated using the magnetron control unit. To activate the magnetron using the control unit, the desired magnetron activation time (that is, the preheating time) was entered along with the magnetron power setting. The power setting refers to the relative amount of the set time that the magnetron was to be activated. For the tests presented in this work, the magnetron power setting was $100 \%$. The surface thermocouple temperature readings, the combustion airflow temperature and flow rate, as well as the analyzer readings were monitored during the preheating phase. Immediately after the magnetron was deactivated (that is, at the end of the preheating phase), the waveguide gate valve was closed, the gate valve in the air supply line to the filter was opened approximately $3 / 4$ of the way to fully open, and the gate valve in the bypass line was then closed. Large handles, bolted to the original valve handles, allowed this process to be down very quickly. The air supplied to the filter initiated the start of the convective combustion portion of the regeneration 
event. The gate valve in the air supply line to the filter was then adjusted until the desired combustion airflow rate was achieved. In some cases the air bleed valve on the air supply cart also had to be adjusted to set the desired combustion airflow rate. Because soot was being removed from the filter, the pressure drop across the filter gradually decreased. To compensate for this effect, the gate valve in the combustion air inlet had to be adjusted periodically during the convective combustion period. After the airflow into the filter had been set at the end of the preheating period (that is, after a period of airflow adjustment to reach the target value), the combustion airflow was typically maintained within $+/-0.7 \mathrm{scfm}\left(+/-0.02 \mathrm{~m}^{3} / \mathrm{min}\right)$ of the target value. The variac was also adjusted, as needed, to maintain constant combustion air temperature, although this was not usually required. The readings from the emissions analyzers as well as the surface thermocouple and water trap thermocouple readings were monitored during the convective combustion period to determine the onset of any problems or anomalies. The combustion airflow was continued for fifteen minutes after the end of the preheating period or until the ADC readouts from the emissions analyzers reached ambient levels, whichever was longer.

At the end of the convective combustion period, the data acquisition programs were stopped, the gate valve in the bypass air line was opened and the gate valve in the filter air supply line was closed. Power to the air heater(s) was discontinued, but the air supply cart remained activated until the air heaters were sufficiently cool. Once the air heaters were cool, the air supply cart was deactivated as well as all the pumps, water supplies, and power supplies. The removable perforated sheets were taken off from the Faraday cage, and the filter assembly was carefully removed and placed in the preconditioning chamber to cool. When the filter had cooled sufficiently, it was placed in 
the conditioning chamber. Once the mass reading had stabilized, the mass was recorded and the regeneration efficiency was calculated (see Equation 3.5.1).

\subsection{Filter Post-regeneration Conditioning}

Once the regenerated filter was conditioned and the regeneration efficiency calculated, the filter was checked for catastrophic failure (that is, melting) by positioning a light source behind the filter. If light passed through any portion of the filter, the filter was damaged and was pressed out of the housing and replaced with a new filter element. If the filter did not appear to be melted, it was carefully backflushed using clean, dry shop air to remove most of the remaining soot. Clean dry air was provided by placing a water separator as well as an air filter in the shop air line. After as much soot as possible was blown out of the filter, the filter assembly was then placed back into the conditioning chamber. When the filter weight had stabilized, the weight was recorded and the mass of soot remaining in the filter was calculated. In most cases, the mass of soot that remained in the filter after the backflushing process was less than $3 \mathrm{~g}$. At this point the filter was ready be loaded again, so the filter was placed into the bypass line of the engine exhaust system, and the soot loading procedures were followed once again. For any filter that was reloaded after it had been regenerated, the exhaust backpressure was closely monitored. If the exhaust backpressure did not rise in a manner similar to that of a new filter, or if the backpressure did not rise at all, the outlet end of the filter was checked for leaks. If the filter element was found to be leaking significantly (in some cases new filters were found to have several cells which leaked), it was pressed out of the filter housing by placing the large end of the stuffing cone beneath the filter housing and using 
the distribution plate and arbor press to transfer the filter from the housing to the stuffing cone. A new filter with Interam ${ }^{\mathrm{TM}}$ mat was than pressed back into the filter housing, and the new filter conditioning process was followed (refer to Section 4.1).

To minimize the number of new filters required for testing, any undamaged filter which had been removed from the filter housing after regeneration was thoroughly backflushed with clean, dry shop air and was soaked in a bath of acetone to dissolve any soot which remained in the filter. After four to five hours, the filter was removed from the acetone bath and was flushed with copious amounts of water. The filter was then blown off with clean, dry shop air, and placed in a small oven to dry. To save funds, the oven was custom-built using an existing toaster oven and spare stainless pipe and steel plate. A photograph of the oven is contained in Appendix N. After the filter had been thoroughly dried, the filter was once again backflushed with clean, dry shop air to ensure as little soot as possible remained in the filter. Several filters which were used in the initial regeneration tests were cleaned using this method, but for the testing presented in this work, none of these filters were used.

\subsection{Test Matrix}

The objective of the research was to determine the relationships that the initial soot mass, preheating time, airflow rate, and airflow temperature had on the regeneration efficiency. Other parameters also affected the regeneration efficiency as well, including the geometric characteristics of the regeneration system. The geometry of the trap housing, the trap position relative to the waveguide outlet, the waveguide dimensions and materials, as well as the magnetron power output were all parameters which affected the 
performance characteristics of the regeneration system. These parameters would have the largest impact on the required preheating time. The properties of soot and the filter element also affected the regeneration results. Due to the variations in each regeneration system, it was expected that results from previous regeneration studies would vary significantly from the results found in this study, especially in terms of the required preheating time for a given initial soot mass. Not as much variation was expected in the required airflow rate or the initial soot mass, because the convective combustion characteristics as well as the maximum allowable internal filter stresses were similar.

The goal of the first regeneration test was to determine the range of preheating times which would used in the test matrix. In the first regeneration test, $15.2 \mathrm{~g}$ of soot was collected on the filter, and several regeneration attempts were performed at preheating times of six minutes or less. The airflow rate was maintained near $5 \mathrm{scfm}$ $\left(0.14 \mathrm{~m}^{3} / \mathrm{min}\right)$ with a target temperature of $300{ }^{\circ} \mathrm{F}\left(149^{\circ} \mathrm{C}\right)$. For these regeneration attempts, the mass of the filter assembly, after the tests, was exactly the same as the assembly mass prior to the test indicating no regeneration had occurred. The preheating time was increased to 15 minutes. In this case, significant regeneration occurred. The actual mass of the combusted soot could not be determined because the Interam ${ }^{\mathrm{TM}}$ matting had not been conditioned prior to the test, so it was expected that some of the mass lost was the vaporization of volatile matter from the Interam ${ }^{\mathrm{TM}}$ matting. Also, since the filter had moved in the housing during the filter loading period (prior to the insertion of filter supports - see Figure 3.1.6), the initial amount of soot collected on the filter was in question. The filter assembly was placed back into the Faraday cage and was regenerated a second time. The preheating time in this case was 17.5 minutes. More soot 
was combusted during this phase, indicating that the test parameters could be tuned to create a higher regeneration efficiency.

The following test matrix was used as a guide for the tests which were performed (that is, the values listed are nominal values; the actual values deviated slightly from those listed).

Table 4.1: Microwave Regeneration Test Matrix

\begin{tabular}{cccc}
\hline Initial Soot Mass (g) & Airflow Rate $(\mathrm{scfm})$ & $\begin{array}{c}\text { Airflow } \\
\text { Temperature }\left({ }^{\circ} \mathrm{F}\right)\end{array}$ & $\begin{array}{c}\text { Preheating Time } \\
(\mathrm{min})\end{array}$ \\
\hline 10 & 5 & 300 & 12.5 \\
17 & 5 & 300 & 12.5 \\
24 & 10 & 300 & 10 \\
24 & 10 & 300 & 12.5 \\
24 & 10 & 300 & 15 \\
24 & 10 & 300 & 15 \\
24 & 10 & 300 & 17.5 \\
24 & 10 & 80 & 12.5 \\
24 & 10 & 150 & 12.5 \\
24 & 10 & 635 & 12.5 \\
24 & 5 & 300 & 12.5 \\
24 & 15 & 300 & 12.5 \\
24 & 20 & 300 & 12.5 \\
30 & 5 & 300 & 12.5 \\
\hline
\end{tabular}

One of the test conditions was repeated to check the repeatability of the filter loading, conditioning, and regeneration systems.

The preheating time range was based on the results of the first regeneration test, bracketing the preheating times used in the first test. The combustion air temperature range was based on a simulation of the expected exhaust temperatures entering the trap if diesel exhaust was used as the combustion air supply. The maximum initial soot mass of $30 \mathrm{~g}$ was based on the amount of soot which could be collected on the filter without generating excessive exhaust backpressure. The lower value of $10 \mathrm{~g}$ was used to 
determine if light soot loads could be effectively regenerated. The initial test matrix included combustion airflow rate values which were much higher than those presented Table 5.1. The initial regeneration tests indicated that extremely low regeneration efficiencies would result if airflow rates above $20 \mathrm{scfm}\left(0.57 \mathrm{~m}^{3} / \mathrm{min}\right)$ were used. Therefore, an airflow rate range of 5 to $20 \mathrm{scfm}\left(0.14 \mathrm{~m}^{3} / \mathrm{min}\right.$ to $\left.0.57 \mathrm{~m}^{3} / \mathrm{min}\right)$ was chosen. The effect of combustion airflow rates less than $5 \mathrm{scfm}\left(0.14 \mathrm{~m}^{3} / \mathrm{min}\right)$ were presented in another microwave study (Popuri, 1999). 


\section{Chapter 5 \\ Microwave Regeneration Results and Discussion}

The effects of the initial soot mass, preheating time (magnetron activation time), airflow rate, and air temperature on the regeneration efficiency were studied using the test matrix presented in Table 4.1. This chapter presents the results of the regeneration testing that was performed using the systems described in Chapter 3. The tests were performed following the procedures outlined in Chapter 4. The results are categorized on the basis of each individual parameter that was studied.

\subsection{Effect of Initial Soot Mass}

The effect of variations in the initial soot mass, entrapped within the filter, on the regeneration efficiency was studied by maintaining constant values of the combustion airflow rate, the combustion air temperature, and the preheating time. The combustion airflow rate was maintained at $5 \mathrm{scfm}\left(0.14 \mathrm{~m}^{3} / \mathrm{min}\right)$ at a temperature of $300{ }^{\circ} \mathrm{F}\left(149{ }^{\circ} \mathrm{C}\right)$, and the preheating time was held constant at 12.5 minutes. Four different soot loads were used to determine if a correlation existed between initial soot loading and regeneration efficiency with nominal values of $10 \mathrm{~g}, 17 \mathrm{~g}, 24 \mathrm{~g}$, and $30 \mathrm{~g}$.

For the first test in this series (labeled Test \#1), 9.6g of soot was collected on the ceramic monolith. The preheating time was 12.5 minutes, the average airflow rate was $4.71 \mathrm{scfm}\left(0.13 \mathrm{~m}^{3} / \mathrm{min}\right)$, and the average inlet combustion air temperature was $293{ }^{\circ} \mathrm{F}$ $\left(145^{\circ} \mathrm{C}\right)$. Plots of the trap surface thermocouple readings (K-type thermocouples with self-adhesive backing, manufactured by Omega) are shown in Figure 5.1.1: 


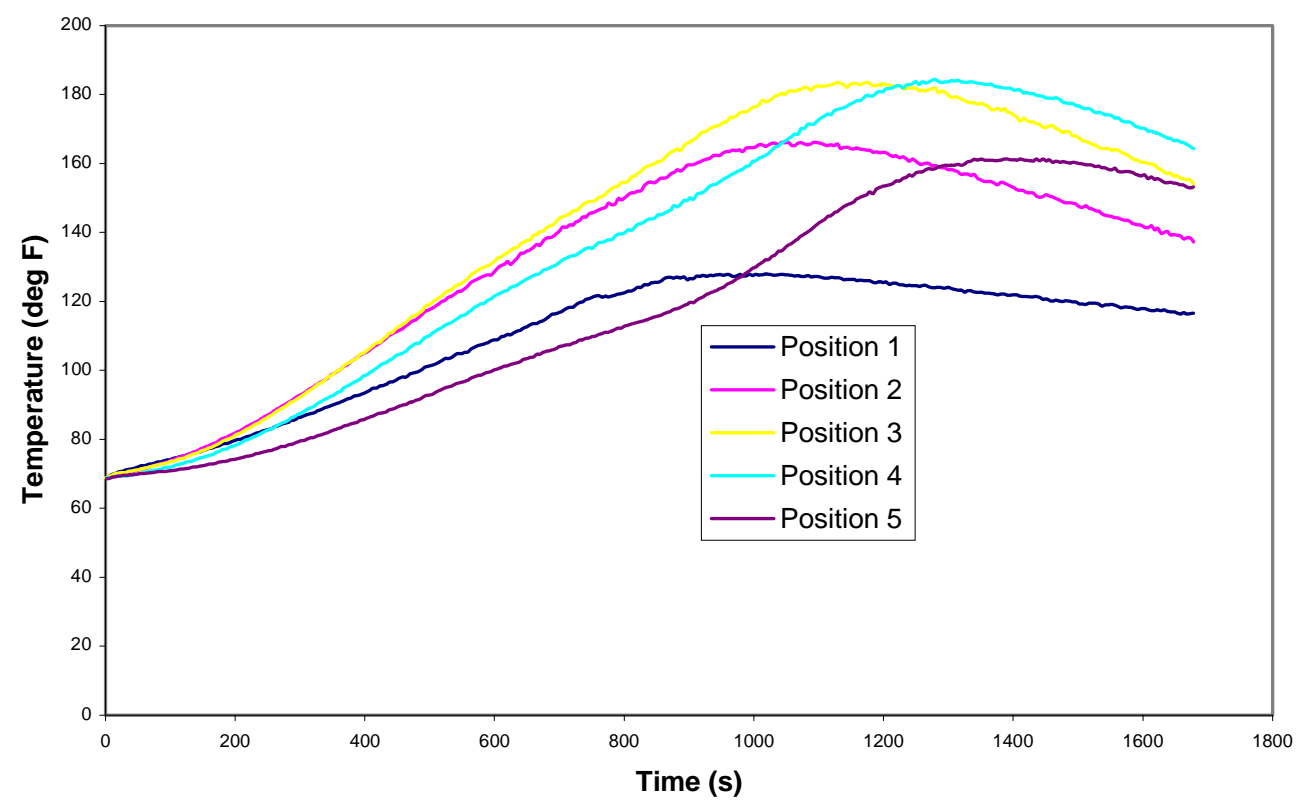

Figure 5.1.1: Test \#1 Trap Surface Temperature Profiles

The trap surface temperature readings were used to give an indication about the relative amount of energy generated during regeneration, and an indication of the position of the flame front during regeneration. Position 1 indicates the thermocouple location nearest to the filter inlet, while position 6 was nearest to the outlet end of the filter. The positions of the surface thermocouples on the trap housing are shown in Figure 5.1.2. 


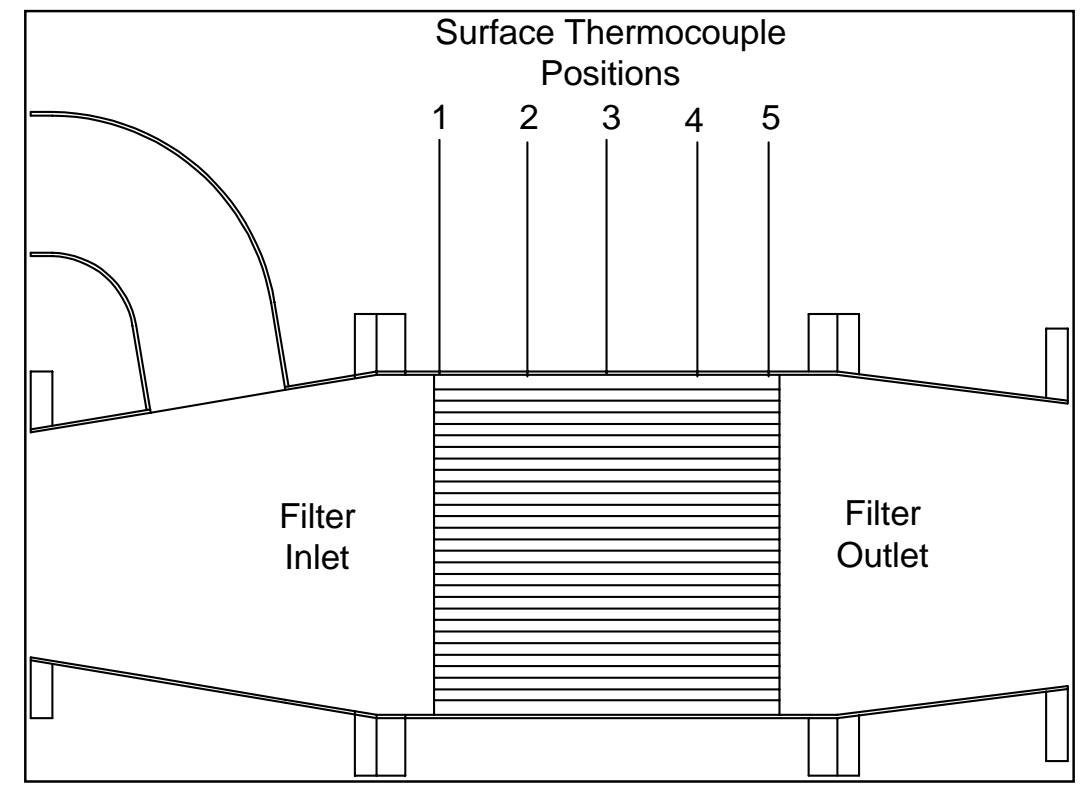

Figure 5.1.2: Surface Thermocouple Positions on the Trap Housing

It can be seen from the surface temperature profiles in Figure 5.1.1 that the temperature of the trap housing continued to increase beyond the preheating phase (after 750s), this indicating that more energy was released during convective combustion. The lowest temperatures were present at the end of the trap housing at the filter inlet because the flame front initiated a small distance inside the filter element and propagated down the filter element (away from the filter inlet face) during the convective combustion phase. Peak surface temperatures of approximately $185^{\circ} \mathrm{F}\left(85^{\circ} \mathrm{C}\right)$ were observed at position 4. Position 5 was near the outlet edge of the filter element, so temperatures were not expected to be as high as the peak temperatures at positions 3 and 4 .

Plots of the combustion airflow rate, combustion air temperature, and trap differential pressure as well as the $\mathrm{ADC}$ readings from the low $\mathrm{CO}$, high $\mathrm{CO}$, and $\mathrm{CO}_{2}$ analyzers are shown in Figures 5.1.3 to 5.1.8. 


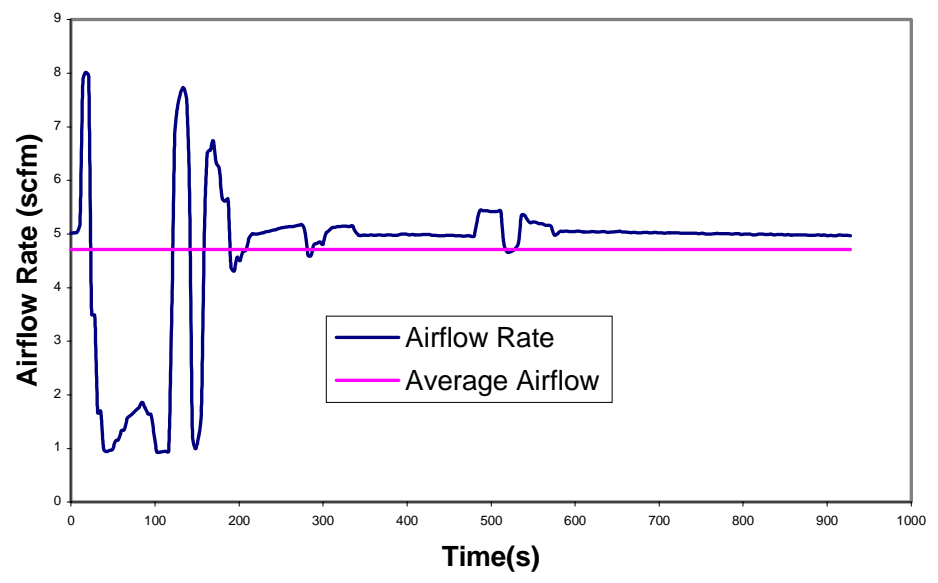

Figure 5.1.3: Test \#1 Combustion Airflow Rate

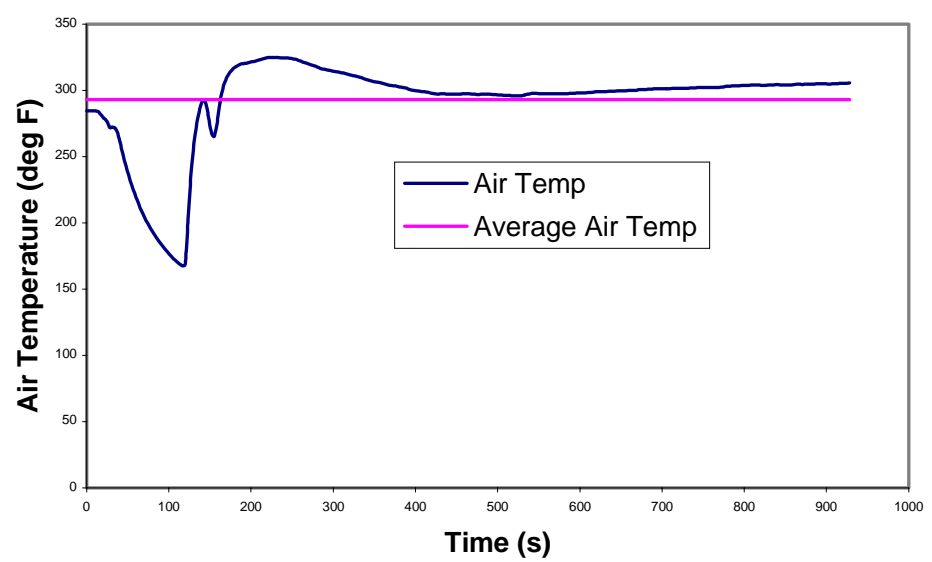

Figure 5.1.4: Test \#1 Combustion Air Temperature

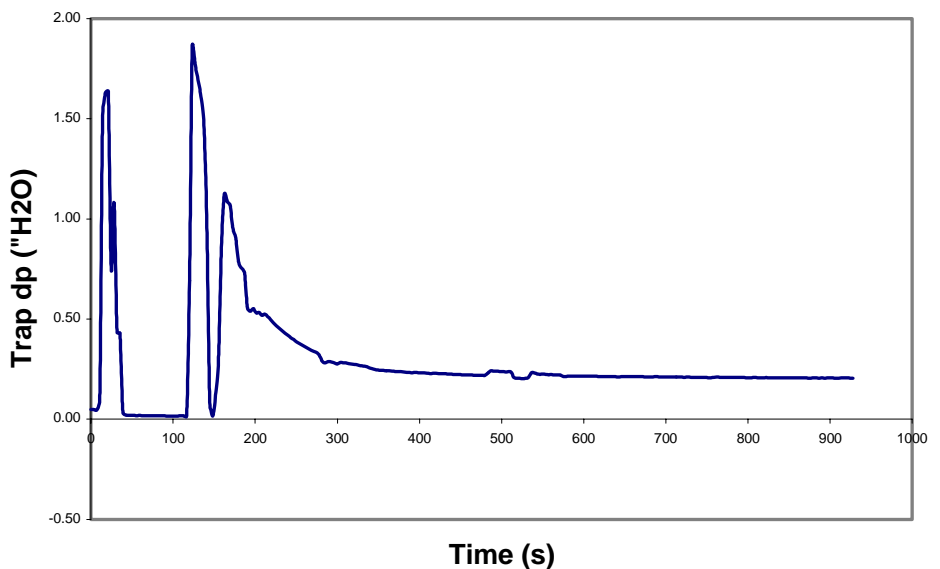

Figure 5.1.5: Test \#1 Trap Differential Pressure 


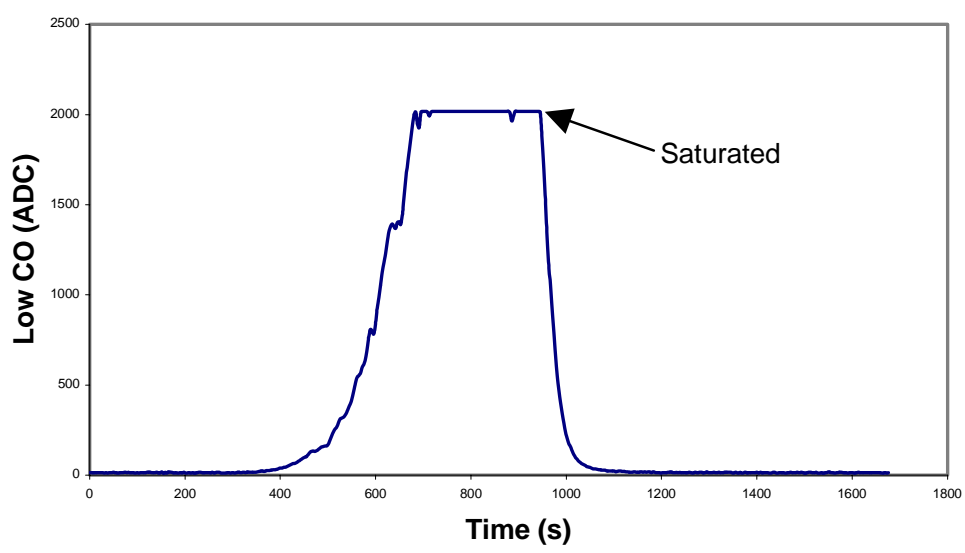

Figure 5.1.6: Test \#1 Low CO Analyzer ADC Output

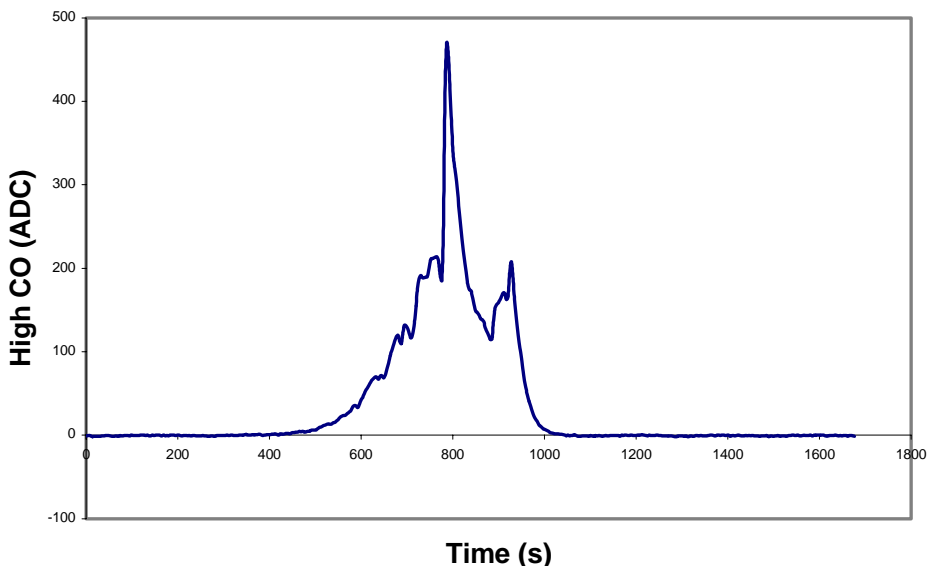

Figure 5.1.7: Test \#1 High CO Analyzer ADC Output

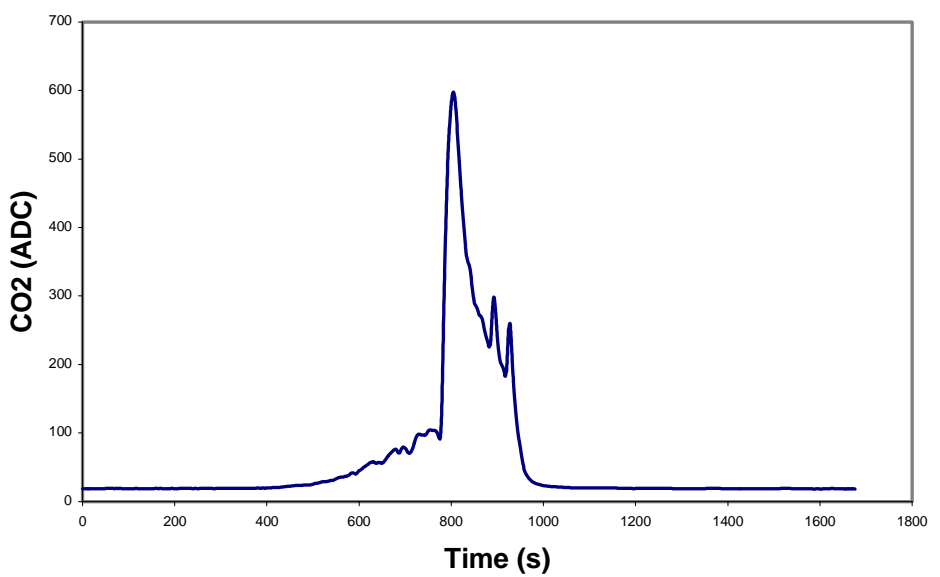

Figure 5.1.8: Test \#1 $\mathrm{CO}_{2}$ Analyzer ADC Output 
It can be seen in Figures 5.1.3 and 5.1.4 that due to the manual control of the combustion air gate valves, some transients occurred in the combustion airflow during the first 180s of the convective combustion period (only the convective combustion time frame is shown in Figures 5.1.3 to 5.1.5). Airflow rates lower than the target value were expected to increase the regeneration efficiency (less energy removed from the filter), and higher airflow rates than the target value were expected to decrease the regeneration efficiency. The transient nature of the airflow rates during the beginning of the convective combustion period were not expected to affect the regeneration trends significantly because the airflow rates tended to oscillate around the target value, and the airflow rate profiles were similar for all tests. Figures 5.1.6 to 5.1.8 display the ADC outputs from the emissions analyzers. These readings were intended to give an indication of the start of the combustion process, as well as an indication as to the relative magnitude of incomplete and complete combustion. The low $\mathrm{CO}$ analyzer output was used to give a better indication of the start of combustion, while the high $\mathrm{CO}$ analyzer output was used to give an indication of the degree of incomplete combustion. The reading from the $\mathrm{CO}_{2}$ analyzer was used to determine the degree of complete combustion. Care must be taken in comparing the magnitudes of the analyzer readings between tests, because the magnitudes are dependent on the dilution ratio as well as the span values of the analyzers. These values were sometimes varied between tests in order to keep the peak values within the analyzer range. The low $\mathrm{CO}$ reading indicates that incomplete (oxygen starved) combustion began during the preheating phase (prior to 750s). This was expected because the microwaves increased the temperature of the soot near the front of 
the filter beyond the soot ignition temperature. No external air was supplied to the filter during the preheating phase, so the air used for combustion had to reach the ignited soot via diffusion. The diffusion airflow rate was insufficient to create complete combustion of the soot, so the $\mathrm{CO}$ was formed. The flat top profile of the low $\mathrm{CO}$ reading shown in Figure 5.1.6 shows that the analyzer had reached its maximum readout, and does not mean that the $\mathrm{CO}$ emissions had stabilized. Figures 5.1.7 and 5.1.8 indicate that once the combustion air was supplied to the filter, the oxygen supplied was sufficient to create complete combustion of the soot.

Only 3.4g of soot was combusted from the filter during test \#1, which corresponds to a regeneration efficiency of $35.4 \%$. This low value of the regeneration efficiency indicates that an insufficient amount of soot was present to absorb the microwaves in the preheating phase or to sustain the combustion process during the convective combustion phase. No filter damage occurred during the regeneration process in test \#2.

For test \#2, the initial soot mass was increased to $17 \mathrm{~g}$. The average airflow rate was $5.05 \mathrm{scfm}\left(0.14 \mathrm{~m}^{3} / \mathrm{min}\right)$ with an average temperature of $304{ }^{\circ} \mathrm{F}\left(151^{\circ} \mathrm{C}\right)$. The preheating time was 12.5 minutes as in test \#1. The trap surface temperature profiles are given in Figure 5.1.9: 


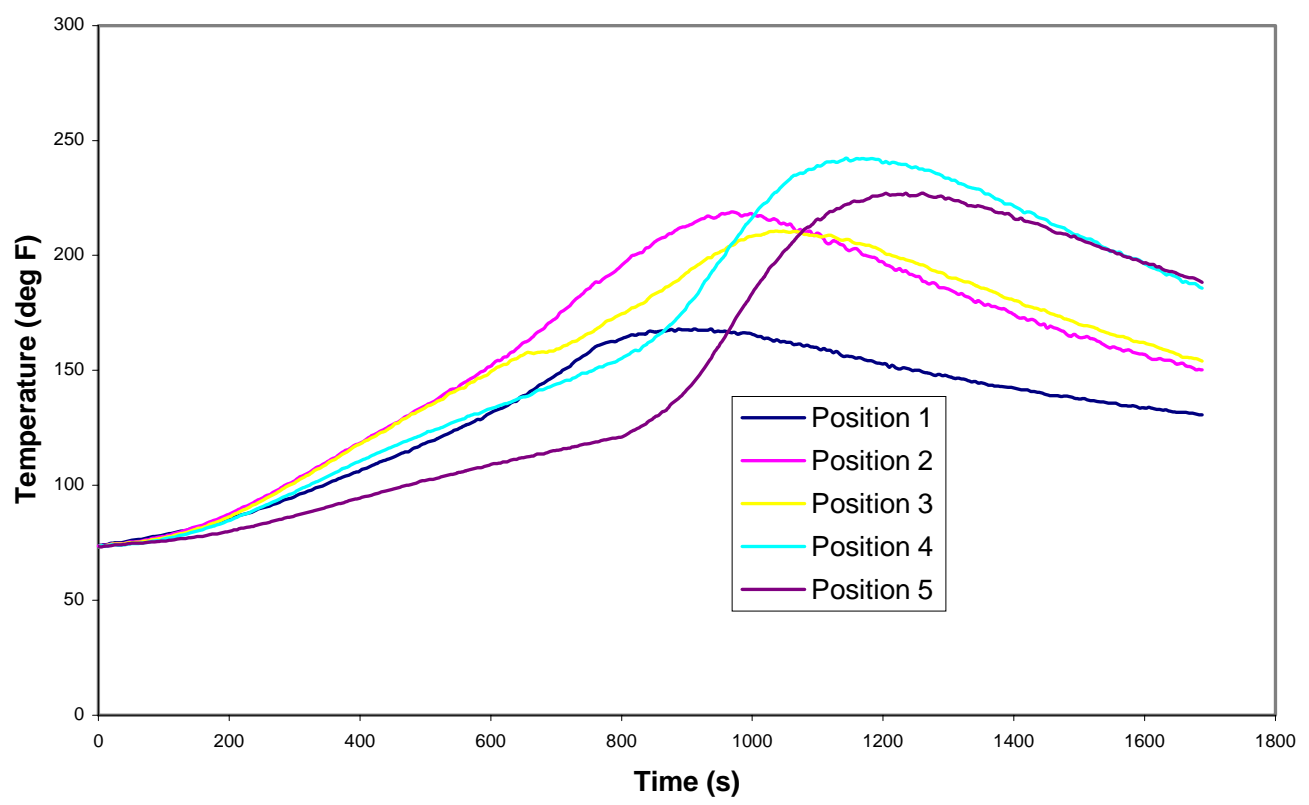

Figure 5.1.9: Test \#2 Trap Surface Temperature Profiles

The peak surface temperatures increased at all positions, indicating that a larger amount of energy was released during combustion relative to test 1 . The peak trap surface temperature occurred at position 4 as in test \#1, and the peak temperature at this position was about $240{ }^{\circ} \mathrm{F}\left(116^{\circ} \mathrm{C}\right)$.

The profiles of the combustion airflow, combustion air temperature, trap differential pressure, and the analyzer readings for test \#2 are contained in Figures 5.1.10 to 5.1.15: 


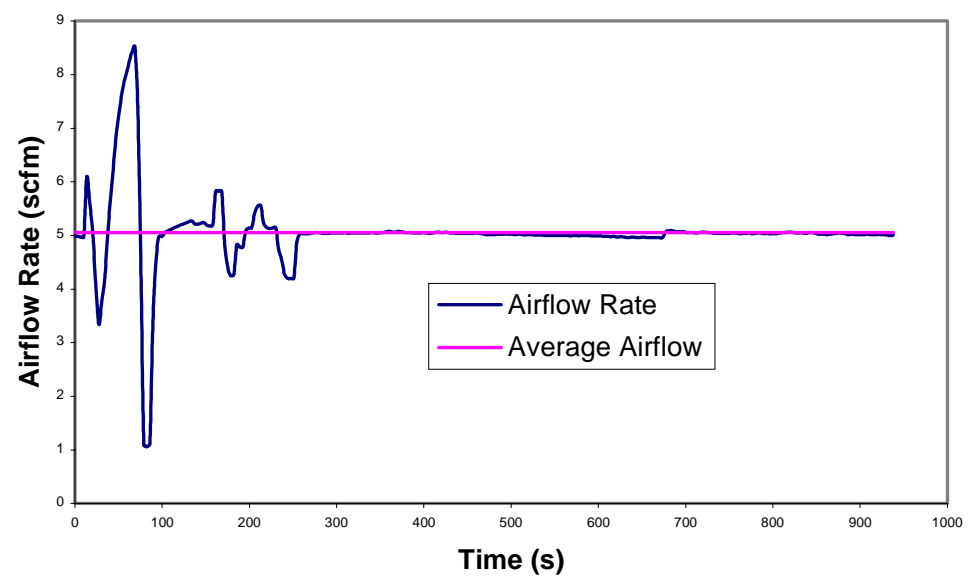

Figure 5.1.10: Test \#2 Combustion Airflow Rate

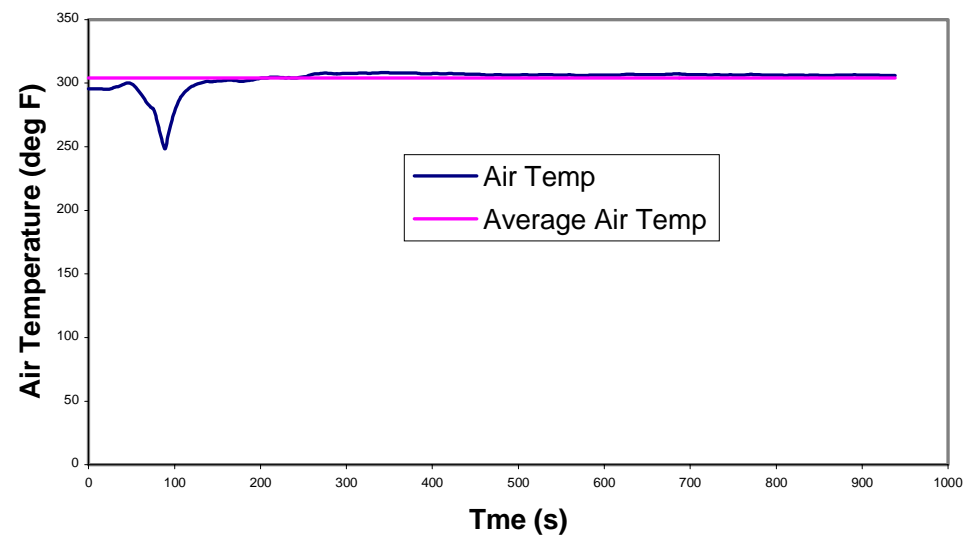

Figure 5.1.11: Test \#2: Combustion Air Temperature

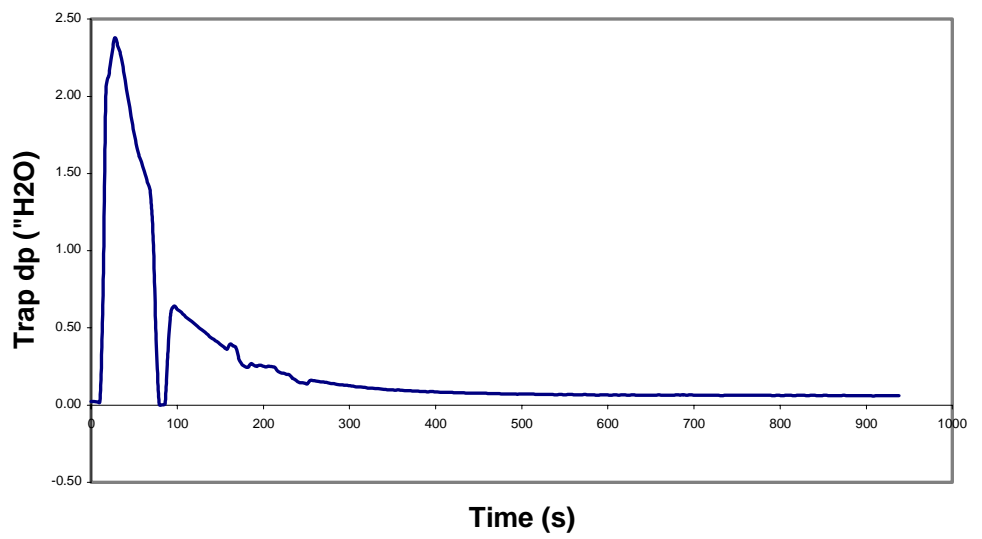

Figure 5.1.12: Test \#2 Trap Differential Pressure 


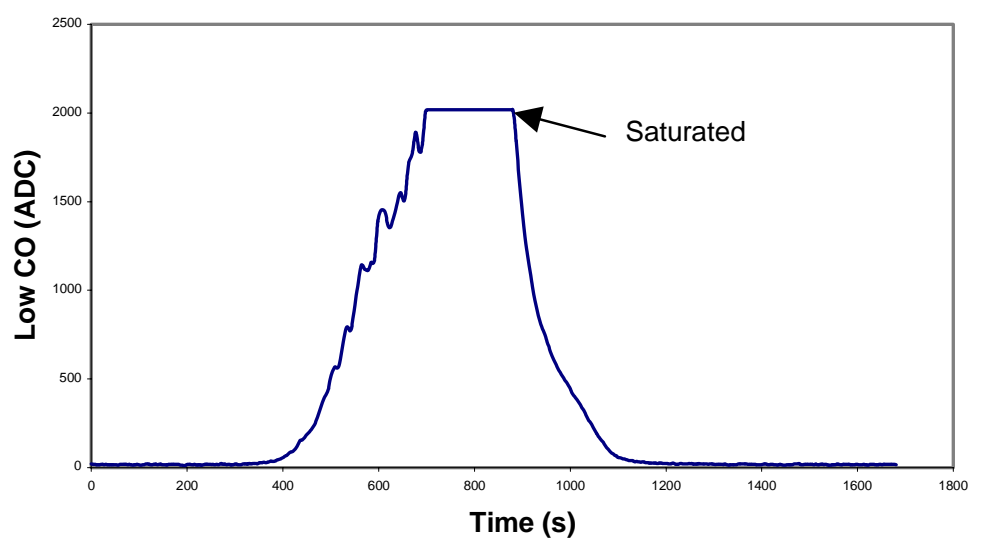

Figure 5.1.13: Test \#2 Low CO Analyzer ADC Output

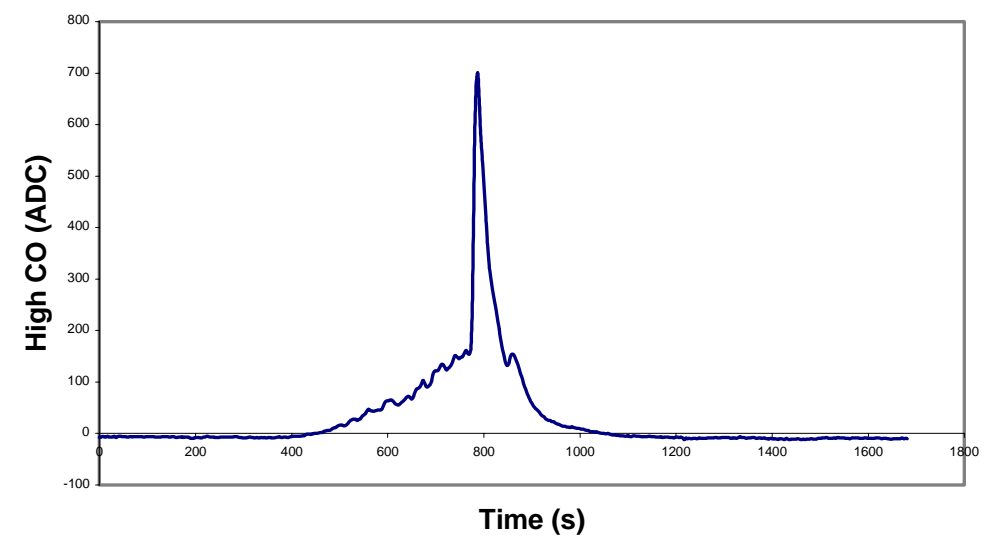

Figure 5.1.14: Test \#2 High CO Analyzer ADC Output

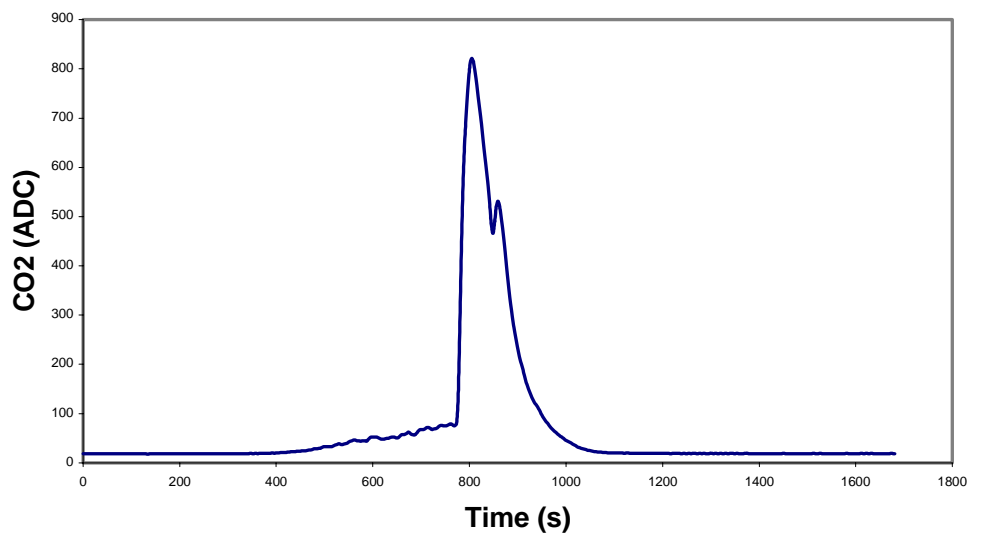

Figure 5.1.15: Test \#2 $\mathrm{CO}_{2}$ Analyzer ADC Output 
Figures 5.1.10 and 5.1.11 show that the transient airflow rates were controlled within the first 100s of the convective combustion period of test \#2. The final trap differential pressure (see Figure 5.1.12) was lower than the final differential pressure in test \#1 indicating that more soot may have been combusted in test \#2. A comparison of the $\mathrm{CO}$ emissions analyzer readings from tests \#1 and \#2 show that the beginning of the combustion process began at about the same time (400s), but the $\mathrm{CO}$ and $\mathrm{CO}_{2}$ emissions rates were much higher during the convective combustion phase in test \#2, again indicating that more soot was combusted. Interestingly, although more soot was combusted in test \#2, the time elapsed during the convective combustion phase of test \#2 was approximately the same as that of test \#1.

Gravimetric analysis showed that $12.4 \mathrm{~g}$ of the initial $17 \mathrm{~g}$ of soot was combusted in test \#2, which corresponds to a regeneration efficiency of $72.9 \%$. The filter suffered no apparent damage during the regeneration process.

For test \#3, the initial soot mass was increased to $23.6 \mathrm{~g}$, while the preheating time was maintained at 12.5 minutes. The average airflow rate provided to the filter during the convective combustion phase was $5.2 \mathrm{scfm}\left(0.15 \mathrm{~m}^{3} / \mathrm{min}\right)$ at an average temperature of $298{ }^{\circ} \mathrm{F}\left(148^{\circ} \mathrm{C}\right)$. The trap surface temperature profiles are given in Figure 5.1.16: 


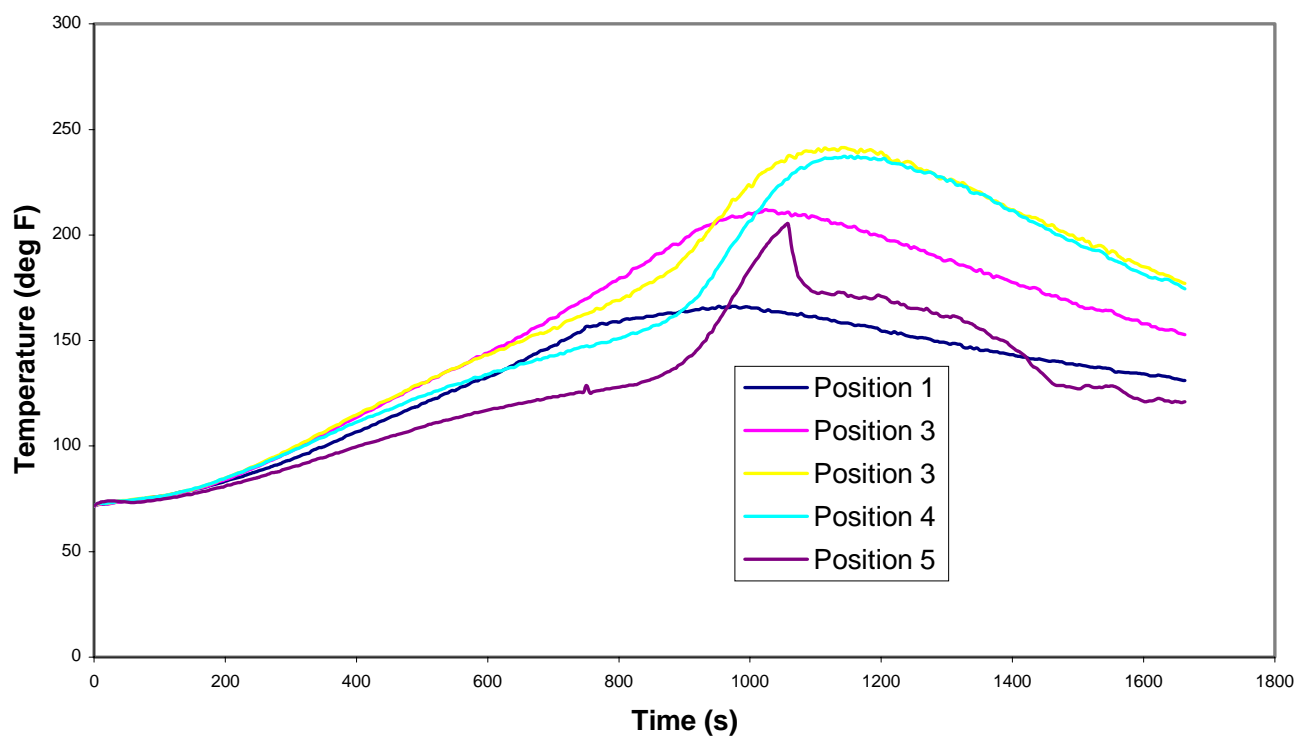

Figure 5.1.16: Test \#3 Trap Surface Temperature Profiles

Considering all the positions, the average trap surface temperatures were slightly higher in test \#3 than in test \#2, indicating more soot combustion. The surface thermocouple in position 5 became detached from the housing during the test, so temperature readings in position 5 (after approximately 1000s) are invalid.

Figures 5.1.17 to 5.1.22 show the profiles of the other measured test parameters.

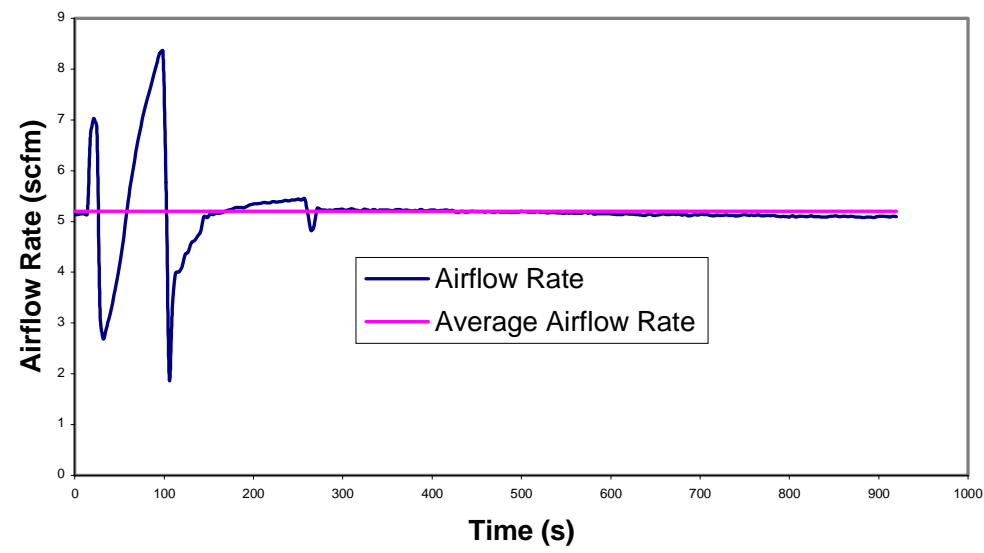

Figure 5.1.17: Test \#3 Combustion Airflow Rate 


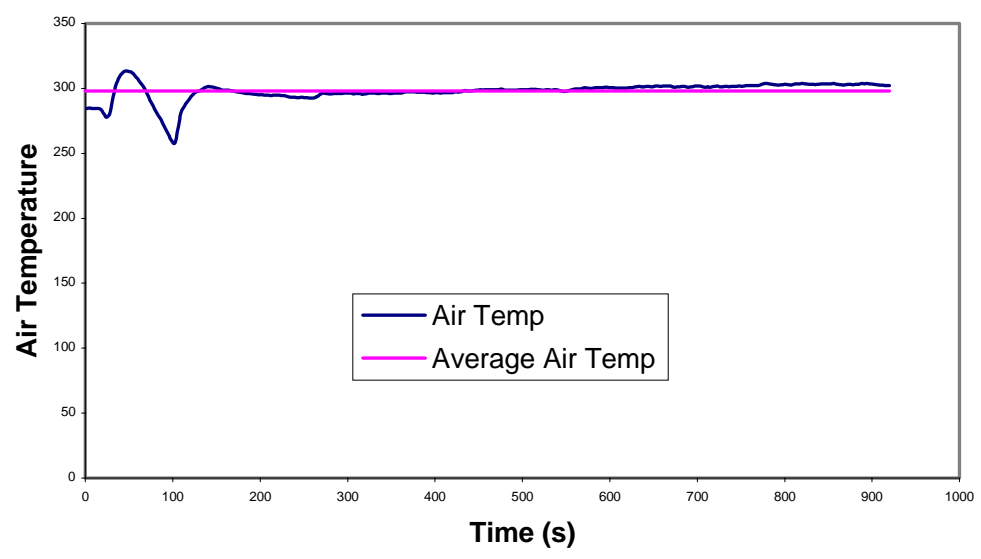

Figure 5.1.18: Test \#3 Combustion Air Temperature

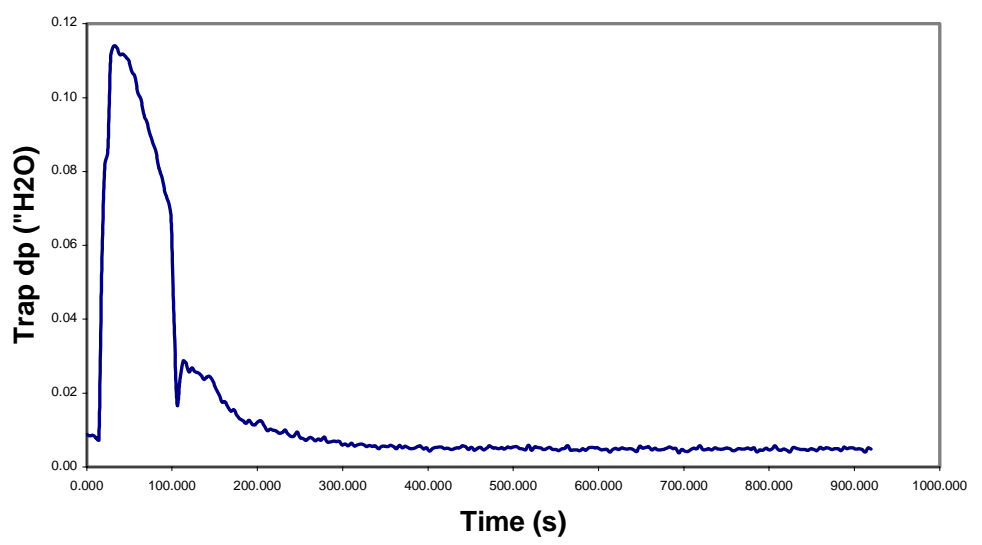

Figure 5.1.19: Test \#3 Trap Differential Pressure

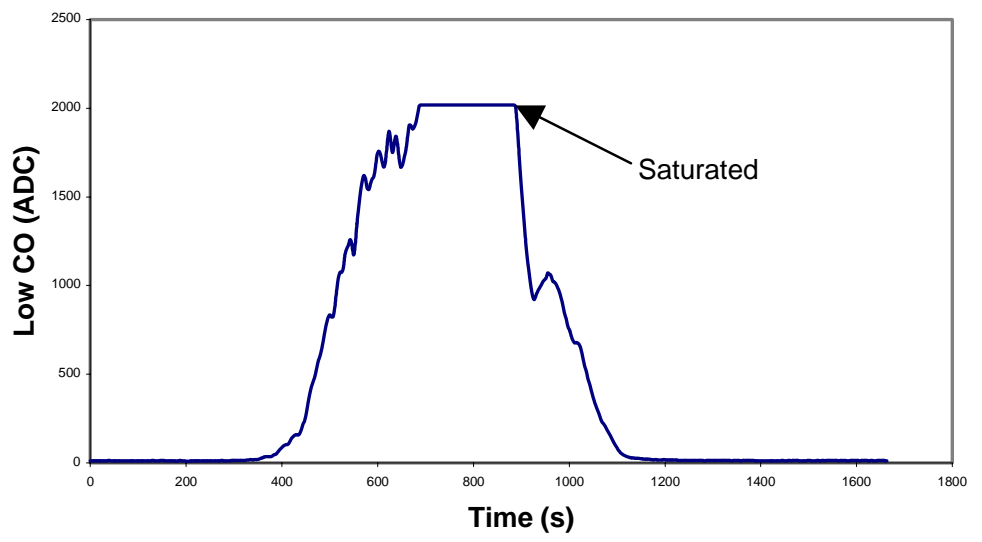

Figure 5.1.20: Test \#3 Low CO Analyzer ADC Output 


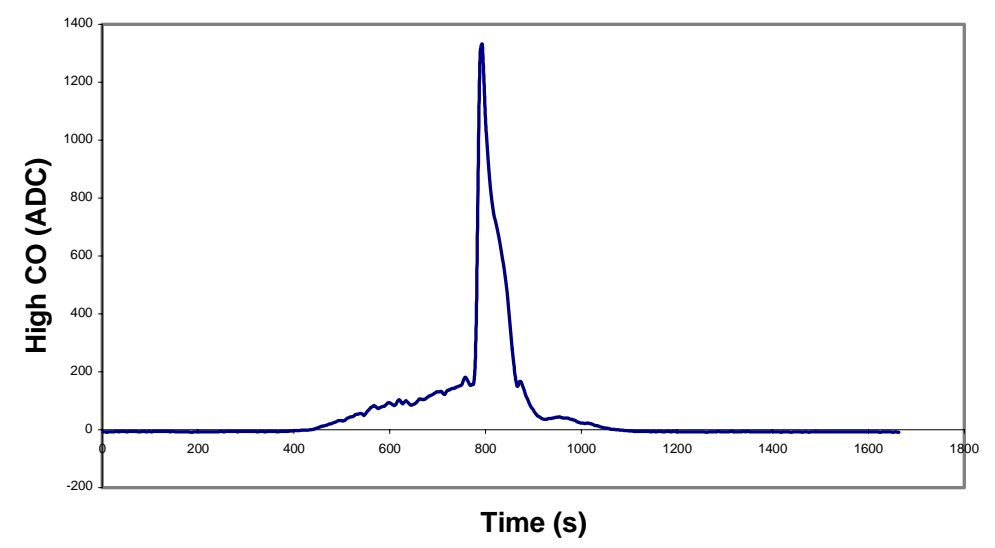

Figure 5.1.21: Test \#3 High CO Analyzer ADC Output

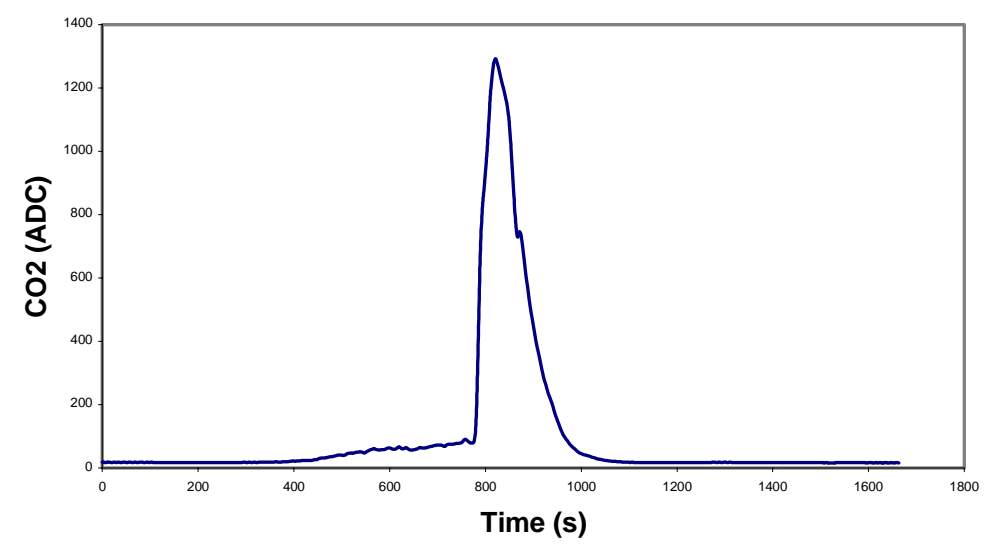

Figure 5.1.22: Test \#3 $\mathrm{CO}_{2}$ Analyzer ADC Output

The various profiles in test \#3 were similar to those in test \#2. It is uncertain as to why the peak trap differential pressures were higher in tests \#1 and \#2, but the final trap differential pressures were similar for tests \#2 and \#3. The emissions analyzer peak readings were higher in test \#3, although the combustion time periods were essentially the same. The gravimetric analysis showed that $13.4 \mathrm{~g}$ of soot had been combusted in test \#3, which was higher than that in test \#2, but the regeneration efficiency was lower in test $\# 3(56.8 \%)$ than in test \#2 (72.9\%). The filter used in test \#3 was not damaged during regeneration. 
The initial soot mass was increased to 29.6 grams for test \#4. The average combustion airflow rate was $5.1 \mathrm{scfm}\left(0.14 \mathrm{~m}^{3} / \mathrm{min}\right)$ with an average temperature of 304 ${ }^{\circ} \mathrm{F}\left(151{ }^{\circ} \mathrm{C}\right)$. The preheating time was 12.5 minutes. The trap housing surface temperature profiles are shown in Figure 5.1.23:

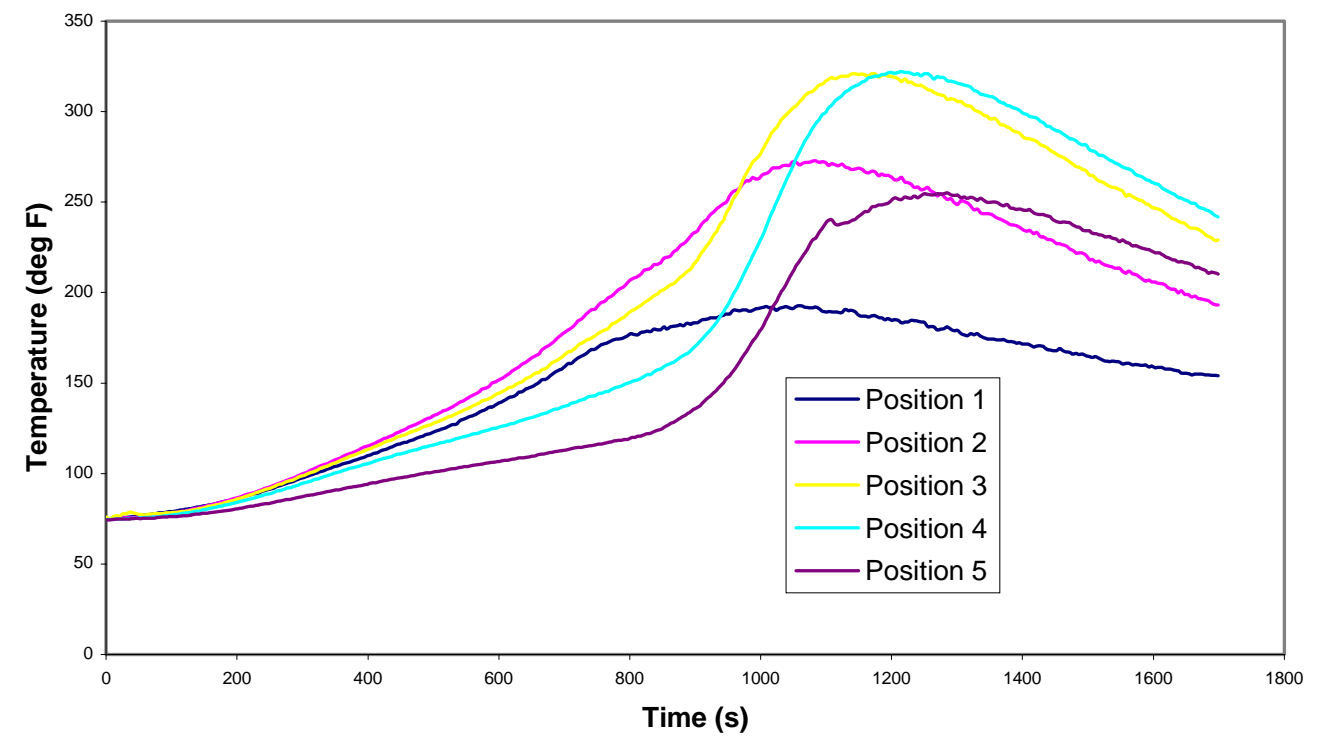

Figure 5.1.23: Test \#4 Trap Surface Temperature Profiles

The average surface temperatures for test \#4 were much higher than those of the previous tests indicating that a large amount of soot had been combusted. The same peak temperature pattern which was present in the first three tests was present in test \#4: the highest peak temperatures typically occurred near the end of the trap due to the exothermic nature of the reaction within the filter. It must be noted again, that due to the transient nature of the reaction and the thermal inertia of the assembly, the temperature patterns within the trap could vary significantly from the surface temperature profiles.

Plots of the other measured regeneration parameters are given in Figures 5.1.24 to

\subsubsection{9.}




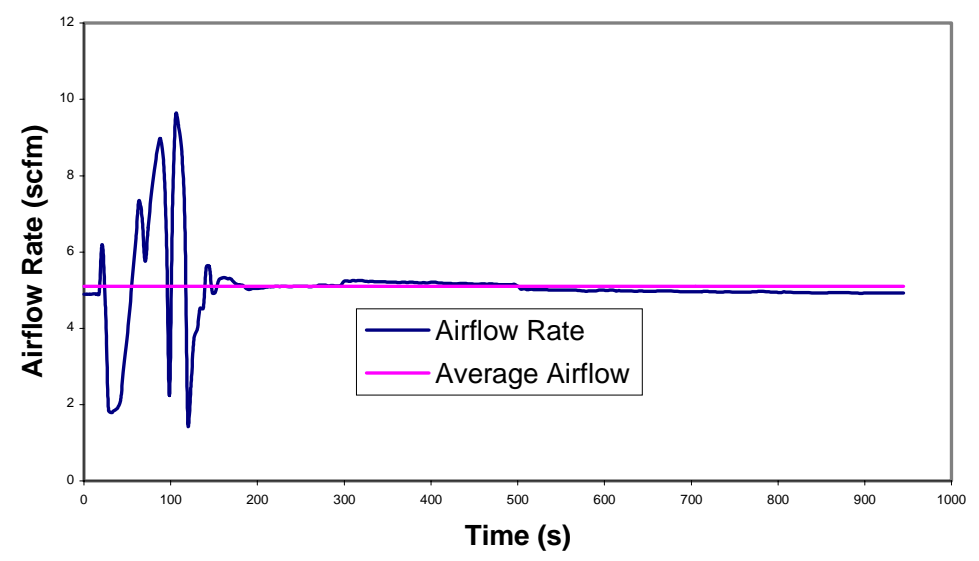

Figure 5.1.24: Test \#4 Combustion Airflow Rate

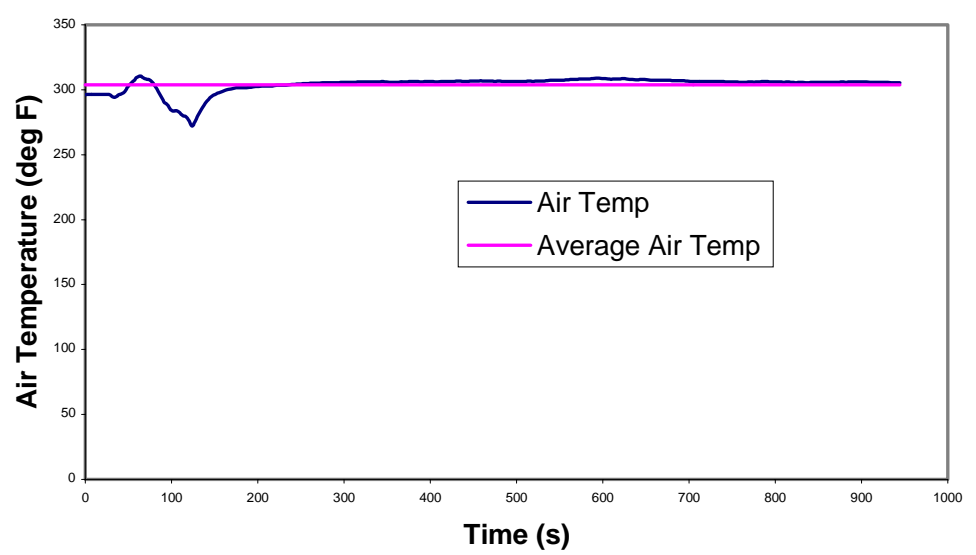

Figure 5.1.25: Test \#4 Combustion Air Temperature

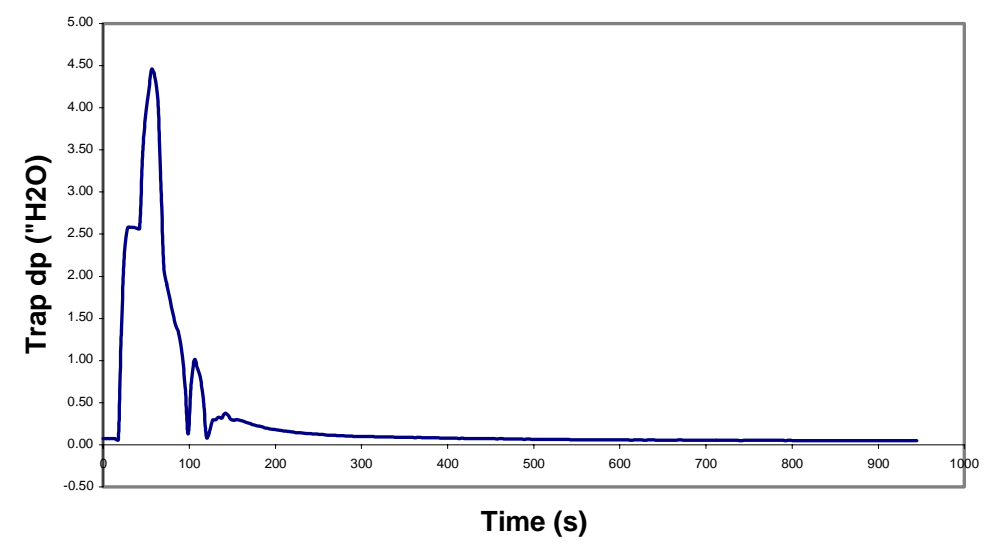

Figure 5.1.26: Test \#4 Trap Differential Pressure 


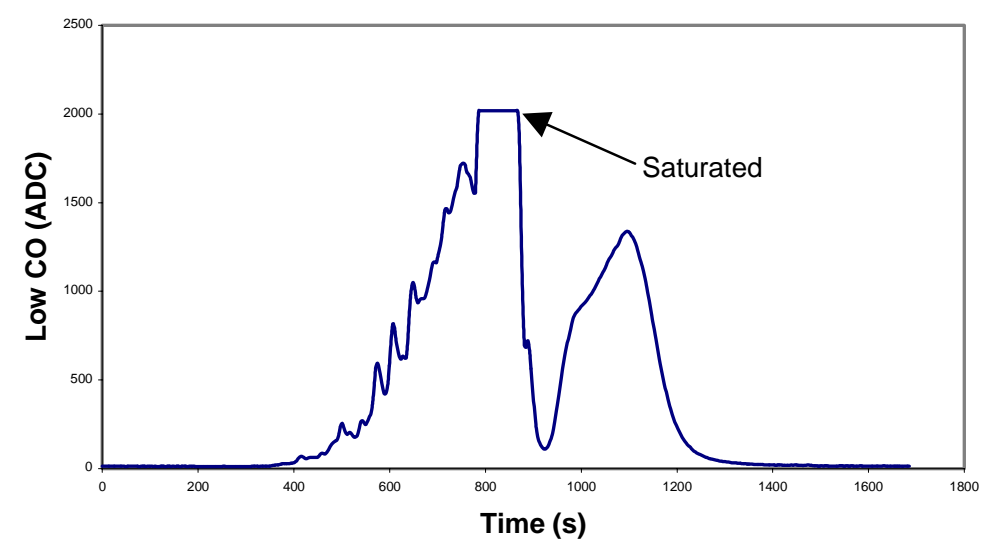

Figure 5.1.27: Test \#4 Low CO Analyzer ADC Output

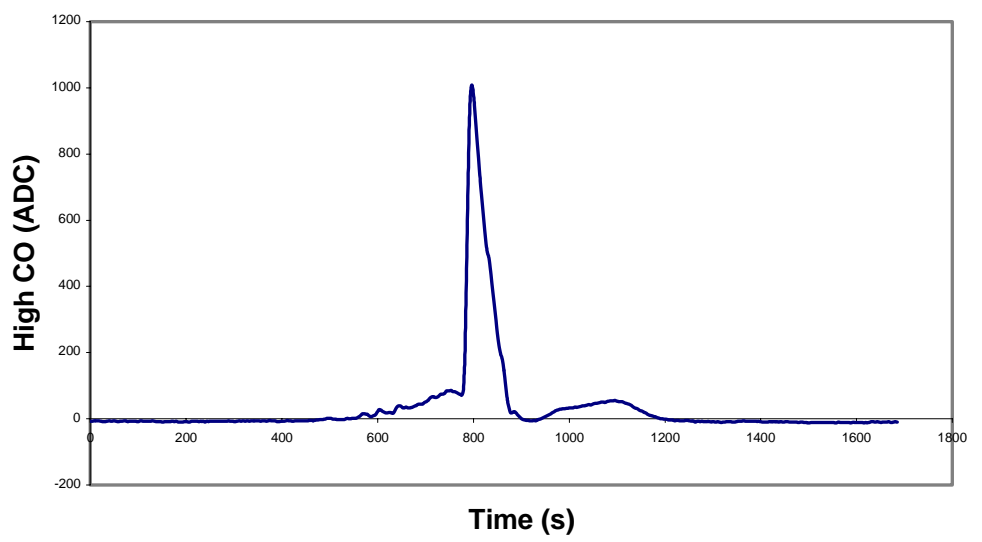

Figure 5.1.28: Test \#4 High CO Analyzer ADC Output

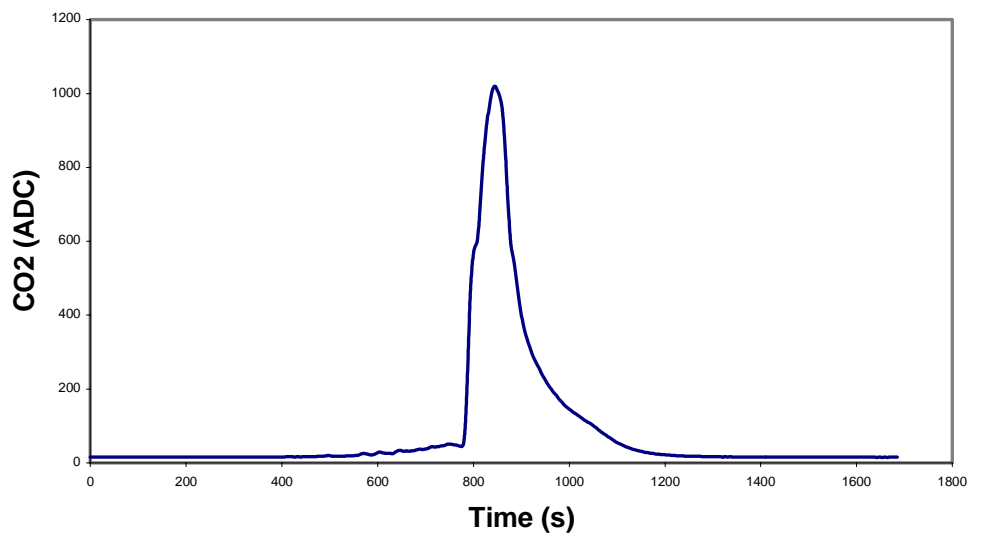

Figure 5.1.29: Test \#4 $\mathrm{CO}_{2}$ Analyzer ADC Output 
Due to the higher initial soot mass the emissions concentrations in test \#4 were expected to be higher than that of the previous tests. In anticipation of this, the dilution ratio was increased, and for this reason the emissions readings could not be compared to the other tests. The double peak in the $\mathrm{CO}$ emissions profiles in Figures 5.1.27 and 5.1.28 indicate that the rate of reaction increased significantly during the convective combustion portion of the regeneration event such that $5 \mathrm{scfm}$ was not sufficient to result in complete combustion. The peak in the $\mathrm{CO}_{2}$ emissions profile coincides very closely with the low point in the $\mathrm{CO}$ emissions profile. The second peak in the $\mathrm{CO}$ profile indicates that the second reaction proceeded very rapidly, such that the airflow rate was insufficient to create complete combustion. Filter damage is expected to have occurred during the second reaction. This latter combustion event could have been caused by the ignition of a large portion of soot near the outlet end of the filter. Also, the emissions readings indicate that combustion was initiated in the same time frame as the previous three tests, but the combustion in test \#4 lasted several minutes longer. These results indicated that severe damage to the filter had occurred, and inspection of the filter verified, that the filter had, indeed melted. In order to view the damage, the filter was cut in half along its centerline. A photograph of the damaged filter is shown in Figure 5.1.30: 


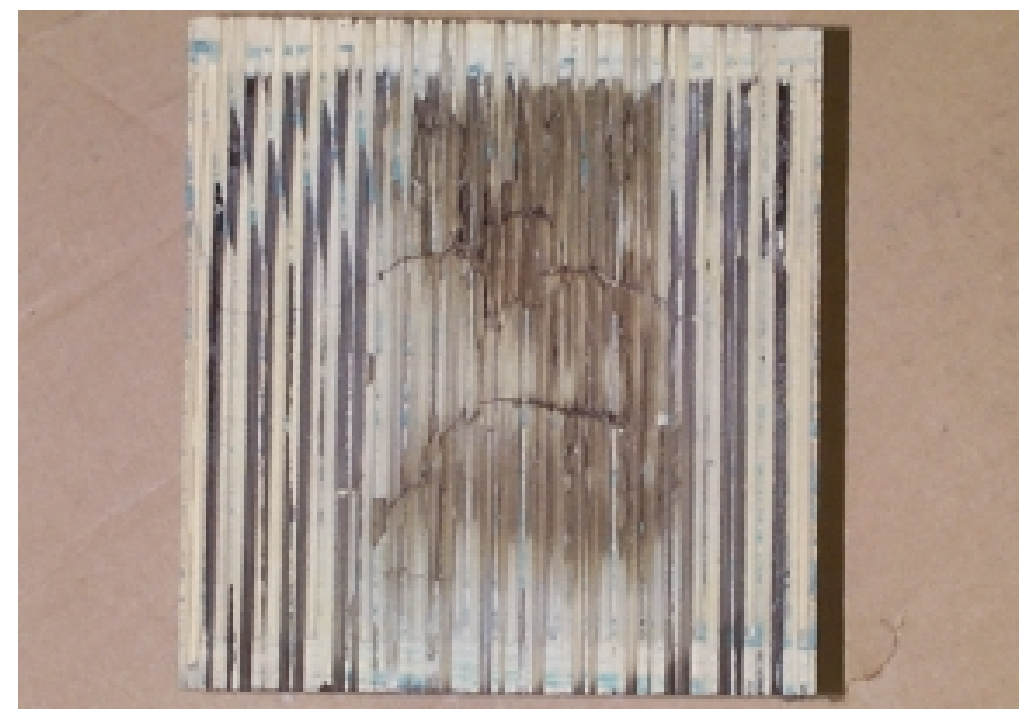

Figure 5.1.30: Damaged Filter

Most of the damage had occurred near the outlet end of the filter, demonstrating that the filter had melted due to uncontrolled convective combustion.

Before the damaged filter was removed from the housing, the filter was weighed to determine the regeneration efficiency. The results showed that $21.4 \mathrm{~g}$ of the initial $29.6 \mathrm{~g}$ had been regenerated. The corresponding regeneration efficiency was $72.3 \%$.

\subsection{Effect of Preheating Time}

In the next series of tests, the effect of preheating time on the regeneration efficiency was investigated. For these tests (tests \#5 to \#9), 24g was the nominal target value for collected soot on the filter, and the nominal airflow rate and temperature were $10 \mathrm{scfm}$ and $300{ }^{\circ} \mathrm{F}$ respectively. The preheating time ranged from 10 minutes to 17.5 minutes. 
For test \#5, 23.6g of soot were collected on the filter. The preheating time was 10 minutes, and the average airflow rate and temperature were $9.9 \mathrm{scfm}\left(0.28 \mathrm{~m}^{3} / \mathrm{min}\right)$ and $31{ }^{\circ} \mathrm{F}\left(155^{\circ} \mathrm{C}\right)$, respectively. Chronologically this was one of the very first tests performed, so the real-time parametric data was limited. A plot of the combustion airflow rate is given in Figure 5.2.1, and a plot of the combustion air temperature profile is given in Figure 5.2.2.

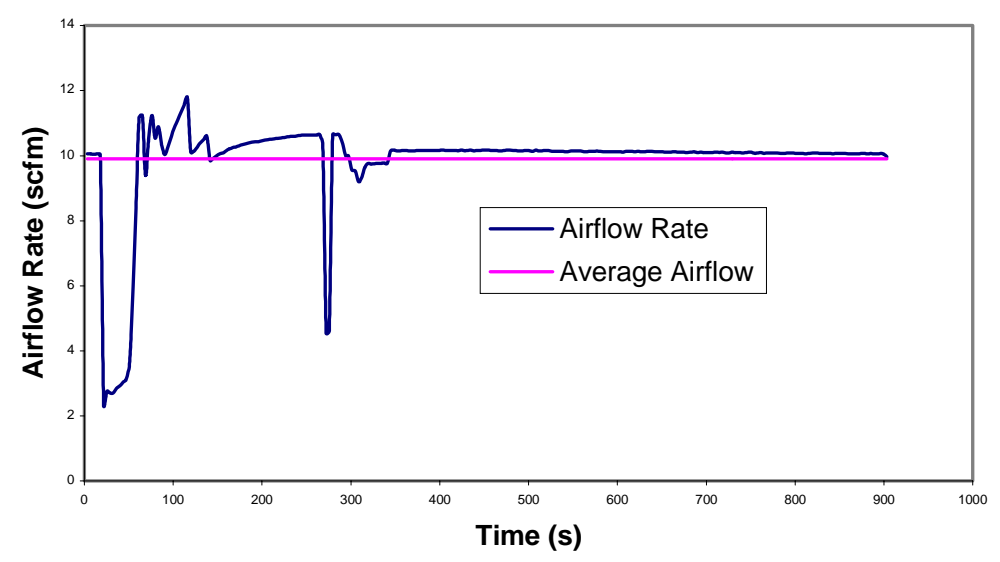

Figure 5.2.1: Test \#5 Combustion Airflow Rate

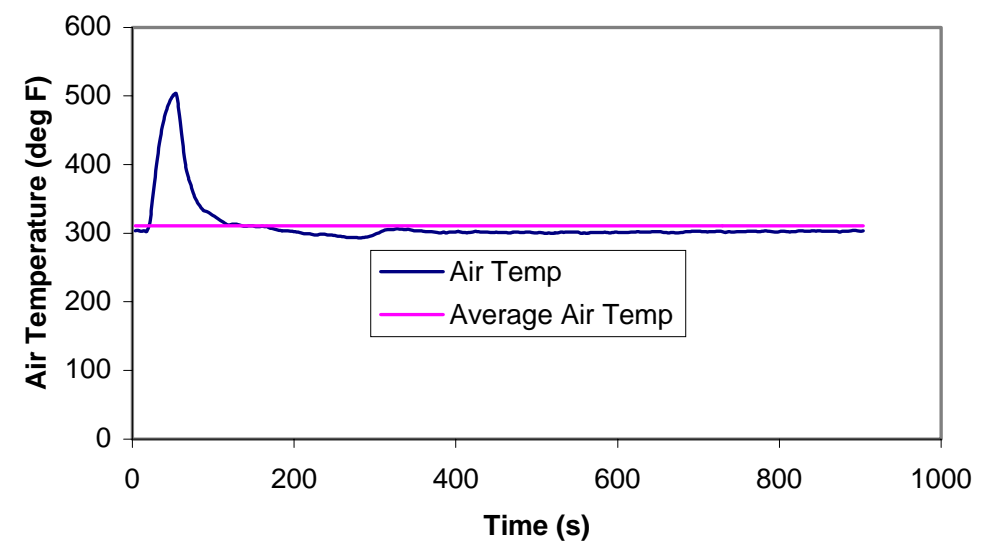

Figure 5.2.2: Test \#5 Combustion Air Temperature

It is apparent from these diagrams that the actual combustion airflow rate and temperature were maintained near the target values within 100s of the convective 
combustion period (again note that the time frame used in the plots for combustion airflow rate and temperature is for the convective combustion phase only).

Subsequent analysis showed that only $7 \mathrm{~g}$ had been removed from the filter during regeneration resulting in a regeneration efficiency of $30 \%$, with no filter damage. It was apparent that for this regeneration system, a 10-minute preheating period was insufficient for substantial soot combustion.

In the second test in this series (test \#6), $24.4 \mathrm{~g}$ of soot were collected, and the preheating time was increased to 12.5 minutes. The average combustion airflow rate and temperature were $9.87 \mathrm{scfm}\left(0.28 \mathrm{~m}^{3} / \mathrm{min}\right)$ and $316{ }^{\circ} \mathrm{F}\left(158{ }^{\circ} \mathrm{C}\right)$, respectively. The trap housing surface temperature profiles for this test are shown in Figure 5.2.3:

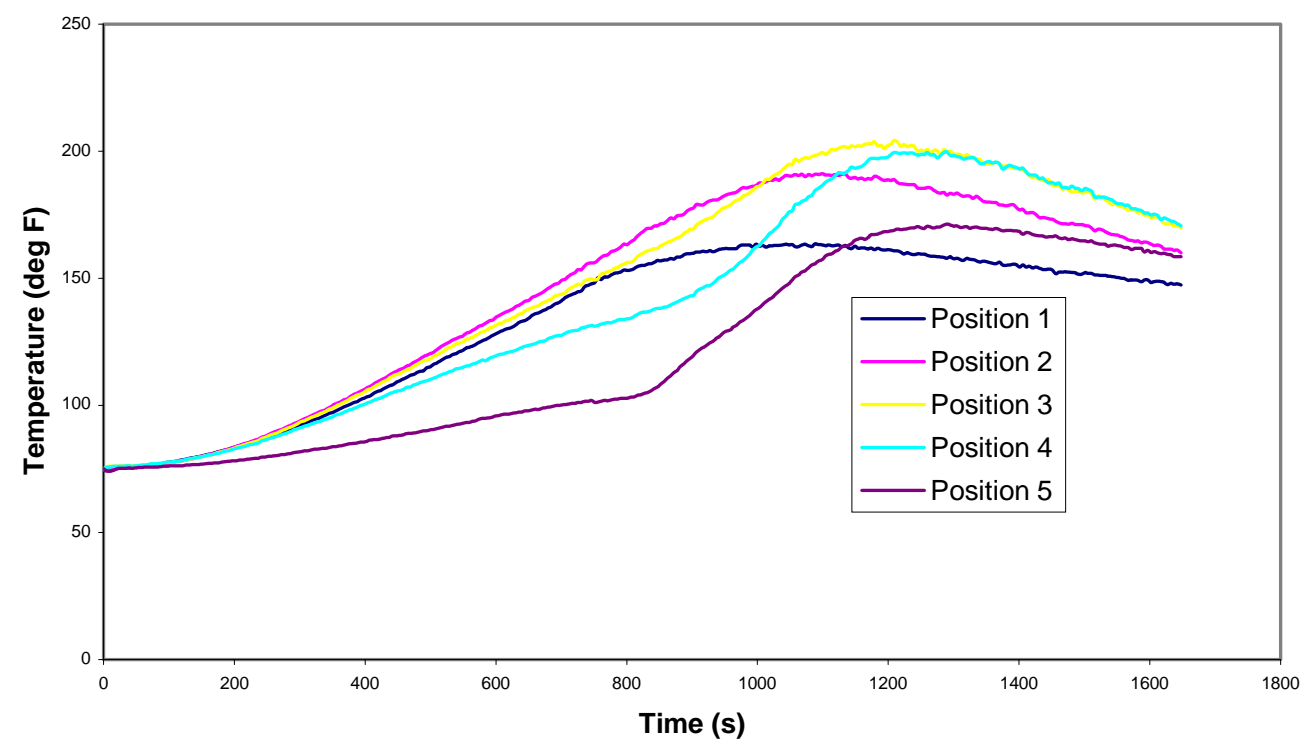

Figure 5.2.3: Test \#6 Trap Surface Temperature Profiles

As in the previous test, the peak surface temperatures were observed in positions 3 and 4 , and in this case, they were approximately $200{ }^{\circ} \mathrm{F}\left(93^{\circ} \mathrm{C}\right)$. 
Plots of the real-time combustion airflow rate and combustion air temperature are shown in Figures 5.2.4 and 5.2.5, respectively (as was the case in test \#5, this was chronologically an early test, so the real-time parametric data was limited):

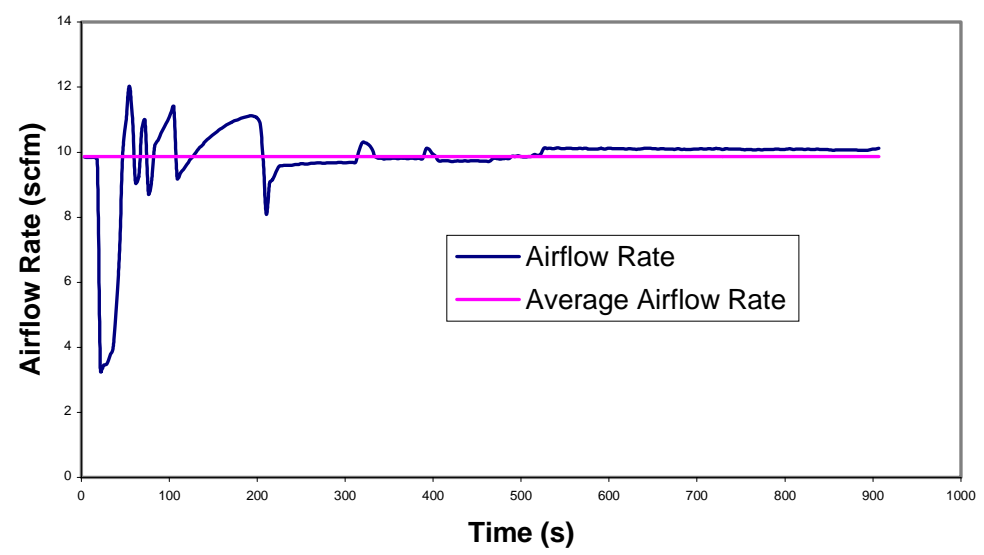

Figure 5.2.4: Test \#6 Combustion Airflow Rate

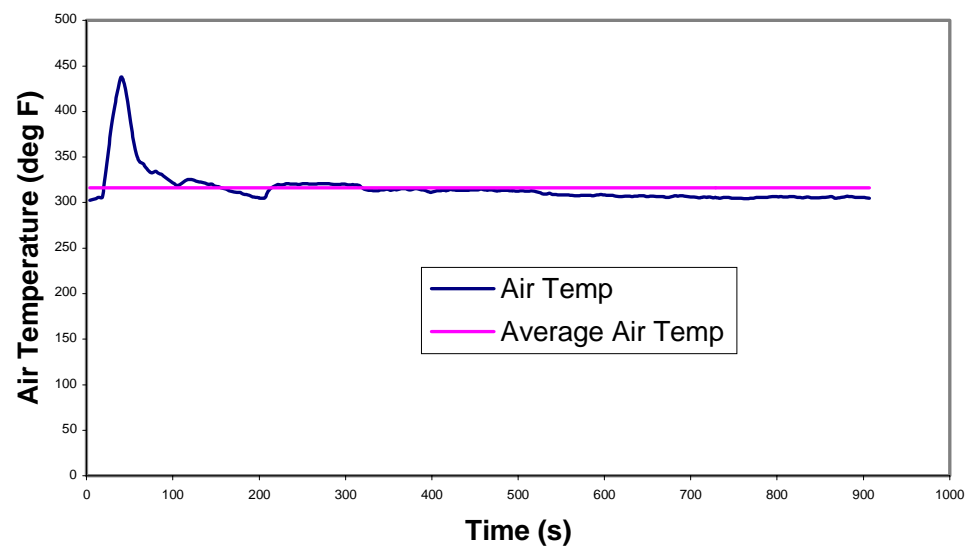

Figure 5.2.5: Test \#6 Combustion Air Temperature

These Figures show that the combustion airflow rate and temperature were controlled near the target values after approximately 70s.

The gravimetric analysis showed that $13.2 \mathrm{~g}$ of soot had been combusted, which corresponded to a regeneration efficiency of $54.1 \%$. No filter damage was found to have occurred during regeneration. 
The preheating time was increased to 15 minutes in the third test in this series (test \#7). The initial soot mass was $23.6 \mathrm{~g}$, and the average combustion airflow rate and temperature were $9.91 \mathrm{scfm}\left(0.28 \mathrm{~m}^{3} / \mathrm{min}\right)$ and $309{ }^{\circ} \mathrm{F}\left(154{ }^{\circ} \mathrm{C}\right)$, respectively. A plot of the trap housing surface temperature profiles are contained in Figure 5.2.6:

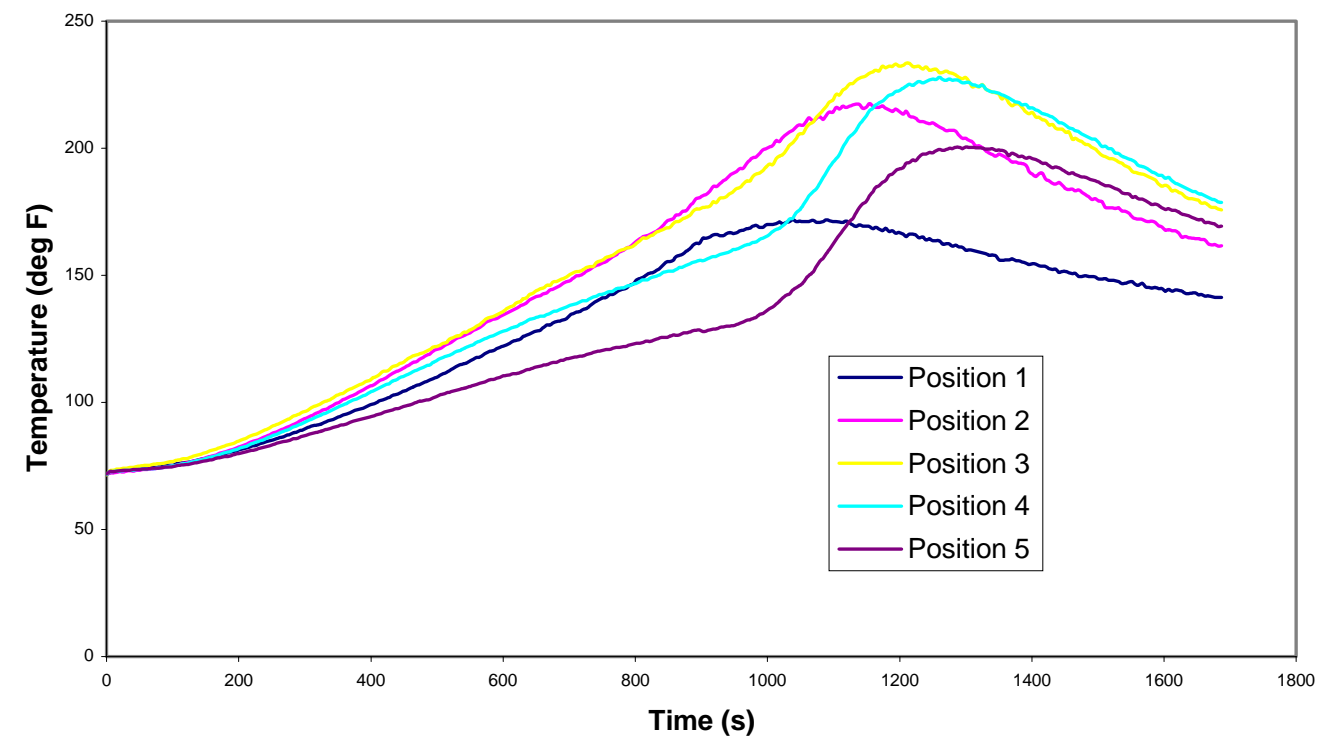

Figure 5.2.6: Test \#7 Trap Surface Temperature Profiles

As seen in Figure 5.2.6, the peak trap housing surface temperatures were about $225^{\circ} \mathrm{F}\left(107^{\circ} \mathrm{C}\right)$.

Plots of the measured regeneration parameters are shown in Figures 5.2.7 to 5.2.12. 


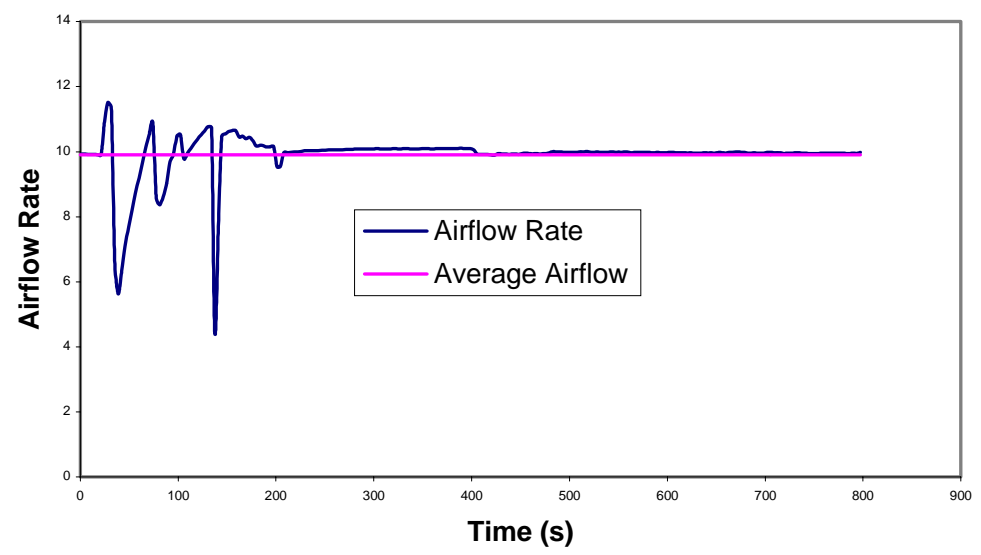

Figure 5.2.7: Test \#7 Combustion Airflow Rate

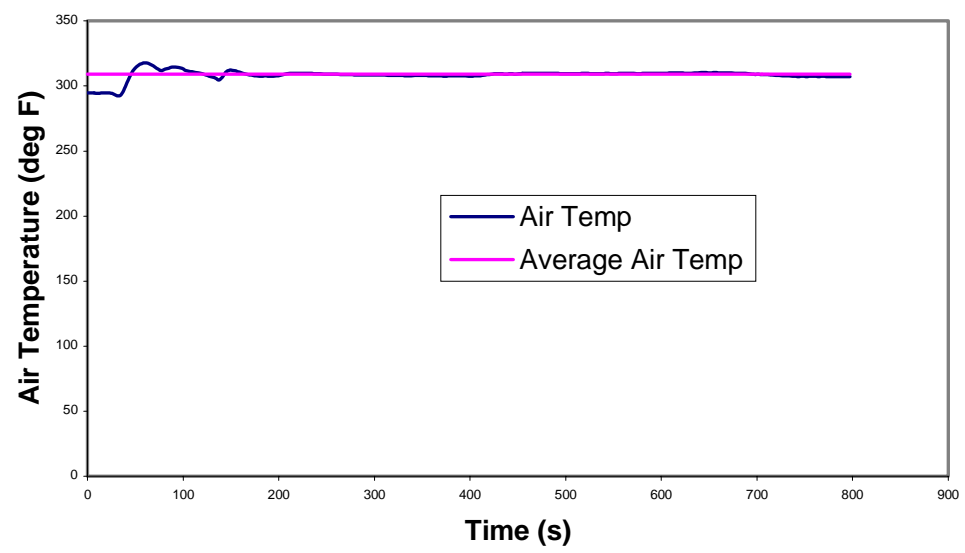

Figure 5.2.8: Test \#7 Combustion Air Temperature

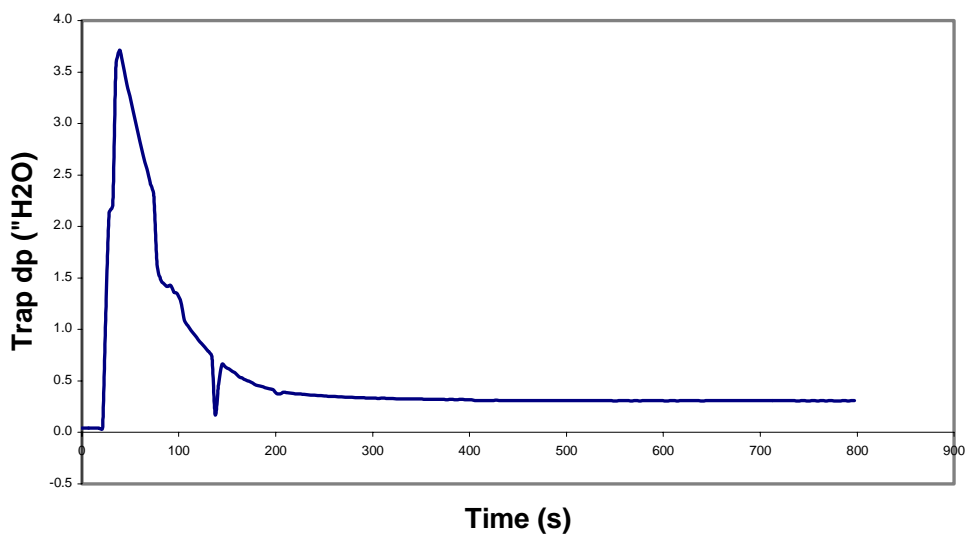

Figure 5.2.9: Test \#7 Trap Differential Pressure 


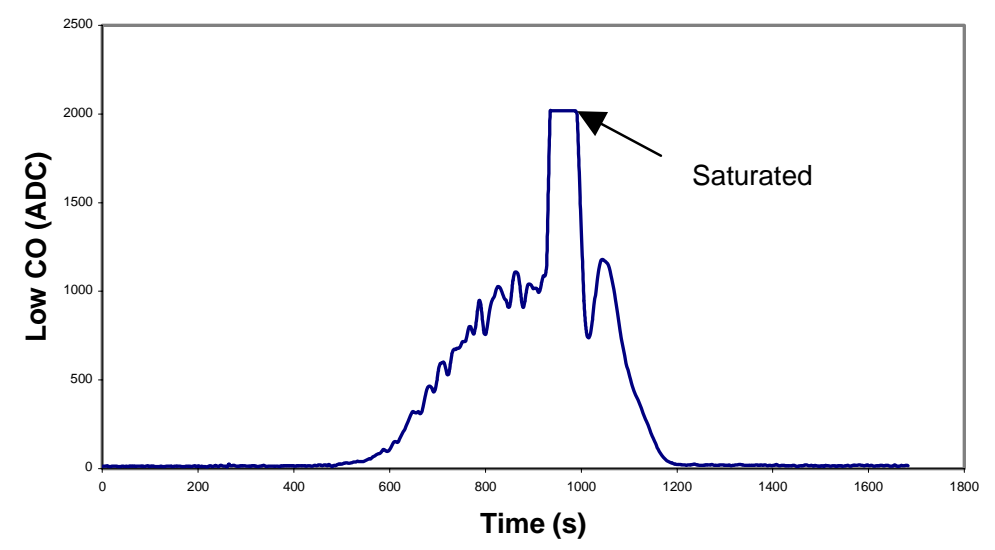

Figure 5.2.10: Test \#7 Low CO Analyzer ADC Output

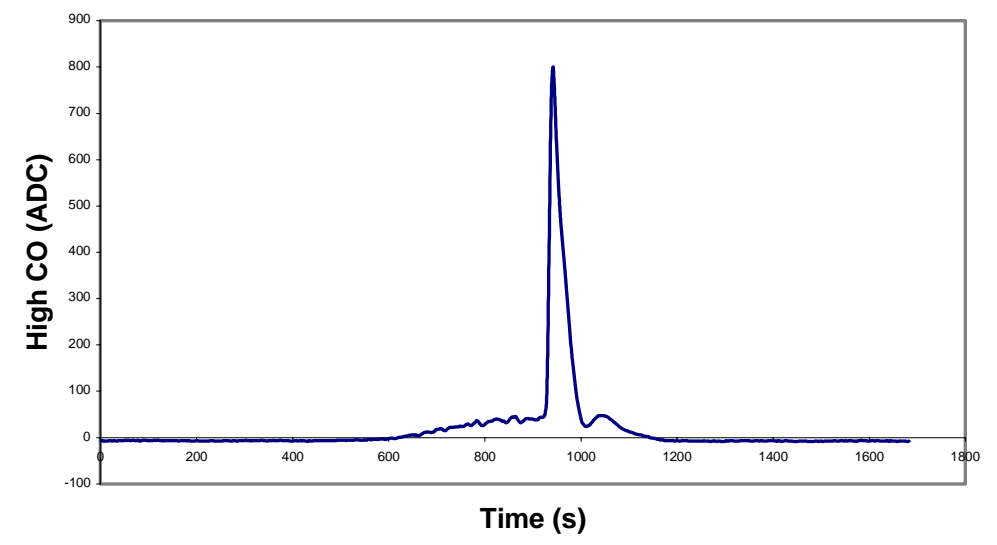

Figure 5.2.11: Test \#7 High CO Analyzer ADC Output

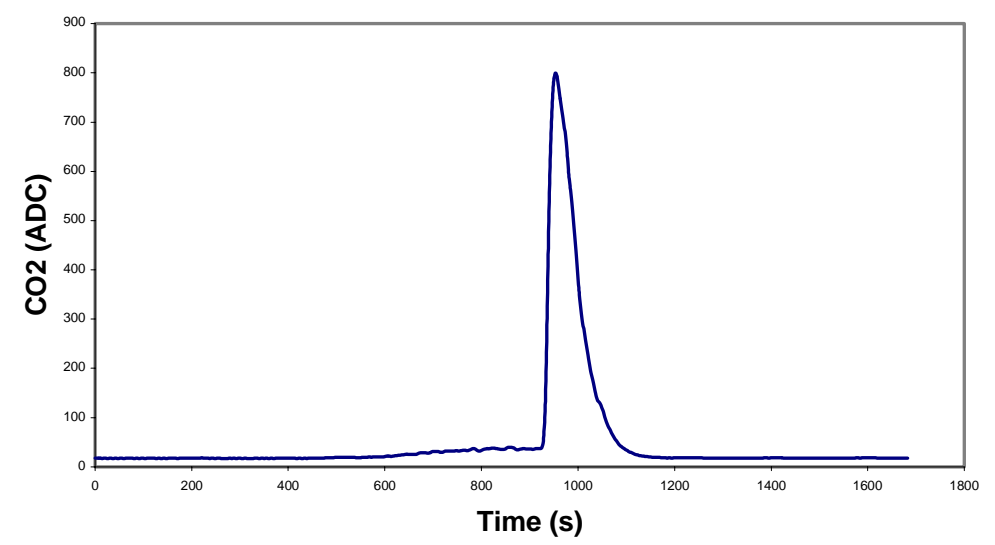

Figure 5.2.12: Test \#7 $\mathrm{CO}_{2}$ Analyzer ADC Output 
It is apparent from the emissions analyzer ADC output graphs that a large amount of $\mathrm{CO}$ was formed during the preheating period due to the oxygen-starved combustion. As was the case in the previous regeneration tests, when external air is provided to the filter, a large spike occurs in the both $\mathrm{CO}$ and $\mathrm{CO}_{2}$ readings as soot oxidation proceeds at a much more rapid rate.

The regeneration efficiency for this test was found to be $54.2 \%$ (12.8g of soot were combusted). The filter incurred no damage during regeneration.

The fourth test in this series (test \#8) was performed to check the repeatability of the regeneration system. The target test parameters were identical to those of test \#7, but the filter element was changed to ensure that filter characteristics did not affect the regeneration results. The trapped soot mass was $24.0 \mathrm{~g}$, the preheating time was 15 minutes, the average airflow rate was $9.94 \mathrm{scfm}\left(0.28 \mathrm{~m}^{3} / \mathrm{min}\right)$, and the average combustion air temperature was $310{ }^{\circ} \mathrm{F}\left(154^{\circ} \mathrm{C}\right)$. A plot of the trap housing surface temperature profiles are shown in Figure 5.2.13:

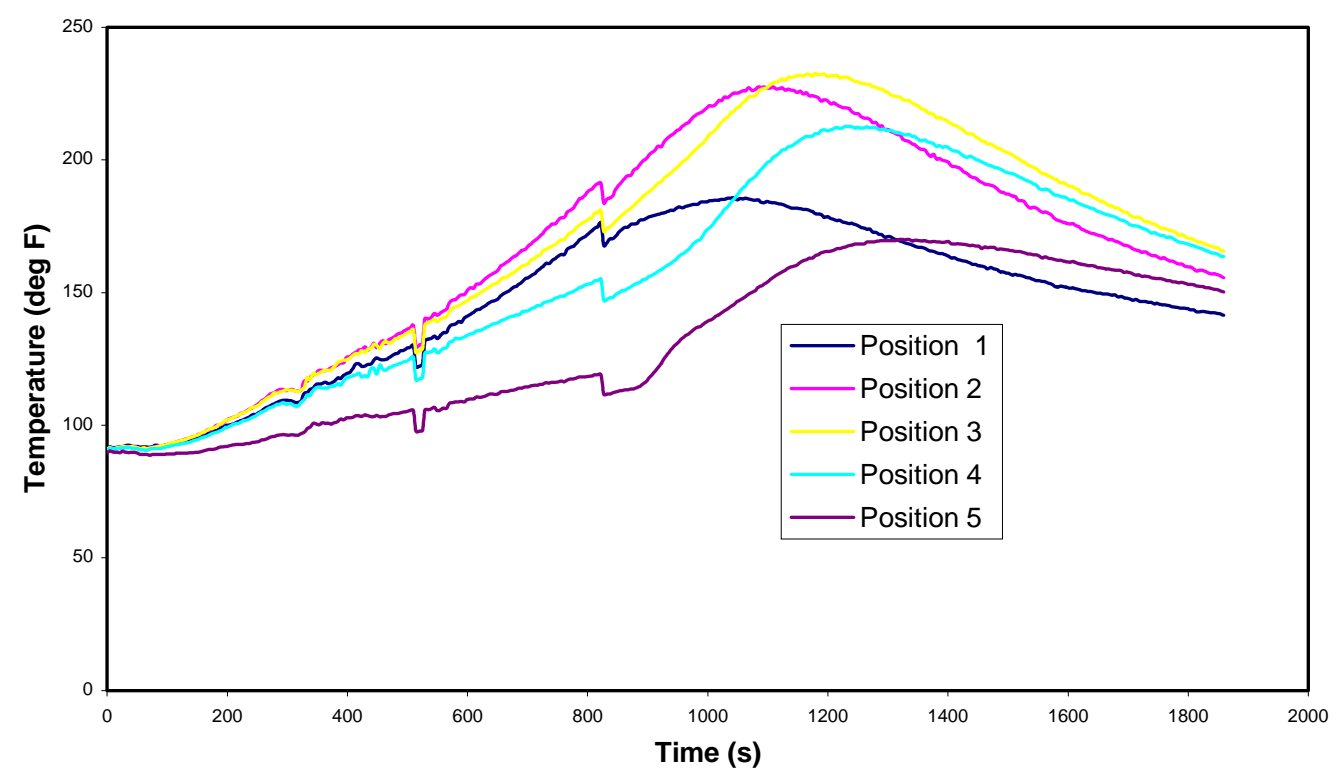

Figure 5.2.13: Test \#8 Trap Surface Temperature Profiles 
The small spikes and discontinuities present in the temperature profiles prior to $800 \mathrm{~s}$ indicate that the electric fields from the high voltage line to the magnetron were creating a small amount of interference in the thermocouple lines (note that the spikes do not appear after the preheating period). The peak trap surface temperatures were found to be on the order to $225^{\circ} \mathrm{F}\left(107^{\circ} \mathrm{C}\right)$. These peak trap temperature profiles are very similar to the profiles in test \#7 (see Figure 5.2.6).

The regeneration efficiency was found to be $51.7 \%$ (12.4g of soot) were combusted from the filter, so the regeneration/loading system and test methods were found to yield repeatable results.

In the final test in this series (test \#9), the preheating time was increased to 17.5 minutes. The initial soot mass was $23.4 \mathrm{~g}$, the average airflow rate was $9.96 \mathrm{scfm}(0.282$ $\left.\mathrm{m}^{3} / \mathrm{min}\right)$, and the average combustion air temperature was $305^{\circ} \mathrm{F}\left(152^{\circ} \mathrm{C}\right)$. A plot of the trap housing surface temperature readings is provided in Figure 5.2.14:

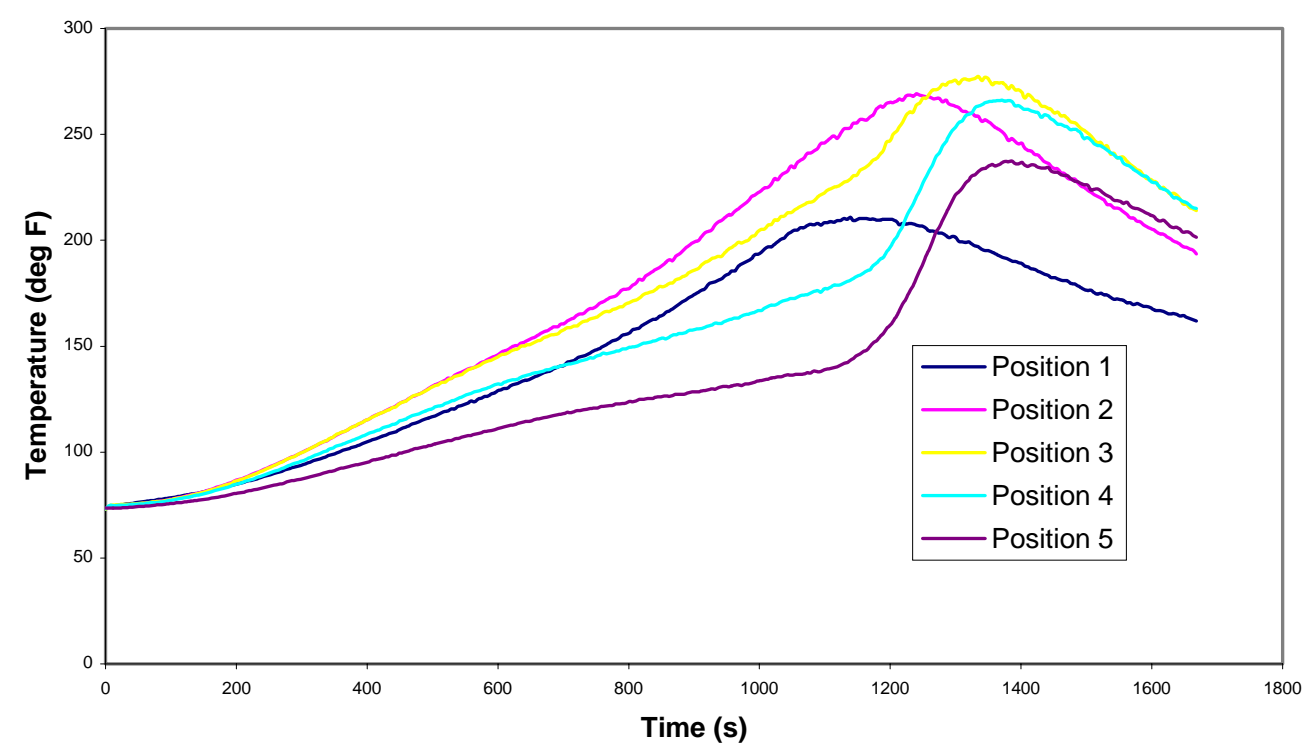

Figure 5.2.14: Test \#9 Trap Surface Temperature Profiles 
The peak trap temperatures were higher than those of the previous tests, indicating that as more energy is provided during the preheating period, the soot is ignited in more channels at the filter entrance, and the soot entrapped in these channels along the length of the trap is burned during the convective combustion phase. The drawback in this process is, of course, the thermal stress that is generated within the filter. The convective combustion phase appears to occur in similar time frames between the tests. The greater the amount of energy released during this time frame, greater will be the thermal stresses will be within the filter.

Plots of the other measured regeneration parameters are shown in Figures 5.2.15 to 5.2.20:

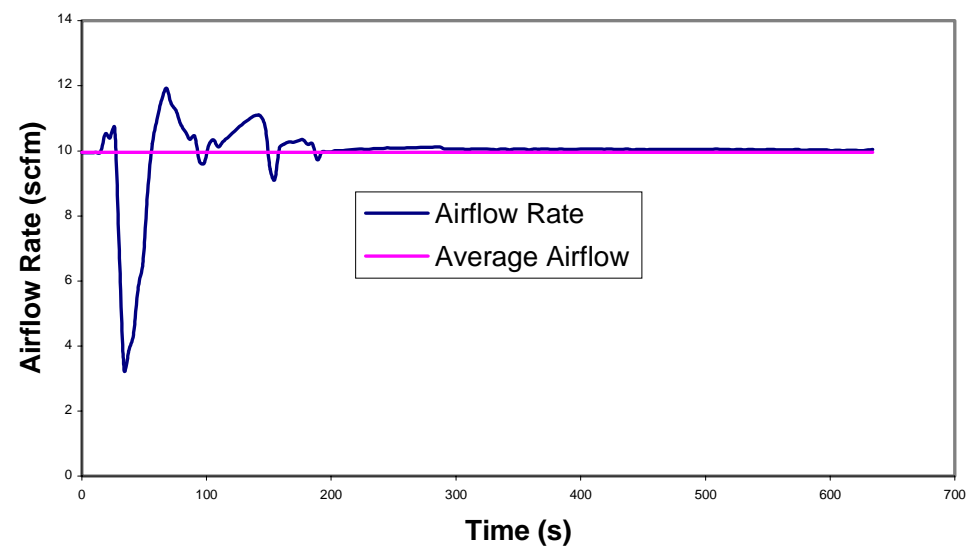

Figure 5.2.15: Test \#9 Combustion Airflow Rate 


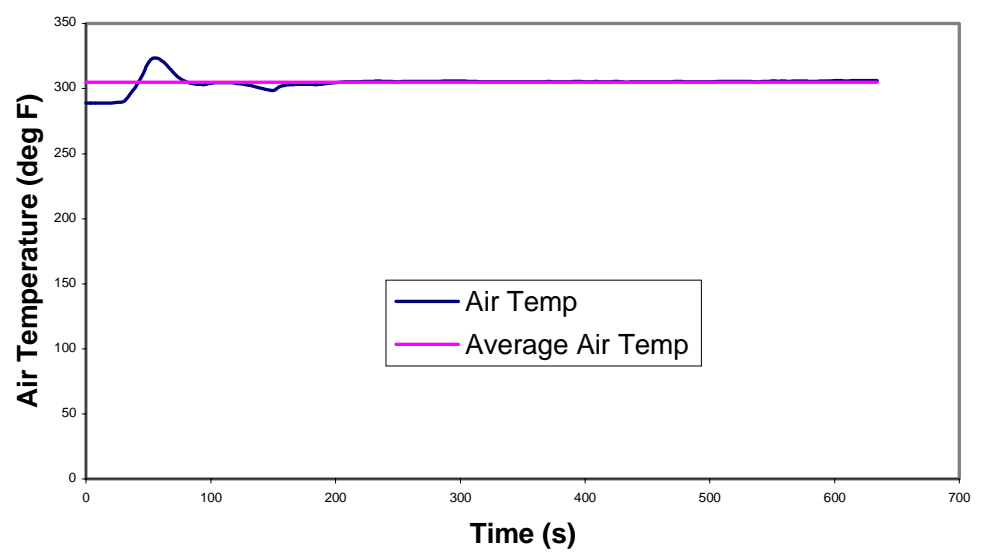

Figure 5.2.16: Test \#9 Combustion Air Temperature

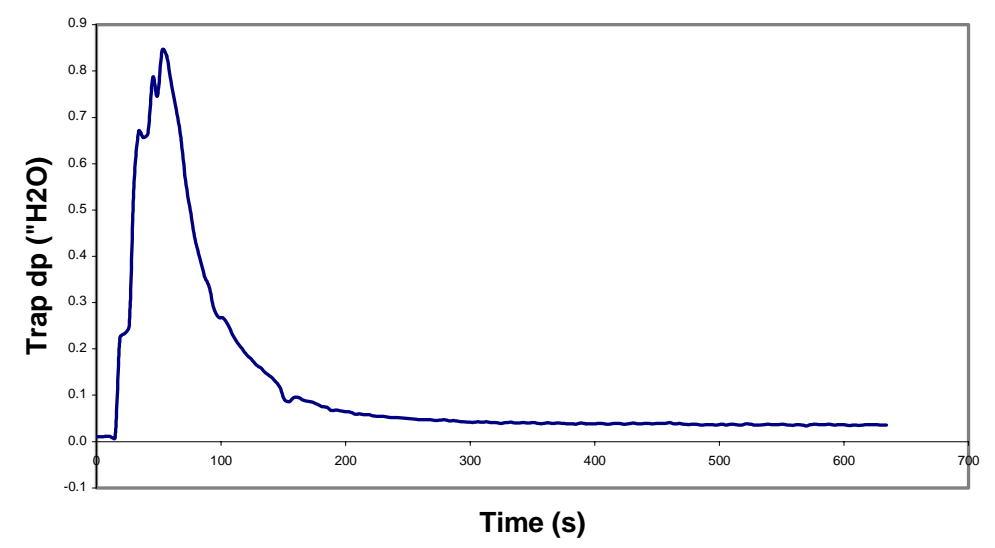

Figure 5.2.17: Test \#9 Trap Differential Pressure

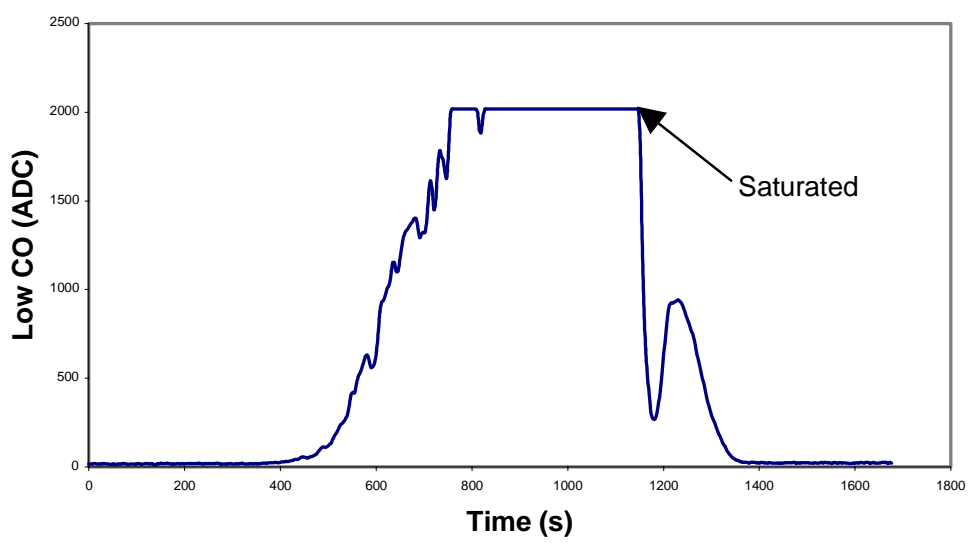

Figure 5.2.18: Test \#9 Low CO Analyzer ADC Output 


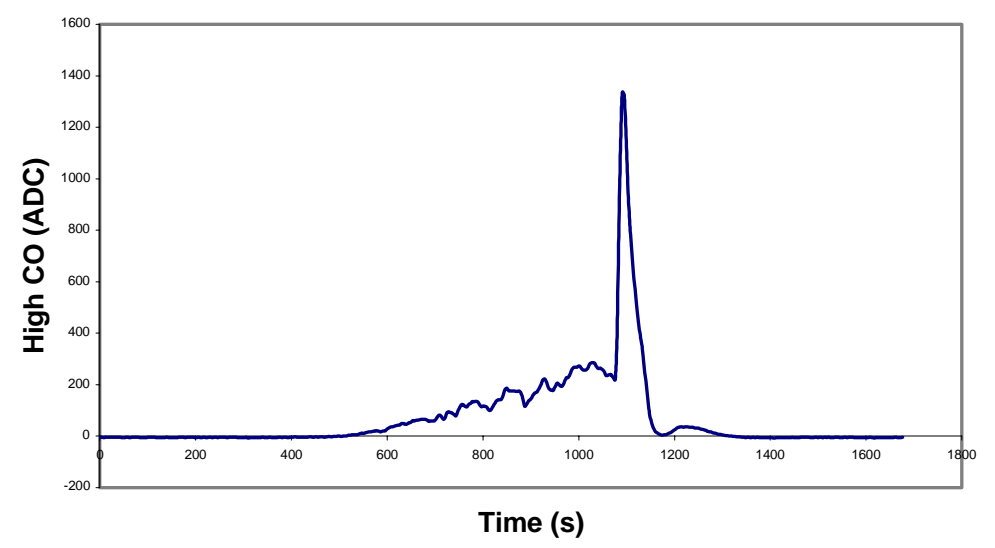

Figure 5.2.19: Test \#9 High CO Analyzer ADC Output

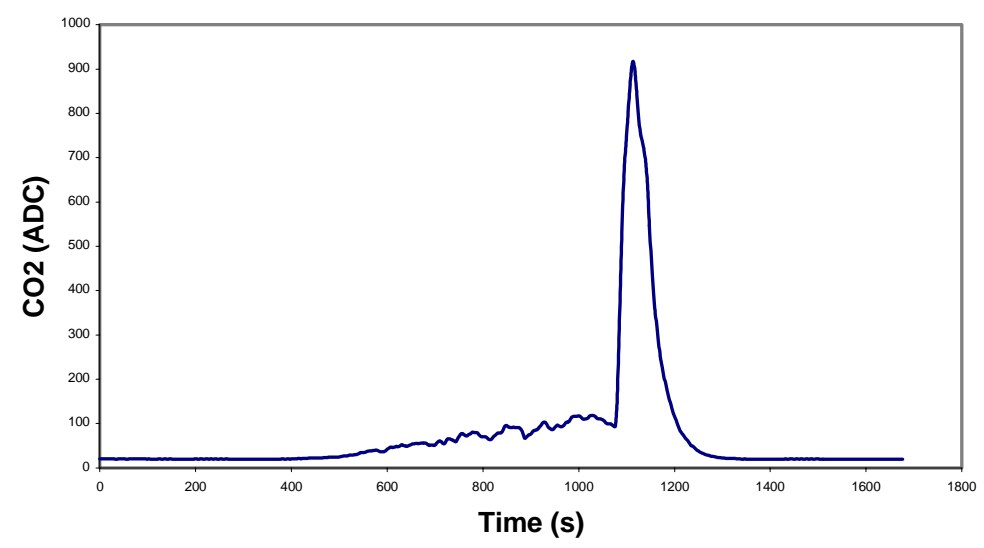

Figure 5.2.20: Test \#9 $\mathrm{CO}_{2}$ Analyzer ADC Output

The initial trap differential pressure in test \#9 is lower than that in test \#7 indicating that more soot may have been combusted prior to the convective combustion phase. It should be noted that the transient nature of the airflow rate during the initial portion of the convective combustion phase made it difficult to reach a firm conclusion regarding the extent of soot combustion during this period. The final trap differential pressures was also lower for test \#9 than in test \#7 indicating more soot had been combusted from the filter. Figure 5.2.18 indicates that a very high concentration of CO was measured during the preheating phase (that is, there existed a long period of oxygen- 
starved combustion). Interestingly, the second peak in the $\mathrm{CO}$ profiles in Figure 5.2.18 indicates that the incomplete combustion rate increased after a majority of the soot had been burned. Filter damage was suspected, but subsequent testing showed that no filter damage had occurred. The higher airflow rates in this series of tests appear to have removed a sufficient amount of energy from the filter during the convective combustion period to prevent filter failure. The second peak in the $\mathrm{CO}$ profile may have been caused by an accumulation of soot in the back portion of the filter. Interestingly, the convective combustion period appears to be similar if not slightly smaller for test \#9 (Figure 5.2.20) than seen in test \#7 (Figure 5.2.12). This could have been caused by higher filter temperatures increasing the combustion rate of the soot.

The gravimetric analysis showed that $15.6 \mathrm{~g}$ of soot had been combusted during regeneration test $\# 9$, resulting in a regeneration efficiency of $66.7 \%$.

\subsection{Effect of Airflow Rate}

The third series of tests was performed to determine the effect of the combustion airflow rate on the regeneration efficiency. The preheating time for all tests was set at 12.5 minutes, the target air temperature was $300{ }^{\circ} \mathrm{F}\left(149{ }^{\circ} \mathrm{C}\right)$, and the target initial soot mass was $24 \mathrm{~g}$. The airflow rate range was $5 \mathrm{scfm}$ to $20 \mathrm{scfm}\left(0.14 \mathrm{~m}^{3} / \mathrm{min}\right.$ to 0.57 $\left.\left.\mathrm{m}^{3} / \mathrm{min}\right)\right)$

The conditions used in test \#3, which had been performed during the first series of tests concerning the effect of initial soot mass on the regeneration efficiency, were identical to those required for the first test in this series (23.6g initial soot mass, 12.5 minute preheating time, $5.2 \mathrm{scfm}\left(0.15 \mathrm{~m}^{3} / \mathrm{min}\right)$ average combustion airflow rate at an 
average temperature of $298{ }^{\circ} \mathrm{F}=148{ }^{\circ} \mathrm{C}$ ). Figures 5.1.16 to 5.1.22 are plots of the measured parameters during regeneration for test \#3. The regeneration efficiency for this test was $56.8 \%$

The conditions used in test \#6, which had been performed earlier to determine the effect of preheating time on the regeneration efficiency, were identical to those required for the second data set in this test series [24.4g initial soot mass, 12.5 minute preheating time, $9.87 \mathrm{scfm}\left(0.279 \mathrm{~m}^{3} / \mathrm{min}\right)$ average combustion airflow rate at an average temperature of $316{ }^{\circ} \mathrm{F}\left(158{ }^{\circ} \mathrm{C}\right)$ ]. Figures 5.2.3 to 5.2.5 display the available measured regeneration parameter data. The regeneration efficiency in this case was found to be $54.1 \%$.

Test \#10 was used to provide the information for the third data set in this series. The initial soot mass was $24.2 \mathrm{~g}$, the preheating time was 12.5 minutes, and the average airflow rate was $15.0 \mathrm{scfm}\left(0.425 \mathrm{~m}^{3} / \mathrm{min}\right)$ at an average air temperature of $301{ }^{\circ} \mathrm{F}(149$ $\left.{ }^{\circ} \mathrm{C}\right)$. A plot of the trap housing surface temperature profiles is shown in Figure 5.3.1:

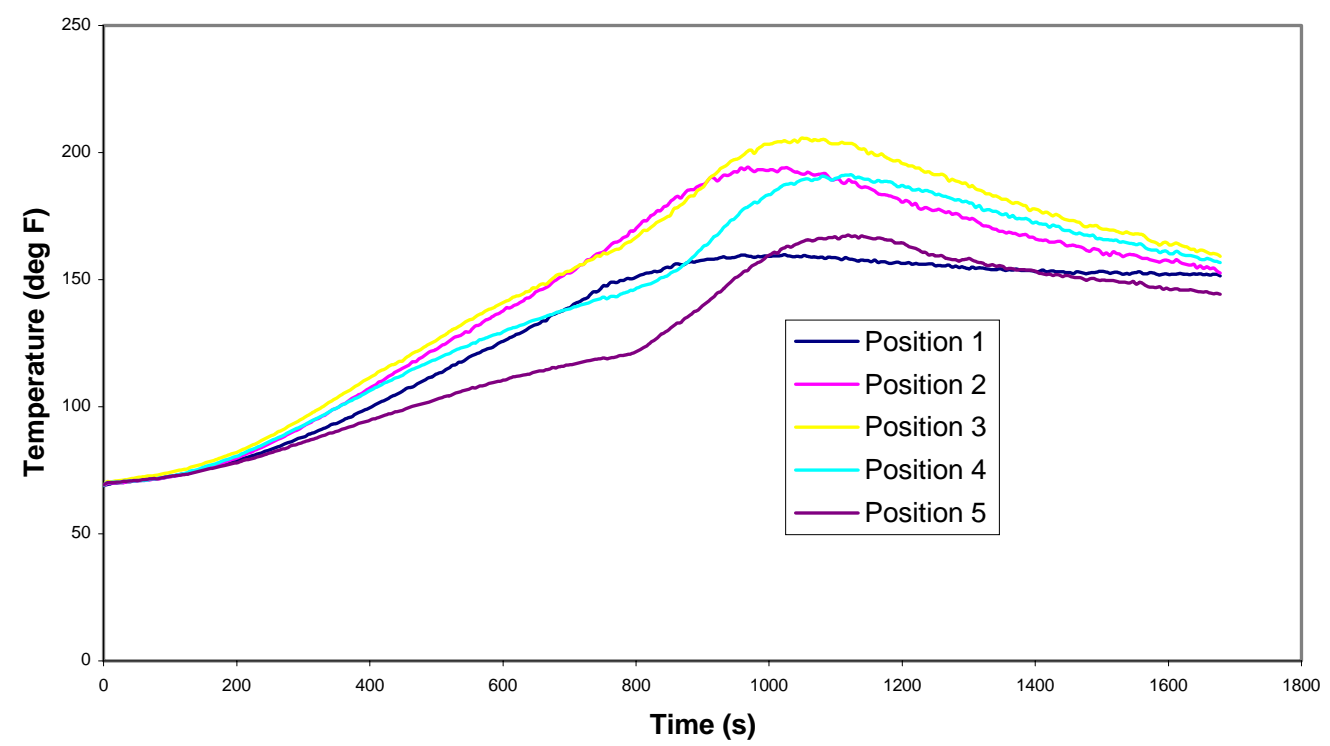

Figure 5.3.1: Test \#10 Trap Surface Temperature Profiles 
The peak temperature profiles were generally lower than those in the previous two tests in this series indicating that less energy was released during regeneration. The peak trap temperatures also occurred earlier in the convective combustion phase relative to the other two tests, and the temperature profiles then began to drop. However, in tests \#3 and \#6, the temperatures had continued to rise beyond 1000s. This indicates that the convective combustion phase in test \#10 was quenched by the increased airflow.

The remaining regeneration parameters for test \#10 are presented in Figures 5.3.2 to 5.3.7:

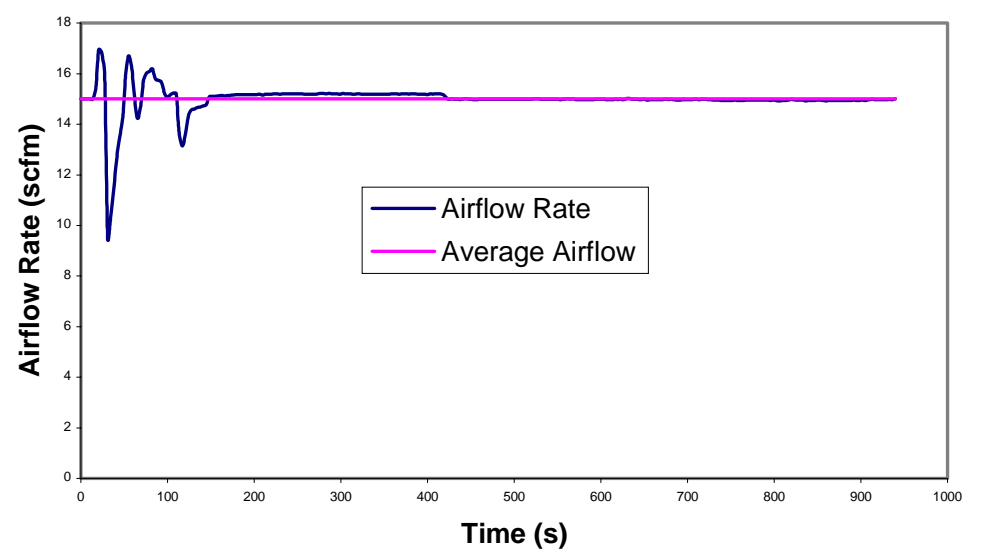

Figure 5.3.2: Test \#10 Combustion Airflow Rate

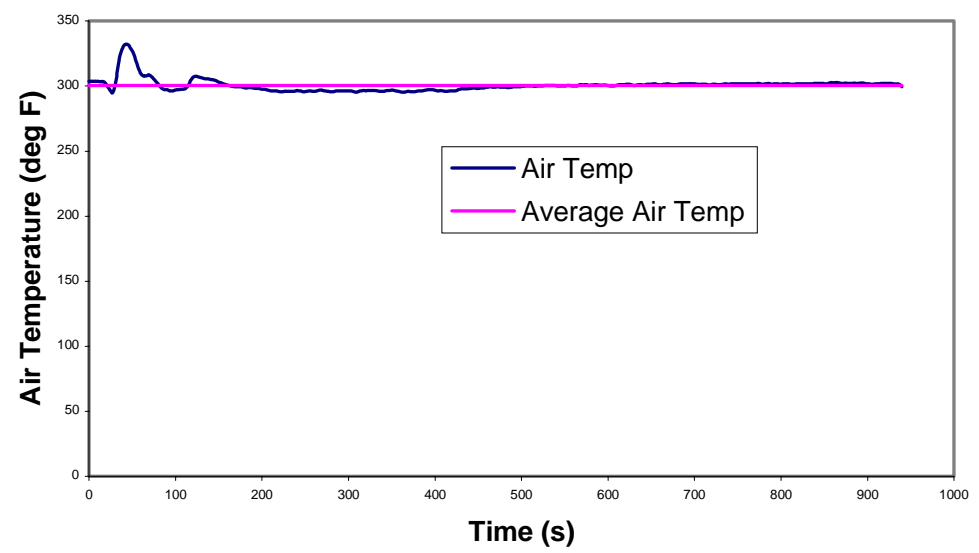

Figure 5.3.3: Test \#10 Combustion Air Temperature 


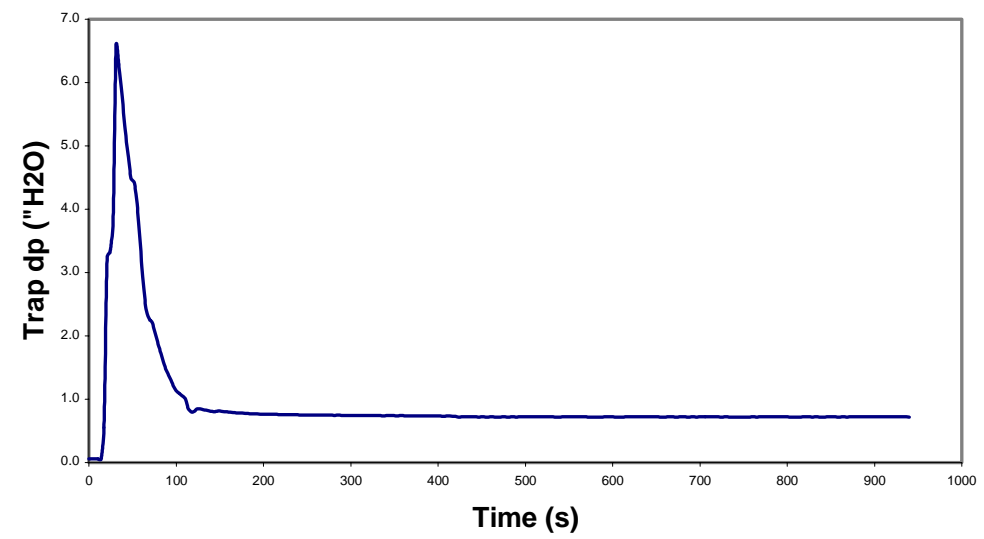

Figure 5.3.4: Test \#10 Trap Differential Pressure

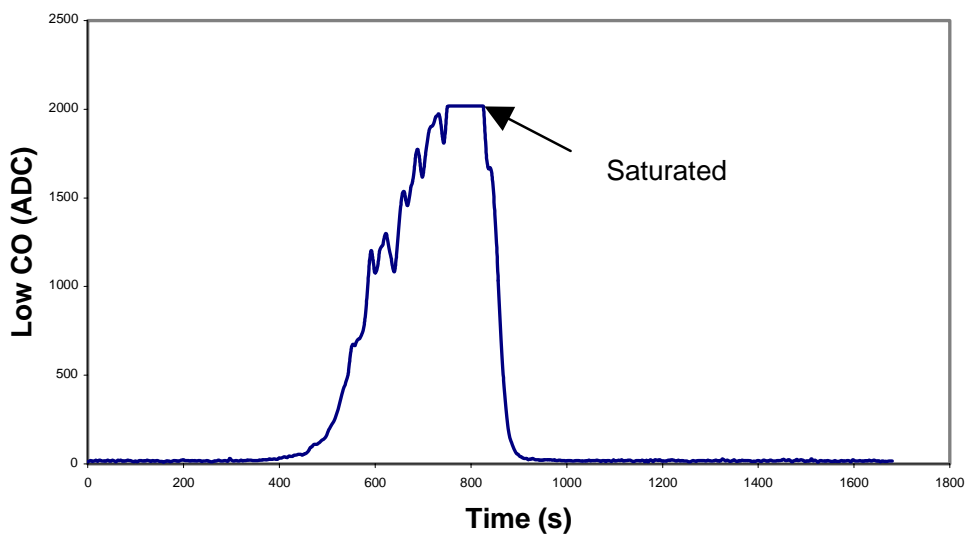

Figure 5.3.5: Test \#10 Low CO Analyzer ADC Output

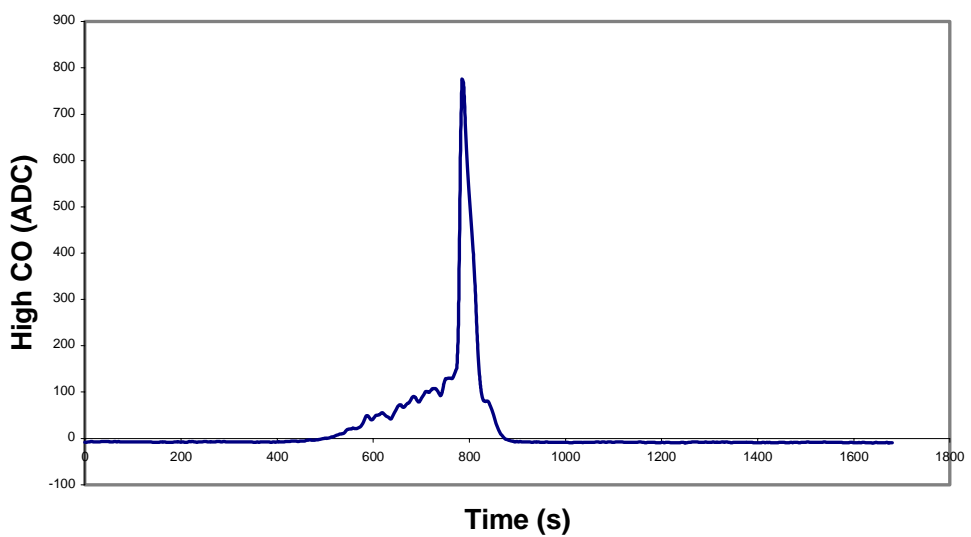

Figure 5.3.6: Test \#10 High CO Analyzer ADC Output 


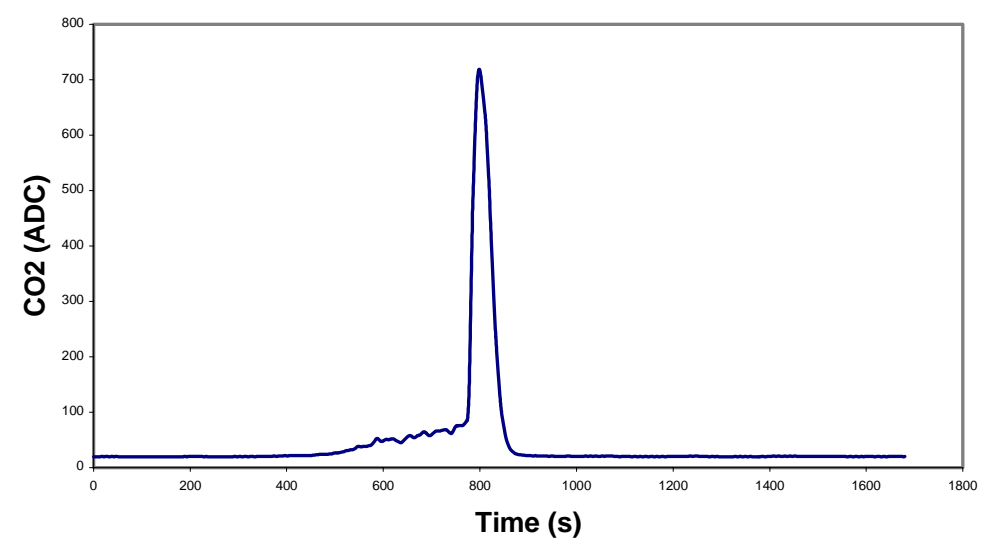

Figure 5.3.7: Test \#10 $\mathrm{CO}_{2}$ Analyzer ADC Output

A comparison of Figures 5.1.20 and 5.3.5 shows that although the soot combustion began at essentially the same time during the preheating phase, the end of the convective combustion phase ended much earlier in test \#10 than in test \#3, again indicating that the soot oxidation process was quenched by the excessive airflow. The results of the gravimetric analysis again demonstrated the effects of reaction quenching, for only $9.4 \mathrm{~g}$ of soot had been burnt of during regeneration. This corresponded to a regeneration efficiency of $38.8 \%$. The filter sustained no damage during the regeneration event in test \#10.

In the final test in this series (test \#11), 24.8g of soot were collected. The preheating time was 12.5 minutes, and the average combustion airflow rate was 19.8 $\operatorname{scfm}\left(0.561 \mathrm{~m}^{3} / \mathrm{min}\right)$ at an average combustion air temperature of $310^{\circ} \mathrm{F}\left(154{ }^{\circ} \mathrm{C}\right)$. A plot of the trap housing surface temperature profiles are contained in Figure 5.3.8: 


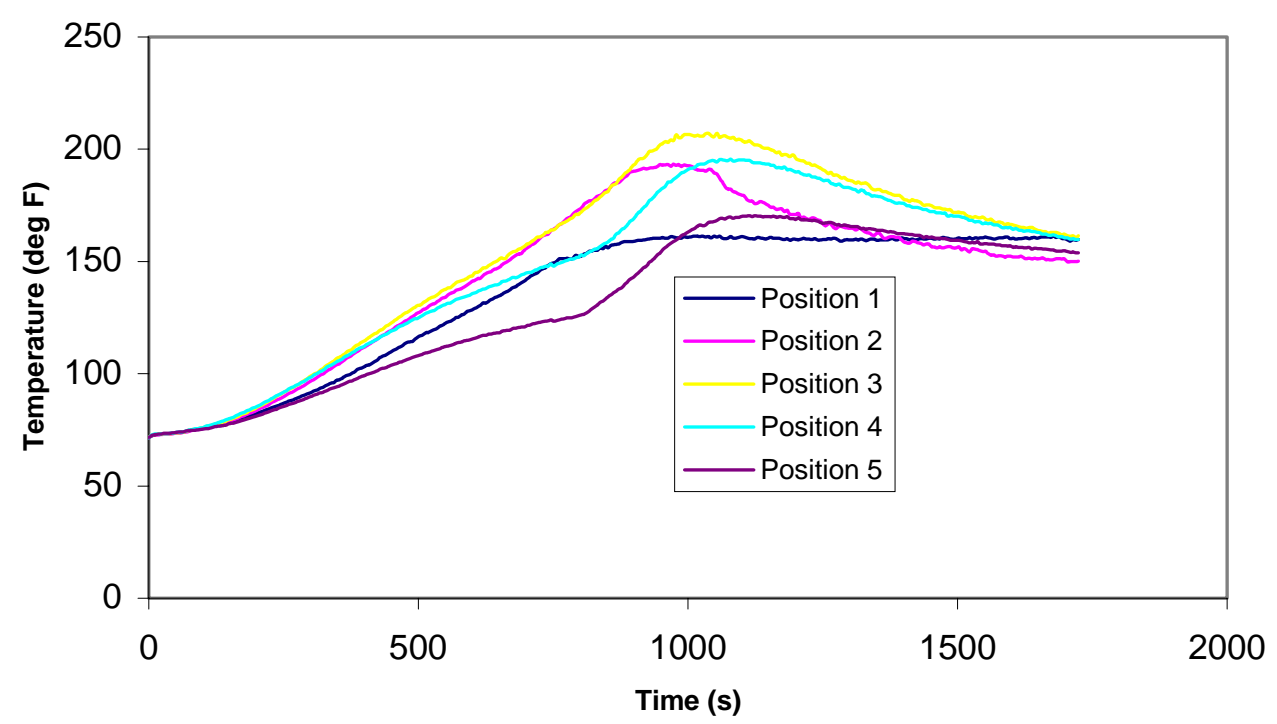

Figure 5.3.8: Test \#11 Trap Surface Temperature Profiles

As in test \#10, the convective combustion reaction began and ended quickly indicating that the combustion was stopped by excessive energy removal by the combustion air. The peak temperatures were quite similar to those observed in test \#10 (see Figure 5.3.1). However, the temperatures more rapidly than the surface temperatures in test \#11 (see Figure 5.3.8).

The remaining measured regeneration parameters for test \#11 are shown in Figures 5.3.9 to 5.3.14: 


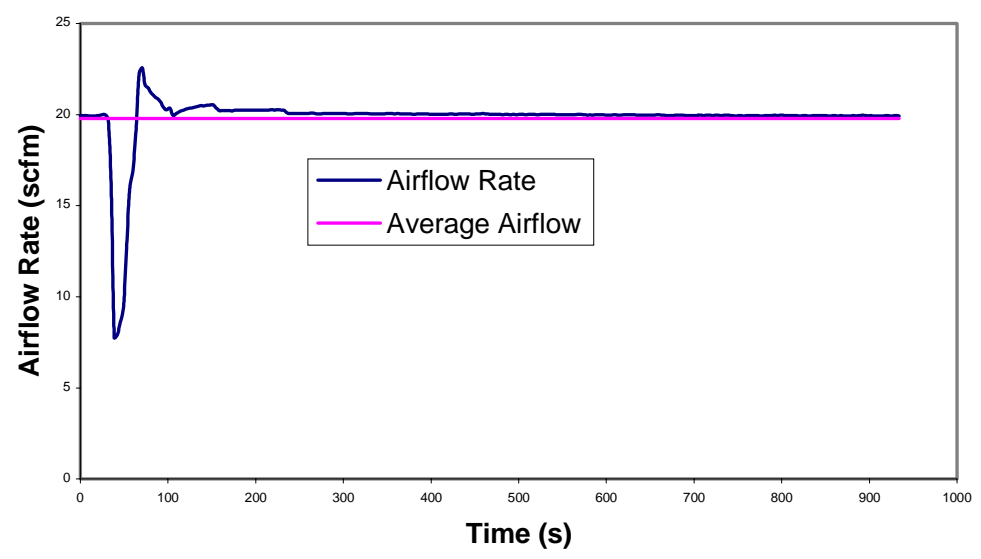

Figure 5.3.9: Test \#11 Combustion Airflow Rate

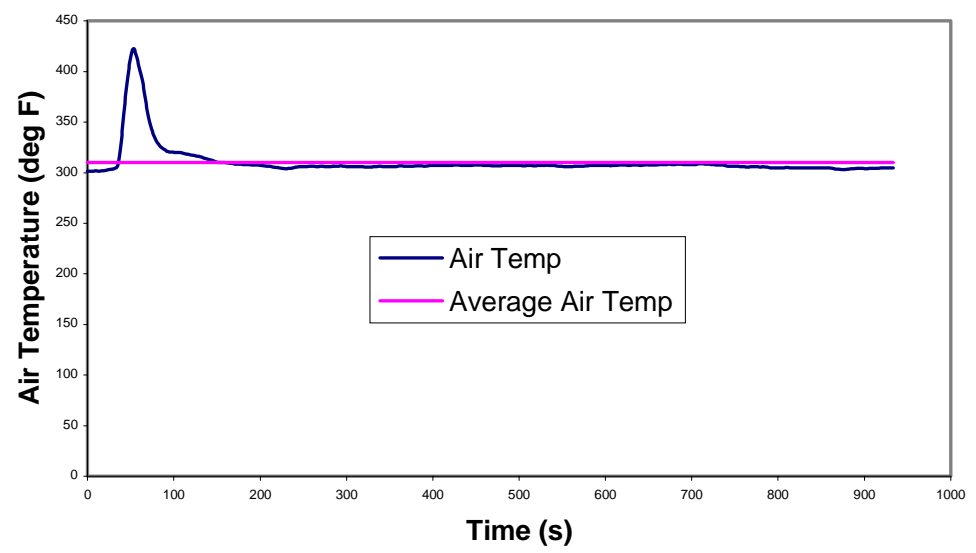

Figure 5.3.10: Test \#11 Combustion Air Temperature

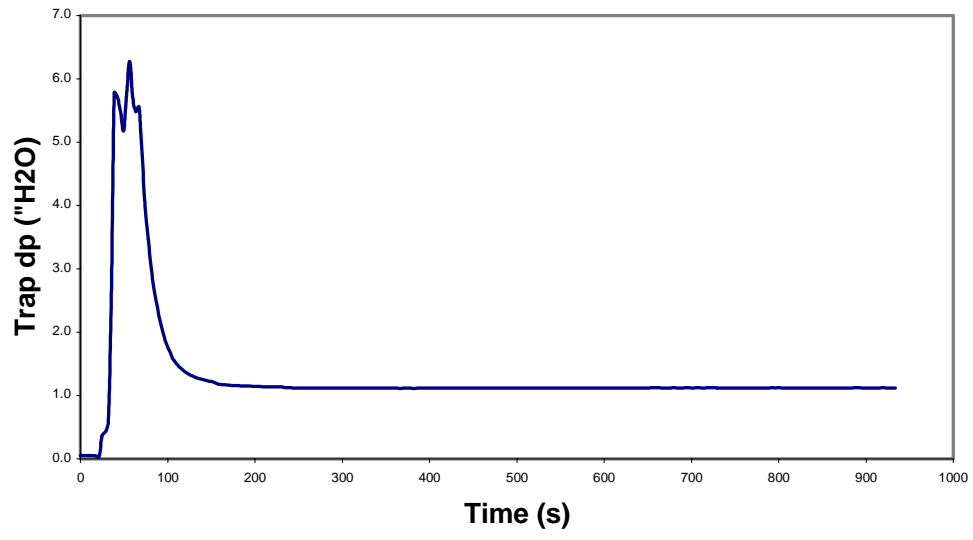

Figure 5.3.11: Test \#11 Trap Differential Pressure 


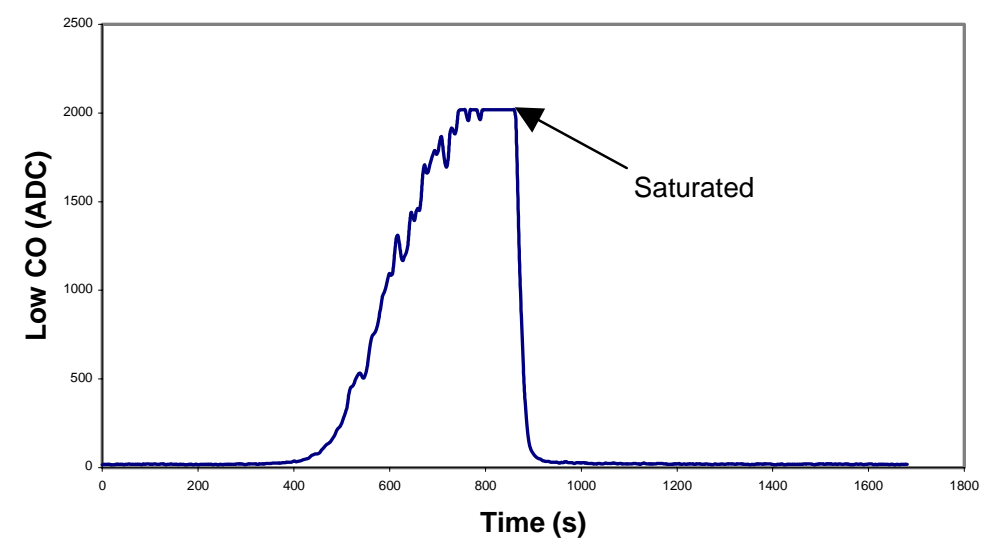

Figure 5.3.12: Test \#11 Low CO Analyzer ADC Output

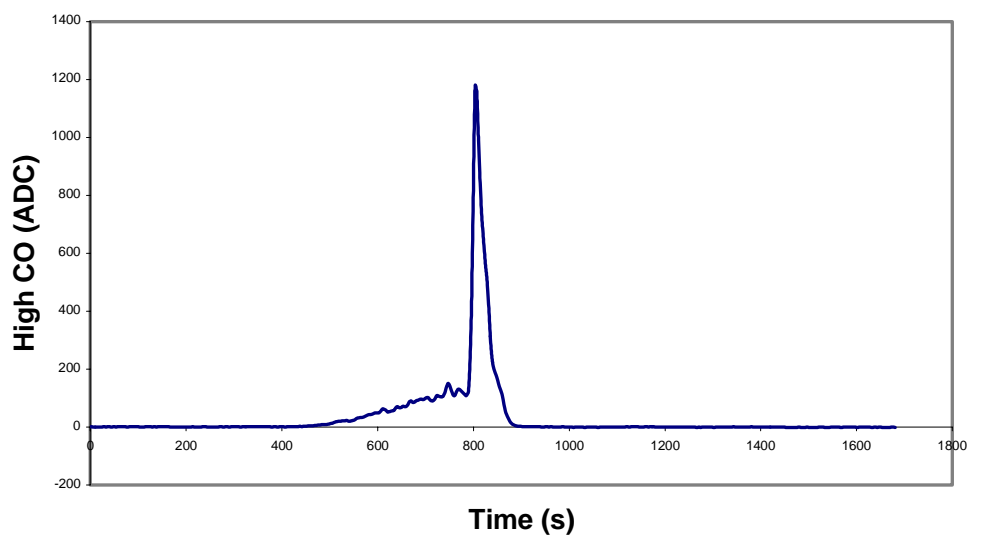

Figure 5.3.13: Test \#11 High CO Analyzer ADC Output

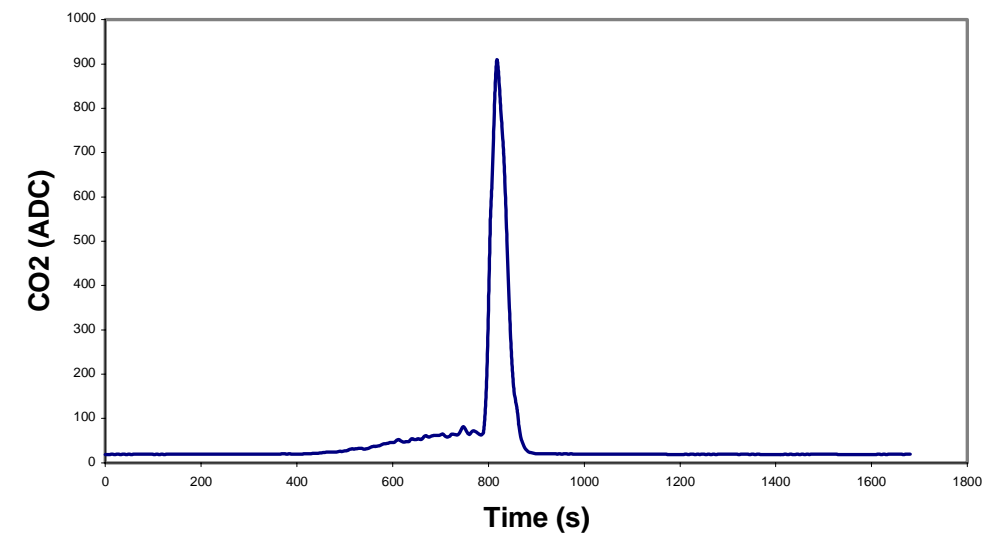

Figure 5.3.14: Test \#11 $\mathrm{CO}_{2}$ Analyzer ADC Output 
A comparison of Figures 5.3.5 and 5.3.12 demonstrates that the convective combustion period in test \#11 ended soon after its initiation as in test \#10. The gravimetric analysis showed that only $9.8 \mathrm{~g}$ of soot had been combusted, which corresponded to a regeneration efficiency of $39.5 \%$. The filter was not damaged during the regeneration event in test \#11.

It was apparent from the results of the tests in this series that the regeneration efficiency tended to increase with decreasing airflow rate. There existed a practical limit to the minimum airflow rate for a given soot loading, preheating time, and combustion air temperature This lower limit for the airflow rate was dictated by the maximum allowable stress within the filter. As the flow rate decreased, less energy was transported from the filter by the combustion air during regeneration which resulted in higher internal filter temperatures. If the combustion flame front moved relatively quickly through the filter, this would result in higher thermal stresses within the filter, which could result in melting or cracking of the filter element. During the regeneration testing, one test was performed during which the bypass gate valve unintentionally remained opened during the convective combustion regeneration phase (test \#12). The target airflow rate was 10 $\operatorname{scfm}\left(0.283 \mathrm{~m}^{3} / \mathrm{min}\right)$, but because the bypass valve remained open, the average airflow rate to the filter was estimated to be much less than $5 \mathrm{scfm}\left(0.14 \mathrm{~m}^{3} / \mathrm{min}\right.$ ) (although the actual value was not known). The initial soot mass was $23.4 \mathrm{~g}$, the preheating time was 17.5 minutes, and the average combustion air temperature was $308{ }^{\circ} \mathrm{F}\left(153{ }^{\circ} \mathrm{C}\right)$. A plot of the trap housing surface temperature profiles are seen in Figure 5.3.15: 


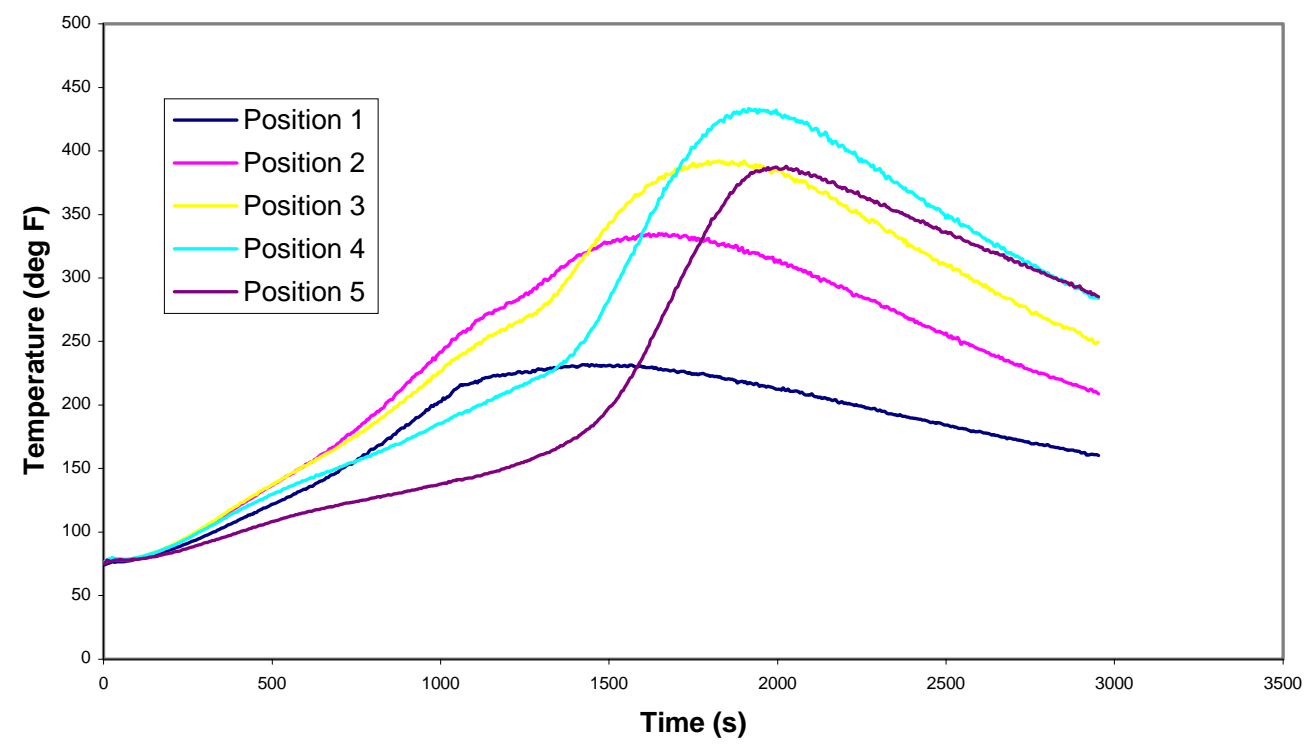

Figure 5.3.15: Test \#12 Trap Surface Temperature Profiles

The peak trap temperatures approached $450{ }^{\circ} \mathrm{F}\left(232{ }^{\circ} \mathrm{C}\right)$ and were found to occur near the filter outlet. The trap temperatures continued to rise well into the convective combustion phase, indicating that a large amount of energy was released during this phase. Plots of the Low $\mathrm{CO}$ and $\mathrm{CO}_{2}$ analyzer readings are shown in Figures 5.3.16 and 5.3.17.

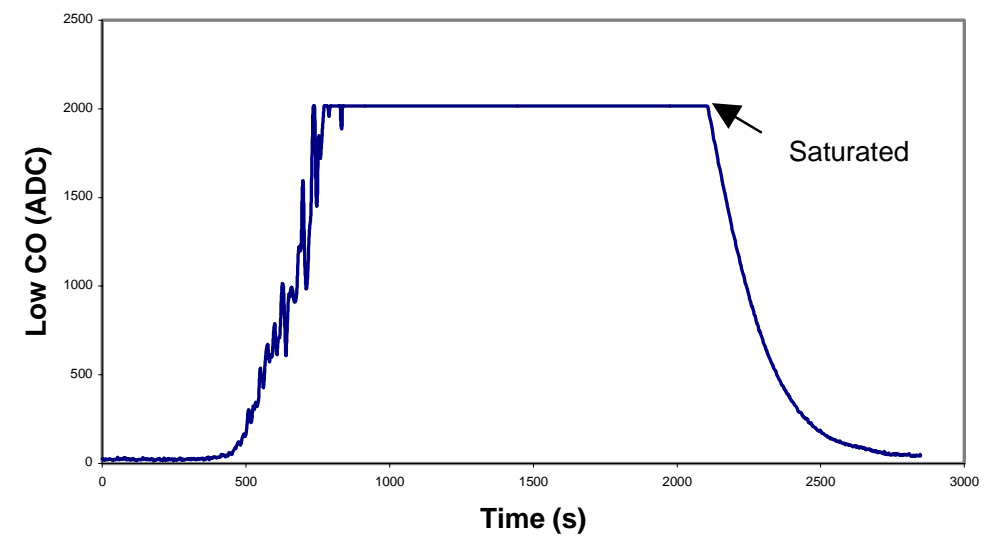

Figure 5.3.16: Test \#12 Low CO Analyzer ADC Output 


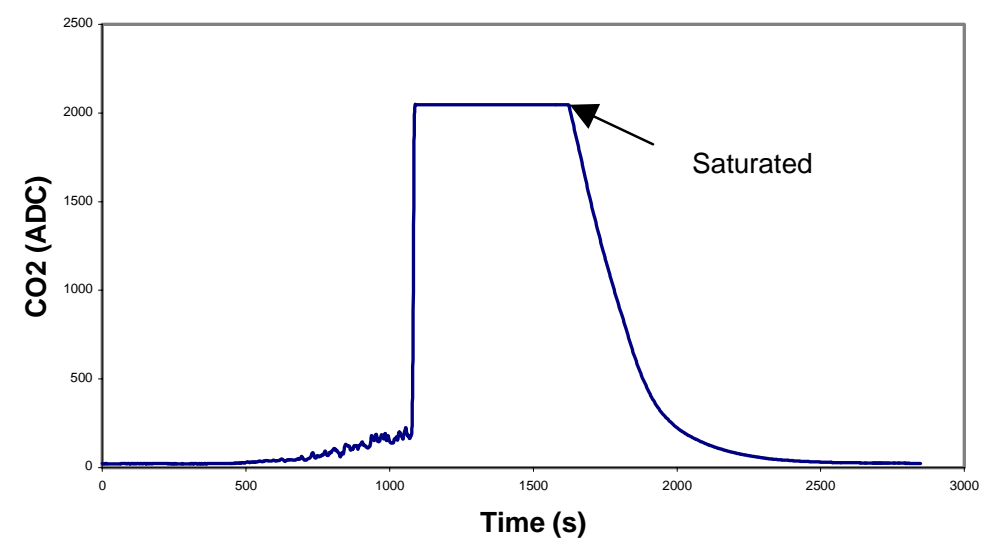

Figure 5.3.17: Test \#12 $\mathrm{CO}_{2}$ Analyzer ADC Output

It is apparent from these graphs that the high initial trap temperatures due to the extended preheating time and low combustion airflow rates allowed the convective combustion period to extend well beyond those seen in any of the previous tests. The negative aspect of this mode of regeneration was the extremely high filter temperatures. An interesting point to note is that the high filter temperatures do not necessarily mean that the trap was damaged. As long as the melting point of the filter material is not exceeded, the temperatures within the trap will not cause any damage. It is typically the thermal stresses within the filter due to extreme temperature gradients that cause filter failure. A comparison of Figures 5.2.14 and 5.3.15 show that the trap surface temperatures did not rise any more rapidly in test \#12 than in test \#9. The trap surface temperatures after 1000s are nearly identical. The trap housing surface temperatures continued to increase in test \#12 due to the lower airflow rates.

The gravimetric analysis showed that $21 \mathrm{~g}$ had been removed from the filter during regeneration. This corresponded to a regeneration efficiency of $89.7 \%$. Due to time 
constraints, the filter element was removed from the housing and replaced with a new filter, although visual inspection did not indicate any filter damage had occurred.

\subsection{Effect of Combustion Air Temperature}

The last series of tests was performed to determine the effect of combustion air temperature on the regeneration efficiency. The preheating time for all the tests in this series was 12.5 minutes, the combustion airflow target value was $10 \mathrm{scfm}\left(0.28 \mathrm{~m}^{3} / \mathrm{min}\right)$, and the target initial soot mass was $24 \mathrm{~g}$. The average combustion air temperatures ranged from $76{ }^{\circ} \mathrm{F}$ to $637{ }^{\circ} \mathrm{F}\left(24{ }^{\circ} \mathrm{C}\right.$ to $\left.336{ }^{\circ} \mathrm{C}\right)$.

For the first test in this series (test \#13), 25.6g of soot were collected within the filter. The preheating time was 12.5 minutes, and the average combustion airflow rate was $9.95 \mathrm{scfm}\left(0.282 \mathrm{~m}^{3} / \mathrm{min}\right)$ at an average temperature of $76{ }^{\circ} \mathrm{F}\left(24{ }^{\circ} \mathrm{C}\right)$. A plot of the trap housing surface temperature profiles is given in Figure 5.4.1:

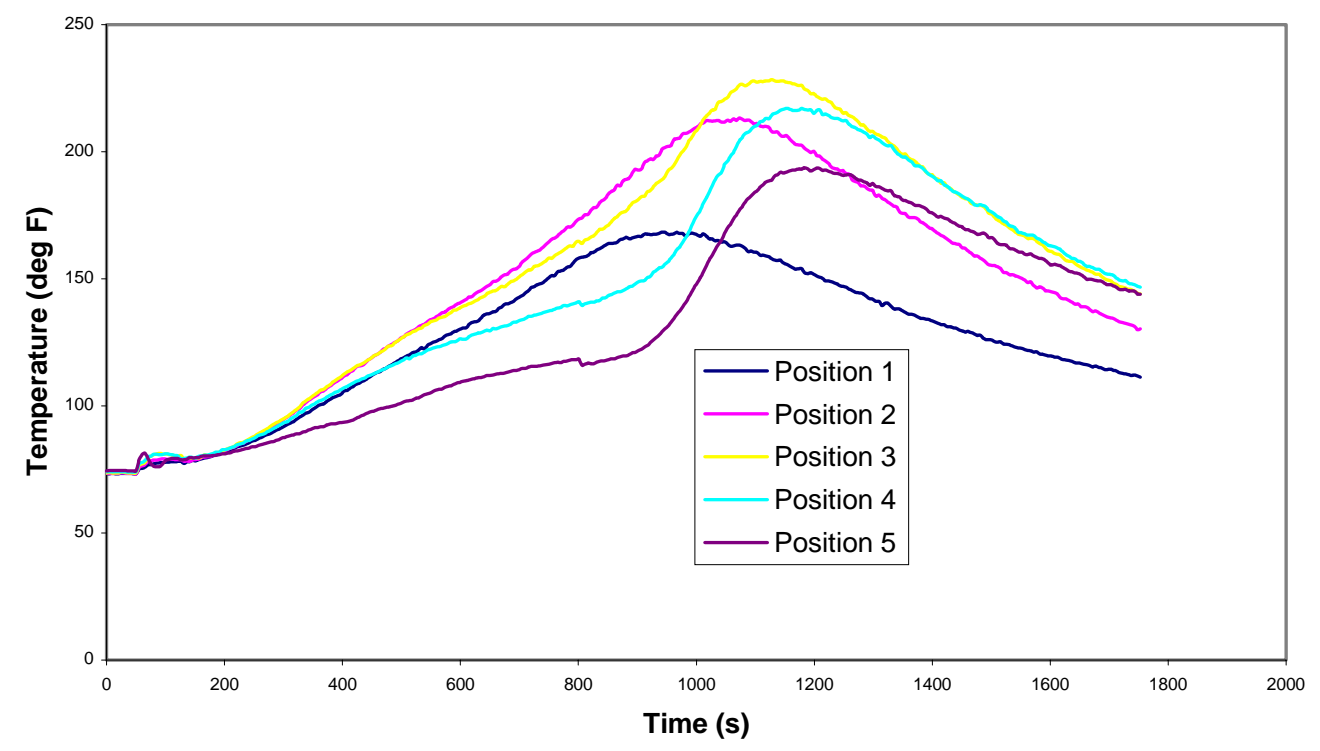

Figure 5.4.1: Test \#13 Trap Surface Temperature Profiles 
Plots of the real-time combustion airflow rate and temperature, which were the only regeneration parameters measured for this test, are given in Figures 5.4.2 and 5.4.3, respectively:

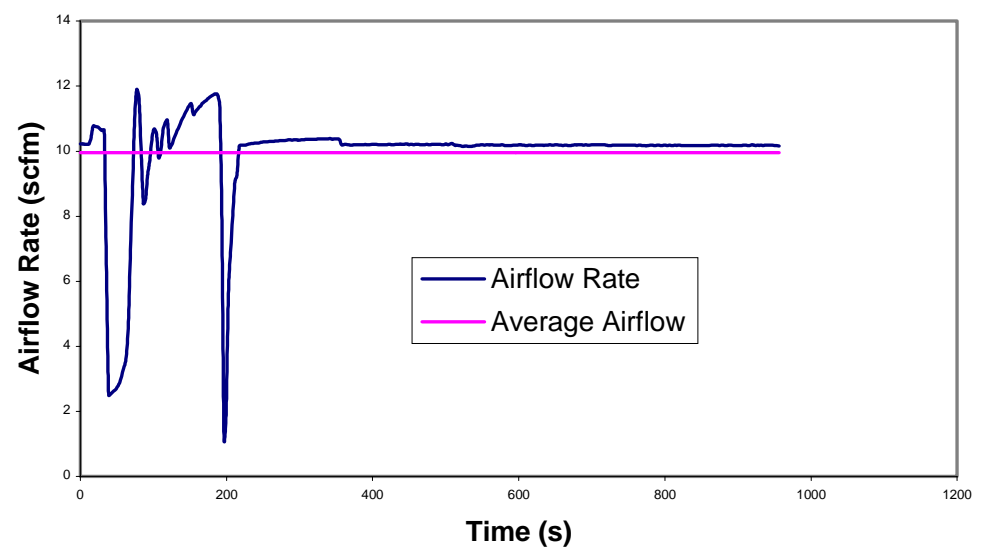

Figure 5.4.2: Test \#13 Combustion Airflow Rate

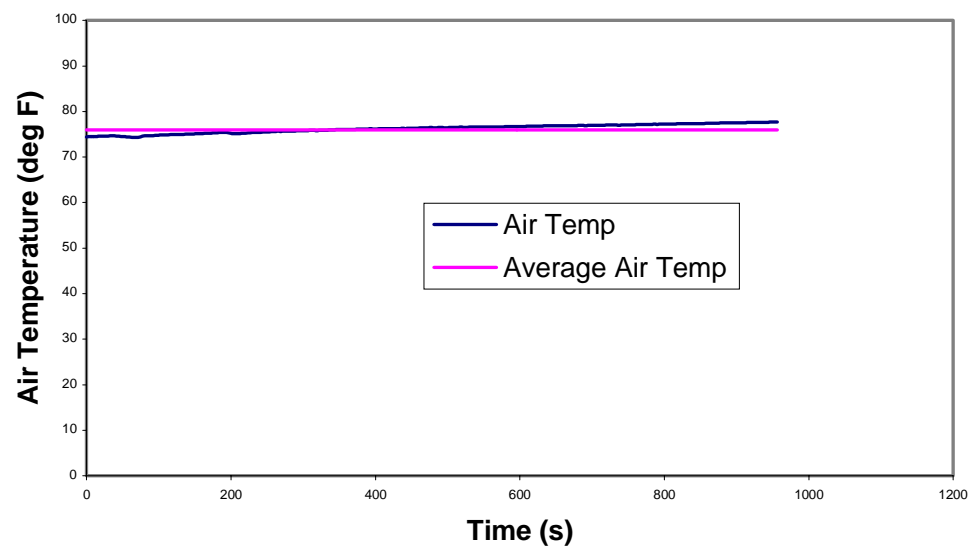

Figure 5.4.3: Test \#13 Combustion Air Temperature

For this test the air heaters were not activated, and as is seen in Figure 5.4.3, a slight increase in combustion air temperature was recorded during the convective combustion phase as the supercharger components slowly approached thermal equilibrium. 
The gravimetric analysis showed that $14.2 \mathrm{~g}$ of soot had been burned from the filter via regeneration, which corresponded to a regeneration efficiency of $55.5 \%$. The filter did not sustain any damage during the regeneration event in test \#13.

For the second test in this series (test \#14), the average combustion air temperature was increased to $152{ }^{\circ} \mathrm{F}\left(67^{\circ} \mathrm{C}\right)$ [target value of $\left.150{ }^{\circ} \mathrm{F}\left(66{ }^{\circ} \mathrm{C}\right)\right]$. The initial trapped soot mass was $24.2 \mathrm{~g}$, the preheating time was 12.5 minutes, and the average airflow rate was $10.0 \mathrm{scfm}\left(0.283 \mathrm{~m}^{3} / \mathrm{min}\right)$. A plot of the trap housing surface temperature profiles is given in Figure 5.4.4:

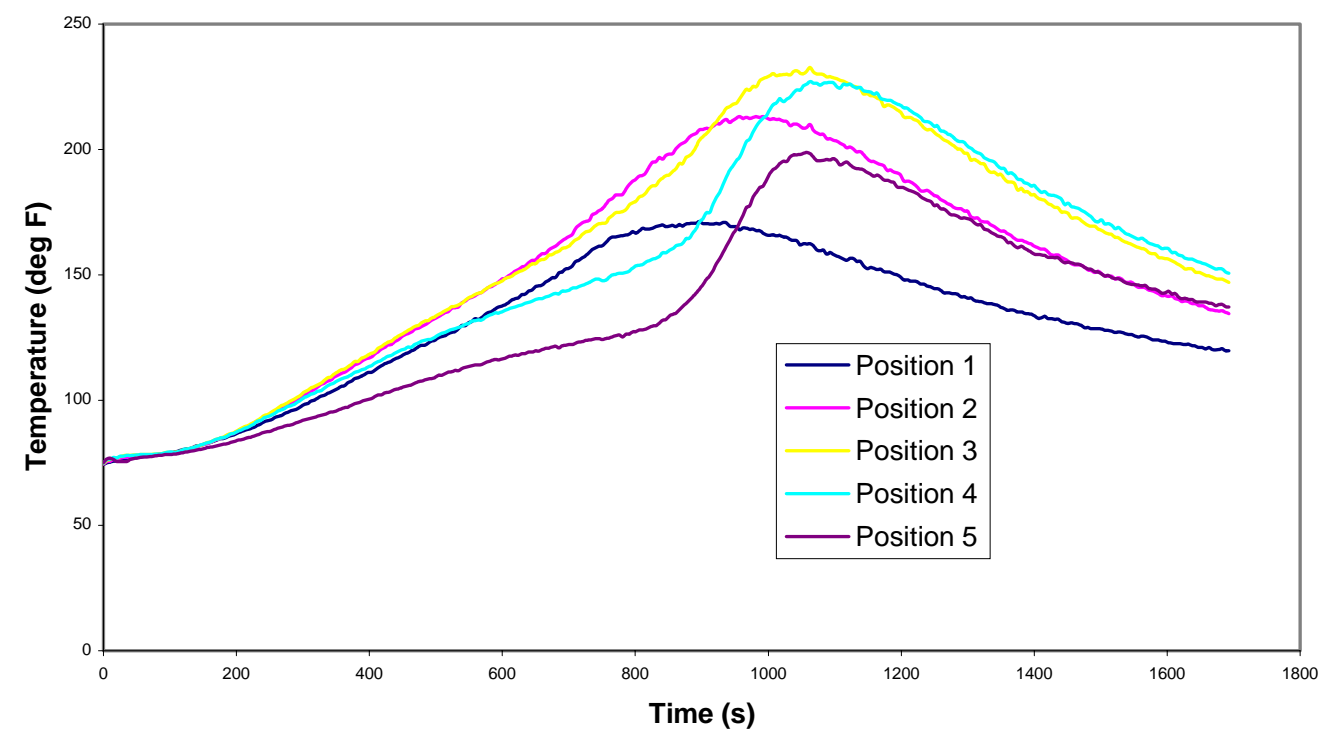

Figure 5.4.4: Test \#14 Trap Surface Temperature Profiles

Plots of the remaining measured regeneration parameters are given in Figures

\subsection{5 to 5.4.9:}




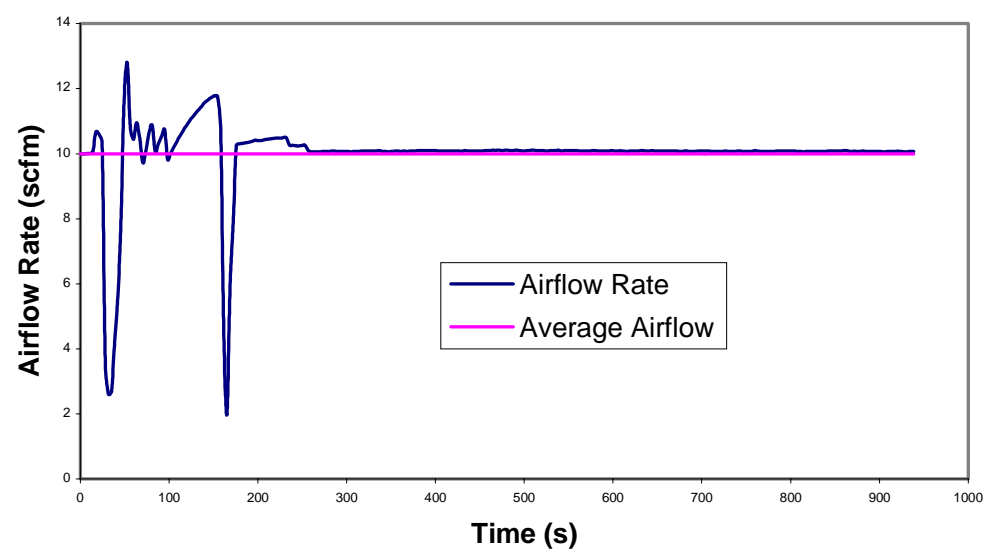

Figure 5.4.5: Test \#14 Combustion Airflow

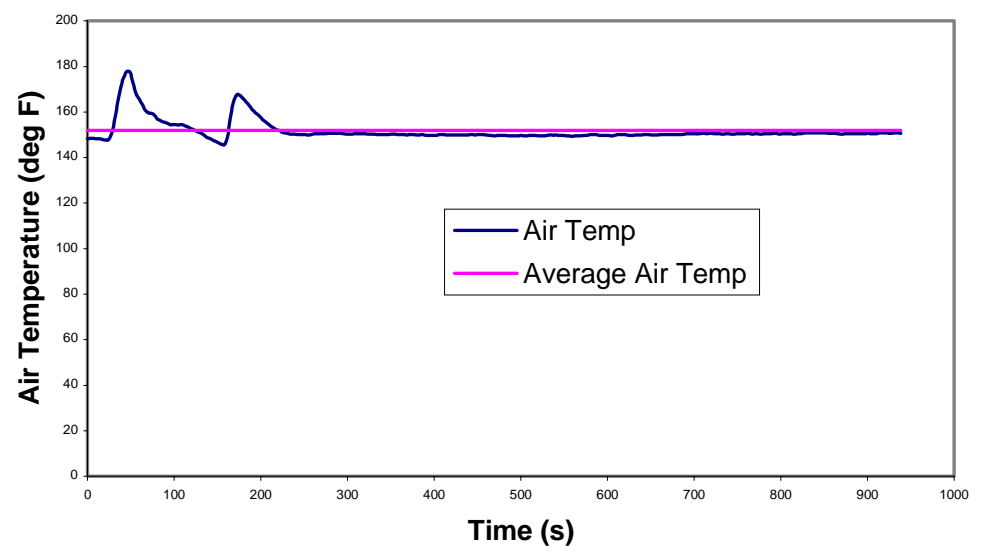

Figure 5.4.6: Test \#14 Combustion Air Temperature

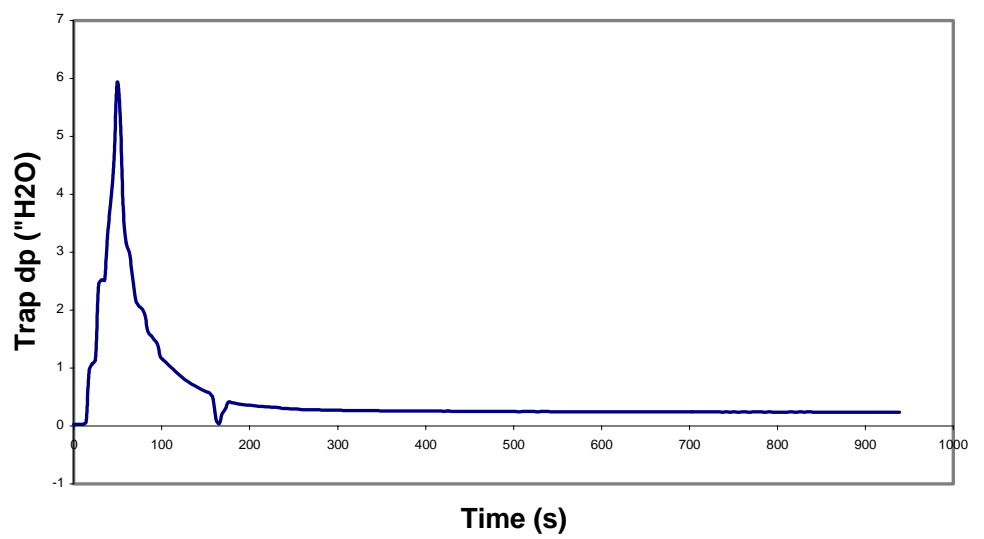

Figure 5.4.7: Test \#14 Trap Differential Pressure 


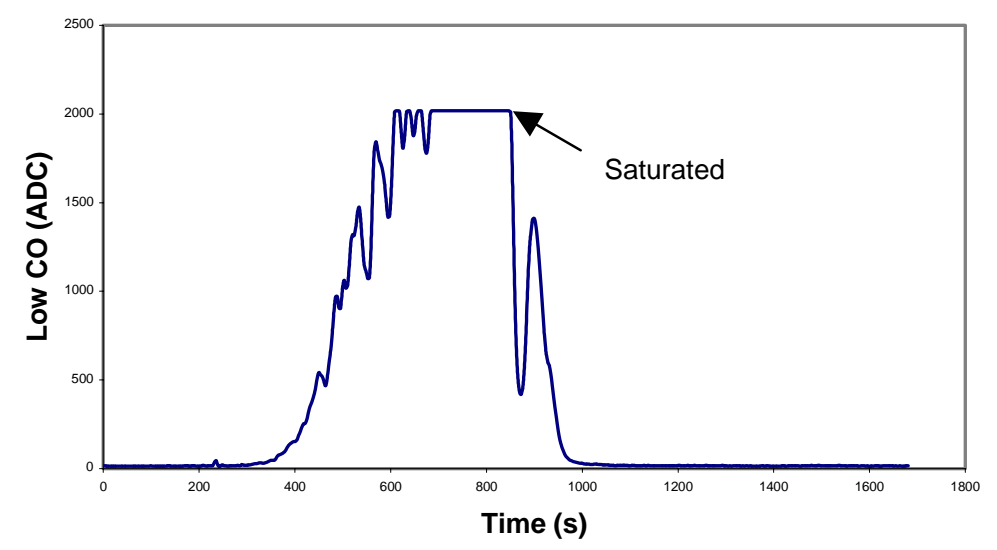

Figure 5.4.8: Test \#14 Low CO Analyzer ADC Output

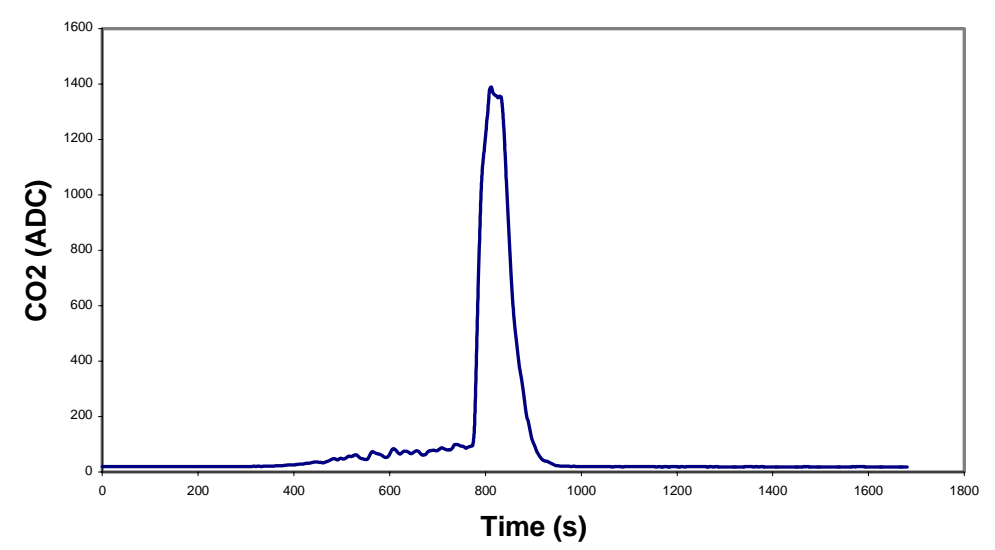

Figure 5.4.9: Test \#14 $\mathrm{CO}_{2}$ Analyzer ADC Output

The gravimetric analysis showed that $13.4 \mathrm{~g}$ of soot had been combusted during the regeneration process in test \#14, which corresponded to a regeneration efficiency of $55.4 \%$. No filter damage occurred during this regeneration.

The third test in this series required a target combustion air temperature of $300{ }^{\circ} \mathrm{F}$ $\left(149{ }^{\circ} \mathrm{C}\right)$, a target soot loading of $24 \mathrm{~g}$, a target airflow rate of $10 \mathrm{scfm}\left(0.28 \mathrm{~m}^{3} / \mathrm{min}\right)$, and a preheating time of 12.5 minutes. These parameters correspond to the target values which were used in test \#6. During test \#6, 13.2g of the initial 23.6g of soot was removed from the filter during regeneration, which corresponded to a regeneration 
efficiency of $54.1 \%$. The average airflow rate was $9.87 \mathrm{scfm}\left(0.279 \mathrm{~m}^{3} / \mathrm{min}\right)$ at an average combustion air temperature of $316^{\circ} \mathrm{F}\left(158^{\circ} \mathrm{C}\right)$. The trap housing temperature profiles as well as the regeneration efficiencies for tests \#6,\#13, and \#14 were found to be very similar (see Figures 5.2.3, 5.4.1, and 5.4.4). The major difference between the surface temperature profiles for the three tests was that the temperatures decreased more rapidly after the convective combustion phase in tests \#13 and \#14. This could be attributed to lower temperatures of the combustion air flowing through the trap. This phenomenon did not affect the regeneration efficiencies between the tests because the combustion had subsided prior to the decrease in the housing surface temperatures.

During the final test in this series, the average combustion air temperature was increased to $637^{\circ} \mathrm{F}\left(336^{\circ} \mathrm{C}\right)$. The preheating time was 12.5 minutes, the average airflow rate was $9.97 \mathrm{scfm}\left(0.282 \mathrm{~m}^{3} / \mathrm{min}\right)$, and the initial soot mass was $24.0 \mathrm{~g}$. The trap housing surface temperature profiles are given in Figure 5.4.10:

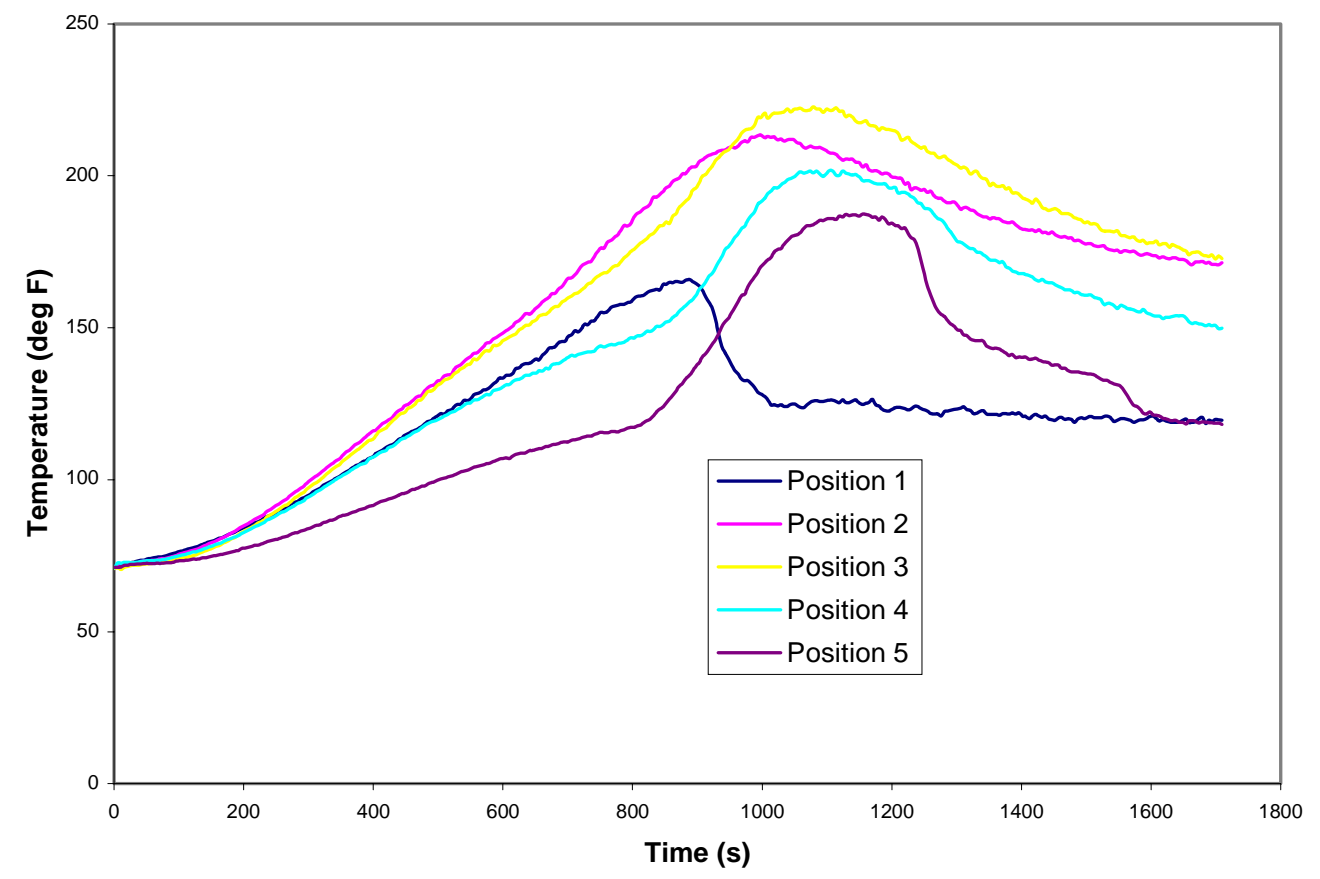

Figure 5.4.10: Test \#15 Trap Surface Temperature Profiles 
The surface thermocouples in positions 4 and 5 became detached from the trap housing during the convective combustion phase, so readings at these locations are inaccurate after approximately 800s and 1100s, respectively. A comparison of Figures 5.4.4 and Figure 5.4.10 shows that the temperature profiles were very similar for tests \#14 and \#15, although due to the higher air temperatures in test \#15, trap housing temperatures did not decrease as quickly after the convective combustion phase. It should be noted that the air temperature was measured immediately after the second air heater in order to ensure that the air exiting the heaters did not exceed the manufacturer's limitation of $1000{ }^{\circ} \mathrm{F}\left(538{ }^{\circ} \mathrm{C}\right)$. The air transfer lines between the air heaters and the trap were not insulated, so the actual air temperature at the trap inlet was less than the measured air temperature. For this reason (and due to heat transfer via conduction, convection, and radiation from the trap housing's outer surface), the surface temperatures of the trap housing did not approach the measured air temperature.

Plots of the remaining measured regeneration parameters are given in Figures 5.4.11 to 5.4.16:

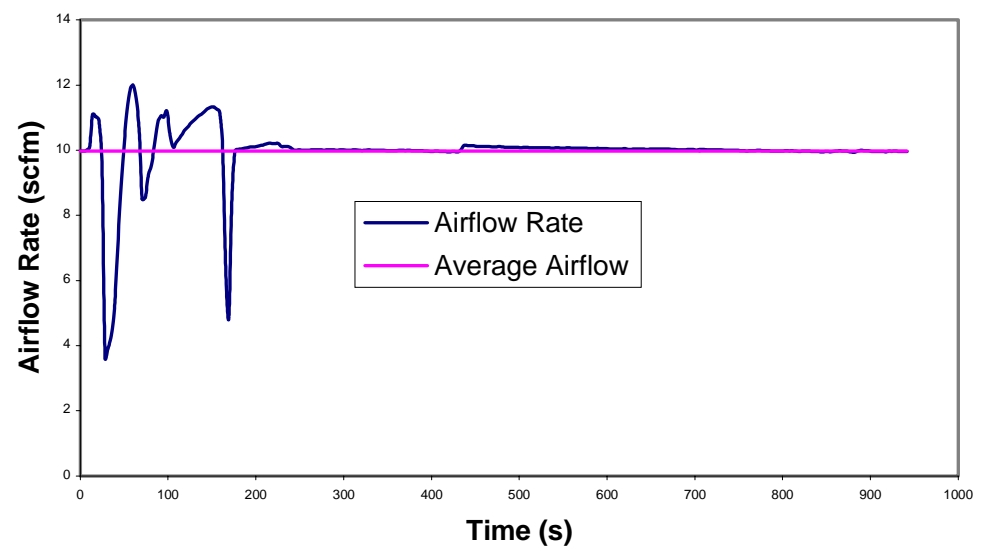

Figure 5.4.11: Test \#15 Combustion Airflow 


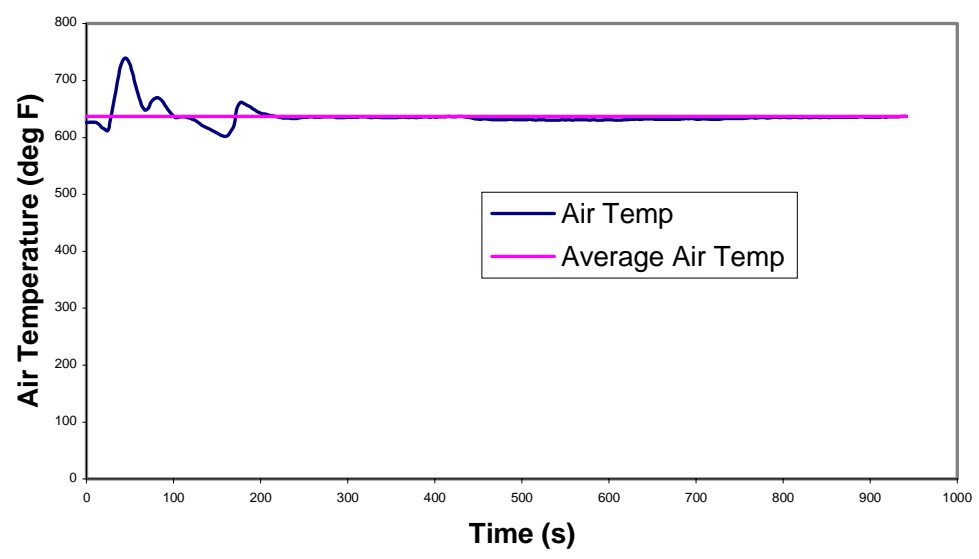

Figure 5.4.12: Test \#15 Combustion Air Temperature

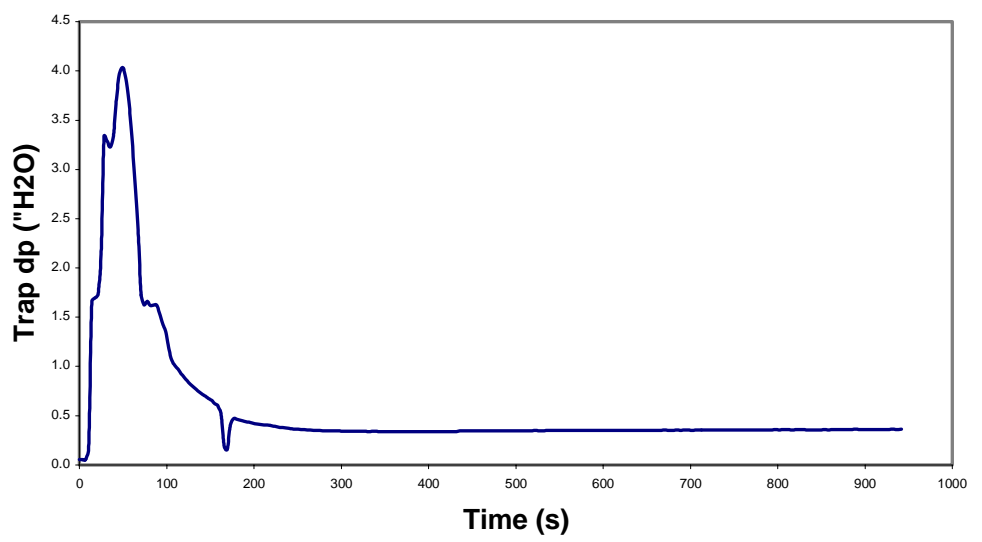

Figure 5.4.13: Test \#15 Trap Differential Pressure

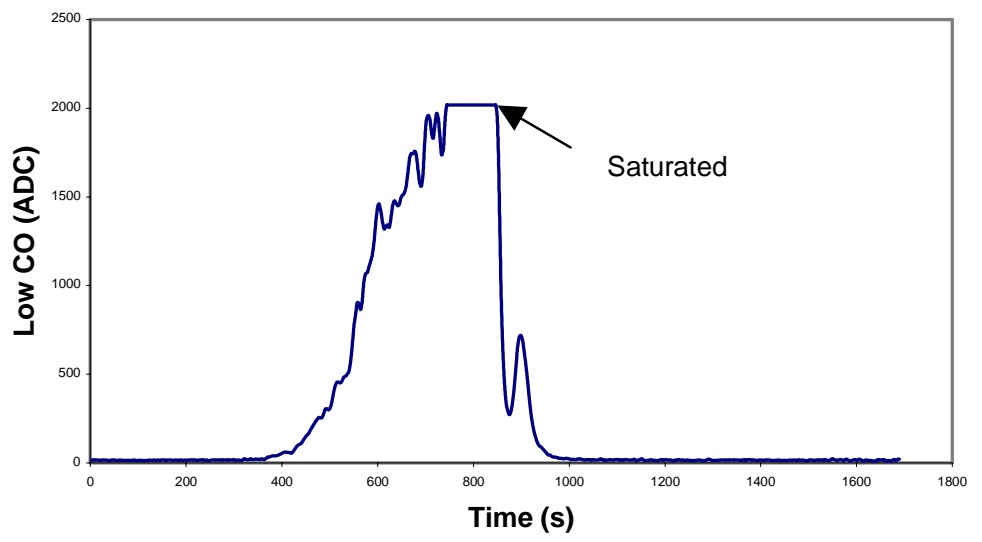

Figure 5.4.14: Test \#15 Low CO Analyzer ADC Output 


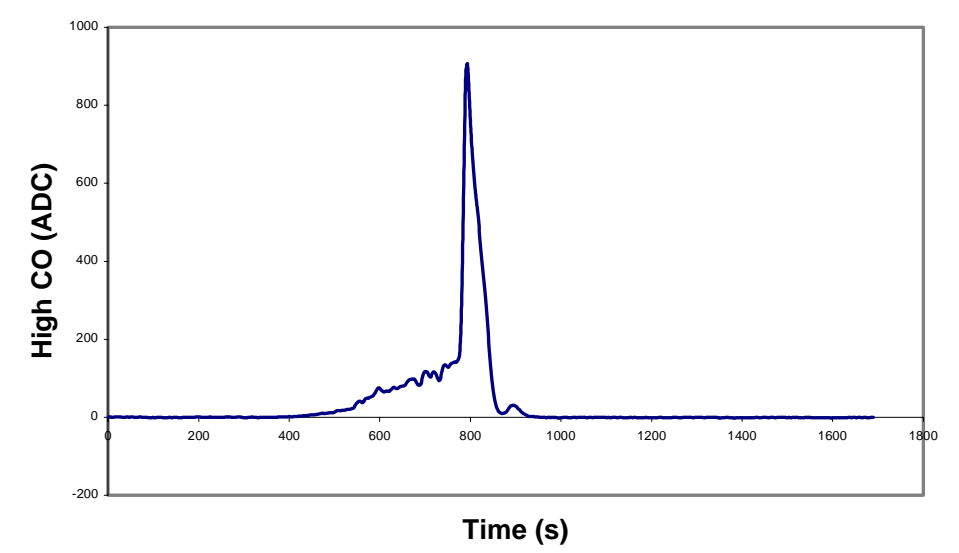

Figure 5.4.15: Test \#15 High CO Analyzer ADC Output

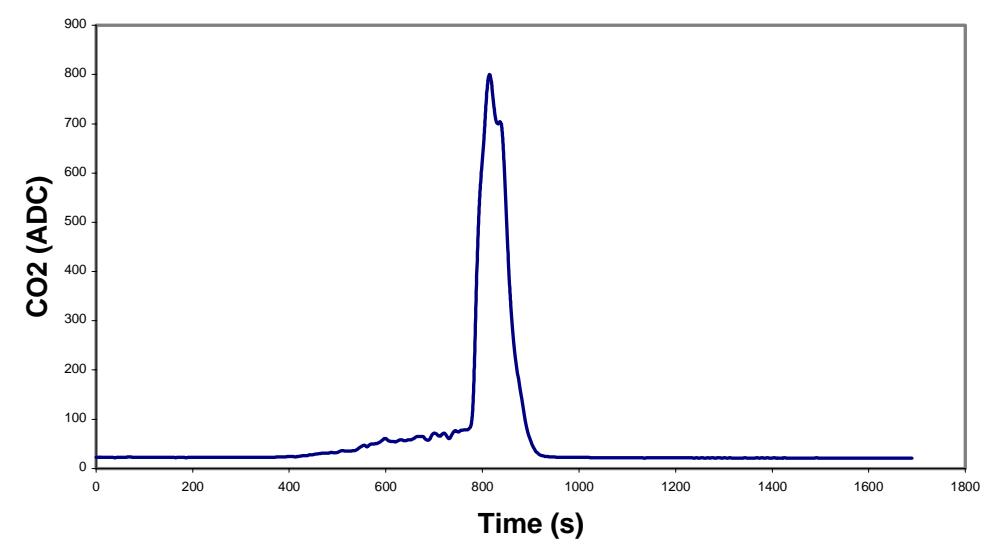

Figure 5.4.16: Test \#15 $\mathrm{CO}_{2}$ Analyzer ADC Output

The gravimetric analysis showed that $12.2 \mathrm{~g}$ of soot were combusted during the regeneration event which corresponded to a regeneration efficiency of $50.8 \%$. The filter was not damaged during regeneration.

In comparing the regeneration data for tests \#13,\#14, \#6, and \#15, it was apparent that the time for the total combustion event were comparable, the regeneration efficiencies did not vary significantly, and the trap housing surface temperature profiles were similar. 


\subsection{Final Results}

All the filters which were regenerated demonstrated a specific regeneration pattern. An elliptical pattern was present on the outlet end of each filter after regeneration. This pattern is shown in Figure 5.5.1:

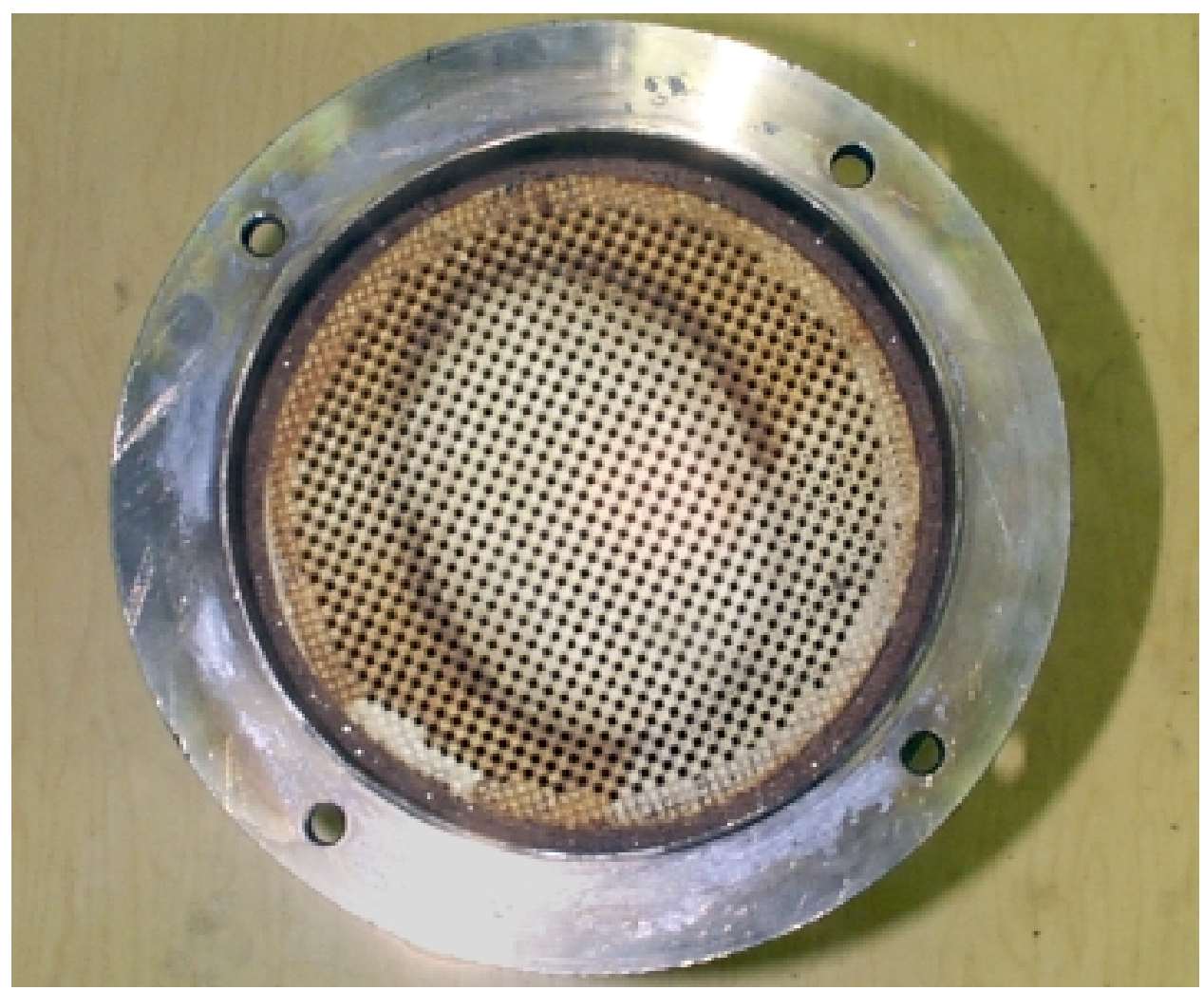

Figure 5.5.1: Filter Outlet Regeneration Pattern

The cells within the ellipse were completely regenerated along the filter axis (except for a small unregenerated section at the filter inlet - see Figure 5.5.2). It was discovered that as the regeneration efficiency increased, the ellipse became larger; and as the regeneration efficiency decreased, the ellipse became smaller. The longer dimension of the ellipse was perpendicular to the longer dimension of the waveguide cross-section. This phenomenon was expected to be a result of the electric field patterns generated, 
within the filter, during the preheating phase. Figures 3.4.1 and 3.4.2 show the electric and magnetic field distributions within the waveguide at one moment in time. It is seen that the electric field is strongest at the center of the long dimension of the waveguide. Because carbon is not magnetic, it was suspected that the electric field would be the predominant factor in the heating of the soot. Apparently, as the microwaves propagated across the diffuser, the electric field pattern was maintained with the electric field peaks occurring near the center of the trap housing (although the electric field pattern was allowed to expand), remaining perpendicular the longer dimension of the waveguide. It was suspected that the change in cross-sectional area within the diffuser would initiate other modes of propagation other than $\mathrm{TE}_{10}$ mode, but apparently, $\mathrm{TE}_{10}$ mode was predominant. The effects of heat transfer within the filter were also expected to affect the regeneration pattern, but not to the same degree as the electric and magnetic fields. This type of regeneration pattern was also expected to be unique to this microwave regeneration system. Changes in the dimensions and materials of the system could change the electric field patterns within the filter during the preheating period, which would alter the regeneration pattern. Modifications to the waveguide, multiple waveguide inlets, and changes in the microwave power and frequency could also affect the regeneration pattern.

The regeneration pattern within the filters was discovered by carefully cutting and removing a section of a regenerated filter. This pattern is displayed in Figures 5.5.2 and 5.5.3: 


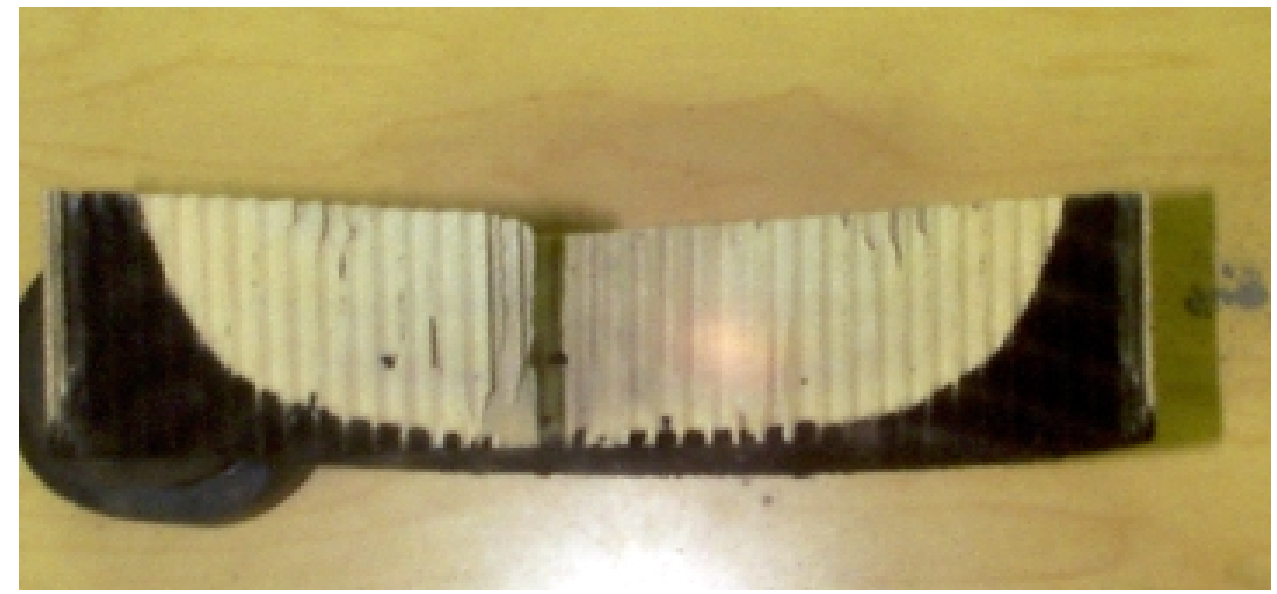

Figure 5.5.2: Internal Regeneration Pattern (side view)

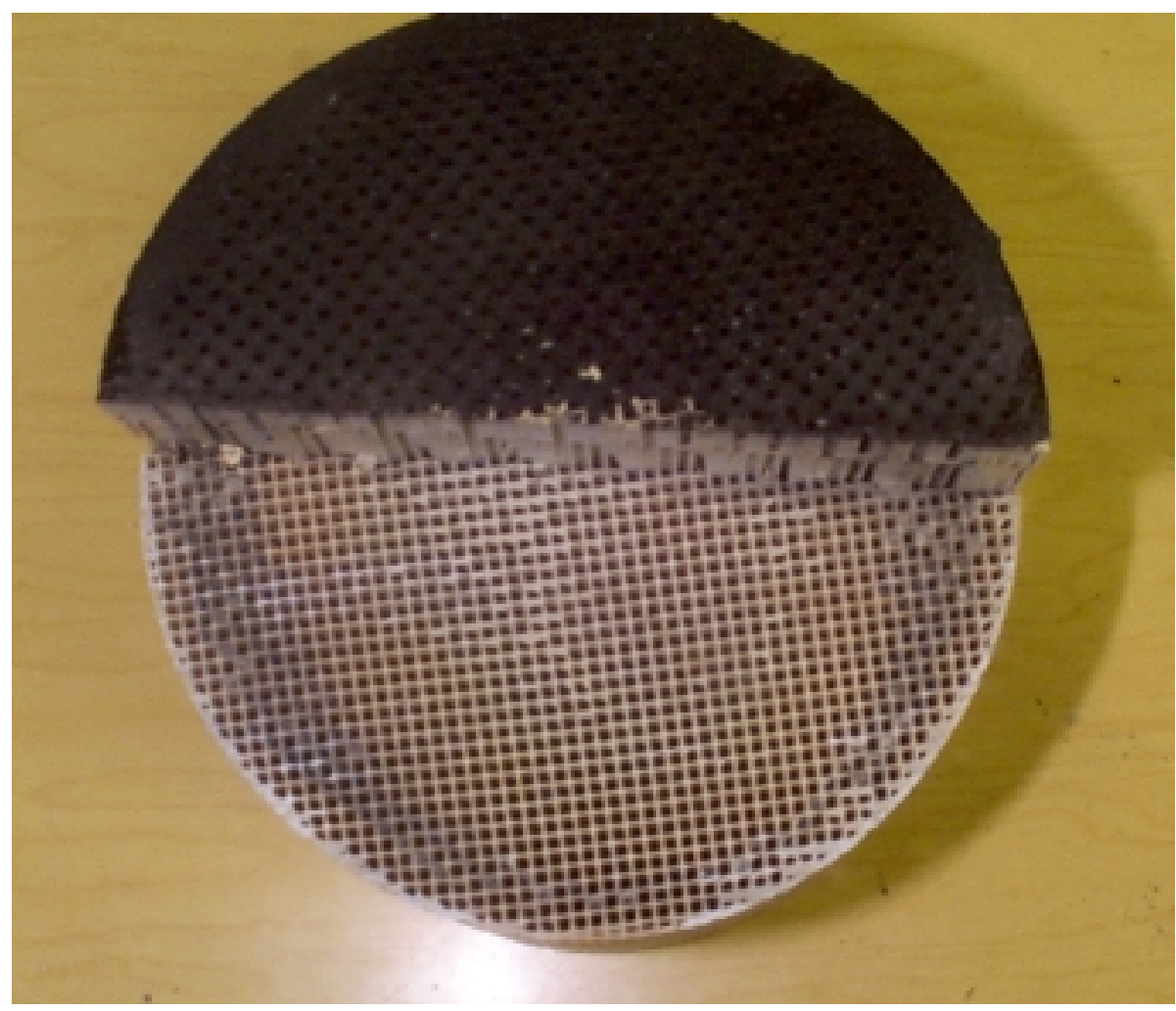

Figure 5.5.3: Internal Regeneration Pattern (top view)

The filter displayed in Figures 5.5.2 and 5.5.3 was regenerated in test \#12. It is apparent that a majority of the filter cells were regenerated. The elliptical pattern along 
the filter cross-section is apparent in Figure 5.5.3. A small layer of soot at the filter inlet was characteristically left on each regenerated filter. This was caused by the penetration depth of the microwaves which were transmitted to the filter. A finite soot depth was required for microwave absorption, so the soot at the filter inlet was not heated to the same degree as the soot located a small distance into the filter.

Data was collected during the filter loading process as well as during regeneration. This data was used to detect and record any problems which occurred during the filter loading process. This data included the exhaust backpressure in the exhaust manifold, the valve angle from the home position (that is, fully-open position), and the mass flow rate ratio of the exhaust flowing through the bypass line and the total exhaust flow. Appendix $\mathrm{O}$ contains plots of this data for test \#2 which was typical of all the other tests during the filter loading phase. It can be deduced from these plots that the exhaust bypass control system was very stable, and was able to maintain the mass flow rate ratio within the deadband of $+/-3 \%$ of the setpoint. These Figures also show that the exhaust backpressure gradually increased during the filter loading process. A small step change occurred in the exhaust backpressure with each incremental step in the exhaust butterfly valve. The exhaust mass flow rate ratio was seen to quickly increase as the exhaust butterfly valve was incrementally closed. The mass flow rate ratio was then observed to slowly decrease as the valve remained stationary and more soot became entrapped in the filter, decreasing the exhaust flow through the bypass line. As soon as the mass flow rate ratio was out of the deadband, the stepper motor was actuated, which closed the valve by $0.9^{\circ}$. This increased the restriction through the main exhaust line, 
thereby forcing more exhaust flow through the bypass line, and subsequently increasing the mass flow rate ratio until it was within the deadband.

As a final summary, the following tables list the parameters and the corresponding regeneration efficiencies for each case. Figures 5.5.4 to 5.5.7 show graphically the effects of initial soot mass, preheating time, combustion airflow rate and combustion air temperature on the regeneration efficiency.

Table 5.1: Effect of Initial Soot Mass on Regeneration Efficiency (Preheating Time $=12.5 \mathrm{~min}$, Combustion Airflow Rate $=5 \mathrm{scfm}$, Combustion Air Temperature $=300^{\circ} \mathrm{F}$ )

\begin{tabular}{ccc}
\hline $\begin{array}{c}\text { Initial Soot Mass } \\
(\mathrm{g})\end{array}$ & $\begin{array}{c}\text { Regeneration Efficiency } \\
(\%)\end{array}$ & Test Number \\
\hline 9.6 & 35.4 & 1 \\
17.0 & 72.9 & 2 \\
23.6 & 56.8 & 3 \\
29.6 & 72.3 & 4 \\
\hline
\end{tabular}

Table 5.2: Effect of Preheating Time on Regeneration Efficiency (Combustion Airflow Rate $=5 \mathrm{scfm}$, Combustion Air Temperature $=300{ }^{\circ} \mathrm{F}$, Initial Soot Mass $=24 \mathrm{~g}$ )

\begin{tabular}{ccc}
\hline $\begin{array}{c}\text { Preheating Time } \\
(\min )\end{array}$ & $\begin{array}{c}\text { Regeneration Efficiency } \\
(\%)\end{array}$ & Test Number \\
\hline 10 & 30.0 & 5 \\
12.5 & 54.1 & 6 \\
15 & 54.2 & 7 \\
15 & 51.7 & 8 \\
17.5 & 66.7 & 9 \\
\hline
\end{tabular}




\section{Table 5.3: Effect of Combustion Airflow Rate on Regeneration Efficiency}

(Preheating Time $=12.5 \mathrm{~min}$, Combustion Air Temperature $=300{ }^{\circ} \mathrm{F}$, Initial Soot Mass $=$ $24 \mathrm{~g})$

\begin{tabular}{ccc}
\hline $\begin{array}{c}\text { Airflow Rate } \\
(\mathrm{scfm})\end{array}$ & $\begin{array}{c}\text { Regeneration Efficiency } \\
(\%)\end{array}$ & Test Number \\
\hline$<5$ & 89.7 & 12 \\
5.2 & 56.8 & 6 \\
9.87 & 54.1 & 6 \\
15.0 & 38.8 & 10 \\
19.8 & 39.5 & 11 \\
\hline
\end{tabular}

Table 5.4: Effect of Combustion Air Temperature on Regeneration Efficiency

(Preheating Time $=12.5 \mathrm{~min}$, Combustion Airflow Rate $=10 \mathrm{scfm}$, Initial Soot Mass $=$ $24 \mathrm{~g})$

\begin{tabular}{ccc}
\hline $\begin{array}{c}\text { Combustion Air } \\
\text { Temperature } \\
\left({ }^{\circ} \mathrm{F}\right)\end{array}$ & $\begin{array}{c}\text { Regeneration Efficiency } \\
(\%)\end{array}$ & Test Number \\
\hline 76 & & 13 \\
152 & 55.5 & 14 \\
316 & 55.4 & 6 \\
637 & 54.1 & 15 \\
\hline
\end{tabular}




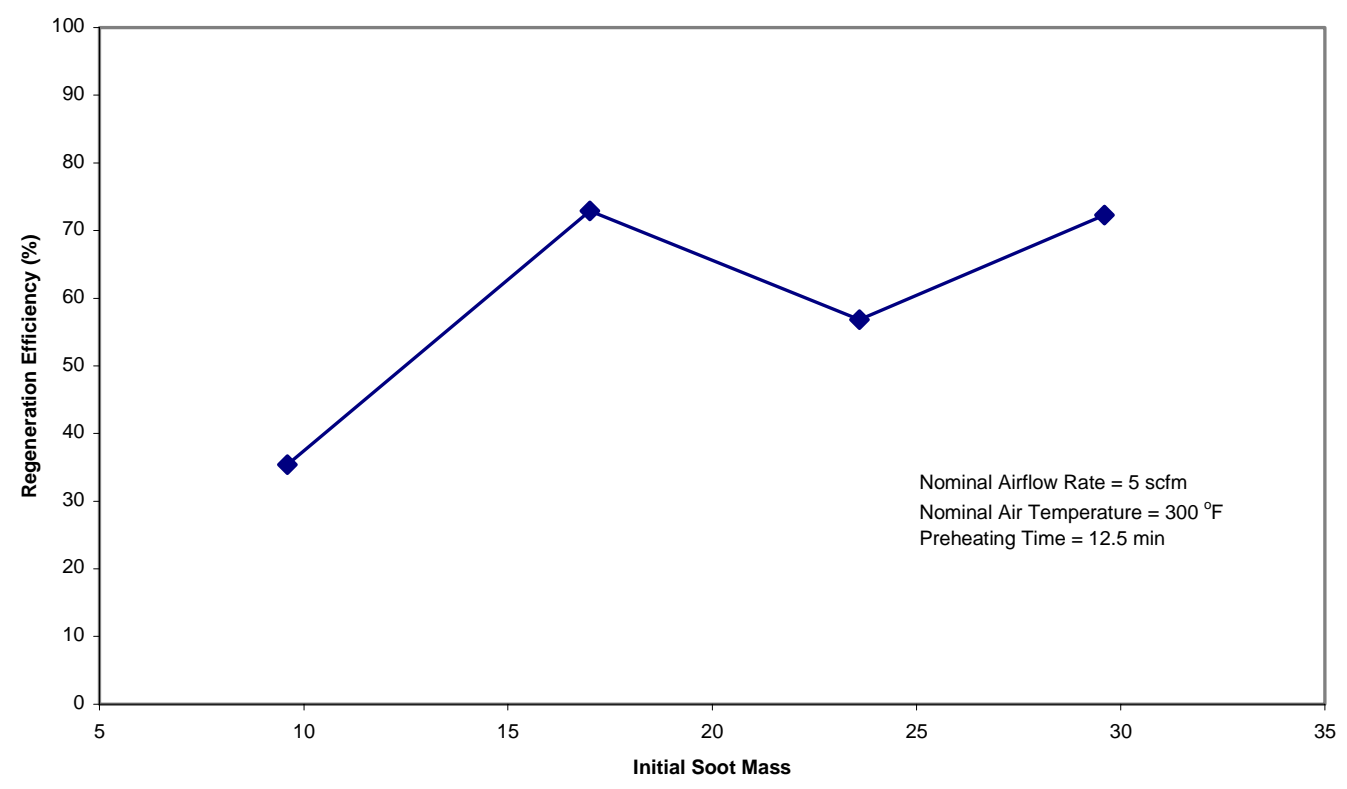

Figure 5.5.4: Effect of Initial Soot Mass on Regeneration Efficiency

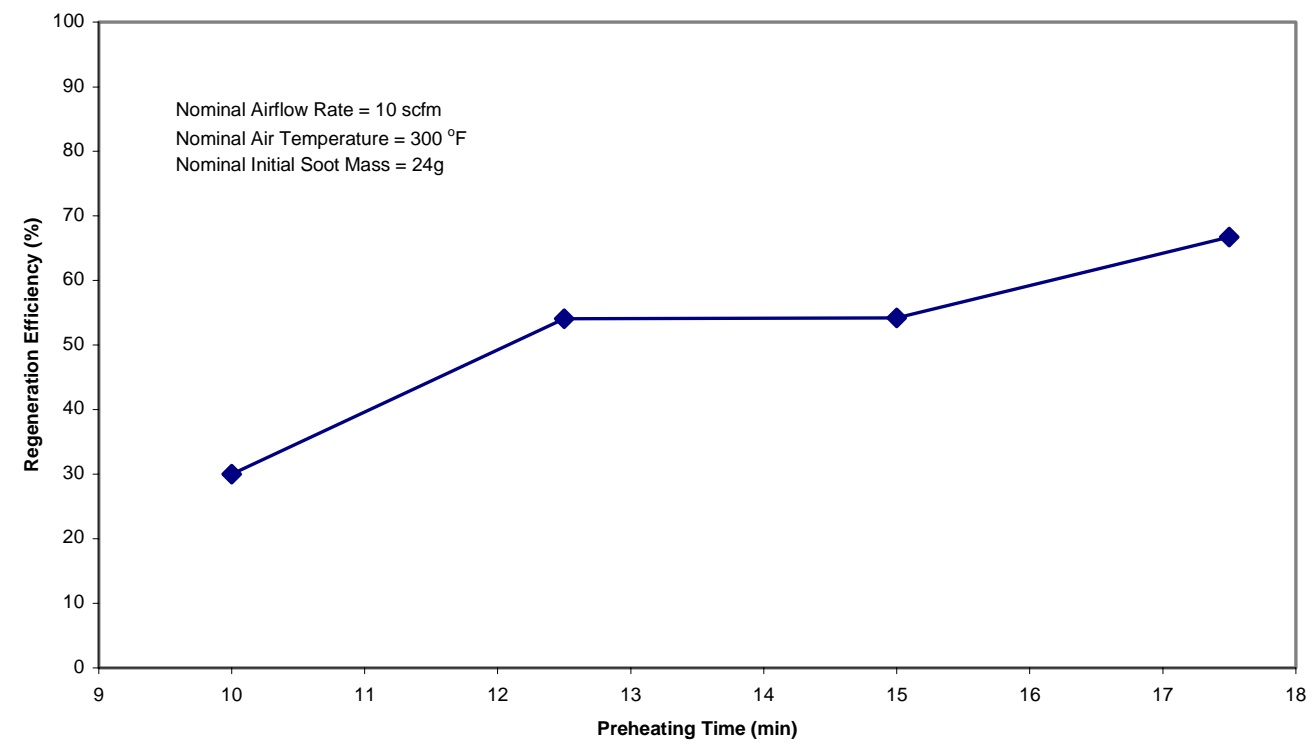

Figure 5.5.5: Effect of Preheating Time on Regeneration Efficiency 


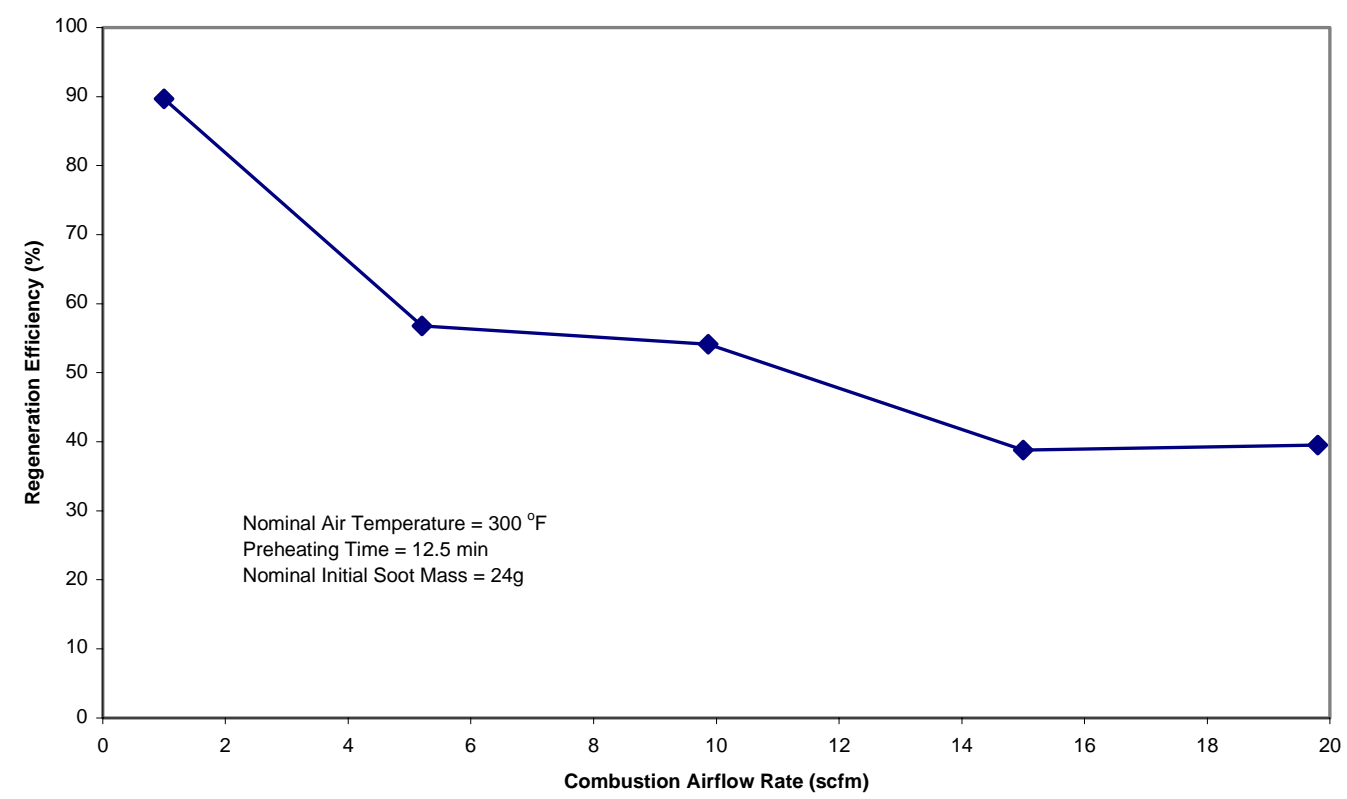

Figure 5.5.6: Effect of Combustion Airflow Rate on Regeneration Efficiency

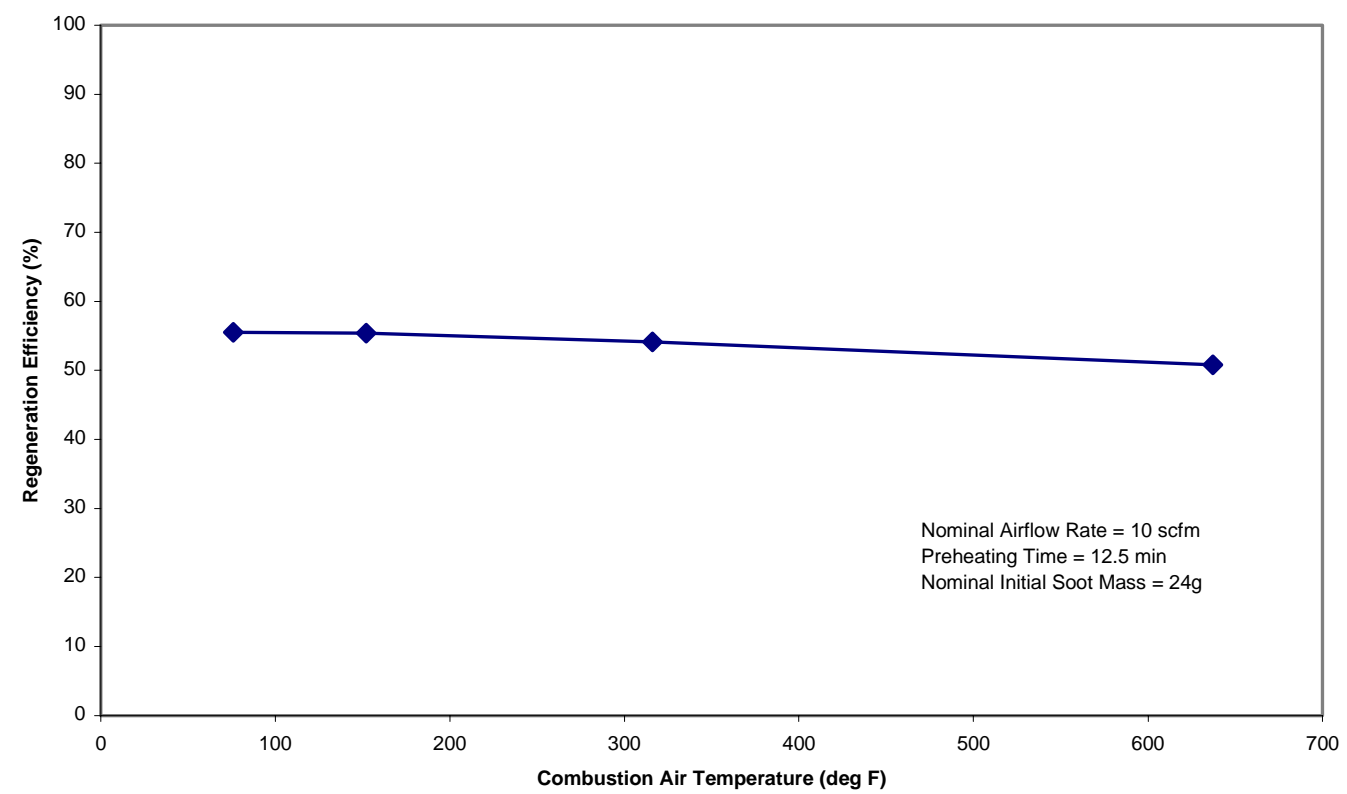

Figure 5.5.7: Effect of Combustion Air Temperature on Regeneration Efficiency 


\section{Chapter 6 \\ Conclusions and Recommendations}

\subsection{Conclusions}

From the results presented in Chapter 5, a number of conclusions can be made. It is apparent from the surface temperature profiles presented in Chapter 5 that the profiles were typically consistent in giving a qualitative estimation of the regeneration efficiency. Higher surface temperatures for longer periods of time corresponded to higher heat release rates. Higher heat release rates indicated that larger amounts of soot were combusted during regeneration. The surface temperature profiles also consistently showed that the peak temperatures occurred at positions 2 and 3 during the preheating phase. This indicates that the majority of the microwave energy was attenuated within approximately the first 2 inches $(5.1 \mathrm{~cm})$ of the filter. The surface temperature measurements also showed that the flame front propagated from the front of the filter which was heated during the preheating phase, to the back of the filter during the convective combustion phase.

The emissions analyzer data demonstrated that the convective combustion phase was very rapid. For all tests, the convective combustion phase occurred within 2 to 2.5 minutes. The convective combustion was so rapid, that the time required for this phase was virtually independent of soot load. The emissions data also indicated that the soot began to burn within the first 400 s to 450 s for most tests. This was to be expected. The soot loading, conditioning, and preheating phases were very consistent. The only other parameter that could have potentially affected the time required for soot ignition was the initial soot mass. The dielectric loss factor for soot is extremely high compared to other 
materials, so virtually all the microwave energy transmitted to the filter was absorbed within a small distance into the filter. The result was that the time required for ignition was independent of the initial soot mass.

Plots of the trap differential pressure given in chapter 5 also indicated that the convective combustion period was very rapid. As soon as the combustion air was supplied to the filter, the trap differential pressure was observed to rise rapidly and then fell rapidly. This indicated that soot was rapidly removed from the filter during the convective combustion phase. In some studies, the regeneration efficiency was calculated using the differential pressure (Arai et al., 1987). In this study, the values for the regeneration efficiency which were calculated using the differential pressure technique were much higher than those calculated using the gravimetric method. For this reason, the differential pressure method of calculating the regeneration efficiency is not recommended because the differential pressure is dependent on the soot loading pattern inside the filter as well as the filter material itself.

An elliptical regeneration pattern was observed in all regeneration events. The pattern was consistent in that as the regeneration efficiency increased, the size of the ellipse increased as well. The elliptical regeneration pattern was believed to be a result of the electric and magnetic field patterns within the filter during the preheating phase. This indicates that the filter geometry can play an important role in the effectiveness of a microwave regeneration system. Because the electric field peaks remained perpendicular to the longer dimension of the waveguide, and because the peaks were distributed farther across the filter face as the microwaves traversed through the diffuser (as indicated by the elliptical regeneration patterns), one would expect that as the distance between the trap 
and the waveguide outlet is increased, more uniform heating of the filter face would occur. Power transmission losses, the generation of other modes of propagation, and space constraints would impose limits the maximum distance that could be employed. The nonuniformity of the heating of the filter face limited the highest regeneration efficiency that could be achieved with a given set of regeneration parameters. More uniform heating would result in higher regeneration efficiencies if the other parameters were held constant.

The data in Table 5.1 indicates that the regeneration efficiency appeared to increase as the initial soot mass increased. This trend is not conclusive due to the high regeneration efficiency which occurred at the initial soot mass of $17.0 \mathrm{~g}$. This value could either be an anomaly or it could be an indication of an ideal initial mass for this microwave regeneration system. It could be speculated that this initial soot mass provided an ideal attenuation factor which allowed the microwave energy to be distributed across the filter face to a more uniform degree than that which occurred at higher initial soot loads. This initial soot mass may also have provided sufficient energy during the convective combustion phase to sustain the reaction to completion. For any regeneration system the optimal initial soot mass represents a balance between the energy release needed to sustain the exothermic reaction during the convective combustion phase and excessive energy release which would damage the filter. For this system, $17.0 \mathrm{~g}$ appears to represent this optimal loading [in conjunction with a preheating time of 12.5 minutes and an airflow rate at or below $\left.5 \mathrm{scfm}\left(0.14 \mathrm{~m}^{3} / \mathrm{min}\right)\right]$.

The data in Table 5.2 demonstrates that as the preheating time was increased, the regeneration efficiency increased as well. As the preheating times increased, more 
energy was imparted to the soot near the front of the filter. This allowed more soot near the periphery of the filter to become heated above the soot ignition temperature which allowed more soot to be combusted during the convective combustion phase. It should be noted that even though a small portion of the soot was combusted during the preheating phase (as was evidenced by the low emissions during the preheating phase), it was the ignition of the soot near the front of a given channel which allowed the reaction to propagate down that channel during the convective combustion phase. As more soot was ignited in the channels at the filter face, more soot was combusted during the convective combustion phase, which resulted in higher regeneration efficiency values. The preheating time was limited because no airflow was present to remove excess energy. Excessively long preheating times resulted in filter damage due to excessive thermal gradients in the radial direction. For this particular microwave regeneration assembly, a preheating time of at least 6 minutes was required to ignite even a small amount of soot.

The data in Table 5.3 demonstrates that the regeneration efficiency was inversely proportional to the combustion airflow rate. The combustion airflow was used to provide the oxygen necessary to oxidize the soot. Low oxygen supply rates would limit the rate of reaction at high soot temperatures. The combustion airflow rate was also used to remove energy from the filter during the convective combustion phase. This energy removal prevented the thermal stresses within the filter from becoming excessively high helped in increasing the filter life. The dual role of the combustion airflow rate made it a very important parameter in terms of regeneration control. As was evidenced in test \#12, low airflow rates did not necessarily result in filter damage. In test \#12, the airflow rate 
was very low. This limited the oxygen supply rate to the reaction zone which resulted in a relatively slow combustion process. The slow rate of energy release allowed sufficient time for the heat generated to propagate both radially and axially. Therefore, the reaction was sustained and no damage to the filter occurred. In practice, it is very difficult to maintain an airflow rate which controls both the reaction rate and removes enough energy to prevent filter damage. For this particular microwave regeneration system, an airflow rate at or less than $5 \mathrm{scfm}\left(0.14 \mathrm{~m}^{3} / \mathrm{min}\right)$ seems appropriate (with a preheating time of 12.5 minutes and an initial soot mass of $17 \mathrm{~g}$ )

The data in Table 5.4 indicates that the regeneration efficiency was not observed to be strongly dependent on the inlet air temperature during the convective combustion phase. It was expected that increased air temperature would result in less energy transfer to the airflow through the filter which would result in higher regeneration efficiency with an increased potential for filter damage. This trend was not observed, and more data are needed to better understand this phenomenon. One explanation may be that the combustion air temperature range which was used in this study was not broad enough to affect the regeneration efficiency. The combustion air temperature measurement was made immediately after the process air heaters. The combustion air was forced to flow through an additional $3 \mathrm{ft}$ to $4 \mathrm{ft}$ of 2.5 " steel tube before it entered the trap. Heat transfer from the combustion air decreased the combustion air temperature before it entered the trap, so the actual combustion air temperature range was narrower than the nominal range. Another explanation is that the mass flow rate of air remained constant, even though the air temperature increased. As the air temperature increased, the air density decreased, so the local velocity of the air through the filter increased as well, which 
would increase the local convective heat transfer coefficients. The increase in the convective heat transfer coefficients may have offset the decrease in the temperature gradients within the filter, so the overall energy removed from the filter by the air may have been similar for each test even though the filter inlet air temperature varied.

\subsection{Recommendations}

The effects of several additional parameters on the regeneration efficiency were determined in the concurrent study to this work (Popuri, 1999). Some of these parameters included trap position relative to the waveguide outlet, soot quality (that is, soot collected at other engine operating conditions), airflow rate during the preheating phase, and multiple preheating/convective combustion phases. Temperature profiles within the filter were also determined during the convective combustion phase by inserting thermocouples into the filter immediately after the preheating phase. Tests were also performed using diesel exhaust as the oxygen supply (that is, on-line or in-cell regeneration). A dual magnetron/waveguide assembly was also designed, fabricated, and tested. This assembly was used to distribute the microwave energy more uniformly over the filter face.

Some recommendations include using automated control for the combustion airflow to the trap. Time constraints precluded the use of an automated system for this testing. A vertical trap arrangement is also recommended in conjunction with low airflow rates. In this way, natural convective forces can be used to sustain the reaction. More fundamental data (that is, more data concerning the effects of initial soot mass, preheating time, combustion airflow rate, and combustion air temperature) are also 
needed to verify the conclusions in this work. Repeat test data and broader ranges of the parameters given in this work would be useful in verifying the observed trends. Different filter materials (including silicon carbide) and trap geometries should also be studied, and larger waveguides should also be tested (such as the WR340) to determine if more uniform heating of the filter face could be achieved. Magnetrons with lower power ratings should also be tested. In this way, the released energy during the preheating phase would have a chance to spread radially outward, preventing overheating at the center of the filter element. An insulated filter housing should also be tested. Much more on-line testing is necessary to determine the practicality of this system. One of the most important additions to this work would be the use of black body sensors in the trap. This would provide temperature data during the preheating phase, which would greatly assist the development of a regeneration control scheme.

A final recommendation is the use of a microwave distribution system between the waveguide and the filter housing. The distribution system could be composed of two horizontal and two vertical vanes. The vanes could be positioned such that the space between them is the same as the waveguide dimensions. Each vane could be hinged nearest to the waveguide outlet. A motor and gearing system could be used to rotate the vanes such that the microwaves would be focused on one area of the filter at a given instant in time. This system would require the use of a water-cooled jacket around the gearing system. The system would be relatively complex, and preheating times would increase, but it is believed that this would provide much more uniform heating of the filter face. 


\section{Bibliography}

Arai, M., Miyashita, S., and Sato, K. (1987): "Development and Selection of Diesel Particulate Trap Regeneration System.” SAE 870012.

Barris, M.A. and Rocklitz, G.J. (1989): “Development of Automatic Trap Oxidizer Muffler Systems." SAE 890400.

Beckwith, T.G., Marangoni, R.D., and Lienhard V, J.H. Mechanical Measurements, $5^{\text {th }}$ ed. Addison-Wesley Publishing Co. Reading, Massachusetts, 1993.

Beer, F.P. and Johnston, E.R. Mechanics of Materials. McGraw-Hill Book Co. New York, New York. 1981.

Bloomfield, L.A. "How Things Work: Microwave Ovens." University of Virginia. http://howthingswork.virginia.edu/microwave_ovens.html

Chunrun, Z., Jiayi, M., Jiahua, C., Lunhui, L., Junmin, L., and Chengbin, L. (1994): "Studies on Regeneration of Diesel Exhaust Particulate Filters by Microwave Energy." SAE 941774.

Cross, Tim. Melling, Inc. Personal Interview. Sept. 29, 1999.

Detroit Diesel Emissions Standards Pamphlet, revised Nov. 1996.

Ferguson, C.R. Internal Combustion Engines: Applied Thermosciences. John Wiley \& Sons. New York, New York, 1986.

Ferguson, D.H. (1993) "Design, Fabrication and Testing of an Emissions Measurement System for a Transportable Heavy Duty Vehicle Emissions Testing Laboratory." M.S. Thesis, Department of Mechanical and Aerospace Engineering, West Virginia University, Morgantown, WV.

Figliola, R.S. and Beasley, D.E. Theory and Design for Mechanical Measurements. John Wiley \& Sons, Inc. New York, New York, 1991.

Fluid Meters: Their Theory and Application, $6^{\text {th }}$ ed. Report of ASME Research Committee on Fluid Meters. New York, New York, 1971.

Gallawa, J.C. You Can Fix Your Microwave Oven! A Practical Video Guide to Safe and Successful Microwave Oven Repair. Microtech Productions, 1994.

Gallawa, J.C. www.gallawa.com/microtech/mwave/html.

Gardid, F., Introduction to Microwaves. Artech House Inc. Dedham, Massachusetts, 1984. 
Garner, C.P. and Dent, J.C. (1989): "Microwave Assisted Regeneration of Diesel Particulate Traps." SAE 890174.

Garner, C.P. and Dent, J.C. (1990): "Development of a Microwave Diesel Particulate Trap Regeneration System.” SAE 905116.

Gautam, M. West Virginia Diesel Study: Draft Final Report. 1998.

Ghandi, O.P. Microwave Engineering and Applications. Pergamon Press. New York, New York. 1981.

Ha, K. and Lawson, A. (1989): "Development of a Diesel Particulate Trap System for a 6V-92TA Engine." SAE 890402.

Haynes, J., Gilmore, B., and Daniels, M. Ford V8 Mustang Automotive Repair Manual. Haynes North America, Inc. Newbury Park, California, 1979.

Health Effects Institute. Diesel Exhaust: A Critical Analysis of Emissions, Exposure, and Health Effects. A Special Report of the Institute's Diesel Working Group. April 1995.

History of Orifice Meters and the Calibration, Construction, and Operation of Orifices for Metering. Report of the Joint Committee on Orifice Coefficients of the American Gas Association. Reprinted by the American Society of Mechanical Engineers. New York, New York, 1935.

Jahnke, J.A., Continuous Emission Monitoring. Van Nostrand Reinhold. New York, New York, 1993.

Jauchem, J.A. (1991): “Alleged Health Effects of Electromagnetic Fields: Misconceptions in the Scientific Literature." Journal of Microwave Power and Electromagnetic Energy, 26(4), pp. 189-195.

Jauchem, J.A. (1993): "Alleged Health Effects of Electric or Magnetic Fields: Additional Misconceptions in the Literature." Journal of Microwave Power and Electromagnetic Energy, 28(3), pp. 140-155.

Jauchem, J. (1995): "Alleged Health Effects of Electromagnetic Fields: The Misconceptions Continue." Journal of Microwave Power and Electromagnetic Energy, 30(3), pp. 165-172.

Kittelson, D.B., Pui, Y.H., and Moon, K.C. (1986): “Electrostatic Collection of Diesel Particles." SAE 860009. 
Kiyota, Y., Tsuji, K., Kume, S., and Nakayama, O. (1986): "Development of Diesel Particulate Trap Oxidizer System.” SAE 860294.

Ludecke, O.A. and Dimick, L. (1983): "Diesel Exhaust Particulate Control System Development." SAE 830085.

Ma., J., Fang, M., Li, P., Zhu, B., Lu, X., and Lau, N.T. (1997): "Microwave-assisted Catalytic Combustion of Diesel Soot." Applied Catalysis A: General, 159(1-2), pp. 211-228.

MacDonald, J.S. and Simon, G.M. (1988): "Development of a Particulate Trap System for a Heavy-duty Diesel Engine." SAE 880006.

Measurement of Fluid Flow in Pipes Using Orifice, Nozzle, and Venturi. $6^{\text {th }}$ ed (1990). ASME MFC-3M-1989. The American Society of Mechanical Engineers. New York, New York, 1990.

Meinrad, S. and Giorgio, C. (1989): "Laboratory Results in Particulate Trap Technology.” SAE 890170.

Meredith, R., Engineer's Handbook of Industrial Microwave Heating. IEE Publication, 1998.

Metaxas and Meredith, Industrial Microwave Heating. IEE Publication, 1983.

Mills, A.F. Heat Transfer. Richard D. Irwin, Inc. Homewood, Illinois. 1992.

Moran, M.J. and Shapiro, H.N. Fundamentals of Engineering Thermodynamics, $2^{\text {nd }}$ ed. John Wiley \& Sons, Inc. New York, New York, 1992.

Munson, B.R., Young, D.F., Okiishi, T.H. Fundamentals of Fluid Mechanics. John Wiley \& Sons, Inc. New York, New York, 1990.

Oriental Motor General Catalog. Oriental Motor U.S.A. Corp. 1997.

Osepchuck, J.M. (1977): “A Review of Microwave Oven Safety.” Journal of Microwave Power, 13(1), pp. 13 - .

Ospechuk, J.M. (1996): "Health and Safety Issues for Microwave Power Transmission." Solar Energy, 56(1), pp. 53-60.

Pattas, K.N., Kikidis, P.S., Aidarinis, J.K., Patsatzis, N.A., and Stamatellos, A.M. (1986): "A Trap Oxidiser System for Urban Buses." SAE 860136.

Plint, M. and Martyr, A. Engine Testing Theory and Practice, $2^{\text {nd }}$ ed. Reed Educational and Professional Publishing, LTD. Woburn, Massachusetts, 1995. 
Popuri, Sriram (1999). "An Experimental and Computational Investigation of Microwave Regeneration of Diesel Particulate Traps.” Dissertation, Department of Mechanical and Aerospace Engineering, West Virginia University, Morgantown, WV.

Riddle, D.F. Calculus and Analytic Geometry, $4^{\text {th }}$ ed. Wadesworth Publishing Co. Belmont, California. 1984.

Roddy, D. Microwave Technology. Prentice Hall. Englewood Cliffs, New Jersey, 1986.

Roussopoulos, K. (1990). “A Convenient Technique for Determining Comparative Volumetric Efficiency.” SAE 900352.

Shigley, J.E. and Mischke, C.R. Mechanical Engineering Design, $5^{\text {th }}$ ed. McGraw Hill, Inc. New York, New York. 1989

Stuchly, M.A. (1977): "Potentially Hazardous Microwave Radiation Sources - a Review." Journal of Microwave Power, 12(4), pp. 369-381.

Suresh Babu, V., Farinash, L., and Seehra, M.S. (1995): "Carbon in Diesel Particulate Matter: Structure, Microwave Absorption, and Oxidation.” J. Mater. Res., 10(5), pp. 1075-1078.

Suresh Babu, V., Popuri, S., Gautam, M., and Seehra, M.S. (1996): “Thermal and Microwave Characteristics of Diesel Particulate Matter in Relation to Microwave Regeneration of Traps.” Appl. Occup. Environ. Hyg., 11(7), pp. 799-803.

Tipler, P.A., Physics for Scientists and Engineers, $3^{\text {rd }}$ ed. Worth Publishers, Inc. New York, New York, 1991.

Wade, W.R., White, J.E., Florek, J.J., and Cikanek, H.A. (1983): “Thermal and Catalytic Regeneration of Diesel Particulate Traps.” SAE 830083.

Walton, F.B., Hayward, P.J., and Wren, D.J. (1990): “Controlled Energy Deposition in Diesel Particulate Filters during Regeneration by Means of Microwave Irradiation." SAE 900327.

Walton, F.B., Archambault, D.P., and Legiehn, M. (1992): "On-line Measurement of Diesel Particulate Loading in Ceramic Filters.” SAE 920564.

Walton, F.B., Archambault, D.P., and Legiehn, M. (1993): “A One-point Calibration Method for the On-line Measurement of Diesel Particulate Loading in Ceramic Filters." SAE 9930366.

Wendland, D.W., Kreucher, J.E., and Andersen, E. (1995). "Reducing Catalytic Converter Pressure Loss with Enhanced Inlet-header Diffusion.” SAE 952398 
Zhi. N., Guanglong, Z., Yong, L., Junmin, L., Xiyan, G., Iunhui, L., and Jiahua, C. (1995): "Analysis of Characteristic of Microwave Regeneration for Diesel Particulate Filter." SAE 952058.

Zhi, N. and He, Y. (1999): "Experimental Study on Microwave Regeneration Characteristics of Diesel Particulate After-treatment System." SAE 1999-011470. 


\section{Appendix A: Exhaust System and Flow Control Components}




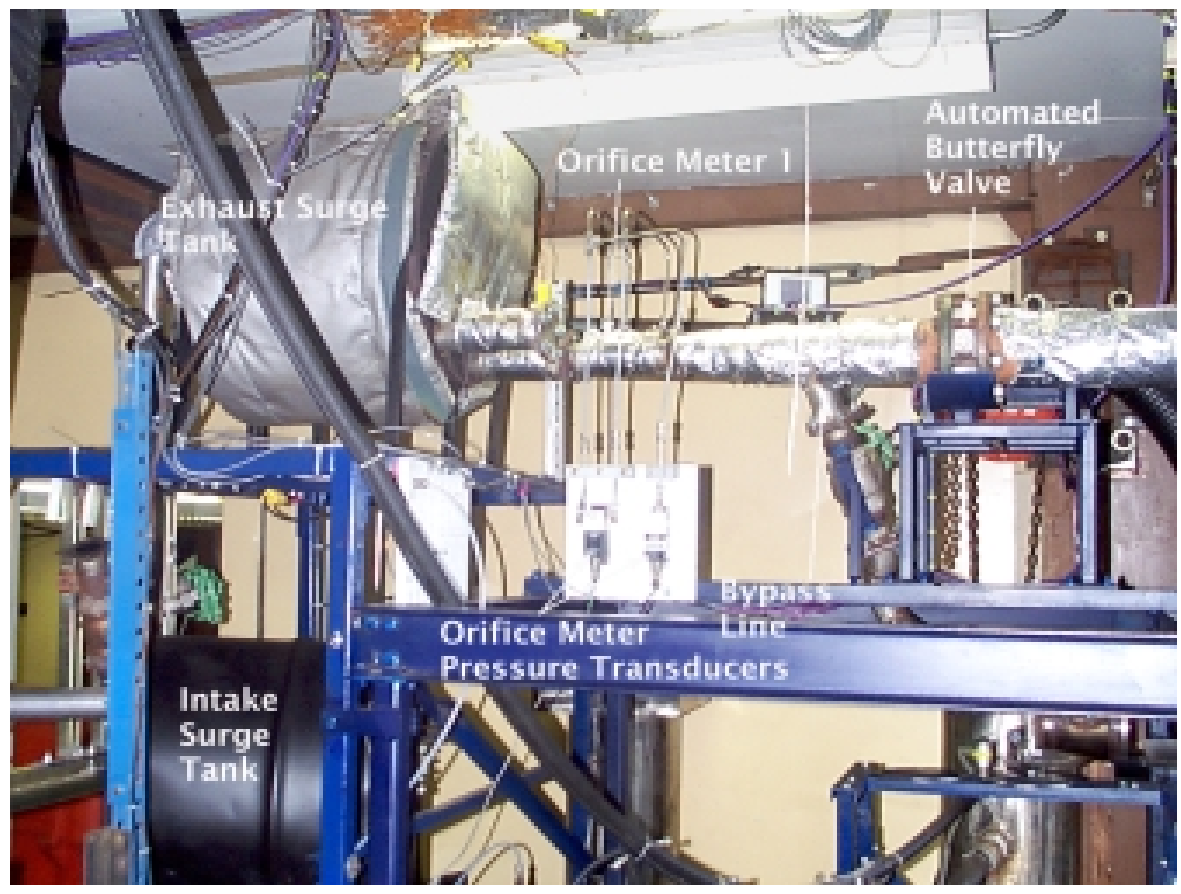

Figure A.1: Exhaust Line Components

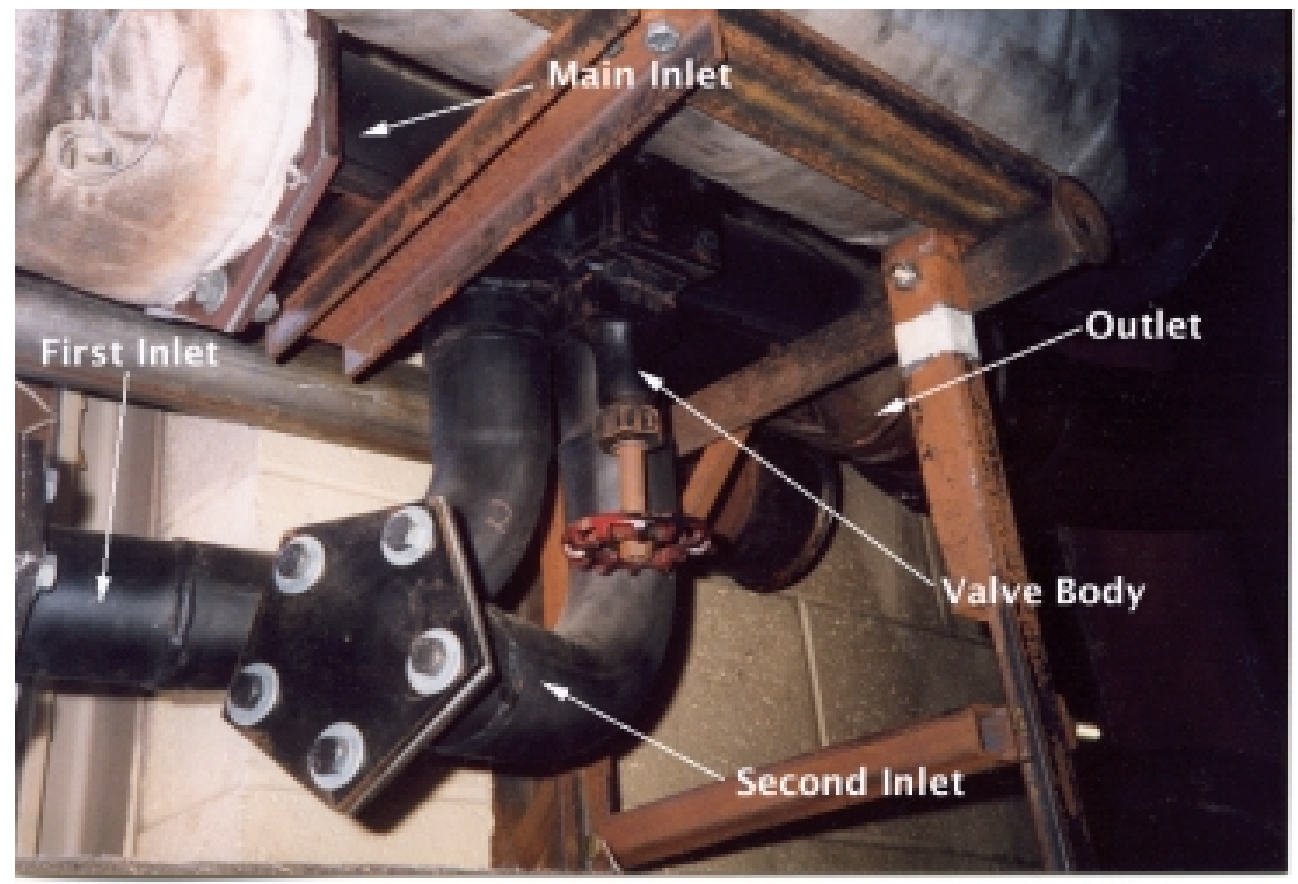

Figure A.2: Sliding Gate Valve 


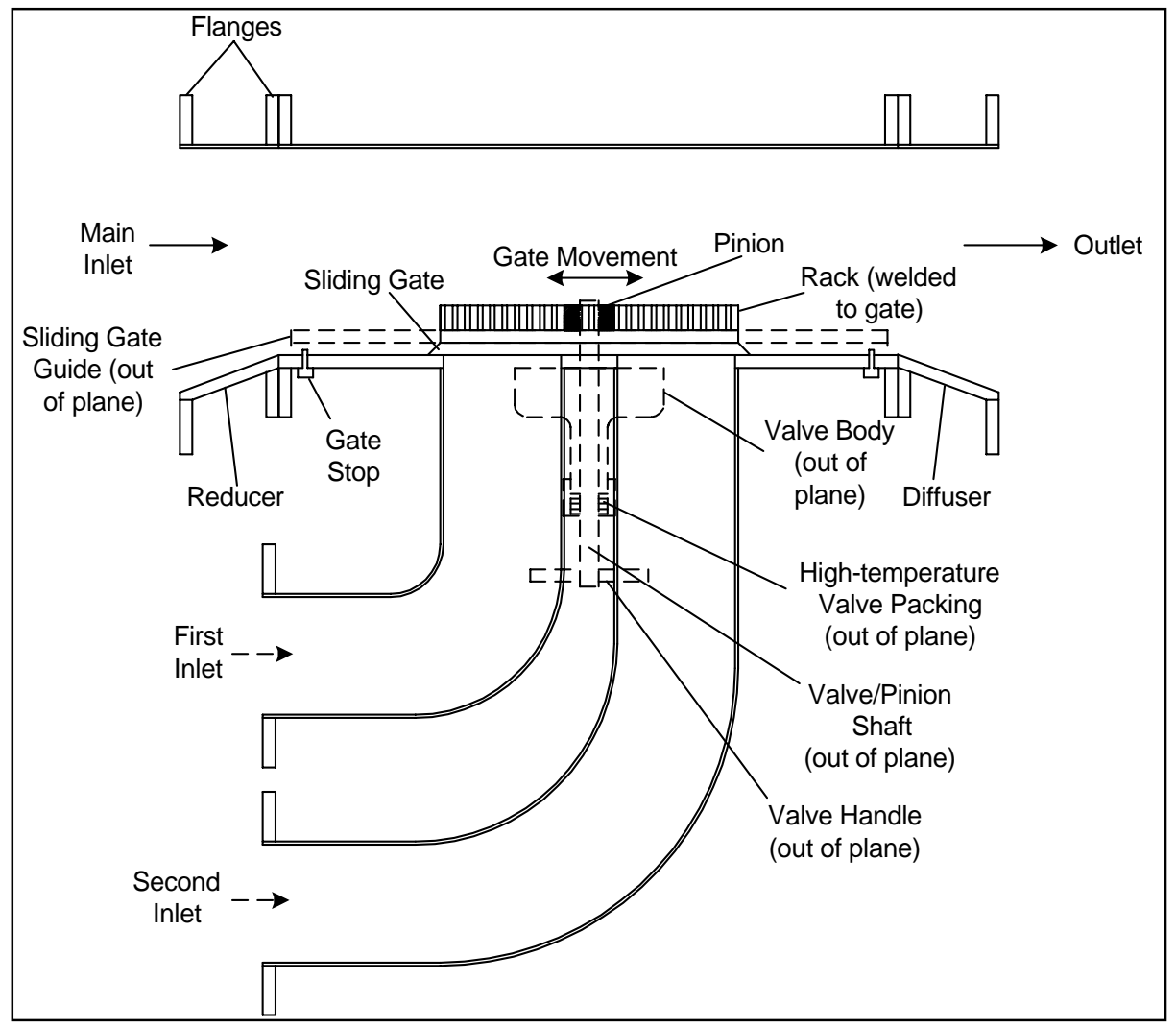

Figure A.3: Sliding Gate Valve Cross-section

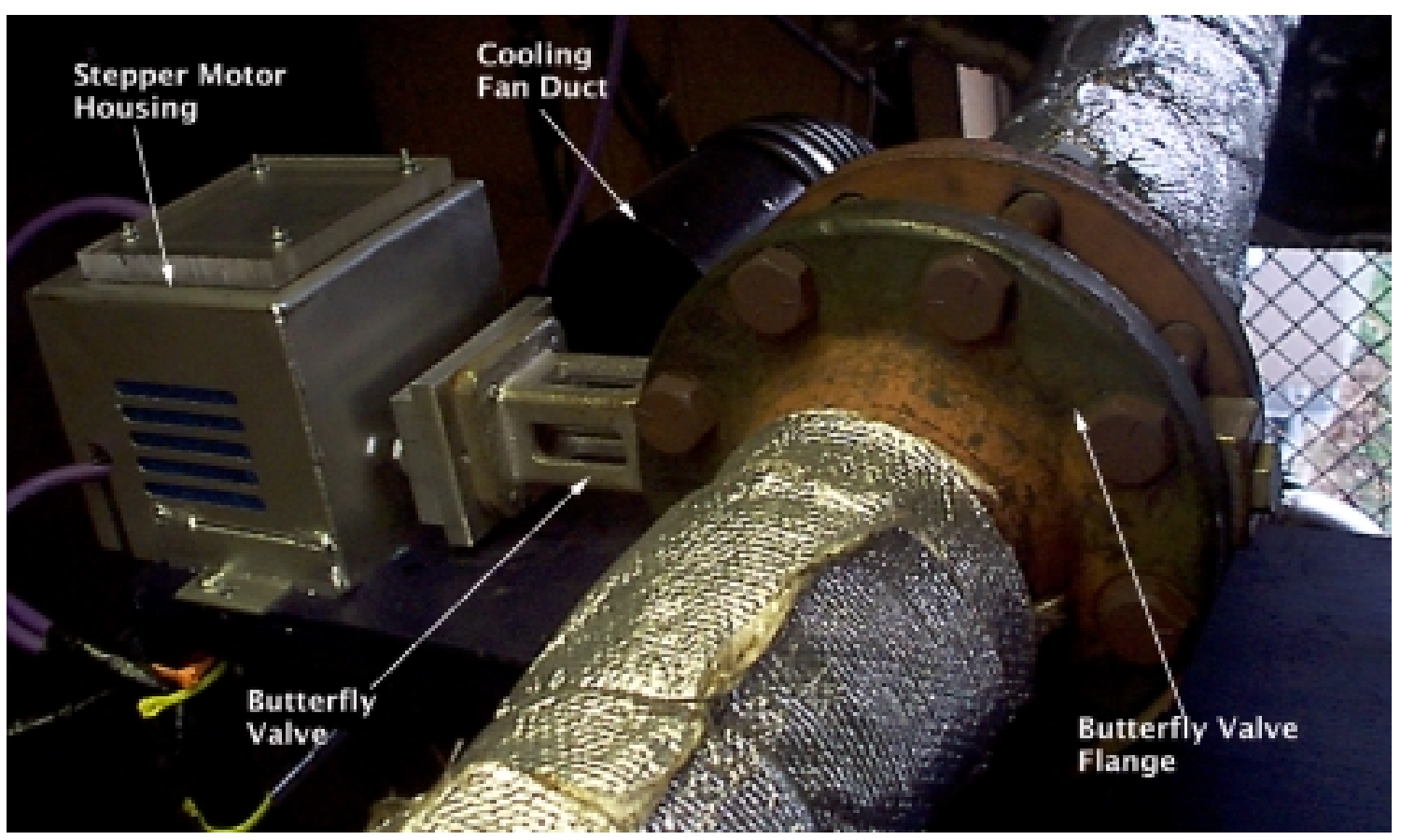

Figure A.4: Automated Butterfly Valve 


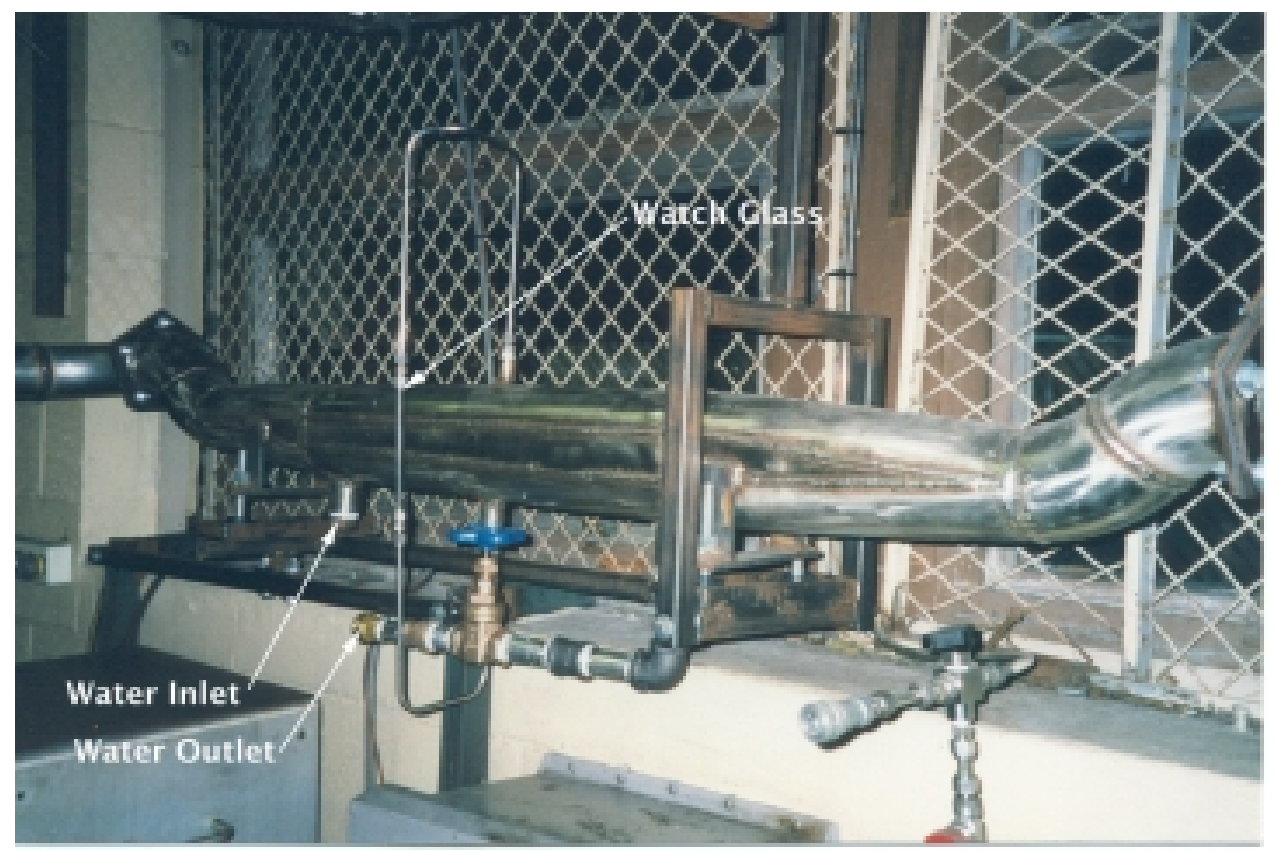

Figure A.5: Microwave Water Trap

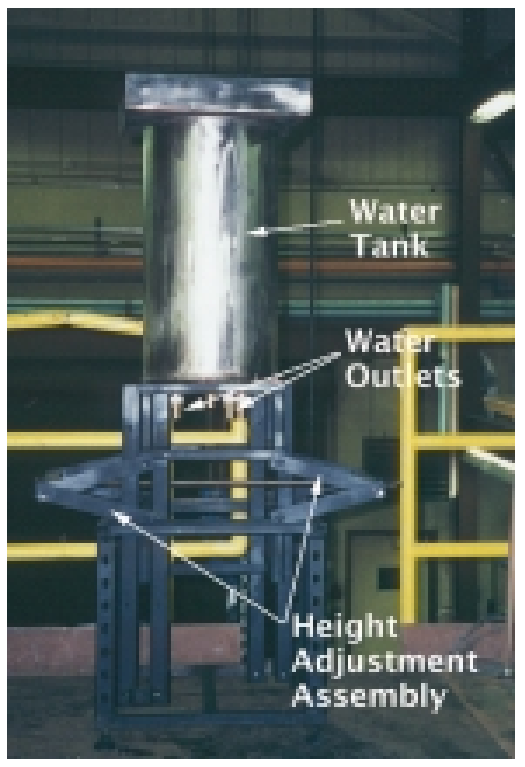

Figure A.6: Adjustable Height Water Tower 


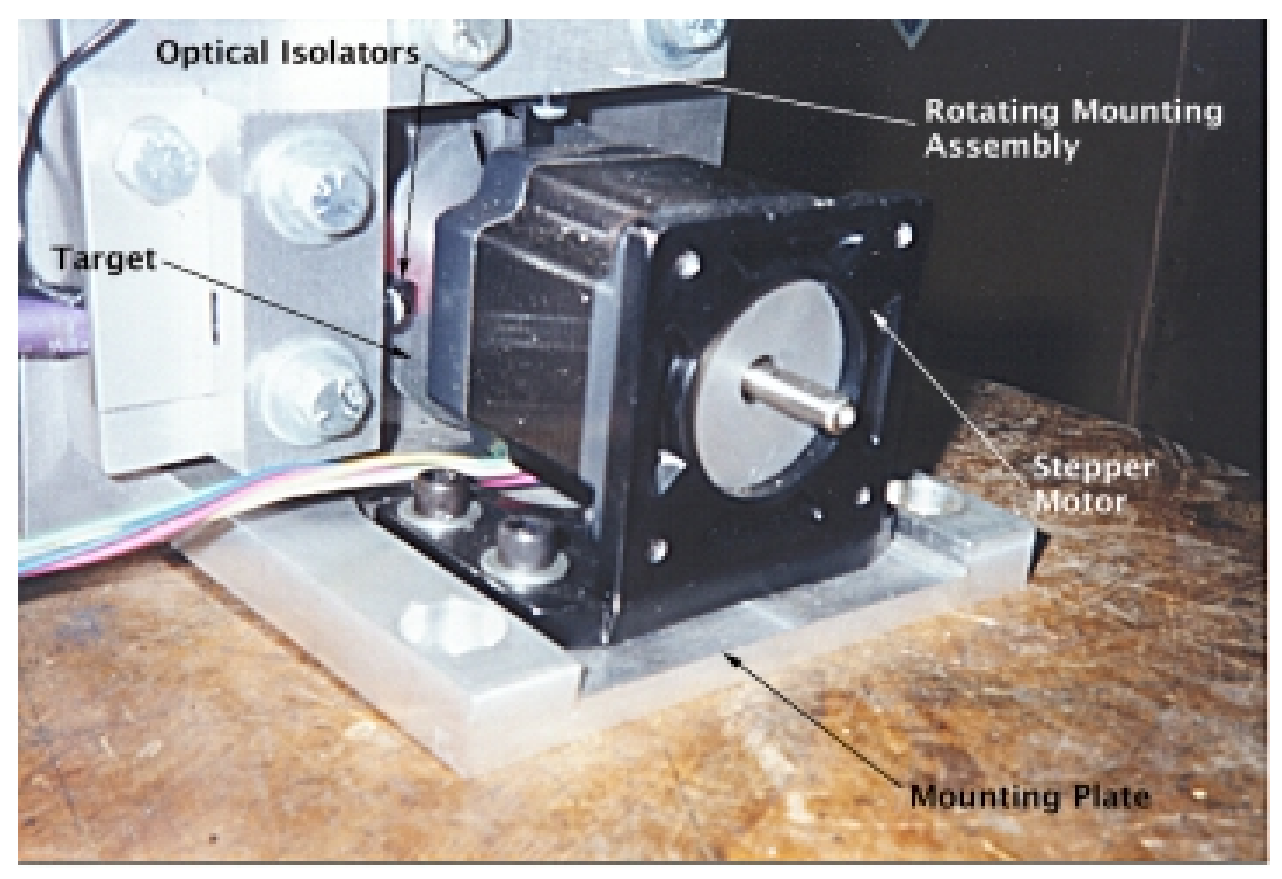

Figure A.7: Stepper Motor Assembly

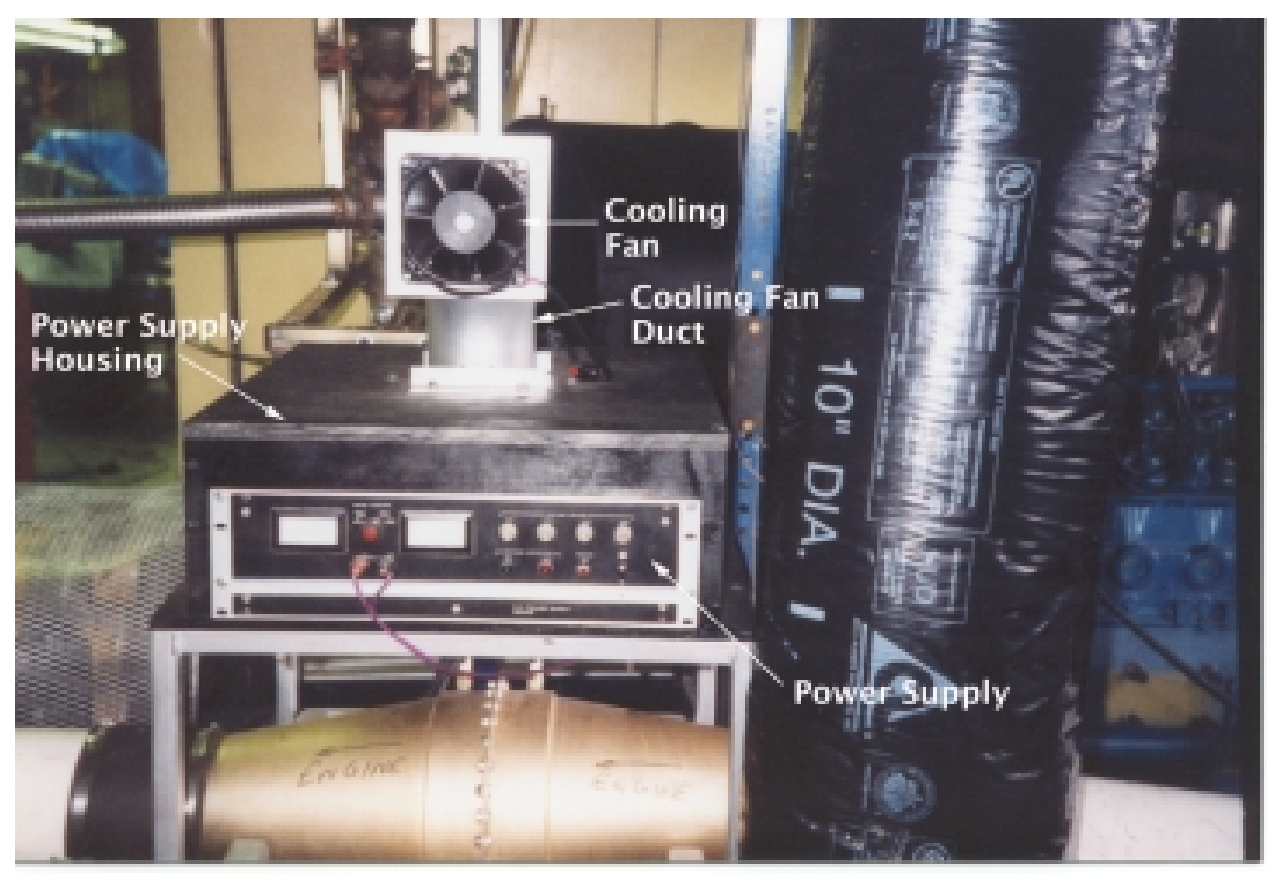

Figure A.8: Power Supply for Stepper Motor Assembly 
Appendix B: Laminar Flow Element Calibration Data 


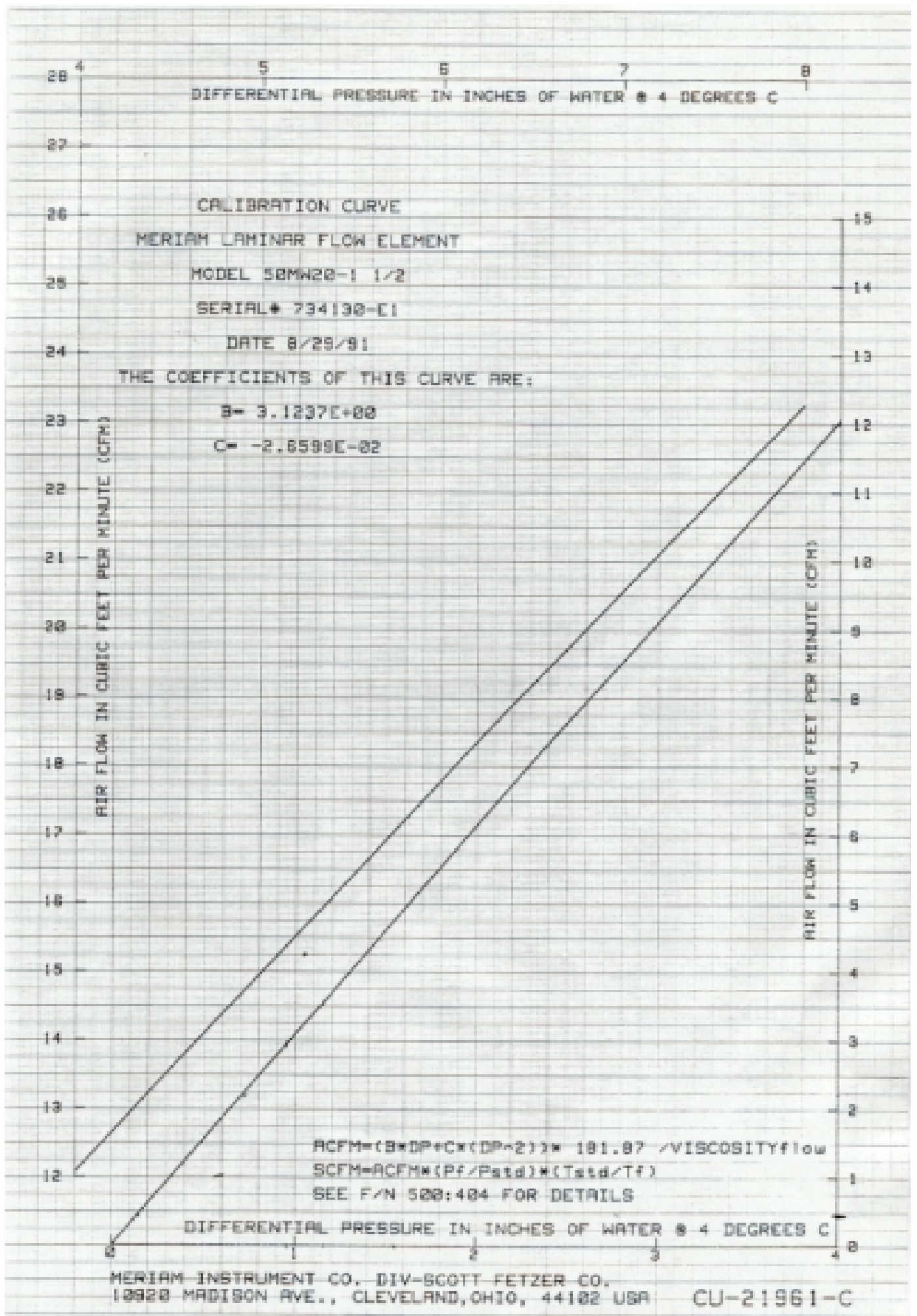

Figure B.1: 25 acfm Laminar Flow Element Calibration Curve (provided by Meriam, Inc.) 


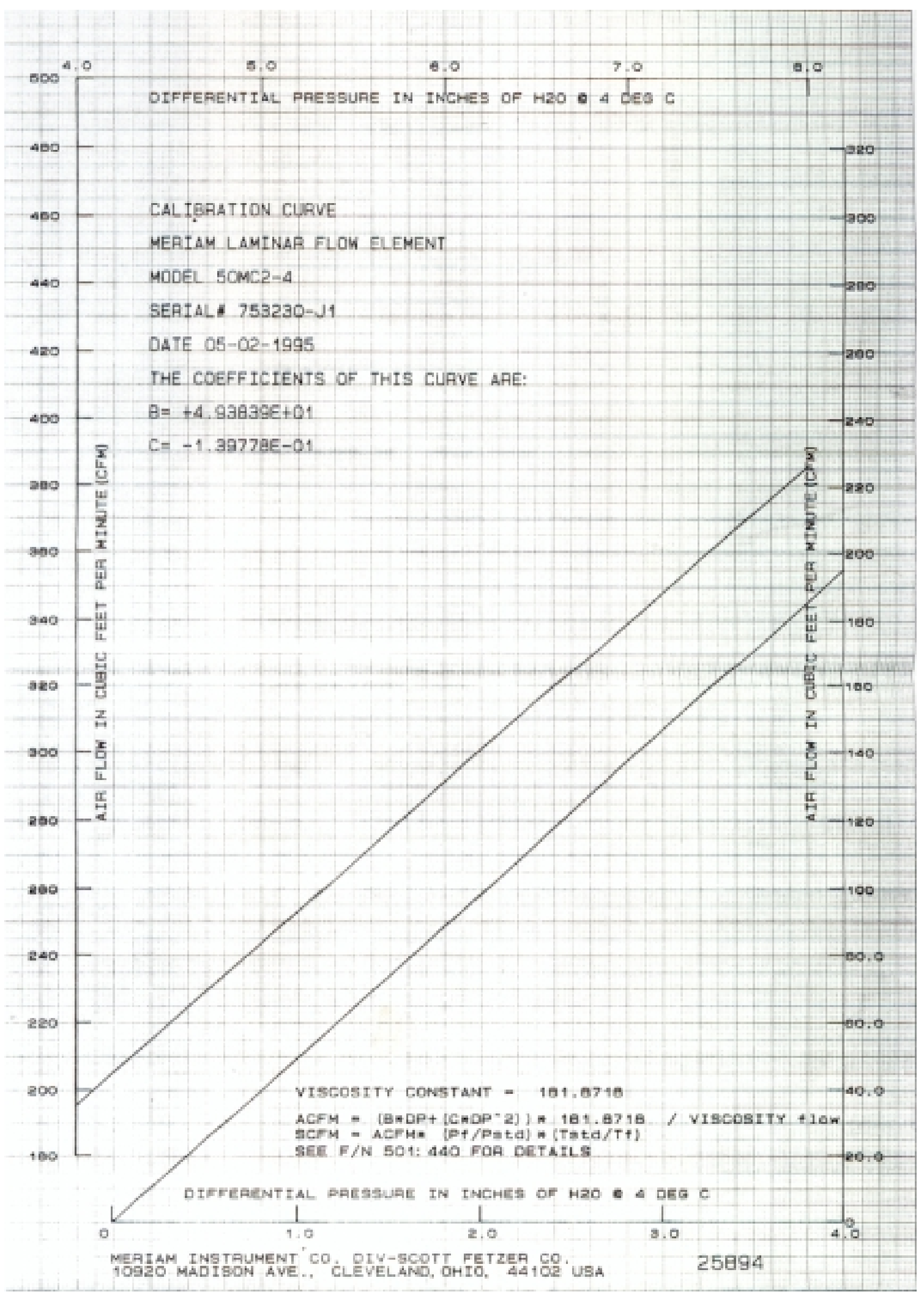

Figure B.2: 400 acfm Laminar Flow Element Calibration Curve (provided by Meriam, Inc.) 
Appendix C: Exhaust Orifice Meter Calibration Program 
' $5-27-98$

' Written by Bret Rankin

- This program is used to calibrate orifice meters using the $400 \mathrm{LFE}$

' It is specifically used for the orifice meters in the exhaust line

' of the MWM

DIM orftemp, delta2, delta, sumqa, sumdp, sumtemp, sumdens AS DOUBLE

DIM orftemp2, sumqa2, sumdp2, sumtemp2, sumdens2, density2 AS DOUBLE

DIM orfabs2, orfdp2, avtemp2, avdens2, avflow2, avdp2 AS DOUBLE

DIM endtime, reftime, time, timey, dt, time2, oltime, orfabs AS DOUBLE

DIM orfdp, qa, avtemp, avdens, avflow, avdp, eltime AS DOUBLE

DIM pf, dp, Tf AS DOUBLE

OPEN "d: \robs \data \number. dat " FOR OUTPUT AS \#4

filenum\# = FREEFILE

OPEN "d: \robs\data\orfdat.dat" FOR OUTPUT AS filenum\#

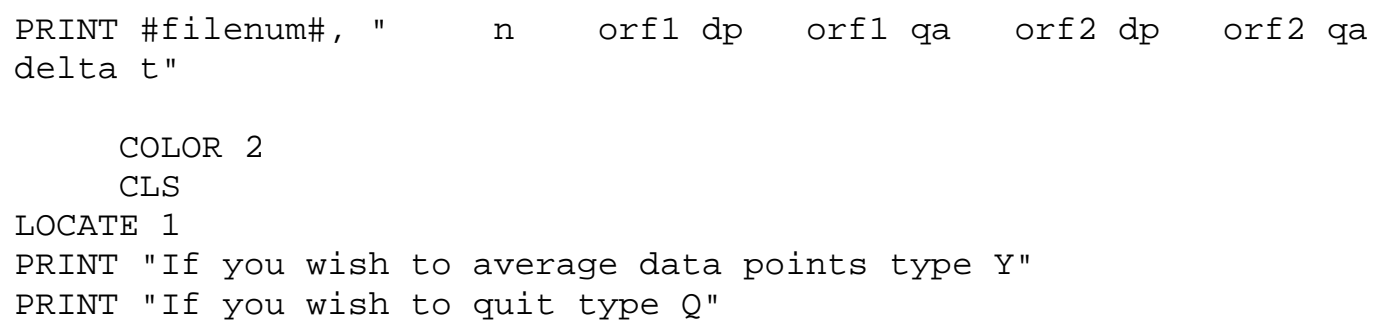

PRINT

$$
q q=500
$$

1

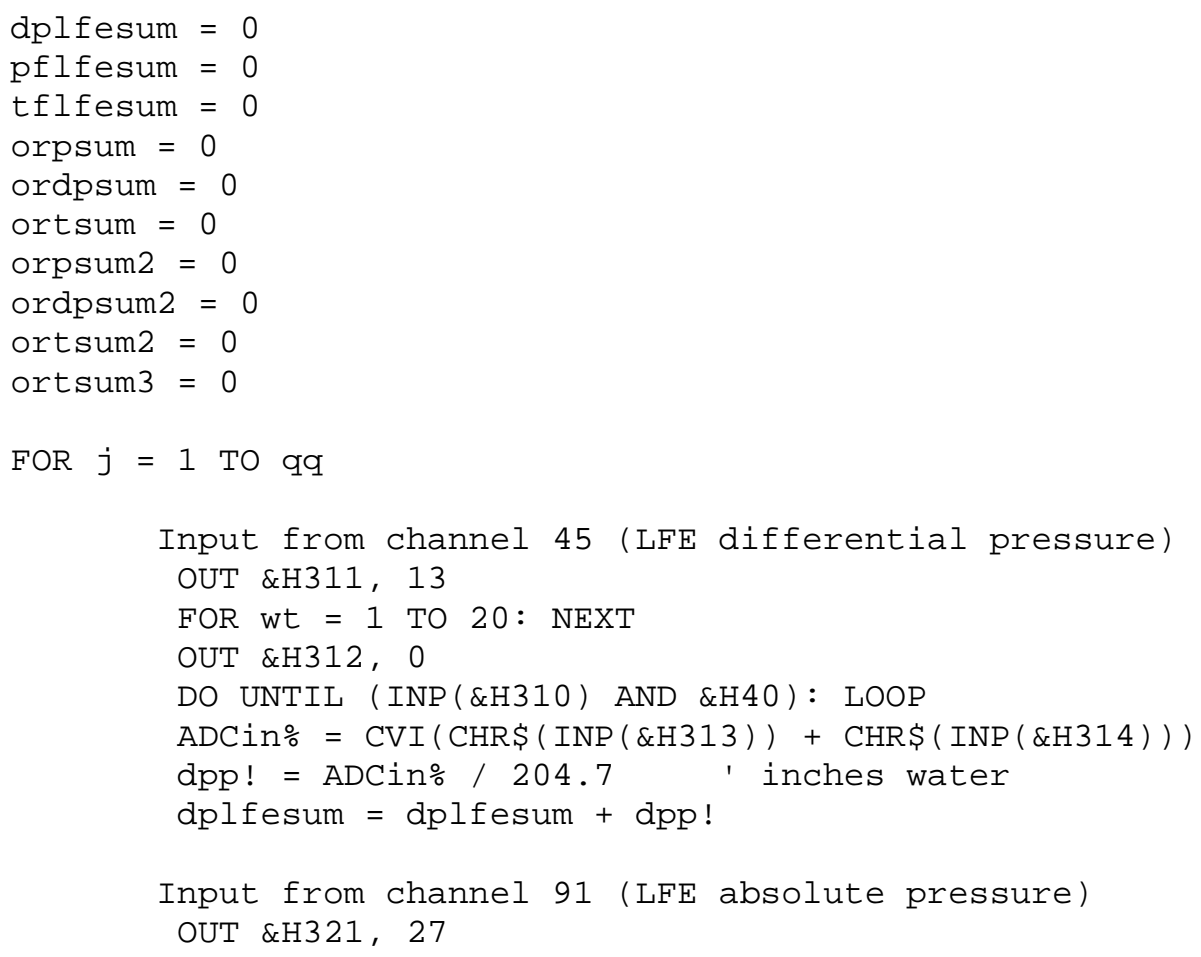




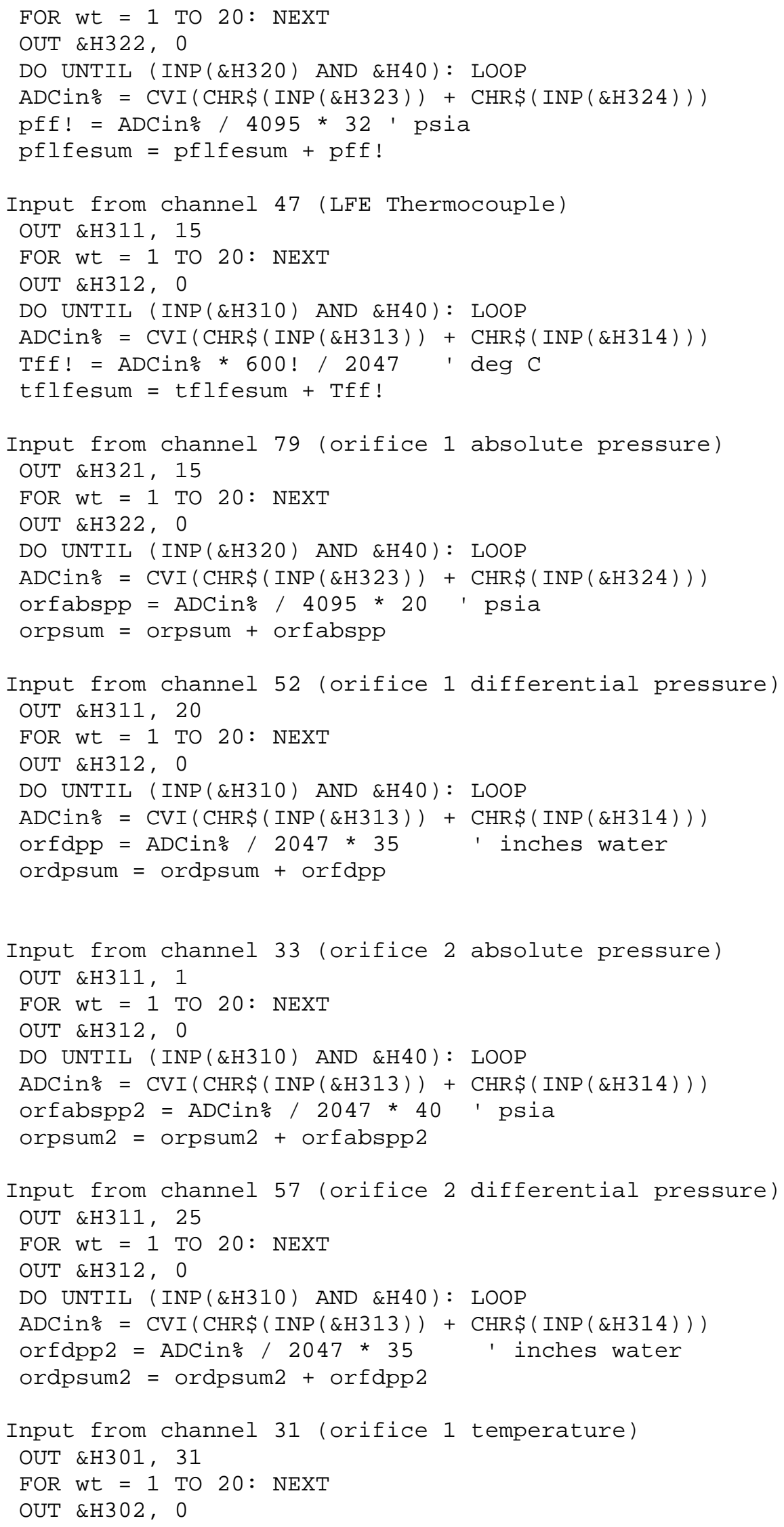




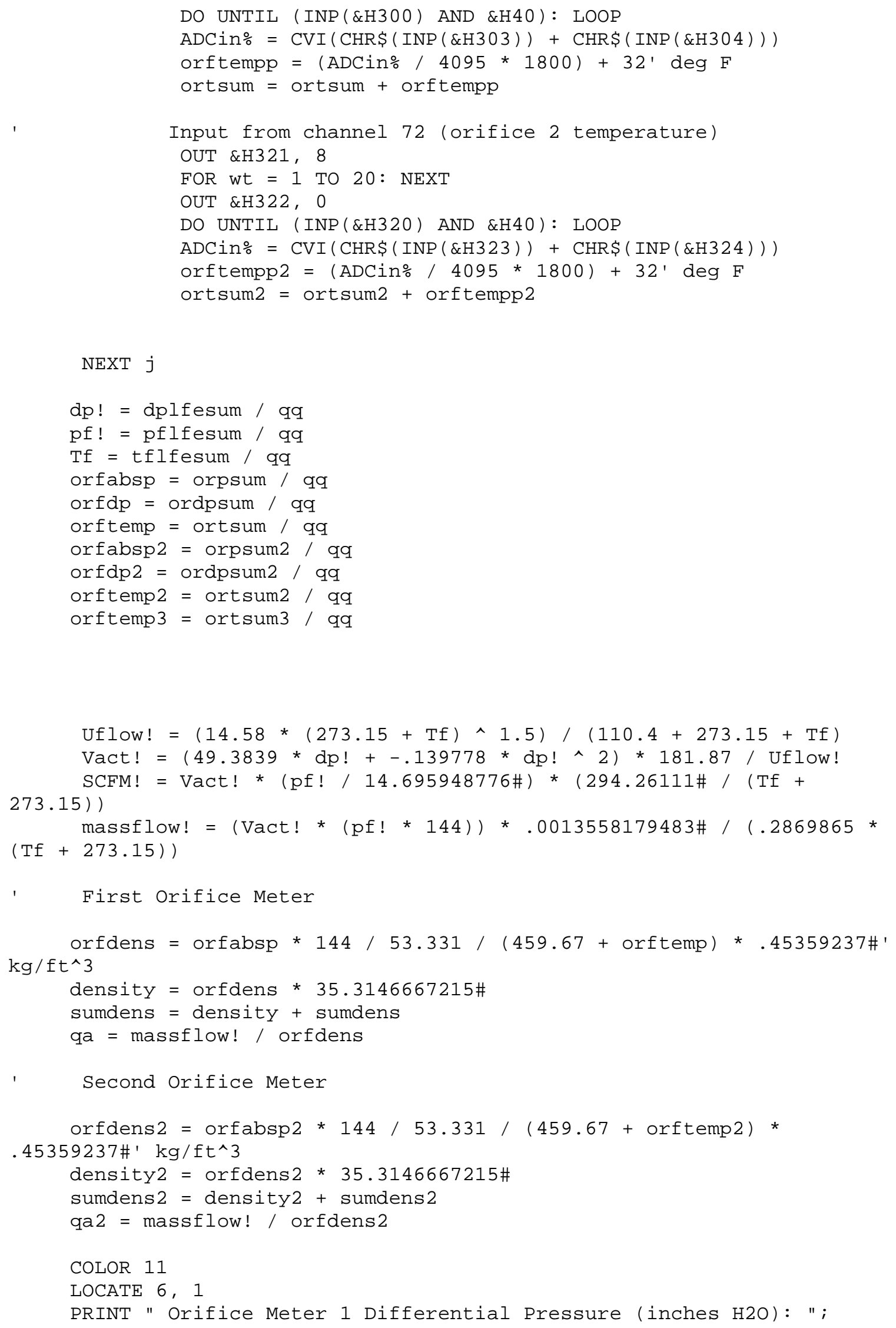




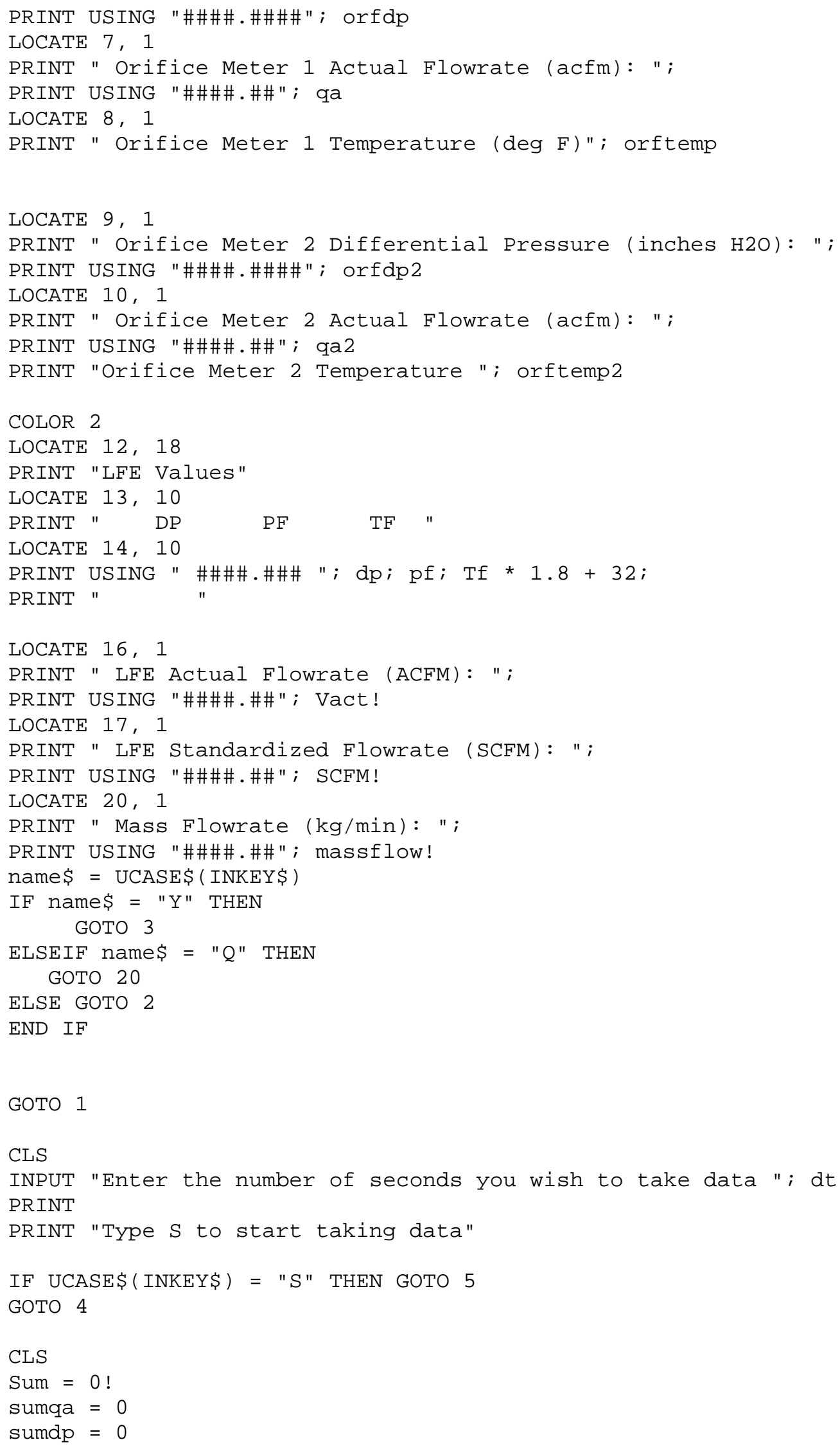




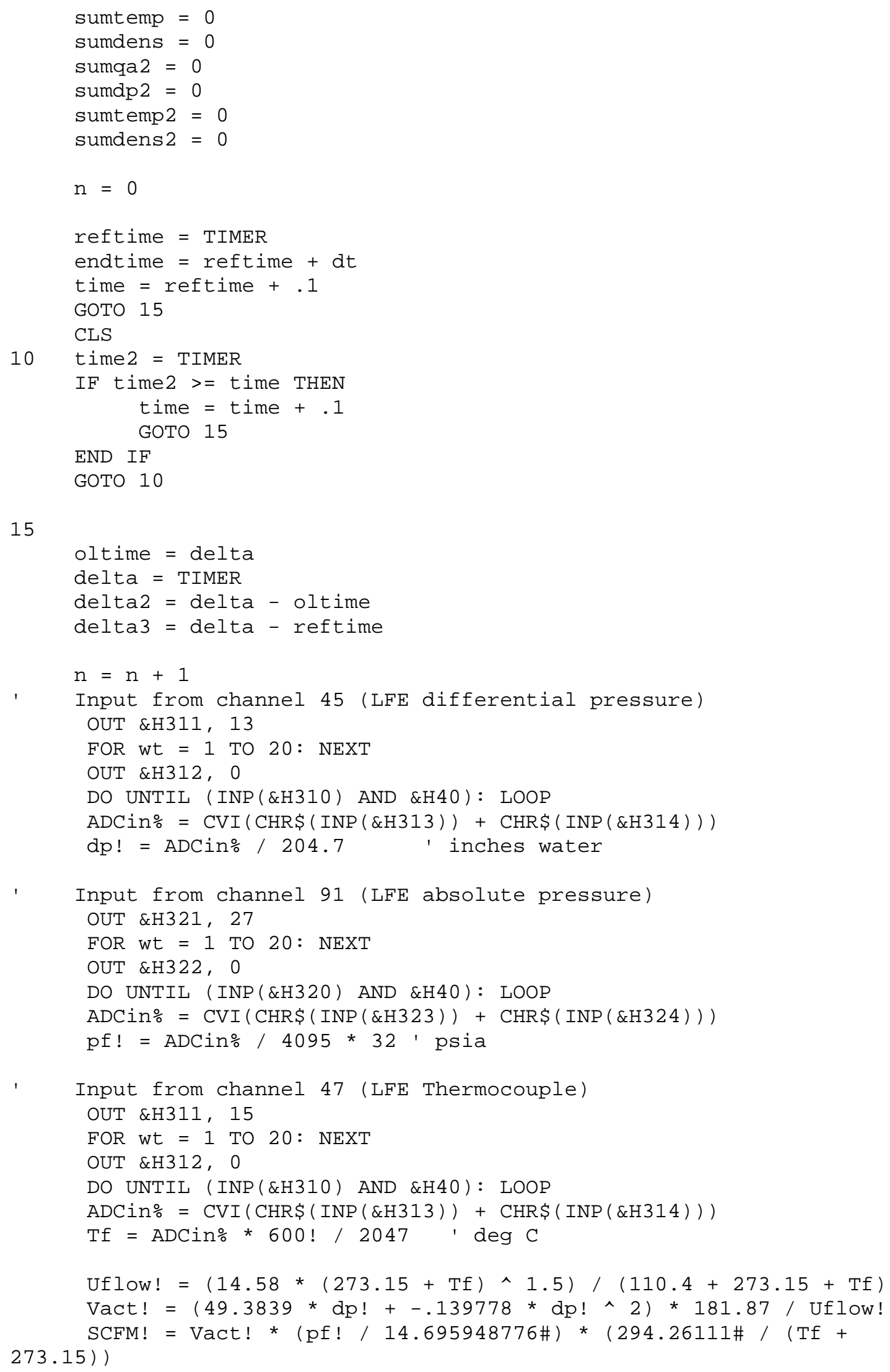




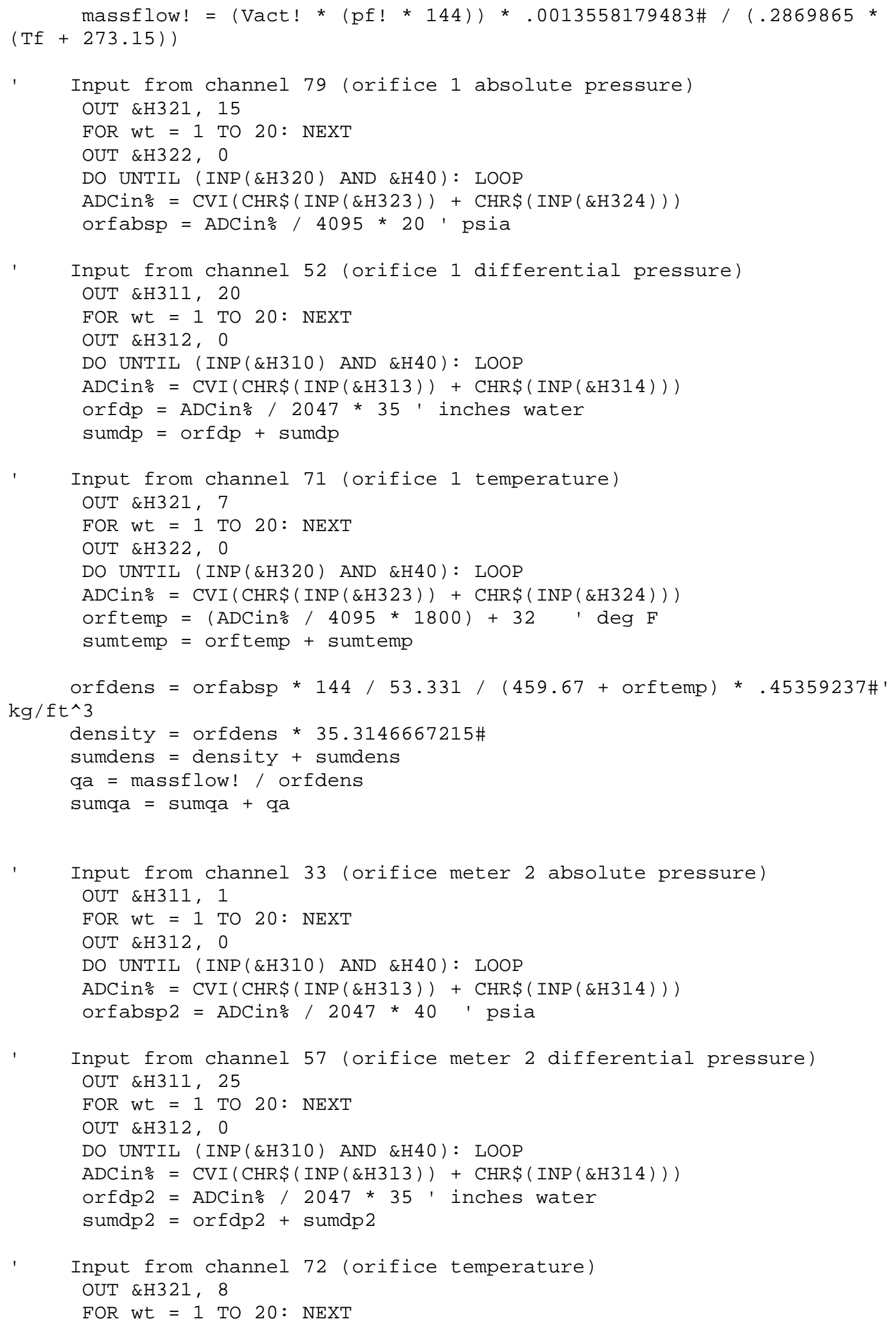




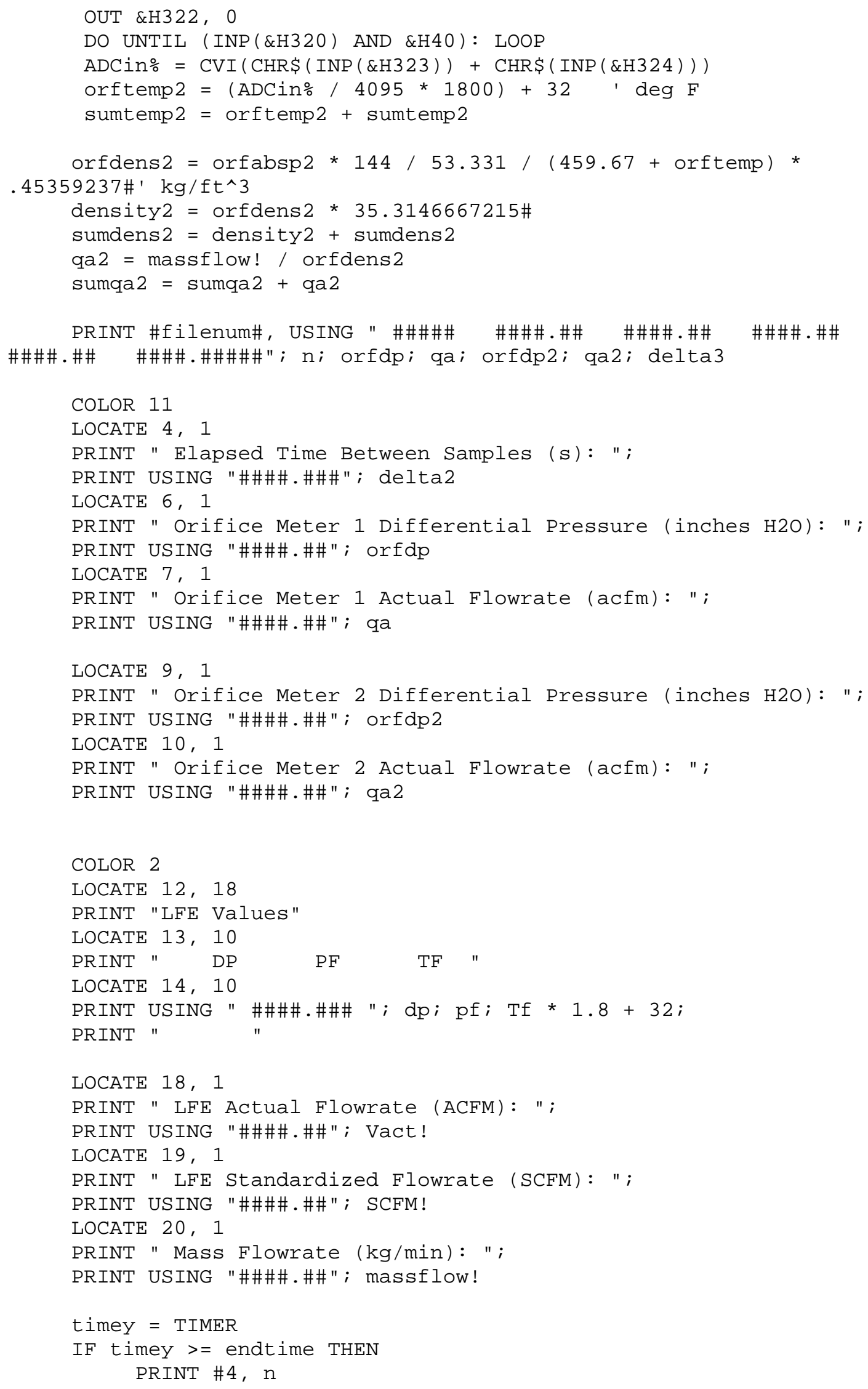




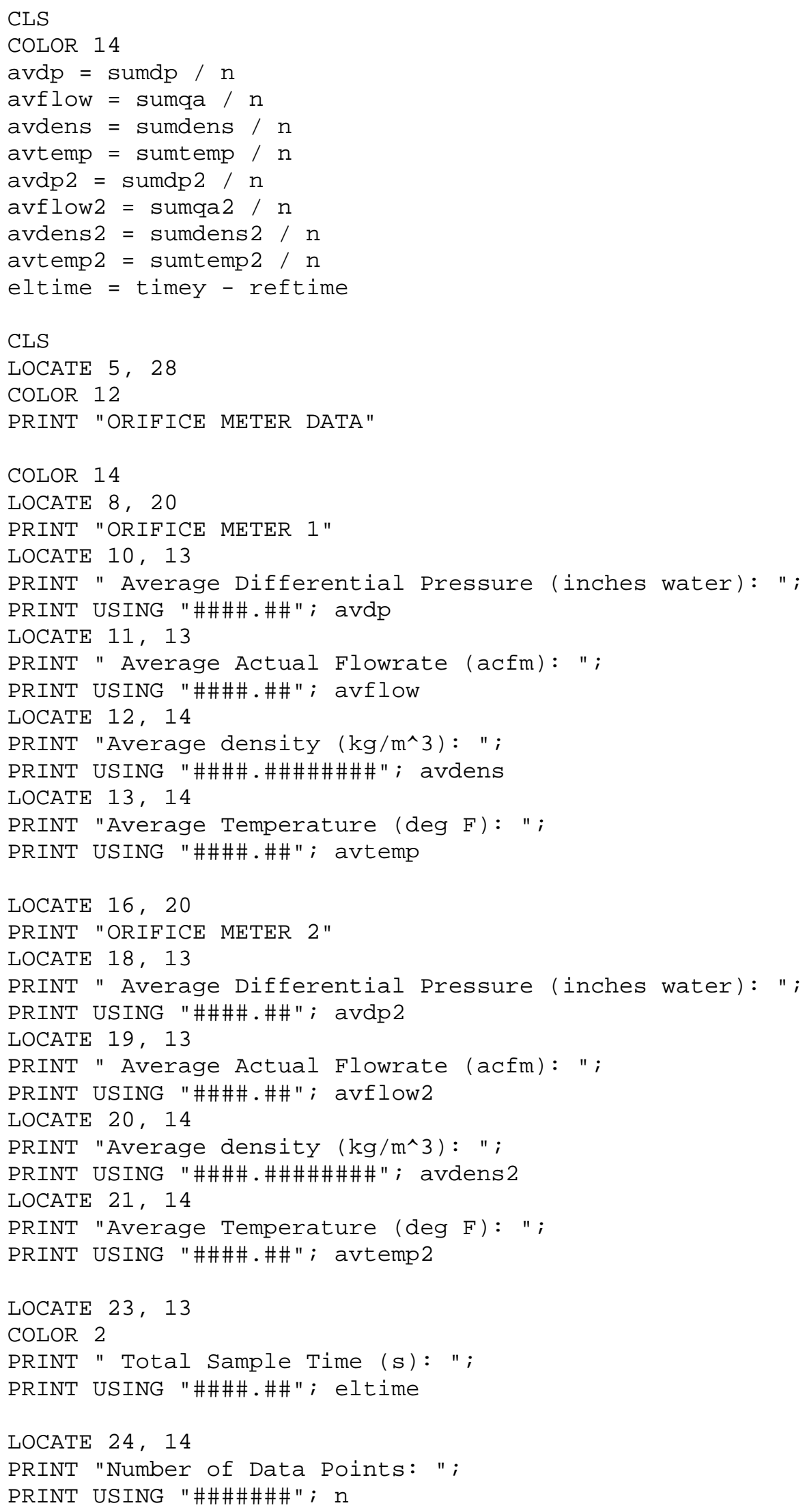


COLOR 0

ELSE GOTO 10

END IF

GOTO 30

20 CLS

LOCATE 15,20

PRINT \#4, n

PRINT "The end"

CLOSE filenum\#

CLOSE \# 4

30 END 


\section{Appendix D: Exhaust Orifice Meter Calibration Data}




\section{Table D.1: Exhaust Orifice Meter Calibration Data}

Orifice Meter 1

Calibration on 6-22-98

\begin{tabular}{||c|c|c||}
\hline $\begin{array}{c}\text { Point } \\
\text { Number }\end{array}$ & $\begin{array}{c}\text { Differential } \\
\text { Pressure } \\
\text { ("H2O) }\end{array}$ & $\begin{array}{c}\text { Actual Flow } \\
\text { Rate (acfm) }\end{array}$ \\
\hline \hline 1 & 0.83 & 63.9 \\
\hline 2 & 1.3 & 81.0 \\
\hline 3 & 2.05 & 100.6 \\
\hline 4 & 2.91 & 119.7 \\
\hline 5 & 3.9 & 139.2 \\
\hline 6 & 5.62 & 166.2 \\
\hline 7 & 7.03 & 186.2 \\
\hline 8 & 8.5 & 203.5 \\
\hline 9 & 10.37 & 226.0 \\
\hline 10 & 12.13 & 245.0 \\
\hline 11 & 15.34 & 275.2 \\
\hline 12 & 17.94 & 297.8 \\
\hline 13 & 19.48 & 312.2 \\
\hline 14 & 23.7 & 342.0 \\
\hline 15 & 29.09 & 377.7 \\
\hline
\end{tabular}

Calibration on 6-23-98

\begin{tabular}{||c|c|c|c||}
\hline $\begin{array}{c}\text { Point } \\
\text { Number }\end{array}$ & $\begin{array}{c}\text { Differential } \\
\text { Pressure } \\
\text { ("H2O) }\end{array}$ & $\begin{array}{c}\text { Actual } \\
\text { Flow Rate } \\
(\mathrm{acfm})\end{array}$ & $\begin{array}{c}\text { Curve Fit }(\mathrm{k}= \\
0.8217)\end{array}$ \\
\hline \hline 1 & 0.1 & 23.2 & 22.14 \\
\hline 2 & 0.31 & 40.4 & 38.98 \\
\hline 3 & 0.72 & 61.0 & 59.40 \\
\hline 4 & 1.34 & 82.8 & 81.04 \\
\hline 5 & 2.14 & 102.2 & 102.41 \\
\hline 6 & 3.16 & 124.3 & 124.45 \\
\hline 7 & 4.41 & 146.7 & 147.02 \\
\hline 8 & 5.82 & 169.2 & 168.89 \\
\hline 9 & 6.96 & 185.0 & 184.70 \\
\hline 10 & 7.96 & 197.7 & 197.52 \\
\hline 11 & 10.21 & 225.1 & 223.70 \\
\hline 12 & 13.02 & 251.0 & 252.61 \\
\hline 13 & 14.88 & 270.6 & 270.06 \\
\hline 14 & 17.93 & 297.6 & 296.44 \\
\hline 15 & 19.62 & 310.9 & 310.10 \\
\hline 16 & 23.38 & 337.7 & 338.51 \\
\hline 17 & 26.71 & 361.9 & 361.82 \\
\hline 18 & 31.07 & 388.4 & 390.23 \\
\hline
\end{tabular}

Orifice Meter 2

Calibration on 6-22-98

\begin{tabular}{||c|c|c||}
\hline $\begin{array}{c}\text { Point } \\
\text { Number }\end{array}$ & $\begin{array}{c}\text { Differential } \\
\text { Pressure } \\
\text { ("H2O) }\end{array}$ & $\begin{array}{c}\text { Actual Flow } \\
\text { Rate }(\mathrm{acfm})\end{array}$ \\
\hline \hline 1 & 0.73 & 64.1 \\
\hline 2 & 1.29 & 81.3 \\
\hline 3 & 1.94 & 101.1 \\
\hline 4 & 2.77 & 120.5 \\
\hline 5 & 3.71 & 140.4 \\
\hline 6 & 5.35 & 168.0 \\
\hline 7 & 6.69 & 188.5 \\
\hline 8 & 8.02 & 206.5 \\
\hline 9 & 9.8 & 229.7 \\
\hline 10 & 11.48 & 249.7 \\
\hline 11 & 14.47 & 281.8 \\
\hline 12 & 16.99 & 306.0 \\
\hline 13 & 18.77 & 321.5 \\
\hline 14 & 22.7 & 354.1 \\
\hline 15 & 28.15 & 394.5 \\
\hline \hline
\end{tabular}

Calibration on 6-23-98

\begin{tabular}{||c|c|c|c||}
\hline $\begin{array}{c}\text { Point } \\
\text { Number }\end{array}$ & $\begin{array}{c}\text { Differential } \\
\text { Pressure } \\
\text { ("H2O) }\end{array}$ & $\begin{array}{c}\text { Actual } \\
\text { Flow Rate } \\
\text { (acfm) }\end{array}$ & $\begin{array}{c}\text { Curve Fit (k } \\
0.8659)\end{array}$ \\
\hline \hline 1 & 0.09 & 23.2 & 22.13 \\
\hline 2 & 0.28 & 40.5 & 39.04 \\
\hline 3 & 0.7 & 61.1 & 61.72 \\
\hline 4 & 1.29 & 83.1 & 83.79 \\
\hline 5 & 2.01 & 102.6 & 104.59 \\
\hline 6 & 2.94 & 124.9 & 126.50 \\
\hline 7 & 4.14 & 147.8 & 150.11 \\
\hline 8 & 5.48 & 170.8 & 172.70 \\
\hline 9 & 6.6 & 187.0 & 189.53 \\
\hline 10 & 7.4 & 200.0 & 200.69 \\
\hline 11 & 9.61 & 228.4 & 228.70 \\
\hline 12 & 12.08 & 255.9 & 256.41 \\
\hline 13 & 14.13 & 276.6 & 277.32 \\
\hline 14 & 17.07 & 305.4 & 304.81 \\
\hline 15 & 18.64 & 320.0 & 318.52 \\
\hline 16 & 22.18 & 349.2 & 347.45 \\
\hline 17 & 25.84 & 376.1 & 375.02 \\
\hline 18 & 30.08 & 405.8 & 404.62 \\
\hline \hline
\end{tabular}




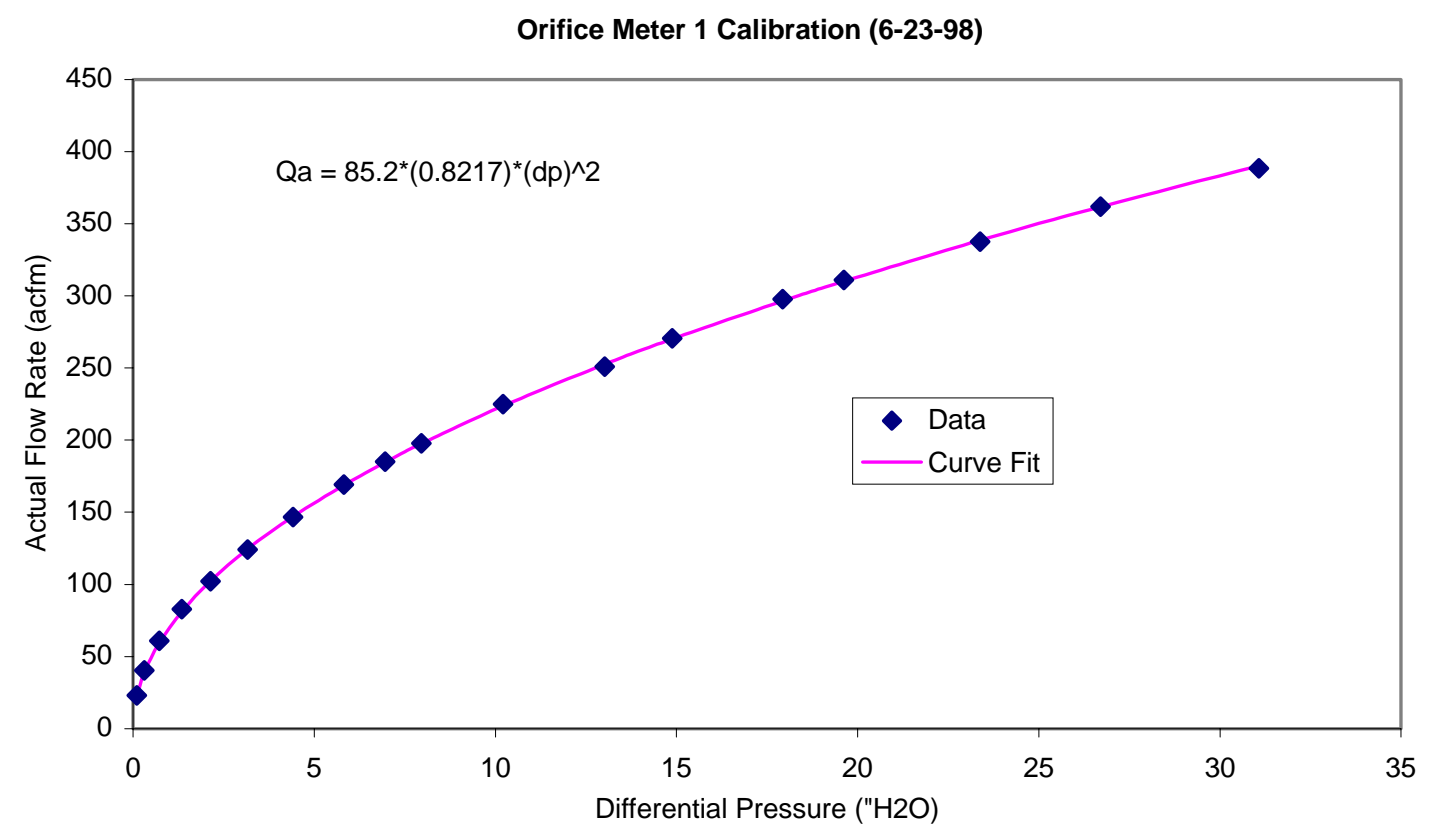

Figure D.1: Orifice Meter 1 Calibration Data

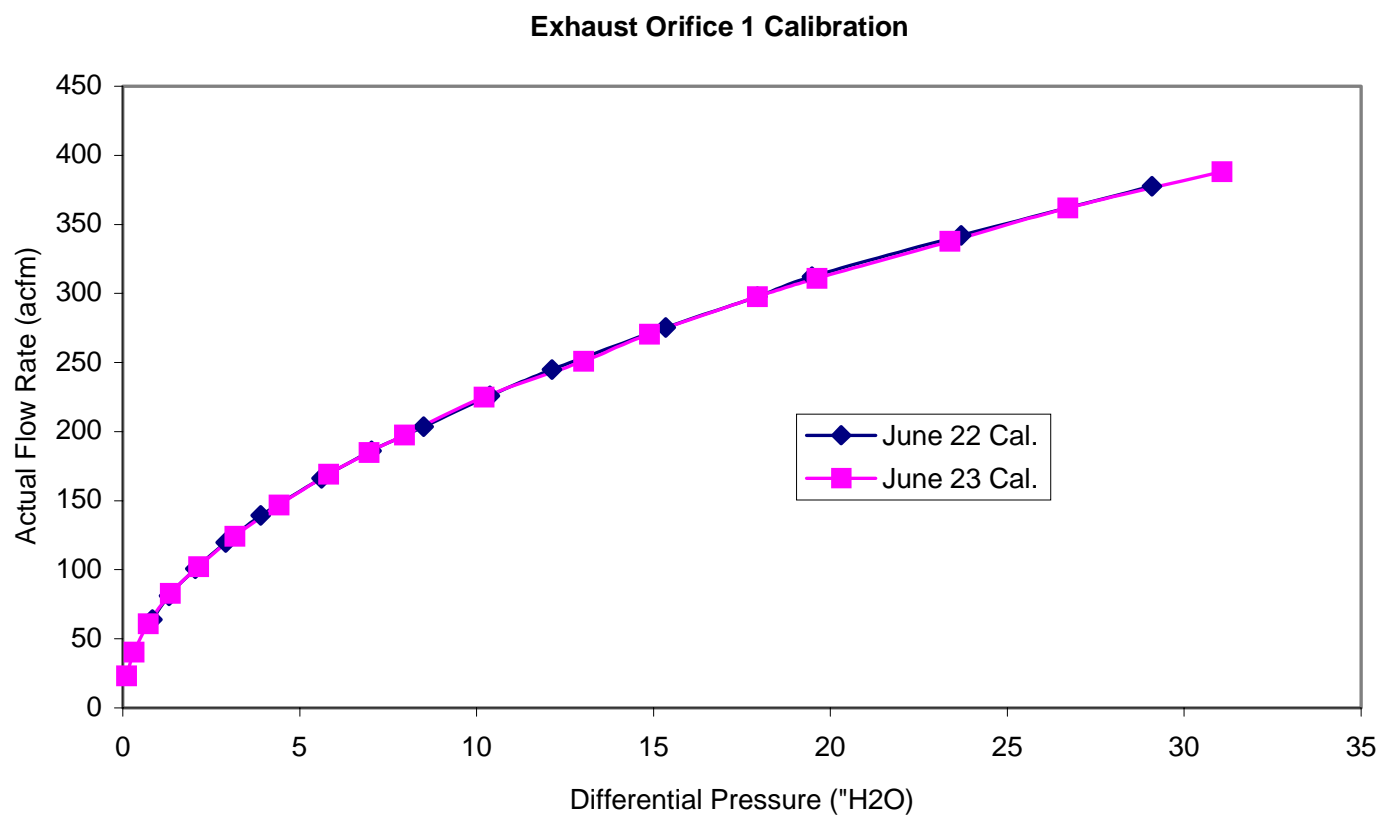

Figure D.2: Orifice Meter 1 Calibration Repeatability Data 


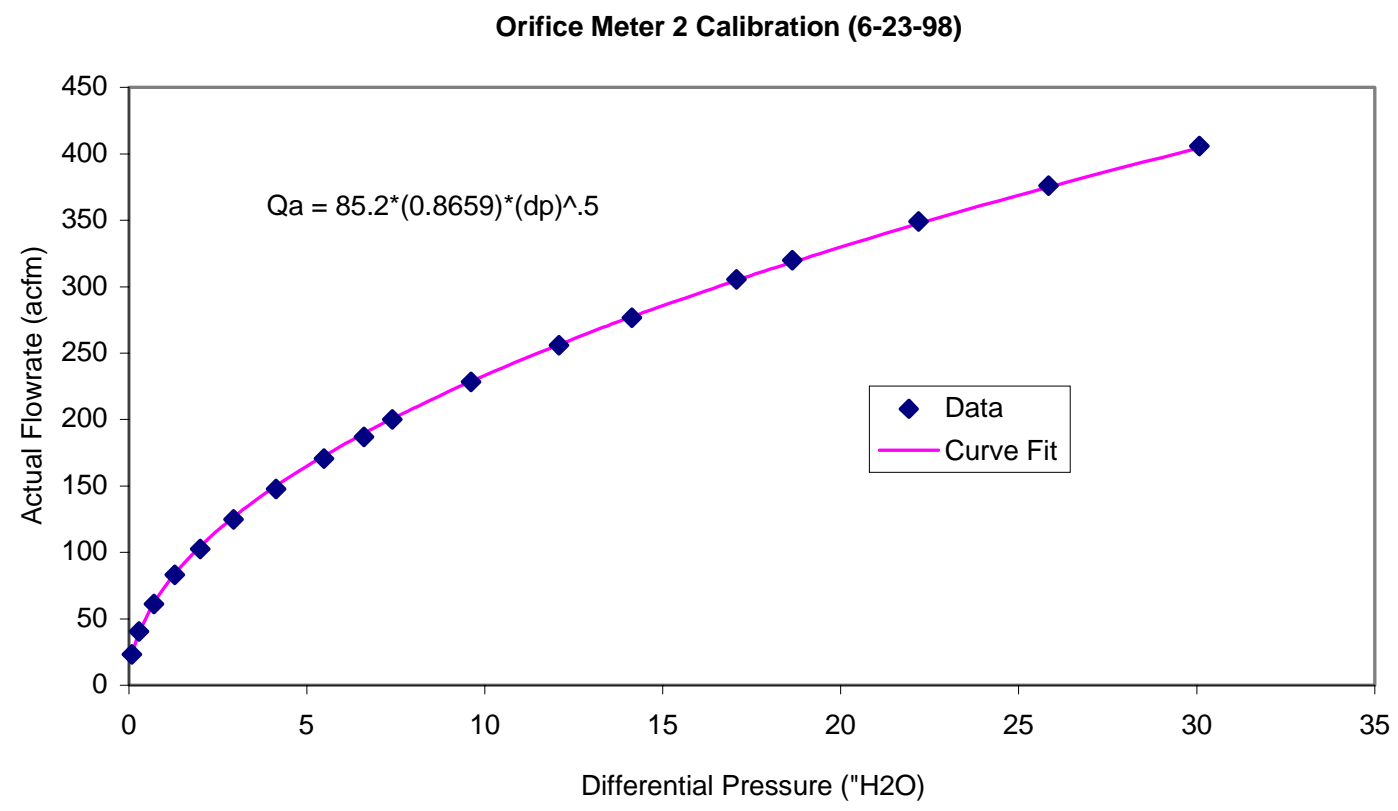

Figure D.3: Orifice Meter 2 Calibration Data

Exhaust Orifice Meter 2 Calibration

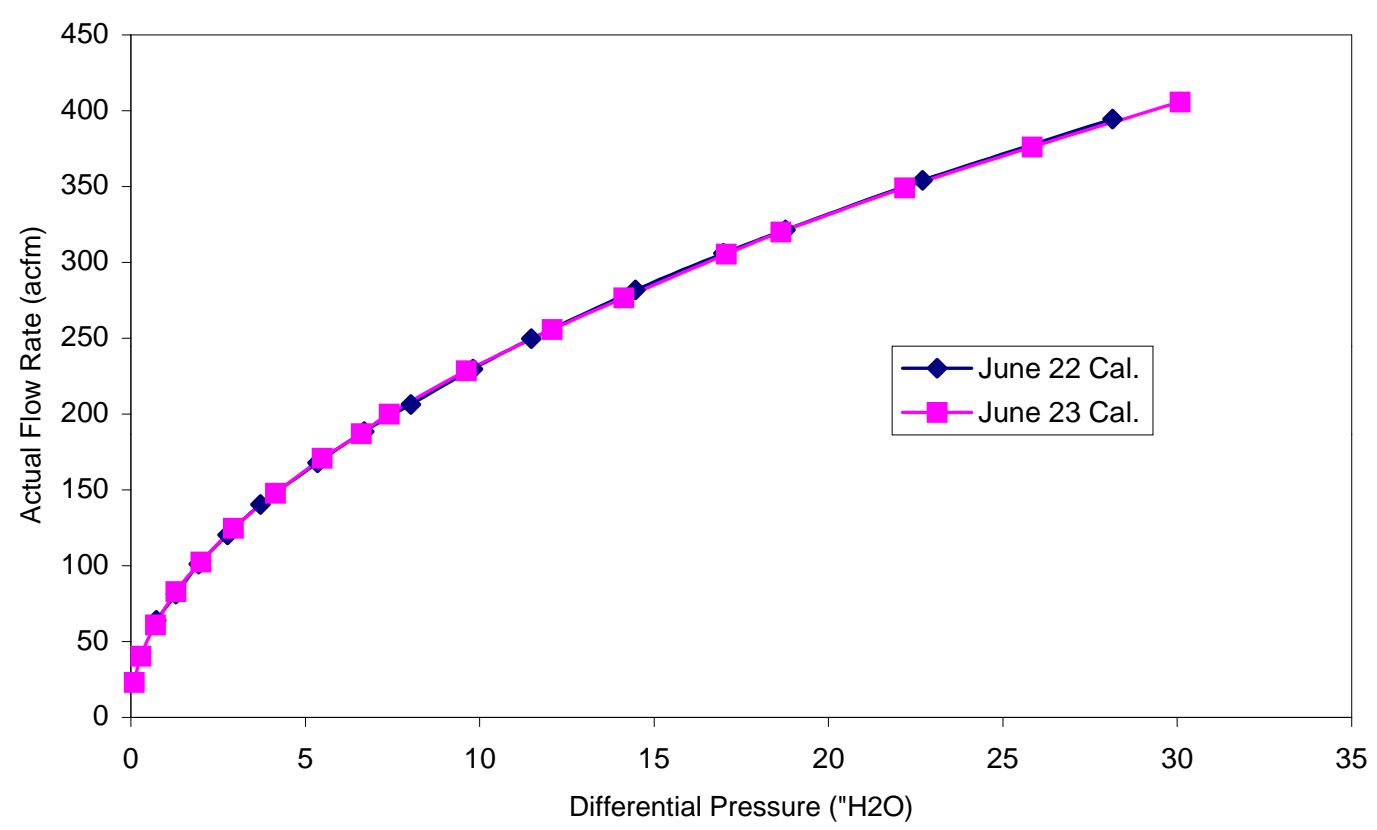

Figure D.4: Orifice Meter 2 Calibration Repeatability Data 


\section{Appendix E: High-flow Calibration Air Filter}




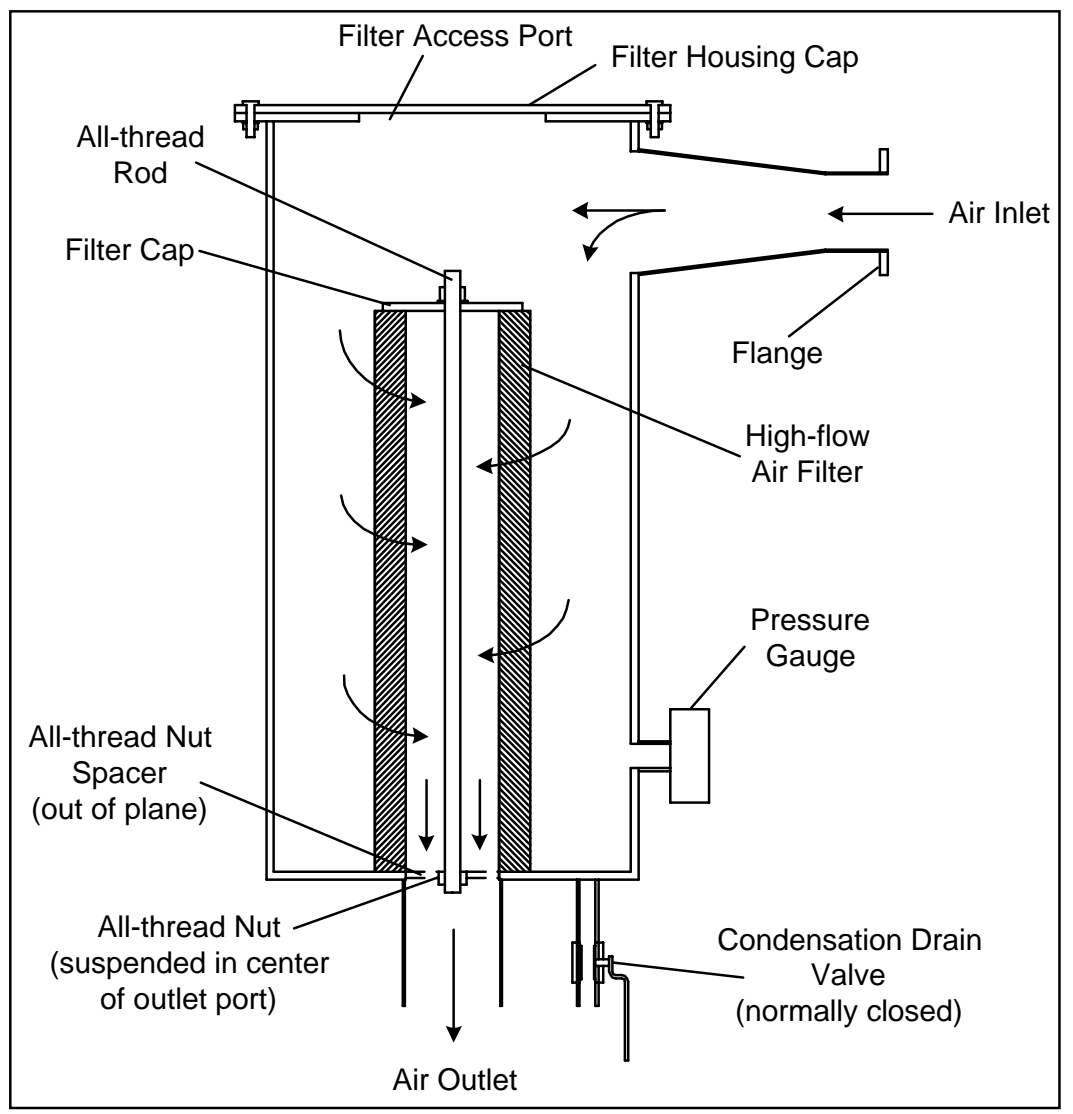

Figure E.1: High-flow Filter Cross-section

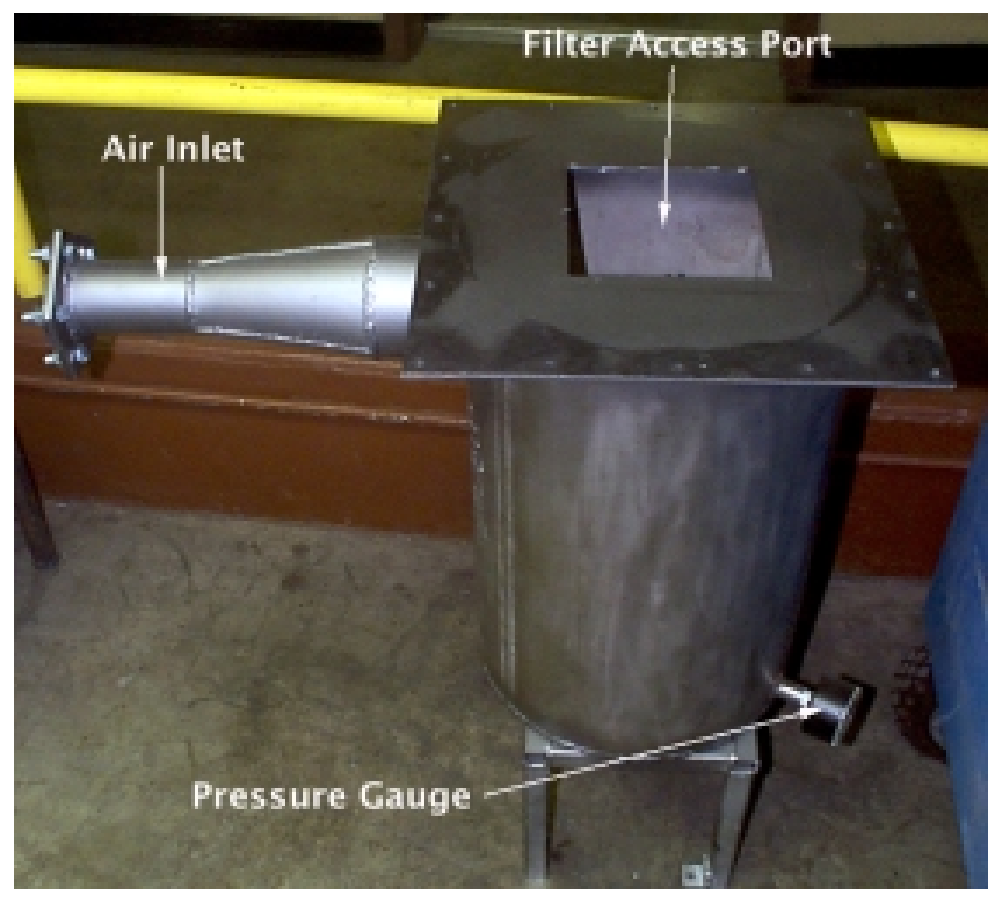

Figure E.2: High-flow Filter Housing 
Appendix F: Exhaust Bypass Flow Control Program 
' $7-23-98$

' Written by Bret Rankin

' This program is used to split the exhaust flow from the MWM

' using a butterfly valve and a stepper motor

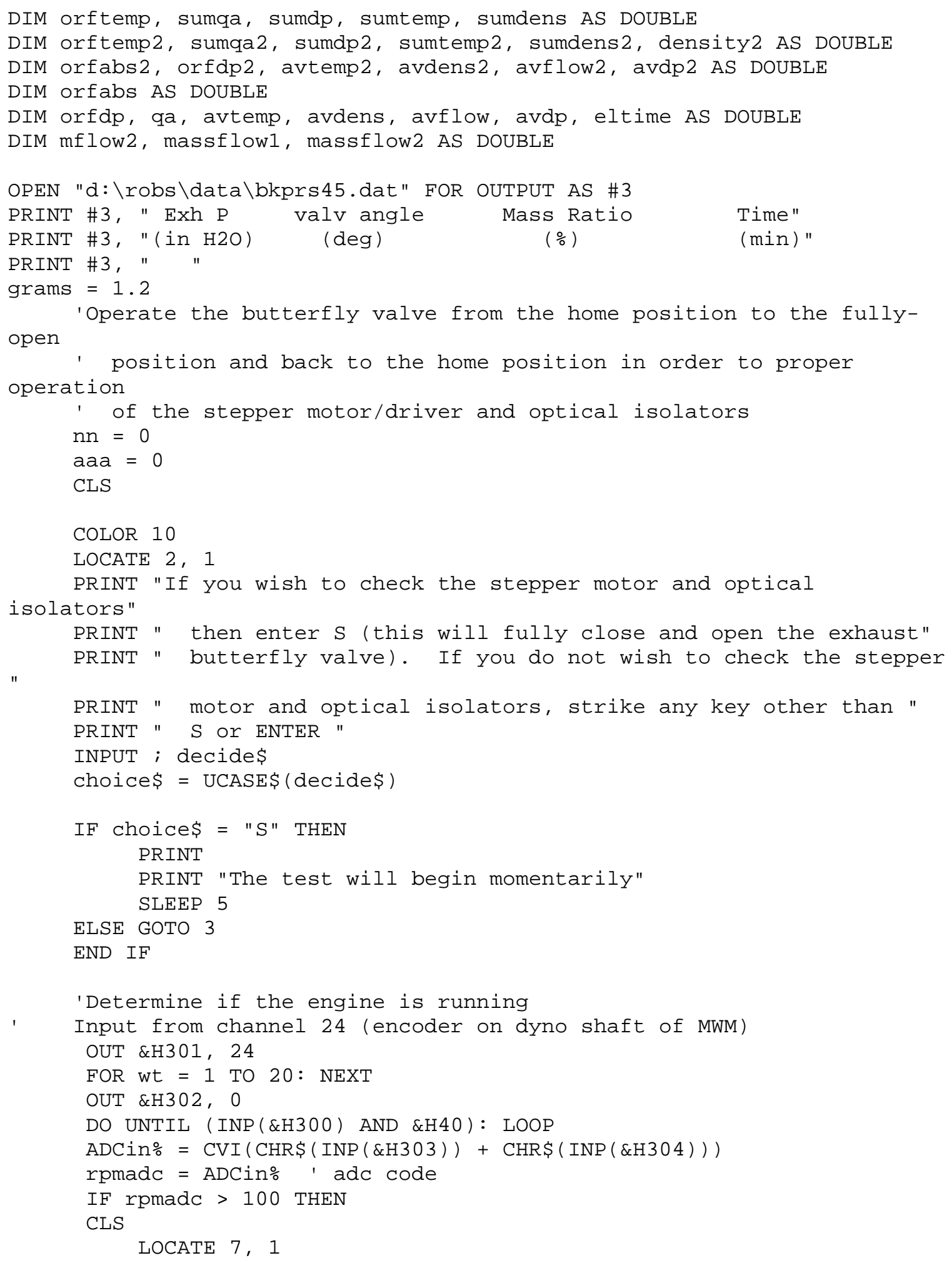




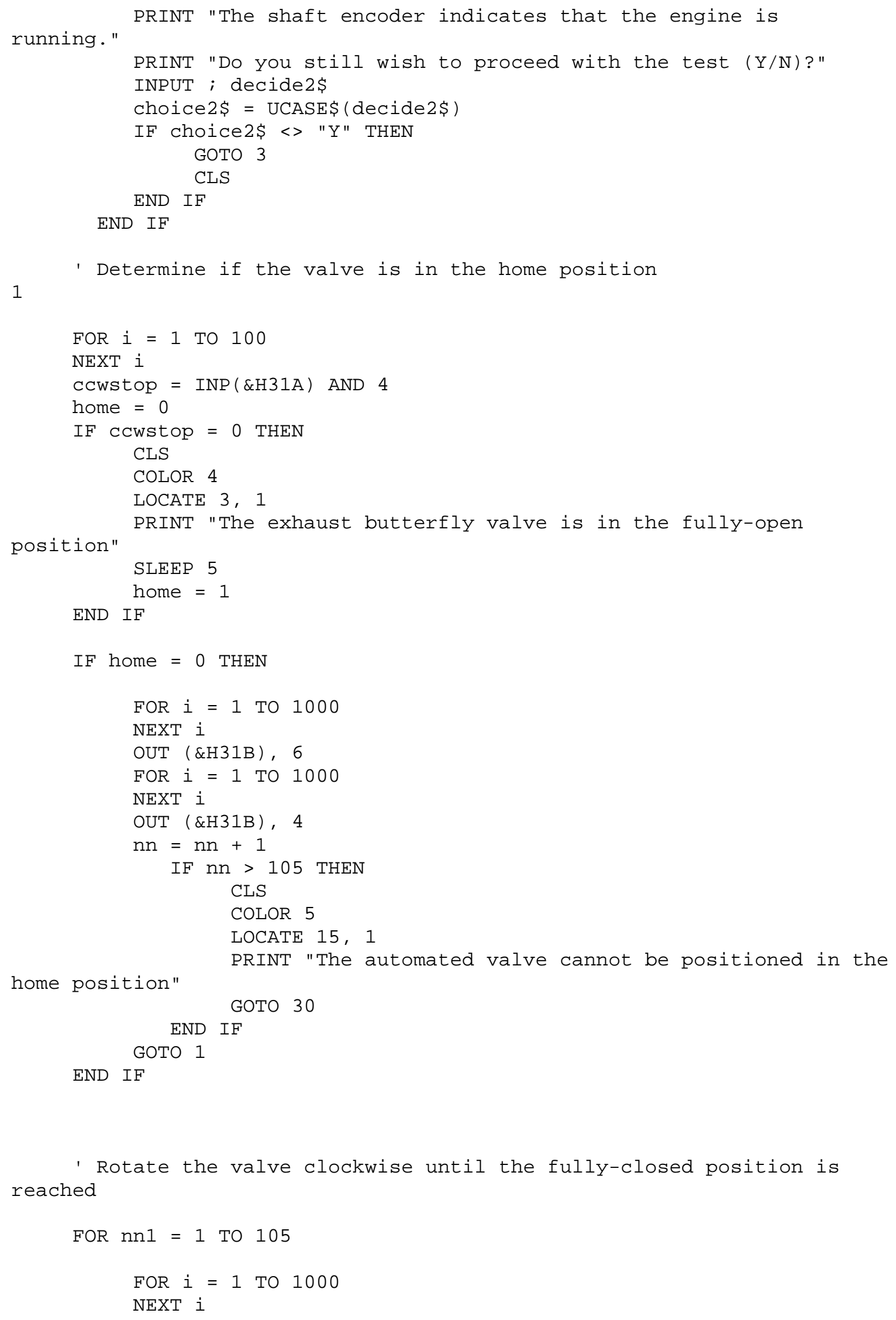




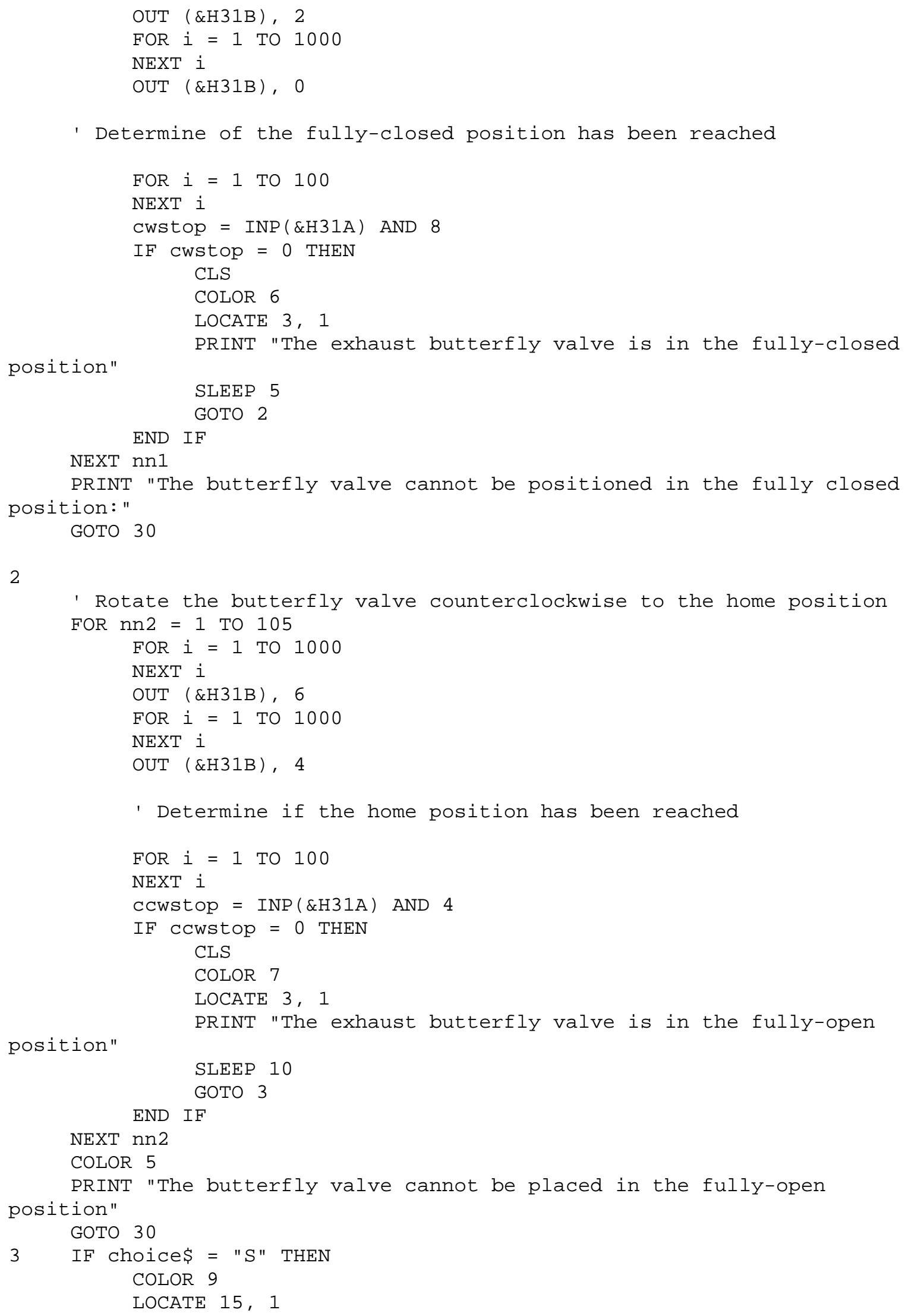




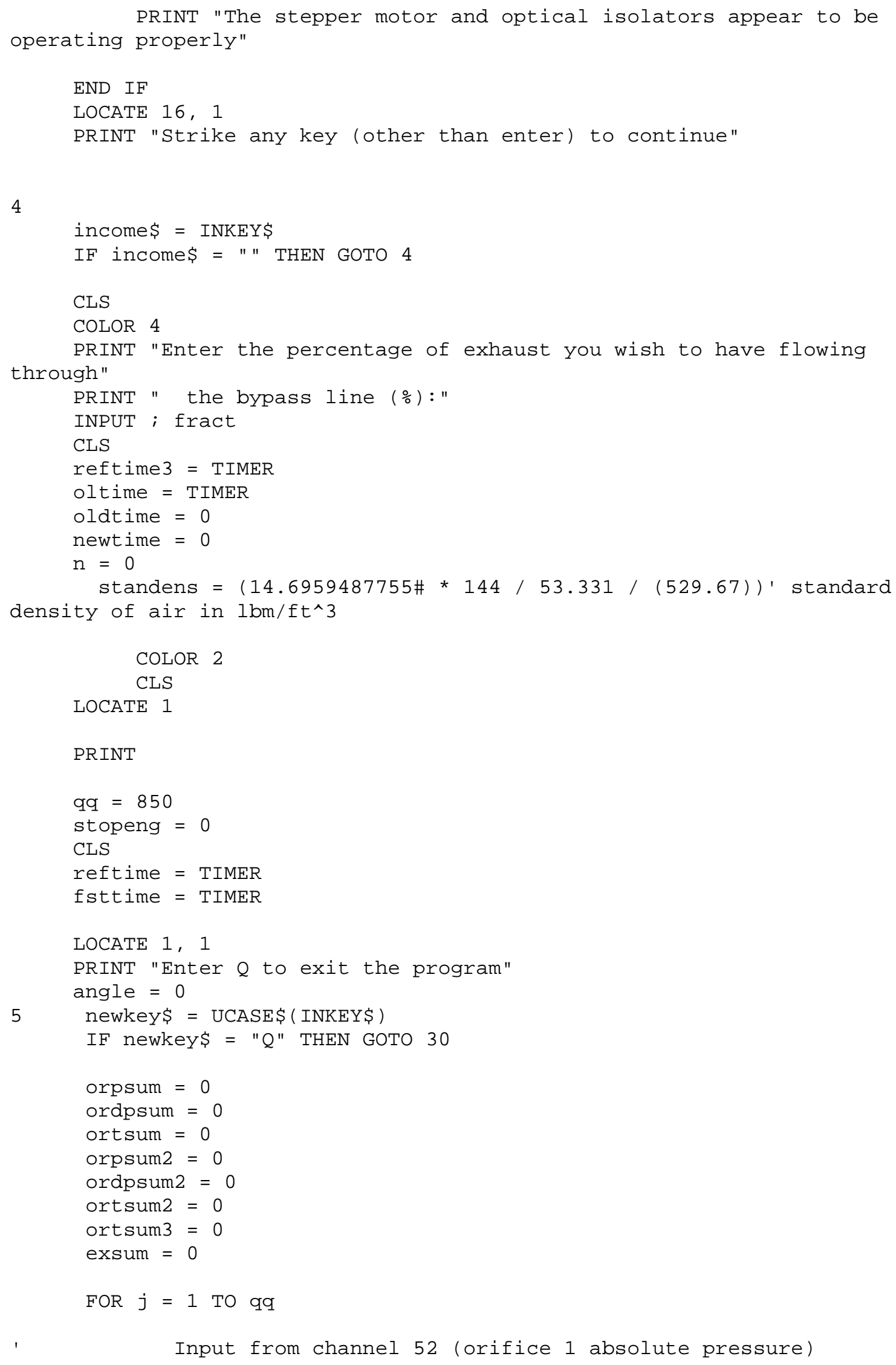




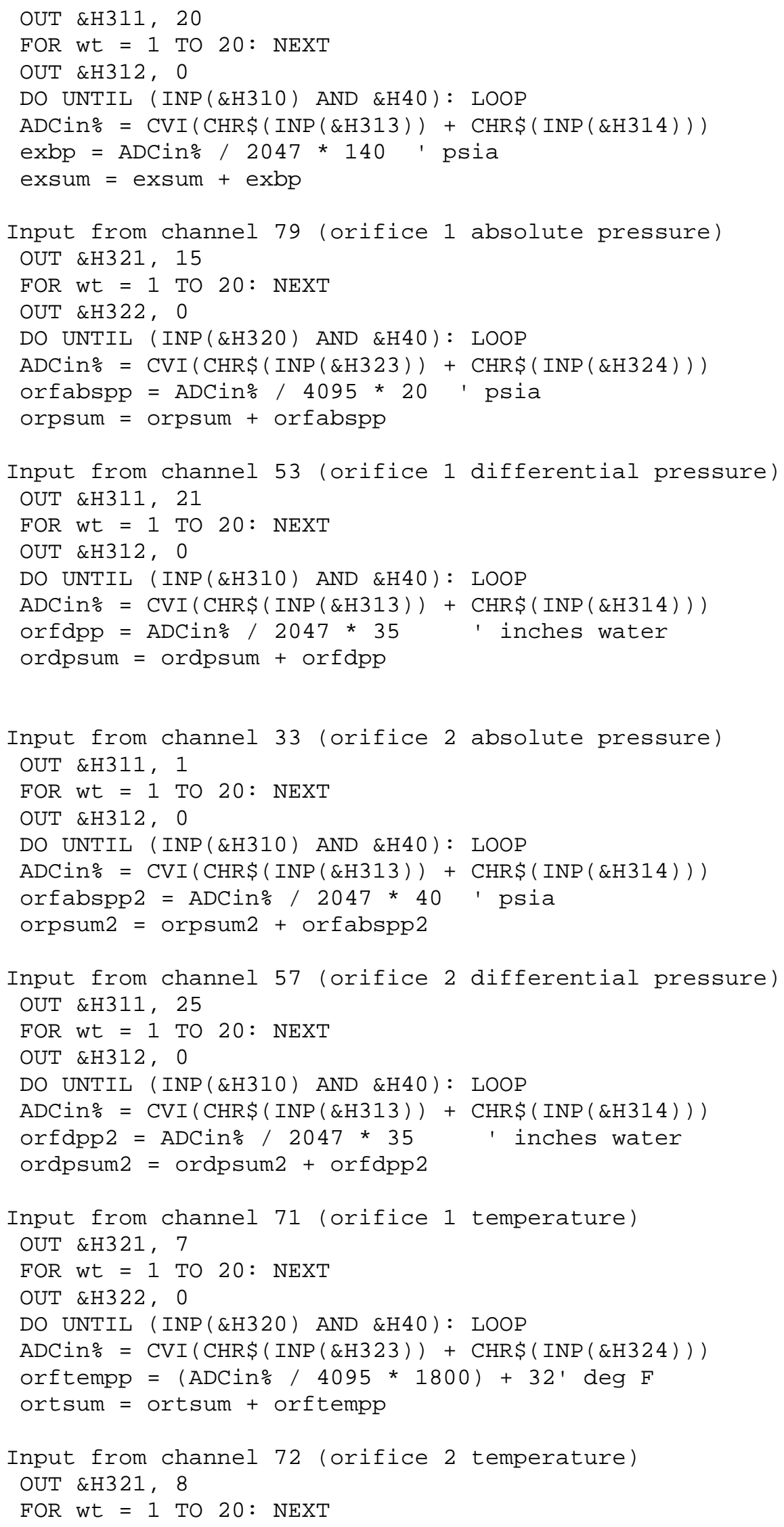




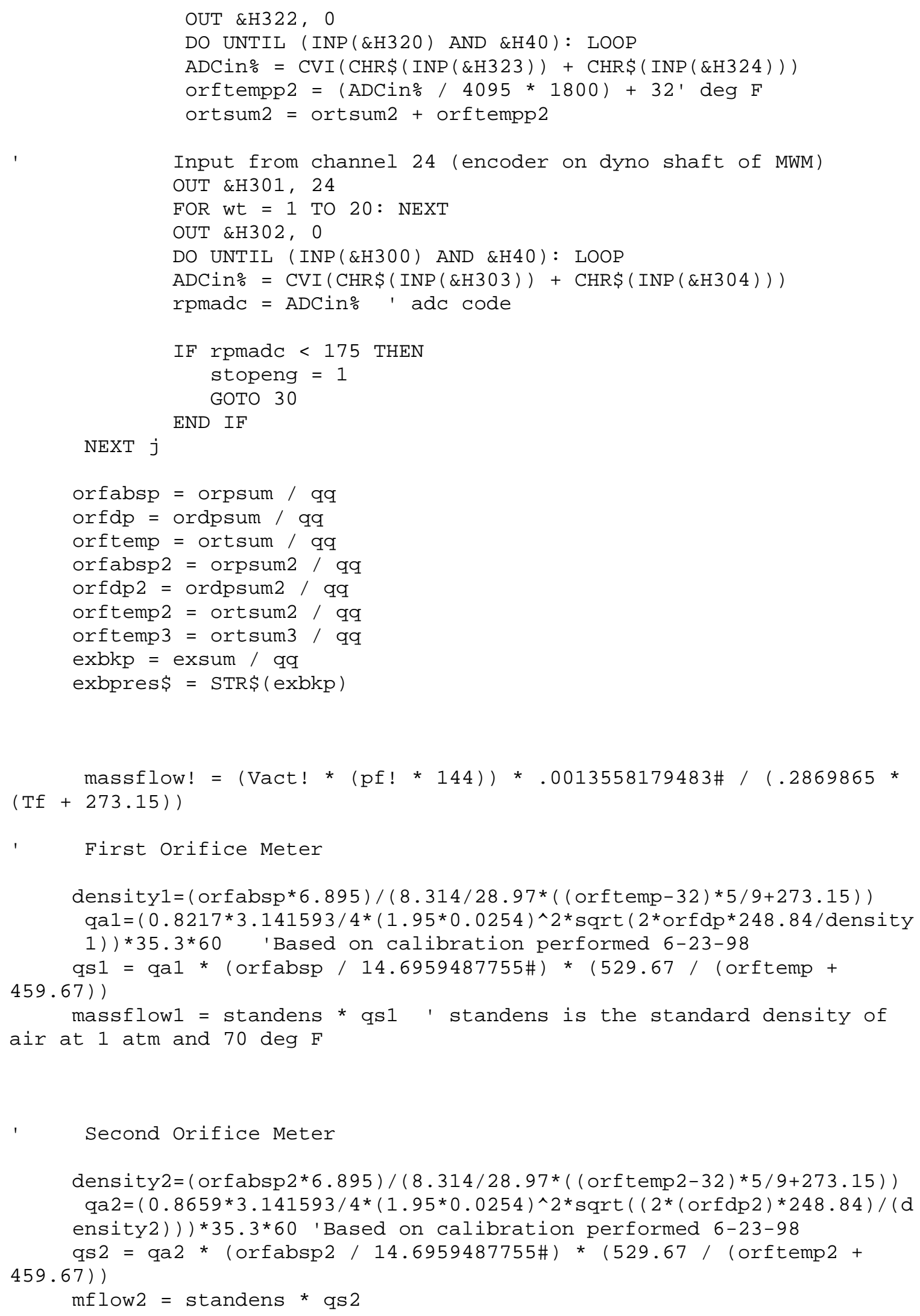




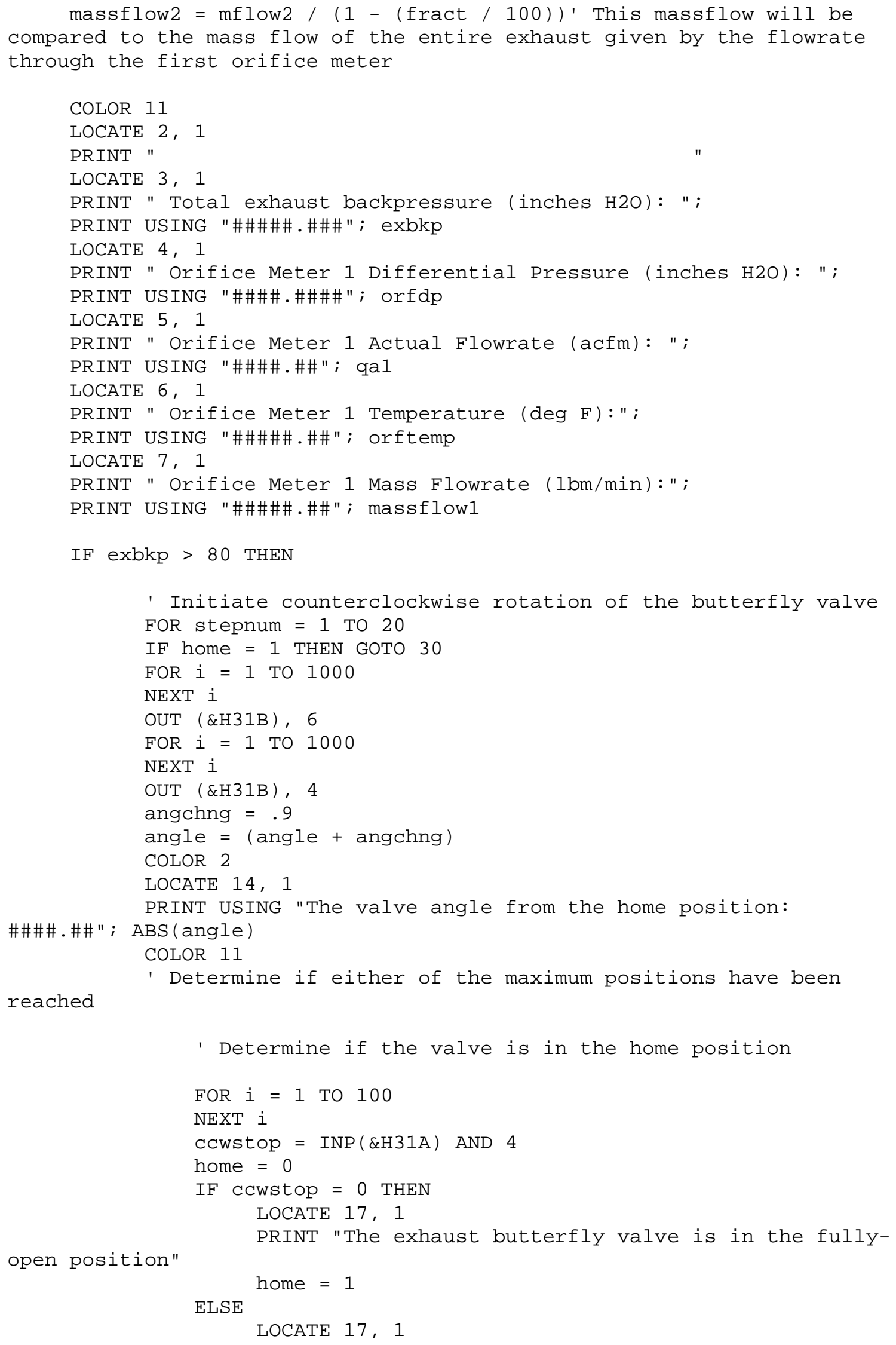


"

PRINT "

END IF

' Determine if the valve is in the fully-closed position

FOR $i=1$ TO 100

NEXT i

cwstop $=\operatorname{INP}(\& H 31 \mathrm{~A})$ AND 8

away $=0$

IF Cwstop $=0$ THEN

LOCATE 19, 1

PRINT "The exhaust butterfly valve is in the fully-

closed position"

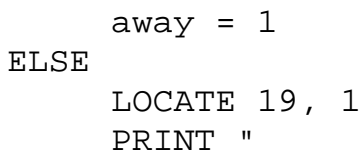

"

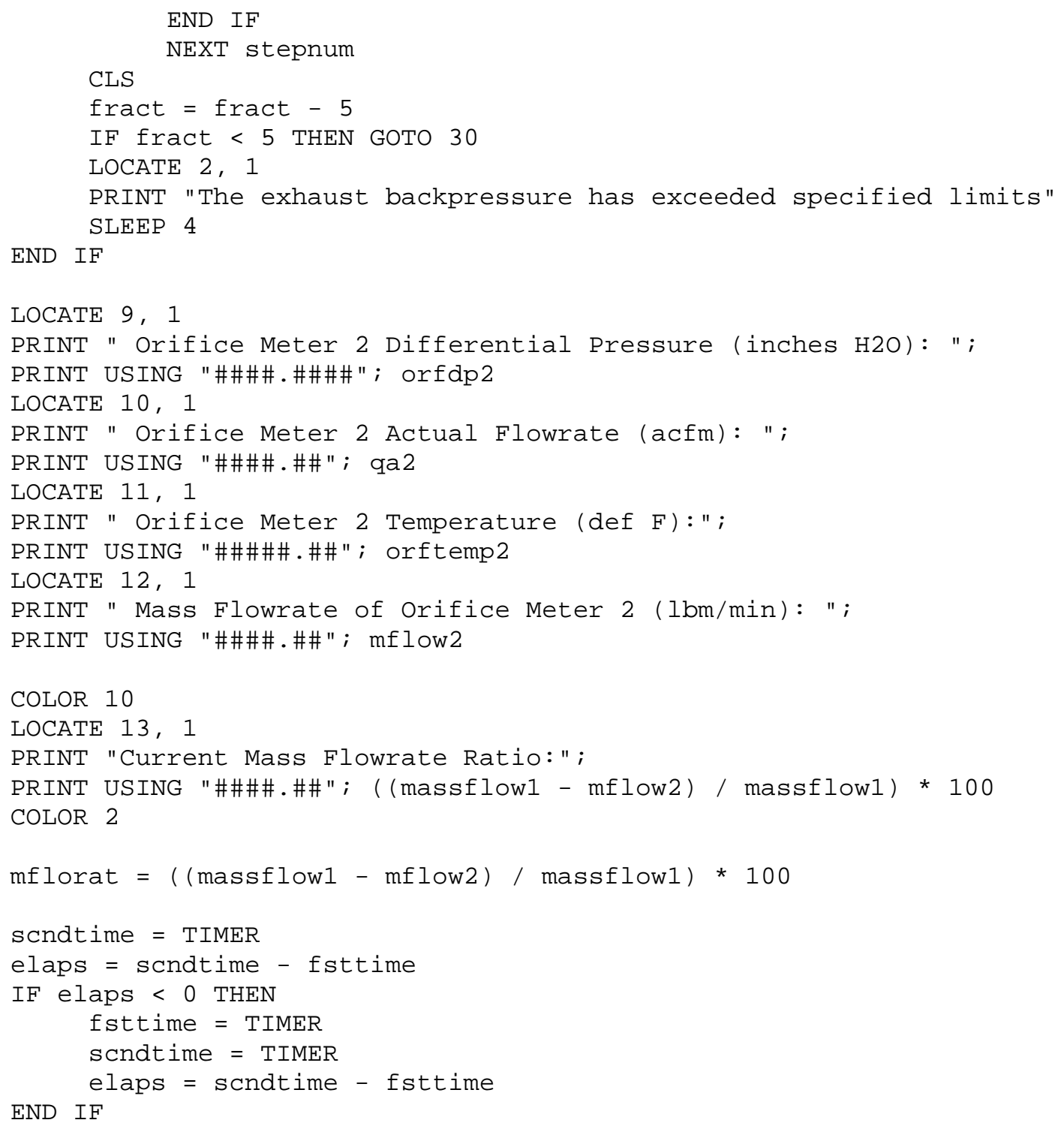




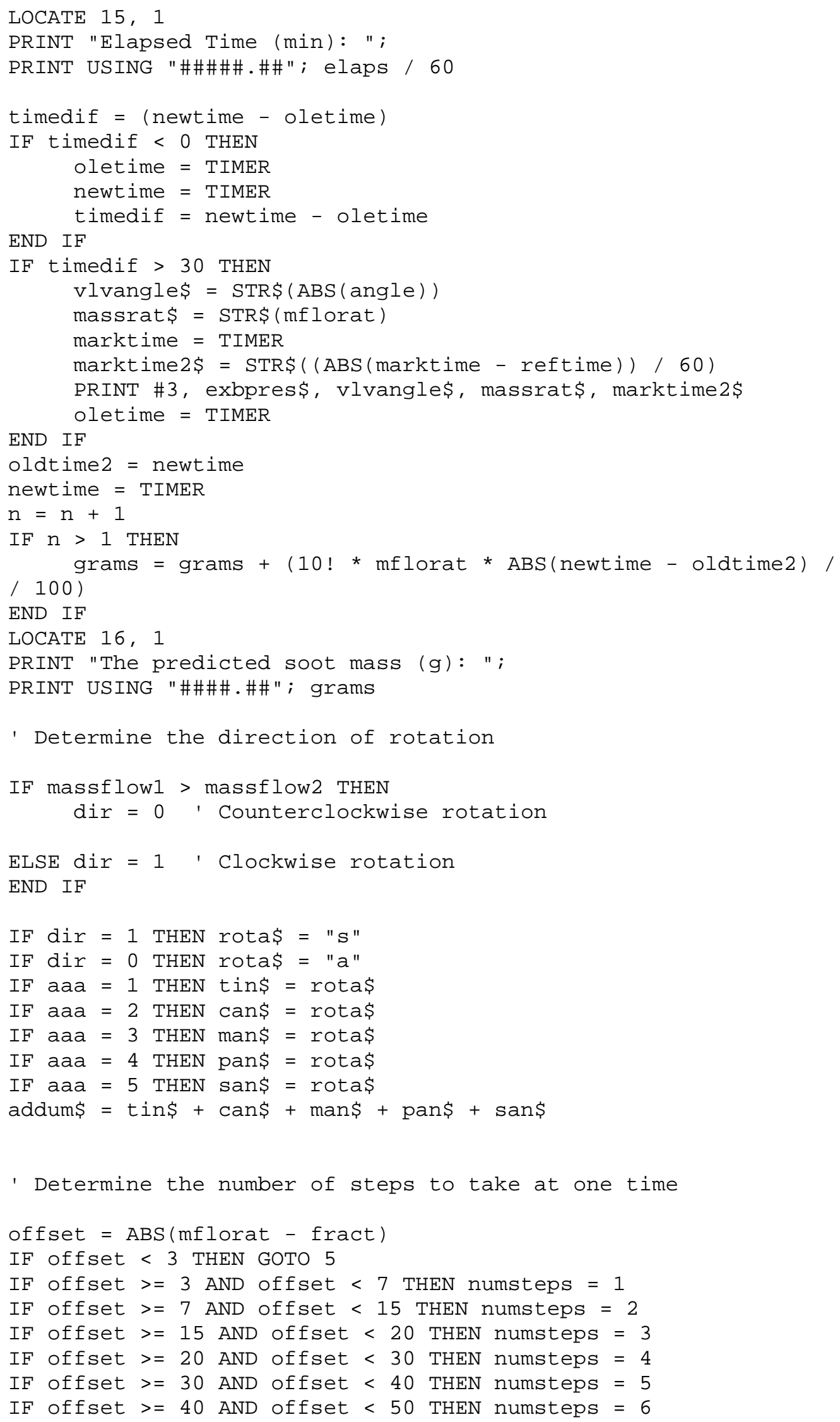




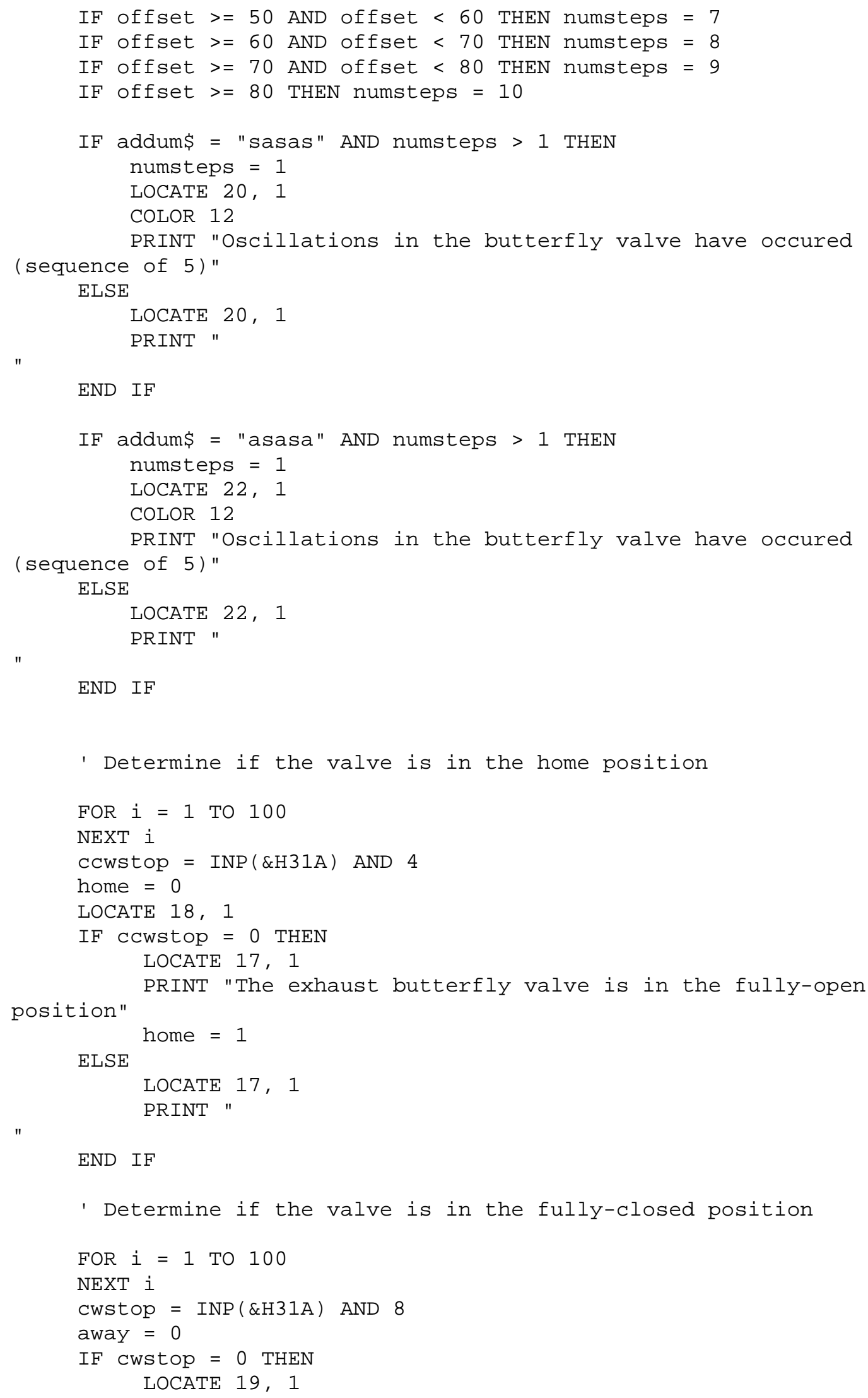




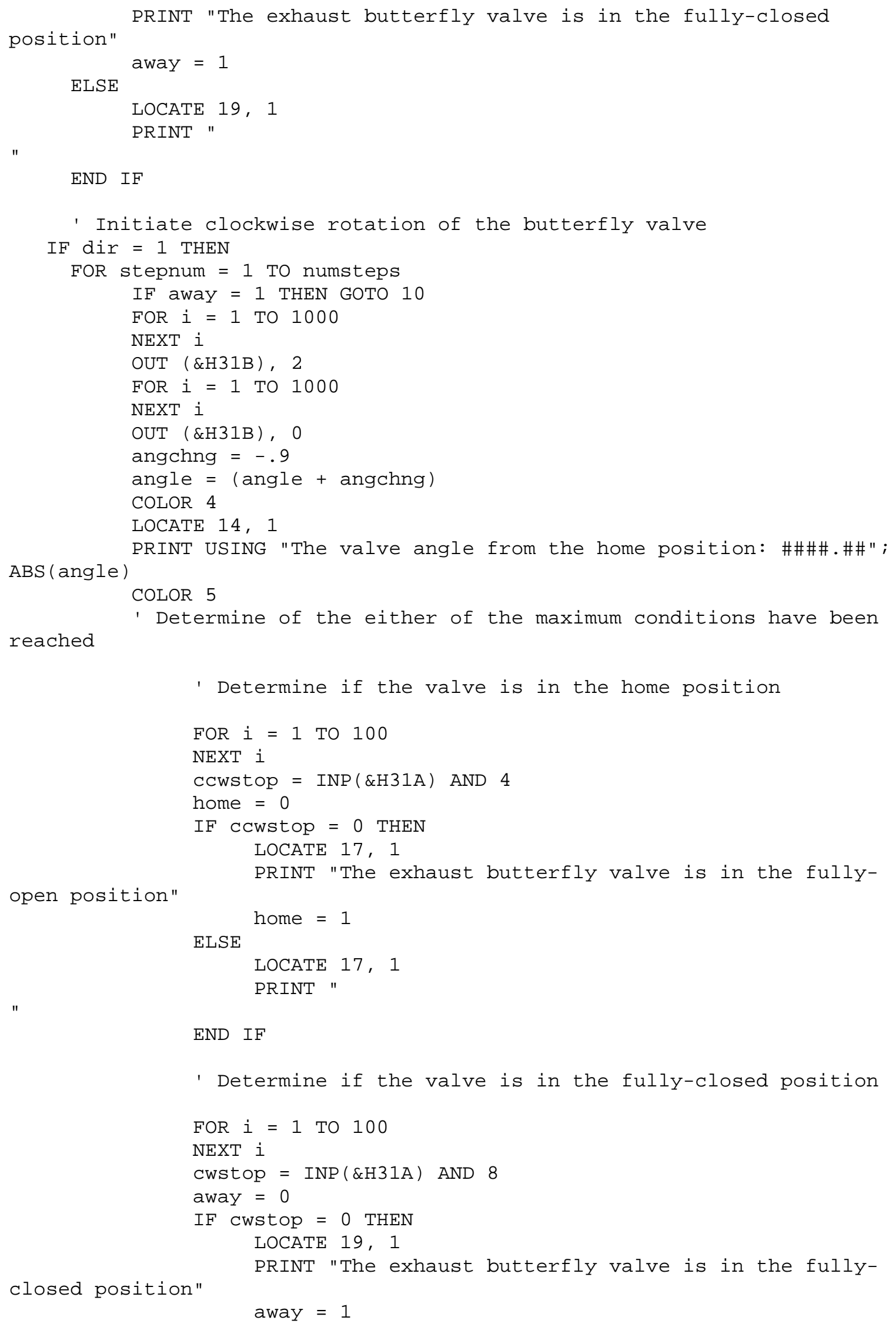




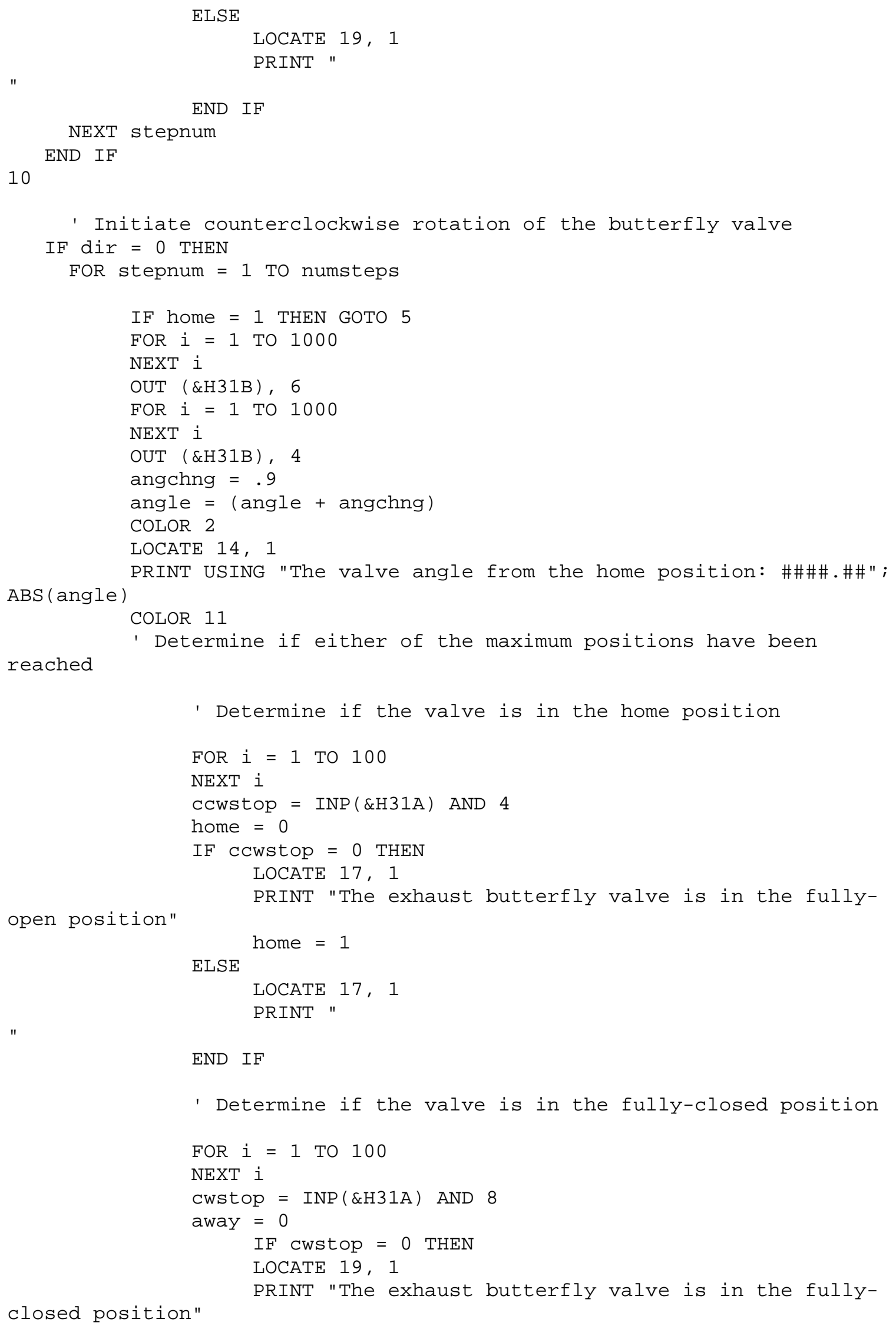




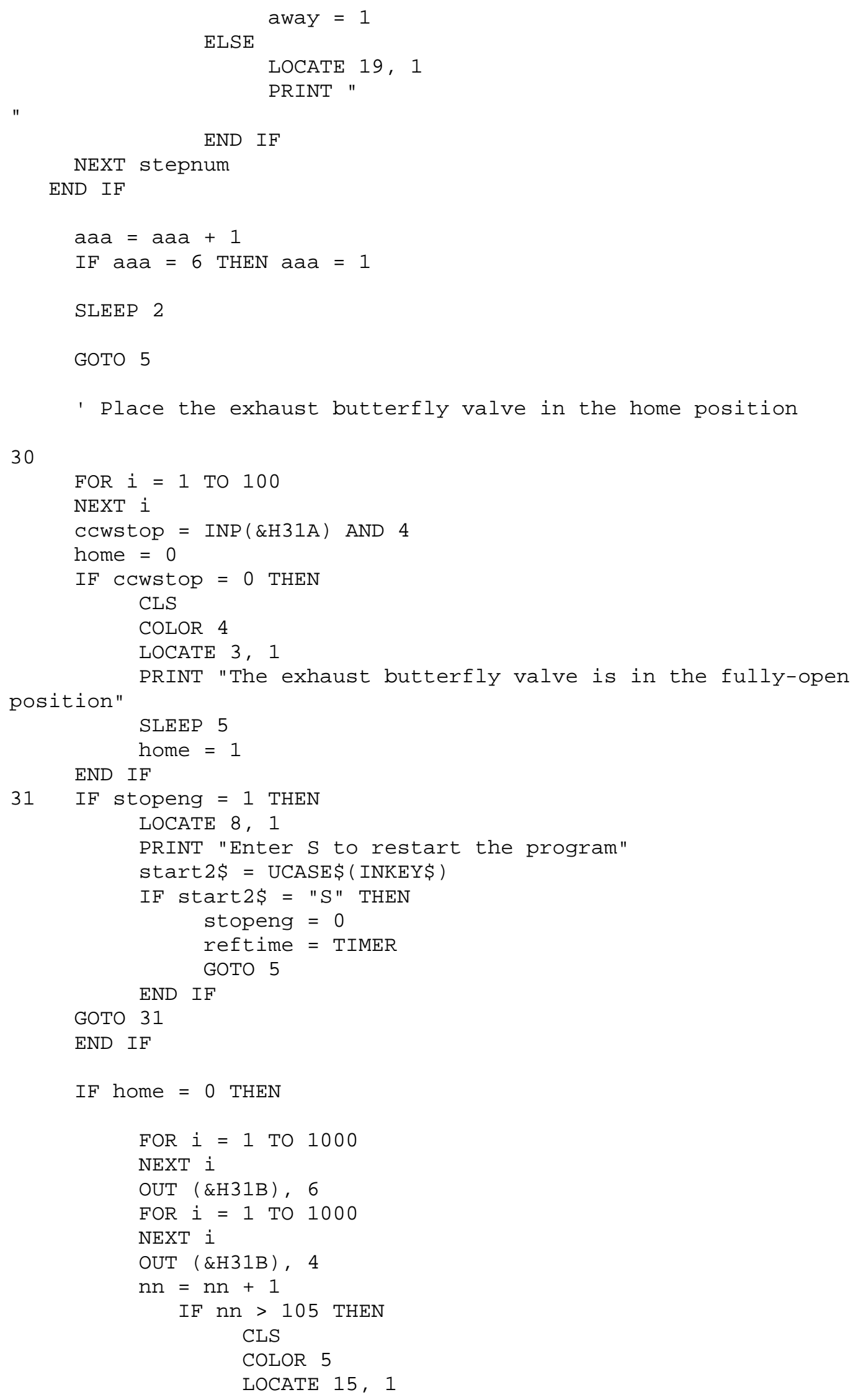




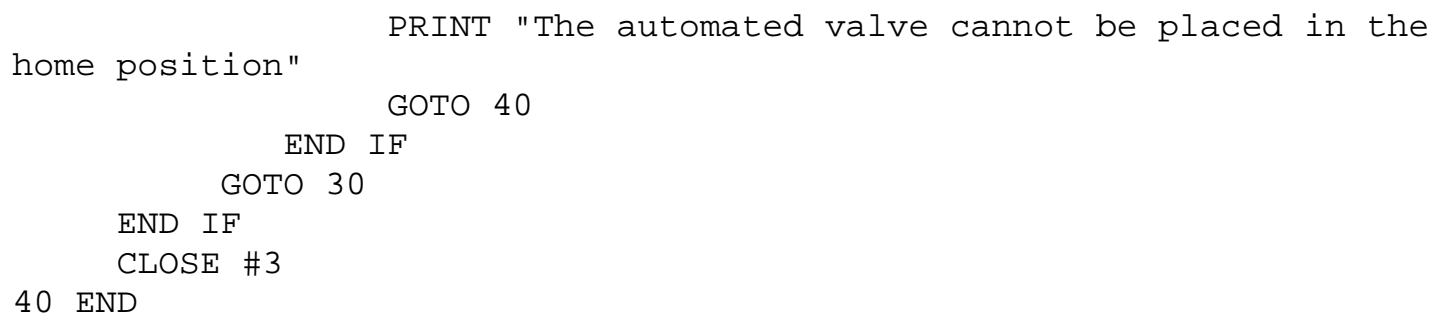


Appendix G: Microwave Generation/Transmission Components 


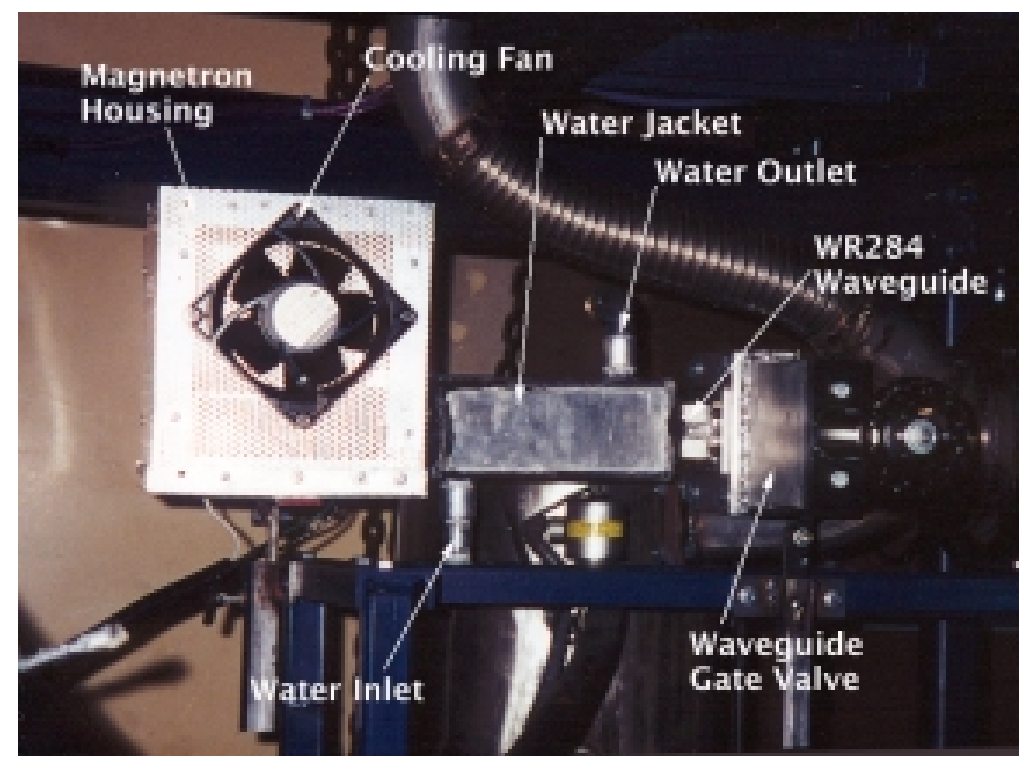

Figure G.1: WR284 Waveguide Assembly

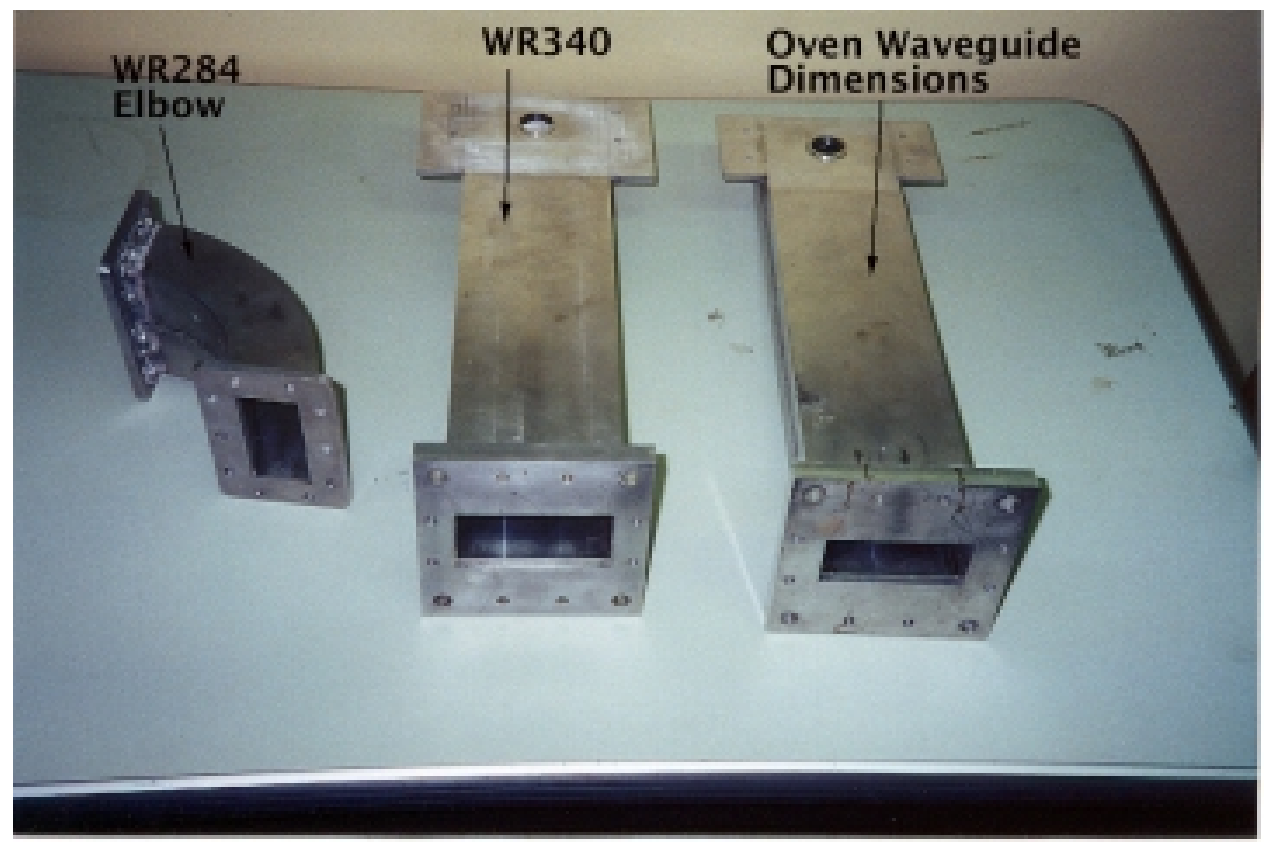

Figure G.2: Waveguides 


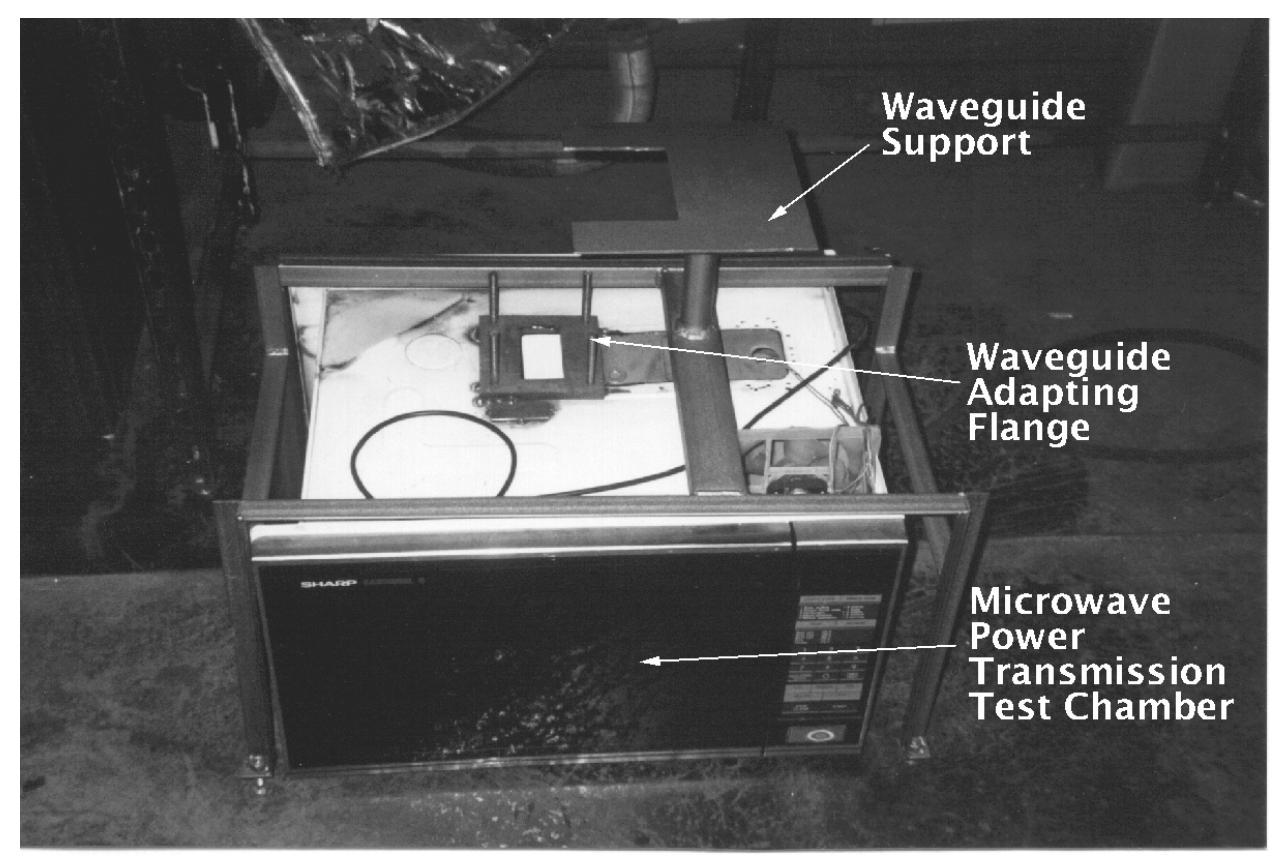

Figure G.3: Microwave Power Transmission Test Chamber

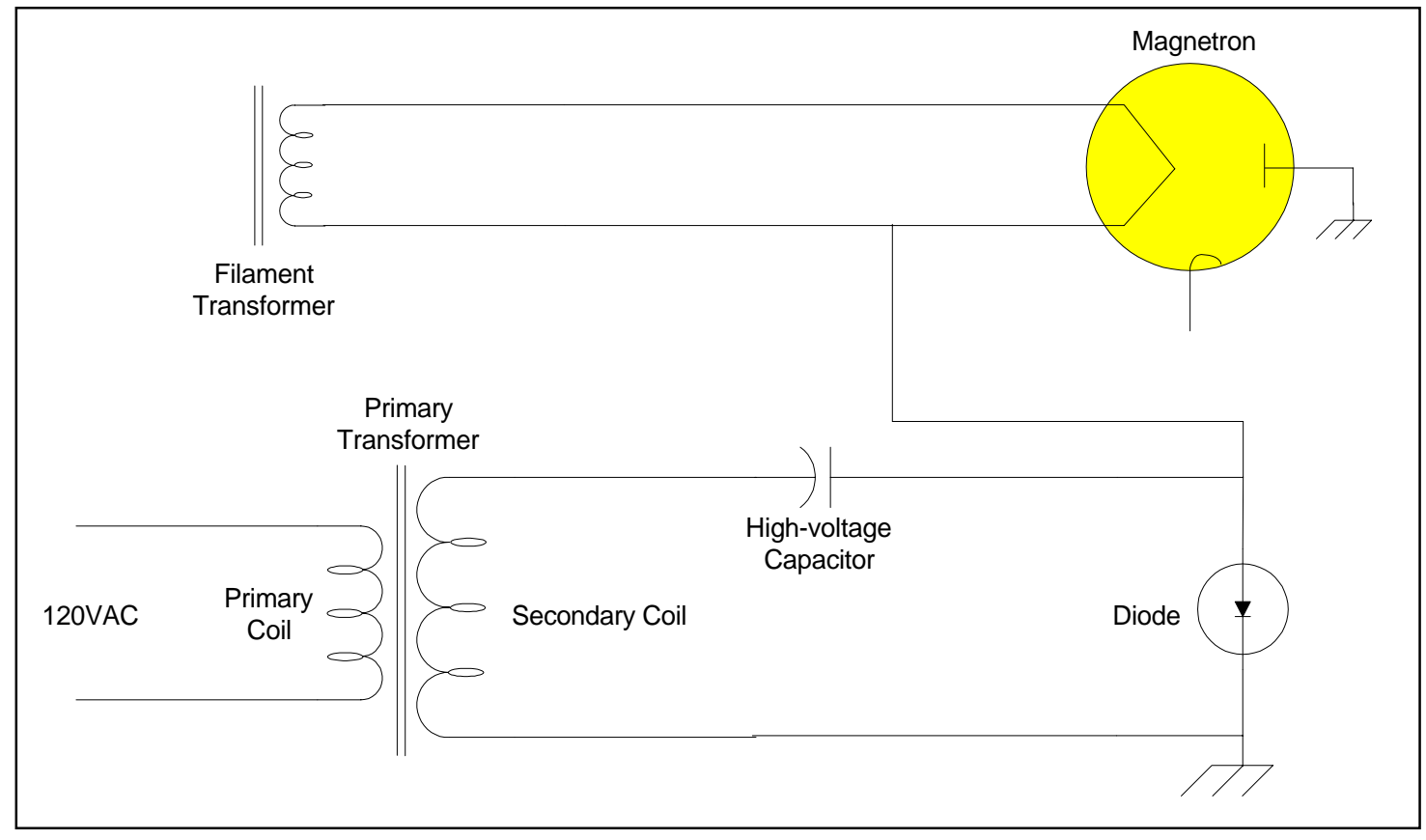

Figure G.4: Voltage Doubler Circuit and Magnetron Schematic (information provided by J.C. Gallawa, www.gallawa.com/microtech/mwave.html) 


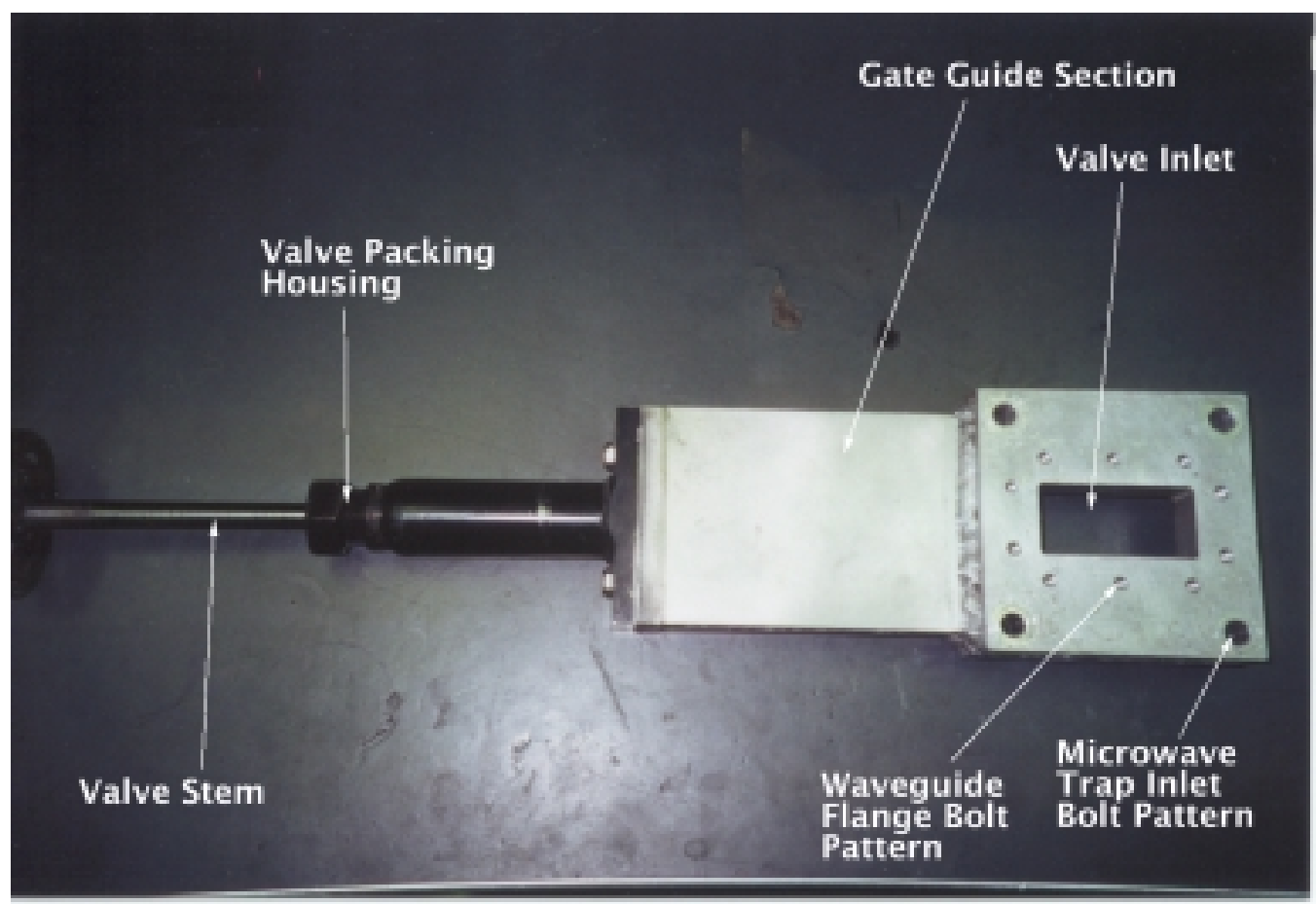

Figure G.5: Waveguide Gate Valve (inlet side)

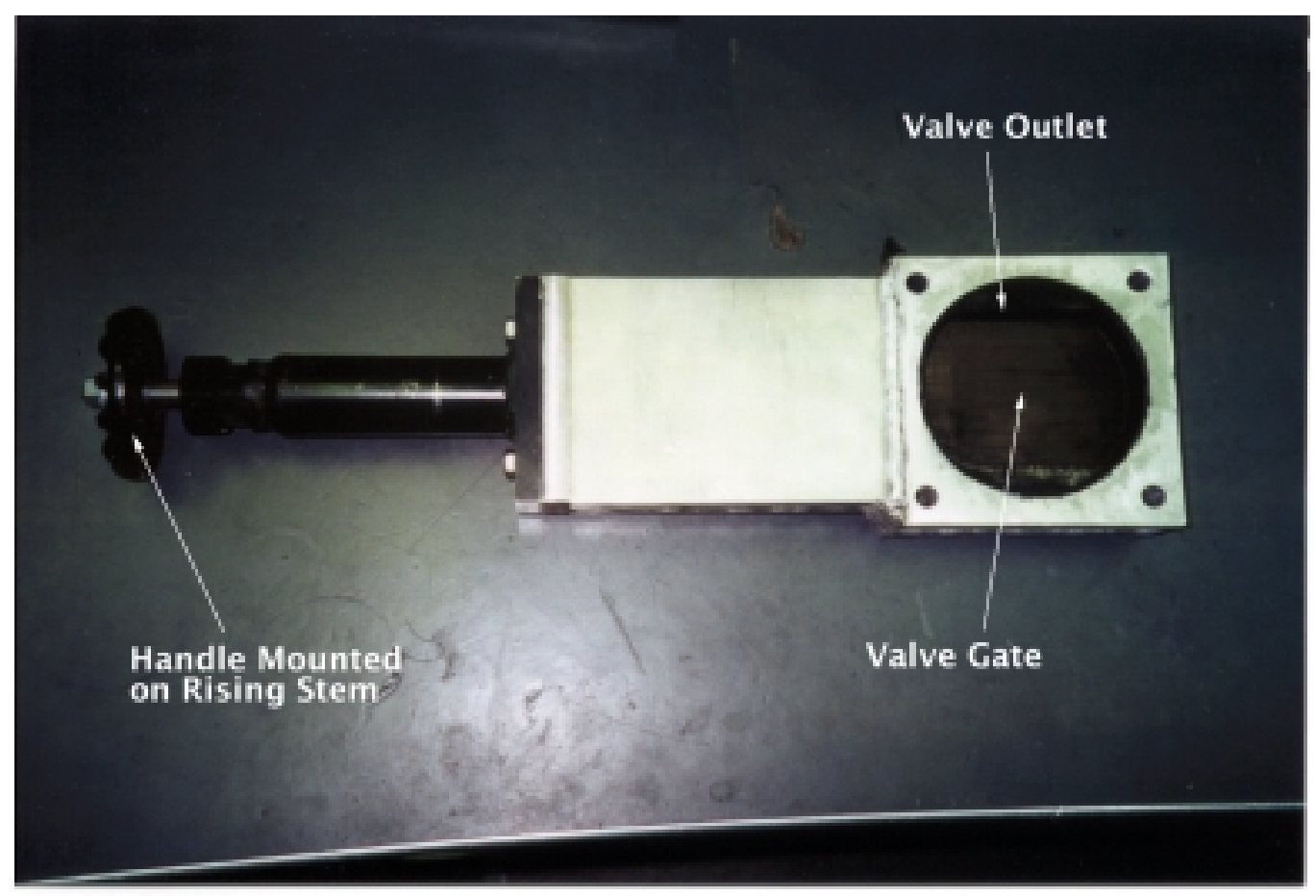

Figure G.6: Waveguide Gate Valve (outlet side) 
Appendix H: Combustion Air Supply Cart 


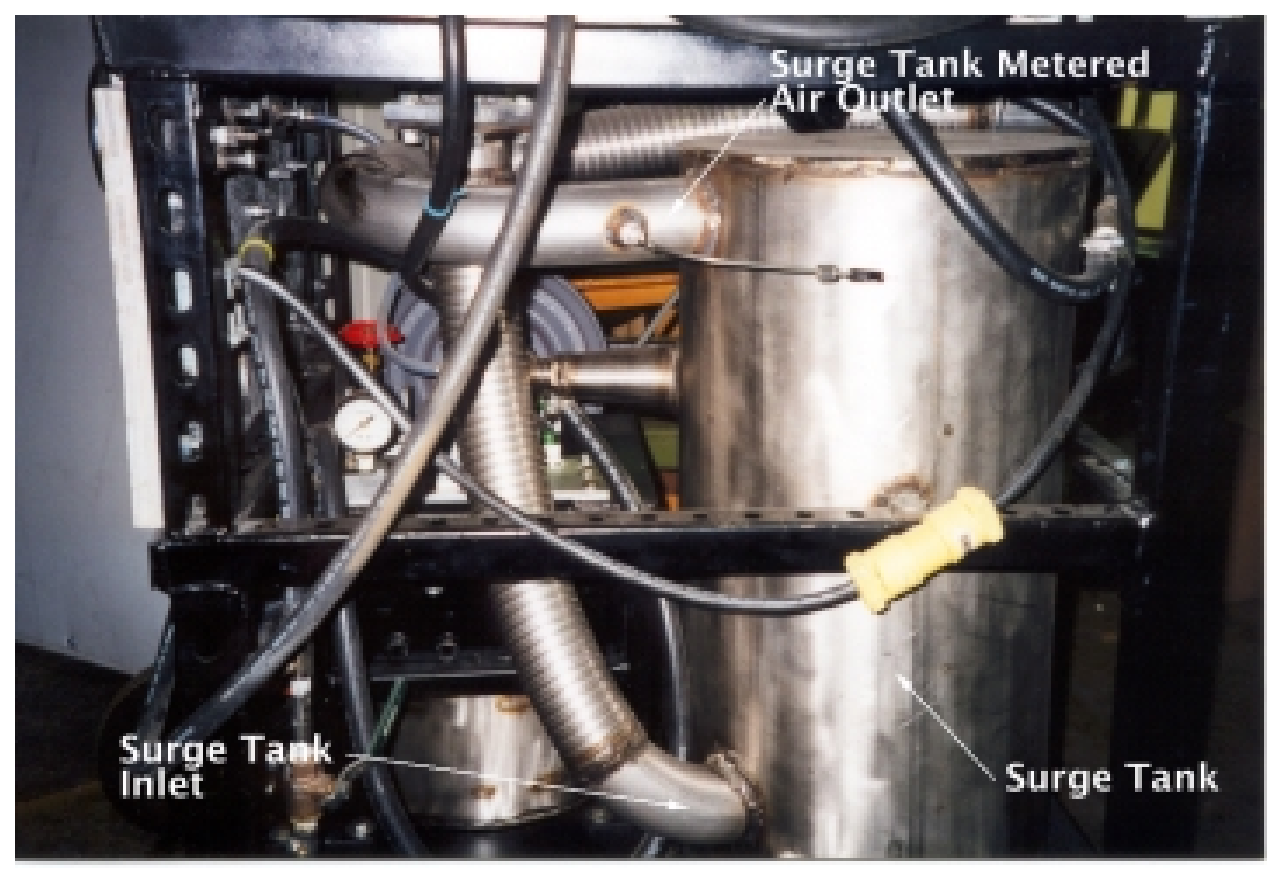

Figure H.1: Air Supply Surge Tank

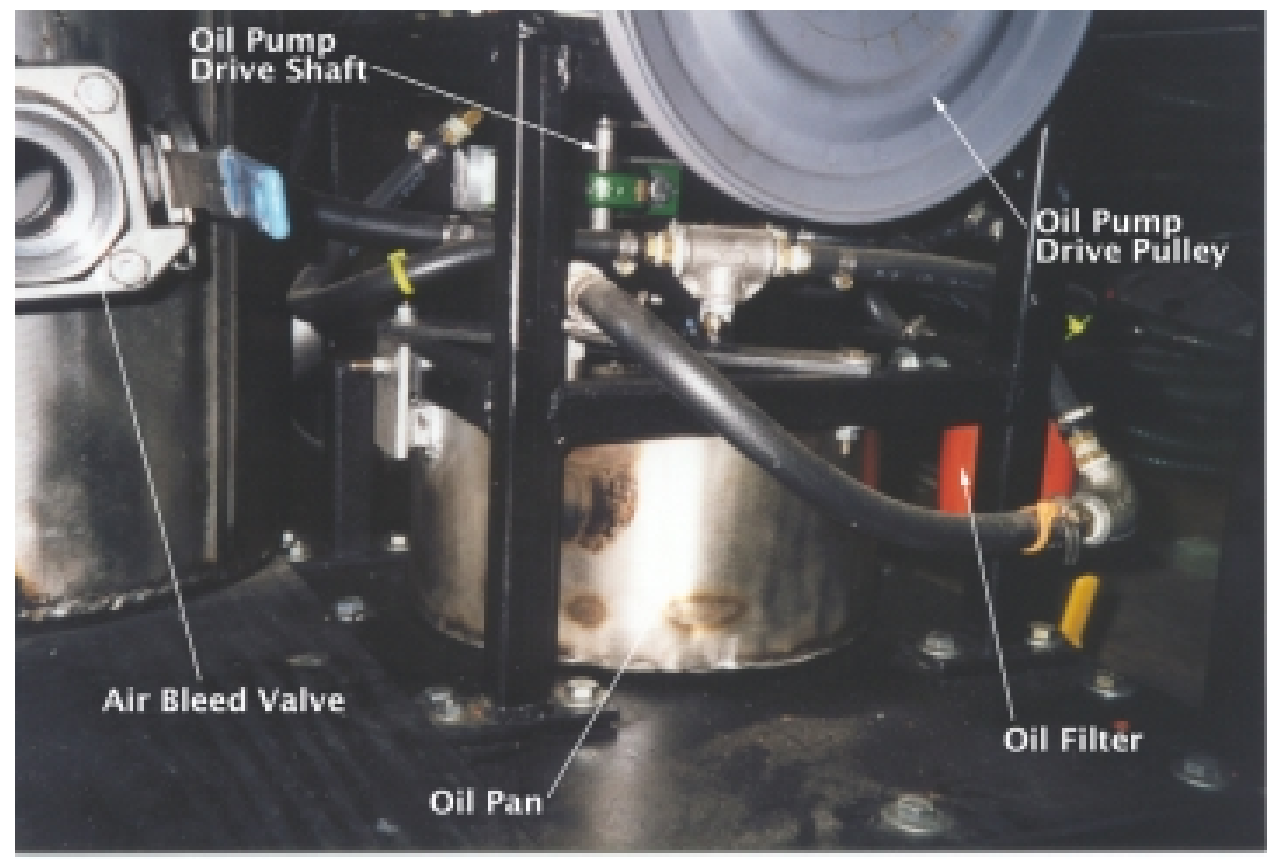

Figure H.2: Air Supply Oil System 


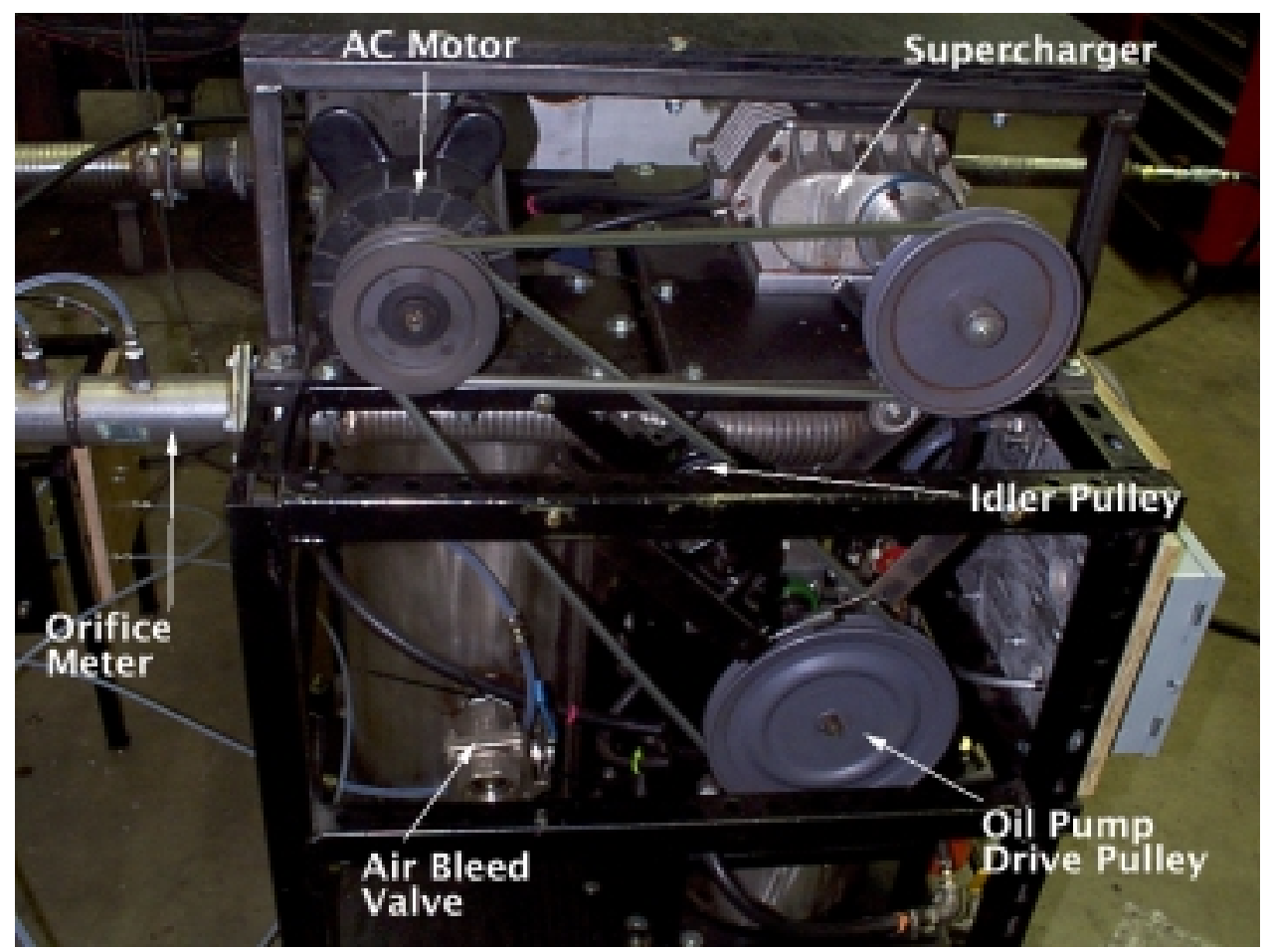

Figure H.3: Air Supply Components (cart side view)

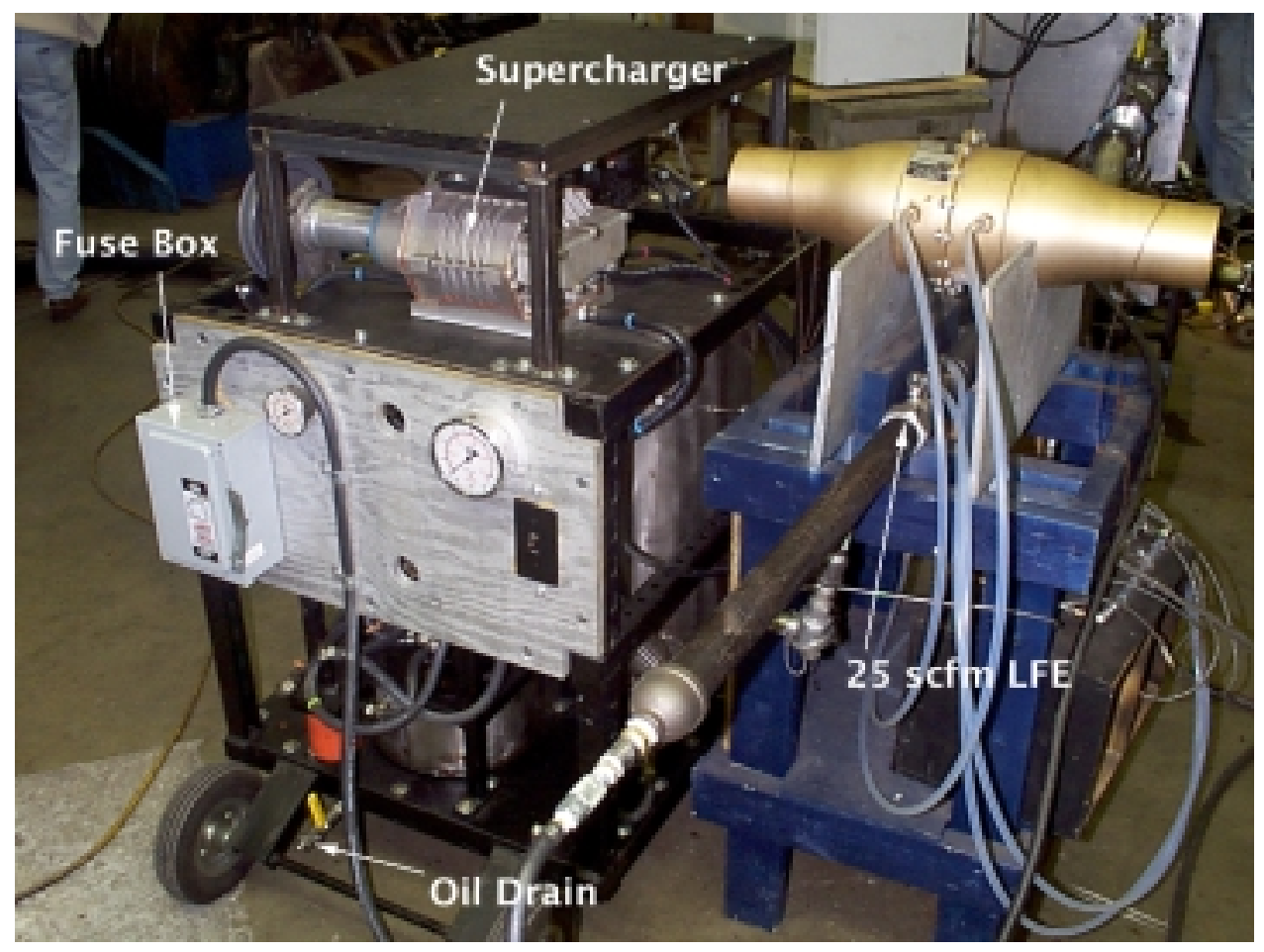

Figure H.4: Air Supply Components (cart rear view) 
Appendix I: Combustion Air Orifice Meter Calibration Data 


\section{Table I.1: Combustion Air Orifice Meter Calibration Data}

Air Supply Cart Orifice Meter Calibration (10-30-98)

Orifice Size $=1 "$

Tubing Inner Diameter $=2.345^{\prime \prime}$

Beta $=0.426$

LFE range $=0$ to $23 \mathrm{scfm}$

Reynolds number range (based on tube inner diameter) $=3.1^{\star} 10^{\wedge} 3$ to $1.2^{\star} 10^{\wedge} 4$

$\mathrm{K}=0.3469$

\begin{tabular}{||c|c|c|c|}
\hline \hline Point & dp ("H2O) & Qa (acfm) & Qa (fit) \\
\hline \hline 1 & 0.34 & 4.91 & 4.54 \\
\hline 2 & 0.84 & 7.39 & 7.13 \\
\hline 3 & 1.22 & 8.82 & 8.60 \\
\hline 4 & 1.71 & 10.36 & 10.18 \\
\hline 5 & 2.01 & 11.22 & 11.03 \\
\hline 6 & 2.58 & 12.69 & 12.50 \\
\hline 7 & 3.11 & 13.8 & 13.72 \\
\hline 8 & 3.89 & 15.39 & 15.35 \\
\hline 9 & 5.08 & 17.46 & 17.54 \\
\hline 10 & 6.46 & 19.58 & 19.78 \\
\hline 11 & 7.97 & 21.61 & 21.97 \\
\hline
\end{tabular}

Air Supply Orifice Meter Calibration (10-30-98)

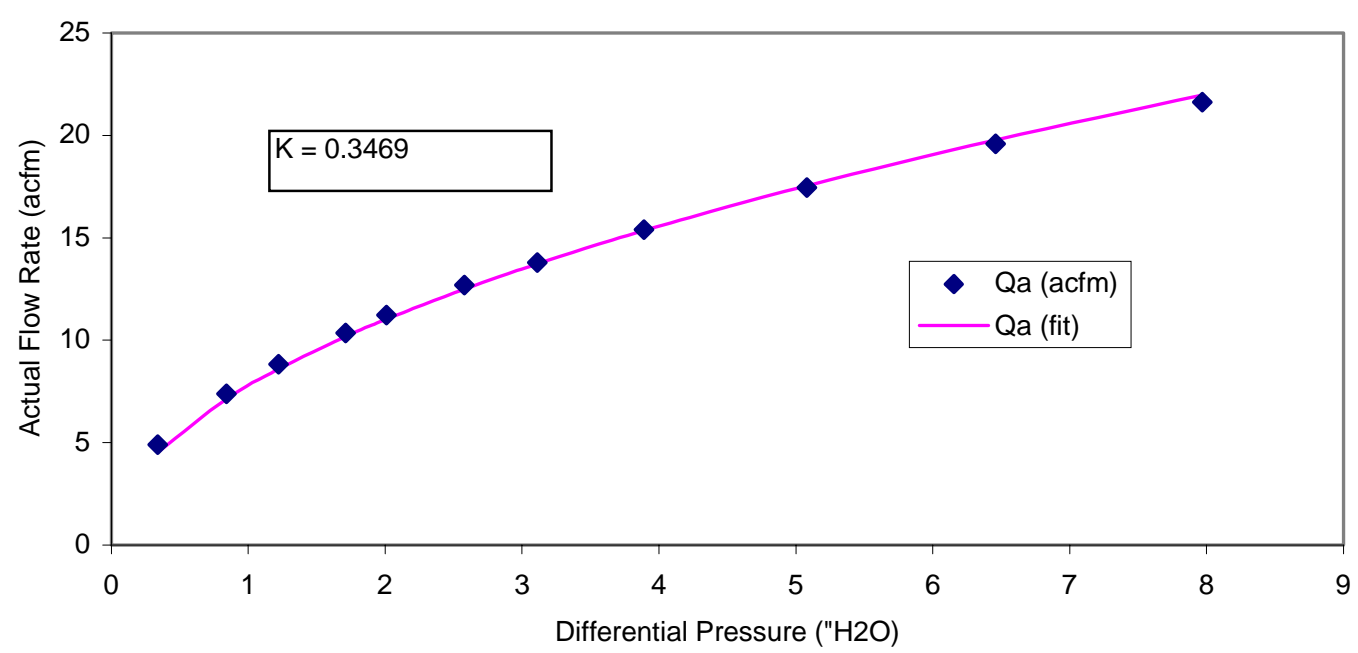

Figure I.1: Combustion Air Orifice Meter Calibration Curve 
Appendix J: Filter Conditioning Assembly 


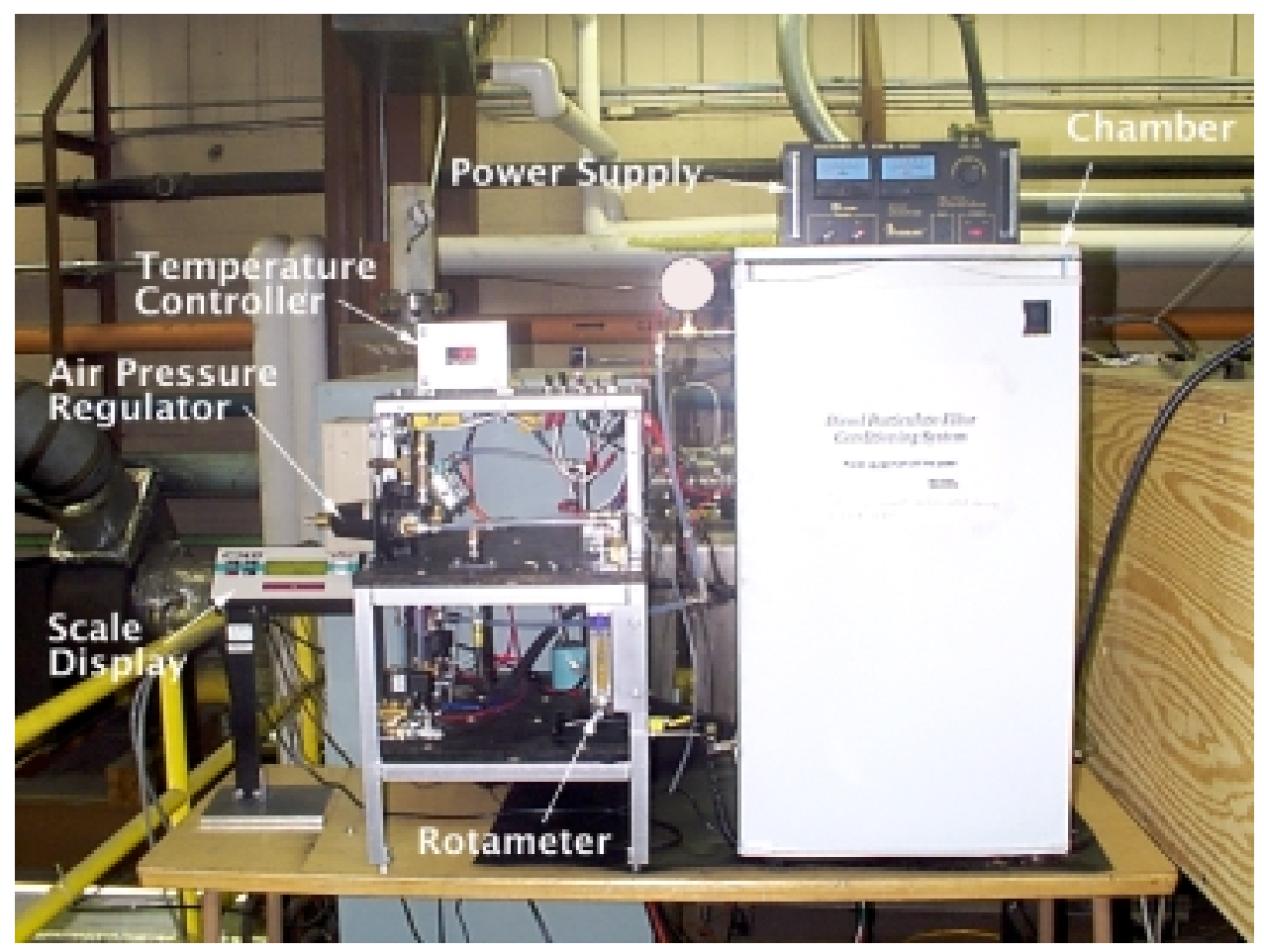

Figure J.1: Filter Conditioning Chamber (external view)

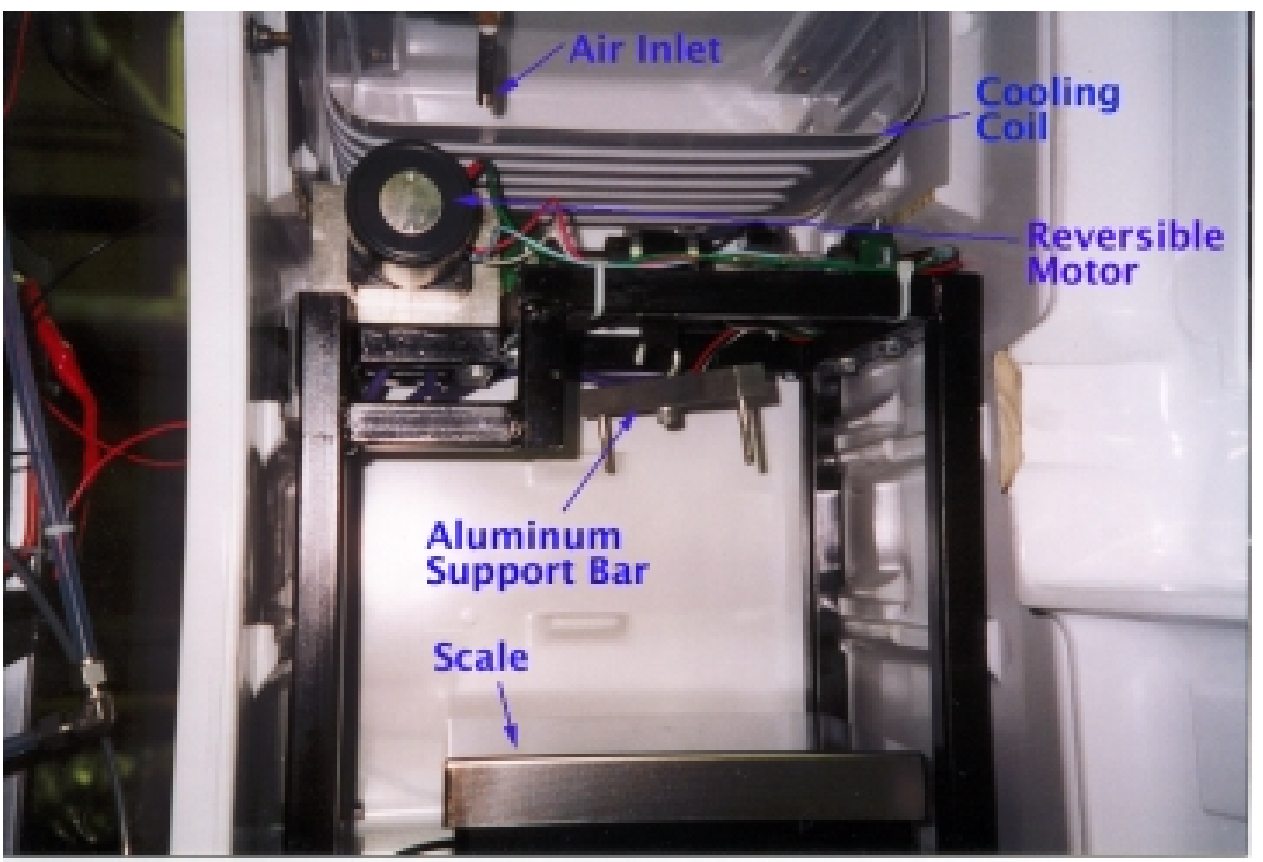

Figure J.2: Filter Conditioning Chamber (internal view) 


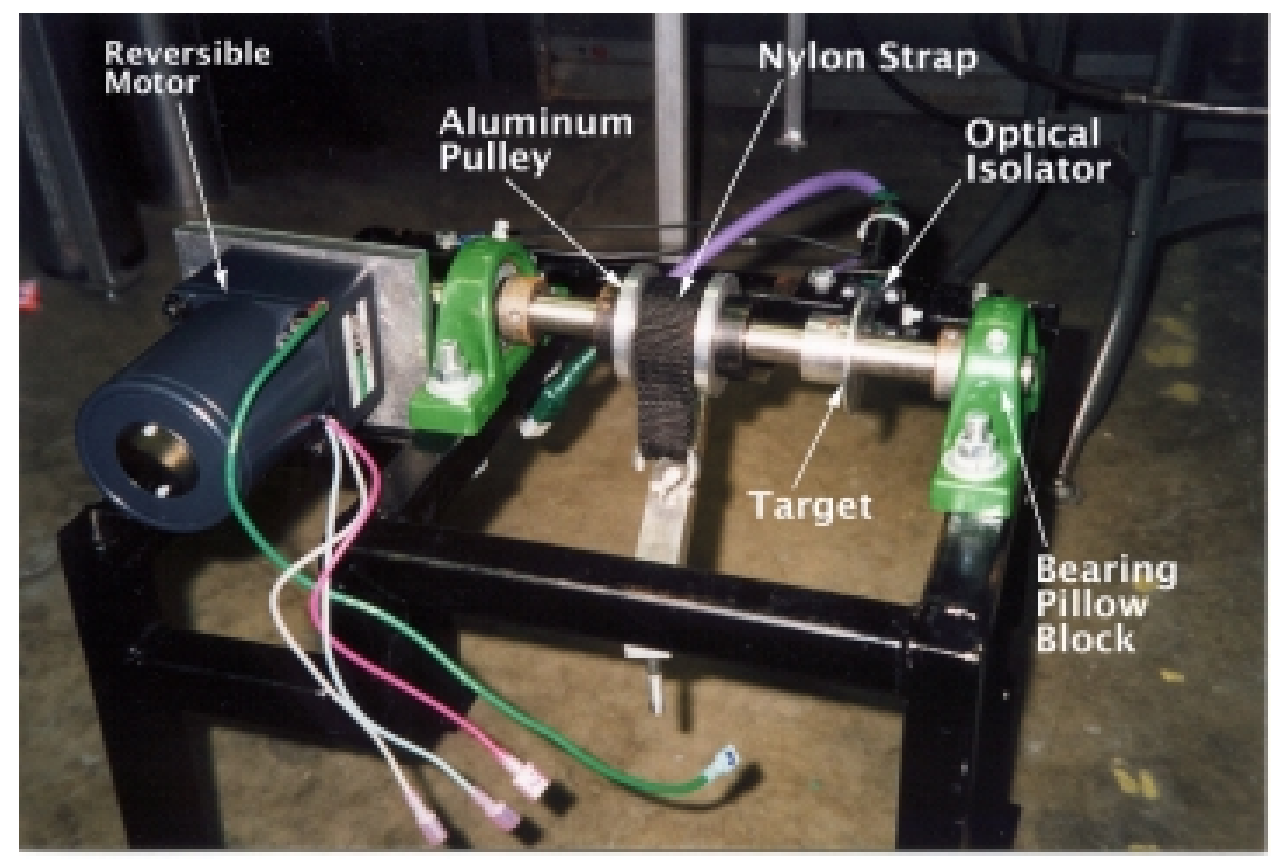

Figure J.3: Filter Conditioning Chamber Filter Support Assembly 
Appendix K: Out-of-cell Regeneration Assembly 


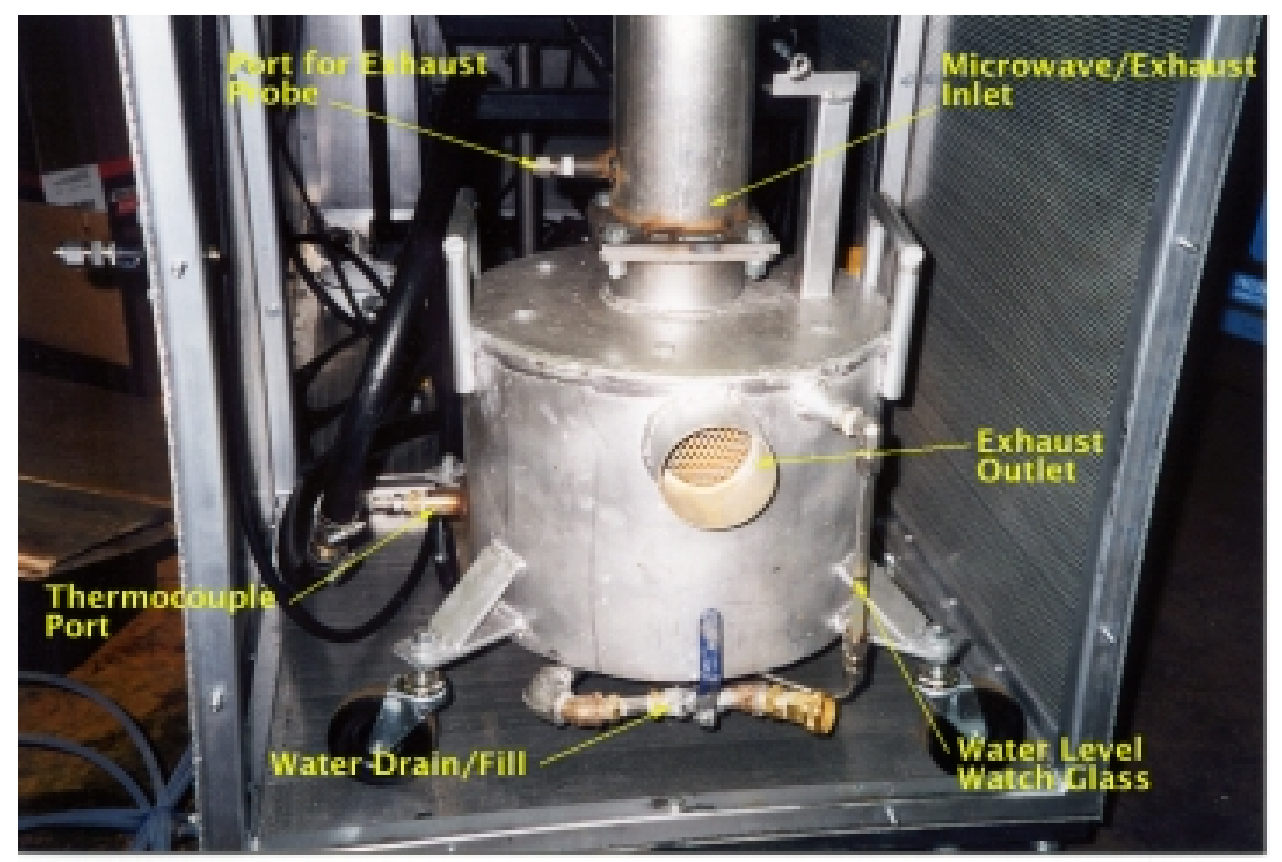

Figure K.1: Out-of-cell Water Trap

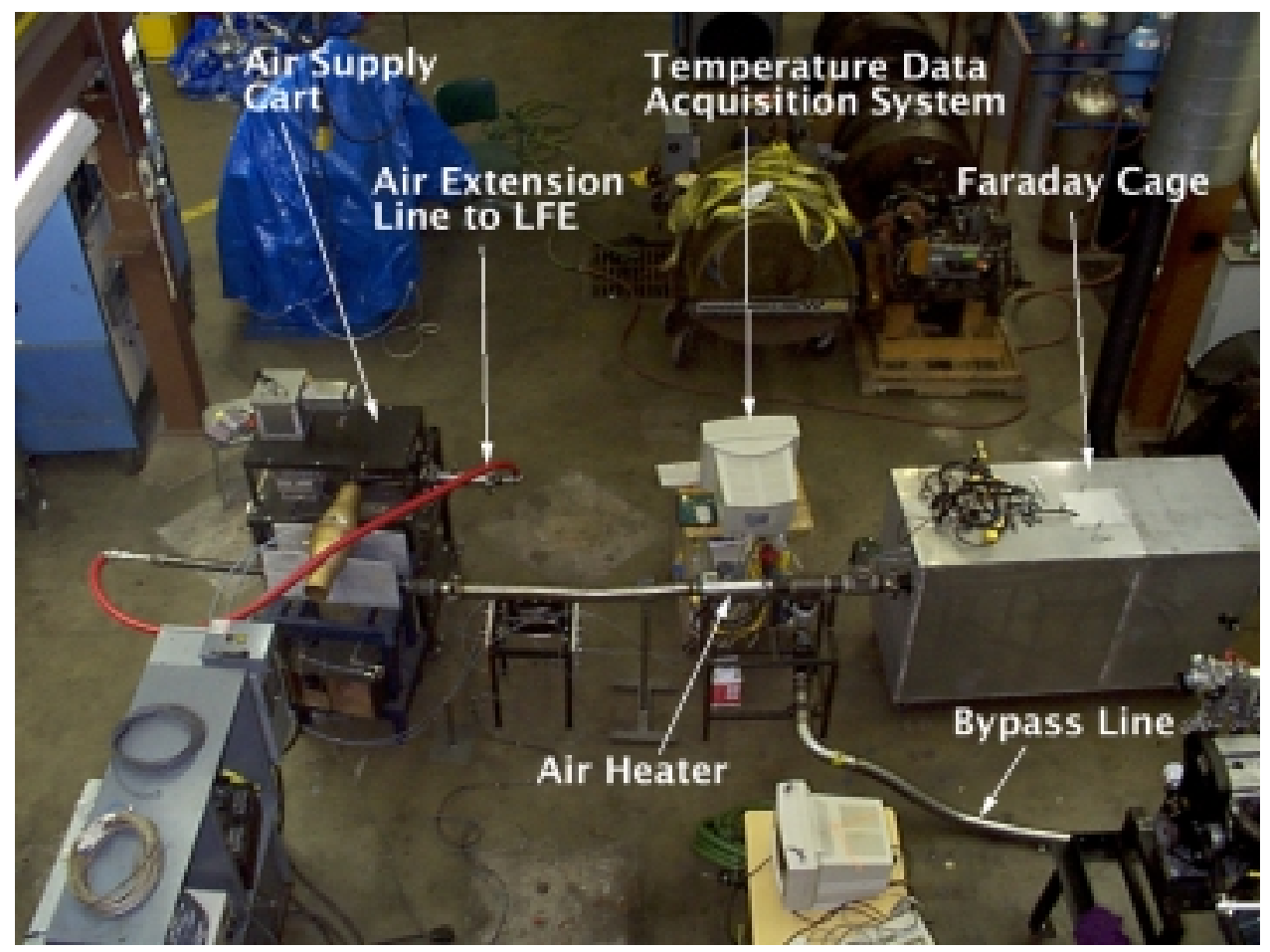

Figure K.2: Out-of-cell Regeneration Assembly (overall view) 


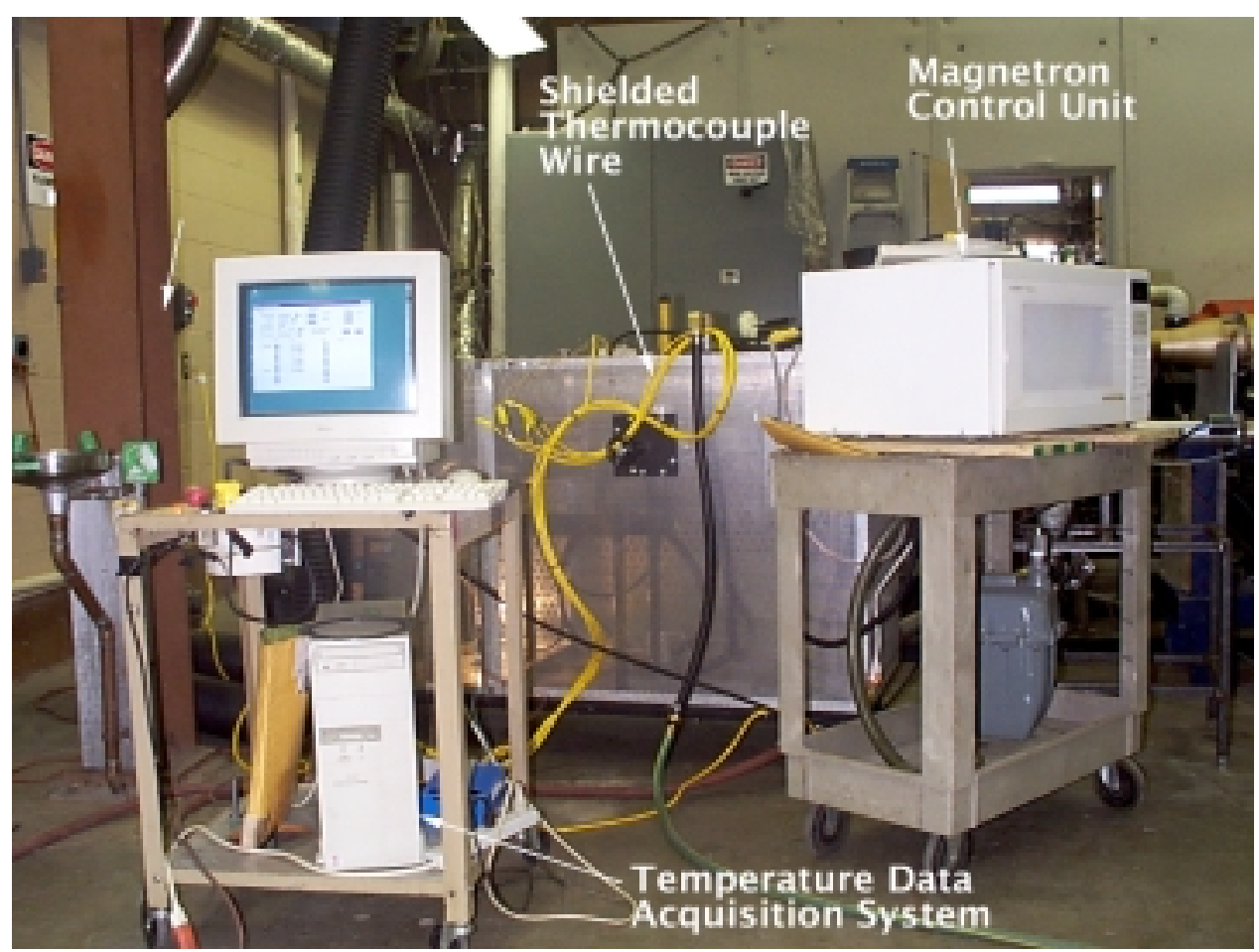

Figure K.3: Out-of-cell Magnetron Control Unit and Data Acquisition System

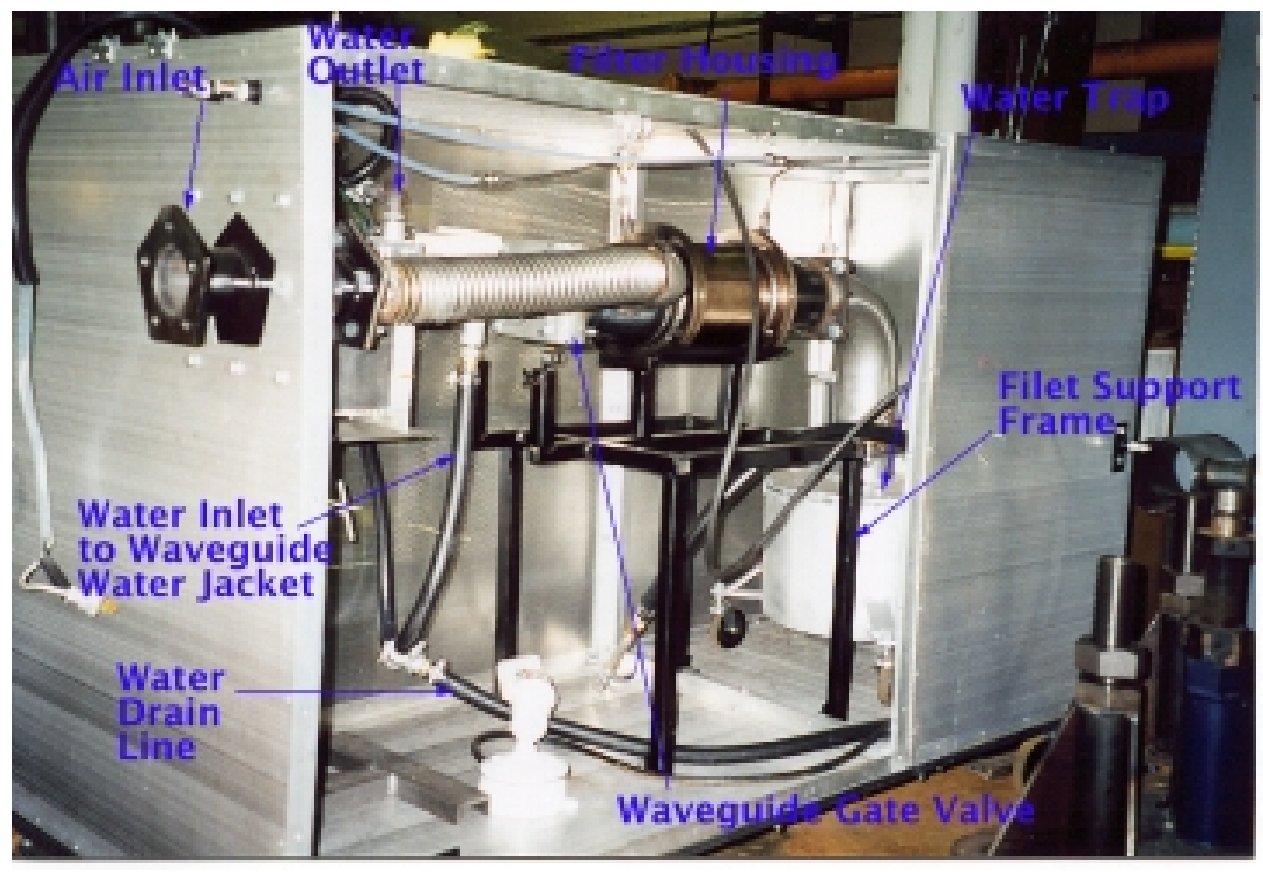

Figure K.4: Out-of-cell Regeneration System Faraday Cage Components 
Appendix L: Regeneration Data Acquisition Program 
' $11-6-98$

' Written by Bret Rankin

' This program is used to monitor the airflow rates,

' temperatures, some gases, and pressures during regeneration

DIM orftemp, sumqa, sumdp, sumtemp, reftime2, averscfm, averprcs AS DOUBLE

DIM reftime, protsum, orfabsp, prcstemp AS SINGLE

DIM orfdp, qa, avtemp, avdp, eltime AS DOUBLE

DIM orfdpp, orfabspp, orftempp, protemp, prtosum AS DOUBLE

DIM orfdp2, orabsp2, eltime2, orftemp2, scfm2, prcstemp2 AS STRING

OPEN "d:|robsldatalregen30.dat" FOR OUTPUT AS \#4

\section{COLOR 2}

CLS

LOCATE 1

PRINT "If you wish to write data points to d:Irobsldatalregen30.dat type Y"

PRINT "If you wish to quit type Q"

PRINT

$$
\begin{aligned}
& \mathrm{qq}=800 \\
& \mathrm{qq} 2=800
\end{aligned}
$$

1

$$
\begin{aligned}
& \text { orpsum }=0 \\
& \text { ordpsum }=0 \\
& \text { ortsum }=0 \\
& \text { protsum }=0 \\
& \text { LoCOsum }=0 \\
& \mathrm{CO} 2 \text { sum }=0 \\
& \text { HiCOsum }=0 \\
& \text { trapdpsum }=0 \\
& \text { FOR } \mathrm{j}=1 \text { TO qq }
\end{aligned}
$$

Input from channel 91 (orifice absolute pressure)

OUT \&H321, 27

FOR $w t=1$ TO 20: NEXT

OUT \&H322, 0

DO UNTIL (INP(\&H320) AND \&H40): LOOP

AdcIn\% $=\mathrm{CVI}(\mathrm{CHR} \$(\operatorname{INP}(\& \mathrm{H} 323))+\mathrm{CHR} \$(\operatorname{INP}(\& H 324)))$

orfabspp $=$ AdcIn $\% / 4095 * 32$ ' psia

orpsum $=$ orpsum + orfabspp

Input from channel 92 (orifice differential pressure)

OUT \&H321, 28

FOR $w t=1$ TO 20: NEXT

OUT \&H322, 0

DO UNTIL (INP(\&H320) AND \&H40): LOOP

AdcIn\% $=\mathrm{CVI}(\mathrm{CHR} \$(\operatorname{INP}(\& H 323))+\mathrm{CHR} \$(\operatorname{INP}(\& H 324)))$

orfdpp $=$ AdcIn $\% / 4095 * 55 \quad$ ' inches water

ordpsum $=$ ordpsum + orfdpp 
Input from channel 30 (orifice temperature)

OUT \&H301, 30

FOR $w t=1$ TO 20: NEXT

OUT \&H302, 0

DO UNTIL (INP(\&H300) AND \&H40): LOOP

AdcIn\% $=\mathrm{CVI}(\mathrm{CHR} \$(\operatorname{INP}(\& \mathrm{H} 303))+\mathrm{CHR} \$(\operatorname{INP}(\& \mathrm{H} 304)))$

orftempp $=($ AdcIn $\% / 2047 * 900)+32 ' \operatorname{deg} \mathrm{F}$

ortsum $=$ ortsum + orftempp

Input from channel 31 (process heater temperature)

OUT \&H301, 31

FOR $w t=1$ TO 20: NEXT

OUT \&H302, 0

DO UNTIL (INP(\&H300) AND \&H40): LOOP

$\operatorname{AdcIn} \%=\operatorname{CVI}(\mathrm{CHR} \$(\operatorname{INP}(\& \mathrm{H} 303))+\mathrm{CHR} \$(\operatorname{INP}(\& \mathrm{H} 304)))$

protemp $=($ AdcIn\% $/ 2047 * 1800)+32 ' \operatorname{deg} \mathrm{F}$

protsum $=$ protemp + protsum

Input from channel 17 (Low CO analyzer)

OUT \&H301, 17

FOR $w t=1$ TO 20: NEXT

OUT \&H302, 0

DO UNTIL (INP(\&H300) AND \&H40): LOOP

AdcIn\% $=\mathrm{CVI}(\mathrm{CHR} \$(\operatorname{INP}(\& \mathrm{H} 303))+\mathrm{CHR} \$(\operatorname{INP}(\& \mathrm{H} 304)))$

$\mathrm{LoCO}=(\operatorname{AdcIn} \%)$

LoCOsum $=\mathrm{LoCO}+$ LoCOsum

Input from channel 18 (CO2 analyzer)

OUT \&H301, 18

FOR $w t=1$ TO 20: NEXT

OUT \&H302, 0

DO UNTIL (INP(\&H300) AND \&H40): LOOP

AdcIn\% $=\mathrm{CVI}(\mathrm{CHR} \$(\operatorname{INP}(\& H 303))+\mathrm{CHR} \$(\operatorname{INP}(\& H 304)))$

$\mathrm{CO} 2=(\operatorname{AdcIn} \%)$

$\mathrm{CO} 2$ sum $=\mathrm{CO} 2+\mathrm{CO} 2$ sum

Input from channel 16 (Hi $\mathrm{CO}$ analyzer)

OUT \&H301, 16

FOR $w t=1$ TO 20: NEXT

OUT \&H302, 0

DO UNTIL (INP(\&H300) AND \&H40): LOOP

$\operatorname{AdcIn} \%=\mathrm{CVI}(\mathrm{CHR} \$(\operatorname{INP}(\& H 303))+\mathrm{CHR} \$(\operatorname{INP}(\& H 304)))$

$\mathrm{HiCO}=($ AdcIn $\%)$

$\mathrm{HiCOsum}=\mathrm{HiCO}+\mathrm{HiCOsum}$

Input from channel 89 (Trap differential pressure)

OUT \&H321, 25

FOR $w t=1$ TO 20: NEXT

OUT \&H322, 0

DO UNTIL (INP(\&H320) AND \&H40): LOOP

$\operatorname{AdcIn} \%=\operatorname{CVI}(\mathrm{CHR} \$(\operatorname{INP}(\& H 323))+\operatorname{CHR} \$(\operatorname{INP}(\& H 324)))$

trapdpp $=$ AdcIn $\% / 4095 * 89 \quad$ 'inches water

trapdpsum $=$ trapdpsum + trapdpp 


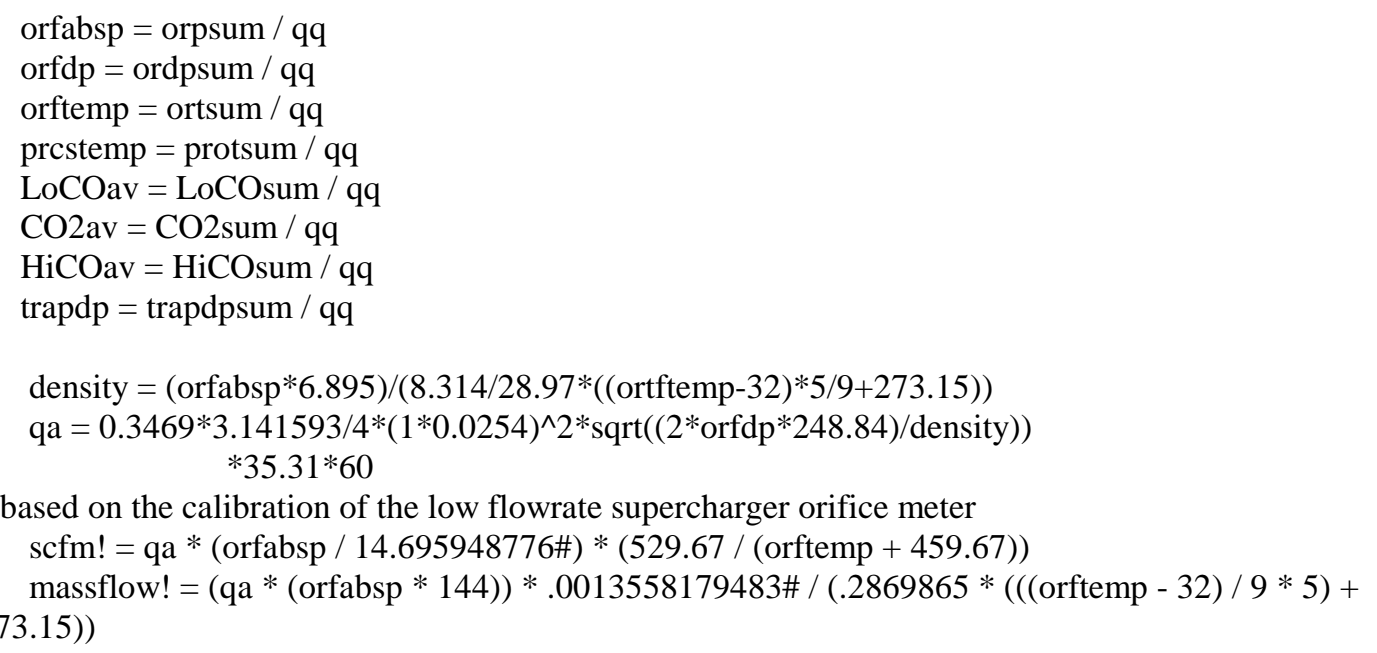

COLOR 11

LOCATE 4,1

PRINT " Orifice Meter Temperature (deg F): ";

PRINT USING "\#\#\#\#.\#\#"; orftemp

LOCATE 6, 1

PRINT " Orifice Meter Differential Pressure (inches H2O): ";

PRINT USING "\#\#\#\#\#\#"; orfdp

LOCATE 8,1

PRINT " Orifice Meter Absolute Pressure (psia): ";

PRINT USING "\#\#\#\#.\#\#"; orfabsp

LOCATE 10,1

PRINT " Orifice Meter Actual Flowrate (acfm): ";

PRINT USING "\#\#\#\#.\#\#"; qa

\section{COLOR 5}

LOCATE 12,1

PRINT " Orifice Meter Standardized Flowrate (scfm): ";

PRINT USING "\#\#\#\#.\#\#"; scfm!

LOCATE 14,1

PRINT " Orifice Meter Mass Flowrate (kg/min): ";

PRINT USING "\#\#\#\#.\#\#"; massflow!

LOCATE 16,1

PRINT " Process Heater Temperature (deg F): ";

PRINT USING "\#\#\#\#.\#\#"; prcstemp

COLOR 10

LOCATE 18,1

PRINT " Low CO analyzer ADC: ";

PRINT USING "\#\#\#\#\#\#\#"; LoCOav

LOCATE 19,1

PRINT " CO2 analyzer ADC: ";

PRINT USING "\#\#\#\#\#.\#\#"; CO2av

LOCATE 20, 1

PRINT " High CO analyzer ADC: ";

PRINT USING "\#\#\#\#\#.\#\#"; HiCOav

LOCATE 22, 1

PRINT " Trap Differential Pressure (in. H20): ";

PRINT USING "\#\#\#\#\#.\#\#"; trapdp 


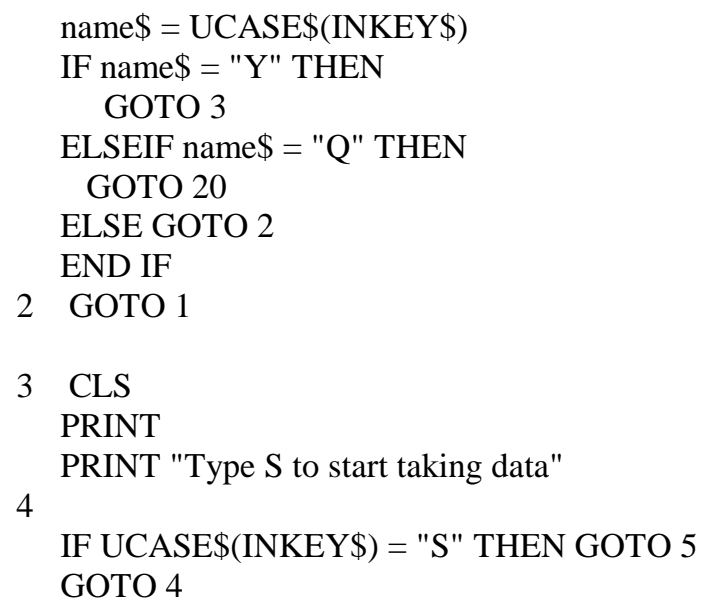


Input from channel 30 (orifice temperature)

OUT \&H301, 30

FOR $w t=1$ TO 20: NEXT

OUT \&H302, 0

DO UNTIL (INP(\&H300) AND \&H40): LOOP

AdcIn\% $=\mathrm{CVI}(\mathrm{CHR} \$(\operatorname{INP}(\& \mathrm{H} 303))+\mathrm{CHR} \$(\operatorname{INP}(\& \mathrm{H} 304)))$

orftempp $=($ AdcIn $\% / 2047 * 900)+32 ' \operatorname{deg} \mathrm{F}$

ortsum $=$ ortsum + orftempp

Input from channel 31 (process heater temperature)

OUT \&H301, 31

FOR $w t=1$ TO 20: NEXT

OUT \&H302, 0

DO UNTIL (INP(\&H300) AND \&H40): LOOP

$\operatorname{AdcIn} \%=\operatorname{CVI}(\mathrm{CHR} \$(\operatorname{INP}(\& \mathrm{H} 303))+\mathrm{CHR} \$(\operatorname{INP}(\& \mathrm{H} 304)))$

protemp $=($ AdcIn\% $/ 2047 * 1800)+32 ' \operatorname{deg} \mathrm{F}$

protsum $=$ protsum + protemp

Input from channel 17 (Low CO analyzer)

OUT \&H301, 17

FOR $w t=1$ TO 20: NEXT

OUT \&H302, 0

DO UNTIL (INP(\&H300) AND \&H40): LOOP

AdcIn\% $=\mathrm{CVI}(\mathrm{CHR} \$(\operatorname{INP}(\& \mathrm{H} 303))+\mathrm{CHR} \$(\operatorname{INP}(\& \mathrm{H} 304)))$

$\mathrm{LoCO}=(\operatorname{AdcIn} \%)$

LoCOsum $=$ LoCO + LoCOsum

Input from channel 18 (CO2 analyzer)

OUT \&H301, 18

FOR $w t=1$ TO 20: NEXT

OUT \&H302, 0

DO UNTIL (INP(\&H300) AND \&H40): LOOP

AdcIn\% $=\operatorname{CVI}(\mathrm{CHR} \$(\operatorname{INP}(\& H 303))+\mathrm{CHR} \$(\operatorname{INP}(\& H 304)))$

$\mathrm{CO} 2=(\mathrm{AdcIn} \%)$

$\mathrm{CO} 2$ sum $=\mathrm{CO} 2+\mathrm{CO} 2$ sum

Input from channel 16 (High $\mathrm{CO}$ analyzer)

OUT \&H301, 16

FOR $w t=1$ TO 20: NEXT

OUT \&H302, 0

DO UNTIL (INP(\&H300) AND \&H40): LOOP

AdcIn\% $=\mathrm{CVI}(\mathrm{CHR} \$(\operatorname{INP}(\& H 303))+\mathrm{CHR} \$(\operatorname{INP}(\& H 304)))$

$\mathrm{HiCO}=($ AdcIn $\%)$

$\mathrm{HiCOsum}=\mathrm{HiCO}+\mathrm{HiCOsum}$

Input from channel 89 (Trap differential pressure)

OUT \&H321, 25

FOR $w t=1$ TO 20: NEXT

OUT \&H322, 0

DO UNTIL (INP(\&H320) AND \&H40): LOOP

$\operatorname{AdcIn} \%=\operatorname{CVI}(\mathrm{CHR} \$(\operatorname{INP}(\& H 323))+\operatorname{CHR} \$(\operatorname{INP}(\& H 324)))$

trapdpp $=$ AdcIn $\% / 4095 * 89 \quad$ 'inches water

trapdpsum $=$ trapdpsum + trapdpp 


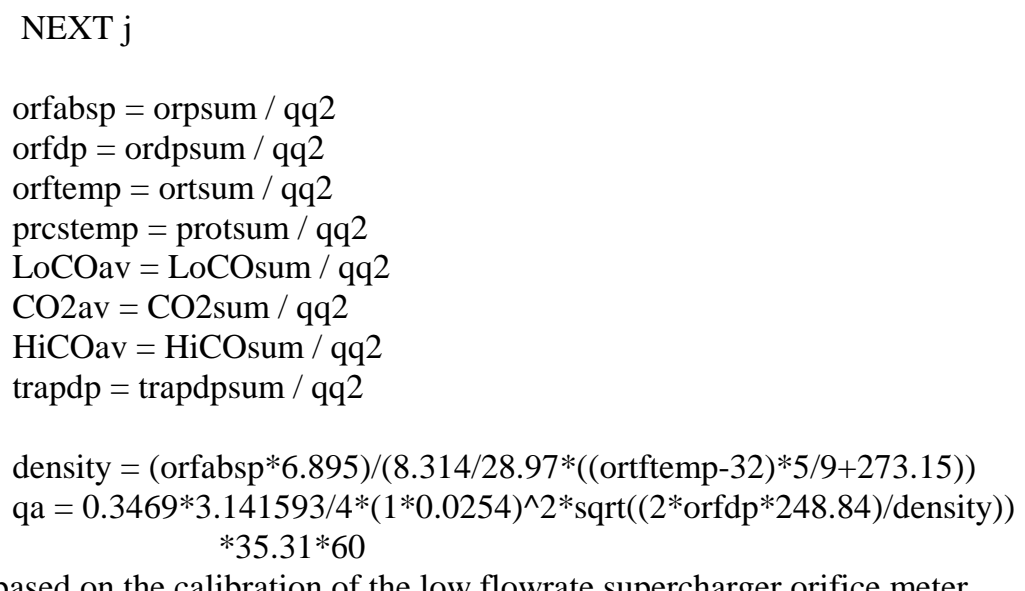

' based on the calibration of the low flowrate supercharger orifice meter

scfm! = qa * (orfabsp / 14.695948776\#) * (529.67 / (orftemp + 459.67) $)$

massflow! $=($ qa $*($ orfabsp $* 144)) * .0013558179483 \# /(.2869865 *((($ orftemp -32$) / 9 * 5)+$ 273.15))

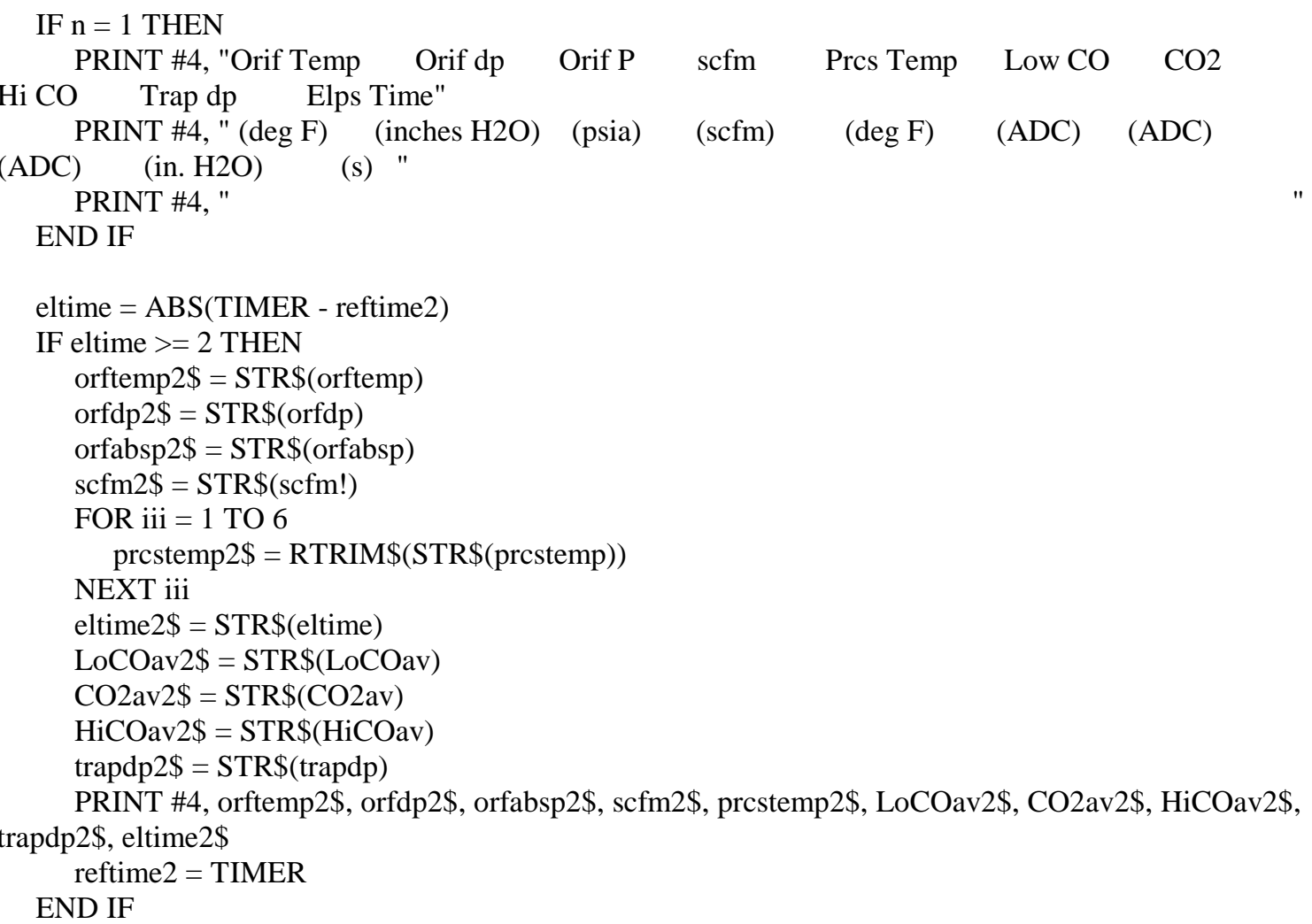

\section{COLOR 11}

LOCATE 4, 1

PRINT " Orifice Meter Temperature (deg F): ";

PRINT USING "\#\#\#\#\#\#"; orftemp

LOCATE 6,1

PRINT " Orifice Meter Differential Pressure (inches H2O): ";

PRINT USING "\#\#\#\#.\#\#"; orfdp

LOCATE 8,1 


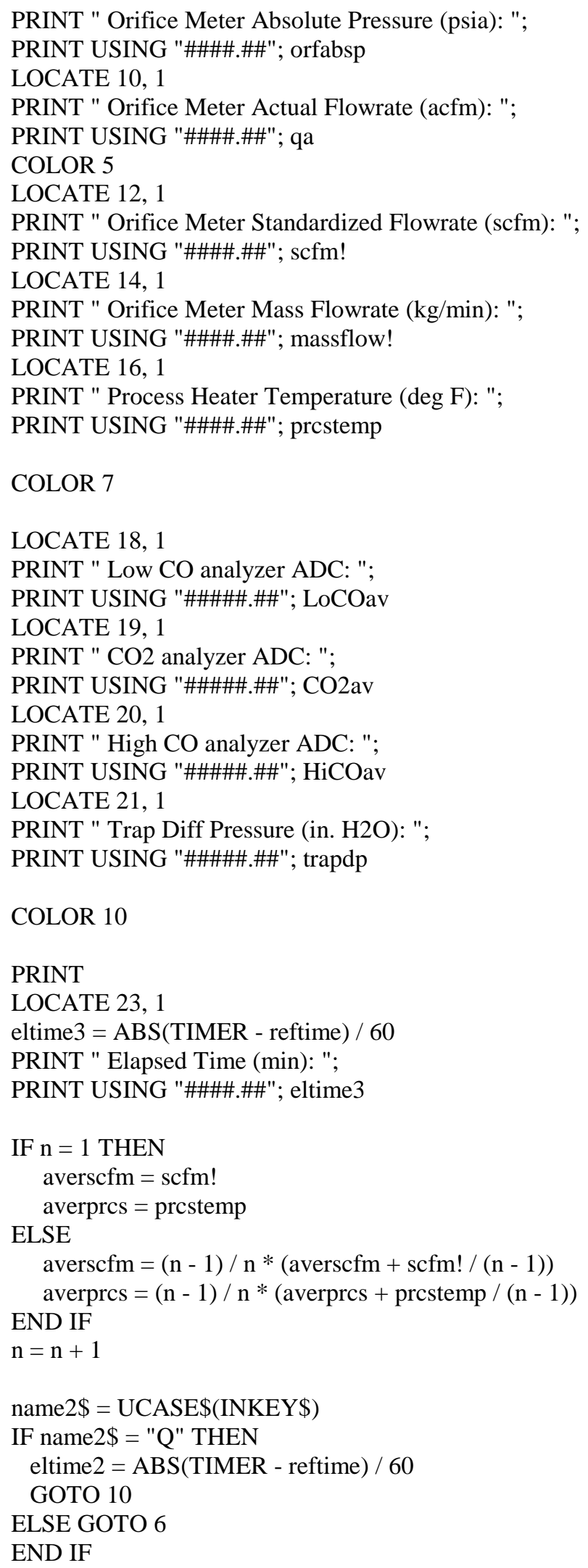


PRINT \#4, " "

PRINT \#4, " "

PRINT \#4, " "

PRINT

PRINT

PRINT

PRINT "ORIFICE METER DATA"

PRINT "Total Sample Time (min): ";

PRINT USING "\#\#\#\#.\#\#"; eltime2

PRINT \#4, "Total Sample Time (min): "; eltime2

PRINT "Number of Data Points: ";

PRINT USING "\#\#\#\#\#\#"; n

PRINT "Average Process Heater Temperature (deg F): ";

PRINT USING "\#\#\#\#.\#\#"; averprcs

PRINT \#4, "Average Process Heater Temperature (deg F): "; averprcs

PRINT "Average Standardized Flowrate (scfm): ";

PRINT USING "\#\#\#\#.\#\#"; averscfm

PRINT \#4, "Average Standardized Flowrate (scfm): "; averscfm

20 CLOSE \#4

LOCATE 20, 30

30 END 
Appendix M: Engine Backpressure Limiting Switch 


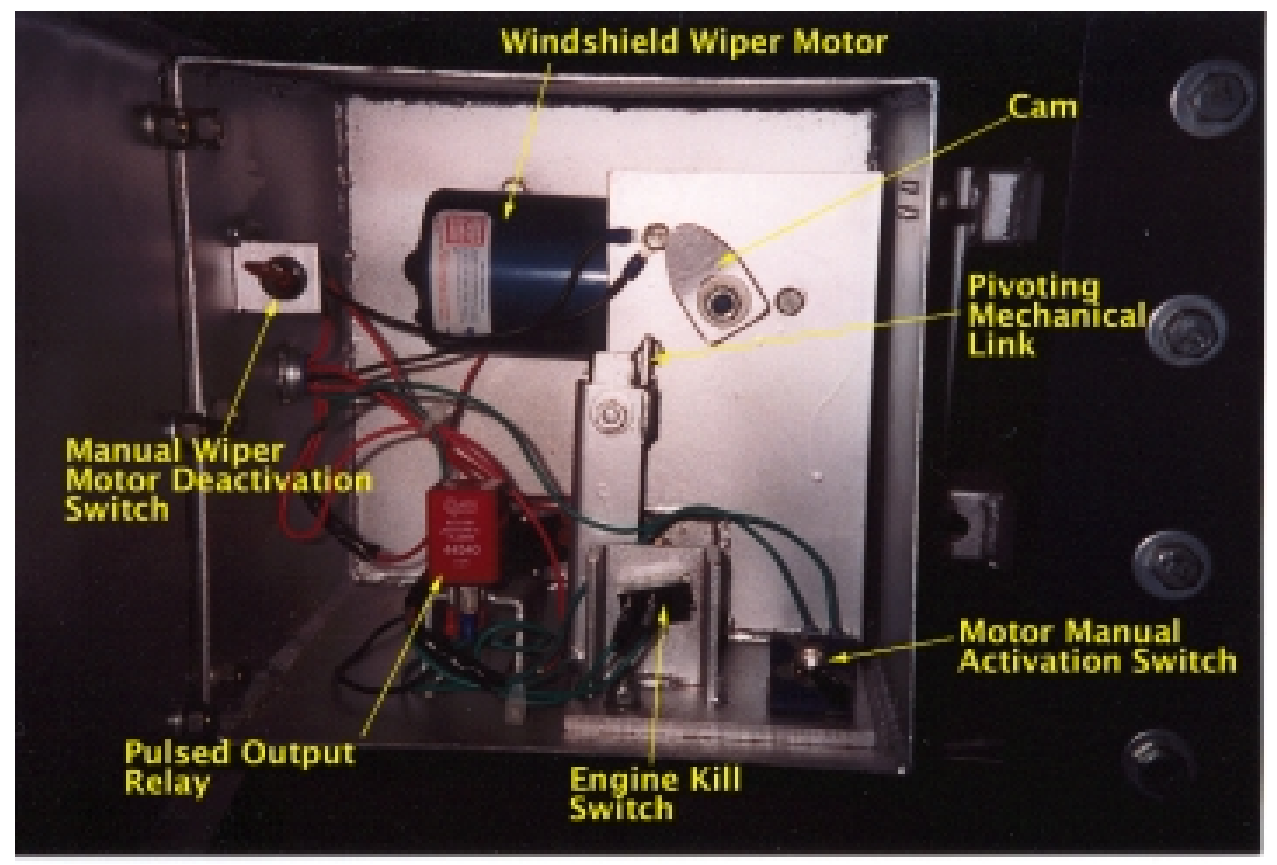

Figure M.1: Engine Protection Control Box 


\section{Appendix N: Filter Preparation Assembly}




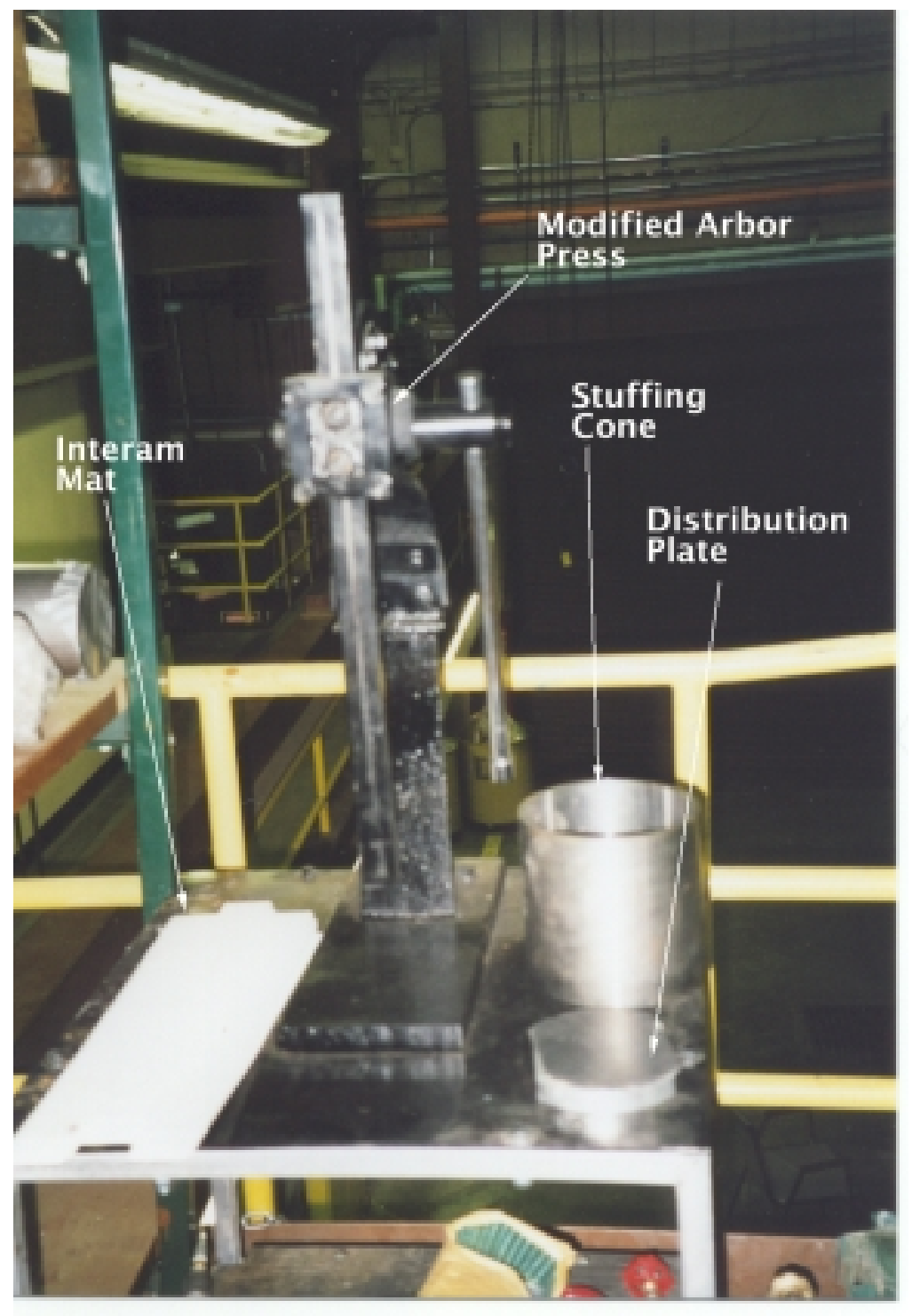

Figure N.1: Filter Insertion Equipment 


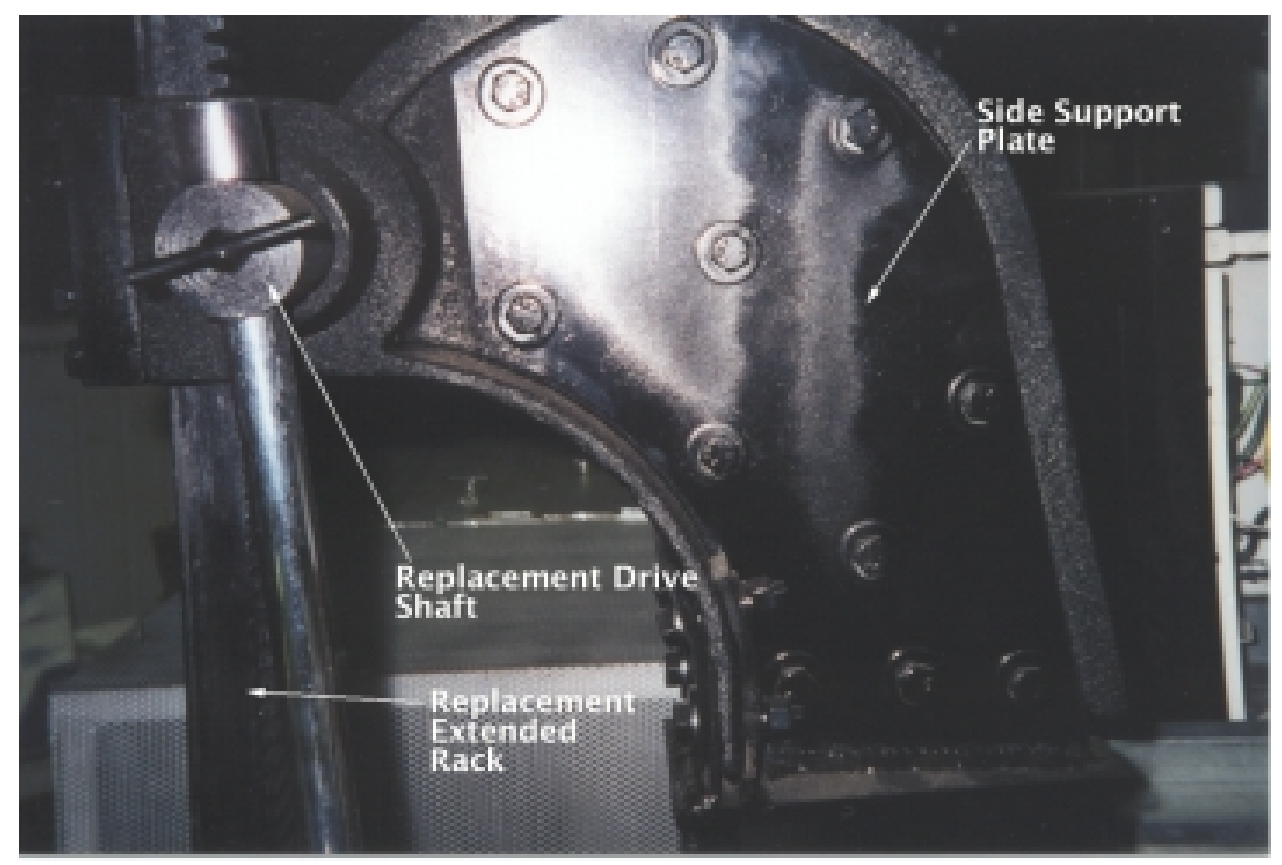

Figure N.2: Arbor Press (side view)

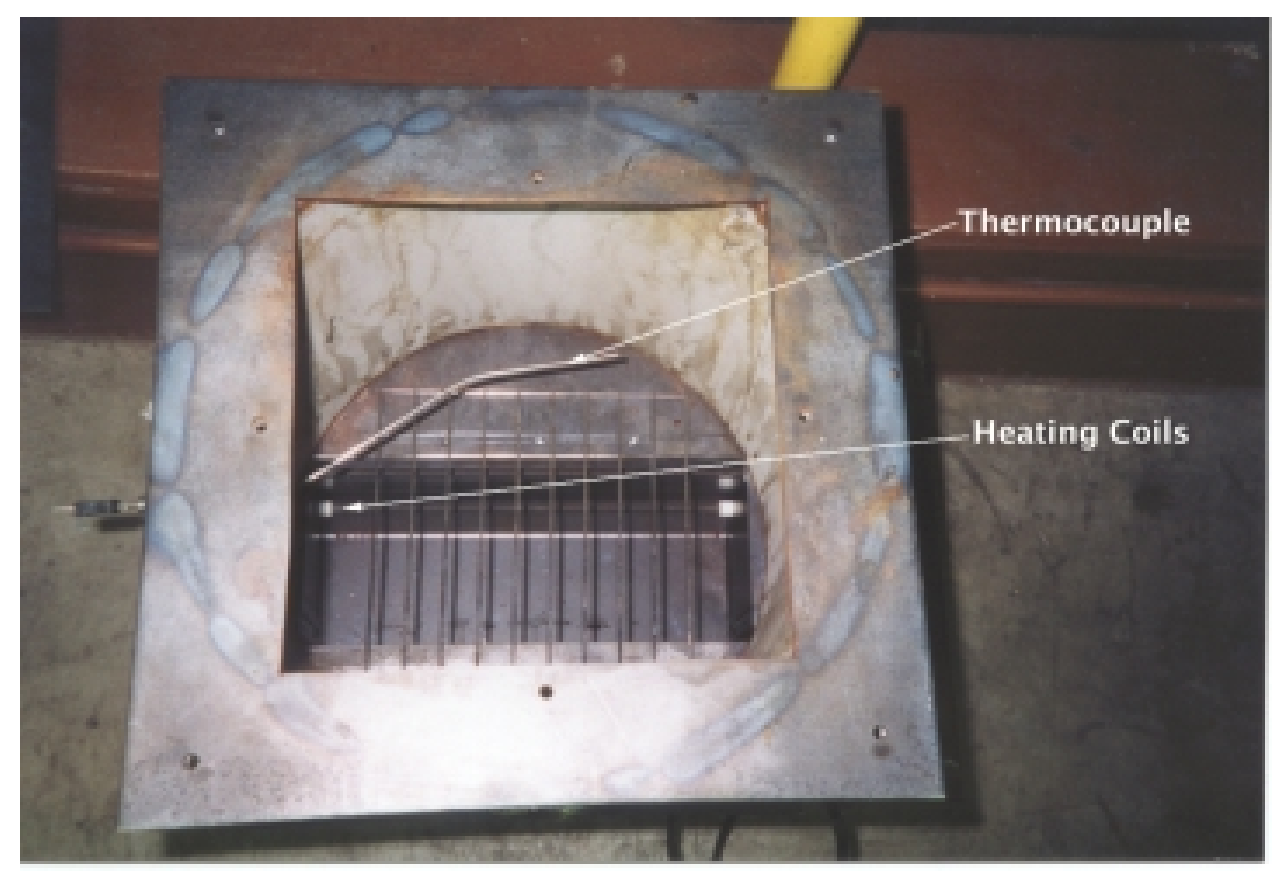

Figure N.3: Small Oven Used to Dry Filters 


\section{Appendix O: Soot Loading Period Data}




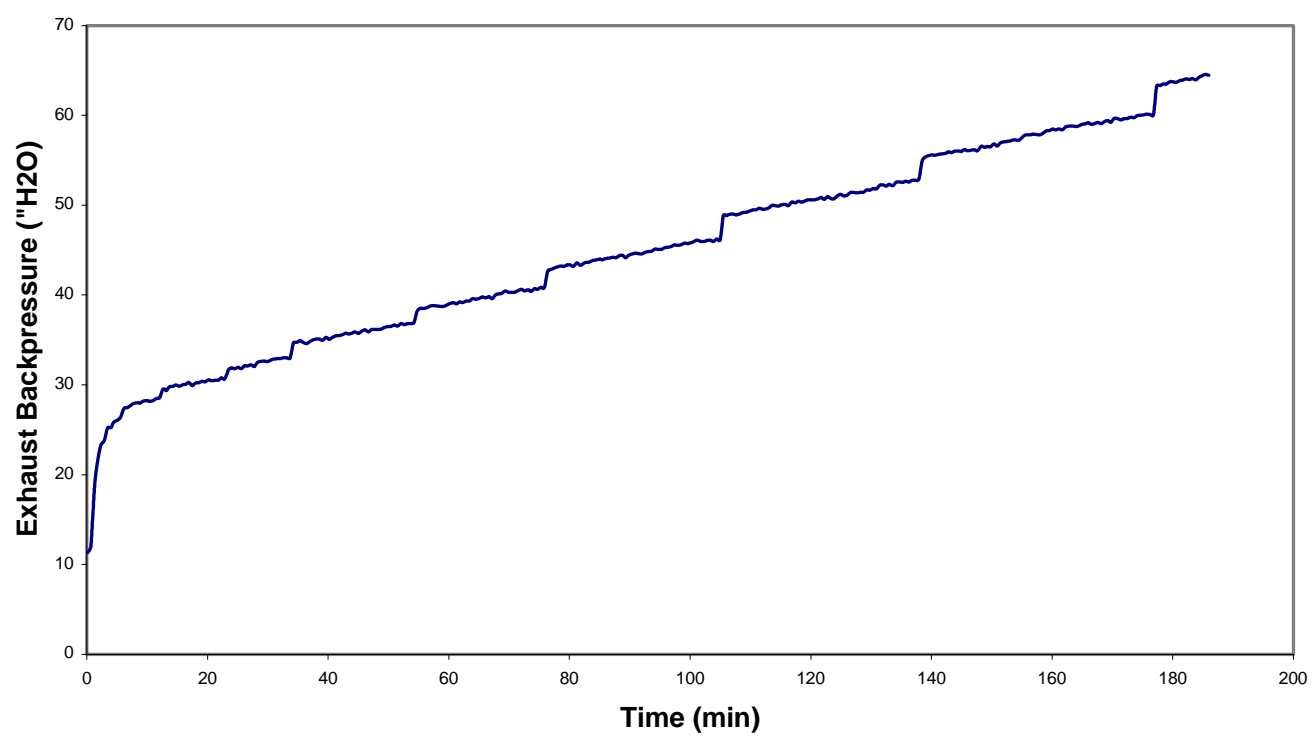

Figure O.1: Engine Exhaust Backpressure Profile during Soot Loading (test \#2)

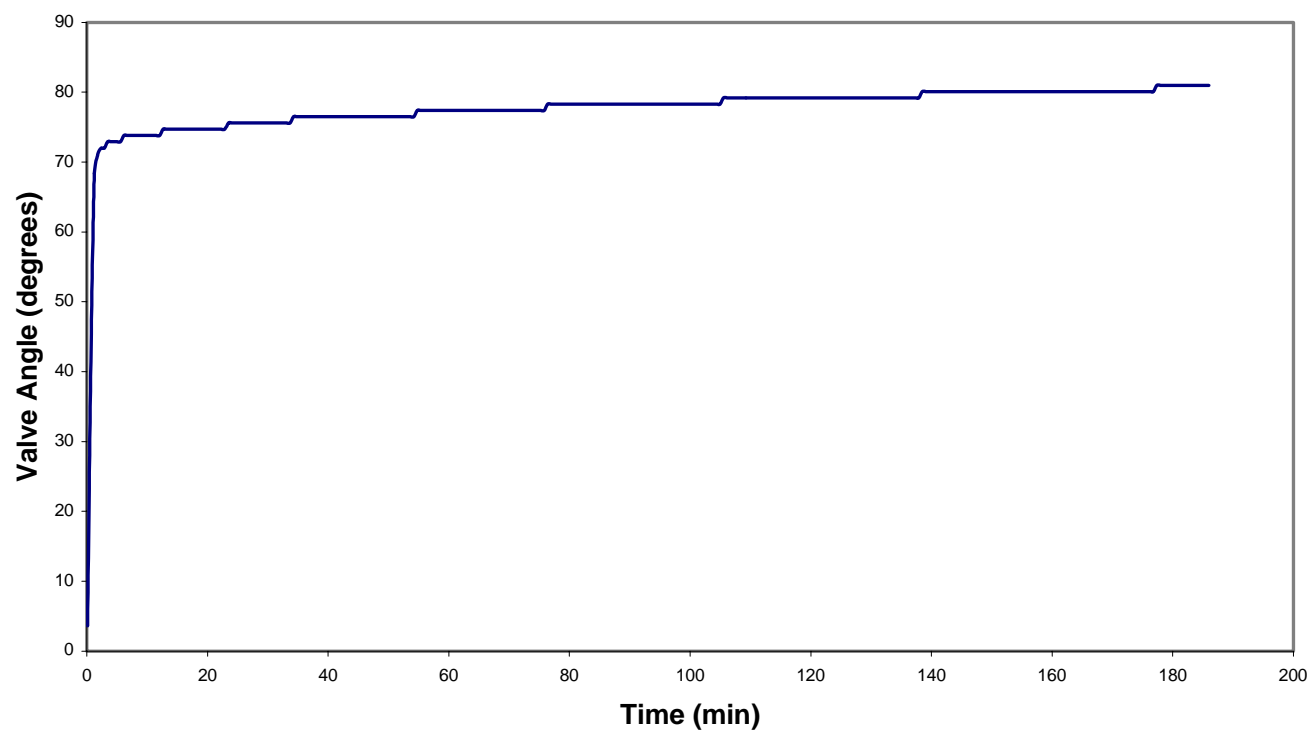

Figure O.2: Valve Position during Soot Loading (degrees from fully-open - test \#2) 


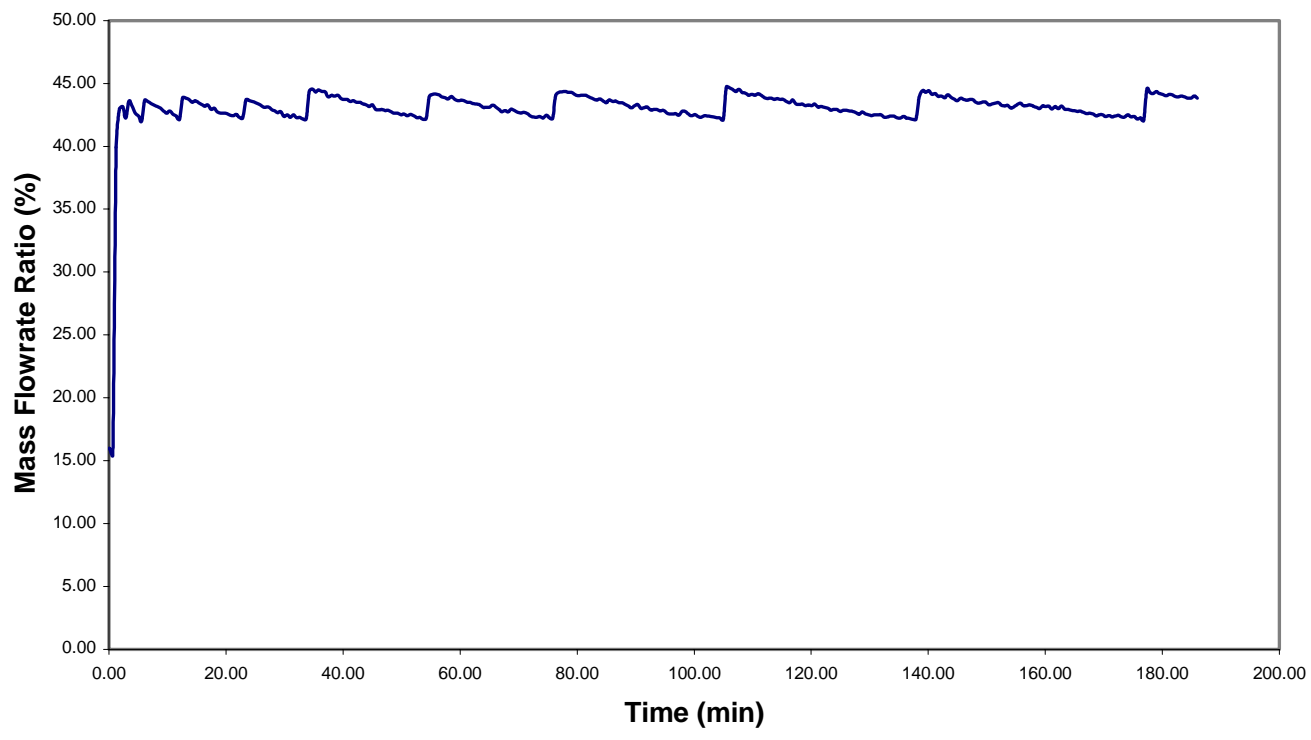

Figure O.3: Mass Flow Rate Ratio during Soot Loading (bypass flow rate/total flow rate x100 - test \#2) 